\title{
Molecular mechanisms underlying the platelet procoagulant response: back to basics
}

Citation for published version (APA):

Mattheij, N. J. A. (2016). Molecular mechanisms underlying the platelet procoagulant response: back to basics. [Doctoral Thesis, Maastricht University]. Maastricht University. https://doi.org/10.26481/dis.20160129nm

Document status and date:

Published: 01/01/2016

DOI:

$10.26481 /$ dis.20160129nm

Document Version:

Publisher's PDF, also known as Version of record

\section{Please check the document version of this publication:}

- A submitted manuscript is the version of the article upon submission and before peer-review. There can be important differences between the submitted version and the official published version of record.

People interested in the research are advised to contact the author for the final version of the publication, or visit the DOI to the publisher's website.

- The final author version and the galley proof are versions of the publication after peer review.

- The final published version features the final layout of the paper including the volume, issue and page numbers.

Link to publication

\footnotetext{
General rights rights.

- You may freely distribute the URL identifying the publication in the public portal. please follow below link for the End User Agreement:

www.umlib.nl/taverne-license

Take down policy

If you believe that this document breaches copyright please contact us at:

repository@maastrichtuniversity.nl

providing details and we will investigate your claim.
}

Copyright and moral rights for the publications made accessible in the public portal are retained by the authors and/or other copyright owners and it is a condition of accessing publications that users recognise and abide by the legal requirements associated with these

- Users may download and print one copy of any publication from the public portal for the purpose of private study or research.

- You may not further distribute the material or use it for any profit-making activity or commercial gain

If the publication is distributed under the terms of Article $25 \mathrm{fa}$ of the Dutch Copyright Act, indicated by the "Taverne" license above, 
Molecular mechanisms underlying the platelet procoagulant response:

\author{
back to basics
}


Molecular mechanisms underlying the platelet procoagulant response: back to basics

Thesis Universiteit Maastricht ISBN 978-90-6464-961-5

(C) Nadine Jacqueline Antoinnette Mattheij, Maastricht 2016

Printed by Proefschriften.nl || GVO drukkers \& vormgevers B.V., Ede Layout and cover by Nadine Mattheij 


\title{
Molecular mechanisms underlying the platelet procoagulant response: back to basics
}

\author{
PROEFSCHRIFT \\ ter verkrijging van de graad van doctor aan de Universiteit Maastricht, \\ op gezag van de Rector Magnificus, Prof. dr. L.L.G. Soete, \\ volgens het besluit van het College van Decanen, \\ in het openbaar te verdedigen op \\ vrijdag 29 januari 2016 om 10.00 uur \\ door
}

Nadine Jacqueline Antoinnette Mattheij

Geboren op 19 augustus 1987 te Sittard 


\section{Promotor}

Prof. Dr. Johan W. M. Heemskerk

\section{Copromotor}

Dr. Judith M.E.M. Cosemans

\section{Beoordelingscommissie}

Prof. Dr. C.P.M. Reutelingsperger (voorzitter)

Prof. Dr. F.C.S. Ramaekers

Prof. Dr. E. Lutgens (Academisch Medisch Centrum, UvA, Amsterdam)

Prof. Dr. J. de Mey (University of Southern Denmark, Odense, Denmark)

Dr. I.M.L.W. Körver-Keularts

This project was supported by the Center for Translational Medicine (INCOAG).

Financial support by Stichting Hart Onderzoek Nederland, an initiative of the Heart Research Institute (www.hartonderzoek.nu) is gratefully acknowledged.

Financial support for publication of this thesis by Stichting Hartsvrienden Rescar Maastricht is gratefully acknowledged

Additional financial support by the Dutch Heart Foundation for the publication of this thesis is gratefully acknowledged.

Additional support for publication of this thesis by Stichting Fonds voor het Hart is gratefully acknowledged. 


\section{CONTENTS}

Chapter $1 \quad$ General introduction.

Chapter 2 The effects of arterial flow on platelet activation, thrombus 15 growth, and stabilization.

Chapter $3 \quad$ Platelet-based coagulation: different populations, different 39 functions.

Chapter 4

Dual mechanism of integrin $\alpha_{\| 1 b} \beta_{3}$ closure in procoagulant 69 platelets.

Chapter 5

Roles of transglutaminase-active coated platelets in fibrin 95 binding and fibrin fiber formations via factor XIII and integrin $\alpha_{\| b} \beta_{3}$, independently of phosphatidylserine exposure.

Chapter 6 Both TMEM16F-dependent and TMEM16F-independent pathways contribute to phosphatidylserine exposure in platelet apoptosis and platelet activation.

Chapter 7

The Scott syndrome protein anoctamin- 6 controls multiple 135 platelet responses including phospholipid scrambling, platelet morphology and calpain-dependent protein.

Chapter 8

Altered protein expression, phosphorylation and cleavage in 161 platelets from Scott syndrome patient revealed by advanced proteomics analysis.

Chapter $9 \quad$ General discussion.

Summary

Samenvatting

Dankwoord

Curriculum Vitae

Publications

Appendix

Platelet CD40L modulates thrombus growth via PI3-kinase $\beta, 235$ and not via CD40 and IKB kinase $\alpha$. 

Chapter 1

General introduction 
Platelet activation and blood paracrine mediators, which attract other coagulation in arterial thrombosis

Arterial thrombosis refers to the formation of a partially or fully occlusive thrombus in the blood at the site of a damaged, often atherosclerotic artery. Current understanding is that two major processes in the blood contribute to arterial thrombus formation, i.e. aggregation of platelets, which make up the core of the thrombus, and assembly of a fibrin clot, which consolidates the thrombus and traps red cells. ${ }^{1-3}$ As such, arterial thrombus formation can be a clinically silent event, when non-essential arteries are occluded or when blood flow is only partly impaired. However, when the thrombus obstructs the blood flow to parts of the heart or brains, it becomes symptomatic and dangerous. Hence, depending on the site and size of a thrombus, arterial thrombosis can lead to heart ischemia, stroke or peripheral arterial disease. $^{2}$

In general, the processes of platelet activation and blood coagulation are highly interdependent. ${ }^{4,5}$ An initial step in the activation of platelets upon vascular damage is the adhesion of flowing platelets to exposed collagen and von Willebrand factor via the two major collagen receptors, i.e. glycoprotein VI (GPVI) and integrin $\alpha_{2} \beta_{1}$, and the von Willebrand factor receptor complex, glycoprotein Ib-V-IX.6,7. The collagenactivated platelets produce a range of flowing platelets to form a platelet aggregate. Some of the highly activated platelets become procoagulant and by allowing the assembly of coagulation factors at their surface can stimulate thrombin formation. Thrombin cleaves fibrinogen into monomeric fibrin, which polymerizes into fibrin fibers that become additionally cross-linked via the transglutaminase factor XIII, and stabilizes the growing thrombus. ${ }^{8}$

The complexity of the mechanism of thrombus formation is addressed in further detail in the review Chapter 2. In the paragraphs below, I will primarily focus on background information of those aspects of the thrombus-forming process that are most relevant for this thesis: platelet heterogeneity, characteristics of procoagulant platelets, and the regulation of membrane phospholipid scrambling.

Heterogeneity in platelets upon thrombus formation: differential role for intracellular calcium

In the classical concept, it is considered that two types of platelets are formed in a growing thrombus: aggregating and procoagulant platelets. ${ }^{7}$ Discriminative in the formation of these platelet populations is the rise in intracellular calcium concentration. Whereas a transient rise in intracellular calcium is sufficient for platelet integrin $\alpha_{11 \mathrm{~b}} \beta_{3}$ 
activation and secretion - two processes that are implicated in platelet aggregation -, a high, sustained rise in calcium is required for the exposure of phosphatidylserine, which enables platelet to become procoagulant., 9 Platelet aggregation is triggered by $a$ conformational change of integrin $\alpha_{11 b} \beta_{3}$, enabling the binding of fibrinogen to this receptor and allowing platelet-platelet interactions via fibrinogen crossbridges. ${ }^{11}$ Aggregated platelets have a relatively minor role in coagulation. ${ }^{12}$ In contrast, platelets with negatively charged phosphatidylserine exposed at the outer membrane actively stimulate the coagulation process. In particular, they provide a surface for the calciumdependent assembly of the tenase and prothrombinase complexes that are responsible for the formation of activated factor $X$ and thrombin, respectively. ${ }^{13} \quad$ Interestingly, phosphatidylserine-exposing platelets characteristically contain inactive $\alpha_{\| 1 \mathrm{~b}} \beta_{3}$ integrins and form large blebbing structures, which may serve to enhance the accessibility to coagulation factors. ${ }^{14}$ How intracellular calcium signaling regulates the formation of these platelet populations is described in more detail in Chapter 3. Whereas the heterogeneity in platelet activation processes is already known for several years, ${ }^{15,16}$ the discriminative mechanisms causing platelet procoagulant response - including integrin inactivation and bleb formation - are not well understood.

Under in vitro conditions, an effective way to stimulate phosphatidylserine exposure, and thus the formation of procoagulant platelets, is by costimulation of the collagen receptor GPVI and thrombin receptors. ${ }^{15,17}$ However, in papers of the Dale group platelets stimulated by collagen and thrombin are defined as a distinctive subpopulation of so-called 'coated' platelets, i.e. containing an extracellular coat of serotonin-derivatized proteins. ${ }^{18-20}$ Interestingly, the definition of coated platelets is divergent and was subject to change over the years. Whereas coated platelets were initially recognized by the presence of serotonin-derivatized proteins at the cell surface ${ }^{18-20}$, Jobe et al. redefined coated platelets as those platelets containing a high surface level of bound fibrinogen, cross-linked via the transglutaminase factor XIII. ${ }^{21}$ In recent years, it is starting to become common to consider coated platelets as more or less equivalent to phosphatidylserineexposing platelets. ${ }^{22}$ However, this immediately raises the question whether the presence of a protein coat would interfere with coagulation factor binding. If and how coated platelets are different from procoagulant platelets is presently unclear. 
Membrane phospholipid scrambling and anoctamins

In resting platelets, the membrane phospholipids are asymmetrically distributed over the two leaflets of the plasma membrane. The cholinecontaining phospholipids, phosphatidylcholine and sphingomyelin, dominate the outer leaflet, while the aminophospholipids, phosphatidylserine and phosphatidylethanolamine, are largely concentrated in the inner leaflet. ${ }^{23,24}$ The traditional view is that this asymmetry is maintained by an ATPdependent aminophospholipid uptake mechanism, directing these phospholipids to the inner membrane leaflet. ${ }^{25,26}$ Triggering of platelets with potent $\mathrm{Ca}^{2+}$-mobilizing agents abolishes this asymmetry by randomization of the phospholipids, a process driven by $\mathrm{Ca}^{2+}{ }_{-}$ influx channels. ${ }^{27,28}$ Alternatively, phospholipid randomization can be achieved in a calcium-independent way by apoptosis. ${ }^{29}$ For long, it has been speculated that the externalization of phosphatidylserine is mediated by specific enzymes, designated as phospholipid scramblases. ${ }^{8}$ Early evidence suggests that the calciumactivated scramblase differs from the protein involved in apoptotic phospholipid scrambling. ${ }^{23}$

Recently, a critical role has been reported for the transmembrane protein anoctamin-6 in $\mathrm{Ca}^{2+}$-dependent phospholipid scrambling in platelets. ${ }^{30,31}$ Anoctamin- 6 is a member of the anoctamin family of calcium-activated chloride channels. This name is derived from the previously supposed selectivity for anions and the presence of eight membrane-spanning domains. ${ }^{32,33}$ Several recent studies have shown that anoctamin- 6 has the capacity to function as both a chloride channel and a cation channel. ${ }^{31,34,35}$ In addition to anoctamin6 , also other members of the anoctamin family may act as regulators of phosphatidylserine exposure, in particular anoctamin-1..$^{32,36,37}$ In which way the anion and cation channel activities relate to the process of phospholipid scrambling in platelets is unknown.

Of great interest in this regard is that for patients identified with the Scott syndrome, critical mutations in the gene ANO6 (previously named TMEM16F), encoding for anoctamin-6, could be established..$^{30,38}$ The Scott syndrome is an rare inherited, moderately severe bleeding disorder, which is characterized by defective calcium-dependent phospholipid scrambling in hematopoietic cells. ${ }^{39,40}$ As a consequence of this defect, platelets and other blood cells from Scott syndrome patients are deficient in phosphatidylserine externalization after triggering with potent calcium-mobilizing agonists. Laboratory tests show normal 
plasma levels of coagulation factors and normal platelet aggregation, but some whole-blood tests are reduced such as prothrombin consumption and thromboplastin inactivation. ${ }^{39}$ This is in line with the mild clinical symptoms seen in Scott syndrome patients, such as excessive bleeding after trauma, but absence of spontaneous hemorrhages like in hemophilia. Initial experiments with patient cells and anoctamin- 6 deficient mice have indicated that the defective calcium-dependent phosphatidylserine externalization in platelets from Scott syndrome patients can be attributed to reduced expression of anoctamin-6. ${ }^{30,38}$ However, whether anoctamin- 6 is also involved in other characteristics of procoagulant platelets such as integrin inactivation and membrane blebbing is unknown. One of the novel omics tools to potentially determine if and how platelets from Scott syndrome patients are different from platelets from control subjects is the use of quantitative proteomics and phosphoproteomics. ${ }^{41}$

\section{Aims and outline of the thesis}

The studies described in this thesis have been directed to better understand the multiple mechanisms that determine the heterogeneity in platelet activation processes leading to aggregating and procoagulant platelets, with a special focus on the role of anoctamin-6.
Chapter 2 provides an extensive overview on the platelet responses implicated in thrombin generation and fibrin formation within the context of arterial thrombus formation and vascular occlusion. The subsequent Chapter $\mathbf{3}$ gives an overview of the different populations of activated platelets that can be distinguished in a growing thrombus, with emphasis on their surface properties and their likely distinct roles in coagulation processes, i.e. thrombin generation, fibrin formation and fibrin clot retraction. Herein, a main distinction is made between, at one side, platelets with highly elevated cytosolic $\mathrm{Ca}^{2+}$ and exposed phosphatidylserine that control thrombin generation, and at the other site, platelets with activated integrin $\alpha_{11 b} \beta_{3}$ that regulate clot retraction.

Chapter 4 studies the mechanism underlying the process of integrin $\alpha_{11 \mathrm{~b}} \beta_{3}$ inactivation or closure in procoagulant platelets. Novel data are provided that calpain-induced cleavage of integrinassociated proteins as well as anoctamin6-dependent phospholipid scrambling are principal determinants of integrin $\alpha_{\| b} \beta_{3}$ inactivation. Detailed studies how coated platelets (activated by collagen/thrombin receptors) differ from phosphatidylserine-exposing platelets are given in Chapter 5. This chapter furthermore reveals a novel function of coated platelets in the regulation of 
platelet-dependent fibrin formation, and identifies redundant roles of integrin $\alpha_{\| 1 \mathrm{~b}} \beta_{3}$ and factor XIII in this process.

In Chapter 6, the role is investigated of anoctamin-6 in phosphatidylserine exposure in platelets stimulated with calcium-mobilizing agonists or apoptotic agents using platelets from a patient with Scott syndrome with dysfunctional mutations in the ANO6 gene. In the ensuing Chapter 7 , additional studies are performed with platelets from Scott patients and anoctamin-deficient mice to determine whether the deficiency in anoctamin- 6 can account for the multiple responses of procoagulant platelets. A pertinent question is whether the formation of membrane blebs, accompanying phosphatidylserine exposure, is a consequence of anoctamin- 6 expression. The studies to further characterize the altered properties of Scott platelets are pursued in Chapter 8. Here, quantitative (phospho)proteomics is used to compare the expression levels and the phosphorylation status of the platelet proteome from a Scott syndrome patient with the platelet proteome from a healthy control. In addition, this chapter describes a new developed tool to detect changes in calpain-dependent protein cleavage between Scott and control platelets. In the general discussion of Chapter 9, the principle findings of this thesis are considered in relation to the current literature.

\section{References}

1. Brass LF, Wannemacher KM, Ma P, Stalker TJ. Regulating thrombus growth and stability to achieve an optimal response to injury. J Thromb Haemost 2011;9 Suppl 1:66-75.

2. Jackson SP. Arterial thrombosis--insidious, unpredictable and deadly. Nat Med 2011;17:1423-1436.

3. Mastenbroek TG, van Geffen JP, Heemskerk JW, Cosemans JM. Acute and persistent platelet and coagulant activities in atherothrombosis. J Thromb Haemost 2015;13 Suppl 1:S272-80.

4. Munnix IC, Cosemans JM, Auger JM, Heemskerk JW. Platelet response heterogeneity in thrombus formation. Thromb Haemost 2009;102:1149-1156.

5. Badimon L, Vilahur G. Thrombosis formation on atherosclerotic lesions and plaque rupture. Journal of Internal Medicine 2014;276:618-632.

6. Ruggeri ZM. The role of von Willebrand factor in thrombus formation. Thromb Res 2007;120 Suppl 1:S5-9.

7. Versteeg $\mathrm{HH}$, Heemskerk JW, Levi M, Reitsma PH. New fundamentals in hemostasis. Physiol Rev 2013;93:327-358.

8. Bevers EM, Comfurius P, Zwaal RF. Regulatory mechanisms in maintenance and modulation of transmembrane lipid asymmetry: pathophysiological implications. Lupus 1996;5:480-487.

9. Heemskerk JW, Vuist WM, Feijge MA, Reutelingsperger $\mathrm{CP}$, Lindhout $\mathrm{T}$. Collagen but not fibrinogen surfaces induce bleb formation, exposure of phosphatidylserine, and procoagulant activity of adherent platelets: evidence for regulation by protein tyrosine kinase-dependent $\mathrm{Ca}^{2+}$ responses. Blood 1997;90:2615-2625.

10. Varga-Szabo D, Braun A, Nieswandt B. Calcium signaling in platelets. J Thromb Haemost 2009;7:1057-1066.

11. Shattil SJ, Kim C, Ginsberg MH. The final steps of integrin activation: the end game. Nat Rev Mol Cell Biol 2010;11:288-300. 
12. Briede JJ, Wielders SJ, Heemskerk JW, Baruch D, Hemker HC, Lindhout T. von Willebrand factor stimulates thrombin-induced exposure of procoagulant phospholipids on the surface of fibrin-adherent platelets. J Thromb Haemost 2003;1:559-565.

13. Munnix IC, Kuijpers MJ, Auger J, Thomassen CM, Panizzi P, van Zandvoort MA, Rosing J, Bock PE, Watson SP, Heemskerk JW. Segregation of platelet aggregatory and procoagulant microdomains in thrombus formation: regulation by transient integrin activation. Arterioscler Thromb Vasc Biol 2007;27:24842490.

14. Cosemans JM, Iserbyt BF, Deckmyn $H$, Heemskerk JW. Multiple ways to switch platelet integrins on and off. J Thromb Haemost 2008;6:1253-1261.

15. Siljander PR, Munnix IC, Smethurst PA, Deckmyn $\mathrm{H}$, Lindhout $\mathrm{T}$, Ouwehand $\mathrm{WH}$, Farndale RW, Heemskerk JW. Platelet receptor interplay regulates collagen-induced thrombus formation in flowing human blood. Blood 2004;103:13331341.

16. Kempton $\mathrm{CL}$, Hoffman $\mathrm{M}$, Roberts $\mathrm{HR}$, Monroe DM. Platelet heterogeneity: variation in coagulation complexes on platelet subpopulations. Arterioscler Thromb Vasc Biol 2005;25:861-866.

17. Briede JJ, Heemskerk JW, van't Veer C, Hemker HC, Lindhout T. Contribution of platelet-derived factor $\mathrm{Va}$ to thrombin generation on immobilized collagen- and fibrinogen-adherent platelets. Thromb Haemost 2001;85:509-513.

18. Alberio $\mathrm{L}$, Clemetson KJ. All platelets are not equal: COAT platelets. Curr Hematol Rep 2004;3:338-343.

19. Dale GL. Coated-platelets: an emerging component of the procoagulant response. J Thromb Haemost 2005;3:2185-2192.

20. Szasz R, Dale GL. COAT platelets. Curr Opin Hematol 2003;10:351-355.

21. Jobe SM, Leo L, Eastvold JS, Dickneite G, Ratliff TL, Lentz SR, Di Paola J. Role of FcRy and factor XIIIA in coated platelet formation. Blood 2005;106:4146-4151.

22. Colucci G, Stutz M, Rochat $S$, Conte $T$, Pavicic $M$, Reusser M, Giabbani E, Huynh A, Thurlemann C, Keller $P$, Alberio $L$. The effect of desmopressin on platelet function: a selective enhancement of procoagulant COAT platelets in patients with primary platelet function defects. Blood 2014;123:1905-1916.
23. Bevers EM, Williamson PL. Phospholipid scramblase: an update. FEBS Lett 2010;584:2724-2730.

24. Zwaal RF, Comfurius P, Bevers EM. Mechanism and function of changes in membranephospholipid asymmetry in platelets and erythrocytes. Biochem Soc Trans 1993;21:248253.

25. Tang X, Halleck MS, Schlegel RA, Williamson P. A subfamily of P-type ATPases with aminophospholipid transporting activity. Science 1996;272:1495-1497.

26. Schroit AJ, Zwaal RF. Transbilayer movement of phospholipids in red cell and platelet membranes. Biochim Biophys Acta 1991;1071:313-329.

27. Harper MT, Londono JE, Quick K, Londono JC, Flockerzi V, Philipp SE, Birnbaumer L, Freichel M, Poole AW. Transient receptor potential channels function as a coincidence signal detector mediating phosphatidylserine exposure. Sci Signal 2013;6:ra50.

28. van Kruchten R, Braun A, Feijge MA, Kuijpers MJ, Rivera-Galdos R, Kraft P, Stoll G, Kleinschnitz C, Bevers EM, Nieswandt B, Heemskerk JW. Antithrombotic potential of blockers of storeoperated calcium channels in platelets. Arterioscler Thromb Vasc Biol 2012;32:17171723.

29. Schoenwaelder SM, Yuan Y, Josefsson EC, White MJ, Yao Y, Mason KD, O'Reilly LA, Henley KJ, Ono A, Hsiao S, Willcox A, Roberts AW, Huang DC, Salem HH, Kile BT, Jackson SP. Two distinct pathways regulate platelet phosphatidylserine exposure and procoagulant function. Blood 2009;114:663-666.

30. Suzuki J, Umeda M, Sims PJ, Nagata S. Calciumdependent phospholipid scrambling by TMEM16F. Nature 2010;468:834-838.

31. Yang H, Kim A, David T, Palmer D, Jin T, Tien J, Huang F, Cheng T, Coughlin SR, Jan YN, Jan LY. TMEM16F forms a $\mathrm{Ca}^{2+}$-activated cation channel required for lipid scrambling in platelets during blood coagulation. Cell 2012;151:111-122.

32. Pedemonte N, Galietta $\amalg$. Structure and function of TMEM16 proteins (anoctamins). Physiol Rev 2014;94:419-459.

33. Picollo A, Malvezzi M, Accardi A. TMEM16 proteins: unknown structure and confusing functions. J Mol Biol 2015;427:94-105.

34. Kunzelmann K, Nilius B, Owsianik G, Schreiber R, Ousingsawat J, Sirianant L, Wanitchakool P, Bevers EM, Heemskerk JW. Molecular functions of anoctamin 6 (TMEM16F): a chloride channel, 
cation channel, or phospholipid scramblase? Pflugers Arch 2014;466:407-414.

35. Shimizu T, lehara T, Sato K, Fujii T, Sakai $H$, Okada Y. TMEM16F is a component of a $\mathrm{Ca}^{2+}$ activated $\mathrm{Cl}$ - channel but not a volume-sensitive outwardly rectifying $\mathrm{Cl}$ - channel. Am J Physiol Cell Physiol 2013;304:C748-759.

36. Fagerberg SK, Skals M, Leipziger J, Praetorius HA. $\mathrm{P} 2 \mathrm{X}$ receptor-dependent erythrocyte damage by $\alpha$-hemolysin from Escherichia coli triggers phagocytosis by THP-1 cells. Toxins 2013;5:472487.

37. Suzuki J, Fujii T, Imao T, Ishihara K, Kuba $H$, Nagata S. Calcium-dependent phospholipid scramblase activity of TMEM16 protein family members. J Biol Chem 2013;288:13305-13316.
38. Castoldi E, Collins PW, Williamson PL, Bevers EM Compound heterozygosity for 2 novel TMEM16F mutations in a patient with Scott syndrome. Blood 2011;117:4399-4400.

39. Weiss HJ, Vicic WJ, Lages BA, Rogers J. Isolated deficiency of platelet procoagulant activity. Am J Med 1979;67:206-213.

40. Zwaal RF, Comfurius P, Bevers EM. Scott syndrome, a bleeding disorder caused by defective scrambling of membrane phospholipids. Biochim Biophys Acto 2004;1636:119-128.

41. Burkhart JM, Gambaryan S, Watson SP, Jurk K, Walter U, Sickmann A, Heemskerk JW, Zahedi RP. What can proteomics tell us about platelets? Circ Res 2014;114:1204-1219. 


\title{
Chapter 2
}

\section{The effects of arterial flow on platelet activation, thrombus growth, and stabilization}

\author{
Cosemans $\mathrm{JM}^{1}$, Angelillo-Scherrer $\mathrm{A}^{2}$, Mattheij $\mathrm{NJ}^{1}$, \\ Heemskerk JW ${ }^{1}$
}

${ }^{1}$ Department of Biochemistry, Cardiovascular Research Institute Maastricht (CARIM), Maastricht University, Maastricht, The Netherlands; ${ }^{2}$ Service and Central Laboratory of Hematology, Lausanne University Hospital, Lausanne, Switzerland

Cardiovascular Research 2013;99:342-352 Reprinted with permission 


\begin{abstract}
Injury of an arterial vessel wall acutely triggers a multifaceted process of thrombus formation, which is dictated by the high-shear flow conditions in the artery. In this overview, we describe how the classical concept of arterial thrombus formation and vascular occlusion, driven by platelet activation and fibrin formation, can be extended and fine-tuned. This has become possible because of recent insight into the mechanisms of: (i) platelet-vessel wall and platelet-platelet communication, (ii) autocrine platelet activation, and (iii) platelet-coagulation interactions, in relation to blood flow dynamics. We list over 40 studies with genetically modified mice showing a role of platelet and plasma proteins in the control of thrombus stability after vascular injury. These include multiple platelet adhesive receptors and other junctional molecules, components of the ADP receptor signalling cascade to integrin activation, proteins controlling platelet shape, and autocrine activation processes, as well as multiple plasma proteins binding to platelets and proteins of the intrinsic coagulation cascade. Regulatory roles herein of the endothelium and other blood cells are recapitulated as well. Patient studies support the contribution of platelet- and coagulation activation in the regulation of thrombus stability. Analysis of the factors determining flow-dependent thrombus stabilization and embolus formation in mice will help to understand the regulation of this process in human arterial disease.
\end{abstract}

\section{Introduction}

At prevalent flow conditions, platelets interact only limitedly with the healthy vessel wall, e.g. to maintain vascular integrity. However, this changes dramatically at conditions of vascular inflammation, damage, or disruption (situations leading to atherogenesis, haemostasis, or arterial thrombosis, respectively), where platelets massively adhere to the activated endothelium or the underlying endothelial matrix. ${ }^{1-3}$ In this overview, we discuss sheardependent mechanisms by which platelets are capable to adhere to activated, damaged or disrupted arterial vessels, and subsequently assemble into a stable or unstable thrombus. ${ }^{4,5}$ We describe how the classical concept of arterial thrombus formation, developed almost 20 years ago, is currently extended and fine-tuned due to better insights into the underlying molecular mechanisms in relation to blood flow dynamics. We illustrate how local changes in fluid shear stress can control both platelet and coagulation activation and, thereby, the growth and stabilization of a thrombus. Furthermore, we recapitulate key roles of the vessel wall and leucocytes in the control of thrombus formation. By comparing 
recently published studies, where the effects of gene knockout have been determined on thrombus stability and embolus formation in mouse, we provide a first encompassing overview of the activation pathways in platelets and blood plasma that may control these processes. Subsequently, we discuss the possible clinical relevance of these findings on flow-dependent thrombus stabilization and embolization. For reasons of space, we only briefly touch the processes of venous thromboembolism and fibrinolysis.

\section{Classical concept of flow-dependent platelet adhesion and thrombus formation}

How platelets adhere at a site of vascular activation or injury greatly depends on the local blood flow and shear conditions. In the arterial system, the mechanical force that is most relevant for platelet adhesion is the shear stress of the blood. ${ }^{6}$ Since the velocity of flowing blood is greater in the centre of the artery than near the vessel wall, blood consists of concentric layers through the artery lumen that markedly differ in flow rate. Shear stress is defined as the force per unit area between such layers, and wall shear stress is the force per unit area applied onto the vessel wall. Accordingly, also the shear rate (expressed as shear stress times the viscosity of the blood) varies through the artery lumen from minimal at the centreline to maximal near the wall. Typical wall shear rates are in the range of 300$800 \mathrm{~s}^{-1}$ in large arteries, and of 500-1600 $\mathrm{s}^{-1}$ in arterioles of the microcirculation. ${ }^{6}$ Especially in stenotic vessels, the wall shear rates can increase up to $10000 \mathrm{~s}^{-1}$ and even higher. ${ }^{7}$ Wall shear rates in the venous part of the circulation are in general low.

At a shear rate of $>500 \mathrm{~s}^{-1}$, initial tethering of platelets to the vessel wall is primarily mediated by interaction of the receptor complex glycoprotein (GP)Ib-VIX to the von Willebrand factor (vWF). This multimeric adhesive protein is abundantly present in the plasma and secreted by endothelial cells. It is also bound to locally activated endothelium and deposits at the exposed extracellular matrix, particularly binding to collagen fibres. ${ }^{8}$ At high wall shear rates (>5000 $\mathrm{s}^{-1}$ ) or at sharp gradients of shear rate, the interaction of GPIb-V-IX with the vWF can be sufficient for unstable thrombus formation, albeit it results in no more than weak intracellular signalling in platelets. ${ }^{9,10}$ The marked shear gradients around stenotic sites, such as present in arteries with advanced atherosclerosis, stimulate the endothelial release of the vWF and trigger GPIb-V-IX-dependent thrombus formation. ${ }^{11}$

The initial, shear-dependent adhesion of platelets is possible due to unique biomechanical properties of the vWF 
bond with GPIb-V-IX, as this is characterized by a very rapid on-rate and facilitated by unfolding of vessel walladhered vWF multimers. ${ }^{2}$ However, the bond between GPIb-V-IX and VWF also has a rapid off-rate, implicating that by itself it is insufficient for stable platelet adhesion, except in situations of quite high-shear rate. The adhesion of platelets to VWF is stabilized by weak activation of integrin $\alpha_{\| 1 b} \beta_{3}$, which mediates the integrin-dependent binding of platelets to VWF, and also facilitates the binding to platelets of plasma components such as fibrinogen and fibronectin. ${ }^{12,13}$ Interestingly, GPIb-V-IXdependent activation of $\alpha_{\| \mathrm{lb}} \beta_{3}$ appears to be impaired in platelets from mice lacking phospholipase D1 by a mechanism that relies on reduced phosphatidic acid production. ${ }^{14,15}$

In both the human and mouse systems, platelet interaction with collagen/vWF provides one of the most potent ways to attain stable adhesion and to trigger platelet activation processes to thrombus formation. 3,12,16 The signalling in platelets occurs by way of interplay between multiple receptors with, next to GPIb-V-IX and $\alpha_{\| b} \beta_{3}$, the immunoglobulin-family collagen receptor, GPVI, and the adhesive collagen receptor, integrin $\alpha_{2} \beta_{1}{ }^{17,18}$ Activation of platelets via GPVI, in complex with the Fc receptor $\gamma$-chain (FcR $\gamma$ ), is mediated by a 'signalosome' of multiple proteins, including various adapter and scaffold proteins (e.g. LAT, Cbl-b), tyrosine protein kinases (e.g. Syk), phosphatidylinositol 3-kinases (PI 3kinases), and small GTP-binding proteins and their regulators (like Rac, Rho, CalDAG-GEFI). ${ }^{19}$ The GPVI-induced signalling culminates in activation of phospholipase C $\gamma 2$ (PLC $\gamma 2)$, which produces second messengers causing an intracellular release of $\mathrm{Ca}^{2+}$, followed by store-regulated influx of extracellular $\mathrm{Ca}^{2+}$ via the $\mathrm{Ca}^{2+}$-sensor STIM1, and activation of downstream protein kinases. $^{20}$ Integrin $\alpha_{2} \beta_{1}$, like other integrins interacting with their substrates, strengthens and stabilizes the adhesion of platelets to collagen. ${ }^{16,18}$ Platelets dispose of signalling mechanisms to tightly synchronize the activation stateand thus adhesiveness - of their various integrins. ${ }^{21}$ Under shear conditions, platelets can also arrest at other extracellular matrix proteins, like thrombospondin-1, but the ensuing signalling pathways are less intensively studied than for adhesion to collagen/vWF. ${ }^{8,22}$

The shear-dependent adhesion and subsequent intracellular signalling leads to a range of biochemical and morphological platelet responses. Alterations in platelet shape occur via remodelling of the actin-myosin cytoskeleton (via Rac1 and Rho-kinase pathways) and polymerization of 
microtubules (with Ran-binding protein 10), resulting in the formation of pseudopods and lamellipods after adhesion. ${ }^{23,24}$ Other prothrombotic responses include enhanced activation of the various integrins, the release of mediator molecules from platelet dense and alpha granules (such as ADP, ATP, and Gas6), the formation of thromboxane $A_{2}$, and the scrambling of membrane phospholipids. ${ }^{3,15,25}$ These processes achieve capturing of flowing platelets, thus leading to a growing platelet aggregate, where platelets primarily interact via activated $\alpha_{\| 1 b} \beta_{3}$ integrins that bridge fibrinogen or fibronectin molecules. At high-shear conditions, platelet-platelet interaction can also be achieved via GPIb-V-IX interacting with $\mathrm{VWF}$, bound itself to the platelet aggregate. ${ }^{26}$ Defects in these activation pathways may lead to impaired haemostasis and bleeding, as described in detail elsewhere. ${ }^{27}$

In the classical concept, the consolidation of a growing platelet thrombus is achieved by activation of the coagulation process. Blood coagulation can be initiated by (extrinsic) tissue factor highly expressed at the surface of subendothelial cells and, alternatively, by collagen and platelet-derived polyphosphates, which trigger the (intrinsic) factor XII pathway of coagulation. ${ }^{28-30}$ Subendothelial tissue factor, particularly on fibroblasts and smooth muscle cells, needs encryption before it becomes active in coagulation, possibly through disulfide bond changes by protein disulfide isomerase. ${ }^{3,31}$ Also tissue factor on microparticles can fulfil such a role. ${ }^{32}$ These initial processes can only become effective if enforced in the propagation phase of coagulation, depending on the exposure of procoagulant phospholipids, formed at the membrane of platelets and other cells by a $\mathrm{Ca}^{2+}$-dependent phospholipid scramblase. ${ }^{3,33}$ Thus, membranes with the surface expression of phosphatidylserine provide an active site for coagulation factor complexes formation and thrombin generation. ${ }^{2,34}$ The generated thrombin produces fibrin fibres at the platelet surface, which are considered to stabilize and consolidate the thrombus, and to mediate plateletdependent clot retraction. ${ }^{35,36}$ This fibrin network can trap flowing erythrocytes and leucocytes, ultimately resulting in full-vessel occlusion.

This sequential scheme of arterial (occlusive) thrombus formation explains why such a wide variety of drugs in use or in study can suppress this process, i.e. blockers of: GPIb-V-IX (humanized antibodies), thromboxane $A_{2}$ formation (aspirin), P2Y 12 receptors (clopidogrel, prasugrel, ticagrelor), $\alpha_{\| 1} \beta_{3}$ integrins (abciximab, eptifibatide, tirofiban), thrombin generation (anticoagulants), and protease-activated receptor (PAR)- 
family thrombin receptors. ${ }^{37}$ However, as discussed extensively elsewhere, minor or major bleeding is a known undesired side effect of essentially all these drug types. ${ }^{15,27}$ This explains the still continuous search for new targets of antithrombotic drugs, where the risk of bleeding is minimal.

\section{Vascular control}

Discussed extensively elsewhere are the molecular processes by which the healthy endothelium suppresses the coagulation process. $^{3}$ The thromboprotective potential of vascular endothelial cells also extends to preventing stable platelet adhesion and activation by a variety of mechanisms (Figure 1). The endothelial products nitric oxide and prostacyclin (prostaglandin $\mathrm{I}_{2}$ ) both act to relax vascular smooth muscle cells and inhibit platelet activation. ${ }^{38}$ Thus, in healthy endothelium, nitric oxide and prostacyclin maintain a low blood pressure, reduce blood shear forces, and suppress platelet activation. Mouse models confirm the antithrombotic roles of both products. Hence, mice lacking endothelial nitric oxide synthase show an impaired vasodilator response in conductance vessels. Mouse models, in which the cOX2-dependent formation of prostacyclin or its action is disrupted, present with a predisposition to thrombotic events. ${ }^{39}$ Another platelet- inhibiting protein at the endothelial surface is the ectonucleotidase CD39, which degrades (endothelial-derived) ATP and ADP, and thus prevents platelet activation by these nucleotides. Furthermore, the adenosine produced by CD39 has anti-platelet activity. ${ }^{40}$ Clearly, these thrombo-protective effects of the vessel wall are abolished upon local damage or disruption of the endothelium. A recent topic of interest is the role of vessel wall-adherent leucocytes in thrombus formation. In certain mouse models, neutrophils can adhere even earlier than platelets upon vascular damage, with as a result increased tissue factor-dependent fibrin generation and platelet accumulation. ${ }^{41}$ Both neutrophils (forming neutrophil extracellular traps) and monocytes (exposing tissue factor) support the thrombotic process especially under conditions of venous thrombosis. ${ }^{42,43}$ The relevance of these processes for the development of arterial thrombosis is still unclear.

\section{New concepts: dynamic, fine-tuned regulation of thrombus growth and stabilization}

The classical scheme described above considers arterial thrombus formation as a simple progressive process, starting with platelet adhesion and ending with occlusion of the locally activated or damaged vessel. However, many experimental studies, either in vivo with 


\section{Thromboprotective vascular function}

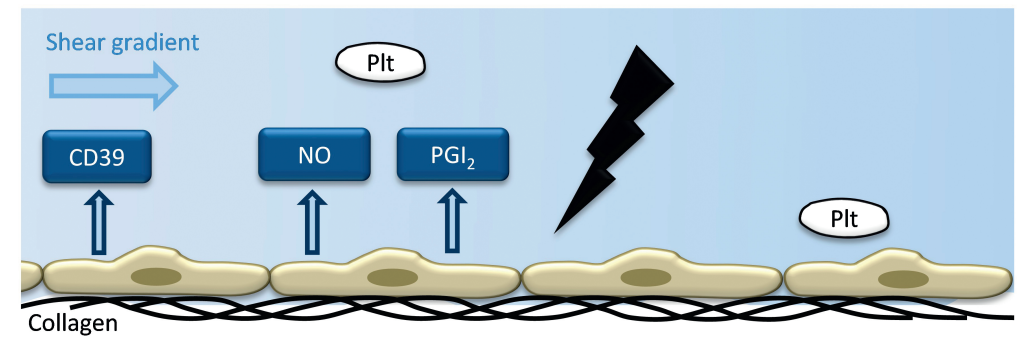

II. Shear induced platelet adhesion (de-adhesion)

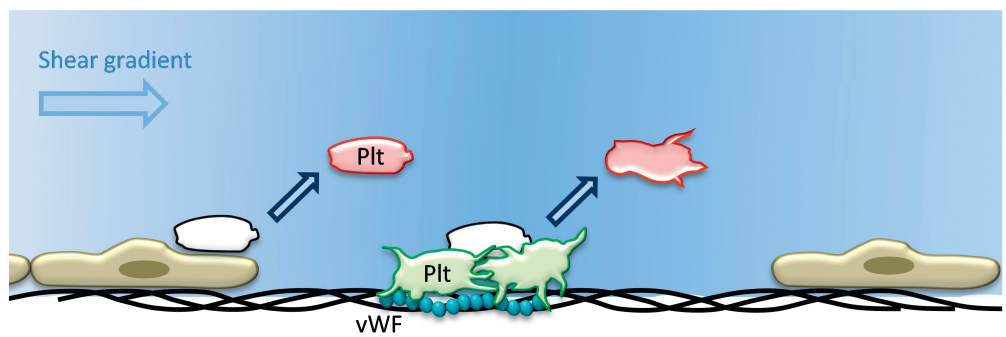

\section{Platelet aggregation (small emboli)}

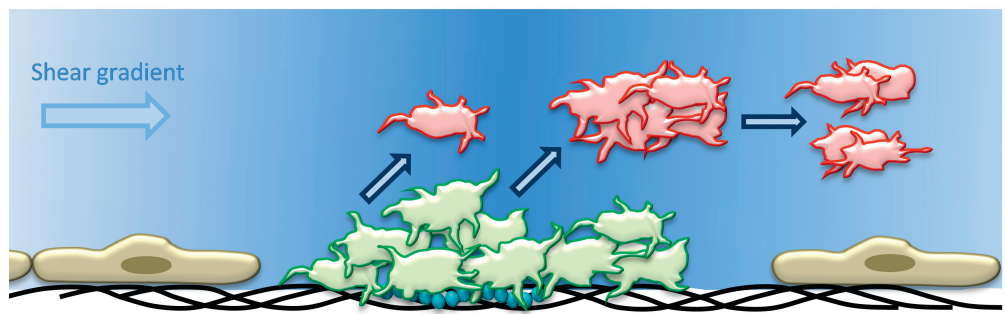

\section{Platelet contraction and procoagulant activity (large emboli)}

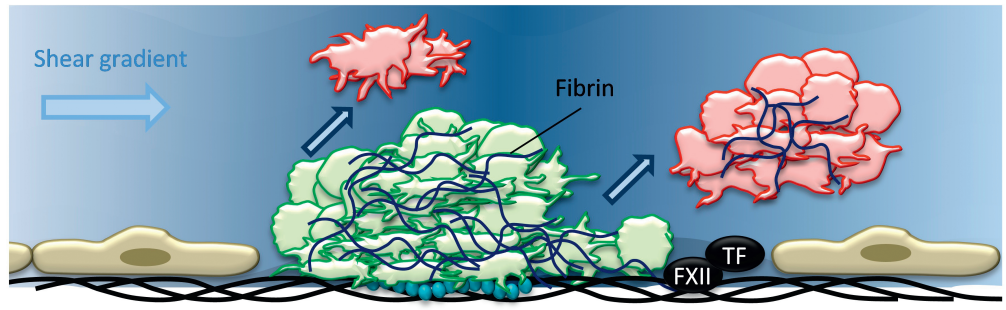

Figure 1. Thrombus growth and instability in a damaged artery. (I) Endothelial activity at the healthy vessel wall prevents platelet (PIt) adhesion. (II) Shear-induced adhesion of platelets at exposed subendothelial collagen/vWF allows platelets to aggregate, partly in a reversible way. (III) During the build-up phase of a thrombus, small emboli are shed. (IV) In a grown thrombus containing contracted and fibrin-anchored platelets, local heterogeneities and blood flow shear gradients allow the shedding of larger emboli. 
experimentally damaged arteries in mice, or in vitro with flow chambers perfused with whole-blood, point to a more complex organization of the thrombosis process in time. In the macro-circulation (carotid artery) and the microcirculation (mesenteric and cremaster arterioles), it is often examined that single platelets can adhere and detach during the buildup phase of a thrombus. Furthermore, once a discernible thrombus has been formed, it contracts and tends to shed smaller or larger emboli for a certain period of time (Figure 1). Accordingly, flow-dependent dynamics of platelet detachment, embolus shedding, and unstable occlusion seem to be common events during the process of thrombus formation. A large number of studies with genetically modified mice point to the involvement of many plateletderived and coagulant proteins in the dynamic regulation of the stability of thrombi formed at arterial flow conditions (Table 1). Hence, the classical concept of thrombus formation needs adjustments accommodating the flowdynamic components. Refinements, particularly, explaining the dynamics and heterogeneities of thrombus build-up and fate, are described below. Participation of vascular- or leucocytederived proteins in the control of thrombus stability has hardly been described in the literature.
Integrin $\alpha_{l l b} b_{3}$ activation and reversible platelet aggregation

Impaired or diminished activation of platelet $\alpha_{\| 1 b} \beta_{3}$ is known to cause instability of thrombi, which are formed under flow in vivo or in vitro, and to stimulate the detachment of single platelets and small aggregates..$^{44,45}$ In vitro observations support the notion that $\alpha_{11 b} \beta_{3}$ activation is a reversible process, and that persistent signalling in platelets is required to keep this integrin in an activated, pro-adhesive conformation. ${ }^{46}$ Several autocrine and paracrine (between platelets) signalling processes appear to contribute to persistent integrin activation, and many of these have been shown to be involved in thrombus stabilization. A prominent factor is the release of ADP and its interaction with platelet $\mathrm{P} 2 \mathrm{Y}_{12}$ receptors, which stimulates integrin activation via a pathway involving PI3-kinase, Akt2, Rap1b, and filamin A (Figure 2). ${ }^{46-49}$ Enforced integrin activation is furthermore achieved by interaction of CD40L with its supposed ligand CD40, both of which are membrane proteins that regulate thrombus stability. ${ }^{50}$ Another mechanism for continued integrin activation is provided by interaction of the soluble molecule Gas6 (present in plasma and limitedly stored in platelets) with the platelet TAM receptors, Tyro, Axl, and Mer..$^{51-53} \mathrm{New}$ 
Table 1. Reported effects of genetic deficiency in mouse on embolization during arterial thrombus formation in vivo or in vitro. Indicated are the mouse genes, the corresponding proteins in blood platelets or plasma, the murine thrombosis model used (flow device in case of in vitro studies), the effect on embolus formation (+, increased; ++ highly increased, -, decreased). Abbreviation: MGI, mouse genome index.

\begin{tabular}{|c|c|c|c|c|c|c|}
\hline Gene defect & MGI & Protein defect & Thrombosis model & Effect on arterial thrombus formation & Emboli & Ref(s). \\
\hline \multicolumn{7}{|c|}{ Platelet receptors and membrane proteins } \\
\hline Axl & 1347244 & Axl (Gas6 receptor) & flow device & increased thrombus disaggregation & + & 53 \\
\hline Adra2a & 87934 & a2 adrenergic receptor & mesentery $/ \mathrm{FeCl}_{3}$ & increased formation of emboli & + & 95 \\
\hline Cd151 & 1096360 & tetraspanin CD151 & carotis/ligation, cremaster/laser & increased thrombus instability & ++ & 56 \\
\hline Cd40lg & 88337 & $\mathrm{CD} 40 \mathrm{~L}$ & mesentery $/ \mathrm{FeCl}_{3}$ & delayed occlusion, more unstable thrombi & ++ & so \\
\hline Fcer1g & 95496 & FcR g-chain & carotis/ligation, cremaster/laser & smaller thrombi, more emboli formed & + & 76,96 \\
\hline Gp1ba & 1333744 & GPIba & carotis/ligation & smaller thrombi, reduced stable platelet adhesion & ++ & 97 \\
\hline Gp5 & 1096363 & GPV & mesentery $/ \mathrm{FeCl}_{3}$ & smaller thrombi, increased detachment & ++ & 98,99 \\
\hline Gp6 & 1889810 & GPVI & carotis $/ \mathrm{FeCl}_{3}$, ligation & smaller thrombi, reduced stable platelet adhesion & ++ & 100,101 \\
\hline Itga2 & 96600 & integrin a2 & mesentery $/ \mathrm{FeCl}_{3}$, flow device & smaller thrombi, more emboli formed & + & 75,102 \\
\hline Lat & 1342293 & LAT & cremaster/laser & smaller thrombi, more emboli formed & ++ & 76 \\
\hline Mertk & 96965 & Mer (Gas6 receptor) & flow device & increased thrombus disaggregation & + & 53 \\
\hline P2yr12 & 1918089 & $\mathrm{P}_{2} \mathrm{Y}_{12}$ receptor & $\begin{array}{l}\text { mesentery/FICl } \\
\text { flow cremaster/laser } \\
\text { fleve }\end{array}$ & smaller thrombi, more emboli formed & ++ & $\begin{array}{l}47,103 \\
103,104\end{array}$ \\
\hline Slamf1 & 1351314 & SLAM (CD84) & mesentery $/ \mathrm{FeCl}_{3}$ & delayed occlusion, more emboli formed & + & 59 \\
\hline Tspan32 & 1350360 & tetraspanin TSSC6 & mesentery $/ \mathrm{FeCl}_{3}$ & increased thrombus instability & + & 55 \\
\hline Tyro3 & 104294 & Sky (Gas6 receptor) & flow device & increased thrombus disaggregation & + & 53 \\
\hline Ceacam1 & 1347245 & CEACAM1 & mesentery $/ \mathrm{FeCl}_{3}$ & larger thrombi, less emboli formed & - & 62 \\
\hline Esam & 1916774 & ESAM & cremaster/laser & larger thrombi, less detachment & - & 63 \\
\hline$\overline{\text { Gja4 }}$ & 95715 & connexin 37 & mesentery $/ \mathrm{FeCl}_{3 \backslash}$ & increased thrombus formation, less emboli & - & 65 \\
\hline \multicolumn{7}{|c|}{ Platelet intracellular signaling proteins } \\
\hline Akt2 & 104874 & Akt2 & carotis $/ \mathrm{FeCl}_{3}$ & smaller thrombi, increased instability & ++ & 105 \\
\hline Cblb & 2146430 & Cbl-b & carotis $/ \mathrm{FeCl}_{3}$ & delayed occlusion, unstable thrombi & + & 106 \\
\hline Flna & 95556 & filamin A & flow device & increased platelet detachment & + & 107 \\
\hline Myh9 & 107717 & myosin heavy chain-9 & carotis $/ \mathrm{FeCl}_{3}$ & reduced thrombus growth, more emboli formed & + & 23 \\
\hline Plcg2 & 97616 & phospholipase $\mathrm{Cg} 2$ & cremaster/ laser, flow device & (smaller) thrombi, increased instability & ++ & 76,108 \\
\hline Prkaa2 & 1336173 & AMPK-a2 & carotis $/ \mathrm{FeCl}_{3}$ & less compact thrombus, more emboli formed & + & 109 \\
\hline Pik3cb & 1922019 & PI 3-kinase-b & flow device & increased thrombus disaggregation & ++ & 46 \\
\hline Pik3cg & 1353576 & PI 3-kinase-g & flow device & unstable thrombi, increased disassembly & ++ & 46 \\
\hline Rac1 & 97845 & Rac1 & cremaster/laser, flow device & increased instability of thrombi & ++ & 110 \\
\hline Ranbp10 & 1921584 & Ran-binding protein 10 & mesentery $/ \mathrm{FeCl}_{3}$ & reduced occlusion, unstable thrombi & + & 24 \\
\hline Rhoa & 1096342 & RhoA & mesentery $/ \mathrm{FeCl}_{3}$ & reduced occlusion, more emboli formed & ++ & 61 \\
\hline Stim1 & 107476 & STIM1 & mesentery $/ \mathrm{FeCl}_{3}$ & delayed occlusion, increased platelet detachment & + & 111 \\
\hline \multicolumn{7}{|c|}{ Plasma proteins } \\
\hline C3 & 88227 & complement factor 3 & cremaster/photochemical & delayed thrombus formation, more emboli & + & 112 \\
\hline F11 & 99481 & factor $\mathrm{XI}$ & mesentery/ $/ \mathrm{FeCl}_{3}$ & increased detachment of thrombi & + & 80 \\
\hline F12 & 1891012 & factor XII & carotis $/ \mathrm{FeCl}_{3}$, mesentery $/ \mathrm{FeCl}_{3}$ & increased detachment of thrombi & ++ & 80,81 \\
\hline Fgg & 95526 & fibrinogen g-chain & carotis $/ \mathrm{FeCl}_{3}$, mesentery $/ \mathrm{FeCl}_{3}$ & increased detachment of thrombi & ++ & 113,114 \\
\hline $\mathrm{Fn}$ & 95566 & fibronectin & mesentery $/ \mathrm{FeCl}_{3}$ & delayed formation of unstable thrombi & ++ & 115 \\
\hline Gas6 & 95660 & Gas6 & flow device & increased thrombus disaggregation & + & 53 \\
\hline Klk4 & 1861379 & prekallikrein & mesentery $/ \mathrm{FeCl}_{3}$ & reduced thrombus formation, more emboli & + & 81 \\
\hline Lep & 104663 & leptin & carotis/ $\mathrm{FeCl}_{3}$ & delayed occlusion, unstable thrombi & + & 116 \\
\hline Serpine1 & 97608 & PAI-1 & carotis $/ \mathrm{FeCl}_{3}$ & longer time to occlusion, unstable thrombi & + & 117 \\
\hline Thbs1 & 98737 & thrombospondin-1 & mesentery/photochemical & prolonged occlusion, more emboli formed & + & 118 \\
\hline Vtn & 98940 & vitronectin & carotis $/ \mathrm{FeCl}_{3}$, mesentery $/ \mathrm{FeCl}_{3}$ & longer time to occlusion, unstable thrombi & ++ & 117,119 \\
\hline Wvf & 98941 & vWF & mesentery $/ \mathrm{FeCl}_{3}$ (venules) & reduced thrombus formation, unstable & + & 120 \\
\hline $\mathrm{Plg}$ & 97620 & plasminogen & carotis/photochemical & shortened occlusion, less emboli & - & 121 \\
\hline
\end{tabular}

data yet suggest that plasma Gas6 may also stimulate the coagulation process by regulating the expression of vascular tissue factor. ${ }^{54}$

Limited integrin activation also explains why, at gradients of shear stress, platelets tend to loosely adhere to a growing thrombus via GPIb-V-IX in an often instable way. ${ }^{10}$ Another family of proteins that is considered to modulate platelet integrin function is provided by the tetraspanins, of which TSSC6 and CD151 are abundantly expressed in the platelet membrane. Tetraspanin control of $\alpha_{11 b} \beta_{3}$ activation may explain why the genetic ablation of TSSC6 or CD151 results in thrombus instability and increased embolus formation. ${ }^{55,56}$

Another mechanism controlling the activation of $\alpha_{11 b} \beta_{3}$ and other integrins is by redox control of free-cysteine thiols in the extracellular chains, particularly by 
the protein disulfide isomerase. ${ }^{57}$ How the redox control affects thrombus stabilization is still unknown.

Contact-dependent signalling to tight platelet interactions

Particularly, the work of Brass et al. has led to substantial insight into so-called contact-dependent activation pathways, by which platelets can tightly interact with each other in a thrombus. 5,58

Contact-dependent signalling occurs by pairs of ligands and receptors, such as ephrin B1-EphA4 (which enforces $\alpha_{11 b} \beta_{3}$ activation and prevents platelet disaggregation), and semaphorin 4Dplexin (which supports Syk-mediated platelet activation); as well as by tight platelet-platelet interactions through JAM- and SLAM-family members. ${ }^{5,59}$ Deficiency in several of these proteins has been found to impair the stabilization of mouse thrombi formed in vivo (Table 1). Jointly, these interaction establish close platelet-platelet contacts, which is considered to be a requirement for the stabilizing contraction of platelets in the thrombus core. ${ }^{58}$ Inside platelets, signalling via Rho-kinase to myosin and actin appears to be a key mechanism transmitting the contractile forces from the cell surface to the cytoskeleton. ${ }^{60}$ This may explain why arterial thrombi in mice lacking RhoA or myosin heavy chain-9 are characteristically unstable and show frequent embolization. ${ }^{23,61} \mathrm{~A}$ different set of contact receptors has been identified that negatively regulates platelet activation and thrombus stability. In mice, the absence of the CEACAM1 or ESAM receptors resulted in an increased thrombus growth and reduced embolus shedding. ${ }^{62,63}$ It is hence tentative to suggest that, within a thrombus, local balances of the platelet-activating and platelet-inhibiting contact signalling events determine which part of the thrombus can contract to form a stable plug, and which part of the thrombus does not contract and is susceptible for detachment of single of aggregated platelets. Intra-thrombus differences in contact-dependent signalling may also explain the reported heterogeneity within a thrombus with contracted, procoagulant, and loosely aggregated platelets. ${ }^{64}$ However, as described above, also the partial penetration of thrombin and fibrin into a thrombus may contribute to this heterogeneity.

A negative role in thrombus stability has also been observed for the contact protein, connexin 37.65 This is a gap junction protein expressed in platelets, as well as in endothelial cells, smooth muscle cells, monocytes, and macrophages. ${ }^{65-67}$ Interestingly, the conclusions from the two publications regarding the role of connexin 37 in platelets are different: one research group concludes that it functions by limiting platelet activation and thrombus 
I. Initial platelet aggregation

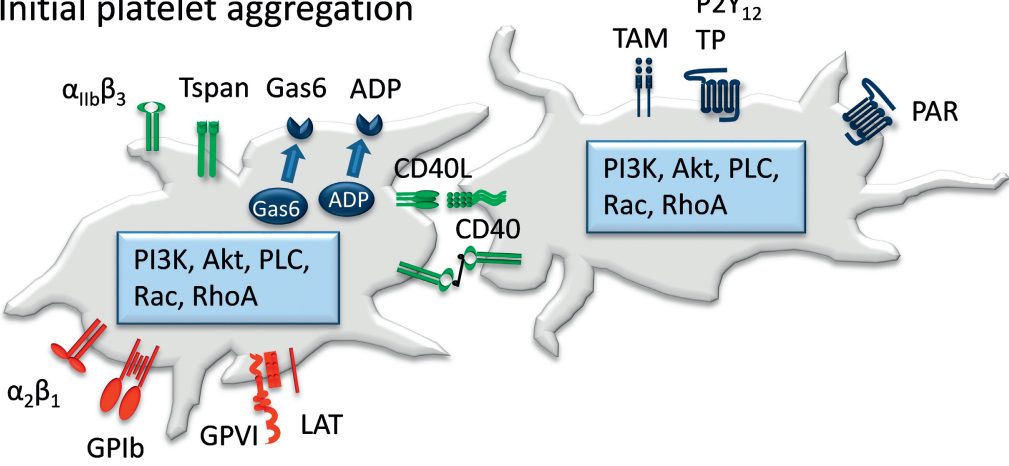

\section{Contact-dependent platelet activation}

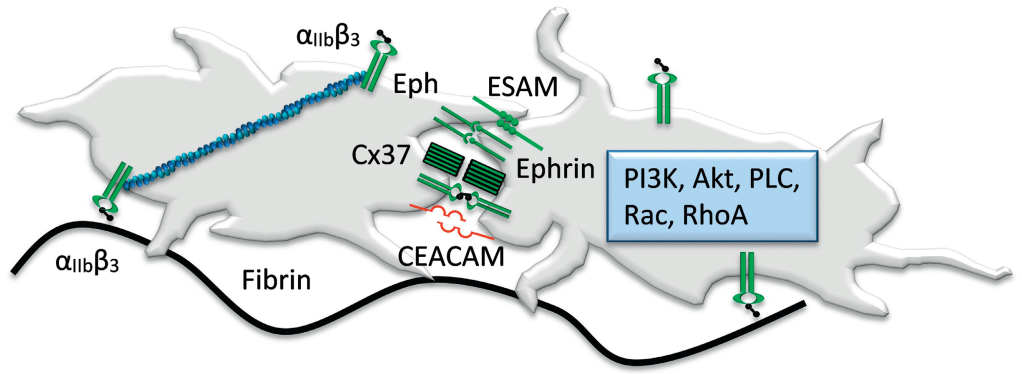

\section{Coagulation factor stimulation}

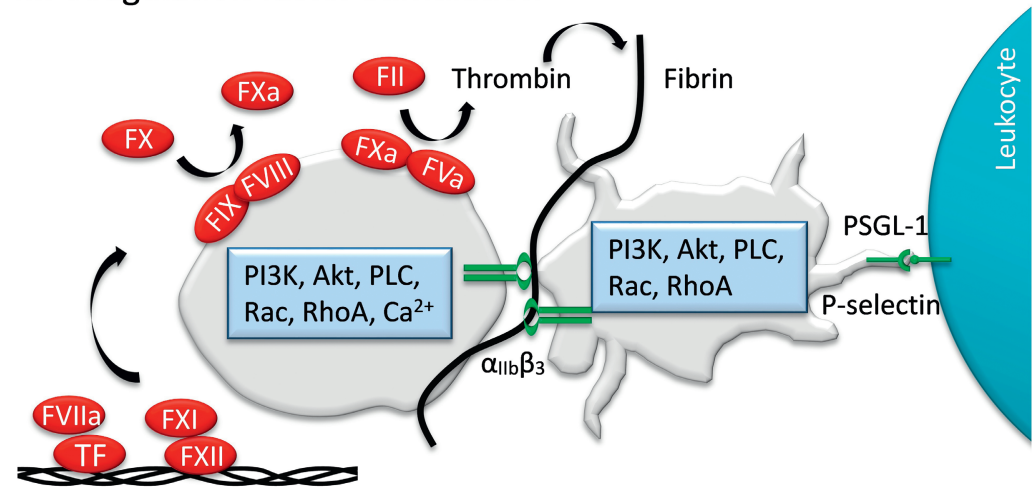

Figure 2. Key platelet and plasma proteins contributing to thrombus stability. (I) Platelet receptors and ligands involved in initial integrin $\alpha_{\| b} \beta_{3}$ activation and reversible platelet aggregation (see Table 1). The absence of these molecules increases thrombus instability. Also indicated is a box with intracellular signalling proteins controlling this process. II. Contact-dependent signalling mechanisms implicated in platelet contraction and irreversible platelet aggregation. Fibrin formed by the coagulation process stabilizes the platelet aggregate. (III) Plasma coagulation factors, via the intrinsic (factor XII, FXII) and extrinsic (tissue factor, TF) pathways, mediating plateletdependent thrombin and fibrin generation, stabilizing a growing thrombus. Also indicated is a primary mechanism of platelet-leucocyte interaction via P-selectin and PSGL-1. See further Versteeg et al. ${ }^{3}$ 
stabilization, ${ }^{65}$ while the other group finds that it promotes platelet activation. ${ }^{67}$ An approach to take this further would be the generation of mice lacking connexin 37 only in platelets.

\section{Multisided regulation by coagulation}

The role of coagulation in thrombus formation and stabilization appears to be more complex than earlier thought. Thrombin that is formed at the thrombus surface contributes to platelet activation by interaction with PARs. ${ }^{68,69}$ Recent evidence suggests that the contribution of PARs to platelet activation is dependent on the blood flow rate. Whereas PARs activate platelets at lowshear conditions, their role becomes diminished at pathologically high shear rates. ${ }^{70}$ Yet, thrombin-induced signalling contributes to the generation of procoagulant PS exposing platelets, which are abundantly formed in arterial thrombi. ${ }^{71}$ There is ongoing research to find other strong agonists-besides thrombin-that can support collageninduced platelet activation (via GPVI). Currently in the spot light are the CLEC-2 receptors, which via an unknown ligand, have been implicated in arterial thrombus formation in mice. ${ }^{72}$ Such strong agonists other than thrombin may also stimulate the contraction of platelets, making an aggregate stable. ${ }^{60}$ On the other hand, fibrin clot retraction, mediated via activated $\alpha_{11 b} \beta_{3}$ integrins, is still considered to be a main mechanism for platelet contraction in a stabilising thrombus. ${ }^{34}$

Although it may be obvious that fibrin formation is needed for a stable thrombus, reports on the effects of thrombin inhibitors in arterial models in vivo primarily point to a reduced thrombus growth, rather than to thrombus instability. ${ }^{73-76}$ A certain amount of fibrin formation yet seems to be important, since in flow devices in vitro the inhibition of fibrin polymerization resulted in shear-induced shedding of emboli. ${ }^{77}$ Mechanistically, these findings are not easy to explain. At the one hand, the formation rates of thrombin and fibrin decrease at a higher shear rate, as a consequence of thrombin dilution by blood flow, which suggests that thrombin generation is a limiting factor in arterial thrombus formation. ${ }^{69,78}$ At the other hand, neither thrombin nor fibrin is uniformly distributed in an arterial thrombus, 73,79 which may imply that a consolidating fibrin network is only present in parts of the thrombus.

Another relevant finding is that especially deficiencies in the intrinsic coagulation pathway (prekallikrein, factor XII, or factor XI) reduce thrombus stability and provoke embolus formation. ${ }^{80,81}$ In agreement with this, pharmacological inhibition of the factor XII pathway results in the formation of 
large emboli shed from arterial but also provide the force for thrombi. ${ }^{82}$ These data point to a thrombus-destabilizing effect upon partial-and likely non-uniformsuppression of the clotting process within a thrombus. More research is needed to understand the precise role of the intrinsic coagulation pathway.

Interestingly, reports on the roles of anticoagulant proteins carried by platelets do not describe effects on thrombus stability. For example, tissuefactor pathway inhibitor located in platelets plays a significant role in the control of thrombus growth, but was not reported to influence thrombus stability. ${ }^{83}$ The same is true for its cofactor, protein S (Calzavarini, AngelilloScherrer, unpublished observations, 2012). More thorough studies to the effect of genetic deficiency restricted to mouse platelet proteins are needed to advance this field.

\section{Disturbances in blood rheology}

An aspect that is discussed extensively elsewhere, ${ }^{2}$ is the contribution of blood flow, and in particular of rheological disturbances, on the stabilization or embolization of near-occlusive thrombi. When a stenotic or otherwise vulnerable vessel tends to become occluded, highshear gradients are generated around the growing thrombus. These flow disturbances will not only accelerate platelet activation and fibrin formation, embolization of smaller or larger platelet aggregates (Figure 1). Flow pulsations by the heart rhythm and vascular distension may further aggravate the extent of embolization and perhaps the size of the emboli, but this has hardly been investigated. Another still poorly studied aspect is how red blood cells-either flowing or when bound to fibrin fibrescontribute to thrombus stability under arterial flow conditions.

\section{Genetic mouse models and flow} chambers: key pathways of thrombus (in)stability identified?

The above described mechanisms point to involvement of a surprisingly high number of proteins in the vessel wall, platelets, and the coagulating plasma, that contribute to the formation and stabilization of an arterial thrombus. Table 1 provides a list of experimental thrombosis studies using mice, where effects have been measured of genetic modification on stable platelet adhesion or shedding of emboli, following damage of vessels of the macro-circulation (carotis artery) or microcirculation (mesenteric or cremaster artery). The evidence for thrombus instability comes from either intravital microscopic observations or rapid changes in blood flow, measured with Doppler probes. Table 2 gives a list of drug interventions that have been shown to influence 
thrombus stability in vitro during the perfusion of the human blood through a flow device at a high arterial shear rate.

As indicated in Table 1, for 44 different mouse genes a notable change in stability of arterial thrombi has been reported. This list mostly concerns genes and proteins that also play a role in the overall process of thrombus growth. In short, referring to the mechanisms described above, this concerns genes implicated in: (i) GPIb-V-IX and GPVIdependent platelet adhesion (also $\alpha_{2} \beta_{1}$, FcR $\gamma$-chain); (ii) GPVI-mediated platelet signalling to $\mathrm{Ca}^{2+}$ rises and beyond (PLCY2, LAT, Cbl-b, STIM1, Rac1); (iii) integrin activation (PI 3-kinases, Akt2, filamin A, tetraspanins); (iv) autocrine and paracrine regulatory mechanisms supporting integrin activation ( $\mathrm{P}_{2} \mathrm{Y}_{12}$, CD40, CD40L, Axl, Mer, Sky, SLAM); (v) and regulation of platelet contraction (RhoA, myosin). Furthermore relevant are genes of plasma proteins involved in: (vi) adhesion to platelets (vWF, fibrinogen, fibronectin, vitronectin, thrombospondin-1); (vii) activation of platelets (Gas6, leptin); and (viii) activation of the intrinsic coagulation cascade (prekallikrein, factors XI, XII). Interestingly, hardly any reports are available on thrombus instability due to specific platelet secretion defects. A suppressive role is reported for negative regulators of the contact activation (CEACAM1, ESAM, connexin 37).
The studies with human blood and flow devices to a certain extent support involvement of the same platelet activation pathways in thrombus stability and embolization in the human system (Table 2). In particular, this concerns a role of the $\alpha_{11 b} \beta_{3}$ activation pathway, in that inhibition of P2Y receptors, PI 3kinases, or the integrins themselves results in embolization. Thrombus instability is also examined upon inhibition of platelet contraction (EphA4, ephrinB1), Gas6 activity or fibrin formation. More work is clearly needed to demonstrate the importance of the other proteins identified in mouse for the human system.

\section{What can we learn more from patient observations?}

In man, thrombosis refers to the pathological condition where thrombi form inopportunely in the lumen of vulnerable vessels, leading to interruption of blood flow, occlusion, and ensuing tissue damage. Antithrombotic drugs, which comprise antiplatelet, anticoagulant, and antifibrinolytic drugs, are commonly used for the treatment and secondary prevention of such thromboses in arteries and veins. ${ }^{2,37}$ The common cause is rupture or erosion of an atherosclerotic plaque or a local disturbance in haemodynamic shear forces in the flowing blood. Arterial 
thrombosis, causing heart attacks, stroke, or limb gangrene, is responsible for almost $50 \%$ of mortality in industrialized countries. Next to treatments stimulating vasodilatation, antiplatelet drugs are the first choice for treatment of (secondary) arterial thrombosis. ${ }^{84}$ It is relevant to note here that non-steroidal antiinflammatory drugs, particularly those which inhibit COX2-dependent formation of prostacyclin in the vessel wall, confer a cardiovascular hazard. ${ }^{39}$ Such drugs antagonize the capacities of prostacyclin to suppress platelet activation and vasoconstriction. This can predispose to thrombosis, hypertension, and atherosclerosis.

Patients with a transient ischaemic attack/stroke or myocardial infarction mostly suffer from thrombosis of the atherosclerotic carotid or coronary artery. Such patients may present with symptomatic emboli that are shed from the earlier formed thrombi. However, in case of acute stroke or post-operatively after carotid endarterectomy, patients may also develop clinically asymptomatic embolization. ${ }^{85}$ Asymptomatic embolization has also been reported following carotid artery stenosis. ${ }^{86}$ In such patients, shedding of platelet emboli from the thrombotic carotid artery can be detected using transcranial Doppler ultrasound, for the major part without pathological consequences. $^{87}$ This indicates that embolization is a frequent phenomenon after a thrombotic event that, although often clinically silent, yet may form an increased risk of becoming symptomatic. More research is clearly needed to ascertain this.

Because of the reduced blood flow in the vein system, venous thrombosis relies more on thrombin and fibrin generation. Patients with venous thrombosis or venous thromboembolism are treated with several types of anticoagulants. 88,89 Vitamin $\mathrm{K}$ antagonists produce their anticoagulant effect by interfering with the $\mathrm{Y}$-carboxylation of vitamin $\mathrm{K}$ dependant prothrombin and factors VII, $I X$, and $X$. Unfractionated heparins are indirect anticoagulants that bind to antithrombin, enhancing its ability to inhibit activated factor $X$, thrombin, and other coagulation factors. Low molecular-weight heparins and analogues (danaparoid, fondaparinux) bind to antithrombin, and selectively potentiate its anti-factor Xa activity. Drugs like lepirudin (also bivalirudin, argatroban, dabigatran) are used as direct, selective inhibitors of thrombin, whereas the novel compounds rivaroxaban, apixaban, and edoxaban are direct inhibitors of factor Xa. Whereas all these drugs have proved to be clinically effective, there is hardly any knowledge on how their action is determined by the local flow conditions at the site of the thrombus. 
Table 2. Reported effects of pharmacological inhibitors on embolization of human thrombi under high-shear flow conditions in vitro. Perfusion studies of human blood flowed over collagen using flow devices. Indicated are the protein target, the inhibitor(s) use and the effect on embolus formation (+, increased).

\begin{tabular}{|c|c|c|c|c|}
\hline $\begin{array}{l}\text { Target protein } \\
\text { Platelet proteins }\end{array}$ & Inhibitor & Effect on arterial thrombus formation & Emboli & Ref(s). \\
\hline EphA4/ephrinB1 & [soluble fragments] & increased platelet disaggregation & + & 122 \\
\hline integrin allbb3 & abciximab, eptifibatide & increased platelet disaggregation & + & 123,124 \\
\hline myosin heave chain-II & blebbistatin & increased thrombus instability & + & 125 \\
\hline \multirow[t]{2}{*}{$\mathrm{P} 2 \mathrm{Y}_{1} / \mathrm{P} 2 \mathrm{Y}_{12}$ receptors } & MRS2179 / ticagrelor / 2-MeSADP) & increased thrombus instability & + & $44,124,126$ \\
\hline & AR-C69931MX & increased platelet disaggregation & + & 46 \\
\hline PI 3-kinase-b & TGX-221 & increased platelet disaggregation & + & 46 \\
\hline RhoA kinase & Y-27632 & reduced thrombus formation, increased instability & + & 60,125 \\
\hline \multicolumn{5}{|l|}{ Plasma proteins } \\
\hline fibrin polymer & GPRP & more unstable thrombi, releasing platelets & + & 77 \\
\hline Gas6 & [depleted plasma] & increased thrombus instability & + & 53 \\
\hline
\end{tabular}

An interesting case is provided by patients with specific coagulation defects in the absence of bleeding. Patients with afibrinogenaemia (complete fibrinogen deficiency) sometimes develop thrombosis. The thrombotic events can be located in either the arterial or venous territories. ${ }^{90}$ It is considered that in these patients thrombin that is formed is more active, since it cannot be inactivated by binding to fibrin. ${ }^{91}$ One of the consequences is increased platelet activation. ${ }^{92}$ The resulting, fibrin-poor thrombi are described as large but loosely packed, confirming that fibrin provides thrombus stability..$^{93}$ Interestingly, emboli are frequently observed in these patients. Treatment comprises concomitant infusion of fibrinogen and an anticoagulant, capable of binding fibrin-bound and free thrombin, e.g. a direct thrombin inhibitor. Severe factor XII deficiency may also provoke pulmonary embolization, e.g. in John Hageman, the index patient with factor XII deficiency. Epidemiological studies show a complex relation between severe factor XII deficiency and increased thrombotic risk. ${ }^{94}$ One of the explanations is that complete deficiency in factor XII restricts the formation of fibrin, and facilitates symptomatic embolization in a similar way as observed in murine studies. More translational research is required to link these clinical observations to those of the mouse models.

\section{Conclusions: the good and the bad of} arterial thrombus stabilization and embolus formation

As described above, mouse experimental thrombosis studies in general indicate that arterial thrombus growth and thrombus stability can be linked processes. Many platelet and plasma proteins that control thrombus growth also appear to play a role in stabilization of the thrombus. This is directly evident from intravital microscopy observations showing that flow-mediated adhesion of platelets can be a reversible event, and 
that single platelets as well as small or large platelet aggregates regularly detach from a thrombus even in wildtype mice. Hence, some degree of instability may be considered as a natural phenomenon in arterial thrombus formation. This is illustrated in Figure 1, schematizing that during thrombus growth smaller and larger emboli are shed. The limited clinical observations so far indicate that such shedding of emboli also occurs in thrombotic human arteries. On the other hand, thrombus growth and stability do not seem to be controlled in exactly the same ways. For instance, there are surprisingly few reports on a role of platelet secretion products in thrombus stabilization (Table 1), whereas platelet secretion is considered to be major determinant of thrombus growth. As schematized in Figure 2, key processes controlling the stability of a thrombus are (i) initial platelet integrin activation controlling platelet aggregation, which can be reversible resulting in shedding of platelet emboli; (ii) contact-dependent signalling, stabilizing the platelet aggregates; and (iii) plasma thrombin and fibrin generation via the intrinsic and extrinsic coagulation pathways, which provides the thrombus with a fibrin network, but still allows shedding of platelet-fibrin emboli (microclots).

In the clinical situation, the shedding of relatively large (fibrin-containing) emboli may be most harmful, giving rise to (semi)occlusive thrombus formation downstream in the vasculature. Clinically silent likely are those emboli that are smaller and prone to disintegration. Presently, we can only speculate on the mechanisms that favour the shedding of large emboli with pathological consequences. An interesting hypothesis is that these are due to local or temporal inhomogeneities in a thrombus, e.g. differences in platelet contraction or local incompleteness of fibrin formation. Thus, partial inhibition of 'later' pathways (irreversibly contracted platelets, platelet-fibrin clots) may result in emboli that are not only larger, but also more stable themselves and clinically symptomatic. Another possibility is that such emboli are formed by partial thrombolysis due to restricted fibrinolytic activity. This clearly needs further study. More thorough investigation is also needed to understand the roles of the natural platelet-inhibiting, coagulation-inhibiting and fibrinolytic pathways in the control of flow-dependent thrombus stability.

\section{Funding}

Swiss National Foundation for Scientific Research 310030-135822/1; Center for Translational Molecular Medicine (INCOAG); Netherlands Heart Foundation (2011T6); ZonMW (MKMD 114021004). 


\section{References}

1. Ruggeri ZM, Mendolicchio GL. Adhesion mechanisms in platelet function. Circ Res 2007;100:1673-1685.

2. Jackson SP. Arterial thrombosis: insidious, unpredictable and deadly. Nat Med 2011;17:1423-1436.

3. Versteeg $\mathrm{HH}$, Heemskerk JW, Levi M, Reitsma PS. New fundamentals in hemostasis. Physiol Rev 2013;93:327-358.

4. Jackson SP. The growing complexity of platelet aggregation. Blood 2007;109:5087-5095.

5. Brass LF, Wannemacher KM, Ma P, Stalker TJ. Regulating thrombus growth and stability to achieve an optimal response to injury. J Thromb Haemost 2011;9 (Suppl. 1):66-75.

6. Kroll MH, Hellums JD, Mclntire LV, Schafer Al, Moake JL. Platelets and shear stress. Blood 1996;88:1525-1541.

7. Sakariassen KS. Thrombus formation on apex of arterial stenoses: the need for a fluid high shear stenosis diagnostic device. Future Cardiol 2007;3:193-201.

8. Ruggeri ZM. Platelet-vessel wall interactions in flowing blood. In: Hemostasis and Thrombosis 2001:683-698.

9. Ruggeri ZM, Orje JN, Habermann R, Federici $A B$, Reininger AJ. Activation-independent platelet adhesion and aggregation under elevated shear stress. Blood 2006;108:1903-1910.

10. Nesbitt WS, Westein E, Tovar-Lopez FJ, Tolouei E, Mitchell A, Fu J, Carberry J, Fouras A, Jackson SP. A shear gradient-dependent platelet aggregation mechanism drives thrombus formation. Nat Med 2009;15:665-673.

11. Westein $E$, van der Meer $A D$, Kuijpers MJ, Frimat JP, van den Berg A, Heemskerk JW. Atherosclerotic geometries spatially confine and exacerbate pathological thrombus formation poststenosis in a von Willebrand factordependent manner. Proc Natl Acad Sci USA 2013;110:1357-1362.

12. Ruggeri ZM, Dent JA, Saldívar E. Contribution of distinct adhesive interactions to platelet aggregation in flowing blood. Blood 1999;94:172-178.
13. Wu YP, Vink T, Schiphorst $M$, van Zanten $\mathrm{GH}$ IJsseldijk MJ, de Groot PG, Sixma JJ. Platelet thrombus formation on collagen at high shear rates is mediated by von Willebrand factorglycoprotein $\mathrm{lb}$ interaction and inhibited by von Willebrand factor-glycoprotein Ilb/IIla interaction. Arterioscler Thromb Vasc Biol 2000;20:1661-1667.

14. Elvers M, Stegner D, Hagedorn I, Kleinschnitz G, Braun A, Kuijpers MJ, Boesl M, Chen Q, Heemskerk JW, Stoll G, Frohman MA, Nieswandt B. Impaired integrin $\alpha_{11 b} \beta_{3}$ activation and sheardependent thrombus formation in mice lacking phospholipase D1. Science Signal 2010;3:103 ra101.

15. Stegner D, Nieswandt B. Platelet receptor signaling in thrombus formation. I Mol Med 2011;89:109-121.

16. Farndale RW, Sixma JJ, Barnes MJ, de Groot PG. The role of collagen in thrombosis and haemostasis. J Thromb Haemost 2004;2:561-573.

17. Siljander PR, Munnix IC, Smethurst PA, Deckmyn $H$, Lindhout T, Ouwehand WH, Farndale RW, Heemskerk JW. Platelet receptor interplay regulates collagen-induced thrombus formation in flowing human blood. Blood 2004;103:13331341.

18. Auger JM, Kuijpers MJ, Senis YA, Watson SP, Heemskerk JW. Adhesion of human and mouse platelets to collagen under shear: a unifying model. FASEB J 2005;19:825-827.

19. Watson SP, Auger JM, McCarty OJ, Pearce AC GPVI and integrin $\alpha_{\| 1} \beta_{3}$ signaling in platelets. $J$ Thromb Haemost 2005;3:1752-1762.

20. Varga-Szabo D, Braun A, Nieswandt B. STIM1 and Orai1 in platelet function. Cell Calcium 2011;50:70-278.

21. Van de Walle G, Schoolmeester A, Iserbyt BF, Cosemans JM, Heemskerk JW, Hoylaerts MF, Nurden A, Vanhoorelbeke K, Deckmyn $\mathrm{H}$. Activation of $\alpha_{\| 1 b} \beta_{3}$ is sufficient but also an imperative prerequisite to activate $\mathrm{a} 2 \mathrm{~b} 1$ on platelets. Blood 2007;109:595-602.

22. Jurk K, Clemetson KJ, de Groot PG, Brodde MF, Steiner M, Savion N, Varon D, Sixma JJ, van Aken $\mathrm{H}$, Kehrel BE. Thrombospondin-1 mediates 
platelet adhesion at high shear via glycoprotein Ib (GPIb): an alternative/backup mechanism to von Willebrand factor. FASEB J 2003;17:14901492.

23. Léon C, Eckly A, Hechler B, Aleil B, Freund $M$, Ravanat $C$, Jourdain $M$, Nonne C, Weber J, Tiedt R, Gratacap MP, Severin S, Cazenave JP, Lanza F, Skoda R, Gachet C. Megakaryocyte-restricted MYH9 inactivation dramatically affects hemostasis while preserving platelet aggregation and secretion. Blood 2007;110:3183-3191.

24. Meyer I, Kunert S, Schwiebert S, Hagedorn I, Italiano JE, Dutting S, Nieswandt B, Bachmann S, Schulze $\mathrm{H}$. Altered microtubule equilibrium and impaired thrombus stability in mice lacking RanBP10. Blood 2012;120:3594-3602.

25. Gibbins JM. Platelet adhesion signalling and the regulation of thrombus formation. I Cell Sci 2004;117:3415-3425.

26. Nesbitt WS, Mangin P, Salem HH, Jackson SP. The impact of blood rheology on the molecular and cellular events underlying arterial thrombosis. J Mol Med 2006;84:989-995.

27. Wei AH, Schoenwaelder SM, Andrews RK, Jackson SP. New insights into the haemostatic function of platelets. $\mathrm{Br} J$ Haematol 2009;147:415-430.

28. Mackman N, Tilley RE, Key NS. Role of the extrinsic pathway of blood coagulation in hemostasis and thrombosis. Arterioscler Thromb Vasc Biol 2007;27:1687-1693.

29. Müller F, Mutch NJ, Schenk WA, Smith SA, Esterl L, Spronk HM, Schmidbauer S, Gahl WA, Morrissey JH, Renné T. Platelet polyphosphates are proinflammatory and procoagulant mediators in vivo. Cell 2009;139:1143-1156.

30. Van der Meijden PE, Munnix IC, Auger JM, Govers-Riemslag JW, Cosemans JM, Kuijpers MJ, Spronk HM, Watson SP, Renné T, Heemskerk JW. Dual role of collagen in factor XII-dependent thrombus and clot formation. Blood 2009;114:881-890.

31. Chen VM, Ahamed J, Versteeg HH, Berndt MC, Ruf W, Hogg PJ. Evidence for activation of tissue factor by an allosteric disulfide bond. Biochemistry 2006;45:12020-12028.
32. Owens AP, Mackman N. Role of tissue factor in atherothrombosis. Curr Atheroscler Rep 2012;14:394-401.

33. Monroe DM, Hoffman M. What does it take to make the perfect clot? Arterioscler Thromb Vasc Biol 2006;26:41-48.

34. Heemskerk JW, Mattheij N, Cosemans JM. Platelet-based coagulation: different populations, different functions. J Thromb Haemost 2013;11:2-16.

35. Reininger AJ, Bernlochner I, Penz SM, Ravanat C, Smethurst P, Farndale RW, Gachet C, Brandl R, Siess W. A 2-step mechanism of arterial thrombus formation induced by human atherosclerotic plaques. J Am Coll Cardiol 2010;55:1147-1158.

36. Cosemans JM, Schols SE, Stefanini L, de Witt S, Feijge MA, Hamulyak K, Deckmyn H, Bergmeier W, Heemskerk JW. Key role of glycoprotein $\mathrm{Ib} / \mathrm{V} / \mathrm{IX}$ and von Willebrand factor in platelet activation-dependent fibrin formation at low shear flow. Blood 2011;117:651-660.

37. Borissoff Jl, Spronk HM, ten Cate H. The hemostatic system as a modulator of atherosclerosis. N Engl J Med 2011;364:17461760 .

38. Moncada S, Higgs EA. Nitric oxide and the vascular endothelium. Handb Exp Pharmacol 2006;176:213-254.

39. Funk CD, FitzGerald GA. COX-2 inhibitors and cardiovascular risk. J Cardiovasc Pharmacol 2007;50:470-479.

40. Johnston-Cox HA, Ravid K. Adenosine and blood platelets. Purinergic Signal 2011;7:357-365.

41. Darbousset $\mathrm{R}$, Thomas GM, Mezouar S, Frère $\mathrm{C}$, Bonier R, Mackman N, Renné T, Dignat-George F, Dubois C, Panicot-Dubois L. Tissue factorpositive neutrophils bind to injured endothelial wall and initiate thrombus formation. Blood 2012;120:2133-2143.

42. Fuchs TA, Brill A, Duerschmied D, Schatzberg D, Monestier M, Myers DD, Wrobleski SK, Wakefield TW, Hartwig JH, Wagner DD. Extracellular DNA traps promote thrombosis. Proc Natl Acad Sci USA 2010;107:15880-15885.

43. Von Brühl ML, Stark $K$, Steinhart $A$, Chandraratne S, Konrad I, Lorentz M, Khandoga 
A, Tirniceriu A, Coletti $R$, Köllnberger $M$, Byrne RA, Laitinen I, Walch A, Brill A, Pfeiler S, Manukyan D, Braun S, Lange P, Riegger J, Ware J, Eckart A, Haidari S, Rudelius M, Schultz C, Echtler K, Brinkmann V, Schwaiger M, Pressner KT, Wagner DD, Mackman N, Engelmann B, Massberg S. Monocytes, neutrophils and platelets cooperate to inititate and propagate venous thrombosis in mice in vivo. J Exp Med 2012;209:819-835.

44. Goto S, Tamura N, Ishida H, Ruggeri ZM. Dependence of platelet thrombus stability on sustained glycoprotein Ilb/IIla activation through adenosine 5-diphosphate receptor stimulation and cyclic calcium signaling. J Am Coll Cardiol 2006;47:155-162.

45. Cosemans JM, Iserbyt BF, Deckmyn $H$, Heemskerk JW. Multiple pathways to switch platelet integrins on and off. J Thromb Haemost 2008;6:1253-1261.

46. Cosemans JM, Munnix IC, Wetzker R, Heller R, Jackson SP, Heemskerk JW. Continuous signaling via phosphoinositide 3-kinase isoforms $b$ and $g$ is required for platelet $A D P$ receptor function in dynamic thrombus stabilization. Blood 2006;108:3045-3052.

47. André $P$, Delaney SM, LaRocca $T$, Vincent $D$, DeGuzman F, Jurek M, Koller B, Phillips DR, Conley PB. P2 $2 \mathrm{Y}_{12}$ regulates platelet adhesion/activation, thrombus growth, and thrombus stability in injured arteries. J Clin Invest 2003;112:398-406.

48. Canobbio I, Stefanini L, Cipolla L, Ciraolo E, Gruppi C, Balduini C, Hirsch E, Torti M. Genetic evidence for a predominant role of $\mathrm{PI} 3 \mathrm{~K} \beta$ catalytic activity in ITAM- and integrin-mediated signaling in platelets. Blood 2009;114:2193-2196.

49. Nieswandt B, Varga-Szabo D, Elvers M. Integrins in platelets. J Thromb Haemost 2009;7 S1:206209.

50. André $P$, Srinivasa Prasad KS, Denis CV, He $M$, Papalia JM, Hynes RO, Phillips DR, Wagner DD. CD40L stabilizes arterial thrombi by a $\beta_{3}$ integrin-dependent mechanism. Nat Med 2002;8:247-252.

51. Angelillo-Scherrer A, Garcia de Frutos $P$, Aparicio C, Melis E, Savi P, Lupu F, Arnout J, Dewerchin M,
Hoylaerts MF, Herbert JM, Collen D, Dahlbäck B, Carmeliet P. Deficiency or inhibition of Gas6 causes platelet dysfunction and protects mice against thrombosis. Nat Med 2001;7:215-221.

52. Angelillo-Scherrer A, Burnier L, Flores N, Savi $P$, DeMol M, Schaeffer P, Herbert J-M, Lemke G, Goff SP, Matsushima GK, Earp HS, Vesin C, Hoylaerts MF, Plaisance S, Collen D, Conway EM, Wehrle-Haller B, Carmeliet P. Role of Gas6 receptors in platelet signaling during thrombus stabilization and implications for antithrombotic therapy. J Clin Invest 2005;115:237-246.

53. Cosemans JM, van Kruchten $R$, Olieslagers $S$, Schurgers LJ, Verheyen FK, Munnix ICA, Waltenberger J, Angelillo-Scherrer A, Hoylaerts MF, Carmeliet P, Heemskerk JW. Potentiating roles for Gas6 and Tyro, Axl and Mer (TAM) receptors in human and murine platelet activation and thrombus stabilization. J Thromb Haemost 2010;8:1797-1808.

54. Foley JH, Conway EM. Gas6 gains entry into the coagulation cascade. Blood 2013;121:570-571.

55. Goschnick MW, Lau LM, Wee JL, Liu YS, Hogarth PM, Robb LM, Hickey MJ, Wright MD, Jackson $D E$. Impaired outside-in integrin $\alpha_{\| 1} \beta_{3}$ signaling and thrombus stability in TSSC6-deficient mice. Blood 2006;108:1911-1918.

56. Orlowski E, Chand R, Yip J, Wong C, Goschnick MW, Wright MD, Ashman LK, Jackson DE. A platelet tetraspannin superfamily member, $\mathrm{CD} 515$, is required for regulation of thrombus growth and stability in vivo. J Thromb Haemost 2009;7:2074-2084.

57. Essex DW. Redox control of platelet function. Antioxid Redox Signal 2009;11:1191-1225.

58. Brass LF, Zhu L, Stalker TJ. Minding the gaps to promote thrombus growth and stability. J Clin Invest 2005;115:3385-3392.

59. Nanda N, Andre P, Bao M, Clauser K, Deguzman F, Howie D, Conley PB, Terhorst C, Phillips DR. Platelet aggregation induces platelet aggregate state stability via SLAM family receptor signalling. Blood 2005;106:3028-3034.

60. Ono A, Westein E, Hsiao S, Nesbitt WS, Hamilton JR, Schoenwaelder SM, Jackson SP. Identification of a fibrin-independent platelet contractile 
mechanism regulating primary hemostasis and thrombus growth. Blood 2008;112:90-99.

61. Pleines I, Hagedorn I, Gupta S, May F, Chakarova L, van Hengel J, Offermanns S, Krohne G, Kleinschnitz C, Brakebusch C, Nieswandt B. Megakaroycyte-specific RhoA deficiency causes macrothrombocytopenia and defective platelet activation in hemostasis and thrombosis. Blood 2012;119:1054-1063.

62. Wong $\mathrm{C}$, Liu $\mathrm{Y}$, Chand $\mathrm{R}$, Wee JL, Oates $\mathrm{L}$, Nieswandt B, Reheman A, Ni H, Beauchmin N Jackson DE. CEACAM1 negatively regulates platelet-collagen interactions and thrombus growth in vitro and in vivo. Blood 2009;113:1818-1828.

63. Stalker TJ, Wu J, Morgans A, Traxler EA, Wang L, Chatterjee MS, Lee D, Quertermouse T, Hall RA, Hammer DA, Diamond SL, Brass LF. Endothelial cell specific adhesion molecule (ESAM) localizes to platelet-platelet contacts and regulates thrombus formation in vivo. $J$ Thromb Haemost 2009;7:1886-1896.

64. Munnix IC, Kuijpers MJ, Auger JM, Thomassen $\mathrm{CM}$, Panizzi $\mathrm{P}$, van Zandvoort MA, Rosing J, Bock PE, Watson SP, Heemskerk JW. Segregation of platelet aggregatory and procoagulant microdomains in thrombus formation. Regulation by transient integrin activation. Arterioscler Thromb Vasc Biol 2007;27:24842490.

65. Angelillo-Scherrer A, Fontana P, Burnier L, Roth I, Sugamele R, Brisset A, Morel S, Nolli S, Sutter E, Chassot A, Capron C, Borgel D, Saller F, Chanson M, Kwak BR. Connexin 37 limits thrombus propensity by downregulating platelet reactivity. Circulation 2011;124:930-939.

66. Chanson M, Kwak BR. Connexin37: a potential modifier gene of inflammatory disease. $J \mathrm{Mol}$ Med 2007;85:787-795.

67. Vaiyapuri S, Jones $\mathrm{Cl}$, Sasikumar $\mathrm{P}$, Moraes LA, Munger SJ, Wright JR, Ali MS, Sage T, Kaiser WJ, Tucker KL, Stain CJ, Bye AP, Jones S, Oviedo-Orta E, Simon AM, Mahaut-Smith MP, Gibbins JM. Gap junctions and connexin hemichannels underpin hemostasis and thrombosis. Circulation 2012;125:2479-2491.
68. Siljander P, Farndale RW, Feijge MA, Comfurius $P$, Kos S, Bevers EM, Heemskerk JW. Platelet adhesion enhances the glycoprotein VIdependent procoagulant response: involvement of p38 MAP kinase and calpain. Arterioscler Thromb Vasc Biol 2001;21:618-627.

69. Berny MA, Munnix IC, Auger JM, Schols SE, Cosemans JM, Panizzi P, Bock PE, Watson SP, McCarty OJ, Heemskerk JW. Spatial distribution of factor $\mathrm{Xa}$, thrombin, and fibrin(ogen) on thrombi at venous shear. Plos One 2010;5:e10415.

70. Lee H, Sturgeon SA, Jackson SP, Hamilton JR. The contribution of thrombin-induced platelet activation to thrombus growth is diminished under pathological blood shear conditions. Thromb Haemost 2012;107:328-337.

71. Munnix IC, Strehl A, Kuijpers MJ, Auger JM, van der Meijden PE, van Zandvoort MA, oude Egbrink M, Nieswandt B, Heemskerk JW. The glycoprotein VI-phospholipase $\mathrm{C}_{2} 2$ signaling pathway controls thrombus formation induced by collagen and tissue factor in vitro and in vivo. Arterioscler Thromb Vasc Biol 2005;25:26732678.

72. May F, Hagedorn I, Pleines I, Bender M, Vögtle T, Eble J, Elvers M, Nieswandt B. CLEC-2 is an essential platelet-activating receptor in hemostasis and thrombosis. Blood 2009;114:3464-3472.

73. Furie B, Furie BC. Thrombus formation in vivo. $J$ Clin Invest 2005;115:3355-3362.

74. Mangin P, Yap CL, Nonne C, Sturgeon SA, Goncalves I, Yuan Y, Schoenwaelder SM, Wright CE, Lanza F, Jackson SP. Thrombin overcomes the thrombosis defect associated with platelet GPVI/FcRg deficiency. Blood 2006;107:43464353.

75. Kuijpers MJ, Pozgajova M, Cosemans JM, Munnix IC, Eckes B, Nieswandt B, Heemskerk JW. Role of murine integrin $\alpha_{2} \beta_{1}$ in thrombus stabilization and embolization: contribution of thromboxane $\mathrm{A}_{2}$. Thromb Haemost 2007;98:1072-1080.

76. Kalia N, Auger JM, Atkinson B, Watson SP. Critical role of FCR g-chain, LAT, PLCg2 and thrombin in arteriolar thrombus formation upon 
mild, laser-induced endothelial injury in vivo. Microcirculation 2008;15:325-335.

77. Colace TV, Muthard RW, Diamond SL. Thrombus growth and embolism on tissue factor-bearing collagen surfaces under flow. Role of trombin with and without fibrin. Arterioscler Thromb Vasc Biol 2012;32:1466-1476.

78. Okorie UM, Denney WS, Chatterjee MS, Neeves KB, Diamond SL. Determination of tissue factor thresholds that trigger coagulation versus venous and arterial shear rates: amplification of $100 \mathrm{fM}$ circulating tissue factor requires flow. Blood 2008;111:3507-3513.

79. Welsh JD, Colace TV, Muthard RW, Stalker TJ, Brass LF, Diamond SL. Platelet-targeting sensor reveals thrombin gradient within blood clots forming in microfluidic assay in mouse. J Thromb Haemost 2012;10:2344-2353.

80. Renné T, Pozgajova M, Grüner S, Schuh K, Pauer HU, Burfeind P, Gailani D, Nieswandt B. Defective thrombus formation in mice lacking coagulation factor XII. J Exp Med 2005;202:271281.

81. Revenko AS, Gao D, Crosby JR, Bhattacharjee G, Zhao C, May C, Gailani D, Monia BP, MacLeod AR. Selective depletion of plasma prekallikrein or coagulation factor XII inhibits thrombosis in mice without increased risk of bleeding. Blood 2011;118:5302-5311.

82. Hagedorn I, Schmidbauer S, Pleines I, Kleinschnitz C, Kronthaler U, Stoll G, Dickneite G Nieswandt B. Factor XIla inhibitor recombinant human albumin infestin-4 abolishes occlusive arterial thrombus formation without affecting bleeding. Circulation 2010;121:1510-1517.

83. Maroney SA, Cooley BC, Ferrel JP, Bonesho CE, Mast AE. Murine hematopoietic cell tissue factor pathway inhibitor limits thrombus growth Arterioscler Thromb Vasc Biol 2011;31:821-826.

84. Ruggeri ZM. Platelets in atherothrombosis. Nat Med 2002;8:1227-1234

85. King A, Markus HS. Doppler embolic signals in cerebrovascular disease and prediction of stroke risk: a systematic review and meta-analysis. Stroke 2009;40:3711-3717.

86. Markus HS, King A, Shipley M, Topakian $R$ Cullinane M, Reihill S, Bornstein NM, Schaafsma
A. Asymptomatic embolisation for prediction of stroke in the Asymptomatic Carotid Emboli Study (ACES): a prospective observational study. Lancet Neurol 2010;9:663-671.

87. Kruis RW, Vlasveld FA, van Dijk D. The (un)importance of cerebral microemboli. Semin Cardiothorac Vasc Anesth 2010;14:111-118.

88. Maan A, Padmanabhan R, Shaikh AY, Mansour $M$, Ruskin JN, Heist EK. Newer anticoagulants in cardiovascular disease: a systematic review of the literature. Cardiol Rev 2012;20:209-221.

89. Schulman S. Advances in the management of venous thromboembolism. Best Pract Res Clin Haematol 2012;25:361-377.

90. Girolami A, de Marinis GB, Bonamigo E, Lombardi AM. Recombinant FVIla concentrateassociated thrombotic events in congenital bleeding disorders other than hemophilias. Hematology 2012;17:346-349.

91. De Bosch NB, Mosesson MW, Ruiz-Sáez A Echenagucia M, Rodriguez-Lemoin A. Inhibition of thrombin generation in plasma by fibrin formation (antithrombin I). Thromb Haemost 2002;88:253-258.

92. Korte W, Feldges A. Increased prothrombin activation in a patient with congenital afibrinogenemia is reversible by fibrinogen substitution. Clin Invest 1994;72:396-398.

93. Remijn JA, Wu YP, IJsseldijk MJ, Zwaginga JJ, Sixma JJ, de Groot PG. Absence of fibrinogen in afibrinogenemia results in large but loosely packed thrombi under flow conditions. Thromb Haemost 2001;85:736-742.

94. Zeerleder $S$, Schloesser $M$, Redondo $M$, Wuillemin WA, Engel W, Furlan M, Lämmle B. Reevaluation of the incidence of thromboembolic complications in congenita factor XII deficiency: a study on 73 subjects from 14 Swiss families. Thromb Haemost 1999;82:1240-1246.

95. Pozgajova M, Sachs UJ, Hein L, Nieswandt B. Reduced thrombus stability in mice lacking the a2A-adrenergic receptor. Blood 2006;108:510514.

96. Dubois C, Panicot-Dubois L, Merrill-Skoloff G, Furie B, Furie BC. Glycoprotein VI-dependent 
and -independent pathways of thrombus formation in vivo. Blood 2006;107:3902-3906.

97. Massberg S, Gawaz M, Grüner S, Schulte V, Konrad I, Zohlhöfer D, Heinzmann U, Nieswandt B. A crucial role of glycoprotein VI for platelet recruitment to the injured arterial wall in vivo. J Exp Med 2003;197:41-49.

98. Moog S, Mangin P, Lenain N, Strassel C, Ravanat C, Schuhler S, Freund M, Santer M, Kahn M, Nieswandt B, Gachet C, Cazenave JP, Lanza F. Platelet glycoprotein $\mathrm{V}$ binds to collagen and participates in platelet adhesion and aggregation. Blood 2001;98:1038-1046.

99. Ni H, Ramakrishnan V, Ruggeri ZM, Papalia JM, Phillips DR, Wagner DD. Increased thrombogenesis and embolus formation in mice lacking glycoprotein V. Blood 2001;98:368-373.

100. Bender M, Hagedorn I, Nieswandt B. Genetic and antibody-induced glycoprotein VI deficiency equally protects mice from mechanically and $\mathrm{FeCl}_{3}$-induced thrombosis. J Thromb Haemost 2011;9:1423-1426.

101. Grüner $S$, Prostredna $M$, Koch $M$, Miura $Y$, Schulte V, Jung SM, Moroi M, Nieswandt B. Relative antithrombotic effect of soluble GPVI dimer compared with anti-GPVI antibodies in mice. Blood 2005;105:1492-1499.

102. Neeves KB, Maloney SF, Fong KP, Schmaier AA, Kahn ML, Brass LF, Diamond SL. Microfluidic focal thrombosis model for measuring murine platelet deposition and stability: PAR4 signaling enhances shear-resistance of platelet aggregates. J Thromb Haemost 2008;6:2193-2201.

103. Stolla M, Stefanini L, Roden RC, Chavez M, Hirsch J, Greene T, Ouellette TD, Maloney SF, Diamond SL, Poncz M, Woulfe DS, Bergmeier W. The kinetics of $\alpha_{\| 1} \beta_{3}$ activation determines the size and stability of thrombi in mice: implications for antiplatelet therapy. Blood 2011;117:10051013.

104. Nergiz-Unal R, Cosemans JM, Feijge MA, van der Meijden PE, Storey RF, van Giezen JJ, oude Egbrink MG, Heemskerk JW, Kuijpers MJ. Stabilizing role of platelet $\mathrm{P}_{2} \mathrm{Y}_{12}$ receptors in shear-dependent thrombus formation on ruptured plaques. Plos One 2010;5:e10130.
105. Woulfe D, Jiang H, Morgans A, Monks R, Birnbaum $M$, Brass LF. Defects in secretion, aggregation and thrombus formation in platelets from mice lacking Akt2. J Clin Invest 2004;113:441-450.

106. Daniel JL, Dangelmaier CA, Mada S, Buitrago L, Jin J, Langdon WY, Tsygankov AY, Kunapuli SP, Sanjay A. Cbl-b is a novel physiological regulator of glycoprotein VI-dependent platelet activation. J Biol Chem 2010;285:17282-17291.

107. Falet $H$, Pollitt AY, Begonja AJ, Weber SE, Duerschmied D, Wagner DD, Watson SP, Hartwig JH. A novel interaction between FlnA and Syk regulates platelet ITAM-mediated receptor signaling and function. J Exp Med 2011;207:1967-1979.

108. Rathore V, Wang D, Newman DK, Newman PJ. Phospholipase $\mathrm{C}_{2} 2$ contributes to stable thrombus formation on VWF. FEBS Lett 2004;27:26-30.

109. Randriamboavonjy V, Isaak J, Fromel T, Viollet B, Fisslthaler B, Preissner KT, Fleming I. AMPK alpha2 subunit is involved in platelet signaling, clot retraction and thrombus stability. Blood 2010;116:2134-2140.

110. McCarty OJ, Larson MK, Auger JM, Kalia N, Atkinson BT, Pearce AC, Ruf S, Henderson RB, Tybulewicz VL, Machesky LM, Watson SP. Rac1 Is essential for platelet lamellipodia formation and aggregate stability under flow. J Biol Chem 2005;280:39474-39484.

111. Varga-Szabo D, Braun A, Kleinschnitz C, Bender $M$, Pleines I, Pham $M$, Renné $T$, Stoll $G$, Nieswandt B. The calcium sensor STIM1 is an essential mediator of arterial thrombosis and ischemic brain infarction. J Exp Med 2008;205:1583-1591.

112. Gushiken FC, Ha H, Li J, Rumbaut RE, AfsharKharghan V. Abnormal platelet function in C3deficient mice. J Thromb Haemost 2009;7:865870.

113. Ni H, Denis CV, Subbarao S, Degen JL, Sato TN, Hynes RO, Wagner DD. Persistence of platelet thrombus formation in arterioles of mice lacking both von Willebrand factor and fibrinogen. J Clin Invest 2000;106:385-392. 
114. Jirouskova M, Chereshnev I, Vaananan H, Degen $\mathrm{JL}$, Coller BS. Antibody blockade or mutation of the fibrinogen gamma-chain C-terminus is more effective in inhibiting murine arterial thrombus formation than complete absence of fibrinogen. Blood 2004;103:1995-2002.

115. Ni H, Yuen PTS, Papalia JM, Trevithick JE, Sakai T, Fässler R, Hynes RO, Wagner DD. Plasma fibronectin promotes thrombus growth and stability in injured arterioles. Proc Natl Acad Sci USA 2003;100:2415-2419.

116. Konstantinides S, Schafer K, Neels JG, Dellas C, Loskutoff DJ. Inhibition of endogenous leptin protects mice from arterial and venous thrombosis. Arterioscler Thromb Vasc Biol 2004;24:2196-2201.

117. Koschnick S, Konstantinides S, Schafer K, Crain K, Loskutoff DJ. Thrombotic phenotype of mice with a combined deficiency in plasminogen activator inhibitor 1 and vitronectin. J Thromb Haemost 2005;3:2290-2295.

118. Bonnefoy A, Daenens K, Feys HB, De Vos R, Vandervoort P, Vermylen J, Lawler J, Hoylaerts MF. Thrombospondin-1 controls vascular platelet recruitment and thrombus adherence in mice by protecting (sub)endothelial vWF from cleavage by ADAMTS-13. Blood 2006;107:955964.

119. Reheman A, Gross $P$, Yang $H$, Chen $P$, Allen $D$, Leytin V, Freedman J, Ni H. Vitronectin stabilizes thrombi and vessel occlusion but plays a dual role in platelet aggregation. J Thromb Haemost 2005;3:875-883.

120. Chauhan AK, Kisucka J, Lamb CB, Bergmeier W, Wagner DD. Von Willebrand factor and factor VIII are independently required to form stable occlusive thrombi in injured veins. Blood 2007;109:2424-2429.

121. Matsuno H, Kozawa O, Okada K, Ueshima S, Matsuo O, Uematsu T. Plasmin generation plays different roles in the formation and removal of arterial and venous thrombus in mice. Thromb Haemost 2002;87:98-104.

122. Prévost $N$, Woulfe DS, Jiang $H$, Stalker TJ, Marchese P, Ruggeri ZM, Brass LF. Eph kinases and ephrins support thrombus growth and stability by regulating integrin outside-in signaling in platelets. Proc Natl Acad Sci USA 2005;102:9820-9825.

123. Speich HE, Furman RR, Lands LT, Moodie GD, Jennings LK. Elevating local concentrations of GPIIb-IIla antagonists counteracts platelet thrombus stability. J Thromb Thrombolysis 2012:in press.

124. Hosokawa K, Ohnishi T, Fukasawa M, Kondo T, Sameshima H, Koide T, Tanaka KA, Maruyama I. A microchip flow-chamber system for quantitative assessment of the platelet thrombus formation process. Microvasc Res 2012;83:154-161.

125. Calaminus SD, Auger JM, McCarty OJ, Wakelam MJ, Mecheskys LM, Watson SP. Myosinlla contractility is required for maintenance of platelet structure during spreading on collagen and contributes to thrombus stability. J Thromb Haemost 2007;5:2136-2145.

126. Stephens $G$, He $M$, Wong $C$, Jurek $M$, Luedemann HC, Shapurian G, Munnelly K, Muir C, Conley PB, Phillips DR, André P. Development of a perfusion chamber assay to study in real time the kinetics of thrombosis and the antithrombotic characteristics of antiplatelet drugs. Thromb J 2012;10:11. 


\section{Chapter 3}

\section{Platelet-based coagulation: different populations, different functions}

Heemskerk JW, Mattheij NJ, Cosemans JM

Department of Biochemistry, Cardiovascular Research Institute Maastricht (CARIM), Maastricht University, Maastricht, The Netherlands

J Thromb Haemost. 2013;11:2-16 Reprinted with permission 


\begin{abstract}
Platelets in a thrombus interact with (anti)coagulation factors and support blood coagulation. In the concept of cell-based control of coagulation, three different roles of platelets can be distinguished: control of thrombin generation, support of fibrin formation, and regulation of fibrin clot retraction. Here, we postulate that different populations of platelets with distinct surface properties are involved in these coagulant functions. Platelets with elevated $\mathrm{Ca}^{2+}$ and exposed phosphatidylserine controlling thrombin and fibrin generation, and platelets with activated $\alpha_{\| b} \beta_{3}$ integrins regulating clot retraction. We review how coagulation factor binding depends on the platelet activation state. Furthermore, the ligands, platelet receptors and downstream intracellular signaling pathways implicated in these coagulant functions are discussed. We integrate this in an adapted model of platelet-based coagulation.
\end{abstract}

\section{Introduction}

After the discovery of platelets as essential blood constituents of an arterial thrombus, it has rapidly become clear that platelets also contribute to fibrin clot formation. Yet, coagulation is often still regarded as a plasmatic process, characterized by initiation, propagation and termination phases of thrombin generation. $^{1}$ In the conventional scheme, the extrinsic coagulation cascade starts with tissue factor binding to factor (F)VIla, whether or not in complex with FXa, resulting in the cleavage of traces of prothrombin into thrombin. Thrombin amplifies its own generation by proteolytically activating other coagulation factors. In a next phase, these active factors are inactivated by anticoagulation factors, such as tissue factor pathway inhibitor, activated protein $\mathrm{C}$, antithrombin and C1 inhibitor.

It is widely accepted that phospholipid membranes containing the negatively charged lipid, phosphatidylserine (PS), are required to propagate and enhance the coagulation reactions. This membrane dependency implies ultimate cellular control of the coagulation process. In the blood system, activated platelets with surface-exposed PS cleave high amounts of FX and prothrombin into the proteolytically active forms, FXa and thrombin. ${ }^{2,3}$ Yet, platelets also have other roles in coagulation. They provide a scaffold for the formation of fibrin fibres $^{3}$ and, once fibrin clots are formed, they regulate the process of clot retraction. ${ }^{4}$

The interwoven nature of platelet activation and the coagulation system has been observed in numerous studies. 
For instance, in the most common in vivo thrombosis models, i.e. ferric chlorideinduced damage of arteries or arterioles, the thrombotic process is similarly sensitive to defects in platelet activation as to inhibition of coagulation. ${ }^{5}$ This in vivo work has shown that: thrombus formation is triggered by collagen, next to tissue factor and thrombin; ${ }^{6-9}$ platelets as well as coagulation contribute to arterial and venous thrombus formation; ${ }^{10,11}$ and fibrin formation occurs already at initial stages of thrombus formation. ${ }^{12}$

Based on literature evidence, we postulate that different platelet populations may have different roles in the coagulation process, depending on their activation state and surface properties. In the following, we will discuss this from the perspectives of: (i) interaction of platelets with (anti)coagulation factors, heterogeneity of platelet populations with respect to control of thrombin generation, fibrin formation and clot retraction, and (iii) receptors and signalling processes leading to these different platelet populations.

\section{Platelet interactions with (anti)coagulation factors}

For coagulation control, platelets need to be able to interact with coagulation factors. Reported evidence for such interactions is summarized below.
Fibrinogen and fibrin. The fibrinogen receptor, integrin $\alpha_{\| 1 b} \beta_{3}$, is the most abundantly expressed platelet glycoprotein (GP). Platelet-fibrinogen binding requires activation of $\alpha_{11 b} \beta_{3}$ via configurational changes, a response that is induced by most platelet agonists. ${ }^{13}$ This integrin is also supposed to bind fibrin. However, whether integrin-bound fibrinogen can be converted into fibrin is unclear. Specific fibrin receptors have not been reported, although a role for platelet GPIb in fibrin binding has been proposed. ${ }^{14}$

Prothrombin and other vitamin $K$ dependent factors. Phospholipid membranes with negatively charged phospholipids, i.e. phosphatidylserine (PS) and to a lesser extent phosphatidylethanolamine (PE), greatly facilitate the binding of coagulation factors and the generation of FXa and thrombin. ${ }^{2,3}$ Platelet activation by strong agonists, e.g. thrombin and collagen is required for PS exposure. As shown by flow cytometry, the PS-exposing platelets characteristically display highaffinity binding sites for vitamin Kdependent (anti)coagulation factors, i.e. prothrombin, FVII, FIX, FX and protein C, $\mathrm{S}$ and Z. ${ }^{3,15}$ Gamma-carboxyglutamate (Gla) domains, which are present in all vitamin K-dependent factors, mediate $\mathrm{Ca}^{2+}$-dependent factor binding to the PS surface. Hence, PS-exposing platelets 
serve as assembly sites for components of the tenase complex (FVIIla, FIXa, FX) and the prothrombinase complex (FVa, FXa, prothrombin).

Investigations

by fluorescence microscopy have shown that labelled FX and prothrombin only bind to PSexposing platelets in a thrombus. ${ }^{16,17}$ However, once cleaved into thrombin, the prothrombin label appeared to redirect to the sites of fibrin fibres, ${ }^{17}$ which is in agreement with indications that fibrin acts as a site for thrombin. So far, specific protein receptors on platelets for vitamin K-dependent factors like FIX or FX have not been identified. ${ }^{2,3}$ A recent proposal, though, is that these factors may stay bound to the platelet surface after formation of cysteine bridges, catalysed by protein disulfide isomerase isoforms. ${ }^{18}$ Unlike some other cell types, platelets lack the signalling FXa receptor, protease-activated receptor 2 (PAR2). ${ }^{19}$ An unexpected finding was that FXa, next to ADAM10/17, influences platelet activation by cleaving the collagen receptor GPVI. ${ }^{20,21}$

Thrombin. Thrombin is the only vitamin K-dependent factor known to bind to specific receptor proteins on platelets. Thrombin interacts with high specificity with protease-activated receptors, i.e. the PAR1 and PAR4 isoforms in human platelets, and the PAR3 and PAR4 isoforms in mouse platelets. Of these, only PAR1 and 4 are cleavable by thrombin. In addition, high-affinity thrombin binding sites are present on GPIb, while GPV serves as a thrombin cleavage substrate. ${ }^{22}$

Tissue factor. Similarly to megakaryocytes, platelets express limited amounts of tissue factor e.g. upon sepsis. ${ }^{23,24}$ It is doubted whether the levels of tissue factor present in platelets are physiologically relevant. ${ }^{25}$ Furthermore, activated platelets release considerable amounts of tissue factor pathway inhibitor (TFPI), which restricts thrombus growth. ${ }^{26}$ Hence, plateletderived TFPI is expected to rapidly inactivate any tissue factor present at the platelet surface.

Factor $V$. Platelet $\alpha$-granules store about $20 \%$ of the blood content of FV. Once released, platelet $\mathrm{FV}$ becomes activated by traces of thrombin. It is reported by one group that platelet-derived $\mathrm{FVa}$ is more resistant to protease inactivation than the FVa in plasma, ${ }^{27}$ but this needs confirmation. FVa binds to PS-exposing (platelet) membranes via its C2 domain. One bound to PS-exposing platelets, it joins FXa to form local prothrombinase complexes. ${ }^{17,28}$ Using flow cytometry, a subpopulation of (thrombin-activated) platelets was detected with intermediate FVa binding. ${ }^{29}$ This is in agreement with the observation that $\mathrm{FVa}$ is incorporated 
into the membrane of coated platelets, ${ }^{30}$ and may point to a gradual accumulation of $\mathrm{FVa}$ at the platelet surface.

Factor VII. In platelets stimulated by collagen and thrombin, binding of recombinant FVIla to GPIb $\alpha$ has been observed, which subsequently leads to FX activation. ${ }^{31}$ The proposed mechanism is that FVIla interaction with the GPIb-V-IX complex facilitates its Gladomain dependent binding to PS membranes. Platelet-bound FVIla can restore thrombus formation of platelets lacking integrin $\alpha_{111} \beta_{3}$ by enhancing PS exposure. $^{32}$ This may explain why recombinant FVIla can be an effective prohemostatic drug in patients with Glanzmann's thrombasthenia.

Factors VIII and IX. While not a vitamin Kdependent factor, FVIIla is able to bind to PS-exposing membranes via its C-2 domain, likely in a similar manner as $\mathrm{FVa}^{33}$ This binding of FVIIla enhances FIXa binding and thus stimulates tenase complex formation and FXa generation on PS-exposing platelets. Since FVIII in plasma is carried by von Willebrand factor (VWF), FVIII can also interact with platelets via VWF and GPIb-V-IX. However, in kinetic studies of fibrin formation, a role for VWF-bound FVIII in platelet coagulant activity could not be detected..$^{34}$ The binding of FIXa appears to be confined to PS-exposing platelets, as determined by annexin A5-binding studies, and relies on prior elevation of cytosolic $\mathrm{Ca}^{2+} .35,36$

Factors XI and XII. Decades ago, it was already proposed that platelets promote fibrin formation in a FXII-dependent manner. ${ }^{37}$ Recent observations point to marked roles of FXI and FXII in arterial thrombus formation in mice, suggesting that platelets in some way stimulate the intrinsic pathway of coagulation. ${ }^{38}$ One explanation for the thrombus-stimulating effect of FXI and FXII is the binding of FXII to collagen, and its subsequent activation in the presence of prekallikrein and high molecular weight kininogen. ${ }^{39}$ There is however also some evidence that FXI and FXII can bind to the platelet surface via GPIb $\alpha .^{40}$ However, an early suggestion that platelet-bound FXla is active and cleaves FIX could not be confirmed. More recent studies with human and mouse platelets point to FXI binding with the platelet apolipoprotein E receptor 2 (ApoER2, LRP8)..$^{41}$ It is still not quite clear whether platelets directly activate FXII. Some studies suggested that polyphosphates released from platelets may fulfil such a role, ${ }^{42}$ but recent data indicate that the size of platelet-derived polyphosphates $(60-100$ phosphate residues) is too small for this action..$^{43}$ On the other hand, platelet-size polyphosphates do accelerate the activation of FXI by thrombin. ${ }^{44}$ 
Factor XIII. The coagulation factor FXIIla acts as a transglutaminase in the crosslinking of fibrin fibers. Experiments with immobilised FXIIla have shown that platelets bind to this protein via the integrins $\alpha_{11 b} \beta_{3}$ and $\alpha_{v} \beta_{3}{ }^{45}$ FXIIla has also been implicated in the chemical crosslinking of secretory proteins from the $\alpha$ granules on the surface of so-called coated platelets (see below). ${ }^{46}$ However, also other tissue-type transglutaminases may fulfil the latter role. ${ }^{47}$

Anticoagulation factors. Platelets secrete significant amounts of the anticoagulant proteins TFPI and protease nexin-1 (PN-1, gene SERPINE2). Binding of TFPI has been detected at the surface of coated platelets. ${ }^{48}$ The protein PN-1 inactivates thrombin, tissue plasminogen activator (tPA) and plasmin, thereby acting as a platelet-dependent, negative regulator of coagulation and fibrinolysis. ${ }^{49}$ The anticoagulant vitamin K-dependent factors, protein $\mathrm{S}$ and protein $\mathrm{C}$, both of which bind to PS membranes, have been shown to suppress thrombin generation at the platelet surface. It is also reported that activated protein $\mathrm{C}$ binds to the platelet LRP8 receptor, ${ }^{50}$ but the importance of this interaction for the regulation of anticoagulation is unknown. The anticoagulant protein $\mathrm{Z}$ acts as a FXa inhibitor, ${ }^{51,52}$ but binding to platelets is unclear. Similarly, binding sites have not been described for anticoagulant proteins like antithrombin and C1 inhibitor, which irreversibly bind to and inactivate the active sites of coagulation factors.

As summarized in Table 1 , most coagulation factors appear to interact preferentially with PS-exposing platelets. Thus, especially these highly activated platelets provide assembly sites for coagulation factor complex formation, resulting in a greatly enhanced generation of $\mathrm{FXa}$ and thrombin. Precisely how the anticoagulation factors act at the platelet surface is not clear. Another unresolved issue is whether all these factors bind to PS-exposing platelets at the same time, or whether fibrin binding of formation perhaps prevents platelet interaction with other factors.

\section{Different platelet populations} controlling distinct coagulation steps

Research to the role(s) of platelets in coagulation is complicated due to the formation of distinct populations of activated platelets, e.g. with or without PS exposure. Below we discuss evidence from the literature how this heterogeneity determines the different roles of platelets in the coagulation process.

Procoagulant platelets (agonist-induced PS exposure). Within a thrombus, formed in a damaged vessel in vivo or on a 
Table 1. Reported interactions of (anti)coagulation factors with platelets. For explanation and references, see text.

\begin{tabular}{|c|c|c|}
\hline $\begin{array}{l}\text { (Anti)coagulation } \\
\text { factor }\end{array}$ & Binding site on platelets and result & Platelet population \\
\hline Fibrin(ogen) & $\begin{array}{l}\text { Fibrinogen: binding to } \alpha \text { llb } \beta 3 \text {. Precursor for fibrin formation. } \\
\text { Fibrin receptor unknown. }\end{array}$ & $\begin{array}{l}\text { Aggregating and clot-retracting } \\
\text { platelets }\end{array}$ \\
\hline Factor II & $\begin{array}{l}\text { FII (prothrombin): binding to PS (via Gla domain) } \\
\text { FIla (thrombin): binding to PAR1,3,4, GPIb-V-IX. }\end{array}$ & $\begin{array}{l}\text { FII: PS-exposing platelets. } \\
\text { Flla: all platelets }\end{array}$ \\
\hline Tissue factor & Weakly expressed. Physiological role unclear & N.a. \\
\hline Factor V & $\begin{array}{l}\text { Released by platelets. Binding to PS (via C2 domain), other } \\
\text { receptors unknown. Activation of prothrombin. }\end{array}$ & PS-exposing and coated platelets \\
\hline Factor VII & $\begin{array}{l}\text { Binding to PS (via Gla domain), GPIb-V-IX. } \\
\text { Activation of FIX and FX }\end{array}$ & PS-exposing platelets \\
\hline Factor VIII & $\begin{array}{l}\text { Binding to PS (via C2-domain), indirectly via GPIb-V-IX. Activation } \\
\text { of FX }\end{array}$ & PS-exposing platelets \\
\hline Factor IX & Binding to PS (via Gla domain). Activation of FX & PS-exposing platelets \\
\hline Factor $\mathrm{X}$ & $\begin{array}{l}\text { Binding to PS (via Gla domain), other receptors unknown. } \\
\text { Activation of prothrombin }\end{array}$ & PS-exposing and coated platelets \\
\hline Factor XI & Binding to LRP8, GPIb-V-IX & Not described \\
\hline Factor XII & Binding site unclear & Not described \\
\hline Factor XII & Binding to integrins $\alpha \mathrm{ll} b \beta 3$ and $\alpha v \beta 3$ & PS-exposing and coated platelets \\
\hline TFPI & Released by platelets, binding site unclear & Coated platelets \\
\hline Protease nexin-1 & Released by platelets, binding site unclear & N.a. \\
\hline Protein C & Binding to PS (via Gla domain), LRP8 & PS-exposing platelets \\
\hline Protein S & Binding to PS (via Gla domain) & PS-exposing platelets \\
\hline
\end{tabular}

collagen matrix in vitro, platelets with different surface properties are clearly distinguishable. ${ }^{53,54}$ Aggregated platelets in the inner thrombus core, close to activating components of the vessel wall, have formed pseudopods, undergone secretion and bind fibrinogen (see below). Discoid platelets at the outer part of growing thrombi may easily detach and lack these activation markers. A distinct population of highly activated platelets is present close to collagen fibres and as patches around a thrombus. These platelets are characterised by surface-exposed PS (detected with the probes annexin A5 and lactadherin), prolonged cytosolic $\mathrm{Ca}^{2+}$ rises, a rounded structure, and capability to bind coagulation factors such as FV and
FX. ${ }^{16,17}$ They furthermore produce procoagulant microparticles. Patches of PS-exposing platelets are particularly formed under coagulant conditions, thereby implying a role of thrombin as platelet agonist. The population of PSexposing platelets has also been described as procoagulant platelets and platelets with a sustained calciuminduced platelet (SCIP) morphology. ${ }^{55,56}$ Several studies have shown that in vivo injection of annexin A5 or lactadherin (chelating exposed PS) significantly impaired thrombus formation in mouse vessels, ${ }^{10,57}$ thus pointing to a functional importance of this platelet population.

Studies with isolated coagulation factors have shown that PS-exposing platelets enhance the activities of tenase and 
prothrombinase complexes by almost 1000-fold. ${ }^{2,58}$ Recent ex vivo flow studies have furthermore indicated that platelets with prolonged high $\mathrm{Ca}^{2+}$ and PS exposure also catalyze fibrin network formation, although fibrin formation can also occur at distant sites. ${ }^{34}$ Jointly, this indicates that PS exposure is a prerequisite for platelet-dependent thrombin generation, with fibrin formation is not directly linked to this.

Coated platelets. Dale and co-workers have identified a population of platelets, formed after stimulation with collagen plus thrombin, which has been termed coated platelets. ${ }^{30,59}$ Characteristic of these platelets is their ability to irreversibly bind several $\alpha$-granular proteins, including $\mathrm{FV}$, thrombospondin, fibrinogen, fibronectin and VWF. ${ }^{60}$ It is considered that these proteins cluster together at the platelet surface and form an immobilised coat. First reports proposed that FXIII activity is required for chemical cross-linking of these granular proteins to serotonin residues on the platelet membrane. ${ }^{46}$ However, in studies using mice deficient in FXIII was shown that at least fibrinogen and VWF bind to coated platelets in the absence of FXIIla, suggesting (additional) involvement of the tissue-type transglutaminase expressed by platelets. ${ }^{47}$ Considering that coated platelets also expose $\mathrm{PS},^{30}$ the question raises whether these two populations are identical. This is also suggested by the findings that coated and PS-exposing platelets are both formed in response to strong agonists (e.g. collagen and thrombin), through the same cellular processes (e.g. mitochondrial permeability transition pore formation), and both shed microparticles. ${ }^{59,61-64}$ Partial overlap of these two populations was indeed observed in dual labelling studies of thrombi with annexin A5 and a serotonin probe. ${ }^{16}$ On the other hand, stimulation of washed platelets with the $\mathrm{Ca}^{2+}$ ionophore $\mathrm{A} 23187$ results in the formation of PS-exposing platelets, which do not appear to have a coat of $\mathrm{FVa}^{30}$ or high fibrin(ogen). ${ }^{47}$ Together, this suggests that coat formation occurs secondarily to PS exposure, most likely as a consequence of the assembly of platelet secretion products and plasma factors at the outer membrane. Whether the formation of a protein coat affects the binding and activation of coagulation factors is unknown.

Aggregating and clot-retracting platelets. The aggregate-forming platelets in a thrombus are characterised by fibrinogen binding and the presence of active integrin $\alpha_{11 b} \beta_{3}$ at their surface (determined with PAC-1 antibody in case of human platelets and JON/A for mouse platelets). As indicated above, this population of platelets differs from the 
PS-exposing platelets, also because the latter tend to close their integrins. ${ }^{53,55}$ Interestingly, under coagulant conditions, the aggregated platelets with activated $\alpha_{11 b} \beta_{3}$ integrins are known to regulate fibrin clot retraction. This process, dependent on platelet fibrin(ogen) binding and integrin outside-in signalling, translates the contractile forces generated in the platelet actin-myosin cytoskeleton to connecting fibrin fibres around platelets. ${ }^{65}$ An diffuse fibrin network is thereby converted into a small and dense platelet-fibrin clot. Under flow conditions, this process is observed as contraction of platelet aggregates and reflects the initial phases of coagulation (see Suppl. Movie). It is also seen as a mechanism for narrowing the gaps between platelets to allow contact-dependent signalling. ${ }^{66}$ Because PS-exposing platelets are non-adhesive, have closed integrins, and a disturbed actin cytoskeleton, ${ }^{56}$ it is quite unlikely that they will participate in clot retraction. This points to a major difference between the aggregating and PS-exposing platelet populations with respect to the regulation of coagulation. While the PS-exposing platelets produce FXa and thrombin outside the platelet plug, the aggregated platelets consolidate the plug by clot retraction.

Apoptotic and necrotic platelets. In a pioneering paper, Schoenwaelder and colleagues describe that the anti-tumour drugs ABT-737 and ABT-263 induce platelet PS exposure at relatively minor rises in cytosolic $\mathrm{Ca}^{2+}{ }^{2+}{ }^{67}$ These compounds inhibit the anti-apoptotic proteins $\mathrm{Bcl}-2 / \mathrm{Bcl}-\mathrm{x}_{\mathrm{L}}$, and cause activation of the Bak/Bax pathway to start a mitochondrial-dependent route of apoptosis and subsequent PS exposure. The mechanism differs from that of agonist-induced PS exposure, since apoptotic PS exposure appears to rely on caspase activation. Other studies indicate that the ABT compounds disrupt normal platelet activation responses, such as secretion, integrin activation and platelet aggregation. ${ }^{68}$ Interestingly, the same or a similar apoptotic pathway is triggered in aging or stored platelets, which show a gradual decline in $\mathrm{Bcl}-\mathrm{x}_{\mathrm{L}}$ expression and also liberate the proapoptotic Bak/Bax proteins. ${ }^{69,70}$ The aging process is slow, requiring a time span of several days to yield PS-positive platelets, as examined with the probes annexin A5 and lactadherin. ${ }^{71-73}$ Although in vitro tests have shown that aging, apoptotic platelets have a coagulant potential and support thrombin generation, it is questionable whether these PS-exposing platelets fulfil a role in coagulation under physiological conditions, since they will be rapidly taken up by scavenging cells in the circulation. 
Because of the distinctions between apoptotic and agonist-stimulated PSexposing platelets, e.g. with respect to caspase activation, it has been suggested that the latter are activated by a necrotic cell death pathway. ${ }^{74}$ Given the common definition of necrosis as premature death of cells due to external sources (e.g., hypoxia or injury), we do not prefer this terminology. Instead, we propose the term 'procoagulant platelets', thus referring to their capability to support thrombin and fibrin generation.

Platelet microparticles. Both procoagulant, PS-exposing ${ }^{75}$ and aging ${ }^{76}$ platelets can release microparticles. As these microparticles in part expose PS they have a thrombin-generating potential. This seems to be relevant in particular at pathophysiological conditions, when elevated levels of platelet-derived microparticles have been measured. ${ }^{77}$ Under normal conditions, their role may be limited, because of rapid interaction with leukocytes and other scavenging cells. ${ }^{78}$ Jointly, this overview points to the presence of two types of activated platelets with fundamentally different roles in the coagulation process. At the one hand, the PS-exposing and coated platelets (with partial overlap) that are characterized by a high activation state, binding of multiple coagulation factors, and the capability to stimulate thrombin generation. These platelets also actively form fibrin, with the coated platelets having a fibrin layer at their surface. On the other hand, aggregating platelets, which characteristically express activated integrins and have a role in fibrin clot retraction, which implies they bind fibrin as well. Although apoptotic (aging) platelets also expose PS, it is unclear whether these have a physiological role in coagulation. As reviewed elsewhere, the mechanisms for this heterogeneity in platelet fate is still incompletely understood. $^{53}$ It seems that intrinsic platelet factors such as platelet size and structure, protein composition, genetic factors and platelet age account only for part of the response heterogeneity. Platelet environmental factors, such as the local rheology, exposure to agonists, surrounding cells and plasma, likely are at least as important. This is further discussed below.

\section{Ligands and receptors mediating platelet PS exposure and fibrin formation}

Most studies investigating the roles of platelets in coagulation have been carried out to determine the regulation of PS exposure and ensuing thrombin generation. Less is known about the mechanisms for controlling fibrin formation by platelets. An overview of the ligands and receptors involved in these processes is given below. 
VWF and GPIb-V-IX. A contribution of the GPIb-V-IX complex to platelet PS exposure, thrombin generation and subsequent fibrin formation has been reported by several groups, that indicated that this stringently relies on the interaction of GPIb with VWF. ${ }^{34,79,80}$ Particularly under coagulant conditions and low shear rate (implying the presence of thrombin), VWF binding to GPIb can lead to prolonged $\mathrm{Ca}^{2+}$ responses, PS exposure, assembly of coagulation factors and formation of fibrin at the platelet surface. ${ }^{34}$ The signalling mechanism downstream of GPIb may involve the actin cytoskeleton. Initially, platelet procoagulant activity via GPIb was considered to rely on the presence of fibrin, interacting with GPIb via VWF. ${ }^{14}$ However, studies with platelets from Bernard-Soulier patients pointed to a fibrin-independent signalling role of GPIb-V-IX to enhance thrombin-induced $\mathrm{Ca}^{2+}$ mobilisation. ${ }^{81}$ In mouse platelets, GPIb $\beta$ was found to potentiate the $\mathrm{Ca}^{2+}$ rises and PS exposure induced by either thrombin- or collagenreceptor agonists. This procoagulant effect was independent of the $\mathrm{N}$ terminal part of GPIb $\alpha$, as it was not affected by endopeptidase cleavage of this glycoprotein. ${ }^{82}$ Interestingly, deficiency in GPV, which is also part of the GPIb-V-IX complex, increased rather than decreased responses of mouse platelets to thrombin by a still undisclosed mechanism. ${ }^{83}$

Thrombin and receptors. The thrombin receptors of human platelets, PAR1 and PAR4, belong to the class of G-protein coupled receptors (GPCR), and elevate cytosolic $\mathrm{Ca}^{2+}$ via $\mathrm{Gq}$ and phospholipase $\mathrm{C} \beta \quad(\mathrm{PLC} \beta) \quad$ stimulation. ${ }^{84}$ The consequence is a oscillatory (spiking) $\mathrm{Ca}^{2+}$ signal, which by itself is insufficient for evoking PS exposure. ${ }^{85}$ However, thrombin markedly enhances collageninduced PS exposure, in which case PAR1 appears to be the primarily acting receptor, ${ }^{2,86}$ rather than the binding of thrombin to GPIb. ${ }^{87}$ Some authors, though, report a role for GPIb in PS exposure, for instance in thrombinstimulated gel-filtered platelets where residual VWF may be present. ${ }^{79}$

An explanation for the primary role of PAR1 in thrombin-mediated PS exposure comes from the recent observation that inhibition of protein kinase C (PKC) negatively regulates $\mathrm{Ca}^{2+}$ rises and PS exposure elicited by PAR1, but not by the other thrombin receptor PAR4. ${ }^{88}$ Yet, PAR4 activation has an assistant role in potentiating $\mathrm{Ca}^{2+}$ rises and PS exposure. ${ }^{89}$ In mouse platelets, where only PAR4 - and not the other receptor PAR3 - is cleaved by thrombin,, 90 thrombin-dependent PS exposure seems to rely on the presence of both isoforms. 
The literature contains some evidence that the PAR isoforms on platelets can be cleaved by other proteases than thrombin. For example, PAR1 cleavage has been reported by ADAM17, a related plasma protease, $^{91}$ or by matrix metalloproteinase- $1 .{ }^{92}$ At present, the physiological relevance of these alternative ways of thrombin receptor cleavage is unclear. The same holds for the reported cleavage of PAR4 by the fibrinolysis protease plasmin ${ }^{93}$ or the neutrophil-derived cathepsin G. ${ }^{94}$

Thromboxane and TP receptors. In spite of the prominent role of thromboxane $A_{2}$ in collagen-induced platelet aggregation, this autocrine agonist is no more than limitedly effective in stimulating PS exposure. In fact, blockade of thromboxane production by aspirin affected PS exposure of collagenadhered platelets only in combination with ADP receptor blockers. ${ }^{95}$ Along the same line, aspirin treatment only slightly affected thrombin generation in coagulating platelet-rich plasma. ${ }^{96}$ In agreement with these findings, stimulation of the platelet TP receptors is known to cause only limited $\mathrm{Ca}^{2+}$ mobilisation.

$A D P$, fibrinogen and receptors. The receptors for ADP (in particular P2Y $\mathrm{Y}_{12}$ ) and fibrinogen (integrin $\alpha_{11} \beta_{3}$ ) appear to have supporting and partially redundant roles in PS exposure and plateletdependent thrombin generation. This was most clearly observed under coagulant conditions, e.g. in tissue factor-activated platelet-rich plasma. In this case, autocrine produced ADP was found to prolong $\mathrm{Ca}^{2+}$ rises and to increase PS exposure via $\mathrm{P}_{2} \mathrm{Y}_{12}$ mediated signalling towards phosphoinositide 3 kinase (PI3K). ${ }^{97,98}$ Blockage of $\mathrm{P}^{2} \mathrm{Y}_{12}$ by intake of the prodrug, clopidogrel, significantly suppressed the procoagulant effect of platelets in coagulating plasma. ${ }^{99}$ Similarly, blockage of this receptor by the active metabolite of prasugrel impaired ADP/collagen induced $\mathrm{Ca}^{2+}$ rises, PS exposure and thrombin generation in whole blood. ${ }^{100,101}$

Recent work indicated that also integrin $\alpha_{\| 1 b} \beta_{3}$ outside-in signalling via PLC and the tyrosine kinase Syk supports thrombin-induced $\mathrm{Ca}^{2+}$ rises and PS exposure, along with platelet-dependent thrombin generation. ${ }^{102}$ The contributing role of $\alpha_{\| 1} \beta_{3}$ partly overlapped with that of autocrine mechanisms via $\mathrm{P}_{2} \mathrm{Y}_{12}$, which is not a surprise given the prominent role of $\mathrm{P}_{2} \mathrm{Y}_{12}$ in integrin activation. These findings explain why integrin antagonists cause marked suppression of tissue factor-induced thrombin generation, and prolong the clotting times in platelet-rich plasma. ${ }^{103,104}$ 
Immune receptor FcyRIIA. There is limited evidence that stimulation of the immune receptor Fc $\gamma R$ IIA on human platelets induces PS exposure and microparticle formation, e.g. via antibodies against the heparin-platelet factor 4 complex. ${ }^{105}$ Platelet activation via this receptor, which likely signals via the Syk-PLC 2 pathway, is considered to contribute to the pathology of heparininduced thrombocytopenia.

Collagen and GPVI. Circulating platelets will encounter vascular collagen only after endothelial damage and luminal exposure of the extracellular matrix. Under in vitro conditions, immobilised fibres of collagen type I provide relatively effective triggers for PS exposure, once platelets are stably adhered via the immunoglobulin-type collagen receptor GPVI. ${ }^{106}$ Studies of platelet interaction with immobilised collagen under flow have indicated that all key constituents of the GPVI signalosome contribute to GPVI-induced PS exposure. In line with this, platelets from mice lacking the FcR $\gamma$-chain, LAT, Syk or PLC $\gamma 2$ or with blocked GPVI showed marked reduction in collagen-dependent PS exposure and thrombin generation. ${ }^{107,108}$ On the other hand, mouse platelets with a gain-offunction mutation in PLC $\gamma 2$ were more active in collagen-dependent PS exposure and thrombus formation. ${ }^{109}$ The adhesive collagen receptor, integrin $\alpha_{2} \beta_{1}$, was found to support procoagulant activity in an indirect way, by enforcing collagen-platelet interactions via GPVI. ${ }^{110}$ Inhibition of the protein tyrosine kinase Syk, which together with Src-family kinases controls PLC $\gamma 2$ activity, suppressed GPVI-induced PS exposure, whereas inhibition of protein phosphatases increased this response. ${ }^{16,111}$ The responsible phosphatase has been unknown for long, but recent data point to involvement of the phosphatase TULA2, which associates to Syk and can negatively regulate GPVI-induced signalling events. ${ }^{112}$ This phosphatase might also control PS exposure.

Even though platelet adhesion to immobilised collagen causes appreciable PS exposure, platelets need costimulation of collagen with other agonists like thrombin to obtain substantial fractions of PS-exposing platelets. $^{2,113}$ This co-stimulation likely has a dual effect: it potentiates the $\mathrm{Ca}^{2+}$ rises in platelets, and also activates the integrins $\left(\alpha_{2} \beta_{1}\right.$ and $\left.\alpha_{11 b} \beta_{3}\right)$ needed for stable platelet adhesion to collagen fibres and for signalling via the lowaffinity GPVI receptors. This is in contrast to the process of collagen-induced platelet aggregation, which is less dependent on high $\mathrm{Ca}^{2+}$ rises, and only requires $\alpha_{11 b} \beta_{3}$ activation via autocrine agonists like ADP and thromboxane. Other ligands of GPVI, such as cross- 
linked collagen-related peptide (low- the snake venom rhodocytin and the affinity) and particularly the snake lymphatic protein podoplanin. ${ }^{114}$ There venom convulxin (high affinity) also are no reports yet on platelet provoke PS exposure, yet again this procoagulant activity induced by CLEC2 response is markedly enhanced by costimulation with thrombin. ${ }^{106}$

Other ligands and receptors. A newly described platelet receptor acting via a similar pathway of LAT-Syk-PLC $\gamma 2$ is the protein CLEC2, which can be activated by

activation.

In addition to collagen, a number of other adhesive proteins have been found to promote PS exposure especially after immobilisation at a surface. For instance, immobilised thrombospondin-1 and oxidised LDL can stimulate PS exposure

\section{Low}

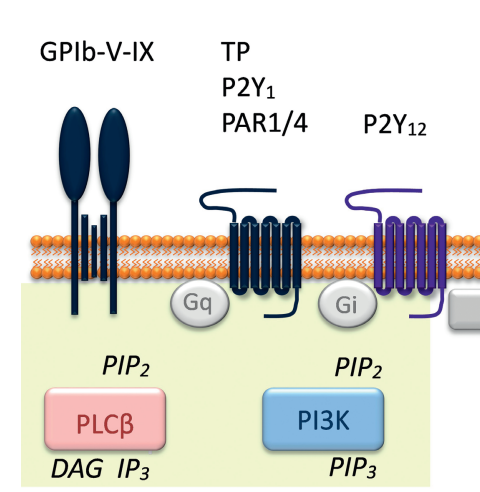
TP $\alpha_{11 \mathrm{~b}} \beta_{3}$

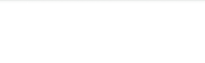

$+\sqrt{2}$<smiles>CCCCCCCC</smiles>

\section{$\mathrm{Ca}^{2+}$}

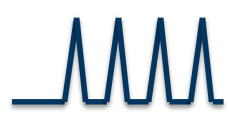

Spiking $\mathrm{Ca}^{2+}$
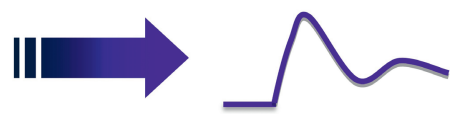

Transient $\mathrm{Ca}^{2+}$

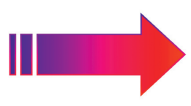

Prolonged high $\mathrm{Ca}^{2+}$

Figure 1. Platelet-based coagulation: signalling towards prolonged high $\mathrm{Ca}^{2+}$ rises, required for PS exposure. Gradient colour bar indicates range of receptors with low $\mathrm{Ca}^{2+}$-mobilising potency due to PLC $\gamma$ activation, causing spiking $\mathrm{Ca}^{2+}$ signals (blue), to receptors with high $\mathrm{Ca}^{2+}$-mobilising potency due to PLCY2 activation, causing prolonged $\mathrm{Ca}^{2+}$ signals (red). Isoforms of PI3K produce the phosphoinositide $\mathrm{PIP}_{3}$, which can stimulate PLC 2 activity. Co-signalling via multiple receptors will result in accumulated $\mathrm{Ca}^{2+}$ signals, to reach threshold levels of prolonged high $\mathrm{Ca}^{2+}$ required for PS exposure. The DAG and $\mathrm{Ca}^{2+}$-dependent effector proteins, PKC and CALDAG$\mathrm{GEFI}$, act as modulators of the $\mathrm{Ca}^{2+}$ signal. See also text. 
of adhered platelets at limited extent via the receptor CD36. ${ }^{115}$

Furthermore, under coagulant conditions with thrombin present, surfaceimmobilised fibrinogen ${ }^{17}$ and laminin ${ }^{116}$ can stimulate PS exposure of adhered platelets via $\alpha_{11} \beta_{3}$ and FXII, respectively. Findings that platelet adhesion favours procoagulant activity are clearly relevant, not only because stable adhesion permits more continued signalling, but also because this provides a way to locally confine the coagulation process to sites of platelet adhesion and activation. In summary, only few physiological agonists, particularly those stimulating GPVI, are capable of inducing PS exposure by themselves. On the other hand, a larger number of agonists, including VWF, fibrinogen, thrombin, $A D P$, antibodies and thrombospondin, appear to enhance the process of (GPVIinduced) PS exposure by stimulating their respective receptors. In most cases the co-agonists act by increasing the $\mathrm{Ca}^{2+}$ signal towards a prolonged high $\mathrm{Ca}^{2+}$ rise (see Fig. 1). Apparently, in order to generate a sufficient $\mathrm{Ca}^{2+}$ signal for PS exposure a certain degree of costimulation is needed of receptors linked to PLC $\gamma$ isoforms ( $\left.\alpha_{\| 1} \beta_{3}, \mathrm{Fc} \gamma \mathrm{RIIA}, \mathrm{GPVI}\right)$ and receptors linked to PLC $\gamma$ isoforms (GPIb, PAR1/4). This is supported by the observation that there is an assistant role of $\mathrm{PI} 3 \mathrm{~K}$ isoforms that produce the phospholipid, phosphatidylinositol trisphosphate $\left(\mathrm{PIP}_{3}\right)$, which acts as membrane binding site and enhancer of PLC $\gamma$ isoforms. ${ }^{117}$ Regarding the control of fibrin formation, contribution of the VWF-GPIb axis has been clarified so far. Given the high activation conditions required for PS exposure, it is reasonable to assume that not all platelets in a thrombus encounter sufficient levels of agonists, thus explaining part of the response heterogeneity. On the other hand, intrinsic platelet factors may contribute as well, e.g. different numbers of receptors or signalling molecules. ${ }^{53}$

\section{Platelet signalling to PS exposure and} fibrin formation: central role of $\mathrm{Ca}^{2+}$

Since the early finding that $\mathrm{Ca}^{2+}$ ionophores (A23187 or ionomycin) cause rapid and full PS exposure in essentially all platelets due to phospholipid membrane scrambling, it is clear that a prolonged high $\mathrm{Ca}^{2+}$ is a sufficient trigger for this platelet response. ${ }^{2,58}$ This is confirmed by the observation that most physiological agonists or combinations provoking PS exposure also induce sustained $\mathrm{Ca}^{2+}$ rises. The recent literature provides novel insight into the signalling pathways involved (see also Fig. 2).

Store-operated $\mathrm{Ca}^{2+}$ entry (SOCE). An initial finding was that $\mathrm{Ca}^{2+}$ entry via SOCE not only prolongs the platelet $\mathrm{Ca}^{2+}$ signal, but also promotes PS exposure. ${ }^{118}$ 
In the last few years, by using murine formation was greatly impaired along knockout and pharmacological with GPVI-induced approaches, a central role of two exposure. ${ }^{119,120,122,123}$ In contrast, no role channel proteins in SOCE has been was found for the paralogues STIM2 and demonstrated. ${ }^{9}$ Stromal interaction Orai3, which are both present in molecule 1 (STIM1) was identified as central $\mathrm{Ca}^{2+}$ sensor in the platelet reticular membrane, monitoring $\mathrm{Ca}^{2+}$ store depletion, while Orai1 was identified as $\mathrm{Ca}^{2+}$ entry channel that is activated through coupling to STIM1. ${ }^{119,120}$ The chaperone protein cyclophilin A appeared to act as a positive $\mathrm{Ca}^{2+}$ modulator of STIM1. ${ }^{121}$ With mouse platelets lacking STIM1 or Orai1, collagen-dependent thrombus platelets. Interestingly, it was found that Orai1 contributes only little to $\mathrm{Ca}^{2+}$ entry in platelets activated by thrombin and PLC $\gamma$. This may explain why in the presence of high thrombin concentrations, PS exposure is only limitedly dependent on STIM1 and Orai1. ${ }^{122}$ Observations like these have raised the question whether another $\mathrm{Ca}^{2+}$ entry mechanism (receptoroperated $\mathrm{Ca}^{2+}$ entry) can operate

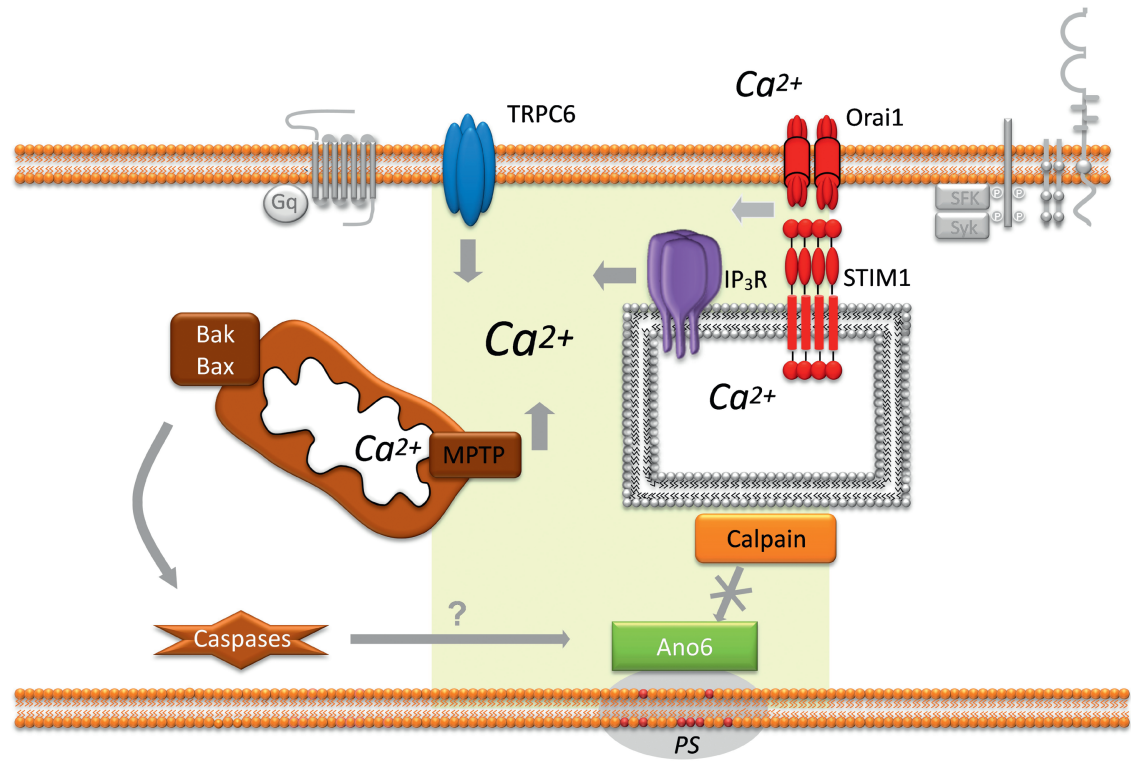

Procoagulant response

Figure 2. Platelet-based coagulation: central role of elevated $\mathrm{Ca}^{2+}$ in $\mathrm{PS}$ exposure. Mechanisms for $\mathrm{Ca}^{2+}$ elevation contributing to PS exposure include: $\mathrm{Ca}^{2+}$ mobilisation from the endoplasmic reticulum via $\mathrm{IP}_{3}$ receptors $\left(\mathrm{IP}_{3} \mathrm{R}\right)$; $\mathrm{Ca}^{2+}$ entry by SOCE via STIM1 and Orai1 channels; and release of mitochondrial $\mathrm{Ca}^{2+}$ via MPTP formation. Elevated $\mathrm{Ca}^{2+}$ activates the protease calpain, triggers phospholipid scrambling via anoctamin 6 , thereby resulting in PS exposure. The apoptotic pathway of PS exposure via Bak/Bak-induced caspase activation is relatively independent of $\mathrm{Ca}^{2+}$. 
downstream of thrombin receptors to facilitate PS exposure. ${ }^{124}$ Recent findings with human and mouse platelets suggest that the cation channel TRPC6 can play such a role. ${ }^{125,126}$ Earlier reports on a function of the isoform TRPC1 in $\mathrm{Ca}^{2+}$ entry $^{127}$ were ruled out because of a complete lack of a phenotype in mouse Trpc1\%- $^{\text {/- }}$ platelets. ${ }^{126,128}$

Transmembrane fluxes of other ions besides $\mathrm{Ca}^{2+}$ may contribute to the procoagulant activity. Prolonged platelet treatment with ouabain, inhibiting the $\mathrm{Na}^{+} / \mathrm{K}^{+}$-ATPase, was found to provoke limited PS exposure and thrombin generation via a small but persistent $\mathrm{Ca}^{2+}$ rise dependent on $\mathrm{Na}^{+}$entry. ${ }^{129}$ In addition, $\mathrm{Na}^{+}$loading via the $\mathrm{Na}^{+} / \mathrm{H}^{+}$ exchanger, ${ }^{130}$ or $\mathrm{Ca}^{2+}$-activated $\mathrm{K}^{+}$ currents (Gardos channels) ${ }^{131}$ may increase platelet PS exposure and prothrombinase activity. The precise mechanisms are not understood.

Mitochondrial collapse. Mitochondrial collapse by MPTP formation can be induced by various forms of cellular stress, e.g. by free oxygen radicals. Several groups have examined a role for this mitochondrial process in platelet procoagulant activity. In $\mathrm{Ca}^{2+}$ ionophorestimulated platelets, inhibition of MPTP formation with cyclosporin A was found to prevent depolarization of the mitochondrial inner membrane potential as well as microparticle formation.
However, PS exposure was only moderately inhibited, indicating that mitochondrial collapse per se is not a strict requirement for PS exposure. ${ }^{132}$ In agreement with this, $\mathrm{Ca}^{2+}$ ionophoreinduced PS exposure was unchanged in platelets from mice deficient in cyclophilin D, which is a component of the MPTP. ${ }^{62}$ Yet, in the cyclophilin D deficient platelets, PS exposure and thrombin generation induced by the receptor agonists convulxin and thrombin was strongly diminished. Along the same line, cyclosporin A was found to suppress the formation of coated platelets in response to convulxin/thrombin. ${ }^{63}$ This implies a role of mitochondrial collapse also in fibrin (coat) formation. In other cells, MPTP formation abolishes the sequestering of $\mathrm{Ca}^{2+}$ in mitochondria. ${ }^{133}$ Hence, also in platelets, mitochondrial collapse may lead to a loss of $\mathrm{Ca}^{2+}$ flux control, thus provoking agonist (convulxin/thrombin)induced PS exposure. In contrast, the apoptosis-induced PS exposure, while also involving mitochondria, is essentially $\mathrm{Ca}^{2+}$-independent and specifically relies on Bak/Bax and caspase activation. ${ }^{74}$

Signalling downstream of $\mathrm{Ca}^{2+}$. The majority of platelet agonists signal via PLC $\beta$ or $\gamma$ isoforms, which produce diacylglycerol (DAG) and the $\mathrm{Ca}^{2+}$ mobilising second messenger inositol 1,4,5-trisphosphate $\left(\mathrm{IP}_{3}\right)$, resulting in 
activation of protein kinase $C$ (PKC) and CalDAG-GEFI (Fig. 1). Detailed studies using knockout mice and specific inhibitors point to a two-sided role for PKC isoforms in platelet activation and PS exposure. ${ }^{134}$ The conventional isoforms PKC $\alpha$ and $P K C \beta$, which are activated by DAG and $\mathrm{Ca}^{2+}$, positively contribute to platelet secretion, $\mathrm{Ca}^{2+}$ signalling and PS exposure. ${ }^{135-137}$ The novel isoform PKC $\theta$, being activated by DAG alone, acts differently, in that it suppresses GPVI-induced $\mathrm{Ca}^{2+}$ mobilisation and PS exposure. ${ }^{136}$ This negative role of PKC $\theta$ can explain why general PKC stimulation with phorbol ester down-regulates these platelet responses. ${ }^{134}$ Yet, some authors report a slight stimulation of platelet function by PKC $\theta .{ }^{138}$ In sum, the role of PKC isoforms in platelet PS exposure (procoagulant response) can be understood in terms of PKC-dependent fine-tuning of the $\mathrm{Ca}^{2+}$ signal.

Mouse experiments furthermore point to a separate role in procoagulant activity of the regulatory protein CaIDAG-GEFI. ${ }^{139}$ It activates the small GTPase Rap1b, thereby supporting integrin activation and other platelet functions. Platelets from CaIDAG-GEFI-deficient mice were found to be substantially impaired in PS exposure during thrombus formation on collagen, by a mechanism that is not yet understood. ${ }^{140}$ It was concluded that CalDAG-GEFI, like STIM1, contributes to the first wave of thrombin generation catalysed by PS-exposing procoagulant platelets. Furthermore, platelet CaIDAGGEFI appeared to regulate fibrin clot formation.

With the recent discovery of the platelet protein anoctamin 6 (TMEM16F gene) as key regulator of $\mathrm{Ca}^{2+}$-dependent phospholipid scrambling and hence PS exposure, $^{141}$ other speculations on proteinous PS translocators have been overruled. ${ }^{77}$ In platelets from patients with Scott syndrome, a moderate bleeding disorder, anoctamin 6 is lacking, while ionomycin- and in agonist-induced PS exposure are greatly impaired, ${ }^{141,142}$ in spite of normal $\mathrm{Ca}^{2+}$ rises. ${ }^{143}$ Anoctamin 6 is a multiple membrane-spanning protein with supposed $\mathrm{Ca}^{2+}$ binding site, but whether it operates alone in phospholipid scrambling and PS exposure is unclear. Another $\mathrm{Ca}^{2+}$ dependent protein contributing to microparticle formation is the protease calpain, but inhibitor studies have indicated that its role in PS exposure is moderate at best. ${ }^{144}$

Taken together, the available evidence indicates that PS exposure in response to agonist stimulation is accomplished by multiple pathways synergising to elevated $\mathrm{Ca}^{2+}$ (Fig. 2). In other words, platelet stimulation with multiple agonists that cause massive $\mathrm{Ca}^{2+}$ store depletion and SOCE, due to STIM1/Orai1 interaction, seems to result in a loss of 
the normal control of $\mathrm{Ca}^{2+}$ handling by $\mathrm{Ca}^{2+}$ pumps, PKCO and MPTP formation, so that cytosolic $\mathrm{Ca}^{2+}$ becomes prolonged high, and the $\mathrm{Ca}^{2+}$-dependent phospholipid scrambling via anoctamin 6 becomes activated. How this facilitates extracellular fibrin formation is unclear.

\section{Platelet signalling to clot retraction: central role of integrins}

The regulation of clot retraction by platelets has been less extensively studied than the process of PS exposure. In the majority of the literature clot retraction is considered as an integrin $\alpha_{\| 11} \beta_{3}$-dependent event. Despite the only sparse mechanistic studies, clot retraction is generally used as a marker of $\alpha_{11 b} \beta_{3}$ outside-in signalling. As platelet integrin signalling is reviewed elsewhere, ${ }^{13}$ we here summarize what is known of the signalling processes implicated in platelet-dependent clot retraction.

Signalling downstream of integrin $\alpha_{l l b} \beta_{3}$. Several investigations, mostly using mouse blood, have indicated that clot retraction is mediated by signalling proteins that also contribute to $\alpha_{111} \beta_{3}$ integrin outside-in signalling. Platelet proteins implicated in clot retraction include the Src-family tyrosine kinases, Src and Fyn, the adapter protein Lnk, AMP-activated protein kinase, and the effector proteins PLC $\gamma 2$ and PI3K $\beta .^{145-147}$ Recent studies point to two phases in platelet-dependent clot retraction upon

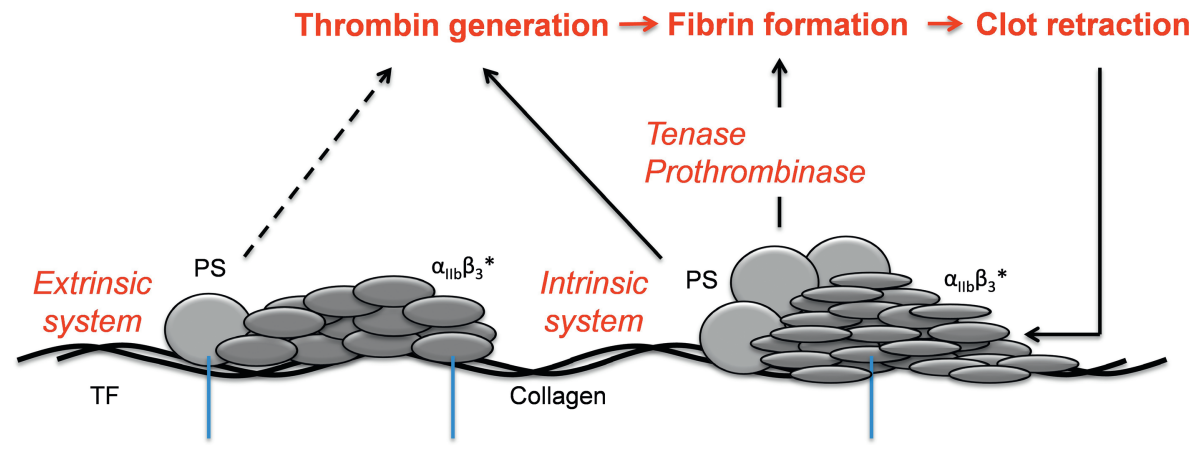

\section{Procoagulant platelets Aggregating platelets Contracting platelets}

Figure 3. Model of platelet-based coagulation. Vascular damage initiates the extrinsic coagulation pathway via tissue factor (TF) and the intrinsic pathway via collagen. Collagen-adhered platelets and in a later stage patches of platelets in a thrombus expose PS, and thereby serve as membrane substrate for the tenase and prothrombinase complexes, resulting in massive thrombin generation. These platelets can also support fibrin formation and form a fibrin coat. Populations of PS-exposing platelets characteristically are high in cytosolic $\mathrm{Ca}^{2+}$, whereas the remaining aggregated platelets in a thrombus display activated integrin $\alpha_{11 b} \beta_{3}$. By interacting with fibrin and in the presence of thrombin, the latter platelets contract and accomplish clot retraction. 
stimulation with thrombin: an initial formation of high-adhesion integrin $\alpha_{11 b} \beta_{3}$ contacts with fibrin, followed by phase where the platelet contractile forces are transmitted to the fibrin clot. ${ }^{65,148}$ The force generation appears to occur via the actin cytoskeleton and depends on activation of myosin IIA via Rho kinase and myosin light-chain kinase. ${ }^{149}$ An extracellular process required for clot retraction is the crosslinking of platelet-associated fibrin fibres by the transglutaminase FXIIla. ${ }^{150}$ The $\mathrm{Ca}^{2+}$-dependent protease calpain suppresses clot retraction, likely due to the cleavage of cytoskeletal proteins. ${ }^{151}$ In this context, it is relevant to note that calpain accomplishes considerable degradation of cytoskeletal proteins in PS-exposing platelets, ${ }^{152}$ thus providing another explanation why the PSexposing platelet population is not involved in clot retraction.

Hence, the signalling processes contributing to platelet-regulated clot retraction, as far as unravelled, rely on integrin $\quad \alpha_{11 b} \beta_{3}$-dependent signalling processes controlling actin-myosin interactions, which are strikingly different from those leading to PS exposure.

\section{References}

1 Mann KG, Brummel K, Butenas S. What is all that thrombin for? J Thromb Haemost 2003;1:150414.

\section{Conclusion}

Taken all together, this leads to an adapted model of platelet-based coagulation, as schematised in Fig. 3. Collagen-adhered platelets and in a later stage patches of platelets in a thrombus, activated by thrombin and other agonists with prolonged high $\mathrm{Ca}^{2+}$, expose PS. PS exposing platelets serve as membrane substrate for multiple coagulation factors, with massive propagation of thrombin generation as a result. These platelets can also support fibrin formation and form a fibrin coat. The remaining aggregated platelets with active $\alpha_{11 b} \beta_{3}$ integrins contract and accomplish clot retraction by interacting with fibrin in the presence of thrombin. This scheme may help to resolve many unanswered questions regarding platelet and coagulation activation in arterial and venous thrombosis.

\section{Disclosure of conflict of interests}

This work was supported by the Cardiovascular Centre (HVC) Maastricht, the Center for Translational Molecular Medicine (CTMM) INCOAG, and the Netherlands Heart Foundation (2011T006).

2 Heemskerk JW, Bevers EM, Lindhout T. Platelet activation and blood coagulation. Thromb Haemost 2002;88:186-93. 
3 Monroe DM, Hoffman M, Roberts HR. Platelets and thrombin generation. Arterioscler Thromb Vasc Biol 2002;22:1381-9.

4 Jurk K, Kehrel BE. Platelets: physiology and biochemistry. Semin Thromb Hemost 2005;31:381-92.

5 Jackson SP. Arterial thrombosis: insidious, unpredictable and deadly. Nat Med 2011;17:1423-36.

6 Chou J, Mackman N, Merrill-Skoloff G, Pedersen B, Furie BC, Furie B. Hematopoietic cell-derived microparticle tissue factor contributes to fibrin formation during thrombus propagation. Blood 2004;104:3190-7.

7 Dubois C, Panicot-Dubois L, Merrill-Skoloff G, Furie B, Furie BC. Glycoprotein VI-dependent and -independent pathways of thrombus formation in vivo. Blood 2006;107:3902-6.

8 Kalia N, Auger JM, Atkinson B, Watson SP. Critical role of FCR $\gamma$-chain, LAT, PLC 2 and thrombin in arteriolar thrombus formation upon mild, laser-induced endothelial injury in vivo. Microcirculation 2008;15:325-35.

9 Stegner D, Nieswandt B. Platelet receptor signaling in thrombus formation. $\mathrm{J} \mathrm{Mol} \mathrm{Med}$ 2011;89:109-21.

10 Kuijpers MJ, Munnix IC, Cosemans JM, van Vlijmen BJ, Reutelingsperger $\mathrm{CP}$, oude Egbrink MG, Heemskerk JW. Key role of platelet procoagulant activity in tissue factor- and collagen-dependent thrombus formation in arterioles and venules in vivo. Differential sensitivity to thrombin inhibition. Microcirculation 2008;15:269-82.

11 Brill A, Fuchs TA, Chauhan AK, Yang JJ, De Meyer SF, Köllnberger M, Wakefield TW, Lämmle B, Massberg S, Wagner DD. Von Willebrand factormediated platelet adhesion is critical for deep vein thrombosis in mouse models. Blood 2011;117:1400-7.

12 Furie B, Furie BC. Thrombus formation in vivo. $J$ Clin Invest 2005;11:3355-62.

13 Shattil SJ, Kim C, Ginsberg MH. The final steps of integrin activation: the end game. Nat Rev Mol Cell Biol 2010;11:288-300.

14 Béguin S, Kumar R, Keularts I, Seligsohn U, Coller BS, Hemker HC. Fibrin-dependent platelet procoagulant activity requires GPIb receptors and von Willebrand factor. Blood 1999;93:56470.

15 Zwaal RF, Schroit AJ. Pathophysiological implications of membrane phospholipid asymmetry in blood cells. Blood 1997;89:112132.

16 Munnix IC, Kuijpers MJ, Auger JM, Thomassen CM, Panizzi P, van Zandvoort MA, Rosing J, Bock PE, Watson SP, Heemskerk JW. Segregation of platelet aggregatory and procoagulant microdomains in thrombus formation. Regulation by transient integrin activation. Arterioscler Thromb Vasc Biol 2007; 27: 2484-90.

17 Berny MA, Munnix IC, Auger JM, Schols SE, Cosemans JM, Panizzi P, Bock PE, Watson SP, McCarty OJ, Heemskerk JW. Spatial distribution of factor $\mathrm{Xa}$, thrombin, and fibrin(ogen) on thrombi at venous shear. Plos One 2010; 5: e10415.

18 Jurk K, Lahav J, van Aken H, Brodde MF, Nofer JR, Kehrel BE. Extracellular protein disulfide isomerase regulates feedback activation of platelet thrombin generation via modulation of coagulation factor binding. J Thromb Haemost 2011; 9: 2278-90.

19 Daubie V, Cauwenberghs $S$, Senden NHM, Pochet R, Lindhout T, Buurman WA, Heemskerk JW. Factor $\mathrm{Xa}$ and thrombin evoke additive calcium and proinflammatory responses in endothelial cells subjected to coagulation. Biochim Biophys Acta 2006; 1763: 860-9.

20 Gardiner EE, Karunakaran D, Shen Y, Arthur JF, Andrews RK, Bernd MC. Controlled shedding of platelet glycoprotein (GP)VI and GPIb/IX/V by ADAM family metalloproteinases. J Thromb Haemost 2007; 7: 1530-7.

21 Al-Tamimi M, Grigoriadis G, Tran H, Paul E, Servadei P, Berndt MC, Gardiner EE, Andrews RK. Coagulation-induced shedding of platelet glycoprotein VI mediated by factor Xa. Blood 2011; 117: 3912-20.

22 Ravanat C, Freund M, Mangin P, Azorsa DO, Schwartz C, Moog S, Schuhler S, Dambach J, Cazenave JP, Lanza F. GPV is a marker of in vivo platelet activation: study in a rat thrombosis model. Thromb Haemost 2000; 83: 327-33. 
23 Panes O, Matus V, Saez CG, Quiroga T, Pereira J, Mezzano D. Human platelets synthesize and express tissue factor. Blood 2007; 109: 5242-50.

24 Rondina MT, Schwertz H, Harris ES, Kraemer BF, Campbell RA, Mackman N, Grissom CK, Weyrich AS, Zimmerman GA. The septic milieu triggers expression of spliced tissue factor mRNA in human platelets. J Thromb Haemost 2011; 9: 748-58.

25 Kretz CA, Vaezzadeh N, Gross PL. Tissue factor and thrombosis models. Arterioscler Thromb Vasc Biol 2010; 30: 900-8.

26 Maroney SA, Cooley BC, Ferrel JP, Bonesho CE, Mast AE. Murine hematopoietic cell tissue factor pathway inhibitor limits thrombus growth. Arterioscler Thromb Vasc Biol 2011; 31: 821-6.

27 Gould WR, Silveira JR, Tracy PB. Unique in vivo modifications of coagulation factor $V$ produce $a$ physically and functionally distinct plateletderived cofactor. J Biol Chem 2004; 279: 2383-93.

28 Majumder R, Quinn-Allen MA, Kane WH, Lentz $B R$. A phosphatidylserine binding site in factor Va C1 domain regulates both assembly and activity of the prothrombinase complex. Blood 2008; 112: 2795-802.

29 Fager AM, Wood JP, Bouchard BA, Feng P, Tracy PB. Properties of procoagulant platelets: defining and characterization the subpopulation binding a functional prothrombinase Arterioscler Thromb Vasc Biol 2010; 30: 2400-7.

30 Alberio L, Safa O, Clemetson KJ, Esmon CT, Dale GL. Surface expression and functional characterization of $\alpha$-granule factor $V$ in human platelets: effects of ionophore A23187, thrombin, collagen, and convulxin. Blood 2000; 95: 1694-702.

31 Weeterings C, de Groot PG, Adelmeijer J, Lisman $\mathrm{T}$. The glycoprotein Ib-V-IX complex contributes to tissue factor-independent thrombin generation by recombinant factor VIla on the activated platelet surface. Blood 2008; 112: 3227-33.

32 Lisman T, Adelmeijder J, Cauwenberghs S, van Pampus EC, Heemskerk JW, de Groot PG. Recombinant factor VIla enhances platelet adhesion and activation under flow conditions at normal and reduced platelet count. J Thromb Haemost 2005; 3: 742-51.

33 Gilbert GE, Novakovic VA, Kaufman RJ, Miao H, Pipe SW. Conservative mutations in the $\mathrm{C} 2$ domains of factor VIII and factor $\mathrm{V}$ alter phospholipid binding and cofactor activity. Blood 2012; 120: 1923-32.

34 Cosemans JM, Schols SE, Stefanini L, de Witt S, Feijge MA, Hamulyak K, Deckmyn H, Bergmeier W, Heemskerk JW. Key role of glycoprotein $\mathrm{Ib} / \mathrm{V} / \mathrm{IX}$ and von Willebrand factor in platelet activation-dependent fibrin formation at low shear flow. Blood 2011; 117: 651-60.

35 London FS, Marcinkiewicz M, Walsh PN. A subpopulation of platelets responds to thrombin- or SFLLRN-stimulation with binding sites for factor IXa. J Biol Chem 2004; 279: 19854-9.

36 London FS, Marcinkiewicz M, Walsh PN. PAR1stimulated factor IXa binding to a small platelet subpopulation requires a pronounced and sustained increase of cytoplasmic calcium. Biochemistry 2006; 45: 7289-98.

37 Walsh PN. Platelet coagulant activities in thrombasthenia. Br J Haematol 1972; 23: 553-69.

38 Renné T, Pozgajova M, Grüner S, Schuh K, Pauer HU, Burfeind P, Gailani D, Nieswandt B. Defective thrombus formation in mice lacking coagulation factor XII. J Exp Med 2005; 202: 27181.

39 Van der Meijden PE, Munnix IC, Auger JM, Govers-Riemslag JW, Cosemans JM, Kuijpers MJ, Spronk HM, Watson SP, Renné T, Heemskerk JW. Dual role of collagen in factor XII-dependent thrombus and clot formation. Blood 2009; 114: 881-90

40 Baglia FA, Shrimpton CN, Emsley J, Kitagawa K, Ruggeri ZM, Lopez JA, Walsh PN. Factor X interacts with the leucine-rich repeats of glycoprotein Iba on the activated platelet. J Biol Chem 2004; 279: 49323-9.

41 White-Adams TC, Berny MA, Tucker EI, Gertz JM, Gailani D, Urbanus RT, de Groot PG, Gruber A, McCarty OJ. Identification of coagulation factor $\mathrm{XI}$ as a ligand for platelet apolipoprotein $\mathrm{E}$ receptor 2 (ApoER2). Arterioscler Thromb Vasc Biol 2009; 29: 1602-7. 
42 Müller F, Mutch NJ, Schenk WA, Smith SA, Esterl L, Spronk HM, Schmidbauer S, Gahl WA, Morrissey JH, Renné T. Platelet polyphosphates are proinflammatory and procoagulant mediators in vivo. Cell 2009; 139: 1143-56.

43 Smith SA, Choi SH, Davis-Harrison R, Huyck J, Boettcher J, Reinstra CM, Morrissey JH. Polyphosphate exerts differential effects on blood clotting, depending on the polymer size. Blood 2010; 116: 4353-9.

44 Choi SH, Smith SA, Morissey JH. Polyphosphate is a cofactor for the activation of factor XI by thrombin. Blood 2011; 118: 6963-70.

45 Magwenzi SG, Ajjan RA, Standeven KF, Parapia LA, Naseem KM. Factor XIII supports platelet activation and enhances thrombus formation by matrix proteins under flow conditions. J Thromb Haemost 2011; 9: 820-33.

46 Dale GL, Friese P, Batar P, Hamilton SF, Reed GL, Jackson KW, Clemetson KJ, Alberio L. Stimulated platelets use serotonin to enhance their retention of procoagulant proteins on the cell surface. Nature 2002; 415: 175-9.

47 Jobe SM, Leo L, Eastvold JS, Dickneite G, Ratliff TL, Lentz SR, Di Paola J. Role of FcRy and factor XIIla in coated platelet formation. Blood 2005; 106: 4146-51.

48 Maroney SA, Haberichter SL, Friese P, Collins ML, Ferrel JP, Dale GL, Mast AE. Active tissue factor pathway inhibitor is expressed on the surface of coated platelets. Blood 2007; 109: 1931-7.

49 Boulaftali Y, Ho-Tin-Noe B, Pena A, Loyau S, Venisse L, Francois D, Richard B, Arocas V, Collet JP, Jandrot-Perrus $M$, Bouton MC. Platelet protease nexin-1, a serpin that strongly influences fibrinolysis and thrombolysis. Circulation 2011; 12: 1326-34.

50 White TC, Berny MA, Tucker El, Urbanus RT, de Groot PG, Fernandez JA, Griffin JH, Gruber A, McCarty OJ. Protein $C$ supports platelet binding and activation under flow: role of glycoprotein Ib and apolipoprotein E receptor 2. J Thromb Haemost 2008; 6: 995-1002.

51 Van 't Veer C, Butenas S, Golden NJ, Mann KG. Regulation of prothrombinase activity by protein S. Thromb Haemost 1999; 82: 80-7.
52 Dayer MR, Ghayour O, Dayer MS. Mechanism of protein Z-mediated inhibition of coagulation factor Xa by Z-protein-dependent inhibitor: a molecular dynamic approach. ISRN Hematol 2012: 2012: 762728.

53 Munnix IC, Cosemans JM, Auger JM, Heemskerk JW. Platelet response heterogeneity in thrombus formation. Thromb Haemost 2009; 102: 1149-56.

54 Nesbitt WS, Westein E, Tovar-Lopez FJ, Tolouei E, Mitchell A, Fu J, Carberry J, Fouras A, Jackson SP. $A$ shear gradient-dependent platelet aggregation mechanism drives thrombus formation. Nat Med 2009; 15: 665-73.

55 Kulkarni S, Jackson SP. Platelet factor XIII and calpain negatively regulate integrin $\alpha_{11 b} \beta_{3}$ adhesive function and thrombus growth. J Biol Chem. 279; 2004:30697-706.

56 Heemskerk JW, Kuijpers MJ, Munnix IC, Siljander PR. Platelet collagen receptors and coagulation. A characteristic platelet response as possible target for antithrombotic treatment. Trends Cardiovasc Med 2005; 15: 86-92.

57 Shi J, Pipe JT, Heegaard CW, Gilbert GE. Lactadherin blocks thrombosis and hemostasis in vivo: correlation with platelet phosphatidylserine exposure. J Thromb Haemost 2008; 6: 1167-74.

58 Bevers EM, Comfurius P, Zwaal RF. Platelet procoagulant activity, physiological significance and mechanisms of exposure. Blood Rev 1991; 5: 146-54.

59 Dale GL. Coated-platelets: an emergic component of the procoagulant response. J Thromb Haemost 2005; 3: 2185-92.

60 Szasz R, Dale GL. Thrombospondin and fibrinogen bind serotonin-derivatized proteins on COAT platelets. Blood 2002; 100: 2827-31.

61 Dale GL, Remenyi G, Friese P. Quantitation of microparticles released from coated-platelets. J Thromb Haemost 2005; 3: 2081-8.

62 Jobe SM, Wilson KM, Leo L, Raimondi A, Molkentin JD, Lentz SR, DiPaola J. Critical role for the mitochondrial permeability transition pore and cyclophilin D in platelet activation and thrombosis. Blood 2008; 111: 1257-65. 
63 Remenyi G, Szasz R, Frieze P, Dale GL. Role of mitochondrial permeability transition pore in coated-platelet formation. Arterioscler Thromb Vasc Biol 2005; 25: 467-71.

64 Yakimenko AO, Verholomova FY, Kotova YN, Ataullakhanov FI, Panteleev MA. Identification of different procoagulatory. Biophys J 2012; 102: 2261-9.

65 Schoenwaelder SM, Ono A, Nesbitt WS, Lim J, Jarman K, Jackson SP. Phosphoinositide 3-kinase p110 $\beta$ regulates integrin $\alpha_{11 b} \beta_{3}$ avidity and the cellular transmission of contractile forces. J Biol Chem 2010; 285: 2886-96.

66 Brass LF, Zhu L, Stalker TJ. Minding the gaps to promote thrombus growth and stability. J Clin Invest 2005; 115: 3385-92.

67 Schoenwaelder SM, Yuan Y, Josefsson EC, White MJ, Tao Y, Mason KD, O'Reilly LA, Henley KJ, Ono A, Hsiao S, Willcox A, Roberts AW, Huang DCS, Salem HH, Kile BT, Jackson SP. Two distinct pathways regulate platelet phosphatidylserine exposure and procoagulant function. Blood 2009; 114: 663-6.

68 Vogler M, Hamali HA, Sun XM, Bampton ET, Dinsdale D, Snowden RT, Dyer MJS, Goodall AH, Cohen GM. BCL-2/BCL-xL inhibition induces apoptosis, disrupts cellular calcium homeostasis and prevents platelet activation. Blood 2011; 117: 7145-54.

69 Kodama T, Takehara T, Hikita H, Shimizu S, Shigekawa M, Li W, Miyagi T, Hosui A, Tatsumi T, Ishida $\mathrm{H}$, Kanto $\mathrm{T}$, Hiramatsu N, Yin XM, Hayashi N. BH3-only activator proteins Bid and Bim are dispensable for Bak/Bax-dependent thrombocyte apoptosis induced by $\mathrm{Bcl}-\mathrm{xl}$ deficiency. Molecular requisites for the mitochondrial pathway to apoptosis in platelets. J Biol Chem 2011; 286: 13905-13.

70 Mason KD, Carpinelli MR, Fletcher JI, Collinga JE, Hilton AA, Ellis S, Kelly PN, Ekert PG, Metcalf D, Roberts AW, Huang DCS, Kile BT. Programmed anuclear cell death delimits platelet life span. Cell 2007; 128: 1173-86.

71 Curvers J, van Pampus EC, Feijge MA, RomboutSestrienkova E, Giesen PL, Heemskerk JW. Decreased responsiveness and development of activation markers of platelets stored in plasma. Transfusion 2004; 44: 49-58.

72 Rand $\mathrm{ML}$, Wang $\mathrm{HH}$, Bang KW, Poon KS, Packham MA, Freedman J. Procoagulant surface exposure and apoptosis in rabbit platelets: association with shortened survival and steadystate senescence. J Thromb Haemost 2004; 2: 651-9.

73 Albanyan AM, Murphy FM, Rasmussen JT, Heegaard CW, Harrison P. Measurement of phosphatidylserine exposure during storage of platelet concentrates using the novel probe lactadherin: a comparison study with annexin V. Transfusion 2009; 49: 99-107.

74 Jackson SP, Schoenwaelder SM. Procoagulant platelets: are they necrotic? Blood 2010; 116: 2011-8.

75 Sims J, Wiedmer T, Esmon CT, Weiss HJ, Shattil SJ. Assembly of the platelet prothrombinase complex is linked to vesiculation of the platelet plasma membrane. Studies in Scott syndrome, an isolated defect in platelet procoagulant activity. J Biol Chem 1989; 264: 17049-57.

76 Cauwenberghs S, Feijge MA, Harper AG, Sage SO, Curvers J, Heemskerk JW. Shedding of procoagulant microparticles from unstimulated platelets by integrin-mediated destabilization of actin cytoskeleton. FEBS Lett 2006; 580: 5313-20.

77 Morel O, Jesel L, Freyssinet JM, Toti F. Cellular mechanisms underlying the formation of circulating microparticles. Arterioscler Thromb Vasc Biol 2010; 31: 15-26.

78 Vasina E, Heemskerk JW, Weber C, Koenen RR. Platelets and platelet-derived microparticles in vascular inflammatory disease. Inflamm Allergy Drug Targets 2010; 9: 346-54.

79 Dörmann D, Clemetson KJ, Kehrel B. The GPIb thrombin-binding site is essential for thrombininduced platelet procoagulant activity. Blood 2000; 86: 2469-78.

80 Béguin S, Keularts I, Al Dieri R, Belluci S, Caen J, Hemker HC. Fibrin polymerization is crucial for thrombin generation in platelet-rich plasma in a vWF-GPIb-dependent process, defective in Bernard-Soulier syndrome. J Thromb Haemost 2004; 2: 170-6. 
81 McNicol A, Sutherland M, Zou R, Drouin J. Defective thrombin-induced calcium changes and aggregation of Bernard-Soulier platelets are not associated with deficient moderate-affinity receptors. Arterioscler Thromb Vasc Biol 1996; 16: 628-32.

82 Ravanat C, Strassel C, Hechler B, Schuhler S, Chicanne G, Payrastre B, Gachet C, Lanza F. A central role of GPIb-IX in the procoagulant function of platelets that is independent of the 45-kDa GPIba N-terminal extracellular domain. Blood 2010; 116: 1157-64.

83 Ramakrishnan V, Reeves PS, DeGuzman F, Deshpande U, Ministri Madrid K, DuBridge RB, Phillips DR. Increased thrombin responsiveness in platelets from mice lacking glycoprotein V. Proc Natl Acad Sci USA 1999; 96: 13336-41.

84 Offermanns S. Activation of platelet function through G protein-coupled receptors. Circ Res 2006; 99: 1293-304.

85 Heemskerk JW, Feijge MA, Henneman L, Rosing J, Hemker HC. The $\mathrm{Ca}^{2+}$-mobilizing potency of athrombin and thrombin-receptor-activating peptide on human platelets. Concentration and time effects of thrombin-induced $\mathrm{Ca}^{2+}$ signaling. Eur J Biochem 1997; 249: 547-55.

86 Andersen H, Greenberg DL, Fujikawa K, Xu WF, Chung DW, Davie EW. Protease-activated receptor 1 is the primary mediator of thrombinstimulated platelet procoagulant activity. Proc Natl Acad Sci USA 1999; 96: 11189-93.

87 Keuren JF, Wielders SJ, Ulrichts $H$, Hackeng $T$, Deckmyn H, Heemskerk JW, Bevers E, Lindhout T. Synergistic effect of thrombin on collageninduced platelet procoagulant activity is mediated through protease-activated receptor-1. Arterioscler Thromb Vasc Biol 2005; 25: 1499505.

88 Harper MT, Poole AW. PKC inhibition markedly enhances $\mathrm{Ca}^{2+}$ signaling and phosphatidylserine exposure downstream of protease-activated receptor-1 but not protease-activated receptor4 in human platelets. J Thromb Haemost 2011; 9: 1599-607.

89 Dorsam RT, Tuluc M, Kunapuli SP. Role of protease-activated and ADP receptor subtypes in thrombin generation on human platelets. J Thromb Haemost 2004; 2: 804-12.

90 Coughlin SR. Thrombin signalling and proteaseactivated receptors. Nature 2000; 407: 258-64.

91 Andrews RK, Karunakaran D, Gardiner EE, Berndt MC. Platelet receptor proteolysis. A mechanism for downregulating platelet reactivity. Arterioscler Thromb Vasc Biol 2007; 27: 1511-20.

92 Trivedi V, Boire A, Tchernychev B, Kaneider NC, Leger AJ, O'Callaghan K, Covic L, Kuliopulos A. Platelet matrix metalloprotease-1 mediates thrombogenesis by activating PAR1 at a cryptic site. Cell 2009; 137: 332-43.

93 Quinton TM, Kim S, Derian CK, Jin J, Kunapuli SP. Plasmin-mediated activation of platelets occurs by cleavage of protease-activated receptor 4 . J Biol Chem 2004; 279: 18434-9.

94 Sambrano GR, Huang W, Faruqi T, Mahrus S, Craik C, Coughlin SR. Cathepsin G activates protease-activated receptor-4 in human platelets. J Biol Chem 2000; 275: 6819-23.

95 Lecut C, Schoolmeester A, Kuijpers MJ, Broers JLV, van Zandvoort MA, Vanhoorelbeke $K$, Deckmyn $H$, Jandrot-Perrus $M$, Heemskerk JW. Principal role of glycoprotein $\mathrm{VI}$ in $\alpha_{2} \beta_{1}$ and $\alpha_{\| \mathrm{lb}} \beta_{3}$ activation during collagen-induced thrombus formation. Arterioscler Thromb Vasc Biol 2004; 24: 1727-33.

96 Vanschoonbeek K, Feijge MA, van Kampen RJW, Kenis H, Hemker HC, Giesen PL, Heemskerk JW. Initiating and potentiating roles of platelets in tissue factor-induced thrombin generation in the presence of plasma: subject-dependent variation in thrombogram characteristics. J Thromb Haemost 2004; 2: 476-84.

97 Léon C, Alex M, Klocke A, Morgenstern E, Moosbauer C, Eckly A, Spannagl M, Gachet C, Engelmann B. Platelet ADP receptors contribute to the initiation of intravascular coagulation. Blood 2004; 103: 594-600.

98 Van der Meijden PE, Schoenwaelder SM, Cosemans JM, Wetzker R, Heller R, Jackson SP, Heemskerk JW. Dual $\mathrm{P}_{2} \mathrm{Y}_{12}$ receptor signaling in thrombin-stimulated platelets: involvement of phosphoinositide 3-kinase $\beta$ but not $\gamma$ isoforms 
in $\mathrm{Ca}^{2+}$ mobilization and procoagulant activity. FEBS J 2008; 275: 371-85.

99 Van der Meijden PE, Feijge MA, Giesen PL, Huijberts $M$, van Raak EP, Heemskerk JW. Platelet $P 2 Y_{12}$ receptors enhance signalling towards procoagulant activity and thrombin generation: a study with healthy subjects and patients at thrombotic risk. Thromb Haemost 2005; 93: 1128-37.

100 Frelinger AL, Jakubowski JA, Li Y, Barnard MR, Linden $M D$, Rarnow I, Fox ML, Sugidachi $A$, Winters KJ, Furman MI, Michelson AD. The active metabolite of prasugrel inhibits adenosine diphosphate- and collagen-stimulated platelet procoagulant activities. J Thromb Haemost 2008; 6: 359-65.

101 Judge HM, Buckland RJ, Sugidachi A, Jakubowski JA, Storey RF. The active metabolite of prasugrel effectively blocks the platelet $\mathrm{P} 2 \mathrm{Y}_{12}$ receptor and inhibits procoagulant and pro-inflammatory reactions. Platelets 2008; 19: 125-33.

102 Van der Meijden PE, Swieringa S, Feijge MA, Gilio K, Hamulyák K, Heemskerk JW. Integrin $\alpha$ llb $\beta 3$ outside-in signaling causes platelet procoagulant activity and thrombin generation. Cell Mol Life Sci 2012; in press.

103 Ilveskero S, Lassila R. Abciximab inhibits procoagulant activity but not the release reaction upon collagen- or clot-adherent platelets. J Thromb Haemost 2003; 1: 805-13.

104 Goto S, Tamura N, Li M, Handa M, Ikeda Y, Handa S, Ruggeri ZM. Differential effects of various anti-GPIIb/IIla agents on shear-induced platelet activation and expression of procoagulant activity. J Thromb Haemost 2003; 1: 2022-30.

105 Lhermusier T, van Rottem J, Garcia C, Xuereb JM, Ragab A, Martin V, Gratacap MP, Sie P, Payrastre B. The Syk-kinase inhibitor R406 impairs platelet activation and monocyte tissue factor expression triggered by heparin-PF4 complex directed antibodies. J Thromb Haemost 2011; 8: 2067-76.

106 Siljander P, Farndale RW, Feijge MA, Comfurius $P$, Kos S, Bevers EM, Heemskerk JW. Platelet adhesion enhances the glycoprotein VIdependent procoagulant response: involvement of p38 MAP kinase and calpain. Arterioscler Thromb Vasc Biol 2001; 21: 618-27.

107 Munnix IC, Strehl A, Kuijpers MJ, Auger JM, van der Meijden PE, van Zandvoort MA, oude Egbrink M, Nieswandt B, Heemskerk JW. The glycoprotein VI-phospholipase C $\mathrm{C} 2$ signaling pathway controls thrombus formation induced by collagen and tissue factor in vitro and in vivo. Arterioscler Thromb Vasc Biol 2005; 25: 2673-8.

108 Auger JM, Kuijpers MJ, Senis YA, Watson SP, Heemskerk JW. Adhesion of human and mouse platelets to collagen under shear: a unifying model. FASEB J 2005; 19: 825-7.

109 Elvers M, Pozgai R, Varga-Szabo D, May F, Pleines I, Kuijpers MJ, Heemskerk JW, Nieswandt B. Platelet hyperactivity and a prothrombotic phenotype in mice with a gain-of-function mutation in phospholipase C $\mathrm{C} 2$. J Thromb Haemost 2010; 8: 1353-63.

110 Siljander PR, Munnix IC, Smethurst PA, Deckmyn $H$, Lindhout $T$, Ouwehand $W H$, Farndale RW, Heemskerk JW. Platelet receptor interplay regulates collagen-induced thrombus formation in flowing human blood. Blood 2004; 103: 1333 41.

111 Heemskerk JW, Vuist WM, Feijge MA, Reutelingsperger $\mathrm{CP}$, Lindhout T. Collagen but not fibrinogen surfaces induce bleb formation, exposure of phosphatidylserine and procoagulant activity of adherent platelets. Evidence for regulation by protein tyrosine kinase-dependent $\mathrm{Ca}^{2+}$ responses. Blood 1997; 90: 2615-25.

112 Thomas DH, Getz TM, Newman TN, Dangelmaier CA, Carpino N, Kunapuli SP, Tsygankov AY, Daniel JL. A novel histidine tyrosine phosphatase, TULA-2, associates with Syk and negatively regulates GPVI signaling in platelets. Blood 2010; 116: $2570-8$.

113 Bevers EM, Comfurius P, van Rijn JL, Hemker HC, Zwaal RF. Generation of prothrombin-converting activity and the exposure of phosphatidylserine at the outer surface of platelets. Eur J Biochem 1982; 122: 429-36.

114 Séverin S, Pollitt AY, Navarro-Nunez L, Nash CA Mourao-Sa D, Eble JA, Senis YA, Watson SP. Sykdependent phosphorylation of CLEC-2. A novel 
mechanism of hem-immunoreceptor tyrosinebased activation motif signaling I Biol Chem 2011; 286: 4107-16.

115 Nergiz-Unal R, Lamers MM, van Kruchten $R$, Luiken JJ, Cosemans JM, Glatz JF, Kuijpers MJ, Heemskerk JW. Signaling role of CD36 in platelet activation and thrombus formation on immobilized thrombospondin or oxidized low density lipoprotein. J Thromb Haemost 2011; 9: 1835-46.

116 White-Adams TC, Berny MA, Patel IA, Tucker EI, Gailani D, Gruber A, McCarty OJ. Laminin promotes coagulation and thrombus formation in a factor XII-dependent manner. J Thromb Haemost 2010; 8: 1295-301.

117 Gilio K, Munnix IC, Mangin P, Cosemans JM, Feijge MA, van der Meijden PE, Olieslagers $S$, Chrzanowska-Wodnicka MB, Lillian R, Schoenwaelder S, Koyasu S, Sage SO, Jackson SP, Heemskerk JW. Non-redundant roles of phosphoinositide 3-kinase isoforms $\alpha$ and $\beta$ in glycoprotein VI-induced platelet signaling and thrombus formation. J Biol Chem 2009; 285: 33750-62.

118 Smeets EF, Heemskerk JW, Comfurius P, Bevers EM, Zwaal RF. Thapsigargin amplifies the platelet procoagulant response caused by thrombin. Thromb Haemost 1993; 70: 1024-9.

119 Varga-Szabo D, Braun A, Kleinschnitz C, Bender $M$, Pleines I, Pham $M$, Renné $T$, Stoll $G$, Nieswandt B. The calcium sensor STIM1 is an essential mediator of arterial thrombosis and ischemic brain infarction. J Exp Med 2008; 205: 1583-91.

120 Braun A, Varga-Szabo D, Kleinschnitz C, Pleines I, Bender $M$, Austinat $M$, Bösi $M$, Stoll $G$, Nieswandt B. Orai1 (CRACM1) is the platelet SOC channel and essential for pathological thrombus formation. Blood 2009; 113: 2056-63.

121 Elvers M, Herrmann A, Seizer P, Münzer P, Beck $S$, Schönberger T, Borst $O$, Martin-Romero FJ, Lang $F$, May $A E$, Gawaz $M$. Intracellular cyclophilin $\mathrm{A}$ is an important $\mathrm{Ca}^{2+}$ regulator in platelets and critically involved in arterial thrombus formation. Blood 2012; 120: 1317-26.

122 Gilio K, van Kruchten R, Braun A, Berna-Erro A, Feijge MA, Stegner $D$, van der Meijden $P E$,
Kuijpers MJ, Varga-Szabo D, Heemskerk JW, Nieswandt B. Roles of STIM1 and Orai1 in glycoprotein VI- and thrombin-dependent procoagulant activity and thrombus formation. J Biol Chem 2010; 285: 23629-38.

123 Bergmeier W, Oh-hora M, McCarl CA, Roden RC, Bray PF, Feske S. R93W mutation in Orai1 causes impaired calcium influx in platelets. Blood 2009; 109: 6875-8.

124 Harper MT, Poole AW. Store-operated calcium entry and non-capacitative calcium entry have distinct roles in thrombin-induced calcium signaling in human platelets. Cell Calcium 2011; 50: 351-8.

125 Ramanathan G, Gupta S, Thielmann I, Pleines I, Varga-Szabo D, May F, Mannhalter C, Dietrich A, Nieswandt B, Braun A. Defective diacylglycerolinduced $\mathrm{Ca}^{2+}$ entry but normal agonist-induced activation responses in TRPC6-deficient mouse platelets. J Thromb Haemost 2012; 10: 419-29.

126 Hassock SR, Zhu MX, Trost C, Flockerzi V, Authi KS. Expression and role of Trpc proteins in human platelets: evidence that Trpc6 forms the store-independent calcium entry channel. Blood 2002; 100: 2801-11.

127 Lopez JJ, Salido GM, Pariente JA, Rosado JA. Interaction of Stim1 with endogenously expressed human canonical Trp1 upon depletion of intracellular $\mathrm{Ca}^{2+}$ stores. J Biol Chem 2006; 281: 28254-64.

128 Varga-Szabo D, Authi KS, Braun A, Bender M, Ambily A, Hassock SR, Gudermann T, Dietrich A, Nieswandt B. Store-operated $\mathrm{Ca}^{2+}$ entry in platelets occurs independently of transient receptor potential (TRP) C1. Pflügers Arch 2008; 457: 377-87.

129 Tomasiak M, Stelmach H, Rusak T, Ciborowski M, Radziwon $\mathrm{P}$. The involvement of $\mathrm{Na}^{+} / \mathrm{K}^{+}$-ATPase in the development of platelet procoagulant response. Acta Biochimica Polonica 2007; 54: 625-39.

130 Bucki R, Pastore JL, Giraud F, Janmey PA, Sulpice JC. Involvement of the $\mathrm{Na}^{+} / \mathrm{H}^{+}$exchanger in membrane phosphatidylserine exposure during human platelet activation. Biochim Biophys Acta 2006; 1761: 195-204. 
131 Wolfs JL, Wielders SJ, Comfurius P, Lindhout T, Giddings JC, Zwaal RF, Bevers EM. Reversible inhibition of the platelet procoagulant response through manipulation of the Gardos channel. Blood 2006; 108: 2223-8.

132 Leytin V, Allen DJ, Mutlu A, Gyulkhandanyan AV, Mykhaylov S, Freedman J. Mitochondrial control of platelet apoptosis: effect of cyclosporin A, an inhibitor of the mitochondrial permeability transition pore. Lab Invest 2009; 89: 374-84.

133 Starkov AA. The molecular identity of the mitochondrial $\mathrm{Ca}^{2+}$ sequestration system. FEBS $J$ 2010; 277: 3652-63.

134 Strehl A, Munnix IC, Kuijpers MJ, van der Meijden PE, Cosemans JM, Feijge MA, Nieswandt B, Heemskerk JW. Dual role of platelet protein kinase $\mathrm{C}$ in thrombus formation: stimulation of pro-aggregatory and suppression of procoagulant activity in platelets. $J$ Biol Chem 2007; 282: 7046-55.

135 Konopatskaya O, Gilio K, Harper MT, Zhao Y, Cosemans JM, Karim AZ, Whiteheart SW, Molkentin JD, Verkade P, Watson SP, Heemskerk JW, Poole AW. PKC $\alpha$ regulates platelet granule secretion and thrombus formation in mice. J Clin Invest 2009; 119: 399-407.

136 Gilio K, Harper MT, Cosemans JM, Konopatskaya O, Munnix IC, Prinzen L, Leitges M, Liu Q, Molkentin JD, Heemskerk JW, Poole AW. Functional divergence of platelet protein kinase C (PKC) isoforms in thrombus formation on collagen. J Biol Chem 2010; 285: 23410-9.

137 Harper MT, Poole AW. Diverse functions of protein kinase $\mathrm{C}$ isoforms in platelet activation and thrombus formation. J Thromb Haemost 2010; 8: 454-62.

138 Nagy B, Bhavaraju K, Getz T, Bynagari YS, Kim S, Kunapuli SP. Impaired activation of platelets lacking protein kinase C- $\theta$ isoform. Blood 2009; 113: 2557-67.

139 Stefanini L, Roden RC, Bergmeier W. CalDAGGEFI is at the nexus of calcium-dependent platelet activation. Blood 2009; 114: 2506-14.

140 Ahmad F, Boulaftali Y, Greene TK, Ouelette TD, Poncz M, Feske S, Bergmeier W. Relative contributions of stromal interaction molecule 1 and CaIDAG-GEFI to calcium-dependent platelet activation and thrombosis. J Thromb Haemost 2011; 9: 2077-86.

141 Suzuki J, Umeda M, Sims PJ, Nagata S. Calciumdependent phospholipid scrambling by TMEM16F. Nature 2010; 468: 834-8.

142 Castoldi E, Collins PW, Williamson PL, Bevers EM. Compound heterozygosity for 2 novel TMEM16F mutations in a patient with Scott syndrome. Blood 2011; 117: 4399-400.

143 Munnix IC, Harmsma M, Giddings JC, Collins PW, Feijge MA, Comfurius P, Heemskerk JW, Bevers EM. Store-mediated calcium entry in the regulation of phosphatidylserine exposure in blood cells from Scott patients. Thromb Haemost 2003; 89: 687-95.

144 Bachelot-Loza C, Badol P, Brohard-Bohn B, Fraiz $N$, Cano E, Rendu F. Differential regulation of platelet aggregation and aminophospholipid exposure by calpain. Br J Haematol 2006; 133: 419-26

145 Takizawa H, Nishimora S, Takayama N, Oda A, Nishikii H, Morita $Y$, Kakinuma S, Yamazaki S, Okamura S, Tamura N, Goto S, Sawaguchi A, Manabe I, Takatsu K, Nakauchi H, Takaki S, Eto K. Lnk regulates integrin $\alpha_{11 ь} \beta_{3}$ outside-in signaling in mouse platelets, leading to stabilization of thrombus development in vivo. J Clin Invest 2010; 120: 179-90.

146 Suzuki-Inoue K, Hughes CE, Inoue O, Kaneko M, Cuyun-Lira O, Takafuta T, Watson SP, Ozaki Y. Involvement of Src kinases and PLCY2 in clot retraction. Thromb Res 2007; 120: 251-8.

147 Randriamboavonjy V, Isaak J, Fromel T, Viollet B, Fisslthaler B, Preissner KT, Fleming I. AMPK alpha2 subunit is involved in platelet signaling, clot retraction and thrombus stability. Blood 2010; 116: 2134-40.

148 Martin V, Guillermet-Guibert J, Chicanne G, Cabou C, Jandrot-Perrus M, Plantavid M, Vanhaesebroeck B, Payrastre B, Gratacap MP. Deletion of the p110 $\beta$ isoform of phosphoinositide 3-kinase in platelets reveals its central role in Akt activation and thrombus formation in vitro and in vivo. Blood 2010; 115: 2008-13.

149 Ono A, Westein E, Hsiao S, Nesbitt WS, Hamilton JR, Schoenwaelder SM, Jackson SP. Identification 
of a fibrin-independent platelet contractile mechanism regulating primary hemostasis and thrombus growth. Blood 2008; 112: 90-9.

150 Kasahara K, Souri M, Kaneda M, Miki T, Yamamoto $\mathrm{N}$, Ichinose $\mathrm{A}$. Impaired clot retraction in factor XIII A subunit-deficient mice. Blood 2010; 115: 1277-9.

151 Schoenwaelder SM, Yuan Y, Cooray P, Salem HH, Jackson SP. Calpain cleavage of focal adhesion proteins regulates the cytoskeletal attachment of integrin $\alpha_{11 b} \beta_{3}$ (platelet glycoprotein IIb/IIla) and the cellular retraction of fibrin clots. J Biol Chem 1997; 272: 1694-702.

152 Verhallen PF, Bevers EM, Comfurius P, Zwaal RF. Correlation between calpain-mediated cytoskeletal degradation and expression of platelet procoagulant activity. A role for the platelet membrane-skeleton in the regulation of membrane lipid asymmetry? Biochim Biophys Acta 1987; 903: 206-17. 



\section{Chapter 4}

\section{Dual mechanism of integrin $\alpha_{11 b} \beta_{3}$ closure in procoagulant platelets}

Mattheij $\mathrm{NJ}^{1}$, Gilio $\mathrm{K}^{1}$, van Kruchten $\mathrm{R}^{1}$, Jobe $S \mathrm{~S}^{2}$, Wieschhaus $A \mathrm{~J}^{3}$, Chishti $\mathrm{AH}^{4}$, Collins $\mathrm{P}^{5}$, Heemskerk JW ${ }^{1}$, Cosemans JM ${ }^{1}$

${ }^{1}$ Department of Biochemistry, Cardiovascular Research Institute Maastricht, Maastricht University, Maastricht, The Netherlands; ${ }^{2}$ Department of Pediatrics,

Emory University, Atlanta, United States; ${ }^{3}$ Department of Pharmacology, University of Illinois, Chicago, United States; ${ }^{4}$ Department of Molecular Physiology and Pharmacology, Tufts University School of Medicine, Boston, United States; ${ }^{5}$ Arthur Bloom Haemophilia Centre, Department of Haematology, Medical School of Cardiff University, Cardiff, United Kingdom

J Biol Chem. 2013;288:13325-13336 Reprinted with permission 


\begin{abstract}
Aggregation of platelets via activated integrin $\alpha_{\| b} \beta_{3}$ is a prerequisite for thrombus formation. Phosphatidylserine-exposing platelets with a key role in the coagulation process disconnect from a thrombus by integrin inactivation via an unknown mechanism. Here we show that $\alpha_{11 b} \beta_{3}$ inactivation in procoagulant platelets relies on a sustained high intracellular $\mathrm{Ca}^{2+}$, stimulating intracellular cleavage of the $\beta_{3}$ chain, talin and Src kinase. Inhibition of calpain activity abolished protein cleavage, but only partly suppressed $\alpha_{\| b} \beta_{3}$ inactivation. Integrin $\alpha_{\| b} \beta_{3}$ inactivation was unchanged in platelets from Capn $1^{-}$mice, suggesting a role of the calpain-2 isoform. Scott syndrome platelets, lacking the transmembrane protein TMEM16F and having low phosphatidylserine exposure, displayed reduced $\alpha_{\| b} \beta_{3}$ inactivation with the remaining activity fully dependent on calpain. In platelets from Ppif/- mice, lacking mitochondrial permeability transition pore (mPTP) formation, agonist-induced phosphatidylserine exposure and $\alpha_{11 b} \beta_{3}$ inactivation were reduced. Treatment of human platelets with cyclosporin A gave a similar phenotype. Together, these data point to a dual mechanism of $\alpha_{11 b} \beta_{3}$ inactivation via calpain(-2) cleavage of integrin-associated proteins and via TMEM16F-dependent phospholipid scrambling with an assistant role of mPTP formation.
\end{abstract}

\section{Introduction}

Integrin $\alpha_{11 b} \beta_{3}$ plays a crucial role in platelet aggregation in response to physiological agonists. Once in its activated conformation, $\alpha_{11 \mathrm{~b}} \beta_{3}$ accomplishes platelet-platelet interactions via bridges of fibrinogen and von Willebrand factor. Under thrombotic conditions in flowing blood, $\alpha_{11 b} \beta_{3}$ dependent platelet aggregation mediates thrombus formation and, finally, occlusion of a damaged cardiac or carotid artery ${ }^{1}$ Microscopic observations have shown that, both in vivo and in parallel-plate flow chambers, the aggregated platelets in a thrombus are surrounded by patches of procoagulant platelets with quite distinct properties. ${ }^{2}$

The latter platelets characteristically are elevated in cytosolic $\mathrm{Ca}^{2+}$, have a rounded morphology with attached microparticles, and exposed the negatively charged lipid, phosphatidylserine (PS). This contrasts to the classical pseudopod-containing structure of aggregated platelets in a thrombus, which do not expose PS. ${ }^{3}$ Time-lapse videos show that the rounded morphology arises during platelet disconnection from the thrombus core, suggesting a wellcontrolled mechanism of platelet detachment. ${ }^{4}$ This population of PSexposing platelets was found to bind 
multiple coagulation factors, greatly promoting the process of thrombin generation. ${ }^{3,5}$ It has been argued that the platelet detachment is mediated by inactivation or closure of previously activated $\alpha_{\| 1 b} \beta_{3}$ integrins. ${ }^{6}$ However, the regulation of such a process is not well understood.

Activation of $\alpha_{\| 1 b} \beta_{3}$ leads to the appearance of high-affinity binding sites for fibrinogen and von Willebrand factor at the platelet surface. The signaling mechanism to $\alpha_{11 b} \beta_{3}$ activation, unraveled in considerable detail, involves several pathways, i.e., via a phospholipase $\mathrm{C}$ and protein kinase $\mathrm{C}$ route, resulting in transient $\mathrm{Ca}^{2+}$ fluctuations, and via phosphoinositide 3kinase route. The consequence is activation of a chain of regulatory proteins CalDAG-GEFI, Rap1b and Rap1GTP-interacting adapter molecule (RIAM); 7,8 and these establish interaction of the cytoskeleton proteins, kindlin-3 and talin-1, with the $\beta_{3}$ chain of the $\alpha_{11 b} \beta_{3}$ complex, with as a result unclasping of the $\alpha_{\| b}$ and $\beta_{3}$ chains., ${ }^{9,10}$ Another proposed mechanism of $\alpha_{11 b} \beta_{3}$ activation is that talin-1 modulates the integrin conformation by a tilting effect on the $\beta_{3}$ chain. ${ }^{11}$

In response to $A D P$ and $A D P$-releasing platelet agonists, the conformational change of $\alpha_{11 b} \beta_{3}$ is considered to be an intrinsically reversible process. ${ }^{6}$ The active integrin itself can evoke multiple signaling events in platelets. ${ }^{12} \mathrm{~A}$ key role in this so-called outside-in signaling pathway is provided by the protein tyrosine kinase Src, which is constitutively associated with the $\beta_{3}$ cytoplasmic tail. ${ }^{13} \mathrm{Src}$, for instance, activates other tyrosine kinases such as Syk. ${ }^{8}$ In addition, a functional role of the $\mathrm{Ca}^{2+}$-dependent thiol protease, calpain, has been suggested in integrin $\alpha_{\| 1} \beta_{3}$ activation and signaling, but this has remained controversial. Calpain may either activate $\alpha_{\| 1} \beta_{3}$ by cleaving talin, ${ }^{14}$ or counteract the high-affinity conformational state of $\alpha_{\| 1 b} \beta_{3}$ by cleaving the cytoplasmic tail of the $\beta_{3}$ chain. ${ }^{15}$

While essentially all platelet agonists cause $\alpha_{\| 1} \beta_{3}$ activation, only strong agonists are capable of inducing the formation of procoagulant, PS-exposing platelets. Effective inducers of the latter response are the combination of the glycoprotein $\mathrm{VI}$ agonist convulxin ( $\mathrm{Cvx}$ ) with thrombin (Thr), or otherwise $\mathrm{Ca}^{2+}$ ionophores such as A23187 and ionomycin. ${ }^{16,17}$ Common to these agonists is that they induce a high and sustained rise in cytosolic $\mathrm{Ca}^{2+}$. which is considered to trigger the $\mathrm{Ca}^{2+}$-operated membrane protein, TMEM16F, which regulates the scrambling of phospholipids and exposure of PS. ${ }^{18,19}$ In platelets from Scott syndrome patients, who lack a functional TMEM16F, agonistinduced PS exposure is greatly diminished. ${ }^{20,21}$ Also a role in TMEM16F- 
mediated phospholipid scrambling is the $\mathrm{Ca}^{2+}$-dependent depolarization of the inner mitochondrial membrane and formation of a mitochondrial permeability transition pore (mPTP). ${ }^{19}$ This is consistent with the observation that mouse platelets lacking cyclophilin $D$ (Ppif gene), an mPTP component, are defective in PS exposure. ${ }^{22}$

Another platelet population often described in the literature is that of coated platelets. ${ }^{23,24}$ These are formed
A

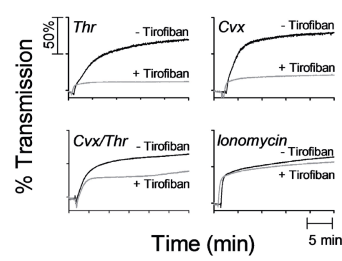

C

Cvx/Thr

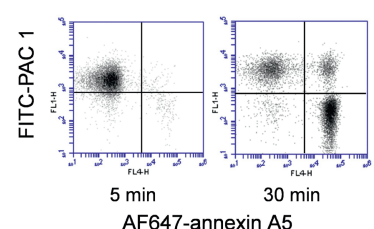

AF647-annexin A5

E

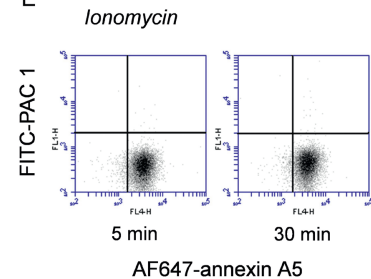

$\mathrm{B}$



D

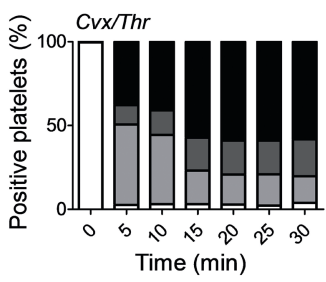

$\mathrm{F}$

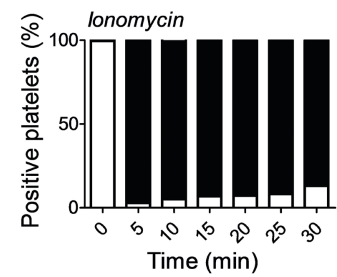

Figure 1. Increase in light transmission, but loss of aggregating potential and inactivation of $\alpha_{11} \beta_{3}$ after platelet stimulation with $\mathrm{Cvx} / \mathrm{Thr}$ or ionomycin. Washed human platelets were stimulated with $\mathrm{Thr}(4 \mathrm{nM}), \mathrm{Cvx}$ (100 $\mathrm{ng} / \mathrm{ml}), \mathrm{Cvx} / \mathrm{Thr}$ or ionomycin $(10 \mu \mathrm{M}) \pm$ tirofiban $(5 \mu \mathrm{g} / \mathrm{ml})$ in the presence of $2 \mathrm{mM} \mathrm{CaCl}$, as indicated. (A) Representative light transmission traces from 5 independent experiments. (B) Single platelet count after 30 min of stimulation. $(C, D)$ Two-color flow cytometry after stimulation at indicated times with $\mathrm{Cvx} / \mathrm{Thr}$; labeling was with FITC-PAC1 mAb plus AF647-annexin A5. (C) Representative dot plots of FL1 (FITC-PAC1 mAb) versus FL4 (AF647-annexin A5) after 5 or 25 min of activation. (D) Percentages of platelet populations: no staining (white bars), staining with PAC1 mAb (light gray bars), double staining (dark gray bars), and annexin A5 positive (black bars). ( $E, F)$ Two-color flow cytometry after stimulation with ionomycin; further as for panels $C$ and $D$. Means \pm S.D. $(n=5),{ }^{*} p<0.05$ vs. Thr (paired T-test). 
by dual stimulation with collagen and thrombin (but not $\mathrm{Ca}^{2+}$ ionophore), and can be characterized by high and stable surface retention of labeled fibrinogen. Fibrinogen as well as other platelet secretion products (e.g. factor V, thrombospondin, fibronectin, von Willebrand factor), bind to these platelets in a $\alpha_{11 b} \beta_{3}$-independent way via transglutaminase activity. Procoagulant and coated platelets represent two not completely overlapping populations, as not all PS-exposing platelets display high fibrinogen binding. ${ }^{2}$

In the present study, we investigated the mechanism of integrin $\alpha_{11 b} \beta_{3}$ inactivation in procoagulant platelets, by determining the functional roles of calpain, Srcdependent signaling, TMEM16F and mPTP formation.

\section{Experimental procedures}

\section{Materials}

Horm type-I collagen was purchased fromNycomed. Convulxin (Cvx) was purified to homogeneity from the venom of Crotalus durissus terrificus (Latoxan). Annexin A5 labeled with Alexa Fluor-647 (AF647) and Fura-2 acetoxymethyl ester were from Invitrogen. Annexin A5 labeled with fluorescein isothiocyanate (FITC) was from Pharmatarget; FITClabeled PAC1 monoclonal antibody (mAb) against activated human integrin $\alpha_{11 b} \beta_{3}$ from $B D$ bioscience; phycoerythrin (PE)labeled JON/A mAb against activated mouse $\alpha_{11 b} \beta_{3}$ from Emfret Analytics. Mouse anti-talin $\mathrm{mAb}$ and anti- $v$-Src were from Sigma; mAb anti-Tyr ${ }^{773} \beta_{3}$ chain (Ab38460) was from Abcam. Rabbit antibodies Ab762, Ab754, and Ab759, directed against (calpain-dependent) cleavage sites of human/mouse integrin $\beta_{3}$, were kindly provided by $\mathrm{Dr}$. X. Du (University of Illinois, Chicago). ${ }^{25}$ Tirofiban came from MSD, human $\alpha$ thrombin from Kordia, and MDL-28170 from Tocris. Pre-stained SDS-PAGE standards and Laemmli sample buffer were from Biorad. Other reagents were purchased from Calbiochem.

\section{Blood Collection and Platelet Preparation}

Blood from healthy volunteers and a Scott syndrome patient was collected in acid-citrate-dextrose anticoagulant after full informed consent (Helsinki declaration). Experiments were approved by the local Medical Ethics Committees. Platelet-rich plasma (PRP) and washed platelets were prepared, as described. ${ }^{26}$ Washed platelets were suspended into Hepes buffer pH 7.45 (10 mM Hepes, 136 $\mathrm{mM} \mathrm{NaCl}, 2.7 \mathrm{mM} \mathrm{KCl}, 2 \mathrm{mM} \mathrm{MgCl}, 5$ $\mathrm{mg} / \mathrm{ml}$ glucose and $1 \mathrm{mg} / \mathrm{ml}$ bovine serum albumin). Final concentration of platelets in plasma or buffer medium was $1 \times 10^{8} / \mathrm{ml}$, unless indicated otherwise.

Animal studies were approved by the local Animal Experimental Committees. Mice homozygous for a targeted deletion 
of the cyclophilin D (Ppif gene) were generated, as described. ${ }^{22}$ The mice were bred on a Sv129 background, and compared to $\mathrm{Ppif}^{+/+}$animals of the same breeding. Calpain-1 deficient mice $\left(\mathrm{Capn}^{-1-}\right)$ were generated, as previously reported. ${ }^{27,28}$ These mice were bred on a $\mathrm{C} 57 \mathrm{BI} / 6$ background and were compared to $\mathrm{Capn}^{+/+}$mice of the same genetic background. Mouse platelets were isolated as described before, ${ }^{29}$ and suspended in modified Hepes buffer $\mathrm{pH}$ 7.45 (5 mM Hepes, $136 \mathrm{mM} \mathrm{NaCl}, 2.7$ $\mathrm{mM} \mathrm{KCl}, 2 \mathrm{mM} \mathrm{MgCl}_{2}, 0.42 \mathrm{mM} \mathrm{NaH}_{2} \mathrm{PO}_{4}$, $5 \mathrm{mg} / \mathrm{ml}$ glucose and $1 \mathrm{mg} / \mathrm{ml}$ bovine serum albumin). Final concentration was $1 \times 10^{8} / \mathrm{ml}$, unless indicated otherwise.

\section{Western Blot Analysis}

Washed platelets in (modified) Hepes buffer $\mathrm{pH} 7.45$ were incubated with the calpain inhibitors, calpeptin $(200 \mu \mathrm{M})$ or MDL28170 (200 $\mu \mathrm{M})$, or vehicle for 15 min, as desired. Platelets were stimulated with Cvx $(100 \mathrm{ng} / \mathrm{ml})$, Thr (8 $\mathrm{nM})$ or ionomycin $(20 \mu \mathrm{M})$. Samples $(5 \times$ $10^{7}$ platelets) were taken at indicated time points, and lysed in ice-cold $4 \times$ lysis buffer ( $\mathrm{NaCl} 600 \mathrm{mM}$, Tris $10 \mathrm{mM}$, EGTA 4 mM, EDTA 4 mM, NP-40 4\%). Lysed samples were separated on $8 \%$ SDSPAGE gels, proteins were transferred to PVDF blotting membranes by semi-dry transfer. Immunostaining was with antibodies against talin (1:500), integrin $\beta_{3}$ (Ab762, 1:10000; Ab754, 1:1000), phospho-Tyr ${ }^{774} \beta_{3}$-chain (1:500), or Src $(2.5 \mu \mathrm{g} / \mathrm{ml})$ for $1 \mathrm{~h}$, followed by overnight incubation with horse radish peroxidasecoupled secondary antibody at $4{ }^{\circ} \mathrm{C}$. Stained blots were visualized with an $\mathrm{ECL}$ system. Blot quantification was by densitometric analysis, as before. ${ }^{30}$

\section{Platelet Aggregation and Activation}

Light transmission traces, reflecting platelet aggregation, were measured using a Chronolog aggregometer under

\begin{tabular}{|l|r|r|r|r|}
\hline MFI \pm SD & \multicolumn{1}{l|l}{ CD61 } & \multicolumn{1}{l|}{ CD41a } & \multicolumn{1}{l|}{ CD42b } \\
\hline Control lgG & $336 \pm 19$ & $337 \pm 19$ & $337 \pm 19$ & $337 \pm 19$ \\
\hline Vehicle & $7616 \pm 1105$ & $25485 \pm 134$ & $766 \pm 50$ & $17154 \pm 883$ \\
\hline Thrombin & $17188 \pm 1397$ & $45995 \pm 344$ & $7282 \pm 943$ & $11338 \pm 3895$ \\
\hline Convulxin & $13811 \pm 828$ & $38928 \pm 3408$ & $5903 \pm 255$ & $13987 \pm 1491$ \\
\hline Thrombin/convulxin & $12327 \pm 1607$ & $40906 \pm 1863$ & $5874 \pm 417$ & $18979 \pm 469$ \\
\hline lonomycin & $8465 \pm 340$ & $24235 \pm 1586$ & $3148 \pm 82$ & $10899 \pm 304$ \\
\hline
\end{tabular}

Supplemental Figure S1. Glycoprotein expression levels of platelets stimulated with different agonists. Washed human platelets were left unstimulated or were stimulated with convulxin (Cvx, $100 \mathrm{ng} / \mathrm{ml}$ ) and/or thrombin (Thr, $4 \mathrm{nM})$ or ionomycin $(10 \mu \mathrm{M})$ in the presence of $2 \mathrm{mM} \mathrm{CaCl}_{2}$ for $30 \mathrm{~min}$. Glycoprotein expression levels were examined by flow cytometry after staining with FITC-labeled mAbs. Unstimulated platelets were also incubated with FITC-labeled control IgG. Data are presented as mean fluorescence intensities $(M F I) \pm S . D .(n=3)$. 
constant stirring $\left(37^{\circ} \mathrm{C}\right)$. Platelets $(1 \times$ $10^{8} / \mathrm{ml}$ ) in Hepes buffer containing $2 \mathrm{mM}$ $\mathrm{CaCl}_{2}$ were stimulated with $\mathrm{Thr}(4 \mathrm{nM})$ and/or Cvx $(100 \mathrm{ng} / \mathrm{ml})$, or with ionomycin $(10 \mu \mathrm{M})$; experiments were in the presence or absence of tirofiban ( 5 $\mu \mathrm{g} / \mathrm{ml})$. Aggregation of platelets was also assessed by single cell count analysis using a Coulter counter (Coulter Electronics).

For flow cytometry, washed human or mouse platelets $\left(1 \times 10^{8} / \mathrm{ml}\right)$ were preincubated with indicated inhibitors or $\mathrm{Me}_{2} \mathrm{SO}$ vehicle for $10 \mathrm{~min}$, and stimulated in the presence of $2 \mathrm{mM}$ $\mathrm{CaCl}_{2}$ with thrombin (4 $\left.\mathrm{nM}\right)$ and/or convulxin $(100 \mathrm{ng} / \mathrm{ml})$, or with ionomycin $(10 \mu \mathrm{M})$. In samples taken after 5-30 min, surface expression of PS was detected with AF647-labeled annexin A5. In addition, activated integrin $\alpha_{\| 1} \beta_{3}$ was detected using FITC-labeled PAC1 mAb for human platelets or PE-labeled JON/A $\mathrm{mAb}$ for mouse platelets. Samples were analyzed with a FACScan flow cytometer (BD Accuri Cytometers).

Platelet samples were fixed and stained for transmission electron microscopy, as described before. ${ }^{30}$ Calpain activity in platelets was assessed using a calpain activity assay kit according to the manufacturer's instructions (Abcam, Cambridge, MA). Results are expressed as relative fluorescence units per $\mathrm{mg}$ lysate protein.
Thrombus Formation on Collagen under Flow

Collagen-induced thrombus formation was assayed, as described before. ${ }^{20,31}$ In brief, PPACK/fragmin-anticoagulated mouse blood was flowed over a coverslip coated with collagen type-I in a transparent parallel-plate perfusion chamber, at shear rate of $1000 \mathrm{~s}^{-1}$ for 4 min. Thrombi formed on the collagen surface were post-stained with AF647annexin $A 5$ and PE-JON/A mAb in modified Hepes buffer pH 7.45, containing $\mathrm{CaCl}_{2}(2 \mathrm{mM})$ and heparin (1 $\mathrm{U} / \mathrm{ml}$ ). Phase-contrast and fluorescence images were captured for analysis of surface area coverage of adherent platelets, and of platelets with active integrins or exposed PS..$^{32}$ Image analysis was performed with Metamorph software Version 7.5.0.0 (MDS Analytical Technologies).

\section{Platelet $\mathrm{Ca}^{2+}$ Responses}

Cytosolic $\mathrm{Ca}^{2+}$ was measured in human platelets, preloaded with fluorescent Fura-2 acetoxymethyl ester (2.5 $\mu \mathrm{M})$ during $45 \mathrm{~min}$ at ambient temperature under gentle rotation. ${ }^{33}$ Washed platelets were stimulated, while recording changes in fluorescence by calibrated ratio fluorometry. Calcium responses were expressed as timeintegrals over baseline $\left[\mathrm{Ca}^{2+}\right]_{\text {. }}$. 
Unstim.

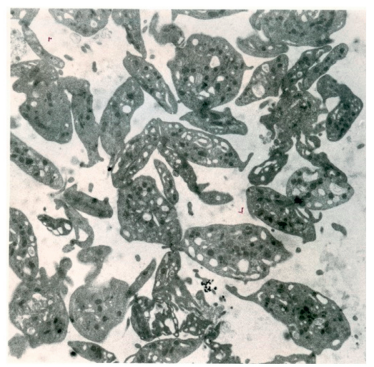

Thrombin

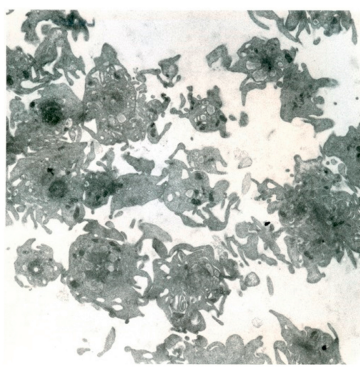

Ionomycin

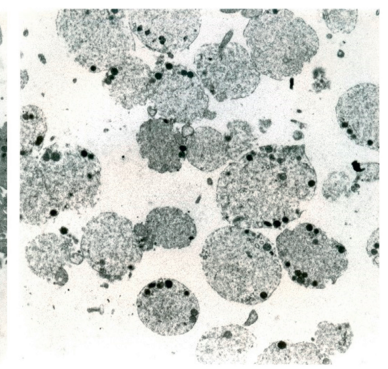

Supplemental Figure S1. Transmission electron microscopic images of unstimulated and various types of stimulated platelets. Washed human platelets were left unstimulated or were stimulated with thrombin (4 $\mathrm{nM})$ or ionomycin $(10 \mu \mathrm{M})$ in the presence of $2 \mathrm{mM} \mathrm{CaCl}_{2}$ for $30 \mathrm{~min}$ (no stirring to prevent ggregation). Platelets were then fixed, pelleted and prepared for transmission electron microscopic observation, as described before (Cosemans, J. Thromb. Haemost. 2010; 8:1797). Shown are representative images (bars $=2 \mu \mathrm{m}$ ).

\section{Statistics}

Significance of differences between control and experimental groups as well as changes between groups over time were determined by 1-way or 2-way analysis of variance followed by a Bonferroni post-hoc test. A Student's ttest was performed to compare paired samples. Data are expressed as means \pm S.D. $P$ values $<0.05$ were considered to be significant.

\section{Results}

Closure of Activated Integrin $\alpha_{\| l b} B_{3}$ in PSExposing Platelets

Earlier work demonstrated the appearance of two distinct populations of platelets during thrombus formation, i.e. co-aggregated platelets with activated $\alpha_{11 \mathrm{~b}} \beta_{3}$ integrins (binding PAC1 $\mathrm{mAb}$ ) and loosely attached platelets showing PS exposure (binding coagulation factors $\mathrm{Va}$ and $\mathrm{Xa}$ and annexin A5). ${ }^{3,20}$ The impaired adhesion of PS-exposing platelets seemingly contrasts to the observation that, in platelet suspensions, the $\mathrm{Ca}^{2+}$-ionophore ionomycin (causing full PS exposure) produces changes in light transmission that are suggestive of platelet aggregation..$^{34,35}$

We reinvestigated this by first stimulating washed human platelets with Thr (4 nM) or Cvx (100 ng/ml). As shown in Fig. $1 A$, this resulted in a rapid increase of light transmission, which was almost fully suppressed by the $\alpha_{11 \mathrm{~b}} \beta_{3}$ antagonist tirofiban (inhibition at $25 \mathrm{~min}$ $87 \pm 3 \%$ and $72 \pm 4 \%$, respectively; mean \pm S.D., $n=4)$. Integrin-dependent platelet aggregation with Thr or Cvx was confirmed by a major reduction in single platelet count (Fig. 1B). 
A Unstim. Iono Cvx/Thr

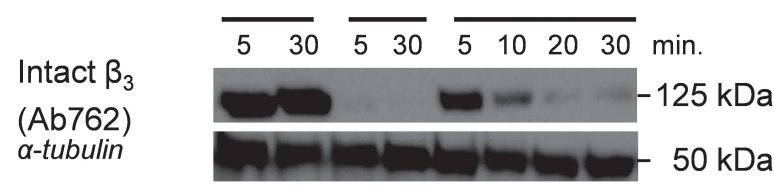

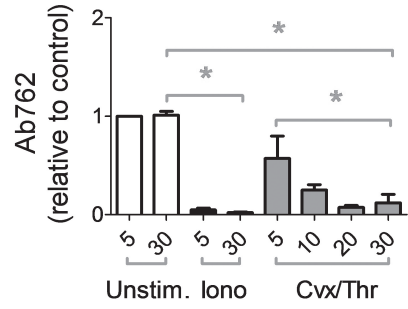

B

Unstim. Iono Cvx/Thr Cleaved $\beta_{3}$
$($ Ab754) $\overline{5 \quad 30} \overline{530} \overline{5102030}$ min. $\alpha$-tubulin


C

Unstim. Iono Cvx/Thr
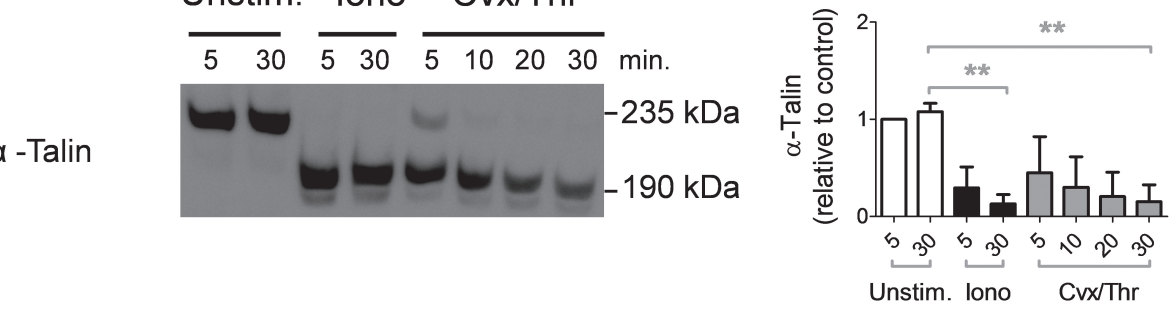

D
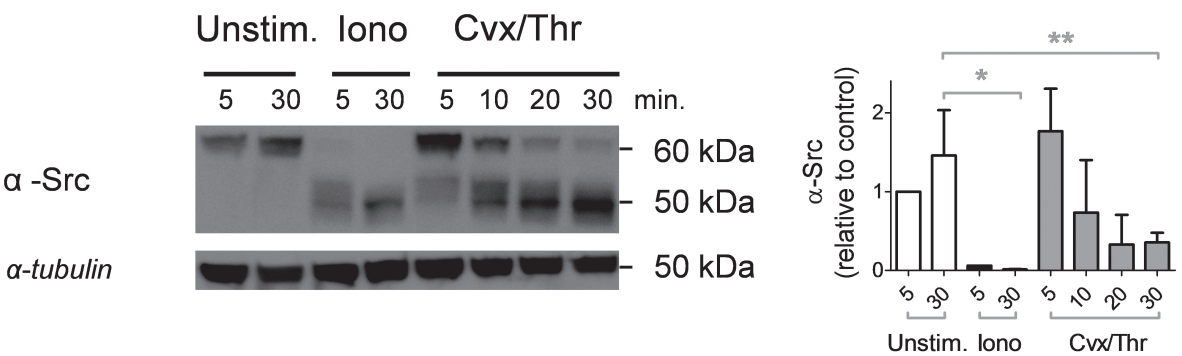

Figure 2. Intracellular cleavage of $\beta_{3}$ chain, talin and Src after platelet stimulation with Cvx/Thr or ionomycin. Platelets were left unstimulated or stimulated with $\mathrm{Cvx} /$ Thr or ionomycin, as described for Fig. 1 . Samples $\left(5 \times 10^{7}\right.$ platelets) were lysed after 5 or $30 \mathrm{~min}$, and subjected to electrophoresis and Western blotting. Blots were stained for: $(A)$ full-length $\beta_{3}$-chain with Ab762, (B) calpain-cleaved $\beta_{3}$-chain with Ab754, anti-talin mAb (C), or anti-Src mAb (D). Shown are representative blots and bar graphs of densitometric analysis of stained bands, corrected for loading control (anti-tubulin mAb). Means \pm S.D. $(n=3-4), *^{*} p<0.05$ (1-way ANOVA, Bonferroni correction). 

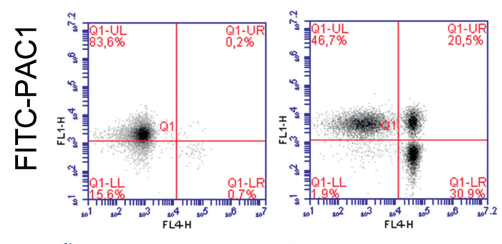

$2 \times 10^{8} \mathrm{plts} / \mathrm{ml}$
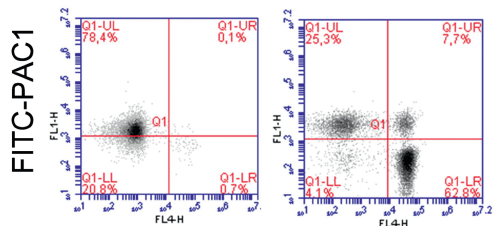

$1 \times 10^{8} \mathrm{plts} / \mathrm{ml}$
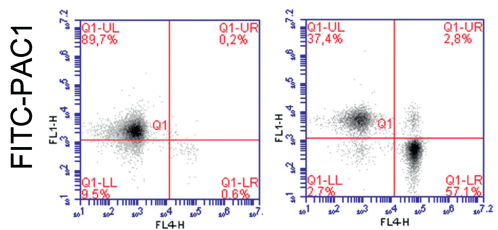

$0.2 \times 10^{8} \mathrm{plts} / \mathrm{ml}$
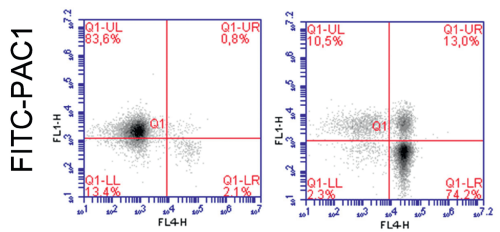

$2 \times 10^{8} \mathrm{plts} / \mathrm{ml}$

$+\mathrm{HA}-1077$

5 min

$30 \mathrm{~min}$

AF647-annexin A5

Supplemental Figure S2. Effect of platelet concentration on appearance of platelet population dual labeled with PAC1 mAb and annexin A5. Washed human platelets at indicated concentrations were stimulated for5-30 min with convulxin $(100 \mathrm{ng} / \mathrm{ml})$ plus thrombin $(4 \mathrm{nM})$ in the presence of $2 \mathrm{mM} \mathrm{CaCl}_{2}$ with or without the Rho kinase inhibitor HA-1077 $(40 \mu \mathrm{M})$. Two-color flow cytometry was performed after labeling with FITC-PAC1 mAb and AF647-annexin A5. Shown are dot plots of FL1 (FITC-PAC1 mAb) versus FL4 fluorescence (AF647-annexin A5), representative of at least 3 experiments.

On the other hand, the combined application of $\mathrm{Cvx} / \mathrm{Thr}$ or addition of ionomycin $(10 \mu \mathrm{M})$ provoked similar rapid increases in light transmission (Fig. $1 A)$. However, the $\mathrm{Cvx} / \mathrm{Thr}$-induced light transmission increase was only partly suppressed with tirofiban (inhibition $60 \pm$ $7 \%$ at $25 \mathrm{~min}$ ). In comparison, tirofiban did not affect the light transmission increase induced by ionomycin $(-9 \pm 8 \%)$. Platelet lysis could be excluded, because single cell count analysis indicated that ionomycin treatment resulted in a platelet count that remained at $90 \%$ of the original count (Fig. 1B). Electron microscopic analysis indicated that, unlike the pseudopod-containing platelets formed by thrombin, ionomycin treatment resulted in single, rounded platelets with a translucent appearance (supplemental Fig. S1). Together, these data indicate that the pseudo 
A

B

C

D

$\alpha-S r c$

$\alpha$-Tubulin

Intact $\beta_{3}$

(Ab762)

$\alpha$-Tubulin

(Ab754)

$\alpha$-Tubulin

a -Talin
Unstim. Cvx/Thr

Veh. Calpep MDL

Unstim. Cvx/Thr

Cleaved $\beta_{3}$

Unstim. Cvx/Thr

Veh. Calpep MDL

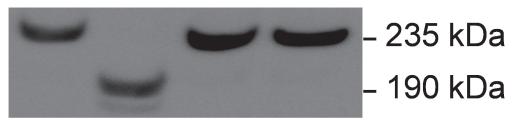

Unstim. Cvx/Thr

$125 \mathrm{kDa}$

$50 \mathrm{kDa}$

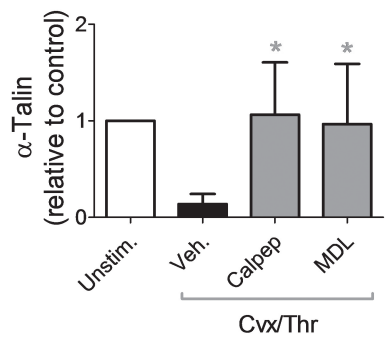

Veh. Calpep MDL

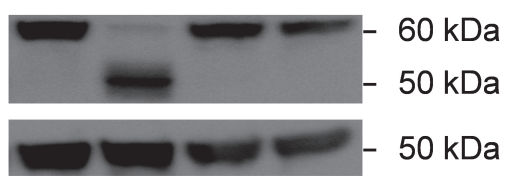

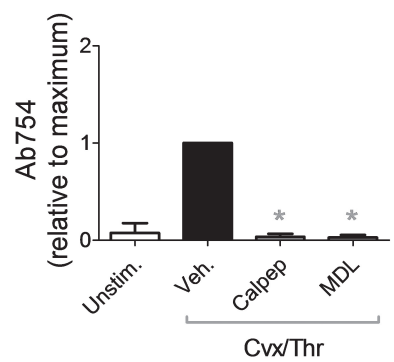

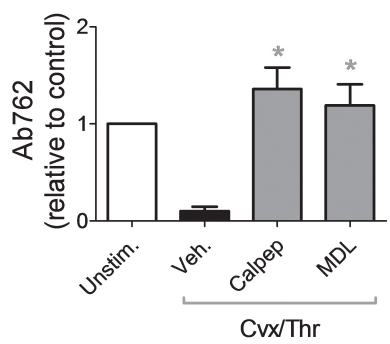

4

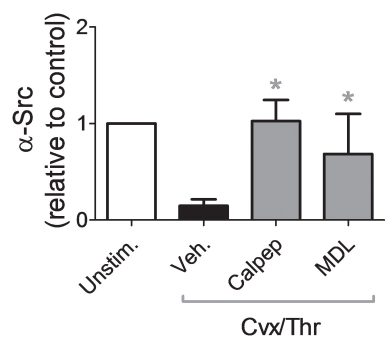

Figure 3. Role of calpain in cleavage of $\beta_{3}$ chain, talin and Src induced by $\mathrm{Cvx} / \mathrm{Thr}$ or ionomycin. Platelets were stimulated as described for Fig. 2, but preincubated for $10 \mathrm{~min}$ with either vehicle or calpain inhibitors, calpeptin $(200 \mu \mathrm{M})$ or MDL-28170 $(200 \mu \mathrm{M})$. Western blots from protein-separated lysates were stained for: (A) full-length $\beta_{3}$-chain with Ab762, (B) calpain-cleaved $\beta_{3}$-chain with Ab754, anti-talin mAb (C), or anti-Src mAb (D). Shown are representative blots and bar graphs of densitometric analysis of stained protein bands, corrected for loading control (anti-tubulin mAb). Means \pm S.D. $(n=4),{ }^{*} p<0.05$ (1-way ANOVA, Bonferroni correction). 
aggregation observed after Cvx/Thr or ionomycin stimulation is a consequence of the morphological change with a rounded and translucent platelet structure, reducing light transmission, rather than a consequence of integrindependent platelet aggregate formation. Absence of integrin activation with these agonists was further demonstrated by dual color flow cytometry, using FITCPAC1 $m A b$ and AF647-annexin A5, probing activated $\alpha_{\| b} \beta_{3}$ and PS exposure, respectively. Upon stimulation with $\mathrm{Cvx} / \mathrm{Thr}$, initially a population of platelets only binding PAC1 mAb was formed, which was gradually replaced by a population of PAC1 negative platelets which only bound annexin A5 (Fig. 1C,D). Within the time interval of 5 to $30 \mathrm{~min}$, $40 \pm 12 \%(n=4)$ of platelets lost the capability to bind PAC1 mAb. Similar results were found when fluorescent lactadherin was used instead of annexin A5 (data not shown). Integrin closure could not be explained by a decrease in expression levels of $\alpha_{11 \mathrm{~b}}$ and $\beta_{3}$ chains, since these levels were even increased after stimulation with Thr, Cvx or Cvx/Thr. This increase in expression levels is explained by an increase membrane surface due to granule secretion, as detected by CD62P expression (supplemental Table S1).

In response to ionomycin $(10 \mu \mathrm{M})$, the majority of platelets bound annexin $A 5$ but not PAC1 mAb (Fig. 1E,F). However, at low ionomycin doses $(<5 \mu \mathrm{M})$, transient PAC1 mAb binding was detected, accompanied by a corresponding reduction in single platelet count (data not shown). Expression levels of $\alpha_{\| b}$ and $\beta_{3}$ remained unchanged after high ionomycin stimulation (supplemental Table S1), thus indicating that this treatment precludes or antagonizes integrin activation. Increased expression levels of $\alpha_{\| l b}$ and $\beta_{3}$ were not observed, which was explained by a diminished secretion after ionomycin stimulation in comparison to Cvx/Thr stimulation.

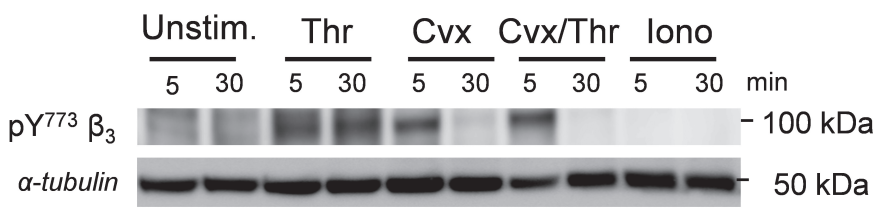

Supplemental Figure S3. Absence of integrin $\beta_{3}$-chain phosphorylation at $\mathrm{Tyr}^{773}$ in platelets stimulated with agonists causing PS exposure. Washed human platelets were left unstimulated or were stimulated with thrombin $(4 \mathrm{nM})$ and/or convulxin $(100 \mathrm{ng} / \mathrm{ml})$ or ionomycin $(10 \mu \mathrm{M})$ in the presence of $2 \mathrm{mM} \mathrm{CaCl}_{2}$, as indicated Western blots of gel-separated samples, taken after 5 or $30 \mathrm{~min}$, were immuno-stained for phospho-Tyr ${ }^{773} \beta_{3}$ chain or for tubulin as a loading control. Shown are representative Western blots. 
Taken together, these results suggest that PS exposure induced by these strong agents is accompanied by either closure of activated integrin or by lack of integrin activation, which prevents the formation of large platelet aggregates.

Interestingly, Fig. 1C-D points to a small population of Cvx/Thr-stimulated platelets, capable to bind both PAC1 $\mathrm{mAb}$ and annexin A5. Flow-cytometric studies were performed to characterize this dual-labeled platelet population. It remained unchanged in size upon stimulation with Cvx/SFLLRN (thrombin receptor-activating peptide) or in the presence of transglutaminase inhibitor, cadaverine (data not shown). This population for the major part $(<4 \%)$ did not exhibit high fibrinogen binding. Hence, these platelets could not be identified as 'coated', i.e. containing a transglutaminase-dependent fibrin coat.
A

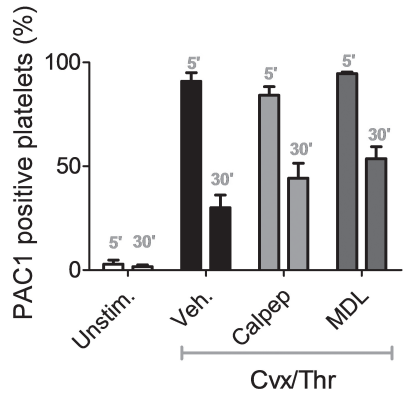

C

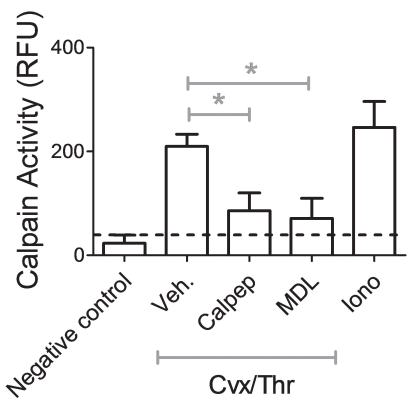

B

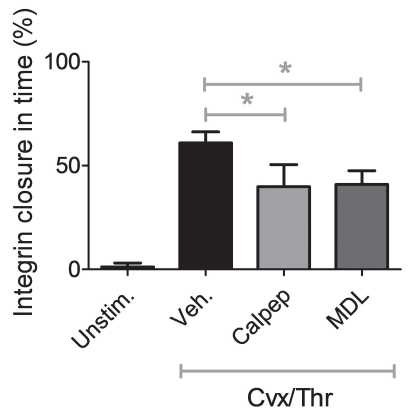

D

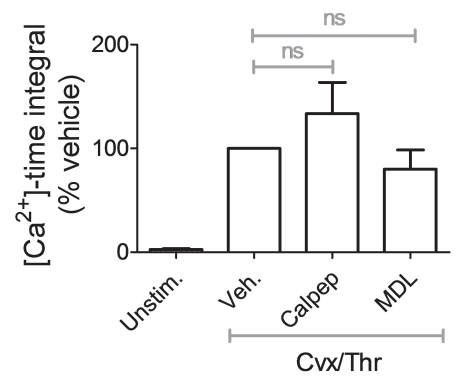

Figure 4. Partial role of calpain in agonist-induced $\boldsymbol{\alpha}_{\| 1} \beta_{3}$ closure. Platelets $\left(1 \times 10^{8} / \mathrm{ml}\right)$ were pretreated with vehicle, calpeptin $(200 \mu \mathrm{M})$ or MDL-28170 $(200 \mu \mathrm{M})$ for $10 \mathrm{~min}$, and then stimulated with Cvx/Thr for 5-30 min. $(A, B)$ Samples were analyzed by flow cytometry in the presence of FITC-PAC1 mAb. Shown that percentages of PAC1-binding platelets (A), and extent of integrin closure between 5 and $30 \mathrm{~min}$ (B). (C) Calpain activity assessed after $30 \mathrm{~min}$ of stimulation. Data are expressed as relative fluorescence units (RFU). (D) Calcium responses in Fura-2-loaded platelets assessed in response to $\mathrm{Cvx} /$ Thr. Shown are changes in $\left[\mathrm{Ca}^{2+}\right]$-time integrals $(\mathrm{nM} \times 10$ $\mathrm{min}$ ) relative to vehicle control. Means \pm S.D. $(n=4),{ }^{*} p<0.05$ (1-way ANOVA, Bonferroni correction). 
Other experiments showed that the population of dual-labeled platelets reduced in size, when incubations were performed at lower platelet count $(\leq 1 \times$ $10^{8} / \mathrm{ml}$ ), or contained a Rho kinase inhibitor, which antagonizes platelet contraction (supplemental Fig. S2). It was thus concluded that it consisted of micro-aggregates of - perhaps contracted - platelets with either active integrins or exposed PS.

Role of Calpain-Mediated Protein Cleavage in Integrin $\alpha_{l \mid b} b_{3}$ Closure

Considering the described role of calpain in $\alpha_{11 b} \beta_{3}$-dependent cleavage of cytoskeletal-associated proteins, $^{25}$ we examined whether relevant targets of this protease were cleaved under conditions of PS exposure. Western blot analysis was performed of gel-separated platelet lysates, using antibodies against the full length intracellular $\beta_{3}$ chain (Ab762) and against a calpain cleavage site in the $\beta_{3}$ chain at residue 754 (Ab754). ${ }^{15}$ Blots were also analyzed for the degradation of talin-1 and Src kinase, using suitable antibodies. After 5 min of stimulation with ionomycin, we noted major cleavage of the $\beta_{3}$ chain, talin and Src into smaller protein fragments (Fig. $2 A-D)$. After stimulation with $\mathrm{Cvx} / \mathrm{Thr}$, cleavage of the $\beta_{3}$ chain, talin and Src required $\sim 20 \mathrm{~min}$ to complete. Flow cytometry experiments, performed in parallel samples, confirmed the presence
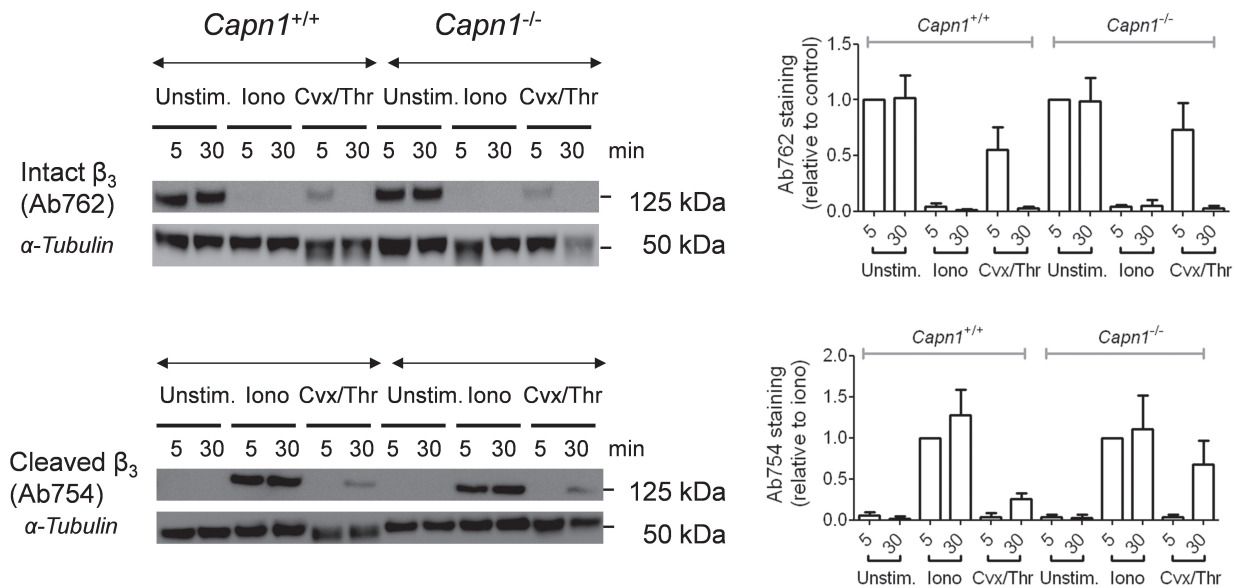

Supplemental Figure S4. Unchanged intracellular cleavage of integrin $\beta_{3}$ chain in activated calpain-1 deficient platelets. Platelets from Capn $1^{\%}$ and $\mathrm{Capn}^{+/+}$mice were left unstimulated or were stimulated with convulxin $(\mathrm{Cvx}, 100 \mathrm{ng} / \mathrm{ml})$ and/or thrombin $(\mathrm{Thr}, 4 \mathrm{nM})$ or ionomycin $(10 \mu \mathrm{M})$ for 5-30 min. Western blots of samples taken at indicated time points were stained for full-length integrin $\beta_{3}$ chain using Ab762 (A), or for cytosolic cleaved $\beta_{3}$-chain using Ab754 (B). Staining for $\alpha$-tubulin was used as loading control. Shown are representative Western blots and bar graphs of densitometric analysis of stained protein bands, normalized for the loading control. Means \pm S.D. $(n=3-4)$. 
of PS exposure and absence of integrin activation with ionomycin and a gradual PS exposure and integrin closure with $\mathrm{Cvx} / \mathrm{Thr}$ (compare Fig. 1). Together, these results suggested that phospholipid scrambling is one of the mechanisms contributing to intracellular integrin cleavage and inability to activation.

Considering that calpain may regulate tyrosine phosphorylation of the $\beta_{3}$ chain, ${ }^{27}$ we checked how platelet stimulation with $\mathrm{Cvx} / \mathrm{Thr}$ or ionomycin influenced the $\beta_{3}$ phosphorylation at $\mathrm{Tyr}^{733}$, i.e. a phosphorylation site indicative for $\alpha_{11 b} \beta_{3}$ outside-in signaling. ${ }^{36}$ Whereas platelet stimulation with Thr alone resulted in persistent $\mathrm{Tyr}^{773}$ phosphorylation, stimulation with Cvx/Thr resulted in a loss of phosphorylation at $30 \mathrm{~min}$, whereas ionomycin did not give any phosphorylation at all (supplementary Fig. S3). Hence, this phosphorylation site appears to be lost in platelets stimulated with the PS-exposing agonists.

To investigate a functional role of calpain activity in this protein degradation, two structurally different pharmacological inhibitors were used, i.e. calpeptin and MDL-28170, both of which are established inhibitors of $\mathrm{Ca}^{2+}$-dependent proteases. $^{28}$ Either compound fully inhibited the degradation of $\beta_{3}$ chain, talin and Src in platelets that were stimulated with $\mathrm{Cvx} / \mathrm{Thr}$ or ionomycin
(Fig. 3A-D).

We then determined effects of these inhibitors on the process of integrin inactivation. In the time frame of 5 to 30 min, calpeptin as well as MDL-28170 significantly, but incompletely affected the integrin closure in response to Cvx/Thr (Fig. 4A,B). Measurement of calpain activity indicated that both calpeptin and MDL-28170 nearly completely blocked this proteolytic activity in the stimulated platelets (Fig. 4C). Neither of the inhibitors affected initial PS exposure (78 $\pm 13 \%$ and $107 \pm$ $12 \%$ of control, respectively). In Fura-2loaded platelets, neither inhibitor changed the Cvx/Thr-induced intracellular $\mathrm{Ca}^{2+}$ rises (Fig. 4D).

Subsequent experiments were performed with mice lacking the major $\mathrm{Ca}^{2+}$-dependent cysteine protease, calpain-1 ( $\mu$-calpain, Capn $1^{-/}$gene), that accounts for $\sim 80 \%$ of the calpain activity in mouse and human platelets. ${ }^{37}$ Assessment of collagen-dependent thrombus formation indicated that the Capn $1^{1-}$ blood formed enlarged thrombi, which displayed increased integrin $\alpha_{\| 1 \mathrm{~b}} \beta_{3}$ activation (JON/A mAb binding), but decreased PS exposure (AF647-annexin A5 binding) in comparison to wild type Capn $1^{+/+}$blood (Fig. 5A). This suggests a negative role of calpain-1 in murine $\alpha_{11 \mathrm{~b}} \beta_{3}$ activation under these conditions. In platelet suspensions stimulated with Cvx/Thr, Capn1 $1^{-/-}$and Capn1 ${ }^{+/+}$platelets 

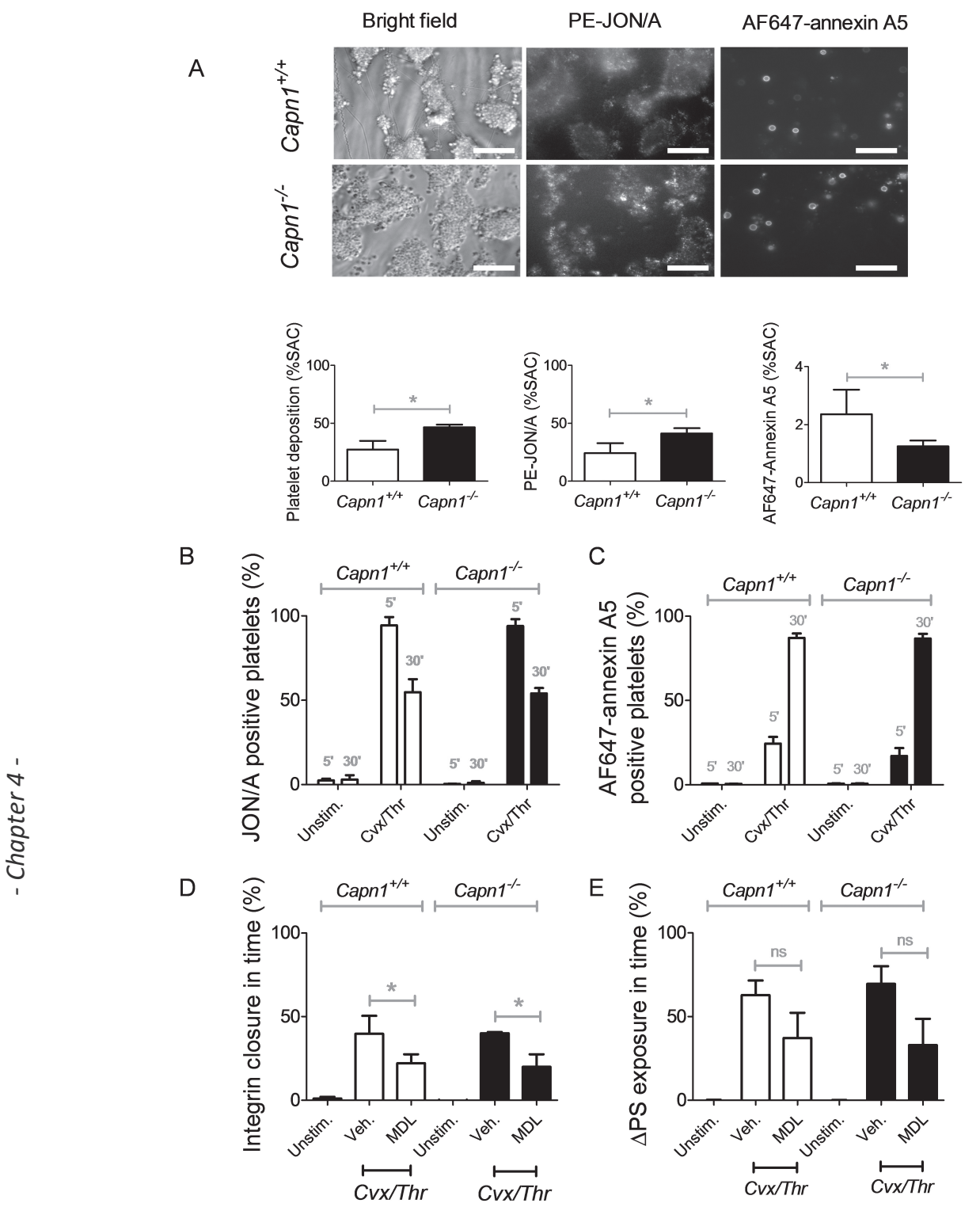

Figure 5. Unchanged agonist-induced PS exposure and $\alpha_{1 \mathrm{lb}} \beta_{3}$ closure in calpain-1 deficient platelets. $(A)$ Blood from Capn $1^{+/+}$or Capn $1^{-/}$mice was perfused over collagen for $4 \mathrm{~min}$ at $1000 \mathrm{~s}^{-1}$. Thrombi were labeled with PEJON/A mAb and AF647-annexin A5. Shown are representative brightfield and fluorescence images (bars $=20 \mu \mathrm{m}$ ), as well as quantitative analyses of (fluorescent) platelet deposition. (B-E) Washed mouse platelets were stimulated with $\mathrm{Cvx} / \mathrm{Thr}$ for 5-30 min, and analyzed by flow cytometry. Shown are percentages of platelets binding PE-JON/A (B) or AF647-annexin A5 (C). Platelets were pretreated with vehicle or MDL-28170 (200 $\mu \mathrm{M})$, as indicated. Treatment effects are shown of time-dependent changes in $\alpha_{11 \mathrm{~b}} \beta_{3}$ closure (D) or PS exposure (E). Means \pm S.D. $(n=3-4),{ }^{*} p<0.05$ vs. vehicle (2-way ANOVA, Bonferroni correction). 
displayed similar $\alpha_{11 b} \beta_{3}$ activation and closure, while also PS exposure was comparable (Fig. 5B,C). Treatment of $\mathrm{Capn}^{-/-}$and $\mathrm{Capn}^{+/+}$platelets with MDL-28170 partly suppressed integrin closure, but did not result in a significant decrease in PS exposure (Fig. 5D,E).

After stimulation with $\mathrm{Cvx} / \mathrm{Thr}$ or ionomycin, the knockout and wild type platelets gave similar cleavage patterns of the integrin $\beta_{3}$ chain (supplemental Fig. S4). Furthermore, total calpain inhibition with MDL-28170 fully blocked the cleavage of $\beta_{3}$-chain in $\mathrm{Capn}^{+/+}$and Capn $^{-/-}$platelets (supplemental Fig. S5). In conclusion, while the pharmacological data suggest a partial role for calpain activity in the process of integrin $\alpha_{11 \mathrm{~b}} \beta_{3}$ closure of PS-exposing mouse and human platelets, calpain-1 (at least in mice) does not appear to be the main $\beta_{3}$ chain/talin-degrading protease or target of the calpain inhibitors.

Role of Phospholipid Scrambling in Integrin $\alpha_{\| b} b_{3}$ Closure

Inactivation of integrin $\alpha_{1 \mathrm{lb}} \beta_{3}$ under conditions of PS exposure may point to a causal link between $\alpha_{11 b} \beta_{3}$ closure and scrambling of membrane phospholipids. This possibility was investigated using platelets from a Scott syndrome patient lacking the transmembrane protein TMEM16F, whose platelets are impaired in phospholipid scrambling in response to $\mathrm{Cvx} / \mathrm{Thr}$ or Ionomycin. ${ }^{38}$ Defective PS exposure in response to $\mathrm{Cvx} / \mathrm{Thr}$ in the patient's platelets was accompanied by a more persistent integrin $\alpha_{11 b} \beta_{3}$ activation (Fig. $6 A, B$ ). In the patient, ionomycin caused partial and transient $\alpha_{11 \mathrm{~b}} \beta_{3}$ activation, indicating that a mechanism of integrin closure was still operating. Interestingly, treatment of the Scott platelets with MDL-28170 fully blocked the time-dependent closure of integrin $\alpha_{\| 1 b} \beta_{3}$, in contrast to the partial blockage observed in control platelets (Fig. 6C). Western blots indicated that the cleavage pattern of the $\beta_{3}$-chain was not affected in Scott platelets after stimulation with ionomycin (Fig. 7) or Cvx/Thr (not shown). Furthermore, the cleavage was fully inhibited by MDL21870. Together, these results suggest a dual mechanism of integrin $\alpha_{\| 1} \beta_{3}$ closure in procoagulant platelets partly via TMEM16F-dependent scrambling of the plasma membrane phospholipids, and partly via calpain-dependent cleavage of intracellular proteins among which the integrin $\beta_{3}$ chain.

Involvement of Mitochondrial Transition Pore Formation in $\alpha_{\| \mathrm{b}} \beta_{3}$ Closure

Considering that mPTP formation plays an important role in Cvx/Thr-stimulated PS exposure in platelets, ${ }^{22}$ we investigated whether this mitochondrial process is also involved in integrin $\alpha_{11 \mathrm{~b}} \beta_{3}$ closure. Experiments were performed with platelets harvested from mice 

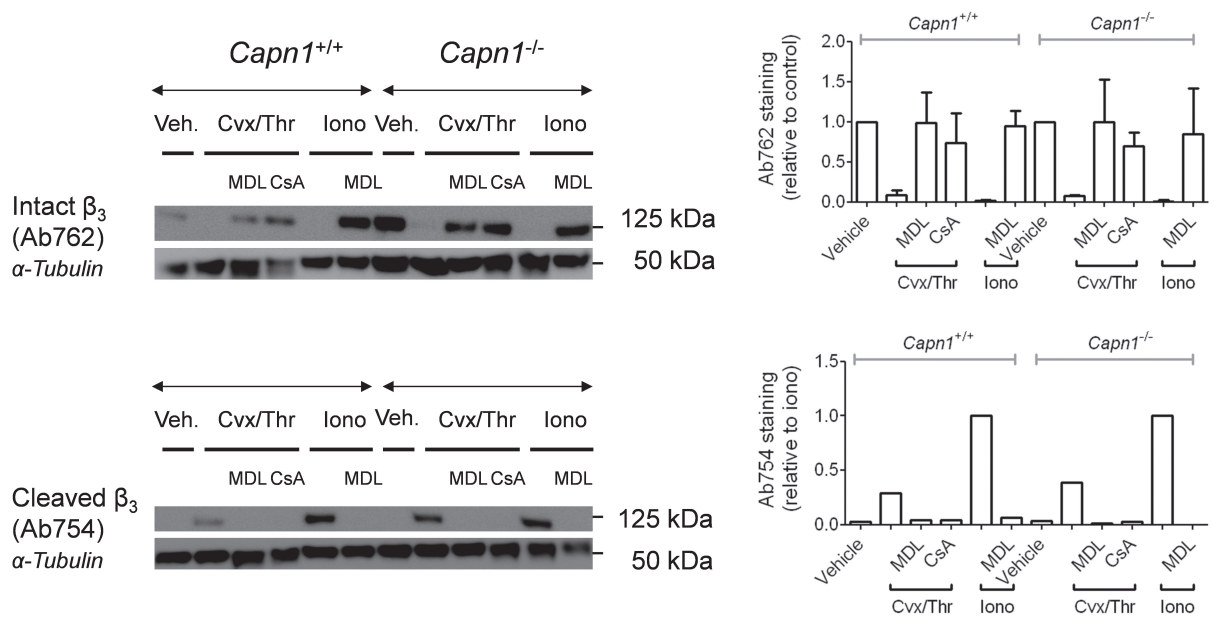

Supplemental Figure S5. Calpain and mPTP inhibitors suppress cleavage of integrin $\beta_{3}$ chain in activated calpain-1 deficient platelets. Platelets from $\mathrm{Capn}^{+/+}$and $\mathrm{Capn}^{-1-}$ mice were left unstimulated or were stimulated for $30 \mathrm{~min}$ with convulxin $(\mathrm{Cvx}, 100 \mathrm{ng} / \mathrm{ml})$ and thrombin $(\mathrm{Thr}, 4 \mathrm{nM})$ or ionomycin $(10 \mu \mathrm{M})$ for $30 \mathrm{~min}$ in the presence or absence of vehicle (DMSO), MDL-28170 $(200 \mu \mathrm{M})$ or cyclosporin A $(5 \mu \mathrm{M})$. Western blots of samples taken at indicated time points were stained for full-length integrin $\beta_{3}$ chain using $A b 762$ (A), or for cytosolic cleaved $\beta_{3}$-chain using Ab754 (B). Staining for $\alpha$-tubulin was used as loading control. Shown are representative Western blots and bar graphs of densitometric analysis of stained protein bands, normalized for the loading control. Means \pm S.D. $(n=3)$.

deficient in cyclophilin D (Ppif gene), which forms part of the mPTP. Hence, Ppif-- mouse platelets allow evaluating integrin closure in a second model, next to Scott platelets, in which PS exposure is blunted. Perfusion of Ppif/- blood over collagen resulted in decreased platelet deposition and PS exposure (AF647annexin A5 binding), when compared to wild type Ppif ${ }^{+/+}$blood (Fig. 8A). Also in suspensions of $P$ pif/- platelets stimulated with $\mathrm{Cvx} / \mathrm{Thr}$, PS exposure was markedly reduced, while $\alpha_{\| 1 \mathrm{~b}} \beta_{3}$ activation and closure were suppressed in a similar way (Fig. 8B). Treatment of wild type $\mathrm{Ppif}^{+/+}$ platelets with cyclosporin $A$, a compound known to block mPTP formation, ${ }^{39}$ suppressed PS exposure and integrin closure to the level observed in the knockout platelets, whereas cyclosporin A treatment of Ppif/- platelets was without any effect. Intracellular $\mathrm{Ca}^{2+}$ rises were not affected in Ppif ${ }^{-1-}$ platelets as compared to controls (unpublished observation, Jobe et al. 2012).

Similar experiments were performed with human platelets treated with cyclosporin A. Again, cyclosporin A suppressed PS exposure as well as integrin closure in response to $\mathrm{Cvx} / \mathrm{Thr}$ (Fig. 8C). In Fura-2-loaded platelets, cyclosporin A did not affect Cvx/Thr- 
A
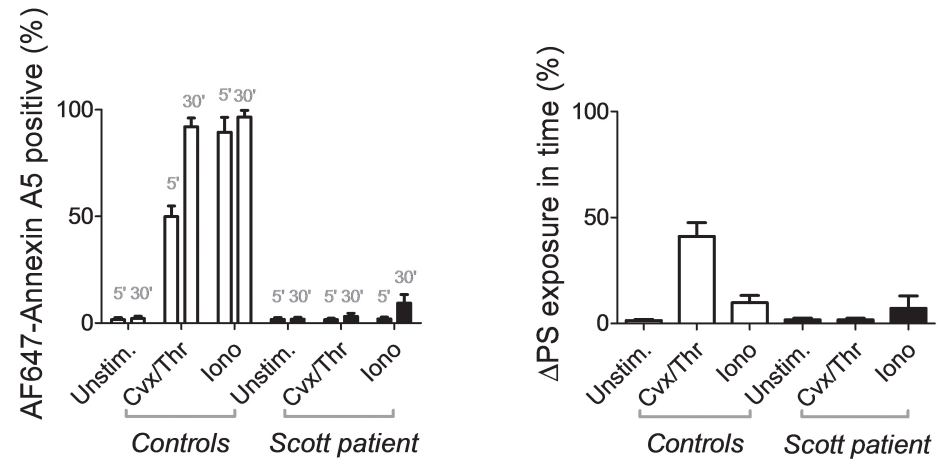

B
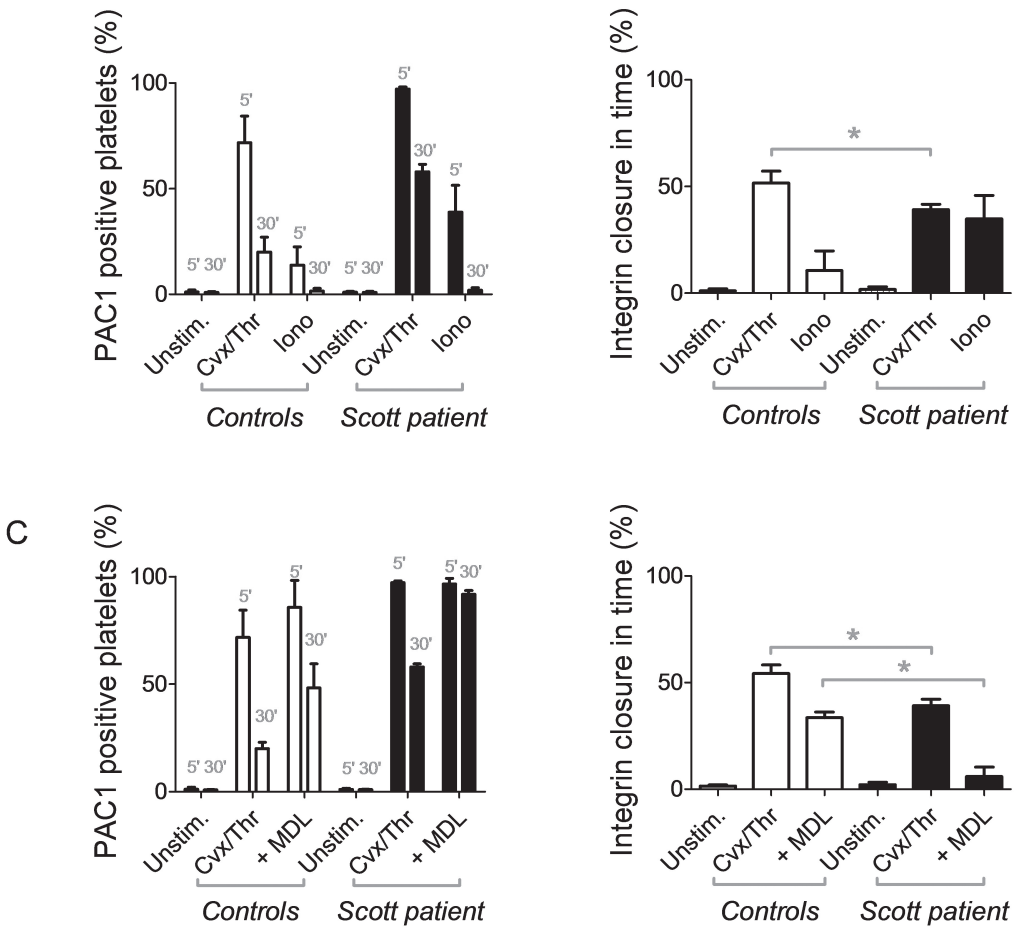

Figure 6. Partial role of TMEM16F in agonist-induced PS exposure and $\alpha_{1 \mathrm{~b}} \beta_{3}$ closure. Platelets from control subjects or a Scott patient (deficient in TMEM16F) were stimulated with $\mathrm{Cvx} / \mathrm{Thr}(100 \mathrm{ng} / \mathrm{ml}, 4 \mathrm{nM})$ or ionomycin $(19 \mu \mathrm{M})$ for 5-30 min, as in Fig. 1. Samples were analyzed by flow cytometry for PS exposure (AF647-annexin A5 binding) or $\alpha_{\| 1} \beta_{3}$ activation (FITC-PAC1 binding), as indicated. (A) Shown are percentages of PS-exposing platelets and increase in PS exposure between 5-30 min; (B) Also, percentages of PAC1-binding platelets and percentages of $\alpha_{\| 1} \beta_{3}$ closure between 5-30 min. (C) Effect of platelet treatment with MDL-28170 (200 $\left.\mu \mathrm{M}\right)$ on PAC1-binding and $\alpha_{\| b} \beta_{3}$ closure. Means \pm S.D. $(n=4),{ }^{*} p<0.05$ vs. vehicle (2-way ANOVA, Bonferroni correction). 


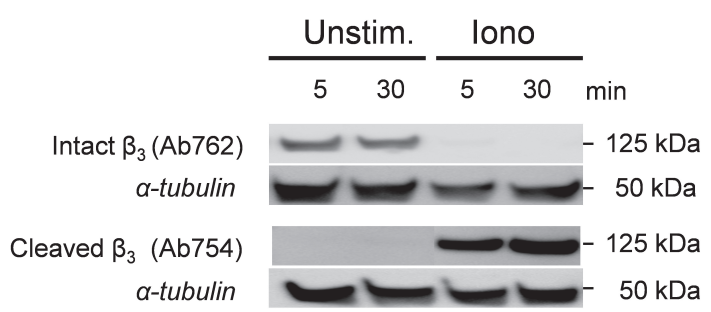

Figure 7. Unchanged agonist-induced cleavage of $\beta_{3}$ chain in the absence of TMEM16F. Platelets from the Scott patient (deficient in TMEM16F) were stimulated with ionomycin for 5-30 min, as in Fig. 1. Western blots from samples were stained for full-length $\beta_{3}$-chain (Ab762) or calpain-cleaved $\beta_{3}$-chain (Ab754). Blots were reprobed with anti-tubulin $\mathrm{mAb}$ as loading control. Shown are representative blots.

induced intracellular $\mathrm{Ca}^{2+}$ rises (data not competence for integrin-dependent shown). In addition, Src cleavage outside-in signaling and downstream observed after prolonged $\mathrm{Cvx} / \mathrm{Thr}$ responses including formation of tight stimulation was prevented by platelet-platelet contacts. This model cyclosporin A treatment (data not provides an explanation for the loose shown). Together, these observations association of PS-exposing platelets in a point to a central role of MPTP formation in PS exposure and integrin closure.

\section{Discusssion}

In this study, we demonstrate a dual mechanism responsible for integrin $\alpha_{\| 1} \beta_{3}$ closure (inactivation) in PS-exposing platelets being dependent on $\mathrm{Ca}^{2+}$ and calpain activity (but not calpain-1), and relying on $\mathrm{Ca}^{2+}$-dependent phospholipid scrambling mediated by the transmembrane protein TMEM16F. The calpain-dependent proteolysis under conditions of PS exposure involves intracellular cleavage of the integrin $\beta_{3}$ chain, talin and Src kinase. These findings implicate that PS-exposing, procoagulant platelets loose not only their capability of integrin-dependent adhesion and aggregate formation, but also the thrombus, and begins to outline a basis for bound coagulation factors and thrombin generation. The recognized mechanisms of integrin closure or inability to activation thus form the basis of earlier recognized heterogeneity of platelets in thrombus formation. . $^{5,20}$

High and sustained elevation in cytosolic $\mathrm{Ca}^{2+}$, a requirement for PS exposure, ${ }^{40}$ appears to be required for achieving optimal integrin closure, most likely calpain activity and TMEM16F. Mouse platelets deficient in calpain-1 showed a moderate increase in integrin activation and reduced PS exposure upon collagendependent thrombus formation, which is consistent with a moderate reduction in $\alpha_{\| 1} \beta_{3}$ closure under these mild activation conditions. This result seemingly contrasts with earlier findings that 


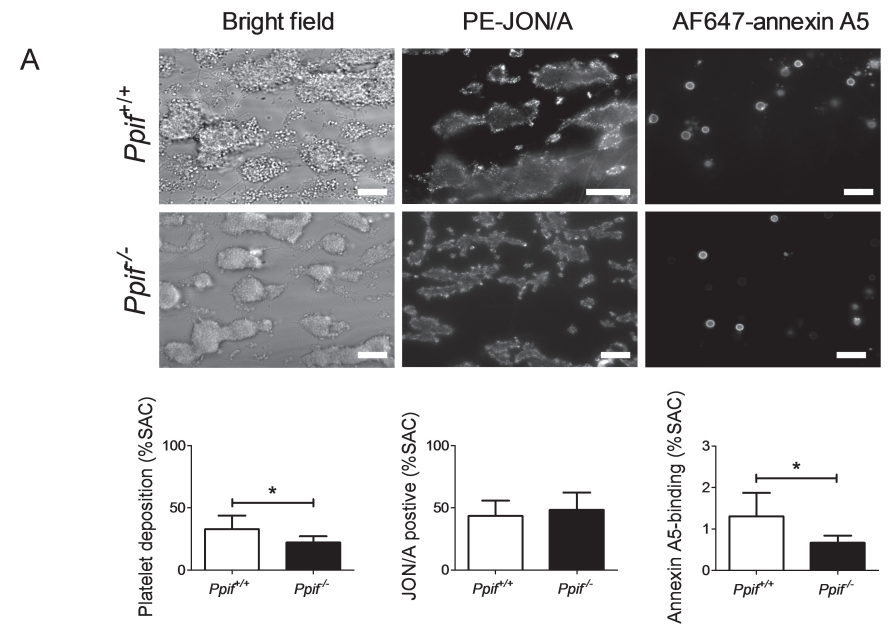

B

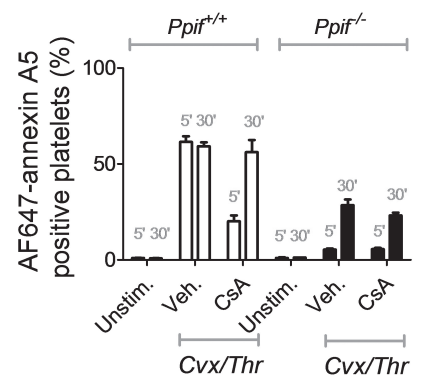

D

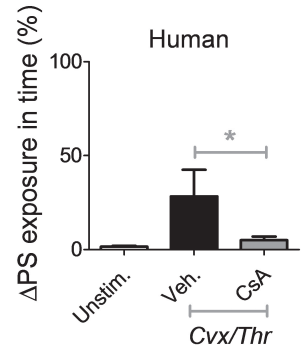

C


Figure 8. Partial role of mPTP formation in agonist-induced PS exposure and $\alpha_{\| 1} \beta_{3}$ closure. (A) Blood from $\mathrm{Ppif}^{+/+}$or Ppif/- mice was perfused over collagen for $4 \mathrm{~min}$ at $1000 \mathrm{~s}^{-1}$. Thrombi were labeled with PE-JON/A mAb and AF647-annexin A5. Shown are representative brightfield and fluorescence images (bars $=20 \mu \mathrm{m}$ ), as well as quantitative analyses of (fluorescent) platelet deposition. $(B, C)$ Washed mouse platelets were pretreated with vehicle $\left(0.2 \% \mathrm{Me}_{2} \mathrm{SO}\right)$ or cyclosporin $\mathrm{A}(4 \mu \mathrm{M})$, stimulated for 5-30 min with $\mathrm{Cvx} / \mathrm{Thr}$, and analyzed by flow cytometry. Bars indicate percentages of platelets binding PE-JON/A (B) or AF647-annexin A5 (C). Means \pm S.D. ( $n$ $=3-4),{ }^{*} p<0.05$ (2-way ANOVA, Bonferroni correction). $(D, E)$ Human platelets, preincubated with vehicle $(0.2 \%$ $\left.\mathrm{Me}_{2} \mathrm{SO}\right)$ or cyclosporin $\mathrm{A}(4 \mu \mathrm{M})$, were stimulated for 5-30 min with $\mathrm{Cvx} / \mathrm{Thr}$. Shown are time-dependent changes in percentages of platelets binding FITC-PAC1 (D) or AF647-annexin A5 (E). Means \pm S.D. $(n=4),{ }^{*} p<0.05$ (1-way ANOVA, Bonferroni correction). 
Capn $1^{-}$platelets show reduced aggregation at low thrombin concentrations, ${ }^{27}$ but stipulates that a direct role of calpain-1 in integrin activation remains subtle. In contrast, we found that the Capn $1^{-/}$platelets show nearly normal integrin closure as well as cleavage of $\beta_{3}$, talin and Src, when stimulated with strong agonists such as Cvx/Thr. Given the complete abolishment of protein cleavage with two calpain inhibitors (calpeptin and MDL-28170), we concluded that another cysteine protease is involved under conditions of high $\mathrm{Ca}^{2+}$ concentration. It is likely that this protease is calpain-2, which accounts for $\sim 20 \%$ of the platelet calpain activity, and is known to require millimolar $\mathrm{Ca}^{2+}$ concentrations for activation. ${ }^{41}$ Given the heterogeneity in intracellular $\mathrm{Ca}^{2+}$ concentrations these high levels can be reached locally in procoagulant platelets. Unfortunately, a role for calpain- 2 could not be directly tested in platelets as calpain-2 deficiency in mice is lethal. ${ }^{42}$ The mechanistic reason for this lethality is still unknown, but a general role for this calpain isoform in cell proliferation and cell cycle progression has been suggested.

Regarding the integrin closure of Cvx/Thr-stimulated platelets, inhibitor studies demonstrated clear, but partial, inhibitory effects of MDL-28170 and calpeptin. In suspensions of platelets were micro-aggregate formation was prevented, both compounds suppressed integrin closure of control platelets by $\sim 50 \%$ (under conditions where the cleavage of $\beta_{3}$ chain, talin and Src were blocked); whereas it fully abrogated the partly impaired and delayed integrin closure in Scott syndrome platelets, which do not show PS exposure. This clearly supports a model of dual mechanism of integrin closure that is in part calpain-dependent (likely through the degradation of proteins implicated in $\alpha_{11 b} \beta_{3}$ activation), and in part mediated by TMEM16F (via $\mathrm{Ca}^{2+}$-mediated phospholipid scrambling). The latter pathway is absent in the Scott syndrome platelets. It is conceivable that the profound intra-membrane changes caused by phospholipid scrambling affect interactions of the integrin $\alpha_{\| l b}$ and $\beta_{3}$ chains or of integrin-associated proteins even in the absence of calpain cleavage. However, the precise mechanism remains to be investigated.

While the calpain-mediated cleavage of specific proteins in PS-exposing platelets has been reported before, ${ }^{4}$ we now show that the protease responsible is not calpain-1, but likely calpain-2. Moreover, this cleavage occurs at a much faster and extensive scale than anticipated, including complete degradation of several proteins that are known to play a key role in integrin activation and signaling, i.e. the $\beta_{3}$ chain, talin and Src kinase. The eventual result will be that 
these PS-exposing platelets (with a prominent role in coagulation) are no longer capable to carry out the Src/Sykand talin-dependent responses of aggregated platelets using active integrins, including clot retraction and tight platelet-platelet contact formation.

Earlier studies have shown a critical role of the mPTP and cyclophilin D in Cvx/Thrinduced but not ionomycin-induced PS externalization. ${ }^{22}$ Using platelets from Ppif/- mice, this was confirmed in the present study. In whole-blood flow assay over collagen, the cyclophilin D-deficient platelets showed a consistent reduction in thrombus formation and PS exposure. Moreover, the reduced PS exposure was accompanied by a similar reduction in integrin closure, thus suggesting a common, mitochondrial-dependent

\section{References}

1. Jackson SP. Arterial thrombosis: insidious, unpredictable and deadly. Nat. Med.

2011;17:1423-1436.

2. Heemskerk JW, Mattheij NJ, Cosemans JM. Platelet-based coagulation: different populations, different functions. J. Thromb. Haemost. 2013;11:2-11.

3. Munnix IC, Kuijpers MJ, Auger J, Thomassen CM, Panizzi P, van Zandvoort MA, Rosing J, Bock PE, Watson SP, Heemskerk JW. Segregation of platelet aggregatory and procoagulant microdomains in thrombus formation: regulation by transient integrin activation. Arterioscler. Thromb. Vasc. Biol. 2007;27:24842490.

4. Kulkarni S, Jackson SP. Platelet factor XIII and calpain negatively regulate integrin $\alpha_{11 \mathrm{~b}} \beta_{3}$ adhesive function and thrombus growth. J. Biol. Chem. 2004;279:30697-30706. denominator for the impairment of PS exposure and $\alpha_{\| l b} \beta_{3}$ inactivation.

Taken together, our findings reveal a novel, dual mechanism of $\alpha_{11 b} \beta_{3}$ inactivation via calpain (not calpain-1) dependent cleavage of integrinassociated proteins and via TMEM16Fdependent phospholipid scrambling, with an assistant role of MPTP formation.

\section{Funding}

This work was supported by the Cardiovascular Centre, Maastricht, the Center for Translational Molecular Medicine Innovative Coagulation Diagnostics (INCOAG), and the Netherlands Heart Foundation grant 2011 T6 (to J. M. E. M. C.) and National Institute of Health grant HL089519 (to A. H. C.).

5. Berny MA, Munnix IC, Auger JM, Schols SE, Cosemans JM, Panizzi P, Bock PE, Watson SP, McCarty OJ, Heemskerk JW. Spatial distribution of factor $\mathrm{Xa}$, thrombin, and fibrin(ogen) on thrombi at venous shear. Plos One 2010;5:e10415.

6. Cosemans JM, Iserbyt BF, Deckmyn $H$, Heemskerk JW. Multiple ways to switch platelet integrins on and off. J. Thromb. Haemost. 2008;6:1253-1261.

7. Shattil SJ, Kim C, Ginsberg MH. The final steps of integrin activation: the end game. Nat. Rev. Mol. Cell Biol. 2010;11:288-300.

8. Watson SP, Auger JM, McCarty OJ, Pearce AC. GPVI and integrin $\alpha_{11 b} \beta_{3}$ signaling in platelets. J. Thromb. Haemost. 2005;3:1752-1762.

9. Ma YQ, Qin J, Plow EF. Platelet integrin $\alpha_{11 b} \beta_{3}$ : activation mechanisms. J. Thromb. Haemost. 2007;5:1345-1352. 
10. Nieswandt B, Varga-Szabo D, Elvers M. Integrins in platelet activation. J. Thromb. Haemost. 2009;7 Suppl 1:206-209.

11. Kim C, Ye F, Hu X, Ginsberg MH. Talin activates integrins by altering the topology of the beta transmembrane domain. J. Cell Biol. 2012;197:605-611.

12. Shattil SJ, Newman PJ. Integrins: dynamic scaffolds for adhesion and signaling in platelets. Blood 2004;104:1606-1615.

13. Arias-Salgado EG, Lizano S, Sarkar S, Brugge JS, Ginsberg MH, Shattil SJ. Src kinase activation by direct interaction with the integrin $\beta$ cytoplasmic domain. Proc. Natl. Acad. Sci. USA 2003;100:13298-13302.

14. Yan B, Calderwood DA, Yaspan B, Ginsberg MH. Calpain cleavage promotes talin binding to the $\beta_{3}$ integrin cytoplasmic domain. J. Biol. Chem. 2001;276:28164-28170.

15. Pfaff M, Du X, Ginsberg, M. H. Calpain cleavage of integrin $\beta$ cytoplasmic domains. FEBS Lett 1999;460:17-22.

16. Arachiche A, Kerbiriou-Nabias D, Garcin I, Letellier T, Dachary-Prigent J. Rapid procoagulant phosphatidylserine exposure relies on high cytosolic calcium rather than on mitochondrial depolarization. Arterioscler. Thromb. Vasc. Biol. 2009;29:1883-1889.

17. Siljander PR, Munnix IC, Smethurst PA, Deckmyn $\mathrm{H}$, Lindhout T, Ouwehand WH, Farndale RW, Heemskerk JW. Platelet receptor interplay regulates collagen-induced thrombus formation in flowing human blood. Blood 2004;103:13331341.

18. Suzuki J, Umeda M, Sims PJ, Nagata S. Calciumdependent phospholipid scrambling by TMEM16F. Nature 2010;468:834-838.

19. Van Kruchten R, Mattheij NJ, Saunders C, Feijge MA, Swieringa F, Wolfs JL, Collins PW Heemskerk JW, Bevers EM. Both TMEM16Fdependent and TMEM16F-independent pathways contribute to phosphatidylserine exposure in platelet apoptosis and platelet activation. Blood 2013;10:1850-7.

20. Munnix IC, Cosemans JM, Auger JM, Heemskerk JW. Platelet response heterogeneity in thrombus formation. Thromb. Haemost 2009;102:1149-1156.

21. Castoldi E, Collins PW, Williamson PL, Bevers EM Compound heterozygosity for two novel TMEM16F mutations in a patient with Scott syndrome. Blood 2011;117:4399-4400.

22. Jobe SM, Wilson KM, Leo L, Raimondi $A$, Molkentin JD, Lentz SR, Di Paola, J. Critical role for the mitochondrial permeability transition pore and cyclophilin D in platelet activation and thrombosis. Blood 2008;111:1257-1265.

23. Dale GL. Coated-platelets: an emergic component of the procoagulant response. J. Thromb. Haemost. 2005;3:2185-2192.

24. Jobe SM, Leo L, Eastvold JS, Dickneite G, Ratliff TL, Lentz SR, Di Paola J. Role of FcRy and factor XIIla in coated platelet formation. Blood 2005;106:4146-4151.

25. Du X, Saido TC, Tsubuki S, Indig FE, Williams MJ, Ginsberg $\mathrm{MH}$. Calpain cleavage of the cytoplasmic domain of the integrin $\beta_{3}$ subunit. J. Biol. Chem. 1995;270:26146-26151.

26. Van der Meijden PE, Schoenwaelder SM, Feijge MA, Cosemans JM, Munnix IC, Wetzker R, Heller $\mathrm{R}$, Jackson SP, Heemskerk JW. Dual $P 2 Y_{12}$ receptor signaling in thrombin-stimulated platelets: involvement of phosphoinositide 3kinase $\beta$ but not $\gamma$ isoform in $\mathrm{Ca}^{2+}$ mobilization and procoagulant activity. FEBS J. 2008;275:371385.

27. Kuchay SM, Kim N, Grunz EA, Fay WP, Chishti AH. Double knockouts reveal that protein tyrosine phosphatase $1 \mathrm{~B}$ is a physiological target of calpain-1 in platelets. Mol. Cell Biol. 2007;27:6038-6052.

28. Kuchay SM, Wieschhaus AJ, Marinkovic $M$, Herman IM, Chishti AH. Targeted gene inactivation reveals a functional role of calpain-1 in platelet spreading. J. Thromb. Haemost. 2012;10:1120-1132.

29. Gilio K, van Kruchten R, Braun A, Berna-Erro A, Feijge MA, Stegner $D$, van der Meijden PE, Kuijpers MJ, Varga-Szabo D, Heemskerk JW, Nieswandt B. Roles of platelet STIM1 and Orai1 in glycoprotein VI- and thrombin-dependent procoagulant activity and thrombus formation. $J$. Biol. Chem. 2010;285:23629-23638. 
30. Cosemans JM, Van Kruchten R, Olieslagers $\mathrm{S}$, Schurgers $\amalg$, Verheyen FK, Munnix IC, Waltenberger J, Angelillo-Scherrer A, Hoylaerts MF, Carmeliet P, Heemskerk JW. Potentiating role of Gas6 and Tyro3, Axl and Mer (TAM) receptors in human and murine platelet activation and thrombus stabilization. J. Thromb. Haemost. 2010;8:1797-1808.

31. Gilio K, Harper MT, Cosemans JM, Konopatskaya O, Munnix IC, Prinzen L, Leitges M, Liu Q, Molkentin JD, Heemskerk JW, Poole AW. Functional divergence of platelet protein kinase $C$ (PKC) isoforms in thrombus formation on collagen. J. Biol. Chem. 2010;285:23410-23419.

32. Cosemans JM, Schols SE, Stefanini L, de Witt S, Feijge MA, Hamulyak K, Deckmyn $H$, Bergmeier W, Heemskerk JW. Key role of glycoprotein $\mathrm{Ib} / \mathrm{V} / \mathrm{IX}$ and von Willebrand factor in platelet activation-dependent fibrin formation at low shear flow. Blood 2011;117:651-660.

33. Heemskerk JW, Feijge MA, Henneman L, Rosing J, Hemker HC. The $\mathrm{Ca}^{2+}$-mobilizing potency of athrombin and thrombin-receptor-activating peptide on human platelets: concentration and time effects of thrombin-induced $\mathrm{Ca}^{2+}$ signaling. Eur. J. Biochem. 1997;249:547-555.

34. Wolfs JL, Comfurius P, Rasmussen JT, Keuren JF, Lindhout T, Zwaal RF, Bevers EM. Activated scramblase and inhibited aminophospholipid translocase cause phosphatidylserine exposure in a distinct platelet fraction. Cell Mol. Life Sci. 2005;62:1514-1525.
35. Fuse I, Higuchi W, Uesugi Y, Aizawa Y. Pathogenetic analysis of three cases with a bleeding disorder characterized by defective platelet aggregation induced by $\mathrm{Ca}^{2+}$ ionophores. Br. J. Haematol. 2001;112:603-608.

36. Naik MU, Stalker TJ, Brass LF, Naik UP. JAM-A protects from thrombosis by suppressing integrin $\alpha_{11 b} \beta_{3}$-dependent outside-in signaling in platelets. Blood 2012;119:3352-3360.

37. Kuchay SM, Chishti AH. Calpain-mediated regulation of platelet signaling pathways. Curr. Opin. Hematol. 2007;14:249-254.

38. Munnix IC, Harmsma M, Giddings JC, Collins PW, Feijge MA, Comfurius P, Heemskerk JW, Bevers EM. Store-mediated calcium entry in the regulation of phosphatidylserine exposure in blood cells from Scott patients. Thromb. Haemost. 2003;89:687-695.

39. Leytin V, Allen DJ, Mutlu A, Gyulkhandanyan AV, Mykhaylov S, Freedman J. Mitochondrial control of platelet apoptosis: effect of cyclosporin A, an inhibitor of the mitochondrial permeability transition pore. Lab. Invest. 2009;89:374-384.

40. Heemskerk JW, Bevers EM, Lindhout T. Platelet activation and blood coagulation. Thromb. Haemost. 2002;88:186-193.

41. Goll DE, Thompson VF, Li H, Wei W, Cong J. The calpain system. Physiol. Rev. 2003;83:731-801

42. Dutt $P$, Croall DE, Arthur JS, Veyra TD, Williams K, Elce JS, Greer PA. m-Calpain is required for preimplantation embryonic development in mice. BMC Dev. Biol.2006; 6:3. 



\section{Chapter 5}

\section{Coated platelets are a subpopulation of phosphatidylserine-exposing platelets and function in platelet-dependent fibrin formation via factor XIII and integrin $\alpha_{11 b} \beta_{3}$}

Mattheij $\mathrm{NJ}^{1}$, Swieringa $\mathrm{F}^{1}$, Berny-Lang $\mathrm{MA}^{2}$, May $\mathrm{F}^{3}$, van der Meijden $P E J^{1}$, Suylen $\mathrm{DPL}^{1}$, Nolte $\mathrm{MW}^{3}$, Hackeng $\mathrm{TM}^{1}$, McCarty $\mathrm{OJ}^{2}$, Heemskerk JWM ${ }^{1}$, Cosemans JMEM ${ }^{1}$

${ }^{1}$ Department of Biochemistry, Cardiovascular Research Institute Maastricht (CARIM), Maastricht University, Maastricht, The Netherlands; ${ }^{2}$ Department of Biomedical Engineering, Oregon Health \& Science University, Portland OR, USA; ${ }^{3} \mathrm{CSL}$ Behring GmbH, Marburg, Germany 


\begin{abstract}
Coated platelets, formed by collagen (convulxin) and thrombin activation, have been characterized in different ways, such as by the formation of a protein coat of $\alpha$ granular proteins or by exposure of procoagulant phosphatidylserine. Accordingly, their functional role has remained unclear. Here, we used a novel transglutaminase probe, Rhod-A14, to identify subpopulations of platelets with a cross-linked protein coat, and compared these with other platelet subpopulations. Platelet stimulation with convulxin/thrombin resulted in initial integrin $\alpha_{\| 1 b} \beta_{3}$ activation, the appearance of a platelet population with high fibrinogen binding - independently of active integrins -, followed by phosphatidylserine exposure and binding of factors $\mathrm{Va}$ and $\mathrm{Xa}$. Transglutaminase-active platelets, detected with Rhod-A14, formed as a subpopulation of the phosphatidylserine-exposing platelets. The high fibrin(ogen) binding relied on the presence of thrombin. This staining pattern was confirmed in tissue-factor triggered platelet-rich plasma. The high fibrin(ogen) and Rhod-A14 binding were antagonized by combined inhibition of transglutaminase activity and $\alpha_{11 b} \beta_{3}$. In thrombi formed on collagen, Rhod-A14 again bound to a subpopulation of phosphatidylserine-exposing platelets via transglutaminase activity and later, under coagulant conditions, to fibrin fibers. Markedly, in thrombi from mice deficient in factor XIII, but not in wild-type thrombi, platelet-driven fibrin formation and RhodA14 binding were abolished by blockage of integrin $\alpha_{\| b} \beta_{3}$. In conclusion, transglutaminase-active 'coated' platelets, with initial $\alpha_{11 b} \beta_{3}$ activation and high fibrinogen binding, form a subpopulation of phosphatidylserine-exposing platelets, and function in platelet-dependent fibrin fiber formation via factor XIII and integrin $\alpha_{\| l b} \beta_{3}$.
\end{abstract}

\section{Introduction}

Platelet activation and blood coagulation are highly reciprocally interacting processes and both essential for thrombosis and hemostasis. Activated platelets support and steer the coagulation process by at least four mechanisms, i.e. by release of coagulation factors like factor $\mathrm{V}$ and XIII; by exposing the procoagulant phospholipid phosphatidylserine (PS) at their outer surface to support thrombin generation; by providing a scaffold for the formation of fibrin fibers; and by causing retraction of the fibrin clot. ${ }^{1,2}$ In a growing thrombus, the aggregated and single, procoagulant platelets form two distinct populations, ${ }^{3,4}$ which is at least partly explained by the high $\mathrm{Ca}^{2+}$ response required for PS exposure and coagulation factor binding, and by the calpain-dependent closure of active 
$\alpha_{11 b} \beta_{3}$ integrins after PS exposure, thus antagonizing inclusion into a platelet aggregate. ${ }^{5,6}$

However, also another platelet class has been identified, usually referred to as coated platelets, ${ }^{7}$ which may partly overlap with the two other platelet populations. ${ }^{3}$ In the initial paper, Dale and co-workers describe COAT platelets (later renamed as coated platelets) as a population of platelets arising after combined stimulation with collagen and thrombin, which bind $\alpha$-granule proteins, including factor $V$, fibrinogen, von Willebrand factor, thrombospondin, fibronectin and $\alpha_{2}$-antiplasmin, in a transglutaminase-dependent way via the formation of covalent serotonin conjugations. ${ }^{8}$

Since the first description, coated platelets are invariably considered as platelets formed after combined stimulation of collagen receptors (e.g. with collagen, convulxin or collagenrelated peptide) and thrombin receptors (e.g. with thrombin or thrombin receptor-activating peptides), but the definition of this population may differ from paper to paper. The Dale group has been using as a characteristic the retention on the platelet surface of secreted proteins, including plateletderived serotonin-derivatized proteins, factor $\mathrm{V}$ and tissue factor pathway inhibitor. ${ }^{9-11}$ Another definition has been used by the Jobe group, i.e. platelets containing high surface levels of fibrinogen, likely through cross-linking via the transglutaminase, factor XIII. ${ }^{12}$ However, in recent years, it is becoming common to consider coated platelets more or less equivalent to PS-exposing platelets, binding the coagulation factors $\mathrm{V}(\mathrm{a})$ and Xa. For instance, platelet subpopulations in patient studies have been characterized using the PS-binding probe, annexin A5. ${ }^{13-16}$ This ambiguity in definition and described properties raises the question, if 'coated' platelets form a platelet subpopulation - after collagen/thrombin receptor stimulation - that is distinguishable from that of PSexposing platelets with perhaps a different function.

In the present paper, we used a specific transglutaminase substrate, i.e. the $\alpha_{2^{-}}$ antiplasmin-derived peptide Rhod-A14, as a tool to identify transglutaminaseactive platelets. We compared the binding of Rhod-A14 to platelets, stimulated via the collagen and thrombin receptors, with other makers of platelet activation. The results indicate that transglutaminase activity partly overlaps but is not identical to PS exposure. We furthermore provide evidence that the transglutaminase activity along with integrin $\alpha_{11 b} \beta_{3}$ activation is required for fibrin anchoring at the platelet surface and platelet-dependent fibrin formation. 


\section{Experimental procedure}

Materials

Horm type-I collagen was purchased from Nycomed. The glycoprotein VI agonist, convulxin came from Stago BNL. Human $\alpha$-thrombin was from Kordia; human factor XIII was from CSL Behring $\mathrm{GmbH}$, and PAR1-activating hexapeptide SFLLRN from Bachem. Annexin A5 labeled with Alexa Fluor-647 (AF647) or fluorescein isothiocyanate (FITC) came from Invitrogen; FITC-labeled thrombospondin from Abcam and HiLyte-488 (HL488)-labeled fibronectin from Tebu-bio. Active-site OG488labeled human factor $\mathrm{Xa}$ and prothrombin as well as AF488-labeled bovine factor $V(a)$ were prepared, as described. ${ }^{17}$ FITC-labeled PAC1 mAb was from Becton Dickinson; FITC-labeled anti-
A
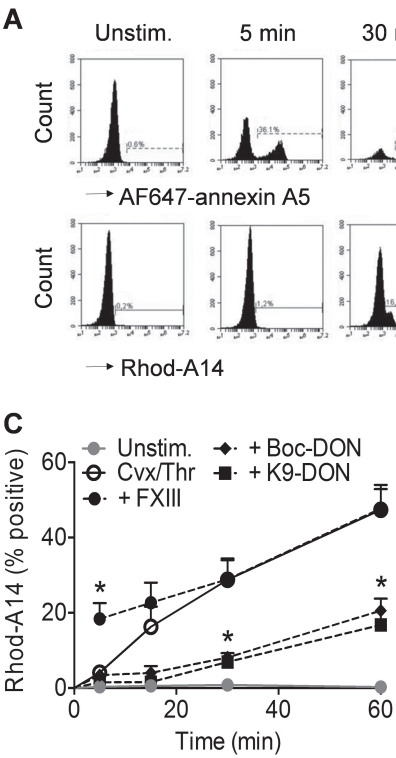

D

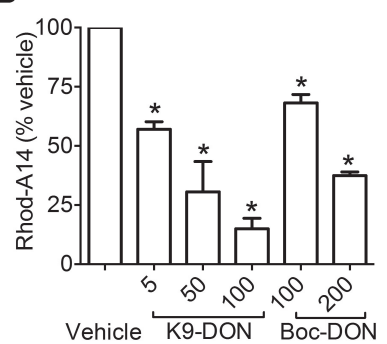

B

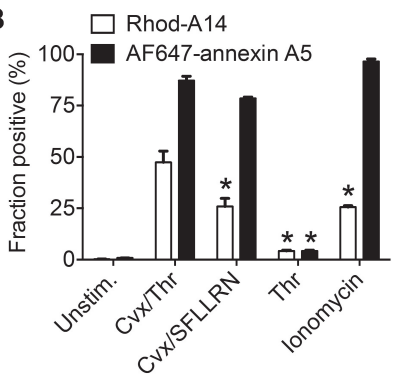

E

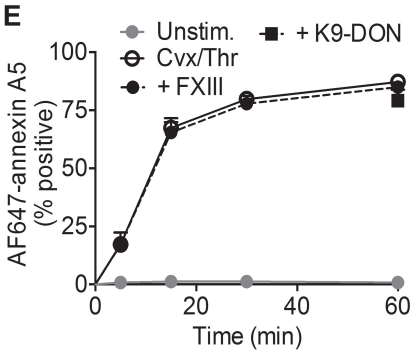

Figure 1. Transglutaminase activity confined to a subpopulation of PS-exposing platelets. (A) Washed human platelets $\left(5 \times 10^{7} / \mathrm{ml}\right)$ were stimulated with convulxin $(\mathrm{Cvx}, 100 \mathrm{ng} / \mathrm{ml})$ plus thrombin $(\mathrm{Thr}, 4 \mathrm{nM})$ in the presence of $0.2 \mathrm{mM} \mathrm{GPRP}$ and $2 \mathrm{mM} \mathrm{CaCl}_{2}$. Samples, taken at given time points, were labeled for 5 minutes with Rhod-A14 and AF647-annexin A5. Platelets were pretreated with K9-DON (100 $\mu \mathrm{M})$, where indicated. Shown are representative histograms obtained by flow cytometry. (B) Platelet subpopulations staining with Rhod-A14 (white bars) or AF647-annexin A5 (black bars) after 60 minutes stimulation with Cvx (100 ng/ml), Thr (4 nM), SFLLRN $(15 \mu \mathrm{M})$ and/or ionomycin $(10 \mu \mathrm{M})$, as indicated. (C-E) Effects of factor XIII and transglutaminase inhibitors on platelet subpopulations staining with Rhod-A14 (C) or AF647-annexin A5 (E) after stimulation with Cvx (100 ng/ml) plus Thr (4 nM). Platelets were preincubated with vehicle (O, solid line), 100 unit/ml factor XIII (•,

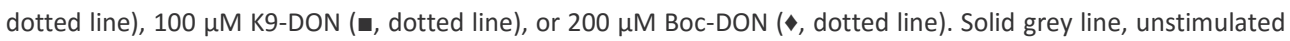
platelets. (D) Dose-dependent inhibition of Rhod-A14 binding (60 minutes) by K9-DON or Boc-DON. Mean \pm SEM $(\mathrm{n}=3-6),{ }^{*} p<0.05$. 
integrin $\beta_{3} m A b$ from $B D$ BioScience; FITC-labeled WAK mAb against plateletbound fibrinogen from WAK Chemie; fibrin-specific $m A b$ (anti-fibrin II $\beta$ chain, clone T2G1) from Accurate Chemical \& Scientific Corporation.

The 14-amino acid transglutaminase peptide substrate, GNQEQVSPLTLLK(Crhodamine)W (Rhod-A14), derived from the $\mathrm{N}$-terminal peptide sequence of $\alpha_{2-}$ antiplasmin, was synthetized as described elsewhere. ${ }^{18}$ The substrate contains the 14 amino acids of $\alpha_{2-}$ antiplasmin, implicated in its conjugation to fibrin. ${ }^{19}$ The tissue-type transglutaminase specific inhibitor, tertbutyloxycarbonyl-(6diazo-5oxonorleucinyl)-QIV-OMe (Boc-DON) and the general transglutaminase inhibitor, Ac-LGPG-DON-SLVIG-NH $\mathrm{N}_{2}$ (K9-DON) came from Zedira. Other chemicals were from sources described before. ${ }^{20}$

Blood Collection and Platelet Preparation Experiments were approved by the local Medical Ethics Committees. Healthy subjects donated blood after full informed consent according to the Helsinki declaration. For coagulation experiments, venous blood was collected into $1 / 10$ volume of $129 \mathrm{mM}$ trisodium citrate. Platelet-rich plasma (PRP) and washed platelets were prepared from acid-citrate-dextrose anticoagulated blood, as described before. ${ }^{21}$ Washed platelets were suspended into Hepes buffer A $(10 \mathrm{mM}$ Hepes, $136 \mathrm{mM} \mathrm{NaCl}$, $2.7 \mathrm{mM} \mathrm{KCl}, 2 \mathrm{mM} \mathrm{MgCl}, 5 \mathrm{mg} / \mathrm{ml}$ glucose, $1 \mathrm{mg} / \mathrm{ml} \mathrm{BSA}$, pH 7.45). Final concentration of platelets in buffer medium was $5 \times 10^{7} / \mathrm{ml}$, unless indicated otherwise.

Animal studies were approved by the local Animal Experimental Committees. Mice deficient in factor XIII A1 subunit ( $F 13 a 1^{\text {tm1Gdi, }}$ abbreviated as $F 13 a 1^{-/}$) were generated, as previously reported. ${ }^{22}$ The mice were bred on a mixed 1290la/CBACa background and were compared to $\mathrm{F} 3 \mathrm{a1^{+/+ }}$ mice of the same backgrounds (Harlan). Murine blood was taken on trisodium citrate for whole-blood flow experiments; other blood samples were taken on acidcitrate-dextrose anticoagulant to isolate washed platelets, as described. ${ }^{20}$ Isolated mouse platelets were resuspended in modified Hepes buffer B (5 mM Hepes, $136 \mathrm{mM} \mathrm{NaCl}, 2.7 \mathrm{mM} \mathrm{KCl}, 2 \mathrm{mM} \mathrm{MgCl}$, $0.42 \mathrm{mM} \mathrm{NaH} \mathrm{PO}_{4}, 5 \mathrm{mg} / \mathrm{ml}$ glucose, 1 $\mathrm{mg} / \mathrm{ml} \mathrm{BSA}, \mathrm{pH} 7.45){ }^{6}$

\section{Flow Cytometric Platelet Analyses}

Washed human or mouse platelets $\left(5 \times 10^{7} / \mathrm{ml}\right)$ were preincubated with indicated inhibitors or $\mathrm{Me}_{2} \mathrm{SO}$ vehicle for 10 minutes, and stimulated with thrombin (4 $\mathrm{nM})$ and/or convulxin (100 $\mathrm{ng} / \mathrm{ml}$ ) in the presence of $2 \mathrm{mM} \mathrm{CaCl}_{2}$. In the activations, $0.2 \mathrm{mM}$ GPRP was added to prevent formation of large fibrin fibres. ${ }^{21}$ Platelet sub-populations were 


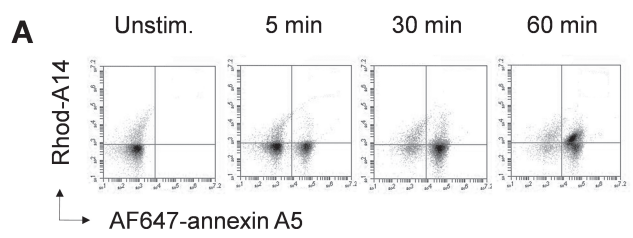

D

B

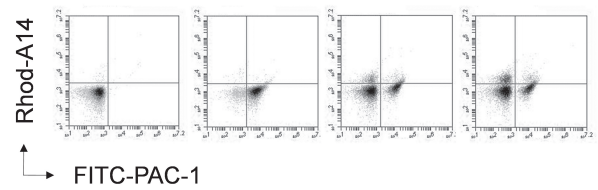

C

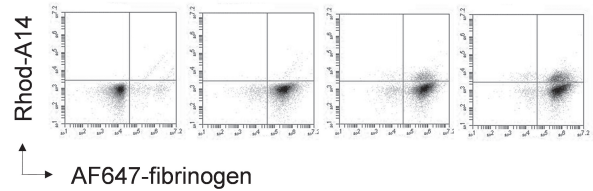

Supplemental Figure 1. Transglutaminase-positive platelets with inactive $\alpha_{11 b} \beta_{3}$ integrin appear after high fibrinogen binding. (A) Washed platelets were stimulated with convulxin and thrombin, as indicated for Figure 1. At given time points, samples were labeled for 5 minutes with Rhod-A14 in combination with AF647-annexin A5, FITC-PAC-1 mAb or AF647-fibrinogen. (A, B, C) Representative dot plots at indicated time points. (D) Time

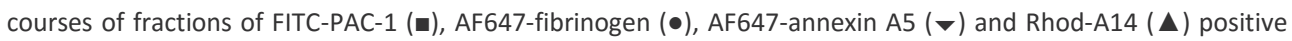
platelets. Mean $\pm \operatorname{SEM}(n=3)$.

distinguished by probing with AF647annexin A5 (1:200), AF488-factor V (20 $n M)$, OG488-factor Xa (100 nM), AF647fibrinogen $(100 \mu \mathrm{g} / \mathrm{ml})$, FITCthrombospondin $(20 \mu \mathrm{g} / \mathrm{ml})$ and HL488fibronectin $(50 \mu \mathrm{g} / \mathrm{ml})$. After staining for 5 minutes, samples were analyzed with a FACScan flow cytometer (BD Accuri Cytometers). ${ }^{6}$ AF647-annexin A5 and AF647-fibrinogen were measured in the FL-4 channel, Rhod-A14 was measured in the FL-2 channel, while other fluorescent probes were measured in the FL-1 channel. Citrate-anticoagulated human PRP was obtained by centrifuging blood at $240 \mathrm{~g}$ for 15 minutes; platelet-free plasma (PFP) then by centrifuging twice at $2630 \mathrm{~g}$ for 10 minutes. Platelet count in PRP was determined with a Thrombocounter (Coulter Electronics), and normalized with autologous PFP. Citrate-anticoagulated human PFP was defibrinated by 30 minutes treatment with ancrod protease $(1.3$ units $/ \mathrm{ml}){ }^{21}$ The formed fibrin clots were removed from the plasma by centrifugation. Reconstituted PRP was activated with tissue factor (2 pM, f.c.) and $\mathrm{CaCl}_{2}$ (16.7 $\mathrm{mM})$ in the presence of GPRP $(2 \mathrm{mM})$ at $37{ }^{\circ} \mathrm{C}$, after which samples were taken for fluorescent labeling. Analysis was by flow cytometry as above. 
A

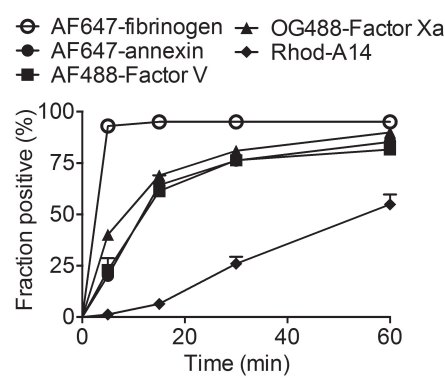

C

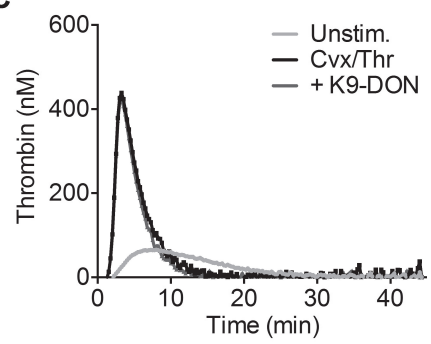

B

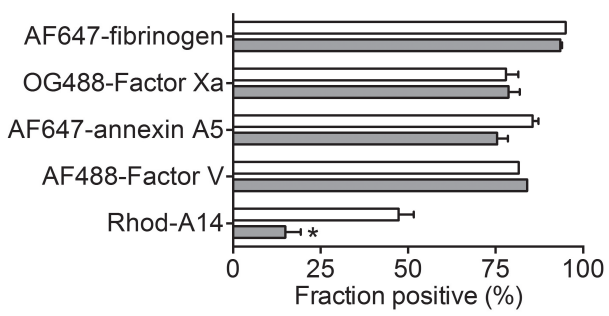

D

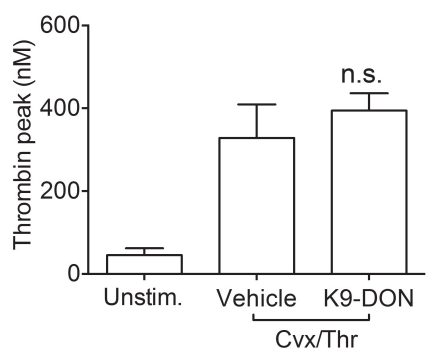

Figure 2. Transglutaminase-positive platelets are not identical to procoagulant platelets. (A-B) Washed platelets were stimulated with convulxin plus thrombin, as indicated for Figure 1. At given time points, samples were taken and labeled with AF647-fibrinogen (O), OG488-factor Xa ( $\mathbf{\Delta}$ ), AF647-annexin A5 (•), AF488-factor V(a) $(\mathbf{\Xi )}$, or Rhod-A14 (४). (A) Fractions of platelets binding the indicated probes. (B) Effect of platelet treatment with K9-DON $(100 \mu \mathrm{M})$ (grey bars) on fractions of positive platelets. (C-D) Citrate-anticoagulated PRP $\left(1 \times 10^{8}\right.$ platelets/ml) was preincubated with vehicle or K9-DON $(100 \mu \mathrm{M})$, and used for measurement of thrombin generation; coagulation was triggered with tissue factor $/ \mathrm{CaCl}_{2}$. Representative thrombin generation curves (C) and quantification of peak height (D). Mean \pm SEM ( $n=3-4),{ }^{*} p<0.05$.

\section{Thrombin Generation}

Thrombin generation was measured in citrate-anticoagulated human PRP. ${ }^{23}$ The PRP was diluted with autologous PFP to a count of $1.5 \times 10^{8}$ platelets $/ \mathrm{ml}$. Samples were activated with convulxin (100 $\mathrm{ng} / \mathrm{ml}$ ) plus thrombin (4 $\mathrm{nM}$ ) or vehicle for 15 minutes. Aliquots (4 volumes) were transferred to a polystyrene 96wells plate (Immulon 2HB, Dynex Technologies), already containing 1 volume of buffer C (20 mM Hepes, 140 $\mathrm{mM} \mathrm{NaCl}, 5 \mathrm{mg} / \mathrm{ml} \mathrm{BSA}$ and $6 \mathrm{pM}$ tissue factor). Coagulation was started by adding 1 volume of buffer D $(2.5 \mathrm{mM} \mathrm{Z-}$ GGR-AMC, 20 mM Hepes, 140 mM NaCl, $100 \mathrm{mM} \mathrm{CaCl} 2$ and $60 \mathrm{mg} / \mathrm{ml} \mathrm{BSA}$ ). Firstderivative curves were converted into curves of nanomolar thrombin concentrations using a calibrator for human $\alpha$-thrombin. ${ }^{24}$ All analyses were in triplicate.

Thrombus Formation on Collagen under Flow

Whole blood thrombus formation on collagen was assayed in the absence or presence of coagulation, as described 
before..$^{25}$ In brief, if no coagulation was required, citrate-anticoagulated mouse blood was recalcified in the presence of hirudin $(3 \mu \mathrm{M})$ and PPACK $(40 \mu \mathrm{M})$. The blood was recalcified and flowed over a coverslip coated with collagen type-I in a transparent parallel-plate perfusion chamber, at wall-shear rate of $1000 \mathrm{~s}^{-1}$ for 4 minutes. ${ }^{26}$ If desired, coagulation was introduced by co-perfusion of mouse blood with 0.5 volume of $\mathrm{Ca}$ Hepes buffer (15 mM CaCl $2,7.5 \mathrm{mM}$ $\mathrm{MgCl}_{2}$ and $0.42 \mathrm{mM} \mathrm{NaH}_{2} \mathrm{PO}_{4}, \mathrm{pH} 7.45$ ) at $1000 \mathrm{~s}^{-1}$. Coagulation of human blood was introduced by co-perfusion with 0.1 volume of adapted $\mathrm{Ca}$-Hepes buffer (75 $\mathrm{mM} \mathrm{CaCl}$, $37.5 \mathrm{mM} \mathrm{MgCl}_{2}, 136 \mathrm{mM} \mathrm{NaCl}$, $5 \mathrm{mM}$ Hepes, $2.7 \mathrm{mM} \mathrm{KCl}, 1 \mathrm{mg} / \mathrm{ml} \mathrm{BSA}$, $\mathrm{pH} 7.45)$ at $1000 \mathrm{~s}^{-1}$. Thrombi formed on collagen were post-stained with RhodA14 and AF647-annexin A5 in Hepes buffer $A$ or $B$, supplemented with $\mathrm{CaCl}_{2}$ (2 $\mathrm{mM}$ ) and heparin (1 unit/ml). Phasecontrast and fluorescence images were captured and analyzed with Metamorph software version 7.5.0.0 (MDS Analytical Technologies), as detailed elsewhere. ${ }^{26}$ Quantitative statistical co-localization on two-color confocal images was performed using the ZEN software 2010 B SP1.

\section{Statistics}

Significance of differences between control and experimental groups as well as changes between groups over time were determined by 1-way or 2-way analysis of variance followed by a Bonferroni post-hoc test. The Student's ttest was performed to compare paired samples. Distribution of fibrin fibers was evaluated by $\chi^{2}$ analysis. ${ }^{27} p$ values $<0.05$ were considered to be significant.

\section{Results}

'Coated' platelets as transglutaminase active platelets

First, we assessed the appearance of a coated platelet population following the initial description of formation of a transglutaminase-dependent protein 'coat' at the platelet surface. ${ }^{8}$ Therefore, we synthetized a fluorescent-labeled 14amino acid transglutaminase peptide substrate, GNQEQVSPLTLLK(Ctetramethylrhodamine)W (Rhod-A14), derived from the $N$-terminal peptide sequence of $\alpha_{2}$-antiplasmin. This peptide contains a glutamine at $Q^{3}$, which serves as a transglutamination site for crosslinking to available $\varepsilon$-amino lysine residues. ${ }^{18}$ The Rhod-A14 peptide was site-specifically labeled with a tetramethylrhodamine group, which did not interfere with its substrate properties. Control experiments indicated that the peptide could act as a substrate for both tissue-type transglutaminase and factor XIIla (not shown, but see below).

Flow cytometric analysis indicated that the labeled Rhod-A14 bound to a 
A

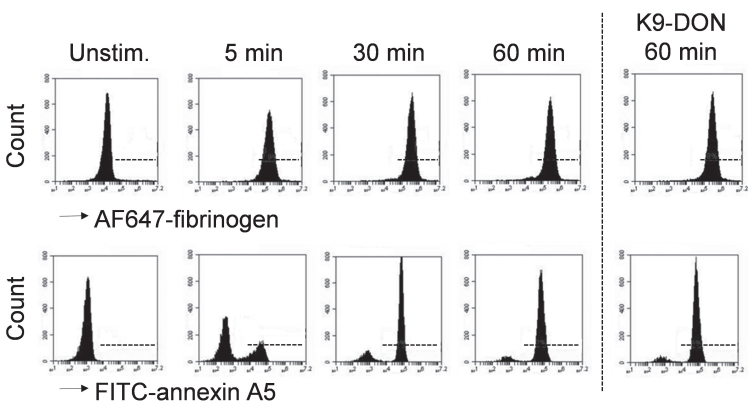

B

C

D
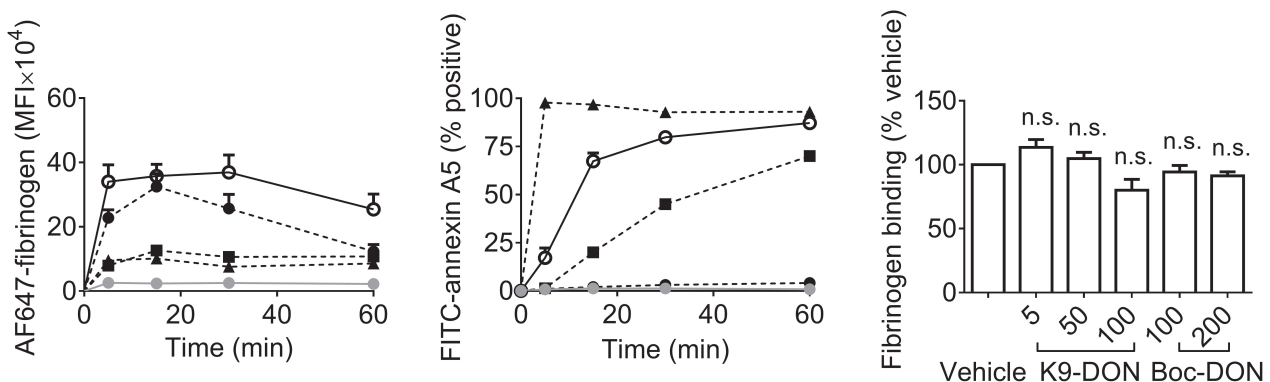

Supplemental Figure 2. High fibrinogen binding precedes PS exposure independently of transglutaminase activity. (A) Washed platelets were stimulated with convulxin (Cvx) plus thrombin (Thr), as indicated for Figure 1. At given time points, samples were taken and stained with AF647-fibrinogen and FITC-annexin A5. Shown are representative histograms obtained by flow cytometry. (B-C) Staining patterns with AF647-fibrinogen (B) and FITC-annexin A5 (C) after platelet stimulation with Cvx/Thr (100 ng/ml, 4 nM) (o), Cvx/SFLLRN (100 ng/ml, 15 M) $(\boldsymbol{\square})$, Thr alone $(4 \mathrm{nM})(\bullet)$ or ionomycin $(10 \mu \mathrm{M})(\boldsymbol{\Delta})$. (D) Platelets were activated with $\mathrm{Cvx} / \mathrm{Thr}$, and pretreated with K9-DON $(50 \mu \mathrm{M})$ or Boc-DON $(200 \mu \mathrm{M})$, as indicated. Limited inhibiting effect on high fibrinogen binding by K9-DON and Boc-DON. Mean \pm SEM $(n=3-6),{ }^{*} p<0.05$

population of convulxin/thrombin activated platelets, which was gradually formed after about 15 minutes and increased to about $50 \%$ until 60 minutes (Figure 1A). This markedly differed from the appearance of PS-exposing platelets, which was already maximal after 15 minutes. Two-color flow cytometry indicated that the Rhod-A14 positive platelets represented a discrete subpopulation: these platelets were in majority PS positive (binding annexin A5), but had inactive $\alpha_{\| 1 b} \beta_{3}$ integrins (no binding of PAC-1 mAb) (Suppl. Figure 1). When comparing various strong platelet agonists, we found that the $\mathrm{Ca}^{2+}$ ionophore ionomycin, whilst causing nearly complete PS exposure, resulted in Rhod-A14 labeling of a subpopulation of $\sim 25 \%$ platelets (Figure 1B). Platelet stimulation with convulxin/SFLLRN resulted in a similar Rhod-A14 positive fraction, whereas stimulation with thrombin alone led to neither Rhod-A14 
incorporation nor PS exposure.

To further characterize the Rhod-A14 positive population, washed platelets were pretreated with purified factor XIII prior to stimulation with convulxin/thrombin. This resulted in an enhanced appearance of the Rhod-A14 binding cells (Figure 1C). Control experiments confirmed the involvement of transglutaminase activity, since all Rhod-A14 binding was antagonized in a dose-dependent way by the general transglutaminase inhibitor K9-DON and the tissue transglutaminase inhibitor Boc-DON (Figure 1D). In sharp contrast, neither the addition of factor XIII nor these inhibitors affected the PS exposure evoked by convulxin/thrombin (Figure 1E). Taken together, these results indicate that the transglutaminase-active, Rhod-A14 positive platelets form as a subpopulation of PS-exposing platelets after collagen/thrombin receptor stimulation.

'Coated' platelets as high fibrinogenbinding platelets

Platelet activation with convulxin/thrombin was found to result in a fraction of platelets displaying high fibrinogen binding, which have also been referred to as coated platelets. ${ }^{12}$ In our
A

OG488-fibrinogen $\square$ AF647-anxA5
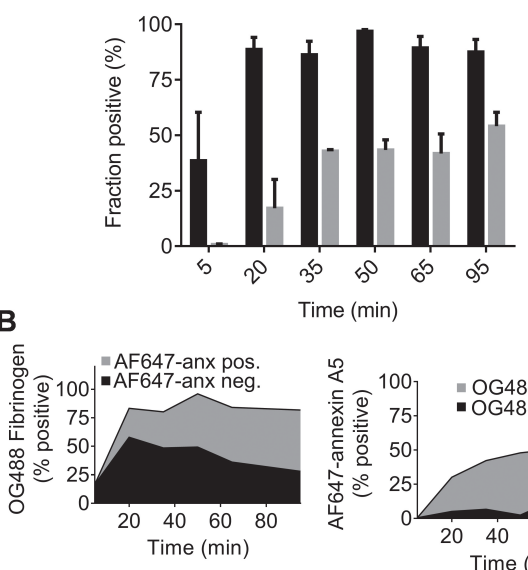

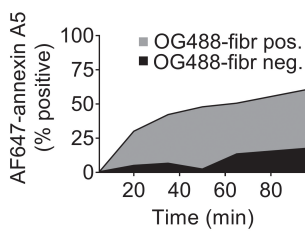

C

FITC-PAC-1 AF647-anxA5
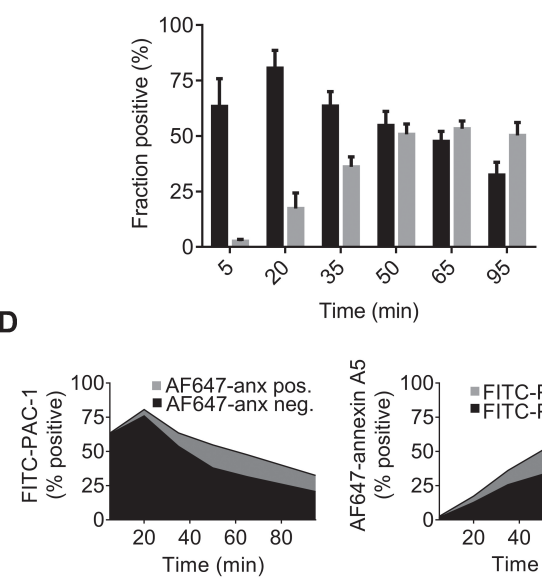

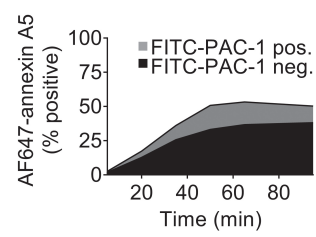

Figure 3. High fibrinogen binding of platelets is independent of $\alpha_{11 b} \beta_{3}$ activation and PS exposure in tissue factor-activated plasma. Defibrinated PFP was reconstituted with platelets and triggered with tissue factor (2 $\mathrm{pM}$ ) and $\mathrm{CaCl}_{2}(16.7 \mathrm{mM})$. Samples were taken for fluorescent labeling at indicated time points. (A-B) Populations of platelets with high binding of OG488-fibrinogen and binding AF647-annexin A5. Shown are total fractions (A), and sub-fractions (B) of high-fibrinogen and annexin A5 binding platelets. (C-D) Populations of platelets binding FITC-PAC-1 mAb and AF647-annexin A5. Shown are total fractions (C) and sub-fractions (D) of platelets positive for FITC-PAC-1 mAb and AF647-annexin A5. Mean \pm SEM $(n=3)$. 
A


B
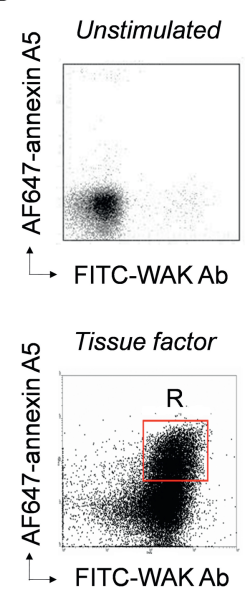

C
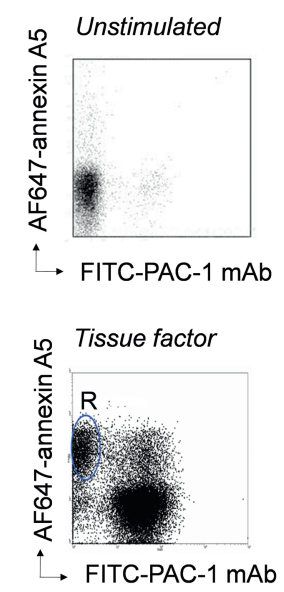

Supplemental Figure 3. Determinants of high fibrinogen binding of platelets in tissue factor-activated plasma. Defibrinated PPP was reconstituted with platelets and activated with tissue factor $(2 \mathrm{pM})$ and $\mathrm{CaCl}_{2}(16.7 \mathrm{mM})$. Samples were taken for fluorescent labeling after 0 and 60 minutes. Shown are representative dot plots obtained by flow cytometry. (A-B) Labeling with AF646-annexin A5 plus FITC-PAC-1 mAb, (C-D) labeling with AF646annexin A5 plus either OG488-fibrinogen or (E) FITC-WAK Ab. Mean \pm SEM ( $n=3-4)$.

hands, after 5 minutes of stimulation with convulxin/thrombin, the binding of fluorescently labeled fibrinogen reached a maximal high level, which was faster than the appearance of PS-exposing platelets (Suppl. Figure 2A-C). Other strong platelet agonists, ionomycin and convulxin/SFLLRN induced only low fibrinogen binding. However, thrombin alone induced similarly high fibrinogen binding as in the presence of convulxin. Notably, the transglutaminase inhibitors K9-DON or Boc-DON affected neither fibrinogen binding nor PS exposure (Suppl. Figure 2D). Interestingly, the extent of fibrinogen binding per platelets slightly declined upon prolonged incubation with convulxin/thrombin, whilst the fraction of fibrinogen-positive platelets remained stable. Dual color flow cytometry indicated that Rhod-A14 binding platelet fraction was a subpopulation of the high fibrinogenbinding cells (Suppl. Figure 1C). Furthermore, a considerable fraction of the high fibrinogen-binding platelets also exposes PS, but these fractions were not identical (Suppl. Figure 2A). Hence, the high fibrinogen binding appears to rely on the presence of thrombin, but not on PS exposure.

'Coated' platelets as procoagulant, PSexposing platelets

In several recent papers, coated platelets have been proposed to be equivalent to 
A

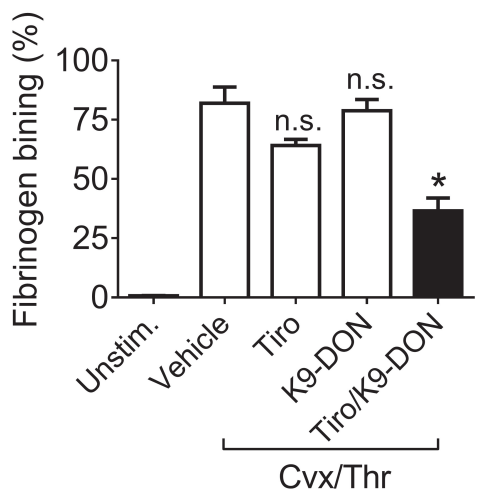

B

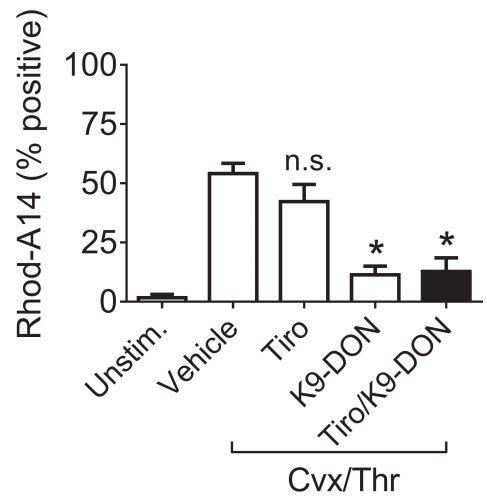

Figure 4. High fibrinogen binding of platelets requires both transglutaminase and $\alpha_{11 b} \beta_{3}$ activities. Washed platelets were stimulated with convulxin $(100 \mathrm{ng} / \mathrm{ml})$ and thrombin $(4 \mathrm{nM})$, as indicated for Figure 1. Preincubation was with vehicle, K9-DON (100 $\mu \mathrm{M})$ and/or tirofiban $(5 \mu \mathrm{g} / \mathrm{ml})$. Flow cytometric data were assessed in the presence of Rhod-A14 and AF647-fibrinogen. Shown are percentages of mean fluorescence intensity of fibrinogen binding (A) and platelets positive for Rhod-A14 (B). Mean \pm SEM $(n=3),{ }^{*} p<0.05$.

coagulation factor binding platelets or the presence of K9-DON did not

PS- exposing platelets. ${ }^{7,13,28}$ To investigate this in more detail, we compared the fractions of convulxin/thrombin-stimulated platelets that bind AF647-annexin A5, OG488factor Xa, FITC-factor $V$ or Rhod-A14. As shown in Figure $2 \mathrm{~A}$, the appearance of a platelet population with binding sites for annexin $A 5$, factor $V$ and factor $X a$ occurred fast with similar kinetics, whereas the formation of Rhod-A14binding platelets was considerably slower. Pre-incubation with transglutaminase inhibitor K9-DON did not influence the binding of annexin A5 nor the coagulation factors, but abolished the binding of Rhod-A14 (Figure 2B). In agreement with this result, influence the process of thrombin generation in PRP (Figure 2C-D). This indicated that the transglutaminase activity of platelets was independent of the interaction of factor $\mathrm{Va}$ and $\mathrm{Xa}$, and of subsequent platelet-dependent thrombin generation, which relies on this interaction. ${ }^{23}$

'Coated' platelets as fibrin-forming platelets

Earlier work demonstrated that platelet stimulation with strong agonists leads to integrin $\alpha_{\| 1 b} \beta_{3}$ activation, followed by PS exposure and calpain-dependent closure of the integrin. ${ }^{6}$ Furthermore, we found that PS exposure instigates the formation of a fibrin network linked to the platelet 
surface. ${ }^{29}$ Here, we reinvestigated this by assessing the determinants of high fibrin(ogen) binding and PS exposure of platelets in tissue factor-activated blood plasma. For this purpose, plasma samples were defibrinated to prevent massive clot formation, ${ }^{21}$ and then reconstituted with washed platelets. After triggering coagulation with tissue factor and calcium, the majority of platelets showed rapid and sustained high fibrinogen binding, followed by the appearance of a platelet subpopulation with PS exposure, as determined by dual- labeling with AF647-annexin A5 and OG488-fibrinogen (Figure 3A). Detailed analysis indicated that only part of the high fibrinogen-binding platelets exposed PS, whereas the majority of PSexposing platelets showed high fibrinogen binding (Figure 3B). High fibrinogen binding again was dependent of the presence of thrombin, since these platelets stained with an anti-fibrin $A b$ and the thrombin inhibitor hirudin substantially suppressed fibrinogen binding (data not shown). High fibrinogen binding of a subpopulation of
A

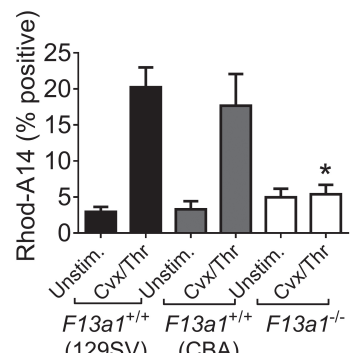

C

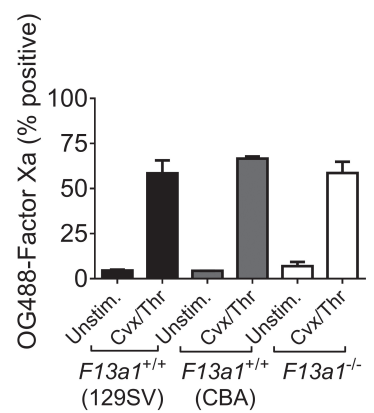

B

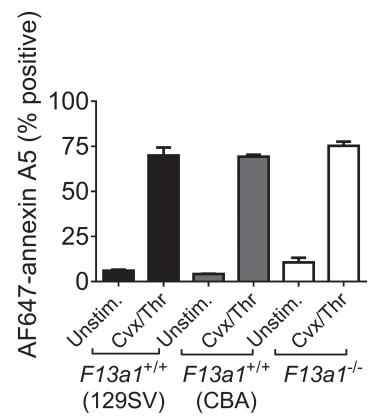

D

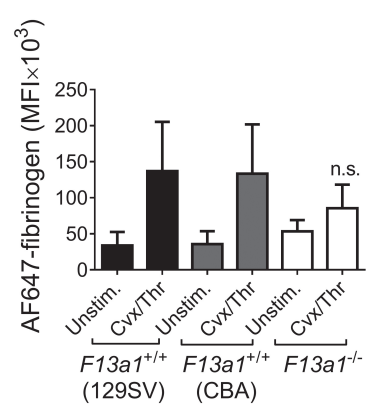

Supplemental Figure 4. Impaired transglutaminase activity and fibrinogen binding of factor XIII-A deficient platelets. Washed platelets from wild-type 1290la or CBACa mice or F13a1\% mice of mixed 129SV/CBA background were stimulated with convulxin $(100 \mathrm{ng} / \mathrm{ml})$ and thrombin $(4 \mathrm{nM})$. After 60 minutes, samples were taken and labeled with Rhod-A14 (A), AF647-annexin A5 (B), OG488-factor Xa (C) or AF647-fibrinogen (D). Shown are fractions of platelets binding the indicated probes. Mean $\pm \operatorname{SEM}(n=3), * p<0.05$. 
A

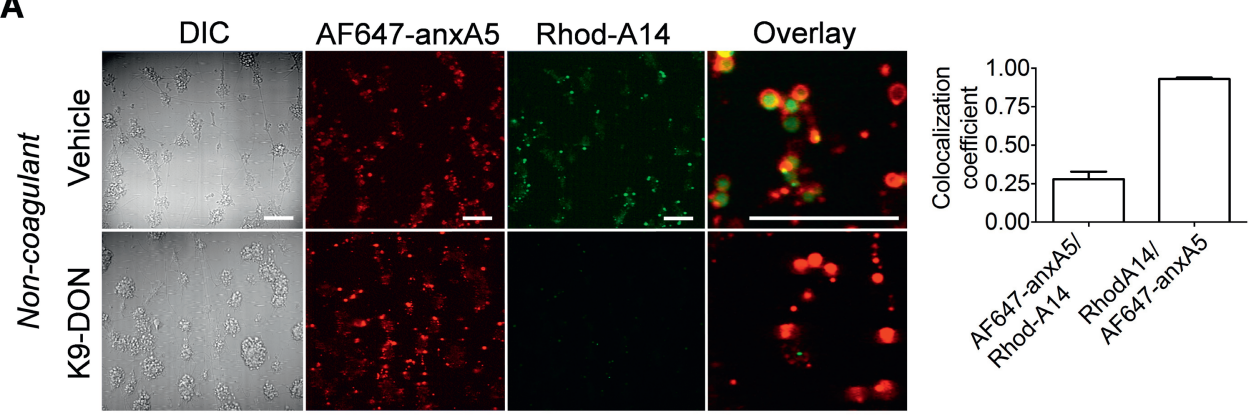

B

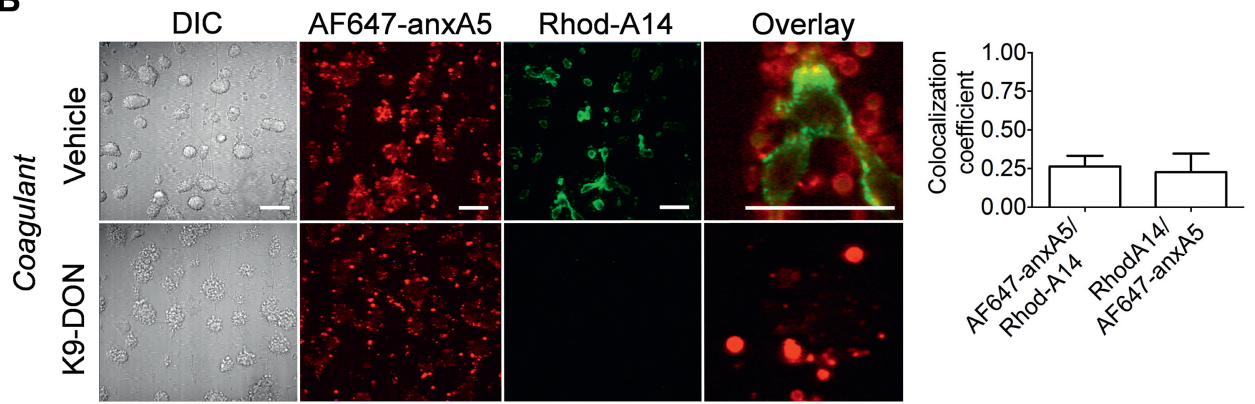

Figure 5. Subpopulation of PS-exposing platelets in thrombi is transglutaminase positive. Human whole blood was perfused over collagen under anti-coagulated (A) or coagulated (B) conditions at shear rate of $1000 \mathrm{~s}^{-1}$. Blood samples were preincubated with vehicle (control) or K9-DON (100 $\mu \mathrm{M})$. (A-B) Representative microscopic images of differential interference contrast (DIC), and confocal images of AF647-annexin A5 or Rhod-A14 fluorescence (bars, $20 \mu \mathrm{m}$ ). Right bar graphs indicate co-localization coefficient of Chl1 and Chl2 (Chl1-T1), and co-localization coefficient of Chl2 and Chl1 (Chl2-T1), as assessed with Zen software. Mean \pm SEM $(n=4),{ }^{*} p<0.05$.

the PS-exposing cells was observed not only with labeled fibrinogen, but also with an antibody (FITC-WAK) recognizing platelet-bound fibrin(ogen) (Suppl. Figure 3). This is in agreement with the results with washed platelets described above that, in the presence of thrombin, the high fibrin(ogen) binding is regulated differently from PS exposure.

Staining of the tissue factor-triggered platelets in plasma with FITC-PAC-1 mAb, recognizing activated integrin $\alpha_{11 b} \beta_{3}$, pointed to rapid integrin activation that subsequently declined (Figure 3C). However, when these platelets were stained for the integrin $\beta_{3}$-chain, fluorescence remained high (not shown), indicating that the integrin was still present and accessible at the platelet surface. In comparison to integrin activation, exposure of PS rose slower in time (Figure $3 \mathrm{C}$ ). Similarly as reported before, $^{6}$ the majority of PAC- 1 mAb positive platelets were annexin $A 5$ 
negative, while the annexin $A 5$ positive platelets were mostly PAC-1 mAb negative (Figure 3D). Dot plots of platelets in plasma, double labeled with AF647-annexin A5 and FITC-PAC-1 mAb, confirmed that most PS-exposing cells were unable to bind PAC-1 mAb (Suppl. Figure $3 \mathrm{C}$ ). In this condition, again a population of PS-positive platelets showed a mean 2.8-fold increase in Rhod-A14 fluorescence above background. Taken together, these results suggests that the high fibrin(ogen)-binding platelet fraction contains a fibrin coat, which precedes PS exposure and primes for binding or Rhod-A14.

Roles of transglutaminases and integrin $\alpha_{111} b_{3}$ in platelet fibrin formation under flow conditions

Suspecting an involvement of transglutaminases and integrin $\alpha_{111} \beta_{3}$ in the high fibrin(ogen) binding, we investigated the effects of transglutaminase inhibitor K9-DON alone or together with the $\alpha_{11 b} \beta_{3}$ inhibitor, tirofiban. In washed platelets stimulated with convulxin/thrombin, the combined presence of the K9-DON and tirofiban blocked the binding of fibrin(ogen) and Rhod-A14 (Figure 4A, B).

In flow experiments, where whole blood was perfused over a collagen surface, we determined the localization of Rhod-A14 binding in thrombi formed on the collagen. Double staining with Rhod-A14 and AF657-annexin A5 indicated that, under non-coagulant conditions (with thrombin inhibitor present), Rhod-A14 binding was restricted to a subpopulation of PS-exposing platelets (Figure 5A). Co-localization analysis demonstrated that the majority of RhodA14 positive pixels also stained with AF647-annexin A5. Addition of K9-DON completely blocked the Rhod-A14 staining, but did not affect PS exposure. Zoomed images indicated that the RhodA14 labeling was confined to balloonshaped, PS-exposing platelets, but often did not label the complete platelet (Figure 5A, right panel).

When thrombi were allowed to form on collagen under coagulant conditions (recalcification without thrombin inhibitor), this resulted in increased Rhod-A14 staining, which again was antagonized by K9-DON, as well as in higher AF637-annexin A5 staining, which was not affected by K9-DON (Figure 5B). In this case, PS-exposing balloon-shaped platelets still bound Rhod-A14, but the majority of the label was located at sites distinct from PS exposure at fibrin fibers. To specifically test the contribution of the transglutaminase factor XIII in RhodA14 binding to platelets, we analyzed platelets from $\mathrm{F} 3 \mathrm{a} \mathrm{1}^{-\mathrm{-}}$ mice, deficient in the A-subunit of factor XIII. Washed platelets from $\mathrm{F} 13 \mathrm{a1}{ }^{-}$mice, when stimulated with convulxin/thrombin, 
showed greatly reduced Rhod-A14 platelets. ${ }^{30}$ Under coagulant conditions, binding in comparison to wild-type large fibrin-containing thrombi were platelets (Suppl. Figure 4A). However, in the $\mathrm{F} 13 \mathrm{a} 1^{\%}$ platelets, PS exposure and the binding of factor $\mathrm{Xa}$ were unchanged (Suppl. Figure 4B, C), while the binding of fibrin(ogen) was reduced but not significant in comparison to $\mathrm{F} 13 \mathrm{a} \mathrm{1}^{+/+}$ platelets (Suppl. Figure 4D).

Flow experiments with $\mathrm{F} 3 \mathrm{a1^{+/+ }}$ or F13a1/- mouse blood over collagen under non-coagulant conditions resulted in thrombi of similar size with no more than low Rhod-A14 labeling (Figure 6A, $B)$. This can be explained by the absence of tissue-type transglutaminase in mouse formed with both $\mathrm{F} 3 \mathrm{al}^{+/+}$and $\mathrm{F} 13 \mathrm{a1} \mathrm{1}^{-/}$ blood (Figure 6C, D). However, Rhod-A14 incorporated only into the fibrin fibers of wild-type thrombi and not of factor XIIIdeficient thrombi. The Rhod-A14 staining again was antagonized by K9-DON, but not by tirofiban. These results hence indicated that the process of fibrin fiber formation can occur in the absence of transglutaminase activity.

In subsequent experiments, $\mathrm{F} \mathrm{Ba1^{+/+ }}$ and $\mathrm{F} 13 \mathrm{a} 1^{-/}$blood was prelabeled with AF647-fibrinogen to investigate in more detail the structure and orientation of

A
Non-coagulant

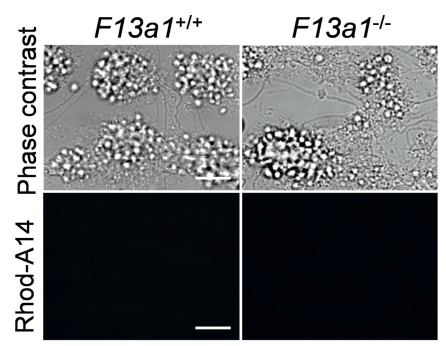

B

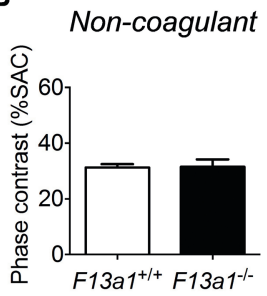

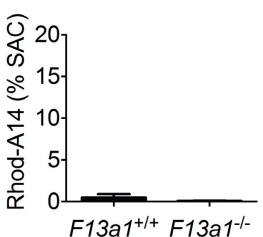

C

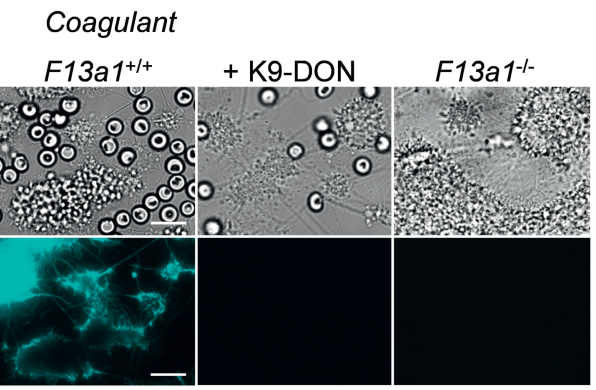

D

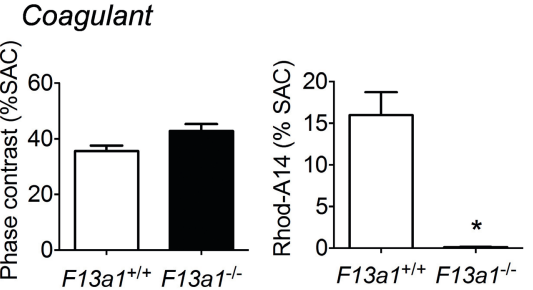

Figure 6. Absence of factor XIII results in fibrin formation without transglutaminase activity. Whole blood from $\mathrm{F} 13 \mathrm{a} 1^{+/+}$or $\mathrm{F} 13 \mathrm{a} 1^{\%-}$ mice was perfused over collagen under non-coagulant (A, B) or coagulant (C, D) conditions during 4 minutes at shear rate of $1000 \mathrm{~s}^{-1}$. Blood samples were preincubated with vehicle (control) or K9-DON $(100 \mu \mathrm{M})$, and post-stained with Rhod-A14. Shown are microscopic images of brightfield and Rhod-A14 fluorescence (bars, $20 \mu \mathrm{m}$ ); also quantification of thrombus size and Rhod-A14 fluorescence. Mean \pm SEM $(n=4)$ $* p<0.05$. 
the fibrin fibers by confocal fluorescence microscopy. Detailed examination indicated that, for wild-type thrombi, fibrin fibers were connected to the platelet surface and oriented to all directions (Figure 7A, B). This staining pattern resembled the star-like formation of fibrin at the platelet surface observed before. ${ }^{29}$ In wild-type thrombi treated with integrin blocker tirofiban and also in factor XIII-deficient thrombi, the orientation of fibrin fibers from platelets was typically more frequent in the direction of the blood flow (Figure 7B). Markedly, the addition of tirofiban to factor XIII-deficient blood nearly completely blocked the star-like orientation of fibrin fibers, but still allowed the plasmatic formation of fibrin fibers rectilinear with the blood flow. These data thus indicate a nonredundancy of the transglutaminase factor XIII and integrin $\alpha_{\| b} \beta_{3}$ in plateletdependent fibrin formation.

\section{Discussion}

The original paper by Dale et al. describes COAT (later renamed coated) platelets as a population of platelets, arising upon combined stimulation with collagen and thrombin, that can bind secreted $\alpha$-granule proteins in a transglutaminase-dependent way. ${ }^{8}$ In the present paper, we used a novel fluorescent-labeled transglutaminase peptide substrate, Rhod-A14, to identify transglutaminase-active platelets and hence further characterize the formation and responses of coated platelets. In particular, we evaluated how transglutaminase-active platelets compared to other platelet populations, earlier proposed as coated platelets, i.e. platelets with PS exposure, binding of coagulation factors $\mathrm{Va}$ and $\mathrm{Xa}$, and high fibrinogen binding.

In washed human platelets, stimulated by convulxin/thrombin, we identified a slowly formed subpopulation of PSexposing platelets capable to bind RhodA14. The Rhod-A14 incorporation was prevented by the general transglutaminase inhibitor K9-DON and the tissue-type transglutaminase inhibitor Boc-DON, while it was enhanced by addition of factor XIII. Factor XIII is also stored into platelets and needs to be externalized and cleaved by thrombin in order to deencrypt its transglutaminase activity. ${ }^{12}$ Markedly, we also observed K9-DON/Boc-DON inhibitable Rhod-A14 binding in the absence of thrombin, e.g. with PSexposing platelets stimulated by ionomycin. These findings thus suggest a role of both factor XIII and tissue-type transglutaminase activities in the binding of the probe to platelets. Indeed, human platelets are known to contain both factor XIII and tissue-type transglutaminases, which can be present at the platelet surface. ${ }^{8,30}$ 


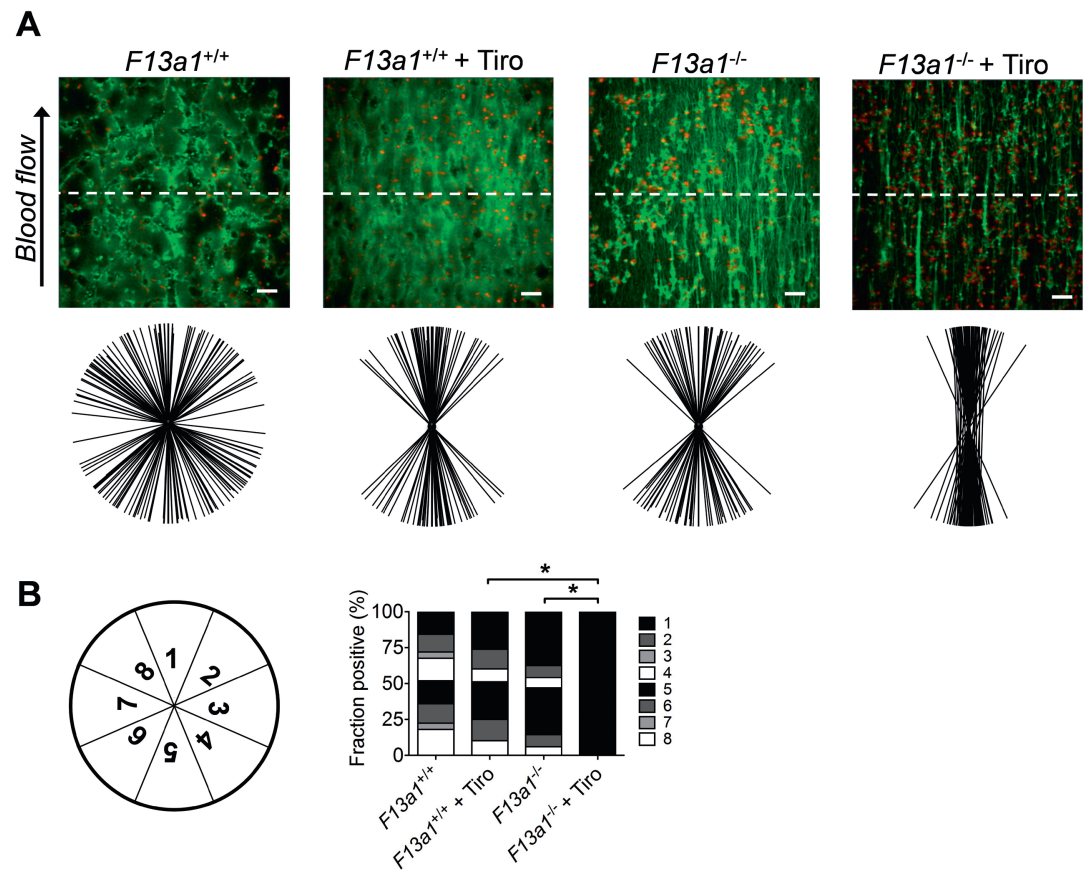

Figure 7. Absence of factor XIII and blockage of integrin $\alpha_{\mathrm{Ilb}} \beta_{3}$ impairs platelet-derived fibrin formation. (A) Blood from $\mathrm{F} 3 \mathrm{al}^{+/+}$or $\mathrm{F} 13 \mathrm{a} 1^{\%}$ mice was flowed over collagen under coagulant conditions (4 minutes, shear rate $\left.500 \mathrm{~s}^{-1}\right)$. Tirofiban $(5 \mu \mathrm{g} / \mathrm{ml}$ ) was added, where indicated. Confocal images of AF647-fibrinogen fluorescence (bars, $20 \mu \mathrm{m})$. (B) Graphically display of the directions (tangents) of all fibrin fibers, traversing an arbitrary line perpendicular to the flow direction (dotted white line). Right panel: quantified octagonal distribution of tangent direction of fibrin fibers. Mean $\pm \operatorname{SEM}(\mathrm{n}=4) * p<0.0001$.

In flow cytometric dot plots, high similarity of the annexin A5- and the convulxin/thrombin-stimulated Rhod- coagulation factor-binding platelet A14-positive platelets appeared as a populations. ${ }^{31,32}$ Furthermore, both in discrete population of platelets with high time of appearance and in subpopulation, fibrin(ogen) binding and PS exposure, the high fibrin(ogen)-binding platelets while only a subpopulation of PS-positive differed from the Rhod-A14-binding and high fibrin(ogen)-binding platelets bound Rhod-A14. We further found that PS exposure, but not Rhod-A14 binding, was accompanied by the binding to platelets of the coagulation factors $\mathrm{Va}$ and $\mathrm{Xa}$. This is in agreement with the results from other groups, also reporting platelets. Hence, in contrast to the habit of others, ${ }^{13,14}$ we consider (transglutaminase-active) coated platelets as non-identical to fibrinogenbinding platelets.

Whereas the formation of $a$ transglutaminase coat appeared to be a 
relatively slow process following of $\alpha_{11 \mathrm{~b}} \beta_{3}$ and transglutaminases. This stimulation of isolated platelets with suggested initial binding of fibrinogen to potent agonists like convulxin/thrombin, Rhod-A14 binding platelets were much faster formed (minutes) during wholeblood thrombus formation on collagen. This can be explained by a rapid availability of transglutaminases like factor XIII in the blood plasma, but it may also point to a relatively slow externalization of platelet-derived transglutaminases in the absence of plasma. Given that transglutaminases are broad-spectrum enzymes, cross-linking $\varepsilon$-( $\gamma$-glutamyl)lysine isopeptide bonds of multiple proteins, ${ }^{33,34}$ it can safely be assumed that Rhod-A14-binding platelets are covered (coated) with a large set of cross-linked proteins at their surface.

Whereas convulxin/thrombin stimulated platelets showed persistently high fibrin(ogen) binding, PAC-1 mAb binding gradually decreased after an initial peak. This is indicative of secondary inactivation of integrin $\alpha_{\| 1 b} \beta_{3}$, such in agreement with earlier results. ${ }^{6,35}$ One explanation for the persistent fibrin(ogen) binding to platelets with apparently inactive integrins, is that the activated $\alpha_{11 b} \beta_{3}$ displays distinct binding sites for fibrinogen and fibrin, allowing interaction with fibrin independently of the classical integrin activation domains. ${ }^{36}$ On the other hand, the high fibrin(ogen) binding of washed platelets was antagonized by combined inhibition the activated integrin, followed by secondary binding of a growing fibrin fiber to platelet surface proteins via transglutaminase activity.

The experiments where thrombus formation was studied in mouse blood clearly indicated that murine factor XIII is required for Rhod-A14 binding, but is dispensable for the formation of fibrin fibers, apparently in the absence of transglutaminase cross-linking. These data are in agreement with those of others, reporting that deficiency in murine factor XIII is dispensable for high fibrinogen binding and PS exposure. ${ }^{12}$ Strikingly, however, we found that the combined absence of factor XIII and blockage of $\alpha_{11 \mathrm{~b}} \beta_{3}$ resulted in abolition of the formation of star-like fibrin patterns at the platelets surface, thus pointing to a combined role of factor XIII and integrin $\alpha_{\| 1} \beta_{3}$ in platelet-driven fibrin fiber formation.

In sum we report the following mechanism for formation of coated, Rhod-A14-binding platelets: initial collagen/thrombin receptor-induced $\alpha_{11 b} \beta_{3}$ activation leads to fibrin(ogen) binding, which on PS-exposing platelets can be consolidated by transglutaminase activity, and act as a scaffold for plateletdriven fibrin fiber formation. Since many of these coated platelets still bind coagulation factors, they can in addition 
have a role in stimulating prothrombinase activity and thrombin generation.

\section{Funding}

This work was supported by research funding from the Center for Translational Molecular Medicine (CTMM) INCOAG to N.J.A.M, J.W.M.H. and J.M.E.M.C.,

\section{References}

1. Cosemans JM, Angelillo-Scherrer A, Mattheij NJ, Heemskerk JW. The effects of arterial flow on platelet activation, thrombus growth, and stabilization. Cardiovasc Res. 2013;99:342-352.

2. de Witt SM, Swieringa F, Cavill R, Lamers MM, van Kruchten R, Mastenbroek T, Baaten C, Coort S, Pugh N, Schulz A, Scharrer I, Jurk K, Zieger B, Clemetson KJ, Farndale RW, Heemskerk JW, Cosemans JM. Identification of platelet function defects by multi-parameter assessment of thrombus formation. Nat Commun. 2014;5:4257.

3. Munnix IC, Cosemans JM, Auger JM, Heemskerk JW. Platelet response heterogeneity in thrombus formation. Thromb Haemost. 2009;102:11491156.

4. Versteeg $\mathrm{HH}$, Heemskerk JW, Levi M, Reitsma PH. New fundamentals in hemostasis. Physiol Rev. 2013;93:327-358.

5. Heemskerk JW, Mattheij NJ, Cosemans JM Platelet-based coagulation: different populations, different functions. J Thromb Haemost. 2013;11:2-16

6. Mattheij NJ, Gilio K, van Kruchten R, Jobe SM, Wieschhaus AJ, Chishti AH, Collins P, Heemskerk JW, Cosemans JM. Dual mechanism of integrin $\alpha_{11 \mathrm{~b}} \beta_{3}$ closure in procoagulant platelets. J Biol Chem. 2013;288:13325-13336.

7. Dale GL. Coated-platelets: an emerging component of the procoagulant response. J Thromb Haemost. 2005;3:2185-2192.

8. Dale GL, Friese P, Batar P, Hamilton SF, Reed GL, Jackson KW, Clemetson KJ, Alberio L. Stimulated platelets use serotonin to enhance their retention
ZonMW MKMD (114021004) to J.W.M.H. and J.M.E.M.C., the Dutch Heart Foundation (2011T6) to J.M.E.M.C.

\section{Conflicts of interest.}

F.M. and M.W.N. are employees of CSL Behring $\mathrm{GmbH}$. All other co-authors declare no relevant conflict of interest.

of procoagulant proteins on the cell surface. Nature. 2002;415:175-179.

9. Alberio LJ, Clemetson KJ. All platelets are not equal: COAT platelets. Curr Hematol Rep. 2004;3:338-343.

10. Szasz R, Dale GL. Thrombospondin and fibrinogen bind serotonin-derivatized proteins on COATplatelets. Blood. 2002;100:2827-2831.

11. Maroney SA, Haberichter SL, Friese P, Collins ML, Ferrel JP, Dale GL, Mast AE. Active tissue factor pathway inhibitor is expressed on the surface of coated platelets. Blood. 2007;109:1931-1937.

12. Jobe SM, Leo L, Eastvold JS, Dickneite G, Ratliff TL, Lentz SR, Di Paola J. Role of FcRgamma and factor XIIIA in coated platelet formation. Blood. 2005;106:4146-4151.

13. Kirkpatrick AC, Tafur AJ, Vincent AS, Dale GL, Prodan $\mathrm{Cl}$. Coated-platelets improve prediction of stroke and transient ischemic attack in asymptomatic internal carotid artery stenosis. Stroke. 2014;45:2995-3001.

14. Prodan $\mathrm{Cl}$, Stoner JA, Cowan LD, Dale GL. Higher coated-platelet levels are associated with stroke recurrence following nonlacunar brain infarction. J Cereb Blood Flow Metab. 2013;33:287-292.

15. Prodan $\mathrm{Cl}$, Vincent AS, Dale GL. Coated-platelet levels are persistently elevated in patients with mild traumatic brain injury. I Head Trauma Rehabil. 2014:in press.

16. Prodan $\mathrm{Cl}$, Szasz R, Vincent AS, Ross ED, Dale GL. Coated-platelets retain amyloid precursor protein on their surface. Platelets. 2006;17:56-60. 
17. Munnix IC, Kuijpers MJ, Auger J, Thomassen CM, Panizzi P, van Zandvoort MA, Rosing J, Bock PE, Watson SP, Heemskerk JW. Segregation of platelet aggregatory and procoagulant microdomains in thrombus formation. Regulation by transient integrin activation. Arterioscler Thromb Vasc Biol. 2007;27:2484-2490.

18. Miserus RJ, Herías MV, Prinzen L, Lobbes MB, Van Suylen RJ, Dirksen A, Hackeng TM, Heemskerk JW, van Engelshoven JM, Daemen MJ, van Zandvoort MA, Heeneman S, Kooi ME. Molecular MRI of early thrombus formation using a bimodal $\alpha 2$ antiplasmin-based contrast agent. JACC Cardiovasc Imaging. 2009;2:987-996.

19. Hara T, Bhayana B, Thompson B, Kessinger CW, Khatri A, McCarthy JR, Weissleder R, Lin CP, Tearney GJ, Jaffer FA. Molecular imaging of fibrin deposition in deep vein thrombosis using fibrintargeted near-infrared fluorescence. JACC Cardiovasc Imaging. 2012;5:607-615.

20. Gilio K, Harper MT, Cosemans JM, Konopatskaya O, Munnix IC, Prinzen L, Leitges M, Liu Q, Molkentin JD, Heemskerk JW, Poole AW. Functional divergence of platelet protein kinase $C$ (PKC) isoforms in thrombus formation on collagen. J Biol Chem. 2010;285:23410-23419.

21. van der Meijden PE, Feijge MA, Swieringa F, Gilio K, Nergiz-Unal R, Hamulyák K, Heemskerk JW. Key role of integrin $\alpha_{11 \mathrm{~b}} \beta_{3}$ signaling to Syk kinase in tissue factor-induced thrombin generation. Cell Mol Life Sci. 2012;69:3481-3492.

22. Lauer P, Metzner HJ, Zettlmeissl G, Li M, Smith AG, Lathe $R$, Dickneite $G$. Targeted inactivation of the mouse locus encoding coagulation factor XIII-A: hemostatic abnormalities in mutant mice and characterization of the coagulation deficit. Thromb Haemost. 2002;88:967-974.

23. Vanschoonbeek K, Wouters K, van der Meijden PE, van Gorp PJ, Feijge MA, Herfs M, Schurgers LJ, Hofker MH, de Maat MP, Heemskerk JW. Anticoagulant effect of dietary fish oil in hyperlipidemia: a study of hepatic gene expression in APOE2 knock-in mice. Arterioscler Thromb Vasc Biol. 2008;28:2023-2029.

24. Hemker HC, Giesen P, Al Dieri R, Regnault V, de Smedt E, Wagenvoord R, Lecompte T, Béguin S. Calibrated automated thrombin generation measurement in clotting plasma. Pathophysiol Haemost Thromb. 2003;33:4-15.

25. Gilio K, van Kruchten R, Braun A, Berna-Erro A, Feijge MA, Stegner $D$, van der Meijden $P E$, Kuijpers MJ, Varga-Szabo D, Heemskerk JW, Nieswandt B. Roles of STIM1 and Orai1 in glycoprotein VI- and thrombin-dependent procoagulant activity and thrombus formation. J Biol Chem. 2010;285:23629-23638.

26. Van Kruchten $R$, Cosemans JMEM, Heemskerk JWM. Measurement of whole blood thrombus formation using parallel-plate flow chambers: a practical guide. Platelets. 2012;23:229-242.

27. Cosemans JM, Munnix IC, Wetzker R, Heller R, Jackson SP, Heemskerk JW. Continuous signaling via PI3K isoforms beta and gamma is required for platelet ADP receptor function in dynamic thrombus stabilization. Blood. 2006;108:30453052.

28. Abaeva AA, Canault M, Kotova YN, Obydennyy SI, Yakimenko AO, Podoplelova NA, Kolyadko VN, Chambost $\mathrm{H}$, Mazurov AV, Ataullakhanov FI, Nurden AT, Alessi MC, Panteleev MA. Procoagulant platelets form an alpha-granule protein-covered "cap" on their surface that promotes their attachment to aggregates. J Biol Chem. 2013;288:29621-29632.

29. Cosemans JM, Schols SE, Stefanini L, de Witt S, Feijge MA, Hamulyák K, Deckmyn H, Bergmeier W, Heemskerk JW. Key role of glycoprotein Ib/V/IX and von Willebrand factor in platelet activationdependent fibrin formation at low shear flow. Blood. 2011;117:651-660.

30. Puszkin EG, Raghuraman V. Catalytic properties of a calmodulin-regulated transglutaminase from human platelet and chicken gizzard. J Biol Chem. 1985;260:16012-16020.

31. London FS, Marcinkiewicz M, Walsh PN. A subpopulation of platelets responds to thrombinor SFLLRN-stimulation with binding sites for factor IXa. J Biol Chem. 2004;279:19854-19859.

32. Panteleev MA, Ananyeva NM, Greco NJ, Ataullakhanov FI, Saenko EL. Two subpopulations of thrombin-activated platelets differ in their binding of the components of the intrinsic factor X-activating complex. J Thromb Haemost. 2005;3:2545-2553. 
33. Nikolajsen CL, Dyrlund TF, Poulsen ET, Enghild JJ, Scavenius C. Coagulation factor XIIla substrates in human plasma: identification and incorporation into the clot. J Biol Chem. 2014;289:6526-6534.

34. Siebenlist KR, Meh DA, Mosesson MW. Protransglutaminase (factor XIII) mediated crosslinking of fibrinogen and fibrin. Thromb Haemost. 2001;86:1221-1228.

35. Kulkarni S, Jackson SP. Platelet factor XIII and calpain negatively regulate integrin $\alpha_{11 b} \beta_{3}$ adhesive function and thrombus growth. J Biol Chem. 2004;279:30697-30706.

36. Podolnikova NP, Yakovlev S, Yakubenko VP, Wang $X$, Gorkun OV, Ugarova TP. The interaction of integrin $\alpha_{l 1 b} \beta_{3}$ with fibrin occurs through multiple binding sites in the $\alpha_{\text {IIb }} \beta$-propeller domain. J Biol Chem. 2014;289:2371-2783. 
Chapter 6

\title{
Both TMEM16F-dependent and TMEM16F- independent pathways contribute to phosphatidylserine exposure in platelet apoptosis and platelet activation
}

\author{
van Kruchten $\mathrm{R}^{1}$, Mattheij $\mathrm{NJ}^{1}$, Saunders $\mathrm{C}^{2}$, Feijge $\mathrm{MA}^{1}$, \\ Swieringa $\mathrm{F}^{1}$, Wolfs $\mathrm{JL}^{1}$, Collins $\mathrm{PW}^{3}$, Heemskerk JW ${ }^{1}$, Bevers EM ${ }^{1}$
}

${ }^{1}$ Department of Biochemistry, Cardiovascular Research Institute Maastricht, University of Maastricht, Maastricht, The Netherlands; ${ }^{2}$ Welsh Blood Service, Pontyclun, United Kingdom; ${ }^{3}$ Arthur Bloom Haemophilia Centre, School of Medicine, Cardiff University, Cardiff, United Kingdom

Blood. 2013;121:1850-185

Reprinted with permission 


\begin{abstract}
Scott syndrome, a bleeding disorder caused by defective phospholipid scrambling, has been associated with mutations in the TMEM16F gene. The role of TMEM16F in apoptosis- or agonist-induced phosphatidylserine (PS) exposure was studied in platelets from a Scott syndrome patient and control subjects. Whereas stimulation of control platelets with the BH3-mimetic ABT737 resulted in 2 distinct fractions with moderate and high PS exposure, the high PS-exposing fraction was markedly delayed in Scott platelets. High, but not moderate, PS exposure in platelets was suppressed by chelation of intracellular $\mathrm{Ca}^{2+}$, whereas caspase inhibition completely abolished ABT737-induced PS exposure in both Scott and control platelets. On the other hand, high PS exposure induced by the $\mathrm{Ca}^{2+}$-mobilizing agonists convulxin/thrombin fully relied on mitochondrial depolarization and was virtually absent in Scott platelets. Finally, PS exposure induced by collagen/thrombin was partly affected in Scott platelets, and the residual PS positive fraction was insensitive to inhibition of caspases or mitochondrial depolarization. In conclusion, TMEM16F is not required for, but enhances, caspase-dependent PS exposure; convulxin-/thrombin-induced PS exposure is entirely dependent on TMEM16F, whereas collagen/thrombin-induced PS exposure results from 2 distinct pathways, one of which involves mitochondrial depolarization and is mediated by TMEM16F.
\end{abstract}

\section{Introduction}

Transbilayer lipid asymmetry in platelets and other cells is maintained by an aminophospholipid translocase, an active transporter pumping aminophospholipids phosphatidylserine (PS) and phosphatidylethanolamine from the outer to the inner leaflet of the plasma membrane. Under particular conditions, phospholipid asymmetry is disrupted by a "scrambling" process, in which the phospholipids become increasingly randomized over both plasma membrane leaflets. ${ }^{1}$ As a consequence, PS, which in resting cells is exclusively located in the inner leaflet, becomes exposed at the membrane outer leaflet and can be probed with the PS-binding proteins annexin A5 or lactadherin. For apoptotic cells, externalized PS provides a signal for removal by the mononuclear phagocytic system. $^{2}$ In blood cells, PS-exposing membranes strongly promote the process of thrombin generation and fibrin clot formation. ${ }^{3,4}$ In platelets, phospholipid scrambling and PS externalization are induced by activation with strong agonists like convulxin/thrombin and collagen/thrombin, stimulating glycoprotein $\mathrm{VI}$, and the platelet 
thrombin Known agonist-induced $\mathrm{Ca}^{2+}$ responses were requirements for agonist-induced found to be unchanged, Scott syndrome phospholipid scrambling are a sustained platelets show diminished PS exposure high intracellular $\mathrm{Ca}^{2+}$ concentration ${ }^{1,3}$ upon stimulation with and loss of the mitochondrialmembrane convulxin/thrombin, collagen/thrombin, potential. ${ }^{7,8}$ Hence, platelets lacking or $\mathrm{Ca}^{2+-}$ ionophore ionomycin compared cyclophilin D, a positive modulator of the with healthy subjects. ${ }^{11}$ Recently, mitochondrial permeability transition TMEM16F was recognized as a protein pore (MPTP), are protected against PS critically involved in $\mathrm{Ca}^{2+}$-induced externalization upon convulxin/thrombin phospholipid scrambling. A homozygous stimulation. ${ }^{9}$ mutation in TMEM16F (IVS12-1G $\rightarrow$ T, Scott syndrome is a rare bleeding disorder in which the $\mathrm{Ca}^{2+}$-dependent causing premature termination of translation) was found in the genome of phospholipid scrambling of platelets and other blood cells is impaired. ${ }^{10}$ Although the propositus Scott patient. ${ }^{12}$ Another Scott syndrome patient appeared to be

A

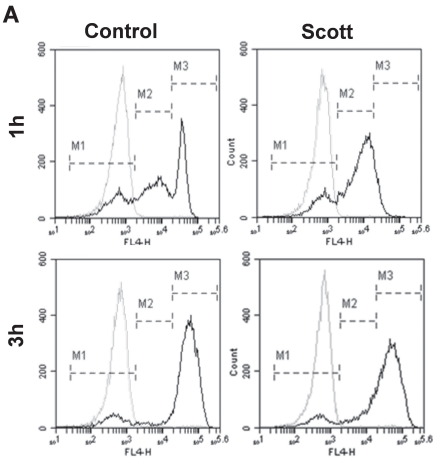

B

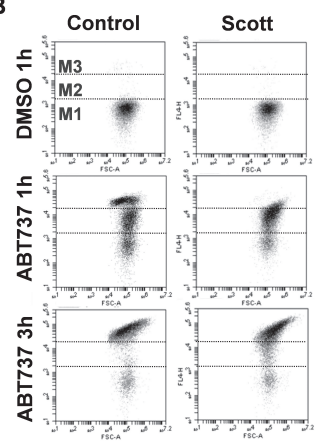

C

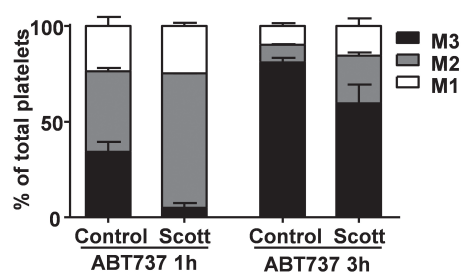

Figure 1. Proapoptotic agent ABT737 causes PS exposure in platelets from a patient with Scott syndrome. Washed platelets from healthy control subjects or a patient with Scott syndrome were treated with ABT737 (10 $\mathrm{mM}$ ) in the presence of $1 \mathrm{mM} \mathrm{CaCl}$. (A) Representative histograms (black lines) for AF647-annexin A5 binding after 1- or 3-h stimulation with $A B T 737$. Markers $M 1, M 2$, and $M 3$ indicate fractions of platelets with no, moderate, or high annexin $A 5$ binding, respectively. Gray curves show unstimulated platelets treated with vehicle. (B) Corresponding dot plots (forward scatter vs AF647 fluorescence) of platelets treated with ABT737 or vehicle.

(C) Distribution of M1, M2, and M3 platelet populations upon ABT737 treatment (10 mM). 
compound heterozygous in TMEM16F, ${ }^{13}$ suggesting that a defective TMEM16F is the cause of the Scott syndrome phenotype.

Besides the agonist-induced pathway, platelets possess a distinct pathway to PS exposure, which was shown to be elicited with ABT737 or ABT263 (Navitoclax), both of which are $\mathrm{BH}-3$ mimetics that activate caspasedependent apoptosis in a Bax/Bakdependent manner. ${ }^{14,15}$ This apoptotic pathway may play a role in the clearance of aging platelets. ${ }^{16} \mathrm{As} \mathrm{Bcl-xL}$ is gradually degraded in such platelets, its restraint of the proapoptotic function of Bax and Bak will gradually diminish in time and hence prime platelets for apoptosis. ${ }^{17,18}$ This explains why $\mathrm{BH}-3$ mimetics like ABT737 and ABT263 induce thrombocytopenia and affect the platelet hemostatic function. ${ }^{19,20}$ Whether TMEM16F is involved in PS exposure upon apoptosis has not been investigated. In this study, we aimed to elucidate the roles of TMEM16F in agonist- and apoptosis-induced PS exposure using platelets from a Scott patient. We provide evidence for TMEM16F-independent phospholipid scrambling in the apoptotic pathway that leads to moderate PS exposure in a caspase-dependent way. The data furthermore point to a TMEM16Findependent process of caspase/mitochondrial-independent PS exposure in

collagen/thrombin.

\section{Methods}

Materials

ABT737 and Ac-DEVD-AFC were obtainedfrom Santa Cruz Biotechnology (Santa Cruz, CA), ABT-263 from Selleckchem (Houston, TX), and annexin A5-labeled with fluorescein isothiocyanate (FITC) from PharmaTarget (Maastricht, The Netherlands). Acetylsalicylic acid (aspirin) was from Genfarma (Maarssen, The Netherlands). Fibrillar type I collagen (Horm) was from Nycomed (Munich, Germany). Fluo-4 acetoxymethyl ester, Alexa Fluor-647 (AF647)-labeled annexin A5, dimethyl BAPTA acetoxymethyl ester, ionomycin, and pluronic F-127 were from Invitrogen (Carlsbad, CA). Apyrase (grade V), dimethylsulfoxide, bovine serum albumin, human fibrinogen, MRS2179, 2-APB, and thrombin were from Sigma-Aldrich (St. Louis, MO). FITC-lactadherin was from Haematologic Technologies (Essex Junction, VT). Tetramethyl rhodamine methyl ester (TMRE) was from Anaspec (San Jose, CA). Q-VD-Oph and cyclosporin A were from Calbiochem (San Diego, CA). A fluorometric assay for caspase 3 activity (BF1100) came from R\&D Systems (Minneapolis, MN). Convulxin was purified as described before. ${ }^{21}$ Cangrelor was kindly provided by AstraZeneca (Mölndahl, Sweden). 
Blood collection and platelet preparation Human blood was obtained from healthy volunteers and a patient from the UK with Scott syndrome after they provided informed consent in accordance with the Declaration of Helsinki under protocols reviewed by the local ethics committees. The UK Scott patient was described earlier as compound heterozygous in TMEM16F with one mutation, IVS6 1 $1 \mathrm{G} \rightarrow \mathrm{A}$, resulting in exon 6 skipping and another mutation (c.1219insT) leading to a premature stop of translation, causing defective TMEM16F expression. ${ }^{13}$ Blood was collected into acid citrate dextrose to prepare washed platelets in $\mathrm{N}$-2hydroxyethylpiperazine-N'-2-

ethanesulfonic acid (HEPES) buffer, $\mathrm{pH}$ 7.45 (136 mM NaCl, 10 mM HEPES, 2.7 $\mathrm{mM} \mathrm{KCl}, 2 \mathrm{mM} \mathrm{MgCl} 2,0.1 \%$ glucose, and $0.1 \%$ bovine serum albumin) as described. ${ }^{22}$ Platelet counts were determined using a Coulter counter (Beckman).

\section{Measurement of PS exposure}

Washed platelets $\left(1 \times 10^{8} / \mathrm{mL}\right)$ were preincubated with inhibitor or vehicle control (dimethylsulfoxide) and activated with indicated agents under nonstirring conditions at $37^{\circ} \mathrm{C}$. For aging experiments, platelets were stored at room temperature in sterile HEPES buffer, pH 7.45, supplemented with $0.2 \%$ penicillin/streptomycin. For experiments performed in the absence of extracellular
$\mathrm{Ca}^{2+}$, HEPES buffer was supplied with 1 mM EGTA. Where indicated, intracellular $\mathrm{Ca}^{2+}$ was chelated by platelet treatment with $20 \mathrm{mM}$ dimethyl BAPTA acetoxymethyl ester. Phospholipid scrambling was measured as PS exposure by labeling in the presence of $2 \mathrm{mM}$ $\mathrm{CaCl}_{2}$ with fluorescent annexin A5 (0.25 $\mathrm{mg} / \mathrm{mL}$ ) or fluorescent lactadherin (16 $\mathrm{nM}$ ). Labeling was done by transferring 2 $\mathrm{mL}$ platelet suspension into $60 \mathrm{~mL}$ measurement buffer with $2 \mathrm{mM} \mathrm{CaCl}_{2}$. After 2 min of labeling, samples were analyzed with an Accuri C6 flow cytometer and Flow C6 software. Threshold forward scatter and side scatter gates were set to exclude microparticles. The range $M 3$ was defined as the annexin A5 fluorescence comprising $95 \%$ of maximally activated platelets using ionomycin. The range M1 was set to include $95 \%$ of all unstimulated platelets, and $\mathrm{M} 2$ was the range between $\mathrm{M} 1$ and $\mathrm{M} 3$.

\section{Calcium measurements}

For measurements of $\left[\mathrm{Ca}^{2+}\right]_{i}$ by flow cytometry, washed platelets $\left(3 \times 10^{8} / \mathrm{mL}\right)$ were loaded for $45 \mathrm{~min}$ with $8 \mathrm{mM}$ Fluo$4 \mathrm{AM}$ in the presence of $0.4 \mathrm{mg} / \mathrm{mL}$ pluronic F-127. Following a wash step, the platelets were resuspended in HEPES buffer, pH 7.45, containing $2 \mathrm{mM} \mathrm{CaCl}_{2}$ and activated by convulxin/thrombin (70 $\mathrm{ng} / \mathrm{mL}, 4 \mathrm{nM}$ ) at $2 \times 10^{6}$ platelets $/ \mathrm{mL}$. 
A
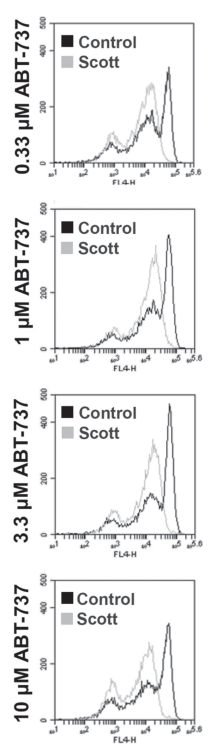
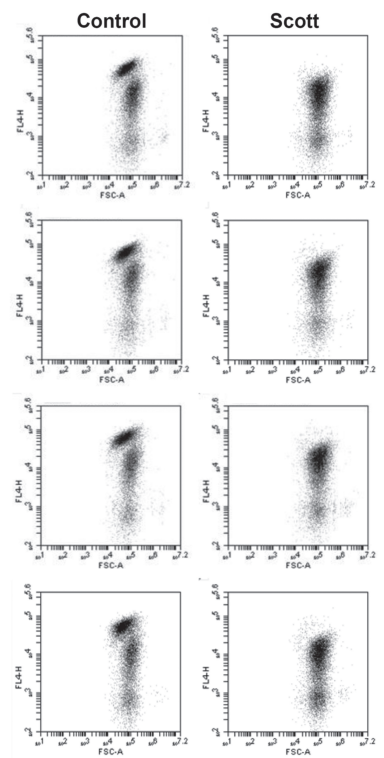

B

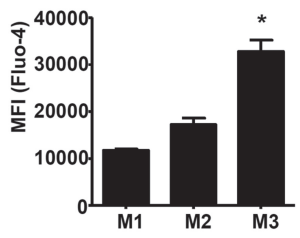

Supplemental Figure 1. Absence of high PS-exposing fraction in Scott syndrome platelets treated with ABT737 (A) Washed platelets from healthy control subjects or a patient with Scott syndrome were stimulated by ABT737 (0.33-10 $\mu \mathrm{M})$ in the presence of $1 \mathrm{mM} \mathrm{CaCl}_{2}$. Representative flow cytometry histograms and dot plots of AF647annexin A5 binding after 1 hour stimulation with ABT737 of control (black) and Scott platelets (grey curves). (B) Fluo-4-loaded platelets were stimulated with ABT737 $(1 \mu \mathrm{M})$ for 1 hour in the presence of $1 \mathrm{mM} \mathrm{CaCl}$. Fluo-4 fluorescence was determined of the M1, M2 and M3 fractions. Mean \pm S.E.M. $(n=4), * p<0.05$.

Detection of mitochondrial

depolarization

Platelets were loaded with TMRE (50 nM) for $30 \mathrm{~min}$ prior to stimulation for assessment of mitochondrial membrane depolarization by flow cytometry. In combination with confocal microscopy, platelets were allowed to adhere to fibrinogen-coated coverslips before stimulation with indicated agonist. Slides were precoated with $500 \mathrm{mg} / \mathrm{mL}$ fibrinogen for $10 \mathrm{~min}$. After stimulation with the indicated agonists, confocal images were taken with a Live-7 Zeiss line-scanning microscope system.
Caspase activity assay

Washed platelets $\left(1 \times 10^{8} / \mathrm{mL}\right)$ were preincubated and activated as indicated. At fixed time points, $100-\mathrm{mL}$ samples were centrifuged ( $2 \mathrm{~min}$ at $2300 \mathrm{~g}$ ), and platelet pellets were resolved into 100 $\mathrm{mL}$ lysis buffer (caspase-3 fluorometric assay, R\&D Systems). Samples in lysis buffer were mixed 1:1 with $50 \mathrm{~mL}$ caspase substrate mix containing $9.8 \mathrm{mM}$ dithiothreitol and $49 \mathrm{mM}$ Ac-DEVD-AFC. Fluorescence was measured in time using a Spectramax M2. Caspase-3 activity was assessed as fluorescence units per minute. 
A

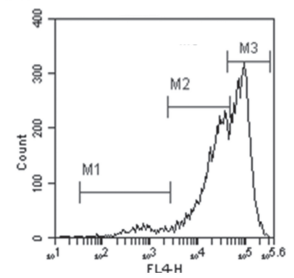

B

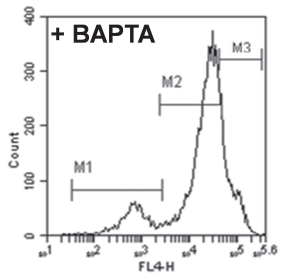

C.

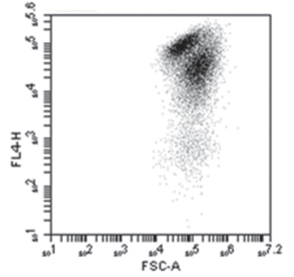

D

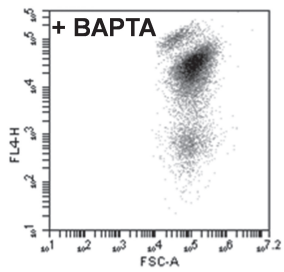

E

$\mathbf{F}$ + BAPTA
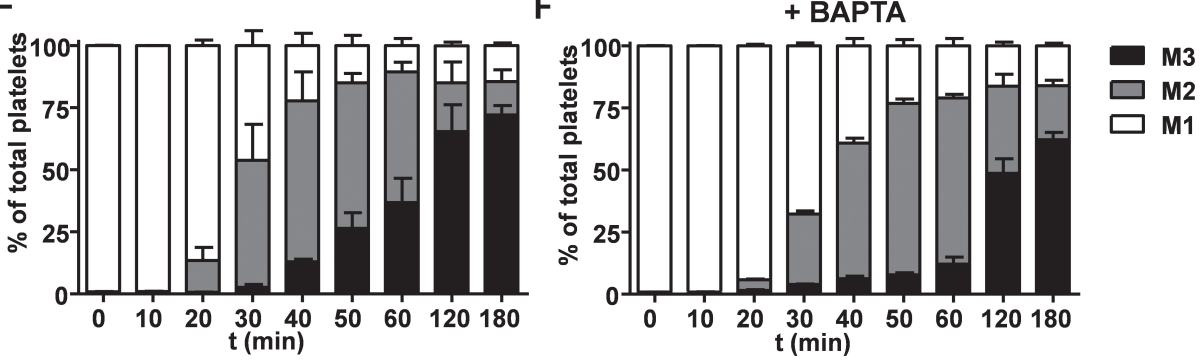

G

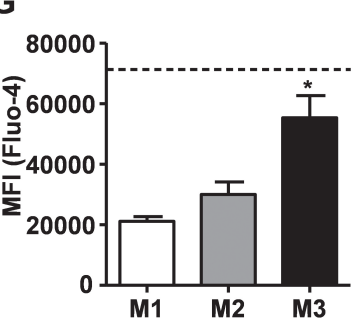

$\mathrm{H}$
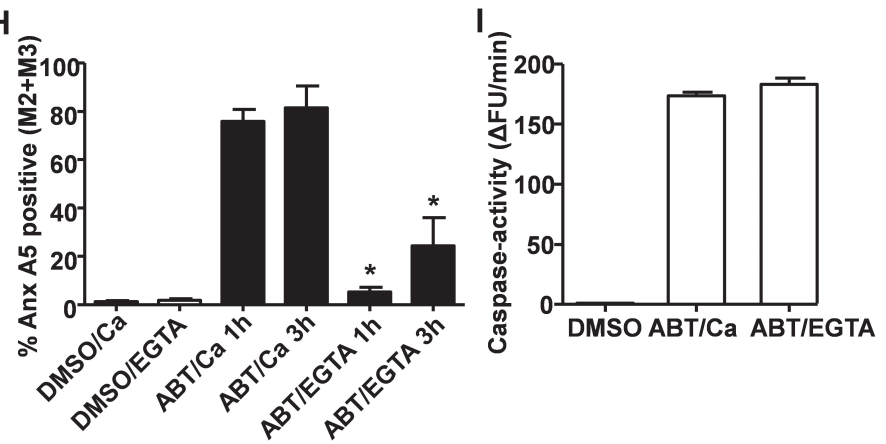

Figure 2. High PS exposure induced by $A B T 737$ depends on elevated intracellular $\mathrm{Ca}^{2+}$. (A-F) Washed platelets were stimulated by $10 \mathrm{mM} \mathrm{ABT737}$ in the absence of $\mathrm{CaCl}_{2}$ or after loading with dimethyl-BAPTA (1 BAPTA) in the presence of $2 \mathrm{mM} \mathrm{CaCl}_{2}$. Representative flow cytometry histograms (A-B) and dot plots (C-D) of AF647-annexin (Anx) A5 binding after 1-h treatment with ABT737. Markers M1, M2, and M3 indicate fractions of platelets with no, moderate, or high Anx A5 binding, respectively. (E-F) Distribution of platelet populations over $M 1, M 2$, and M3 during treatment in time. (G) Platelets were loaded with the intracellular $\mathrm{Ca}^{2+}$ probe Fluo-4 and stimulated with ABT737 (10 mM, $1 \mathrm{~h}$ ) in the presence of $1 \mathrm{mM} \mathrm{CaCl}$. Fluo-4 fluorescence was determined for the M1, M2, and $\mathrm{M} 3$ fractions. Dotted line represents maximal Fluo-4 fluorescence obtained with $10 \mathrm{mM}$ ionomycin, as positive control. (H) Anx A5 binding of platelets stimulated by $A B T 737$ in the presence of $1 \mathrm{mM} \mathrm{CaCl} 2$ or $1 \mathrm{mM}$ EGTA after 1 to $3 \mathrm{~h}$. (I) Caspase activity (arbitrary fluorescence units/min) of ABT737-stimulated platelets in the presence of $1 \mathrm{mM} \mathrm{CaCl}_{2}$ or $1 \mathrm{mM} \mathrm{EGTA}$. Mean \pm SEM (n 5 3-6); ${ }^{*} p<.05$.

\section{Statistical analysis}

Data are presented as means \pm SEM. As appropriate, the significance of differences was determined by analysis of variance analysis with Bonferroni posttesting, paired $t$ test, or the independent samples $t$ test, using GraphPad Prism software. 
Results

BH3-mimetics induce delayed PS exposure in Scott syndrome platelets

To investigate the role of TMEM16F in apoptosis-induced PS exposure, platelets from a patient with Scott syndrome and from healthy control subjects were treated with the BH3-mimetic ABT737. As shown in Figure 1A, a 1-h treatment with 10 mM ABT737 caused $~ 70 \%$ of the platelets to expose PS for both control and Scott platelets. However, whereas for control platelets the histogram of the annexin A5-positive fraction gave a bimodal distribution with moderate (marker region $\mathrm{M} 2$ ) and high (marker region M3) PS exposure, the Scott platelets exhibited a fraction with mainly moderate PS exposure. Similar results were found at lower concentrations of ABT737, ranging from 3.3 to $0.33 \mathrm{mM}$ (supplemental Figure 1A). Note that the extent of annexin $A 5$ binding in the $M 3$ fraction of the ABT737-treated control platelets was comparable with that of platelets stimulated with ionomycin or convulxin/thrombin (see below). A similar bimodal labeling pattern was found with the PS-selective probe, FITClactadherin (data not shown). Prolonged incubation with ABT737 up to $3 \mathrm{~h}$ increased the fraction with the highest (M3) annexin A5 binding at the expense of the fraction with moderate (M2) annexin A5 binding for both Scott and control platelets (Figure $1 \mathrm{~A}-\mathrm{C}$ ). Similar results were obtained with the related compound ABT263 (data not shown).
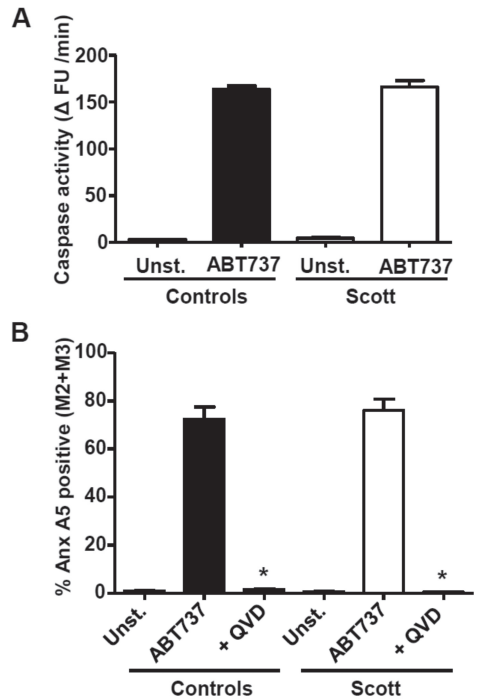

Supplemental Figure 2. ABT737-induced PS exposure in Scott syndrome platelets is caspase-dependent. Washed platelets from healthy control subjects or a patient with Scott syndrome were stimulated by ABT737 $(10 \mu \mathrm{M})$ in the presence of $1 \mathrm{mM} \mathrm{CaCl}_{2}$. (A) Caspase activity after 1 hour of ABT737 treatment (arbitrary fluorescence units/min). (B) Effects of caspase inhibition ( $20 \mu \mathrm{M}$ Q-VD-Oph, 10 minutes) on percentage of annexin A5-positive platelets ( $M 2$ plus M3 fractions). Mean \pm S.E.M. $(n=3), * p<0.05$.

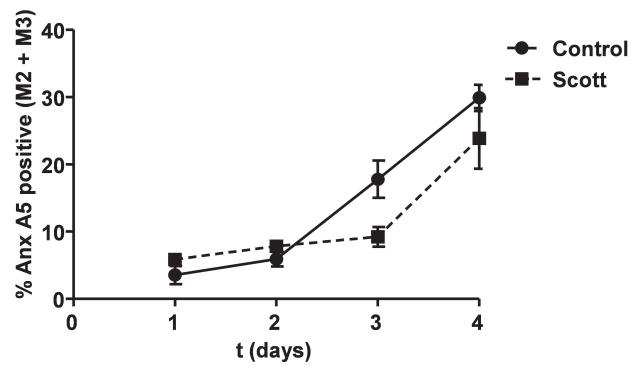

Figure 3. Prolonged storage causes PS exposure in Scott syndrome platelets. Percentage of annexin (Anx) A5-positive platelets ( $M 2$ and $M 3$ fractions) from healthy controls and Scott patient during 1 - to 4-h storage at room temperature in sterile buffer medium. Mean \pm SEM $(n=3)$. 
The ABT737-induced PS exposure in platelets was previously shown to be dependent on caspase proteases. ${ }^{14}$ This was confirmed by the measurement of caspase activity in platelets. Comparable caspase activity was detected in Scott syndrome platelets and platelets from controls (supplemental Figure 2A), ruling out the possibility that a difference in caspase activity attributed to the observed effects. Furthermore, the pancaspase inhibitor Q-VD-Oph completely abolished ABT737-induced PS exposure in both Scott syndrome and control platelets (supplemental Figure 2B). These data suggest that the proapoptotic agent ABT737 activates 2 mechanisms leading to PS exposure, one of which causes a gradual increase in PS exposure that is independent of TMEM16F and one resulting in high PS exposure that requires the presence of a functional TMEM16F.

Because TMEM16F is considered to be essential for $\mathrm{Ca}^{2+}$-dependent phospholipid scrambling, we questioned to what extent the scrambling process observed after ABT737 treatment is regulated by intracellular $\mathrm{Ca}^{2+}$ levels. Indeed, chelation of intracellular $\mathrm{Ca}^{2+}$ levels in platelets loaded with dm-BAPTA resulted in strong suppression of the high annexin A5-binding population, with little effect on the moderate PS-exposing fraction (Figure 2A-F). Furthermore, Fluo4 measurements revealed that the high annexin A5-binding fraction had increased $\mathrm{Ca}^{2+}$ levels compared with the moderate PS-exposing fractions (Figure 2G). However, chelation of extracellular $\mathrm{Ca}^{2+}$ by $1 \mathrm{mM}$ EGTA resulted in a significant suppression of ABT737induced PS-exposure in both the moderate and high annexin A5-binding populations (Figure $2 \mathrm{H}$ ). The defective PS exposure in the presence of EGTA was not due to a reduction in caspase activity (Figure 2I). Further experiments with aspirin (100 mM), P2Y $Y_{1}$ blocker MRS2179 (50 mM), and $\mathrm{P}^{2} \mathrm{Y}_{12}$ blocker cangrelor $(10 \mathrm{mM})$ indicated that the fractions of moderate and high annexin A5-binding platelets changed with $<2 \%$ by blocking of the secondary mediator release.

Normal PS exposure in Scott syndrome platelets during prolonged storage

A gradual increase in surface-exposed PS can be observed in platelets that are stored for a prolonged time (C.S., unpublished data, 2012). To determine whether Scott syndrome platelets possess a similar mechanism to expose PS under aging conditions, Scott and control platelets were stored up to $4 \mathrm{~d}$ at room temperature. As shown in Figure 3, the patient's platelets were equally able to expose PS upon storage as controls, indicating that in vitro aging-related PS exposure occurs independently of TMEM16F activity. 
Convulxin-/thrombin-stimulated Scott platelets do not expose PS despite normal cyclophilin $D$-mediated mitochondrial depolarization and intracellular $\mathrm{Ca}^{2+}$ response

Mitochondrial depolarization through cyclophilin D-dependent formation of the MPTP has been shown to be crucial for convulxin-/thrombin-induced PS exposure in platelets. ${ }^{9}$ Involvement of cyclophilin D-mediated mitochondrial depolarization was assessed by measuring TMRE fluorescence and by investigating the effect of the MPTP inhibitor cyclosporin A. Stimulation of Scott syndrome platelets by convulxin/thrombin did not cause significant PS exposure (Figure 4A), whereas in healthy controls, $40 \%$ of the platelets became annexin A5 positive. This response was almost completely suppressed by cyclosporin A. The lack of PS exposure in convulxin-/thrombinstimulated Scott platelets was not due to the absence of mitochondrial depolarization, as demonstrated by flow cytometry (Figure 4B). The loss of TMRE from mitochondria in Scott platelets stimulated with convulxin/thrombin was confirmed by confocal microscopy (Figure 4E-F). No differences in intracellular $\mathrm{Ca}^{2+}$ levels were found between Scott syndrome platelets and healthy controls after convulxin/thrombin stimulation (Figure $5 A-C)$, which is in line with previous results showing normal store-operated $\mathrm{Ca}^{2+}$ entry with such agonists. ${ }^{11}$

Analysis of the flow cytometry histograms revealed a marked difference between ABT737 and convulxin/thrombin stimulation. Whereas ABT737 treatment resulted in 2 populations of platelets with moderate and high PS exposure, after convulxin/thrombin stimulation, even at early time points, only high PS-exposing platelets residing in marker region $\mathrm{M} 3$ were found (Figure 4C-D). Because this response was virtually absent in Scott platelets, we concluded that convulxin/thrombin-induced PS exposure depends on a functional TMEM16F.

Collagen/thrombin stimulation induces an additional pathway to platelet PS exposure, which is independent of caspases, cyclophilin D, or TMEM16F In previous studies, it was found that collagen-/thrombin-induced PS exposure is only partially impaired in platelets from patients with Scott syndrome. ${ }^{10,11}$ We questioned whether the residual PS exposure observed after collagen/thrombin stimulation in Scott platelets results from activation of the apoptotic pathway. Figure 6A shows that caspase inhibition by Q-VD-Oph did not affect the fraction of PS-exposing platelets induced by collagen/thrombin in either Scott platelets or healthy control platelets, indicating no 
A

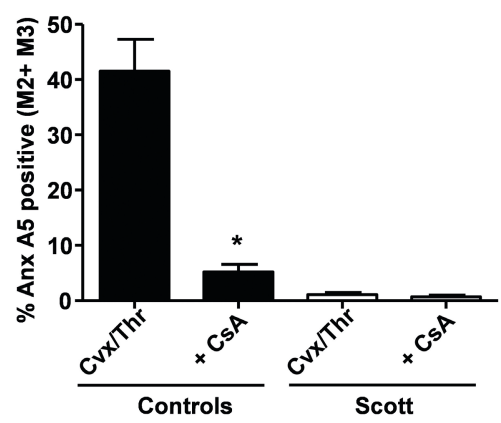

B

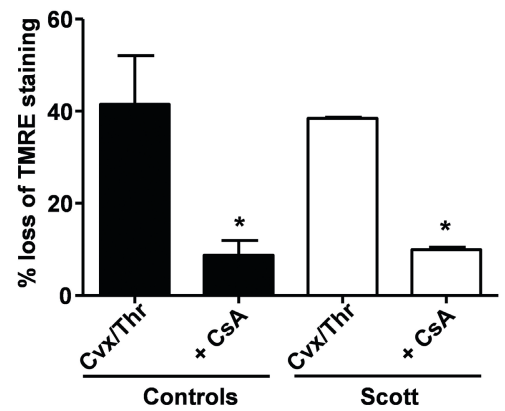

C

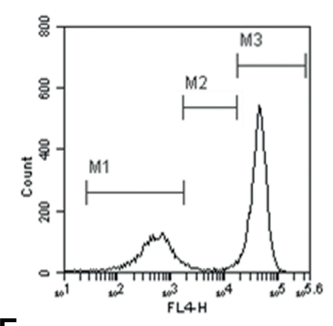

$\mathbf{E}$

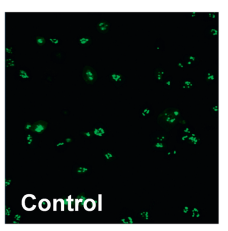

$\mathbf{F}$

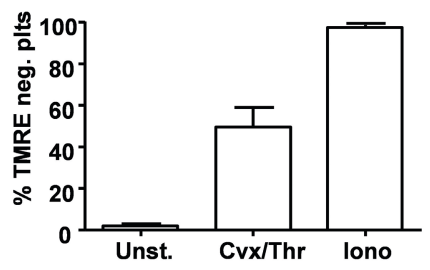

Figure 4. Cvx-/Thr-induced PS exposure is absent in Scott syndrome platelets despite normal cyclophilin Ddependent mitochondrial depolarization. (A-D) Platelets from healthy controls or a Scott patient were loaded with TMRE and preincubated with vehicle (dimethylsulfoxide) or cyclosporin A (CSA) $(4 \mu \mathrm{M})$ for 10 min prior to stimulation by $\mathrm{Cvx} / \mathrm{Thr}(70 \mathrm{ng} / \mathrm{mL}, 4 \mathrm{nM}$, for $15 \mathrm{~min}$ ) in the presence of $2 \mathrm{mM} \mathrm{CaCl}$. Graphs show annexin (Anx) A5 binding (A) and loss of TMRE (B) of washed control and Scott syndrome platelets. (C-D) Representative histogram and bar graph showing the distribution of $\mathrm{Cvx}$-/Thr-stimulated control platelets (15 $\mathrm{min}$ ) over the fractions M1, M2, and M3. (E-F) TMRE-loaded Scott platelets adhered to fibrinogen (10 $\mathrm{min}$ ) were stimulated with $\mathrm{Cvx} / \mathrm{Thr}(70 \mathrm{ng} / \mathrm{mL}, 4 \mathrm{nM})$ or ionomycin $(10 \mu \mathrm{M})$ in the presence of $2 \mathrm{mM} \mathrm{CaCl}_{2}$. (E) Representative images after 15-min stimulation, (F) The percentage of TMRE-negative platelets. Mean \pm SEM $(n=3-6) ;{ }^{*} P<.05$.

appreciable contribution of the apoptotic pathway in collagen-/thrombin-induced PS exposure.

We then asked whether the residual PSexposing activity is cyclophilin Dmediated. The collagen-/thrombininduced PS exposure in Scott syndrome appeared insensitive to inhibition with cyclosporine $A$, whereas this compound effectively reduced mitochondrial depolarization (Figure 6A-B). Treatment of control platelets resulted in a reduction of collagen-/thrombin-induced PS exposure from $53 \%$ to $19 \%$ and a correspondingly reduced mitochondrial depolarization. These data suggest that collagen/thrombin activates 2 different pathways leading to PS exposure, one that requires MPTP formation and is dependent on TMEM16F and one that does not involve MPTP and functions independently of TMEM16F. Control 
studies showed that both collagen- healthy controls have an additional /thrombin- and convulxin-/thrombin- platelet fraction with high annexin A5 induced PS exposure are entirely binding despite the fact that the total dependent on intracellular $\mathrm{Ca}^{2+}$, as fraction of annexin-positive platelets is platelet treatment with dm-BAPTA virtually the same for the patient and virtually abolished PS exposure ( $<4 \%$ PS- healthy controls. This argues for a partial positive platelets).

\section{Discussion}

In this study, we show that Scott syndrome platelets have retained the capacity to expose PS upon ABT737induced apoptosis. Remarkably, though, Scott syndrome platelets show only moderate levels of annexin A5 binding after $1 \mathrm{~h}$ of ABT737 treatment, whereas role of TMEM16F in apoptotic PS exposure. Because TMEM16F is reported to be crucial for $\mathrm{Ca}^{2+}$-induced phospholipid scrambling ${ }^{12}$ and the fraction of high annexin A5-binding platelets correlates with platelets high in intracellular $\mathrm{Ca}^{2+}$, we propose that next to a TMEM16F-independent mechanism, a TMEM16F-dependent mechanism is activated during platelet apoptosis,

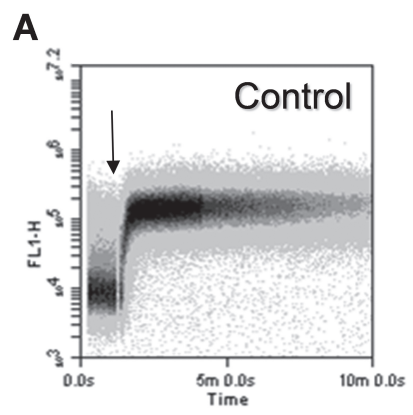

B

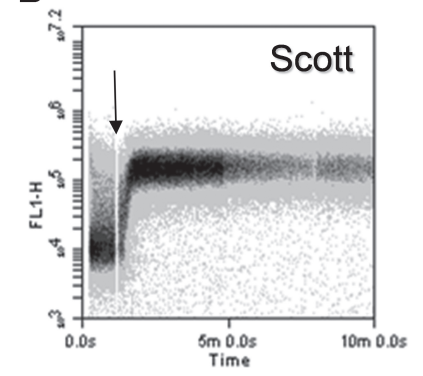

C

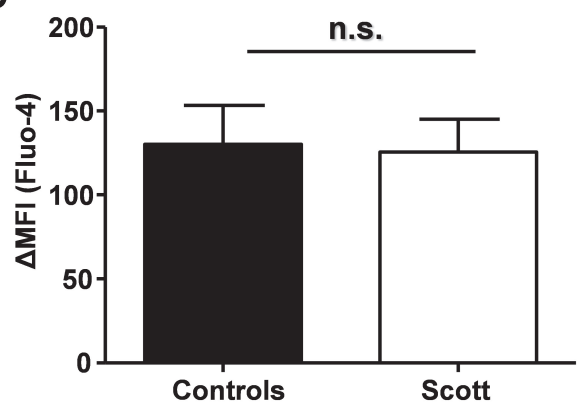

Figure 5. Scott syndrome platelets display normal convulxin (Cvx)-/thrombin (Thr)-induced Ca ${ }^{2+}$ responses. (A-B) Time drive of fluorescence increase of washed control (A) and Scott syndrome (B) platelets loaded with Fluo-4 and activated by $\mathrm{Cvx} / \mathrm{Thr}(70 \mathrm{ng} / \mathrm{mL}, 4 \mathrm{nM})$ in the presence of $2 \mathrm{mM} \mathrm{CaCl}$. (C) Average change in mean fluorescence intensity (MFI), representing cytosolic $\mathrm{Ca}^{2+}$, after 10 min stimulation. n.s., not significant. 
which accelerates the appearance of PSexposing platelets. The high annexin A5binding population was effectively suppressed by chelation of intracellular $\mathrm{Ca}^{2+}$, which is in concordance with TMEM16F being a $\mathrm{Ca}^{2+}$-dependent scramblase..$^{12}$ Interestingly, the onset of the TMEM16F-dependent scrambling process (Figure 2E platelets in the region M3) appears to be delayed compared with the initiation of the TMEM16Findependent scrambling (region M2). Because the apoptotic process compromises $\mathrm{Ca}^{2+}$ homeostasis, ${ }^{23,24}$ it is not unlikely that a certain time span of increased cytosolic $\mathrm{Ca}^{2+}$ concentration is required to activate the TMEM16Fdependent scrambling mechanism. We do not know whether the actual rates of phospholipid scrambling differ between $\mathrm{M} 3$ and M2 platelets. It is tempting to speculate that the scrambling process in the M3 platelets is similar to that of ionomycin-induced scrambling, although it should be noted that apoptosisinduced PS exposure is caspase dependent, whereas ionomycin-induced PS exposure is not. Previously, induction of apoptosis in Scott syndrome lymphoid cells resulted in phospholipid scrambling similar to that in control lymphoid cells. ${ }^{25}$ In that study, the rate of lipid scrambling did not increase when apoptotic control B-lymphocytes were treated with $\mathrm{Ca}^{2+}$ ionophore, suggesting different pathways leading to lipid scrambling rather than the existence of more than one scramblase protein.

Although the role of high cytosolic $\mathrm{Ca}^{2+}$ in agonist-induced PS exposure is well recognized, ${ }^{1}$ it is unclear how $\mathrm{Ca}^{2+}$ affects phospholipid scrambling in apoptotic cells. In this paper, we show an inhibitory effect of chelating extracellular $\mathrm{Ca}^{2+}$ on ABT737-induced PS exposure. The lack of response upon removal of extracellular $\mathrm{Ca}^{2+}$ cannot be explained by decreased activity of the apoptotic machinery itself, as caspase activity is not affected by removal of extracellular $\mathrm{Ca}^{2+}$. Previously, Schoenwaelder et al ${ }^{14}$ have shown that ABT737-induced filamin and gelsolin cleavage was not affected by chelation of extracellular $\mathrm{Ca}^{2+}$. Our data indicate that, while the high PS-exposing platelet fraction M3 is absent upon chelation of intracellular $\mathrm{Ca}^{2+}$, the moderate PSexposing fraction $\mathrm{M} 2$ also has a $\mathrm{Ca}^{2+}$ sensitive component. At present, we cannot distinguish whether this $\mathrm{Ca}^{2+}$ dependency is located at the level of signaling events downstream of caspase activity or at the level of the scramblase activity.

The most pronounced defect in Scott syndrome platelets was found upon activation with convulxin/thrombin; whereas these agonists induced $\sim 40 \%$ PS-positive platelets in healthy control platelets, PS exposure was virtually absent in the patient platelets. However, $\mathrm{Ca}^{2+}$ responses and mitochondrial 
depolarization were not affected in the patient platelets, indicating that the defect is downstream of $\mathrm{Ca}^{2+}$ signaling and MPTP formation. This finding is supported by a report showing that mitochondrial depolarization is normal in a canine model of impaired phospholipid scrambling. ${ }^{26}$ Inhibition of MPTP formation by cyclosporin A almost completely abrogated agonist-induced PS exposure in healthy control platelets (Figure 4A), in line with observations by Jobe et al. ${ }^{9}$ Together, these data suggest that MPTP formation is required but not sufficient for agonist-induced platelet PS exposure via TMEM16F.

PS exposure induced by collagen/thrombin was only partially impaired in Scott syndrome platelets, confirming previous observations. ${ }^{11,27}$ The residual PS exposure typically was insensitive to inhibition by cyclosporin A (MPTP formation) or inhibition of caspases. In platelets from healthy controls, cyclosporin A was unable to completely suppress collagen-/thrombininduced PS exposure. Earlier, Dasgupta and colleagues $^{28}$ reported a partial

A

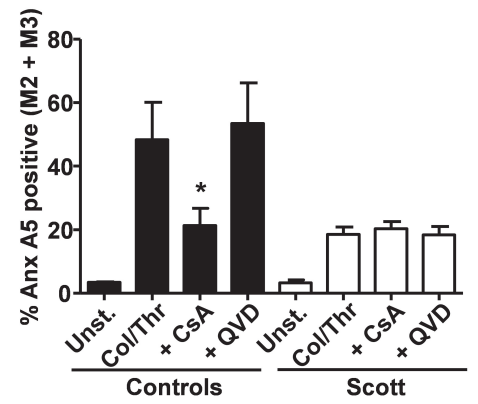

B

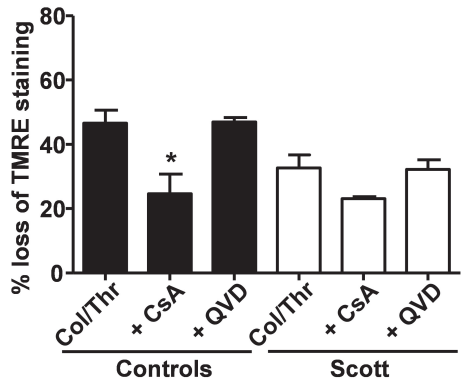

Figure 6. Residual collagen-/thrombin-induced PS exposure in Scott syndrome platelets is insensitive to Q-VDOph or cyclosporin A (CsA). Annexin (Anx) A5 binding (A) and TMRE loss (B) of washed control and Scott syndrome platelets stimulated by collagen (Col)/thrombin (Thr) $(10 \mu \mathrm{g} / \mathrm{mL}, 4 \mathrm{nM})$ for $15 \mathrm{~min}$ in the presence of 2 $\mathrm{mM} \mathrm{CaCl} 2$ preincubated with vehicle (dimethylsulfoxide), Q-VD-Oph $(20 \mu \mathrm{M})$, or CsA $(4 \mu \mathrm{M})$ for $10 \mathrm{~min}$. Mean \pm $\operatorname{SEM}(\mathrm{n}=3-6) ;{ }^{*} P<.05$. 
impairment in collagen-/thrombininduced PS exposure of cyclophilin Ddeficient murine platelets. Taken together, these data suggest that 2 distinct pathways to PS exposure become activated by combined collagen/thrombin stimulation: a pathway sensitive to cyclosporin A inhibition and dependent on TMEM16F, and another pathway, which is cyclosporin A insensitive and operational in the absence of TMEM16F. This may explain the complete deficiency of PS exposure in Scott syndrome platelets activated by convulxin/thrombin, as the latter is more dependent on MPTP formation. ${ }^{9}$ The difference in PS exposure between stimulation with collagen/thrombin and convulxin/thrombin is interesting, because both collagen and convulxin are well-recognized GPVI agonists. ${ }^{21}$ We emphasize, however, that this difference has been repeatedly observed on different occasions. The distinct effects observed with collagen, compared with convulxin, may indicate the involvement of platelet collagen receptors other than GPVI (eg, integrin $\alpha 2 \beta 1$, GPIb via von Willebrand factor) in collagen-/thrombininduced PS exposure. ${ }^{29}$

\section{References}

1. Bevers EM, Williamson PL. Phospholipid scramblase: an update. FEBS Lett. 2010;584:27242730.

2. Fadok VA, Voelker DR, Campbell PA, Cohen JJ, Bratton DL, Henson PM. Exposure of
Acknowledging the inherent limitations of in vitro experimentation, this study demonstrates that TMEM16F-dependent and -independent phospholipid scrambling can be induced in platelets upon apoptosis, aging, and activation. However, it is still unclear whether TMEM16F by itself can act as a phospholipid scramblase or whether this protein has a regulatory function. If TMEM16F proves to be a scramblase itself, this will imply the existence of at least one additional and perhaps more proteins with scramblase activity in platelets. The identification of novel proteins with scramblase activity or the identification of novel regulators of scramblase activity will create new opportunities for interfering with phospholipid scrambling, with consequences for platelet procoagulant activity, life span, and storage.

\section{Funding}

This work was supported by the Cardiovascular Centre, Maastricht, the Center for Translational Molecular Medicine INCOAG, and the Landsteiner Foundation for Blood Transfusion Research (1006).

phosphatidylserine on the surface of apoptotic lymphocytes triggers specific recognition and removal by macrophages. I Immunol. 1992;14:2207-2216. 
3. Heemskerk JW, Bevers EM, Lindhout T. Platelet activation and blood coagulation. Thromb Haemost. 2002;88:186-193.

4. Lentz BR. Exposure of platelet membrane phosphatidylserine regulates blood coagulation. Prog Lipid Res. 2003;42:423-438.

5. Heemskerk JW, Kuijpers MJ, Munnix IC, Siljander PR. Platelet collagen receptors and coagulation. A characteristic platelet response as possible target for antithrombotic treatment. Trends Cardiovasc Med. 2005;15:86-92.

6. Rosing J, van Rijn JL, Bevers EM, van Dieijen G, Comfurius $\mathrm{P}$, Zwaal RF. The role of activated human platelets in prothrombin and factor $\mathrm{X}$ activation. Blood. 1985;65:319-332.

7. Arachiche A, Kerbiriou-Nabias D, Garcin I, Letellier T, Dachary-Prigent J. Rapid procoagulant phosphatidylserine exposure relies on high cytosolic calcium rather than on mitochondrial depolarization. Arterioscler Thromb Vasc Biol. 2009;29:1883-1889.

8. Dale GL, Friese P. Bax activators potentiate coated-platelet formation. J Thromb Haemost. 2006;4:2664-2669.

9. Jobe $S M$, Wilson $K M$, Leo $L$, Raimondi $A$, Molkentin JD, Lentz SR, Di Paola J. Critical role for the mitochondrial permeability transition pore and cyclophilin D in platelet activation and thrombosis. Blood. 2008;111:1257-1265.

10. Zwaal RF, Comfurius P, Bevers EM. Scott syndrome, a bleeding disorder caused by defective scrambling of membrane phospholipids. Biochim Biophys Acta. 2004;1636:119-128.

11. Munnix IC, Harmsma M, Giddings JC, Collins PW, Feijge MA, Comfurius P, Heemskerk JW, Bevers EM. Storemediated calcium entry in the regulation of phosphatidylserine exposure in blood cells from Scott patients. Thromb Haemost 2003;89:687-695.

12. Suzuki J, Umeda M, Sims PJ, Nagata S. Calciumdependent phospholipid scrambling by TMEM16F. Nature. 2010;468:834-838.

13. Castoldi E, Collins PW, Williamson PL, Bevers EM. Compound heterozygosity for 2 novel TMEM16F mutations in a patient with Scott syndrome. Blood. 2011;117:4399-4400.
14. Schoenwaelder SM, Yuan Y, Josefsson EC, White MJ, Yao Y, Mason KD, O'Reilly LA, Henley KJ, Ono A, Hsiao S, Willcox A, Roberts AW, Huang DC, Salem HH, Kile BT, Jackson SP. Two distinct pathways regulate platelet phosphatidylserine exposure and procoagulant function. Blood. 2009;114:663-666.

15. Zhang H, Nimmer PM, Tahir SK, Chen J, Fryer RM, Hahn KR, Iciek LA, Morgan SJ, Nasarre MC, Nelson R, Preusser LC, Reinhart GA, Smith ML, Rosenberg $\mathrm{SH}$, Elmore SW, Tse C. Bcl-2 family proteins are essential for platelet survival. Cell Death Differ. 2007;14:943-951.

16. Kile BT. The role of the intrinsic apoptosis pathway in platelet life and death. J Thromb Haemost. 2009;7 Suppl 12:14-217.

17. Kodama T, Takehara T, Hikita H, Shimizu S, Shigekawa M, Li W, Miyagi T, Hosui A, Tatsumi T, Ishida $\mathrm{H}$, Kanto $\mathrm{T}$, Hiramatsu N, Yin XM, Hayashi N. BH3-only activator proteins Bid and Bim are dispensable for Bak/Bax-dependent thrombocyte apoptosis induced by $\mathrm{Bcl}-\mathrm{xL}$ deficiency: molecular requisites for the mitochondrial pathway to apoptosis in platelets. J Biol Chem. 2011;286:13905-13913.

18. Mason KD, Carpinelli MR, Fletcher JI, Collinge JE, Hilton AA, Ellis S, Kelly PN, Ekert PG, Metcalf D, Roberts AW, Huang DC, Kile BT. Programmed anuclear cell death delimits platelet life span Cell. 2007;128:1173-1186.

19. Schoenwaelder $\mathrm{SM}^{1}$, Jarman $\mathrm{KE}$, Gardiner EE, Hua M, Qiao J, White MJ, Josefsson EC, Alwis I, Ono A, Willcox A, Andrews RK, Mason KD, Salem $\mathrm{HH}$, Huang DC, Kile BT, Roberts AW, Jackson SP. Bcl$\mathrm{xL}$-inhibitory $\mathrm{BH} 3$ mimetics can induce a transient thrombocytopathy that undermines the hemostatic function of platelets. Blood. 2011;118:1663-1674.

20. Vogler M, Hamali HA, Sun XM, Bampton ET, Dinsdale D, Snowden RT, Dyer MJ, Goodall AH, Cohen GM. BCL2/BCL-X(L) inhibition induces apoptosis, disrupts cellular calcium homeostasis, and prevents platelet activation. Blood. 2011;117:7145-7154

21. Siljander P, Farndale RW, Feijge MA, Comfurius $P$, Kos S, Bevers EM, Heemskerk JW. Platelet adhesion enhances the glycoprotein $\mathrm{V}$ 
dependent procoagulant response: Involvement of p38 MAP kinase and calpain. Arterioscler Thromb Vasc Biol. 2001;21:618-627.

22. van der Meijden PE, Feijge MA, Giesen PL, Huijberts $M$, van Raak LP, Heemskerk JW. Platelet $\mathrm{P}_{2} \mathrm{Y}_{12}$ receptors enhance signaling towards procoagulant activity and thrombin generation. A study with healthy subjects and patients at thrombotic risk. Thromb Haemost. 2005;93:1128-1136.

23. Jackson SP, Schoenwaelder SM. Procoagulant platelets: are they necrotic? Blood. 2010;116:2011-2018.

24. Zong WX, Thompson CB. Necrotic death as a cell fate. Genes Dev. 2006;20:1-15.

25. Williamson $P$, Christie A, Kohlin T, Schlegel RA, Comfurius P, Harmsma M, Zwaal RF, Bevers EM. Phospholipid scramblase activation pathways in lymphocytes. Biochemistry. 2001;40:8065-8072.
26. Brooks MB, Catalfamo JL, Friese P, Dale GL. Scott syndrome dogs have impaired coated-platelet formation and calcein-release but normal mitochondrial depolarization. J Thromb Haemost. 2007;5:1972-1974.

27. Rosing J, Bevers EM, Comfurius $P$, Hemker HC, van Dieijen G, Weiss HJ, Zwaal RF. Impaired factor $X$ and prothrombin activation associated with decreased phospholipid exposure in platelets from a patient with a bleeding disorder. Blood. 1985;65:1557-1561.

28. Dasgupta SK, Argaiz ER, Mercado JE, Maul HO, Garza J, Enriquez AB, Abdel-Monem H, Prakasam A, Andreeff M, Thiagarajan P. Platelet senescence and phosphatidylserine exposure. Transfusion. 2010;50:2167-2175.

29. Nieswandt B, Watson SP. Platelet-collagen interaction: is GPVI the central receptor? Blood. 2003;102:449-461. 



\section{Chapter 7}

\section{Survival protein anoctamin-6 controls multiple platelet responses including phospholipid scrambling, swelling and protein cleavage}

Mattheij $\mathrm{NJ}^{1}$, Braun $\mathrm{A}^{2}$, van Kruchten $\mathrm{R}^{1}$, Castoldi $\mathrm{E}^{1}$, Pircher $\mathrm{J}^{3}$, Baaten $\mathrm{CC}^{1}$, Wülling $\mathrm{M}^{4}$, Kuijpers $\mathrm{MJ}^{1}$, Köhler $\mathrm{R}^{5}$, Poole $A \mathrm{~W}^{6}$, Schreiber $\mathrm{R}^{7}$, Vortkamp $\mathrm{A}^{4}$, Collins $\mathrm{PW}^{8}$, Nieswandt $\mathrm{B}^{2}$, Kunzelmann $\mathrm{K}^{7}$, Cosemans $\mathrm{JM}^{1}$, Heemskerk $\mathrm{JW}^{1}$

${ }^{1}$ Department of Biochemistry, Cardiovascular Research Institute Maastricht (CARIM), University of Maastricht, Maastricht, the Netherlands; ${ }^{2}$ Rudolf Virchow

Centre \& DFG Research Centre for Experimental Biomedicine, University of Würzburg, Würzburg, Germany; ${ }^{3}$ Walter Brendel Centre of Experimental Medicine and German Centre of Cardiovascular Research, partner site Munich Heart Alliance, Ludwig-Maximilians-Universität München, Germany; ${ }^{4}$ Department of Developmental Biology, Centre for Medical Biotechnology, University of DuisburgEssen, Germany; ${ }^{5}$ Aragon Institute of Health Sciences I+CS/IIS and ARAID, Zaragoza,

Spain; ${ }^{6}$ School of Physiology and Pharmacology, University of Bristol, Bristol, United Kingdom; 'Institute of Physiology, University of Regensburg, Regensburg, Germany; ${ }^{8}$ Arthur Bloom Haemophilia Centre, School of Medicine, Cardiff University, Cardiff, United Kingdom

FASEB J: In press 


\begin{abstract}
Purpose: The Scott syndrome is a rare bleeding disorder, characterized by altered $\mathrm{Ca}^{2+}$-dependent platelet signaling with defective phosphatidylserine (PS) exposure and microparticle formation, and is linked to mutations in the ANO6 gene, encoding anoctamin-6 (Ano6). We investigated how the complex platelet phenotype of this syndrome is linked to defective expression of anoctamins or other ion channels. Procedures: Mice were generated with heterozygous of homozygous deficiency in Ano6, Ano1 or $\mathrm{Ca}^{2+}$-dependent $\mathrm{K}_{\mathrm{Ca}} 3.1$ Gardos channel. Platelets from these mice were extensively analyzed on molecular functions, and compared to platelets from a Scott patient. Findings: Deficiency in Ano1 or Gardos channel did not reduce platelet responses compared to control mice ( $P>0.1)$. In two mouse strains, deficiency in Ano6 resulted in reduced viability with increased bleeding time to 28.6 minutes (control 6.4 minutes, $P<0.05)$. Platelets from the surviving Ano6-deficient mice resembled Scott patient platelets in: (i) normal collagen-induced aggregate formation $(P>0.05)$ with reduced PS exposure (-65 to 90\%); (ii) lowered $\mathrm{Ca}^{2+}$-dependent swelling (-80\%) and membrane blebbing (-90\%); (iii) reduced calpain-dependent protein cleavage $(-60 \%)$; and (iv) moderately affected apoptosis-dependent PS exposure. Conclusions: Mouse deficiency of Ano6 but not of other channels, affects viability and phenocopies the complex changes in platelets from hemostatically impaired Scott patients.
\end{abstract}

\section{Introduction}

The uncommon Scott syndrome is characterized as a mild bleeding disorder associated with a low prothrombin consumption in blood serum. Platelets from Scott patients show a defect in $\mathrm{Ca}^{2+}$-induced phosphatidylserine exposure and microparticle formation, but unchanged $\mathrm{Ca}^{2+}$ signaling and aggregation..$^{1-4}$ For long it has been recognized that the defective PS exposure in blood cells from Scott patients results from impaired phospholipid scrambling, a process that normally abolishes the asymmetric distribution of PS and phosphatidylethanolamine over the plasma membrane upon persistent elevation of cytosolic $\mathrm{Ca}^{2+} .5-7$ Consequence of the defective PS exposure is a markedly impaired procoagulant activity of platelets, which agrees with the bleeding phenotype. ${ }^{8}$ On the other hand, it is described that PS exposure induced by apoptosis ${ }^{9}$ is no more than little affected in the blood cells from Scott patients. ${ }^{10,11}$

Recently, in two unrelated Scott syndrome patients, dysfunctional mutations have been identified in the ANO6 gene (alternatively named TMEM16F), which codes for the integral 
membrane protein anoctamin 6 induced phospholipid scrambling. In (Ano6). ${ }^{12,13}$ In a murine B-cell line model, the silencing of Ano6 resulted in an impairment of $\mathrm{Ca}^{2+}$-dependent PS exposure. ${ }^{12} \mathrm{~A}$ role of anoctamins as transporters for the negatively charged PS was also confirmed by structural analysis. ${ }^{14}$ In addition, there is substantial electrophysiological evidence that Ano6, like other members of the anoctamin family, can operate as a $\mathrm{Ca}^{2+}$ induced ion channel that is permeable to chloride ions, monovalent cations and calcium ions. ${ }^{10,15-17}$ We and others have reported that in blood cells from Scott patients ${ }^{10}$ and Ano6-deficient mice ${ }^{17}$ this ion conductance is markedly reduced. Hence, the question arises which other (patho)physiological relevant functions are regulated by Ano6 than only $\mathrm{Ca}^{2+}$ dependent phospholipid scrambling. Several observations in the literature are compatible with a broader role of Ano6. For instance, platelets from Scott syndrome patients show reduced $\mathrm{Ca}^{2+}$ dependent microvesiculation, ${ }^{1,3}$ impaired inactivation of the integrin $\alpha_{11 b} \beta_{3},{ }^{18}$ and defective aging-dependent PS exposure. ${ }^{19}$

On the other hand, Scott platelets are not completely devoid of PS exposure and procoagulant activity, when stimulated with $\mathrm{Ca}^{2+}$-mobilizing agonists such as thrombin plus collagen. ${ }^{6,11}$ This suggests involvement of other proteins beside Ano6 in the regulation of $\mathrm{Ca}^{2+}$ platelets as well as erythrocytes, a role in PS exposure of has been proposed for volume-sensitive $\mathrm{Cl}^{-}$channels; ${ }^{20}$ and for intermediate conductance $\mathrm{Ca}^{2+}$-activated $\mathrm{K}^{+}$channels, known as $\mathrm{K}_{\mathrm{Ca}} 3.1$ or Gardos channels. ${ }^{21,22}$

Furthermore, overexpression studies suggest that also other members of the anoctamin family can contribute to PS exposure. ${ }^{23}$ In particular the isoform Ano1 is of interest, since in erythrocytes it regulates $\alpha$ hemolysin-induced phospholipid scrambling. ${ }^{24}$ Hence, the question can be raised if a gene defect in ANO6 alone is sufficient for the altered blood cell properties in the Scott syndrome.

In the present paper, we used several molecular and functional approaches to unravel the apparently multiple and nonredundant functions of Ano6 in platelets and erythrocytes. We compared the alterations in platelet properties of a Scott patient in comparison to platelets from healthy control subjects; and furthermore compared the platelet properties of several new strains of Ano6-deficient mice, as well as from mice lacking Ano1 or Gardos channels. Our data point to a remarkable set of phenotypic changes linked to defective Ano6 expression in both man and mouse, including low residual $\mathrm{Ca}^{2+}$-dependent PS exposure, absence of swelling morphological changes, presence of 
alternative Ano6 splice variants, and a moderate bleeding tendency.

\section{Methods}

\section{Materials}

ABT-737 was obtained from Santa Cruz Biotechnology, annexin A5 labeled with fluorescein isothiocyanate (FITC) was from PharmaTarget; Alexa Fluor-647 (AF647)-labeled annexin A5 and ionomycin were purchased from Invitrogen. The glycoprotein VI agonist convulxin was purified, as described (25). FITC-labeled anti-mouse CD62P (Pselectin) monoclonal antibody (mAb) as well as phycoerythrin (PE)-conjugated JON/A mAb directed against the active conformation of mouse integrin $\alpha_{11 b} \beta_{3}$ were from Emfret Analytics. Human $\alpha$ thrombin was from Sigma-Aldrich. Affinity-purified polyclonal rabbit antibodies directed against human and mouse Ano1 (DOG-1) and Ano6 (G-14 against extracellular domain) were from Santa Cruz, anti- $\alpha$-tubulin mAb came from Abcam. Rabbit antibody directed against mouse $\mathrm{K}_{\mathrm{Ca}} 3.1$ was obtained as described. ${ }^{26}$ Sources of other materials were as reported before. ${ }^{18}$

A
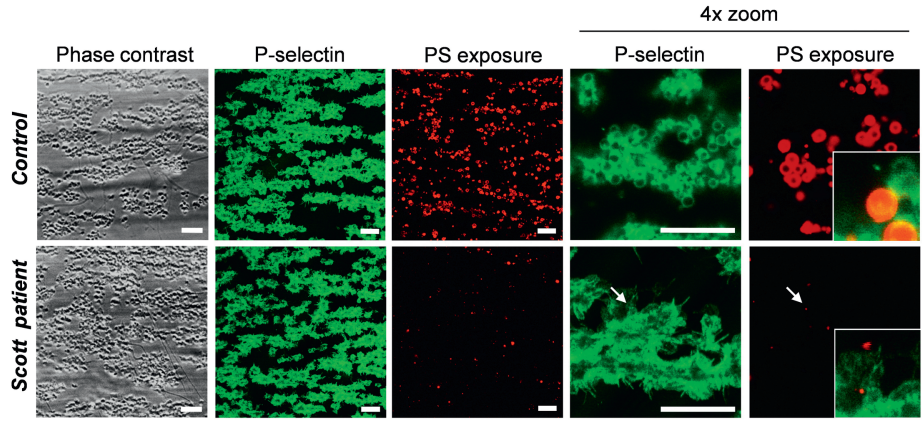

B

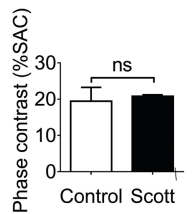

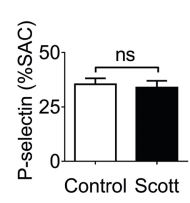
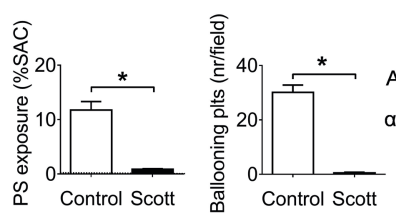

C

Figure 1. Normal thrombus formation with residual PS exposure and abolished ballooning in Scott syndrome. Blood from healthy control subjects or a Scott patient was perfused over a collagen surface for 4 min at $1000 \mathrm{~s}^{-1}$. Formed thrombi were stained with FITC- $\alpha$ CD62P (P-selectin) mAb and AF647-annexin A5 (PS exposure). A) Representative phase-contrast and fluorescence images (bars $25 \mu \mathrm{m}$ ), zoomed in as indicated (inserts $25 \times 25$ $\mu \mathrm{m})$. Arrow indicates non-ballooning platelet with small patches of PS exposure. B) Surface-area-coverage (SAC\%) of aggregated platelets, P-selectin expression, PS exposure and ballooning. For PS exposure, dotted line indicates background fluorescence (no platelet thrombi). C) Western blots of control and Scott platelet lysates, stained for Ano6, and reprobed with anti- $\alpha$-tubulin mAb as lane loading control. Means $\pm \mathrm{SE}(n=3), * P<0.05$ ( 2 -way ANOVA). 
Blood donors

Blood was obtained from healthy volunteers and an accessible patient with Scott syndrome, after full informed consent (Helsinki declaration), under protocols reviewed by the local ethics committees. The Scott patient has been genotyped as compound heterozygous for two different mutations in the ANO6 gene (alias TMEM16F), with one splicing mutation (IVS6 $+1 \mathrm{G} \rightarrow \mathrm{A}$ ) causing exon 6 skipping, and another mutation in exon 11 (c.1219insT) leading to a premature stop of translation. ${ }^{13}$ An analysis of splice variants is described in the Supplemental Materials.

\section{Animals}

Mouse experiments were approved by the local animal care and use committees. Experiments were performed using genetically modified and corresponding wild-type animals from the same breeding, simultaneously at the same location. Mice with a homozygous deficiency of the Gardos channel $\mathrm{K}_{\mathrm{Ca}} 3.1\left(\mathrm{KCnn}^{-/}\right)$and wild-type littermates $\left(\mathrm{KCnn}^{+/+}\right)$had a mixed 129Sv/C57BL/6 background, and were generated and genotyped, as described. ${ }^{27}$ Homozygous Kcnn4\% mice suffer from hypertension, but survive normally. ${ }^{27,28}$ Mice with megakaryocytes and platelets homozygously deficient in anoctamin 1 (Ano1 gene, alias Tmem16a) were generated by crossing Ano $1^{\mathrm{fl} / \mathrm{fl}}$ mice with transgenic mice expressing a Crerecombinase after the PF4 promoter (C57BL/6 background). The mice were genotyped using the following nucleotide primers: wild-type Ano1 $^{+/+}$(229 bp, 2165 bp in flox) GCAGAAAAGT GCCAGAGACC (forward), TTTCCAATGG CCTAGACCTG (reverse); for $A n o 1^{-1}$ (462 bp in flox) ATAGCAGCTT TGCTCCTTCG (forward), CTCGTCCTGC AGTTCATTCA (reverse).

In two laboratories (Würzburg, Regensburg), the AW-382 embryonic stem (ES) cell clone Ano6 ${ }^{\mathrm{gt}(\mathrm{AW} 0382)}$ (Ano6 $^{\text {AW }}$, Wellcome Trust Sanger Institute, MGI: 3857206, stock number 020701-UCD) was used to generate mice with genetic deficiency of Ano6 (alias Tmem16f). The ES cell clone contains a $\beta$ geo reporter gene trap in intron 3 of Ano6 which disturbs mRNA transcription and synthesis of the protein. Male chimeras derived from the embryonic stem cell line were bred with C57BL/6 females to generate heterozygous $A n o 6^{A W+/-}$ mice. The latter were crossbred at C57BL/ 6 background to obtain homozygous deficient mice. Presence of the gene trap cassette was detected by PCR using the following primers: TTATCGATGA GCGTGGTGGT TATGC (forward); GCGCGTACAT CGGGCAAATA ATATC (reverse).

In addition, mice from the Ano6 $6^{\text {tm1Avor }}$ (Ano6 ${ }^{\text {Avor }}$ ) strain were used, generated as described. ${ }^{29}$ To reduce postnatal lethality of homozygous mutants, Ano6 ${ }^{\text {Avort/- }}$ mice 
were crossed on a C57B6L background to obtain Ano6 Avor-l animals. Mice were genotyped for heterozygous or homozygous deficiency in Ano6 expression by PCR. ${ }^{29}$ Per strain, wildtypes were used from the same breeding. Analysis of murine Ano6 splice variants is described in the Supplemental Materials.

\section{Embryonic development}

Inbred, pregnant female $\mathrm{Ano6}^{+/-}$mice were sacrificed at gestational days 10.5 , 12.5 or 16.5 . Viable embryos and death bodies were counted, and embryos were checked for macroscopic abnormalities.

Blood collection and isolation of platelets and erythrocytes

Human blood was collected into PPACK/fragmin for flow perfusion studies, as described before. ${ }^{30}$ Other samples were collected into trisodium citrate for preparation of $\mathrm{PRP}^{31}$ or into acid-citratedextrose anticoagulant for preparation of isolated platelets. ${ }^{18}$ Washed cells were suspended into HEPES buffer pH 7.45 (10 mM HEPES, $136 \mathrm{mM} \mathrm{NaCl}, 2.7 \mathrm{mM} \mathrm{KCl}, 2$ $\mathrm{mM} \mathrm{MgCl}, 5 \mathrm{mM}$ glucose and $0.1 \%$ bovine serum albumin); $2 \mathrm{mM} \mathrm{CaCl}_{2}$ was added directly before the experiments. Cell concentrations were determined with a Beckman Coulter counter.

Blood was obtained from adult mice via orbital puncture under anesthesia, according to the local ethical permissions. Mouse blood was collected into
PPACK/heparin/fragmin for flow perfusion studies, as described before. ${ }^{32}$ Blood was also collected into trisodium citrate for preparation of PRP. ${ }^{18}$ For platelet isolation, mouse blood was taken into $1 / 6$ volume of acid-citratedextrose anticoagulant (ACD: $85 \mathrm{mM}$ sodium citrate, $78 \mathrm{mM}$ citric acid, and 11 $\mathrm{mM}$ D-glucose). Platelets ${ }^{18}$ and erythrocytes $^{22}$ were separated by centrifugation, washed, and suspended in modified HEPES buffer pH 7.45 (5 mM HEPES, $136 \mathrm{mM} \mathrm{NaCl}, 2.7 \mathrm{mM} \mathrm{KCl}, 2 \mathrm{mM}$ $\mathrm{MgCl}_{2}, 0.42 \mathrm{mM} \mathrm{Na}_{2} \mathrm{HPO}_{4}, 5 \mathrm{mM}$ glucose, and $0.1 \%$ bovine serum albumin); $2 \mathrm{mM}$ $\mathrm{CaCl}_{2}$ was added directly before the experiments. Cell concentrations were determined with a Coulter counter.

\section{Flow cytometric analyses}

Suspensions of washed human platelets were activated, as described. ${ }^{11}$ Washed mouse platelets in suspension ( $1 \times 10^{11} /$ l)

\begin{tabular}{|c|c|c|c|c|}
\hline & Ano1 $^{+/+}$ & Ano1 $\%$ & $\mathrm{Ano6}^{+/+}$(AW) & Ano6 $^{+l-}(\mathrm{AW})$ \\
\hline Count $\left(10^{6} / \mu \mathrm{L}\right)$ & n.d. & n.d. & $582 \pm 51$ & $590 \pm 21$ \\
\hline Size $(A U)$ & n.d. & n.d. & $324 \pm 14$ & $326 \pm 12$ \\
\hline GPIb & $319 \pm 4$ & $327 \pm 14$ & $343 \pm 9$ & $344 \pm 10$ \\
\hline GPV & $279 \pm 7$ & $257 \pm 2$ & $245 \pm 5$ & $251 \pm 3$ \\
\hline GPVI & $54 \pm 4$ & $47 \pm 5$ & $37 \pm 0.7$ & $37 \pm 1$ \\
\hline GPIX & $370 \pm 10$ & $351 \pm 4$ & $351 \pm 5$ & $360 \pm 6$ \\
\hline$\alpha_{110} \beta_{3}$ & $487 \pm 17$ & $504 \pm 12^{*}$ & $391 \pm 20$ & $401 \pm 11$ \\
\hline$\alpha_{2}$ & $44 \pm 2$ & $42 \pm 3$ & $42 \pm 1$ & $42 \pm 1$ \\
\hline CD9 & $1155 \pm 27$ & $1116 \pm 18$ & $1114 \pm 9$ & $1144 \pm 18$ \\
\hline$\beta_{1}$ & $134 \pm 4$ & $133 \pm 7$ & $113 \pm 4$ & $119 \pm 3$ \\
\hline CLEC2 & $111 \pm 6$ & $119 \pm 9$ & $100 \pm 3$ & $107 \pm 9$ \\
\hline
\end{tabular}

Suppl. Table S1. Surface expression of glycoproteins on mouse platelets with homo- or heterozygous deficiency in Ano1 or Ano6. Data are from mouse strain $A n o 6^{A W}$ and corresponding wild-types. Shown are mean fluorescence intensities, unless indicated otherwise. Means \pm SE $(n=4)$. 
A

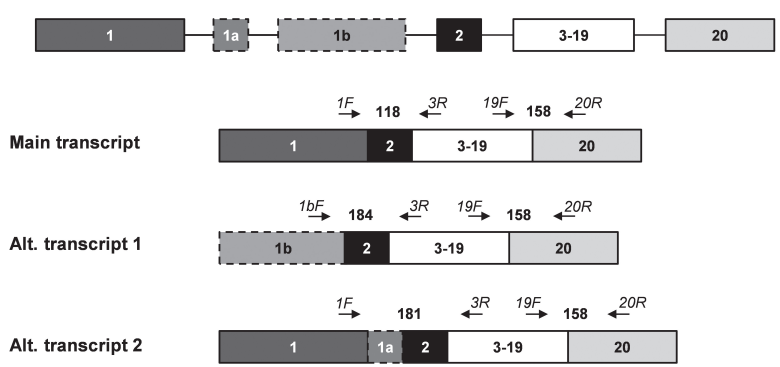

B
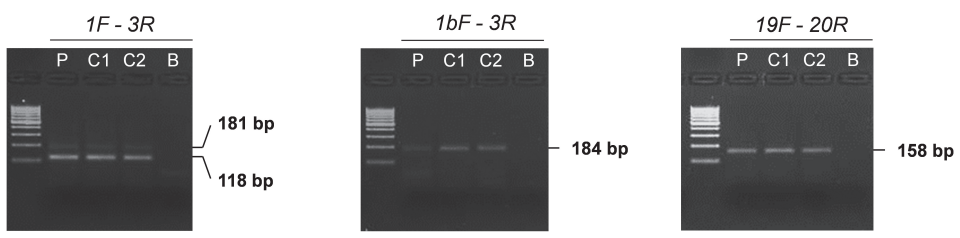

Supplement Figure S1. Screening for alternative transcripts in the Scott patient. Blood (2.5 ml) was collected from the Scott patient and two normal controls. Total blood cell RNA was isolated using Trizol Reagent and quantified spectrophotometrically. Alternatively spliced ANO6 transcripts were amplified using transcript-specific primers based on the transcript information available from www.ensembl.org. A) Schematic representation of the human ANO6 pre-mRNA and mature mRNAs, including alternative transcript 1 (ENST00000441606) and alternative transcript 2 (ENST00000423947). Main transcript corresponds to (ENST00000320560). In alternative transcript 1 , exon 1 is replaced by exon 1 b (light grey), which contains a viable start codon for initiation of translation. Alternative transcript 2 contains an extra exon 1a (dark grey) between exons 1 and 2. Note that the reading frame from exon 2 onwards is the same as in the main transcript. $B$ ) Amplification of different portions of the Ano6 cDNA in the Scott patient (lanes P), in the two normal control subjects (lanes C1-C2), and in a blank sample (lane B).

were stimulated in the presence of $2 \mathrm{mM}$ $\mathrm{CaCl}_{2}$ with indicated agonists or vehicle at room temperature. Platelet samples were analyzed for PS after $30 \mathrm{~min}$ of activation and labeling with AF647annexin A5 (1:200). ${ }^{18}$ Other labels used were FITC-anti-P-selectin mAb (1:10) to detect $\mathrm{P}$-selectin expression and PEJON/A mAb (1:10) to detect integrin $\alpha_{\| 1} \beta_{3}$ activation. For apoptosis induction, platelets were stimulated with the $\mathrm{BH} 3$ mimetic ABT-737 (1 $\mu \mathrm{M})$ for $1 \mathrm{~h}$ at $37^{\circ} \mathrm{C} .{ }^{18}$ Washed mouse erythrocytes ( $1 \mathrm{x}$ $10^{11} /$ l) were activated with ionomycin in the presence of $1 \mathrm{mM} \mathrm{CaCl} 2$ at $37{ }^{\circ} \mathrm{C}$. Samples were analyzed with a BD Facs Calibur or BD Accuri C6 flow cytometer. Glycoprotein expression levels on platelets were determined by flow cytometry as described elsewhere. ${ }^{33}$ Data analysis was performed using the programs WinMDI or CFlow Plus.

\section{Light transmission measurements}

Changes in light transmission were monitored in suspensions of washed platelets $\left(1 \times 10^{11} / \mathrm{I}\right)$, activated with agonists in the presence of $\mathrm{CaCl}_{2}(2 \mathrm{mM})$ 
under constant stirring at $37^{\circ} \mathrm{C}$, using a Chronolog aggregometer. Tirofiban (5 $\mu \mathrm{g} / \mathrm{ml}$ ) was present if indicated. Hypotonic shock response ${ }^{34}$ was induced by adding $125 \mu \mathrm{l}$ of distilled water with(out) $\mathrm{CaCl}_{2}$ (4 mM) and/or ionomycin $(10 \mu \mathrm{M})$ to $250 \mu \mathrm{l}$ PRP. Transmission changes were recorded with a Chronolog aggregometer under stirring at $37^{\circ} \mathrm{C}$.

A
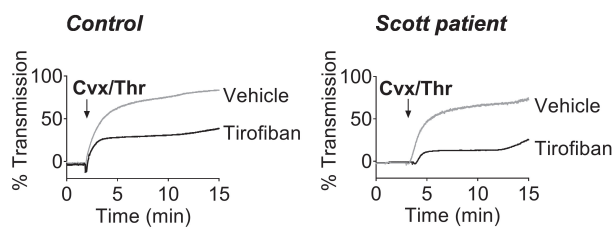

ํ.
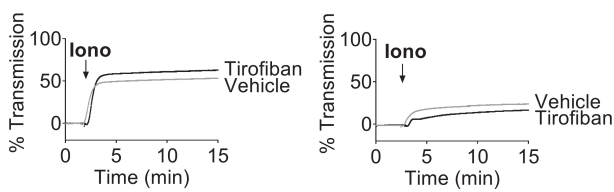

B
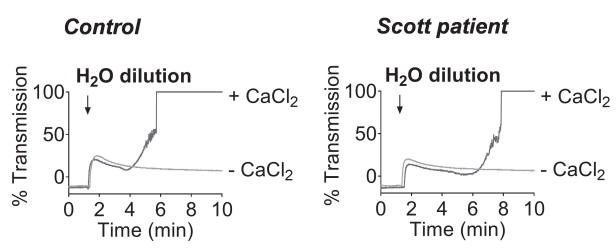

Whole blood thrombus formation

Collagen-induced thrombus formation was assayed using PPACK/fragminanticoagulated human ${ }^{35}$ or mouse ${ }^{36}$ blood, basically as described. In brief, blood samples were flowed over a coverslip coated with collagen type-I in a transparent parallel-plate perfusion chamber, at a shear rate of $1000 \mathrm{~s}^{-1}$ for 4

C
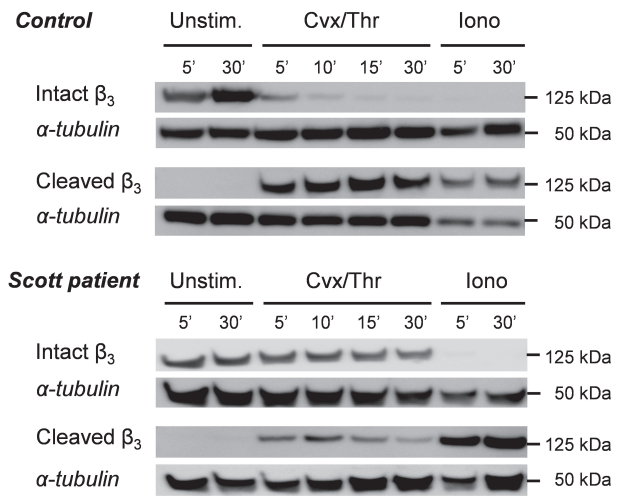

D

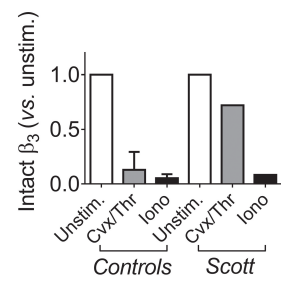

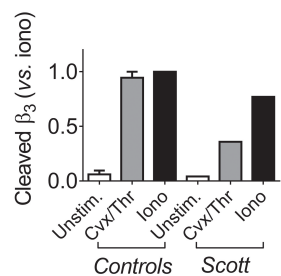

Figure 2. Integrin $\alpha_{11 b} \beta_{3}$-independent turbidity changes and reduced integrin cleavage by Scott syndrome platelets. A) Suspensions of washed platelets from control subjects or Scott patient in $\mathrm{CaCl}_{2}$-containing medium were stimulated with convulxin $(\mathrm{Cvx}, 100 \mathrm{ng} / \mathrm{ml})$ plus thrombin $(\mathrm{Thr}, 4 \mathrm{nM})$ or with ionomycin (lono, $10 \mu \mathrm{M})$ in the presence or absence of tirofiban $(2 \mu \mathrm{g} / \mathrm{ml})$. Shown are representative changes in light transmission $(n=3)$. B) Hypotonic shock response of PRP induced by dilution (33\%) in the presence or absence of $\mathrm{CaCl}_{2}(4 \mathrm{mM})$. Shown are representative traces of changes in light transmission. C) Western blots probed for the intact and cleaved $\beta_{3}$ chain (detected with Ab762 and Ab754, respectively) of platelets stimulated with Cvx/Thr or lono in the presence of $\mathrm{CaCl}_{2}$. Blots (representative for 3 performed) were reprobed with anti- $\alpha$-tubulin $\mathrm{mAb}$ as lane loading control. $D$ ) Quantification of $\beta_{3}$ chain cleavage ( $5 \mathrm{~min}$ ) from densitometric profiles. Means $\pm \operatorname{SE}(n=4$ controls). 


\begin{tabular}{|c|c|c|c|c|c|c|c|}
\hline & Ano1 $^{+/+}$ & Ano1 ${ }^{\prime-}$ & $\operatorname{Ano6}^{+/+}(\mathrm{AW})$ & Ano6 $^{+/-}(\mathrm{AW})$ & Ano6 $^{+/+}$(PAC) & Ano6 $^{+/-}(\mathrm{PAC})$ & Ano6 $^{-1}$ (PAC) \\
\hline \multicolumn{8}{|l|}{ Integrin activat. (\%) } \\
\hline ADP & n.d. & n.d. & $42 \pm 10$ & $26 \pm 5$ & $45 \pm 7$ & $44 \pm 10$ & $50 \pm 9$ \\
\hline Thr & $80 \pm 10$ & $81 \pm 9$ & $78 \pm 3$ & $69 \pm 5$ & $86 \pm 5$ & $73 \pm 14$ & $80 \pm 5$ \\
\hline Cvx/Thr & $76 \pm 11$ & $73 \pm 15$ & $72 \pm 5$ & $66 \pm 5$ & $55 \pm 10$ & $56 \pm 11$ & $59 \pm 1$ \\
\hline Ionomycin & n.d. & n.d. & $7 \pm 2$ & $3 \pm 1$ & $6 \pm 2$ & $6 \pm 4$ & $4 \pm 2$ \\
\hline \multicolumn{8}{|l|}{ P-selectin expr. (\%) } \\
\hline ADP & n.d. & n.d. & $10 \pm 3$ & $9 \pm 2$ & $14 \pm 6$ & $3 \pm 0.6$ & $2 \pm 1$ \\
\hline Thr & $84 \pm 7$ & $81 \pm 9$ & $85 \pm 4$ & $88 \pm 3$ & $76 \pm 9$ & $86 \pm 8$ & $60 \pm 11$ \\
\hline Cvx/Thr & $82 \pm 7$ & $82 \pm 8$ & $86 \pm 3$ & $85 \pm 4$ & $90 \pm 5$ & $83 \pm 8$ & $84 \pm 3$ \\
\hline Ionomycin & $64 \pm 6$ & $61 \pm 7$ & $67 \pm 4$ & $57 \pm 4$ & $70 \pm 3$ & $71 \pm 6$ & $60 \pm 2$ \\
\hline \multicolumn{8}{|l|}{ PS exposure (\%) } \\
\hline ADP & n.d. & n.d. & $0.7 \pm 0.1$ & $1 \pm 0.3$ & $1 \pm 0.2$ & $2 \pm 1$ & $1 \pm 0.4$ \\
\hline Thr & $18 \pm 3$ & $15 \pm 1$ & $15 \pm 2$ & $15 \pm 6$ & $17 \pm 3$ & $11 \pm 4$ & $7 \pm 3^{*}$ \\
\hline Cvx/Thr & $53 \pm 5$ & $55 \pm 3$ & $76 \pm 12$ & $63 \pm 5$ & $72 \pm 5$ & $64 \pm 5$ & $15 \pm 2^{*}$ \\
\hline Ionomycin & $58 \pm 10$ & $42 \pm 9$ & $87 \pm 6$ & $92 \pm 2$ & $85 \pm 2$ & $88 \pm 4$ & $5 \pm 1^{*}$ \\
\hline
\end{tabular}

Suppl. Table S2. Activation properties of mouse platelets homo- or heterozygously deficient in Ano1 or Ano6. Washed platelets from indicated mice were stimulated with ADP (10 $\mu \mathrm{M})$, thrombin (Thr $4 \mathrm{nM})$, convulxin/thrombin ( $\mathrm{Cvx} 100 \mathrm{ng} / \mathrm{ml}$, Thr $4 \mathrm{nM}$ ) or ionomycin (iono $10 \mu \mathrm{M}$ ) plus $2 \mathrm{mM} \mathrm{CaCl}$, as indicated. Fractions of platelets binding PE-JON/A mAb (integrin activation), FITC- $\alpha$ CD62P mAb (P-selectin) or AF647annexin A5 (PS exposure) were assessed after $15 \mathrm{~min}$. Data are from mouse strains Ano6 ${ }^{A W}$ and $A n o 6^{A v o r}$ and corresponding wild-types. Means $\pm \mathrm{SE}(n=4-6){ }^{*} P<0.05$ compared to corresponding wild-type.

min. Thrombi formed on the collagen surface were post-stained with AF647annexin A5, FITC-anti-CD62P mAb and $\mathrm{PE}-J O N / \mathrm{A}$ mAb in (modified) HEPES buffer $\mathrm{pH} 7.45$ supplemented with $\mathrm{CaCl}_{2}$ (2 $\mathrm{mM})$ and heparin $(1 \mathrm{U} / \mathrm{ml})$. Phasecontrast and fluorescence images were captured for analysis of surface area coverage of adherent platelets, and of platelets with active integrins, P-selectin exposure or PS exposure. ${ }^{30}$ Image analysis was performed using Metamorph software Version 7.5.0.0 (MDS Analytical Technologies). ${ }^{37}$

\section{Western blot analyses}

Washed platelet or erythrocyte suspensions were lysed with ice-cold $4 x$ lysis buffer (600 mM NaCl, $10 \mathrm{mM}$ Tris, 4 mM EGTA, 4 mM EDTA, 4\% NP40). Samples $\left(5 \times 10^{7}\right.$ human platelets, $1 \times 10^{8}$ mouse platelets) were separated on $8 \%$ SDS-PAGE gels, transferred to blotting membranes by semi-dry transfer. $^{18}$ Membranes were immunostained with antibodies against $\mathrm{K}_{\mathrm{Ca}} 3.1$, Ano1, Ano6 (all 1:1000) or integrin $\beta_{3}$ (Ab762, 1:10000; Ab754, 1:1000), and later reprobed with $\alpha$-tubulin (1:1000). Incubation with secondary horseradish peroxidasecoupled antibody was overnight at $4{ }^{\circ} \mathrm{C}$, and visualization with an $\mathrm{ECL}$ system. Quantification was performed by densitometric analysis of stained blots, as described. ${ }^{18}$ 
Statistics

Intervention effects were statistically compared with a paired sample $t$ test, using the statistical package for social sciences (SPSS, version 11.0). Groups were compared by 2-way ANOVA (Bonferroni correction, if required).

\section{Results}

Residual PS exposure and abolished swelling of Scott platelets during thrombus formation

Platelet aggregation and PS exposure (procoagulant activity) in response to the main collagen receptor, glycoprotein VI (GPVI), can simultaneously be quantified in thrombi formed during whole-blood perfusion over a collagen surface. ${ }^{35,38}$ In flow studies with blood from a Scott patient, ${ }^{19}$ we established that platelet adhesion, aggregate formation and $\alpha$ granule secretion (expression of $\mathrm{P}$ selectin) were similar to the platelet responses of healthy control subjects (Fig. $1 A-B)$. In contrast, collagen-induced PS exposure was greatly reduced, but not completely abolished with the patient blood. Interestingly, the residual PS exposure appeared as patches on platelets with a normal, non-swollen shape (Fig. 1A, inserts). This contrasted to the large, ballooning morphology (diameter $\sim 10 \mu \mathrm{m}$ ) of platelets from control subjects with high PS exposure. Quantification of the recorded microscopic images indicated that essentially no ballooning platelets were formed with Scott blood (Fig. 1A, right panel). Hence, the major defect of GPVIdependent PS exposure in Scott platelets is accompanied by absence of platelet ballooning.

Identification of human ANO6 splice variants

An explanation for the low PS exposure in patient's platelets may be residual expression of the ANO6 gene. However, no Ano6 protein could be detected on western blots from Scott platelets (Fig. $1 C)$. This was confirmed by quantitative proteomic analysis, ${ }^{39}$ showing a $>160$ fold reduction of identified Ano6 peptides in the Scott platelets (F. Solari, N. Mattheij, R Zahedi, unpublished data, 2015). On the other hand, in line with a previous report, ${ }^{13}$ Ano6 mRNA was readily detectable in the patient's blood cells. RT-PCR analysis indicated expression of the default transcript as well as two alternatively spliced transcripts 1 and 2 (Supplemental Fig. S1). Due to the nature of the two mutations in the patient's cells (a splicing mutation in intron 6 and a frameshift mutation in exon 11), it is unlikely that these alternative transcripts are translated into a functional Ano6 protein, except for some residual correctly spliced premRNA transcribed from the IVS6+1G>A allele. 
A

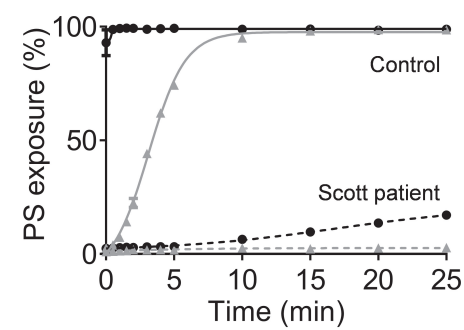

B

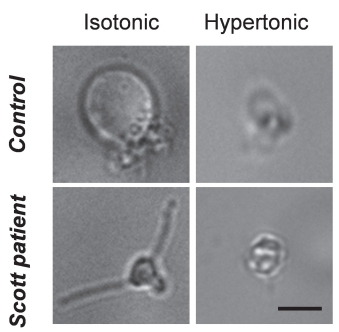

Supplement Figure S2. Hypertonic media induced delayed PS exposure and absence of ballooning structures. A) Control and Scott platelets were activated by ionomycin $(10 \mu \mathrm{M})$ for indicated time-points in isotonic (black lines) or hypertonic (grey lines) HEPES buffer and labeled with FITC-annexin A5. Means \pm SE $(n=4)$ B) Representative phase contrast images of platelets form control and Scott platelets stimulated by ionomycin for $15 \mathrm{~min}$ in isotonic or hypertonic HEPES buffer (bars $=5 \mu \mathrm{m}$ ).

Reduced aggregation-independent lighttransmission changes and integrin inactivation of Scott platelets

In platelets from control subjects, stimulation with convulxin/thrombin (stimulating GPVI and thrombin receptors) or ionomycin ( $\mathrm{Ca}^{2+}$ ionophore, conditions as in Fig. $2 A$ ) resulted in $51 \pm 3 \%$ and $85 \pm 11 \%$ of PS-exposing platelets, respectively (means $\pm \mathrm{SE}, n=8$ ). These values were not influenced by the integrin $\alpha_{\| 1} \beta_{3}$ inhibitor, tirofiban $(P>0.30)$. In Scott platelets, the same agonists evoked severely reduced but residual PS exposure of $1.7 \pm 0.5 \%$ and $2.0 \pm 0.6 \%$ platelets $(n=3)$. Light transmission recording with control platelets indicated that convulxin/thrombin and ionomycin provoked rapid clearance of the cell suspensions, which effect was only partly reduced by tirofiban, inhibiting platelet aggregation (Fig. $2 A$, left panels). In line with earlier data, ${ }^{18}$ this suggested that the residual increase in light transmission was due to shape change from discoid platelets to translucent, ballooned structures. Such ballooned platelets could indeed be observed by microscopy (Suppl. Fig S2). In contrast, Scott platelets showed only limited changes in light transmission after stimulation in the presence of tirofiban (Fig. 2A, right panels). In this case, no ballooned structures were seen (Suppl. Fig. S2). Light transmission changes due to platelet swelling can also be assessed in the hypotonic shock response, which measures the reaction of platelets in plasma to dilution with water. ${ }^{34}$ Waterinduced light transmission changes were comparable for control and Scott platelets, even in the presence of $\mathrm{CaCl}_{2}$ to stimulate $\mathrm{Ca}^{2+}$-dependent ion fluxes (Fig. 2B). With $\mathrm{CaCl}_{2}$ present, the late increase in light transmission accompanying balloon formation however was markedly delayed with Scott platelets. To determine a role of 
ion influxes, platelets were then cleavage of the integrin $\beta_{3}$-chain, which stimulated with ionomycin in hypertonic results in inactivation of $\alpha_{11 b} \beta_{3} .{ }^{18}$ Similarly, medium. Hypertonia resulted in delayed in Scott platelets stimulation with PS exposure and residual ballooning in ionomycin resulted in rapid $\beta_{3}$-chain control platelets, but failed to induce PS exposure or ballooning in Scott platelets (Suppl. Fig. S2).

In control cells, $\mathrm{Ca}^{2+}$-induced PS exposure is accompanied by calpain-mediated cleavage which was complete within 5 $\min$ (Fig. 2C-D).

However, stimulation with convulxin/thrombin led to a markedly delayed cleavage in the patient's

A

B

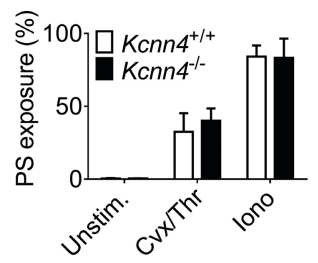

C
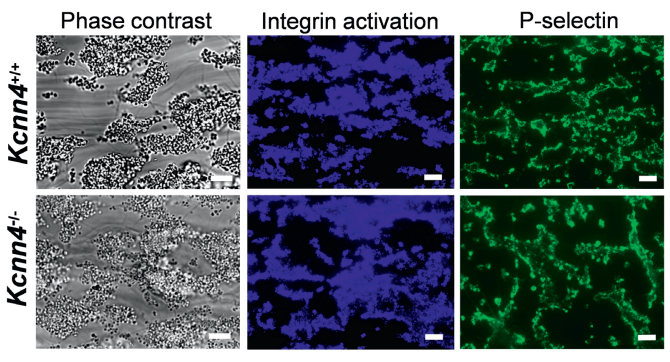

PS exposure
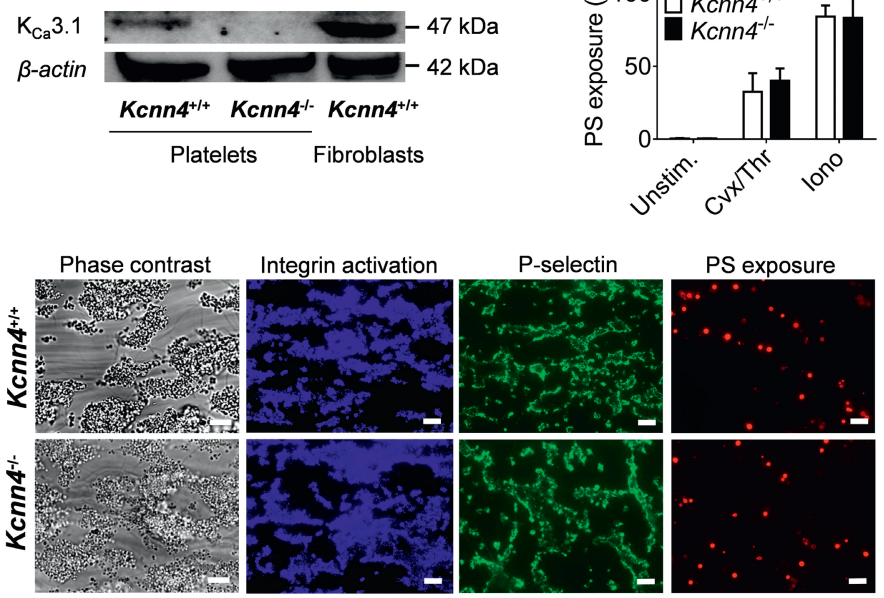

D
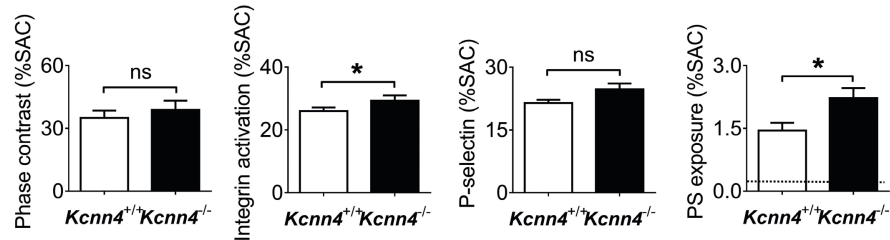

Figure 3. Unchanged thrombus formation and PS exposure of mice lacking $\mathrm{K}_{\mathrm{ca}} 3.1$ Gardos channels. A) Expression of $\mathrm{K}_{\mathrm{Ca}} 3.1$ protein in platelets from corresponding $\mathrm{Kcnn}^{+/+}$and $\mathrm{Kcnn} 4^{-/}$mice; control lane refers to murine fibroblasts. Western blots are from cell lysates probed with anti-murine KCa3.1 mAb, and reprobed with anti- $\beta$-actin mAb as loading control. B) Washed platelets from $\mathrm{Kcnn}^{+/+}$or $\mathrm{KCnn}^{\%}$ mice in $\mathrm{CaCl}_{2}$-containing medium were stimulated with convulxin $(\mathrm{Cvx}, 100 \mathrm{ng} / \mathrm{ml})$ plus thrombin (Thr, $4 \mathrm{nM}$ ) or with ionomycin (Iono, 10 $\mu \mathrm{M})$, as indicated. Flow cytometric measurement of platelets binding A647-annexin A5, determined after 15 min. C-D) Blood from $\mathrm{KCnn}^{+/+}$and $\mathrm{KCnn} 4^{-\%}$ mice was perfused over collagen for $4 \mathrm{~min}$ at $1000 \mathrm{~s}^{-1}$. Thrombi were stained with PE-JON/A mAb (integrin activation) FITC- $\alpha$ CD62P mAb (P-selectin expression) and AF647-annexin A5 (PS exposure). C) Representative phase-contrast and fluorescence images (bars $25 \mu \mathrm{m}$ ); D) quantitative analysis of surface-area-coverage (SAC\%) of thrombi or fluorescence. Dotted line indicates background fluorescence for PS exposure (no platelet thrombi). Means \pm SE ( $n=5-7),{ }^{*} P<0.05$ (2-way ANOVA). 
platelets in comparison to control platelets. Together, these data point to a major defect in $\mathrm{Ca}^{2+}$ and tonicdependent light transmission clearance (balloon formation) and a partial defect in integrin $\beta_{3}$-chain cleavage in $\mathrm{Ca}^{2+}$ activated Scott platelets.

Subtle role of murine Gardos channels in platelet PS exposure and thrombus formation

Pharmacological studies with human platelets suggest a role for Gardos ( $\left.\mathrm{K}_{\mathrm{Ca}} 3.1\right) \mathrm{K}^{+}$channels in agonist-induced PS exposure (22). We reinvestigated a role of these channels in $\mathrm{KCnn}^{-/-}$mice lacking the $\mathrm{K}_{\mathrm{Ca}} 3.1$ protein. Western blot analysis indicated weak expression of the 47-kDa channel protein in platelets (Fig.
$3 A$ ) and erythrocytes (not shown) of wild-type, but not of $\mathrm{KCnn}^{-\%}$ mice. After stimulation with convulxin/thrombin or ionomycin, $\mathrm{KCnn}^{+/+}$and $\mathrm{Kcnn} 4^{-/-}$ platelets were equally high in PS exposure (Fig. 3B). Whole-blood perfusion over collagen resulted in subtle changes in thrombus formation (Fig. 3C). Whereas the overall deposition of Kcnn4deficient platelets was unchanged $(P>0.1)$, these platelets were slightly, but significantly more increased in $\alpha_{11 b} \beta_{3}$ activation and PS exposure (Fig. 3D). Jointly, these data point to a minor negative, rather than a positive role for the murine $\mathrm{K}_{\mathrm{Ca}} 3.1$ channel in collagendependent PS exposure.

A

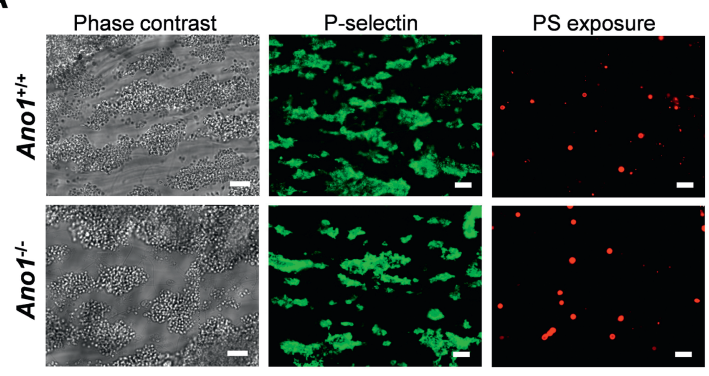

B

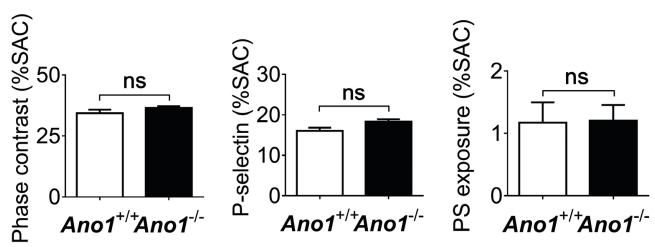

Supplement Figure S3. Unchanged thrombus formation by Ano1-deficient platelets. Blood from Ano1- deficient and corresponding wild-type mice was perfused over collagen for 4 minutes at $1000 \mathrm{~s}-1$. Thrombi were stained with FITC- $\alpha$ CD62P mAb (P-selectin) and AF647- annexin A5 (PS exposure). A) Representative phase contrast and fluorescence images (bars $=25 \mu \mathrm{m})$. B) Results of quantitative image analysis. Means \pm SE $(n=7-8)$. 
A Ano6 ${ }^{A W}$

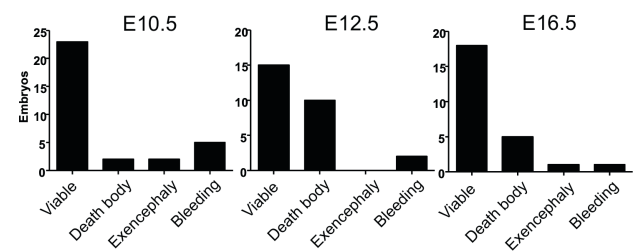

B Ano6 ${ }^{\text {AW }}$
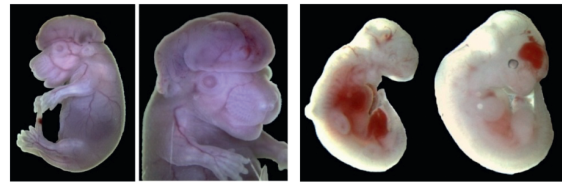

C Ano6 ${ }^{A W}$

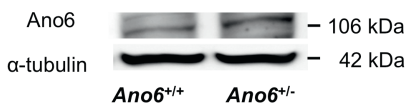

D Ano6 Avor $^{2}$

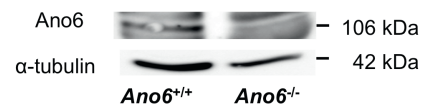

Figure 4. Embryonic lethality after breeding of Ano6-deficient mice. A) Viability of embryos generated by inbreeding of heterozygous $A_{n o 6^{+-}}$mice (Ano6 ${ }^{A W}$ strain) at gestational days (E) 10.5, 12.5 or 16.5. B) Embryo presenting with exencephaly (left, E16.5), embryos presenting with major abdominal and intracranial bleeding (E12.5). C-D) Westerns blots of Ano6 protein expression in platelet lysates from (C) heterozygous Ano6 ${ }^{+/-}$mice $\left(A n o 6^{A W}\right.$ strain) and $(D)$ homozygous Ano6 ${ }^{-1-}$ mice (Ano6 $6^{\text {Avor }}$ strain).

No role for murine Ano1 in platelet PS exposure or thrombus formation

The isoform Ano1 is an ubiquitously expressed ion channel displaying $\mathrm{Ca}^{2+}$ dependent $\mathrm{Cl}^{-}$conductance, which has been implicated in hemolysis-induced PS exposure of erythrocytes. ${ }^{24,40}$ Evaluation of platelets from mice with genetic deficiency in Ano1 showed normal expression of the main surface glycoproteins (Suppl. Table S1) and normal activation in comparison to wildtype platelets with respect to agonistinduced integrin $\alpha_{\| 11} \beta_{3}$ activation, Pselectin expression and PS exposure
(Suppl. Table S2). Measurements of whole-blood thrombus formation on collagen demonstrated that platelet deposition, P-selectin expression and PS exposure were similar for Ano1-deficient and corresponding wild-type mice (Suppl. Fig. 3, $P>0.1$.

Lethality of Ano6-deficient mice and identification of Ano6 splice variants

Several approaches were followed to obtain mice with genetic deficiency of Ano6. In two laboratories, we generatedheterozygous $\mathrm{Ano6}^{+/}$mice using the stem cell clone AW-382, 
carrying a $\beta$-geo reporter gene trap in the Ano6 gene (Ano6 ${ }^{A W}$ strain). These mice produced alive offspring with the gene trap insertion (data not shown), although at a lower number than expected. We hence investigated the embryos in heterozygous females at days (E) 10.5, 12.5 and 16.5 of gestation. Morphological examination indicated that, at all time points, most embryos developed normally. However, several embryos were detected as death bodies, with exencephaly, or with signs of abdominal or intracranial bleeding (Fig. $4 A-B)$. Western blot analysis indicated that platelets from surviving $\mathrm{Ano6}^{\mathrm{AW+}+\text { - }}$ mice with gene trap insertion had significant expression of Ano6 protein
(Fig. 4C), and hence were not homozygously deficient in this gene. In addition, we used heterozygous Ano6deficient mice from the Ano6 ${ }^{\text {Avor }}$ strain, described before. ${ }^{29}$ Inbreeding resulted in offspring with $\sim 30 \%$ of the expected number of Ano6 ${ }^{\text {Avor-l- }}$ sucklings. In contrast to the Ano6 ${ }^{A W}$ strain, no lethality or obvious bleeding was seen in fetuses at days E14.5-18.5. As described, ${ }^{29}$ several deficient fetuses died around birth, e.g. due to asphyxia. However, $\sim 30 \%$ of Ano6 $^{-/}$mice survived longer than 2 months (Ano6 ${ }^{\text {Avor }}$ strain), and these were used for phenotypic analysis. RT-PCR analyses of tissues from the surviving Ano6 Avor-/- mice (C57BL/6 background) showed residual Ano6

A

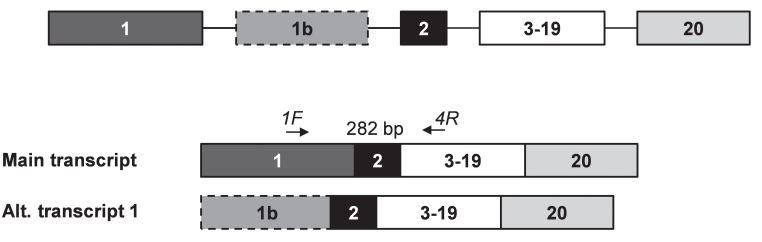

B

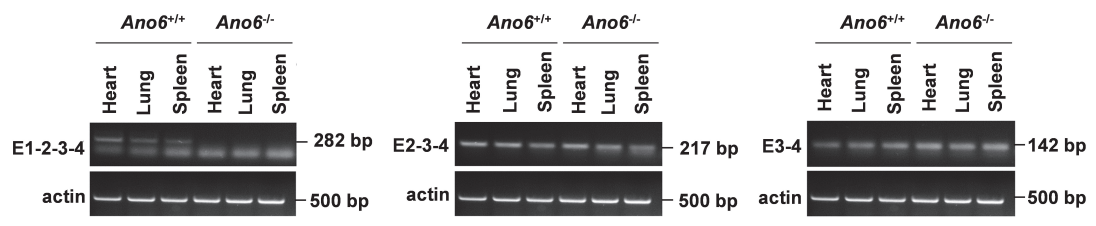

Supplement Figure S4. Screening for alternative transcripts in Ano6 deficient mice. A) Schematic representation of the mouse Ano6 pre-mRNA, including main transcript (ENSMUSG00000064210) and alternative transcript 1 (unpublished). Alternative transcript 1 contains exon $1 \mathrm{~b}$ as a starting codon. B) (Left panel) cDNA was isolated

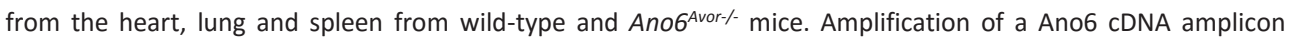
spanning exons 1-4 yielded expected 282 bp fragment in heart, lung and spleen from control mice (lane 1-3), while Ano6 deficient mice lack this fragment (lane 4-6). Amplification of a Ano6 cDNA amplicon spanning exons 2-4 (middle panel) and exon 3-4 (right panel) yielded the expected 217 bp and 142 bp fragments, respectively. 
A

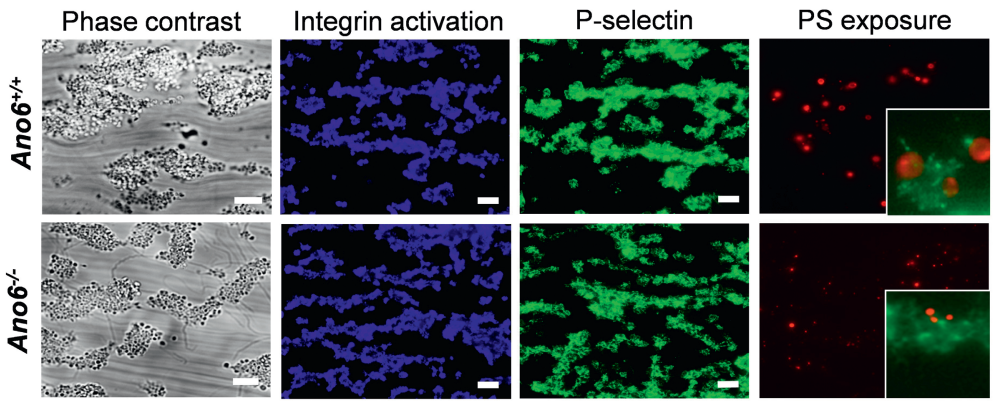

B
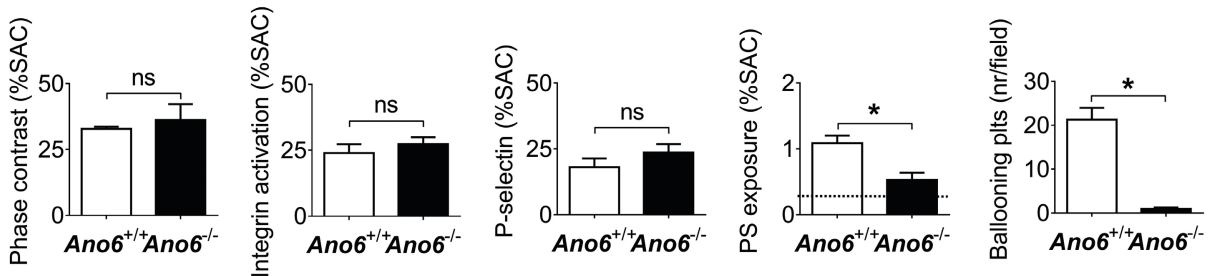

Figure 5. Normal thrombus formation, residual PS exposure and abolished ballooning in the absence of Ano6. Blood from corresponding $A n o 6^{+/+}$and $A n o 6^{-/-}$mice (Ano6 $6^{\text {Avor }}$ strain) was perfused over collagen for 4 min at 1000 $\mathrm{s}^{-1}$. Thrombi on the surface were stained as indicated for Fig. 3. A) Representative phase-contrast and fluorescence images (bars $25 \mu \mathrm{m}$; inserts $25 \times 25 \mu \mathrm{m}$ ). B) Surface area coverage (SAC\%) of thrombi or fluorescence from integrin activation, P-selectin expression, PS exposure and ballooning. Dotted line indicates background fluorescence for PS exposure (no platelet thrombi). Means \pm SE $(n=3),{ }^{*} P<0.05$ (2-way ANOVA).

mRNA expression, which was explained by the presence of alternative transcript 1 (Suppl. Fig. S4). Western blot analysis indicated that in platelets from Ano6 ${ }^{\text {Avor- }}$ 1- mice the $106 \mathrm{kDa}$ Ano6 protein was absent (Fig. 4D), thus indicating that the alternative transcript was not efficiently transcribed. Markedly, tail bleed time was prolonged in adult Ano6 ${ }^{\text {Avor-l- }}$ mice (28.6 $\pm 7.5 \mathrm{~min})$ in comparison to Ano6 ${ }^{\text {Avort/- }}(4.9 \pm 1.8 \mathrm{~min})$ and Ano6 $6^{\text {Avort/+ }}$ $(6.4 \pm 1.6 \mathrm{~min}$ ) animals (means $\pm \mathrm{SE}, n=$ $5-7, P<0.05)$.
Residual PS exposure and abolished swelling of Ano6-deficient mouse platelets in thrombus formation

We then compared activation characteristics of platelets from mice of the $A n o 6^{A W}$ an $A n o 6^{A v o r}$ strains. Platelets from both types of heterozygous mice expressed normal levels of surface glycoproteins (Suppl. Table S1), and were unchanged in $\alpha_{11 b} \beta_{3}$ activation, P-selectin expression and PS exposure, when compared to corresponding wild-type platelets (Suppl. Table S2). Flow perfusion experiments, performed with 
Ano6 ${ }^{\text {AW+/- }}$ or Ano6 $6^{\text {Avort/- }}$ blood did not reveal significant changes in parameters of thrombus formation, including PS exposure, in comparison to the wild-type blood (Suppl. Fig. 5-6). On the other hand, isolated erythrocytes from heterozygous Ano6 $6^{\text {AW+1- }}$ or Ano6 $6^{\text {Avort/- }}$ mice displayed a significant lower ionomycin-induced PS exposure by $\mathbf{3 4 . 0}$ $\pm 6.6 \%$ or $31.6 \pm 8.1 \%$, respectively, compared to corresponding wild-type erythrocytes (means $\pm \mathrm{SE}, n=4-5$, $P<0.05)$.

We then assessed thrombus formation on collagen using blood from surviving adult homozygous deficient Ano6 ${ }^{-/}$mice (Ano6 ${ }^{\text {Avor }}$ strain). Thrombus formation as such was unchanged, with similar platelet adhesion, integrin $\alpha_{11 b} \beta_{3}$ activation and P-selectin expression, in comparison to thrombi from wild-type mice (Fig. 5A-B). However, while wildtype thrombi showed $1-2 \%$ of the surface as PS exposure, as before, ${ }^{18}$ the Ano6 ${ }^{\text {Avor- }}$ 1- thrombi displayed a substantial $76.2 \pm$ $2.6 \%$ ( $n=4, P<0.05$ ) reduction of this parameter (Fig. 5B). High-magnification images indicated residual patches of PS exposure in some of the collagen-bound Ano6 ${ }^{\text {Avor-l- }}$ platelets (Fig. 5A, insert). Notably, these platelets with residual PS exposure were smaller in size than the 8 $\mu \mathrm{m}$-ballooning structures seen with wildtype platelets. Image quantification

A Ano6 ${ }^{\text {AW }}$
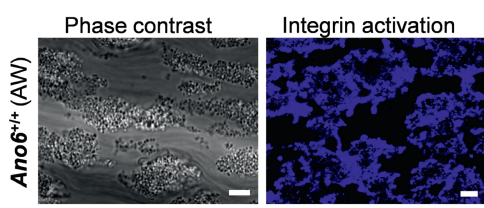

P-selectin

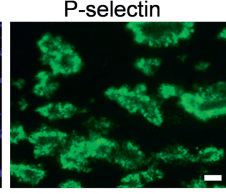

PS exposure
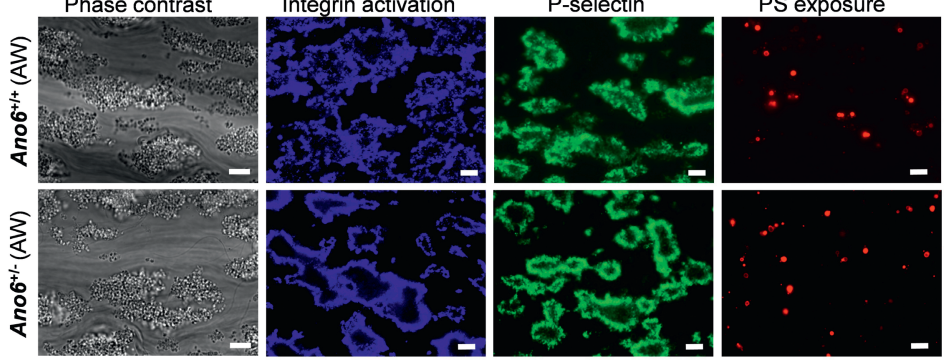

\section{B Ano6 ${ }^{\text {AW }}$}
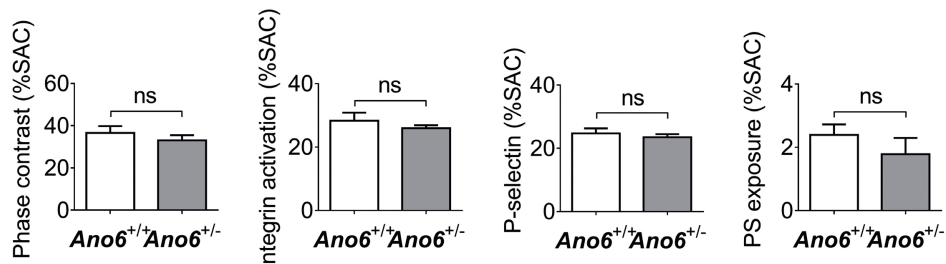

Supplement Figure S5. Unchanged thrombus formation by heterozygous Ano6 ${ }^{A W+/}$ platelets. Blood from $A n o 6 \mathrm{AW}+$ - or corresponding wild-type mice was perfused over collagen for $4 \mathrm{~min}$ at $1000 \mathrm{~s}^{-1}$. Thrombi were stained with PE-JON/A mAb (integrin activation), FITC- $\alpha$ CD62P mAb (P-selectin) and AF647- annexin A5 (PS exposure). A) Representative microscopic images (bars $=25 \mu \mathrm{m}$ ). B) Results of quantitative image analysis. Means \pm SE $(n=5-6)$. 
A

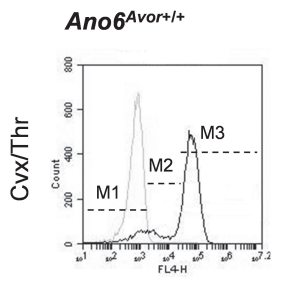



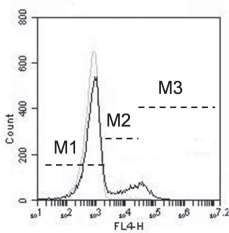

B

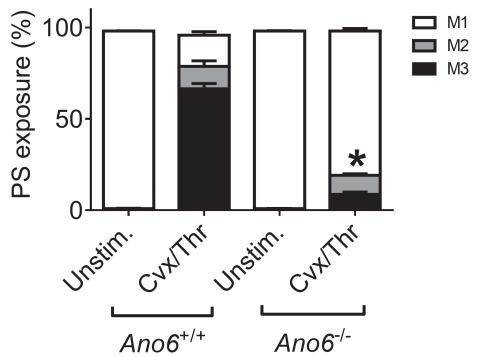

C

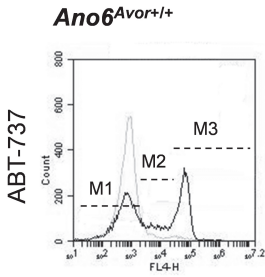

Ano6 Avor-1- $^{-12}$

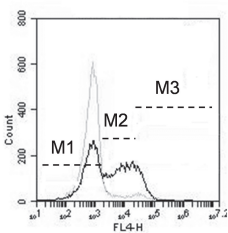

Figure 6. Residual $\mathrm{Ca}^{2+}$-dependent PS exposure by Ano6-deficient platelets. $A-B$ ) Washed platelets from corresponding $\mathrm{Ano6}^{+/+}$and $\mathrm{Ano6}^{-/}$mice (Ano6 ${ }^{\text {Avor }}$ strain) were stimulated in $\mathrm{CaCl}_{2}$-containing medium with convulxin (Cvx $100 \mathrm{ng} / \mathrm{ml}$ ) plus thrombin (Thr, $4 \mathrm{nM}$ ) for $30 \mathrm{~min}$. C-D) Washed platelets were stimulated with the BH3 mimetic ABT-737 (10 $\mu \mathrm{M})$ for $1 \mathrm{~h}$. Shown are representative histograms of AF647-annexin A5 binding after stimulation (black lines) or vehicle controls (grey lines). Markers M1, M2 and M3 indicate fractions of platelets with no, moderate or high annexin A5 binding, respectively. Means $\pm \mathrm{SE}(n=3-4), * P<0.05$ vs. wild-type (2-way ANOVA).

further learned that platelet ballooning was essentially abolished in Ano6 $6^{\text {Avor- }-1}$ blood samples (Fig. 5B).

Activation studies indicated that ADP-, thrombin- and convulxin-induced integrin activation and P-selectin expression were unaffected in washed Ano6 ${ }^{\text {Avor-/- }}$ platelets (Suppl. Table S2). On the other hand, in these knockout platelets PS exposure in response to ionomycin (data not shown) or convulxin/thrombin (Fig. 6A-B) was strongly impaired. In $\sim 10 \%$ of the platelets residual, low PS exposure was observed after stimulation with convulxin/thrombin.

Human Scott platelets display a partly reduced PS exposure in response to the apoptosis-stimulating agent ABT-737. ${ }^{11}$ In particular, low cytometric analysis of ABT-737-treated patient's platelets indicated a reduced fraction with high PS exposure (M3 fraction), and an increased fraction with moderate PS exposure (M2 fraction), which can form at minimal or low $\mathrm{Ca}^{2+}$ rises. We studied this ABT-737induced response in Ano6 ${ }^{\text {Avor-l- }}$ platelets, and noted that, similarly, the $\mathrm{M} 2$ fraction 
(moderate PS exposure) was increased at the expense of the M3 fraction (high PS exposure), when compared to wildtype control platelets (Fig. 6C-D).

Impaired aggregation-independent light transmission changes and integrin inactivation of Ano6-deficient mouse platelets

Similarly to human platelets, wild-type mouse platelets stimulated with convulxin/thrombin or ionomycin, showed light transmission changes in the presence of tirofiban to block platelet aggregation due to clearance of the platelet suspension (Fig. 7A). This clearance was substantially lower (-80\%) for Ano6-deficient platelets. In PRP, we monitored the dilution-induced hypotonic shock response, which was similar for Ano6-deficient and wild-type platelets (Fig. 7B). Yet, with $\mathrm{CaCl}_{2}$ present, the later increase in light transmission accompanying balloon formation was greatly delayed in the deficient platelets. Finally, we determined the cleavage of the integrin $\beta_{3}$-chain in response to convulxin/thrombin, which remained partial for $30 \mathrm{~min}$ in Ano6 ${ }^{\text {Avor-l- }}$ platelets (reduction to -60\%), whereas it was complete in this time frame in $\mathrm{Ano6}^{\text {Avort++ }}$ platelets (Fig. 7C-D). Ionomycin-induced $\beta_{3}$-chain cleavage was not different in the presence or absence of Ano6. In control experiments, we established that the $\beta_{3}$-chain cleavage was annulled by the calpain inhibitor calpeptin, as described before, ${ }^{18}$ indicating it was due to calpain-dependent proteolytic activity. Together, these findings demonstrate a major deficiency in $\mathrm{Ca}^{2+}$-dependent light transmission clearance (balloon formation) and a partial defect in integrin $\beta_{3}$-chain cleavage in platelets from the Ano6-deficient mice.

\section{Discussion}

In the present paper, we compared the activation properties of human Scott platelets with those of mouse platelets lacking one of the transmembrane proteins previously linked to PS exposure, the $\mathrm{K}_{\mathrm{Ca}} 3.1$ Gardos channels or the anoctamins 1 or 6 . Although pharmacological evidence (using clotrimazol and charybdotoxin) has suggested a positive role of the $\mathrm{K}_{\mathrm{Ca}} 3.1$ channels in PS exposure in human platelets, ${ }^{22}$ we could not confirm this in Kcnn $4^{\%}$ mice. Instead, upon thrombus formation on collagen, $\mathrm{K}_{\mathrm{Ca}} 3.1$ deficiency increased PS exposure along with integrin activation, suggesting that this channel suppresses rather than stimulates platelet activation. Assuming that the $\mathrm{K}_{\mathrm{Ca}} 3.1$ channels act similarly in human and mouse platelets, the difference with previously published data, ${ }^{21,22}$ might be explained by offtarget effects of the pharmacological inhibitors used. 
The anoctamin Ano1 can function as a $\mathrm{Ca}^{2+}$-activated $\mathrm{Cl}^{-}$channel, ${ }^{16,23}$ and has been implicated in PS exposure in erythrocytes treated with $\alpha$-hemolysin. ${ }^{24}$ In smooth muscle cells, Ano1 can regulate cell proliferation. ${ }^{40}$ In the present experiments, we could not confirm a role of Ano1 in $\mathrm{Ca}^{2+}$-dependent PS exposure, given that Ano1\% mouse platelets responded normally to collagen, convulxin/thrombin or ionomycin. Earlier studies indicated that murine deficiency in Ano6 affects mineral deposition in skeletal tissue ${ }^{29}$ and arterial thrombus formation in vivo. ${ }^{17}$ By cross-breeding we could obtain viable and adult Ano6 $^{-1}$ offspring from mice of the Ano6 ${ }^{\text {Avor, }}$, but not of the $A n o 6^{A W}$ strain. Although this remains to be confirmed, the survival of the Ano6 ${ }^{\text {Avor-l- }}$ mice might be related to the expression of alternative Ano6 mRNA transcripts in key tissues. On the other hand, heterozygous $\mathrm{Ano6}^{\mathrm{AW+}+-}$ and Ano6 ${ }^{\text {Avort- }}$ mice survived normally without obvious phenotypic defects. In the heterozygous mice, thrombus formation and platelet activation properties were unchanged in our hands, but heterozygous erythrocytes from both lines showed a reduced ionomycininduced PS exposure.Using blood from the surviving Ano6 ${ }^{\text {Avor-l- }}$ mice, we found

\section{A Ano6 Avor $^{2}$}
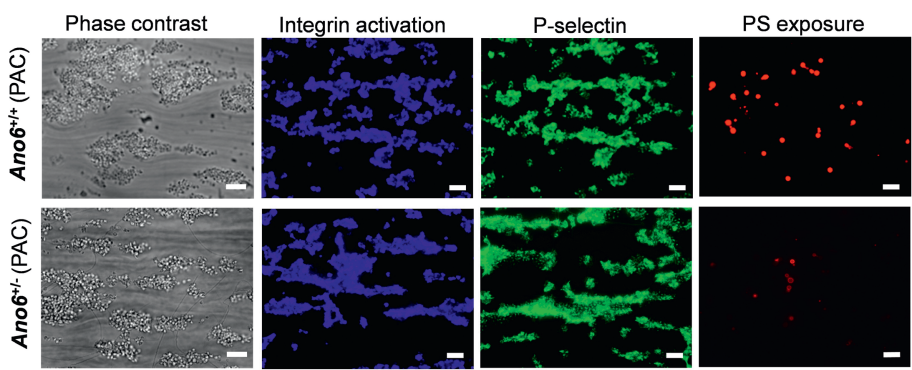

\section{B Ano6 Avor}
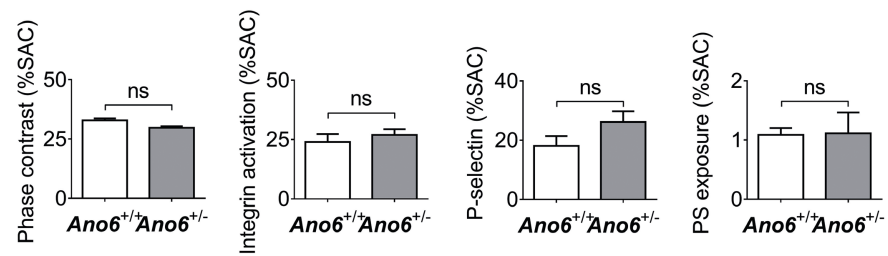

Supplement Figure S6. Unchanged thrombus formation by heterozygous Ano6 ${ }^{\text {Avor }}$ platelets. Blood from heterozygous Ano6 $^{\text {Avor }}$ or corresponding wild-type mice was perfused over collagen for 4 min at $1000 \mathrm{~s}-1$. Thrombi were stained with PE-JON/A mAb (integrin activation), FITC- $\alpha$ CD62P mAb (P-selectin) and AF647annexin A5 (PS exposure). A) Representative microscopic images (bars $=25 \mu \mathrm{m}$ ). B) Results of quantitative image analysis. Mean \pm SE $(n=4)$. 
that collagen-dependent thrombus formation was unchanged in terms of platelet deposition, aggregation, integrin activation and secretion. On the other hand, collagen-dependent PS exposure in platelets was greatly but not completely reduced, and morphological changes to a ballooning structure were abolished. A similar, combined defect in platelet PS exposure and ballooning was observed with blood from the Scott patient.

Phenotypic resemblance of the Ano6 $6^{\text {Avor- }}$ I- and patient platelets was also noticed

A
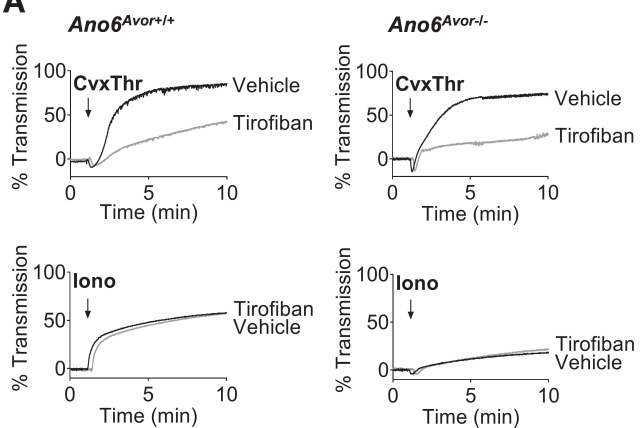

B
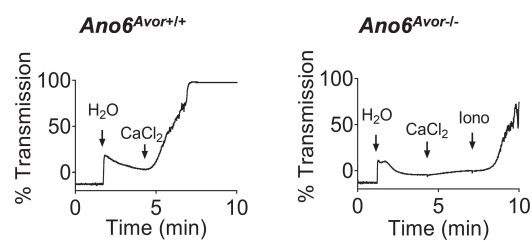

from flow cytometric studies. In both Ano6 ${ }^{-1}$ and Scott platelets, PS exposure was mostly, yet incompletely reduced after convulxin/thrombin treatment, and was slightly diminished upon apoptosis stimulation with ABT-737. Furthermore, the platelets from Ano6-deficient mice and the Scott patient displayed a reduction in convulxin/thrombin-induced integrin $\beta_{3}$ cleavage, likely due to reduced calpain activation. ${ }^{18}$ Together, these data indicate that the functional and morphological alterations found in
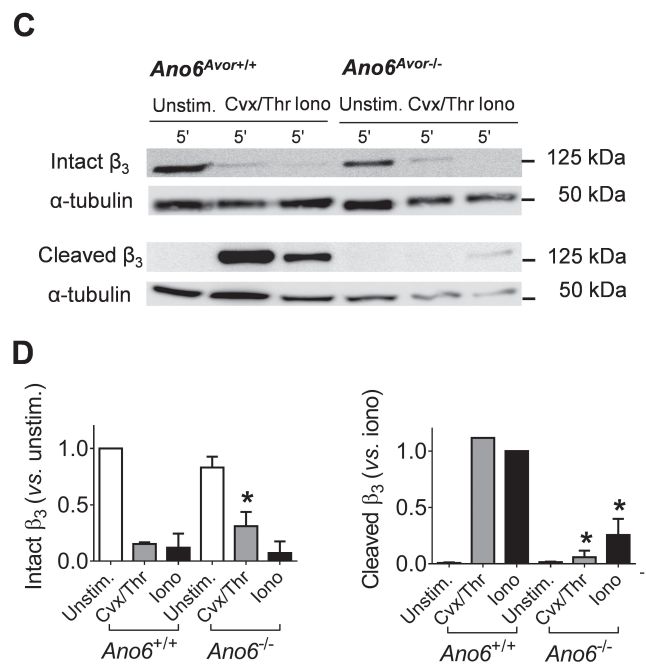

Figure 7. Integrin $\alpha_{11 b} \beta_{3}$-independent turbidity changes and reduced integrin cleavage by Ano6-deficient platelets. A) Suspensions of washed platelets from corresponding Ano6 ${ }^{+/+}$and Ano6 ${ }^{-/-}$mice (Ano6 $6^{\text {Avor }}$ strain) in $\mathrm{CaCl}_{2}$-containing medium were stimulated with convulxin ( $\mathrm{Cvx}, 100 \mathrm{ng} / \mathrm{ml}$ ) plus thrombin (Thr, $\left.4 \mathrm{nM}\right)$ or with ionomycin (Iono, $10 \mu \mathrm{M}$ ) in the presence or absence of tirofiban $(2 \mu \mathrm{g} / \mathrm{ml})$. Shown are representative changes in light transmission $(n=3)$. B) Hypotonic shock response of PRP by water dilution (33\%) in the presence or absence of $\mathrm{CaCl}_{2}(4 \mathrm{mM})$. Shown are representative traces of changes in light transmission. $C$ - $D$ ) Western blots probed for the intact and cleaved integrin $\beta_{3}$ chain (detected with Ab762 and Ab754, respectively) of platelets stimulated with $\mathrm{Cvx} / \mathrm{Thr}$ or lono (concentrations as above) in the presence of $\mathrm{CaCl}_{2}$. Blots (representative for 3 performed) were reprobed with anti- $\alpha$-tubulin $\mathrm{mAb}$ as lane loading control. $D$ ) Quantification of $\beta_{3}$ chain cleavage from densitometric profiles. Means \pm SE $(n=3),{ }^{*} P<0.05$. 
platelets from the Scott patient are quite well phenocopied in platelets from Ano6deficient mice.

As summarized elsewhere, ${ }^{17,23,41,42}$ Ano6 can function not only as a $\mathrm{Ca}^{2+}$ dependent phospholipid scramblase, but also as a chloride and cation channel. The inability of Ano6-deficient platelets to form balloons - like Scott platelets suggests a defect in $\mathrm{Ca}^{2+}$-dependent ion influx and swelling. This idea is confirmed by our finding that a hypertonic environment markedly delays the PS exposure and balloon formation. The swelling seems to be a consequence of multiple ion influxes, as we found that specific depletion of $\mathrm{Cl}^{-}$or $\mathrm{Na}^{+}$ions was without effect (N. Mattheij, unpublished 2014). On the other hand, it should be noted that also other $\mathrm{Ca}^{2+}$ channels, in particular Orai1 and TRPC isoforms, can contribute to PS exposure in platelets. ${ }^{43,44}$

The Scott syndrome has been described as a moderate bleeding disorder, with hemorrhagic episodes only after trauma or childbirth. ${ }^{2,3}$ Although the syndrome is rare (with 3 patients characterized so far), it is likely underdiagnosed. The present

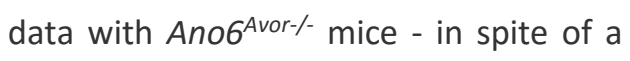
reduced survival - point to limited hemostatic insufficiency, as mouse tail bleed times were increased. The residual platelet PS exposure, and delayed thrombin and fibrin generation in addition, may offer an explanation for the limited severity of bleeding. Interestingly, we have identified in both mouse and human samples alternative splice variants of Ano6. In agreement with this finding, also other authors describe the expression of Ano6 splice variants - which differ in their $\mathrm{N}$-terminal cytoplasmic domains, but are similar in PS scrambling activities -, in different human tissues. ${ }^{45}$ In man, the nature of the two ANO6 gene mutations in the Scott patient leads to impaired translation of all identified splice variants. In mouse, the tissue distribution of the splice variants is still unclear. These variants might be of functional importance during embryonic development and at later life. On the other hand, we could not detect Ano6 protein expression, and hence find no evidence for a role of these splice variants, in the residual PS exposure in human Scott syndrome or mouse Ano6 ${ }^{\text {Avor-/- }}$ platelets. Not unlikely, other $\mathrm{Ca}^{2+}$-dependent anoctamin isoforms, ${ }^{23}$ enforced by Orai1 and TRPC Ca ${ }^{2+}$ entry channels, ${ }^{43,44}$ may account for the low PS exposure in the absence of Ano6 channels.

\section{Funding}

This work was supported by grants from the Cardiovascular Center Maastricht, and the Dutch Heart Foundation 2011T6 (NJAM, JMEMC and JWMH); and Deutsche Forschungsgemeinschaft DFG SFB699, project A7\&A12 (RS and KK). 


\section{References}

1. Sims PJ, Wiedmer T, Esmon CT, Weiss HJ, Shattil SJ. Assembly of the platelet prothrombinase complex is linked to vesiculation of te platelet plasma membrane. Studies in Scott syndrome: an isolated defect in platelet procoagulant activity. J. Biol. Chem 1989;264:17049-17057.

2. Toti F, Satta N, Fressinaud E, Meyer D, Freyssinet JM. Scott syndrome, characterized by impaired transmembrane migraton of procoagulant phosphatidylserine and haemorrhagic complications, is an inherited disorder. Blood 1996;87:1409-1415.

3. Satta N, Toti F, Fressinaud E, Meyer D, Freyssinet JM. Scott syndrome: an inherited defect of the procoagulant activity of platelets. Platelets 1997;8:117-124.

4. Munnix IC, Harmsma M, Giddings JC, Collins, PW, Feijge MA, Comfurius P, Heemskerk JW, Bevers EM. Store-mediated calcium entry in the regulation of phosphatidylserine exposure in blood cells from Scott patients. Thromb. Haemost. 2003;89:687-695.

5. Bevers EM, Comfurius P, Zwaal RF. Changes in membrane phospholipid distribution during platelet activation. Biochim. Biophys. Acta. 1983;736:57-66.

6. Zwaal RF, Schroit AJ. Pathophysiological implications of membrane phospholipid asymmetry in blood cells. Blood 1997;89:11211132.

7. Williamson $P$, Christie $A$, Kohlin $T$, Schlegel RA, Comfurius P, Harmsma M, Zwaal RF, Bevers EM. Phospholipid scramblase activation pathways in lymphocytes. Biochemistry 2001;40:8065-8072.

8. Heemskerk JW, Mattheij NJ, Cosemans JM. Platelet-based coagulation: different populations, different functions. J. Thromb. Haemost. 2013;11:2-11.

9. Schoenwaelder SM, Yuan $Y$, Josefsson EC, White MJ, Yao Y, Mason KD, O'Reilly LA, Henley KJ, Ono A, Hsiao S, Willcox A, Roberts AW, Huang DC, Salem HH, Kile BT, Jackson SP. Two distinct pathways regulate platelet phosphatidylserine exposure and procoagulant function. Blood 2009;114:663-666.
10. Kmit A, van Kruchten R, Ousingsawat J, Mattheij NJ, Senden-Gijsbers B, Heemskerk JW, Schreiber R, Bevers EM, Kunzelmann K. Calcium-activated and apoptotic phospholipid scrambling induced by Ano6 can occur independently of Ano6 ion currents. Cell Death Dis. 2013;4:e611.

11. Van Kruchten R, Mattheij NJ, Saunders C, Feijge MA, Swieringa F, Wolfs JL, Collins PW, Heemskerk JW, Bevers EM. Both TMEM16F-dependent and TMEM16F-independent pathways contribute to phosphatidylserine exposure in platelet apoptosis and platelet activation. Blood 2013;121:18501857.

12. Suzuki J, Umeda M, Sims PJ, Nagata S. Calciumdependent phospholipid scrambling by TMEM16F. Nature 2010;468:834-838.

13. Castoldi E, Collins PW, Williamson PL, Bevers EM. Compound heterozygosity for 2 novel TMEM16F mutations in a patient with Scott syndrome. Blood 2011;117:4399-4400.

14. Brunner JD, Lim NK, Schenck S, Duerst A, Dutzler R. X-ray structure of a calcium-activated TMEM16 lipid scramblase. Nature 2014;516:207-212.

15. Martins JR, Faria D, Kongsuphol P, Reisch B, Schreiber R, Kunzelmann K. Anoctamin 6 is an essential component of the outwardly rectifying chloride channel. Proc. Natl. Acad. Sci. U.S.A. 2011;108:18168-18172.

16. Tian $Y$, Schreiber R, Kunzelmann K. Anoctamins are a family of $\mathrm{Ca}^{2+}$-activated $\mathrm{Cl}^{-}$channels. J. Cell Sci. 2012;125:4991-4998.

17. Yang $H$, Kim A, David T, Palmer $D$, Jin $T$, Tien J, Huang $F$, Cheng $T$, Coughlin SR, Jan YN, Jan LY. TMEM16F forms a $\mathrm{Ca}^{2+}$-activated cation channel required for lipid scrambling in platelets during blood coagulation. Cell 2012;151:111-122.

18. Mattheij NJ, Gilio K, van Kruchten R, Jobe SM, Wieschhaus AJ, Chishti AH, Collins P, Heemskerk JW, Cosemans JM. Dual mechanism of integrin $\alpha_{11 b} \beta_{3}$ closure in procoagulant platelets. J. Biol. Chem. 2013;288:13325-13336.

19. Clark SR, Thomas CP, Hammond VJ, Aldrovandi M, Wilkinson GW, Hart KW, Murphy RC, Collins PW, O'Donnell VB. Characterization of platelet aminophospholipid externalization reveals fatty acids as molecular determinants that regulate 
coagulation. Proc. Natl. Acad. Sci. U.S.A. 2013;110:5875-5880.

20. Okada Y, Shimizu T, Maeno E, Tanabe S, Wang X, Takahashi N. Volume-sensitive chloride channels involved in apoptotic volume decrease and cell death. J. Membr. Biol. 2006;209:21-29.

21. Lang PA, Kaiser S, Myssina S, Wieder T, Lang F, Huber SM. Role of $\mathrm{Ca}^{2+}$-activated $\mathrm{K}^{+}$channels in human erythrocyte apoptosis. Am. J. Physiol. 2003;285:C1553-1560.

22. Wolfs JL, Wielders SJ, Comfurius $P$, Lindhout $T$, Giddings JC, Zwaal RF, Bevers EM. Reversible inhibition of the platelet procoagulant response through manipulation of the Gardos channel. Blood 2006;108:2223-2238.

23. Suzuki J, Fujii T, Ishihara K, Kuba H, Nagata S. Calcium-dependent phospholipid scramblase activity of TMEM16 protein family members. J. Biol. Chem. 2013;288:13305-13316.

24. Skals M, Jensen UB, Ousingsawat J, Kunzelmann K, Leipziger J, Praetorius HA. Escherichia coli $\alpha$ hemolysin triggers shrinkage of erythrocytes via $\mathrm{K}_{\mathrm{Ca}} 3.1$ and TMEM16A channels with subsequent phosphatidylserine exposure. J. Biol. Chem. 2010;285:15557-15565.

25. Siljander $P$, Farndale RW, Feijge MA, Comfurius $P$, Kos S, Bevers EM, Heemskerk JW. Platelet adhesion enhances the glycoprotein VIdependent procoagulant response: Involvement of p38 MAP kinase and calpain. Arterioscler. Thromb. Vasc. Biol. 2001;21:618-627.

26. Grgic I, Kaistha BP, Paschen S, Kaistha A, Busch C, Si H, Köhler K, Elsässer HP, Hoyer J, Köhler R. Disruption of the Gardos channel ( $\left.\mathrm{K}_{\mathrm{ca}} 3.1\right)$ in mice causes subtle erythrocyte macrocytosis and progressive splenomegaly. Pflügers Arch. 2009;458:291-302.

27. Si H, Heyken WT, Wolfle SE, Tysiac M, Schubert R, Grgic I, Vilianovich L, Giebing G, Maier T, Gross V, Bader M, de Wit C, Hoyer J, Kohler R. Impaired endothelium-derived hyperpolarizing factormediated dilations and increased blood pressure in mice deficient of the intermediateconductance $\mathrm{Ca}^{2+}$-activated $\mathrm{K}+$ channel. Circ. Res. 2006;99:537-544.

28. Brahler S, Kaistha A, Schmidt VJ, Wolfle SE, Busch C, Kaistha BP, Kacik M, Hasenau AL, Grgic I, Si H,
Bond CT, Adelman JP, Wulff $\mathrm{H}$, de Wit C, Hoyer J, Kohler R. Genetic deficit of SK3 and IK1 channels disrupts the endothelium-derived hyperpolarizing factor vasodilator pathway and causes hypertension. Circulation 2009;119:2323-2332.

29. Ehlen HW, Chinenkova M, Moser M, Munter HM, Krause Y, Gross S, Brachvogel B, Wuelling M, Kornak U, Vortkamp A. Inactivation of anoctamin$6 /$ Tmem16f, a regulator of phosphatidylserine scrambling in osteoblasts, leads to decreased mineral deposition in skeletal tissues. J. Bone Miner. Res. 2013;28:246-259.

30. Van Kruchten R, Cosemans JM, Heemskerk JW. Measurement of whole blood thrombus formation using parallel-plate flow chambers: a practical guide. Platelets 2012;23:229-242.

31. Van der Meijden PE, Feijge MA, Swieringa F, Gilio K, Nergiz-Unal R, Hamulyak K, Heemskerk JW. Key role of integrin $\alpha_{\| 1 b} \beta_{3}$ signaling to Syk kinase in tissue factor-induced thrombin generation. Cell. Mol. Life Sci. 2012;69:3481-3492.

32. Kuijpers MJ, van der Meijden PE, Feijge MA, Mattheij NJ, May F, Govers-Riemslag J, Meijers JC, Heemskerk JW, Renné T, Cosemans JM. Factor XIla regulates the pathological process of thrombus formation on ruptured plaques. Arterioscler. Thromb. Vasc. Biol. 2014;34:16741680.

33. Deppermann C, Cherpokova D, Nurden $P$, Schulz JN, Thielmann I, Kraft P, Vogtle T, Kleinschnitz C, Dutting $S$, Krohne G, Eming SA, Nurden AT, Eckes B, Stoll G, Stegner D, Nieswandt B. Gray platelet syndrome and defective thrombo-inflammation in Nbeal2-deficient mice. J. Clin. Invest.2013, pii: 69210.

34. Holme S, Moroff G, Murphy S. A multi-laboratory evaluation of in vitro platelet assays: the tests for extent of shape change and response to hypotonic shock. Transfusion 1998;38:31-40.

35. De Witt SM, Swieringa F, Cavill R, Lamers MM, van Kruchten R, Mastenbroek T, Baaten C, Coort S, Pugh N, Schulz A, Scharrer I, Jurk K, Zieger B, Clemetson KJ, Farndale RW, Heemskerk JW, Cosemans JM. Identification of platelet function defects by multi-parameter assessment of thrombus formation. Nat. Commun. 2014;5:4257. 
36. Gilio K, Munnix IC, Mangin P, Cosemans JM, Feijge MA, van der Meijden PE, Olieslagers $S$, Chrzanowska-Wodnicka MB, Lillian R, Schoenwaelder S, Koyasu S, Sage SO, Jackson SP, Heemskerk JW. Non-redundant roles of phosphoinositide 3-kinase isoforms $\alpha$ and $\beta$ in glycoprotein VI-induced platelet signaling and thrombus formation. J. Biol. Chem. 2009;285:33750-33762.

37. De Witt S, Swieringa F, Cosemans JM, Heemkerk JW. Thrombus formation on microspotted arrays of thrombogeneic surfaces. Nat. Protocol Exchange 2014, 3309.

38. Kuijpers MJ, Schulte V, Bergmeier W, Lindhout $T$, Brakebusch C, Offermanns S, Fässler R, Heemskerk JW, Nieswandt B. Complementary roles of glycoprotein $\mathrm{VI}$ and $\alpha_{2} \beta_{1}$ integrin in collagen-induced thrombus formation in flowing whole blood ex vivo. FASEB J. 2003;17:685-687.

39. Burkhart JM, Vaudel M, Gambaryan S, Radau S, Walter U, Martens LJ, Sickmann A, Zahedi RP. The first comprehensive and quantitative analysis of human platelet protein composition allows the comparative analysis of structural and functional pathways. Blood 2012;120:e73-e82.

40. Wang $M$, Yang $H$, Zheng LY, Zhang $Z$, Tang YB, Wang GL, Du YH, Lv XF, Liu J, Zhou JG, Guan YY. Downregulation of TMEM16A calcium-activated chloride channel contributes to cerebrovascular remodeling during hypertension by promoting basilar smooth muscle cell proliferation. Circulation 2012;125:697-707.

41. Kunzelmann K, Nilius B, Owsianik G, Schreiber R, Ousingsawat J, Sirianant L, Wanitchakool P, Bevers EM, Heemskerk JW. Molecular functions of anoctamin 6 (TMEM16F): a chloride channel, cation channel, or phospholipid scramblase? Pflügers Arch. 2014;466:407-414.

42. Shimizu T, Ichara T, Sato K, Fujii T, Sakai H, Okada $\mathrm{Y}$. TMEM16F is a component of a $\mathrm{Ca}^{2+}$-activated $\mathrm{Cl}^{-}$channel but not a volume-sensitive outwardly rectifying $\mathrm{Cl}^{-}$channel. Am. J. Physiol. 2013;304:C748-759.

43. Harper MT, Camacho-Londono JE, Quick K, Camacho-Londono J, Flockerzi V, Phillipp SE, Birnbaumer L, Freichei M, Poole AW. Transient receptor potential channels function as a coincidence signal mediating phosphatidylserine exposure. Sci. Sign. 2013;6:ra50.

44. Van Kruchten R, Braun A, Feijge MA, Kuijpers MJ, Rivera-Galdos R, Kraft P, Stoll G, Kleinschnitz G, Bevers EM, Nieswandt B, Heemskerk JW. Antithrombotic potential of blockers of storeoperated calcium channels in platelets. Arterioscler. Thromb. Vasc. Biol. 2012;32:17171723.

45. Scudieri P, Caci E, Venturini A, Sondo E, Pianigiani G, Marchetti C, Ravazzolo R, Pagani F, Galietta LJ. Ion channel and lipid scramblase activity associated with expression of TMEM16F/ANO6 isoforms. J. Physiol. 2015;593:3829-3948. 



\section{Chapter 8}

Altered protein expression, phosphorylation and cleavage in platelets from rare Scott syndrome patient revealed by advanced proteomics analysis

Mattheij $\mathrm{NJ}^{1 *}$, Solari $\mathrm{FA}^{2 *}$, Burkhart $\mathrm{J}^{2}$, Swieringa $\mathrm{F}^{1}$, Collins $\mathrm{PW}^{3}$, Cosemans JM ${ }^{1}$, Sickmann $A^{2}$, Heemskerk JW ${ }^{1 *}$, Zahedi RP ${ }^{2 *}$

${ }^{1}$ Department of Biochemistry, Cardiovascular Research Institute Maastricht (CARIM), Maastricht University, Maastricht, The Netherlands, ${ }^{2}$ Leibniz-Institut für Analytische Wissenschaften-ISAS-e.V., Dortmund, Germany, ${ }^{3}$ Arthur Bloom Haemophilia Centre, School of Medicine, Cardiff University, Cardiff, United Kingdom

*Equal contribution Submitted 


\begin{abstract}
Introduction: The Scott syndrome is a rare bleeding disorder characterised by mutations in the transmembrane protein, anoctamin-6. Platelets from Scott patients are impaired in $\mathrm{Ca}^{2+}$-dependent phosphatidylserine exposure, membrane blebbing and microparticle formation. We hypothesized that also altered protein levels and post-translational protein modifications contribute to this complex phenotype.

Methods: Well-purified washed platelets from healthy control donors and a Scott patient were left unstimulated or were stimulated with thrombin. Platelets were also stimulated with the strong $\mathrm{Ca}^{2+}$-elevating agonists, convulxin/thrombin or ionomycin, which in case of Scott platelets were greatly deficient in phosphatidylserine exposure and membrane blebbing. Samples were used for advanced quantitative (phospho)proteomics analysis and determination of neo-N-termini representing proteolytic cleavage sites.
\end{abstract}

Results: Quantitative proteomics analysis (2,225 unique proteins) indicated 125 proteins with decreased expression and 88 proteins with increased expression levels in Scott platelets compared to control platelets. Changed expression was most frequently observed in membrane receptors \& channels, mitochondrial proteins, metabolic and signalling \& adapter proteins, such in accordance with the relatively high numbers of proteins in these classes. In Scott platelets, anoctamin- 6 could not be detected, whereas the channel protein aquaporin-1 was highly upregulated. Analysis of 1,566 unique phosphopeptides (corresponding to 716 proteins) indicated major differences in Scott and control platelets after stimulation with convulxin/thrombin or ionomycin. A limited number of Scott proteins were decreased in phosphorylation (e.g., proteins linked to the cytoskeleton or regulating phosphatidylserine exposure); a much higher number of Scott proteins were increased in phosphorylation (e.g, cytoskeleton-linked, membrane and signalling proteins). In total 1,613 neo-N-termini were identified in the Scott and control platelets, 180 of which were confirmed to be calpain-regulated (corresponding to 106 proteins). A distinct set of 23 neo-N-termini (corresponding to 23 proteins) was identified as caspase-regulated. In the Scott platelets, most calpain-produced neo-N-termini were down-regulated after convulxin/thrombin stimulation (in particular from cytoskeleton-linked and key signalling proteins), and upregulated after ionomycin stimulation (a variety of proteins).

Conclusion: Advanced proteomic profiling provides novel insight into the altered protein composition and post-translational protein machinery explaining the major $\mathrm{Ca}^{2+}$ - and cytoskeleton-dependent membrane alterations in Scott syndrome platelets. 


\section{Introduction}

The Scott syndrome is a very rare, moderately mild bleeding disorder, identified in the clinic by a reduced prothrombin consumption of the blood serum. The syndrome is characterised by a congenital deficiency in calciumdependent phospholipid scrambling. ${ }^{1,2}$ As a result of this defect, platelets and other blood cells are incapable to externalise the aminophospholipids, phosphatidylserine

and phosphatidylethanolamine in response to strong, $\mathrm{Ca}^{2+}$-mobilising agents. ${ }^{3-5}$ In platelets, the exposure of PS appears to be regulated by a high and persistent elevation in cytosolic $\mathrm{Ca}^{2+}$ or, alternatively, in a less $\mathrm{Ca}^{2+}$-dependent way by apoptosis. ${ }^{6,7}$ Surface exposure of PS induces the binding of multiple coagulation factors to the platelet surface with as a result a potently increased generation of thrombin. 8,9 Defective PS exposure of Scott cells can hence explain the bleeding phenotype.

Recently, a critical role was reported for the transmembrane protein anoctamin- 6 (gene ANO6, alias TMEM16F), in the $\mathrm{Ca}^{2+}$-dependent PS exposure of platelets. ${ }^{10} \mathrm{~A}$ role of this protein in the Scott syndrome was confirmed by the finding of dysfunctional mutations in the ANO6 gene of two unrelated Scott patients. ${ }^{10,11}$ This anoctamin has also been identified as a $\mathrm{Ca}^{2+}$-dependent ion channel with permeability to chloride ions and cations. ${ }^{5,12}$ In one of the Scott patients - the only one healthy in the world and investigated in the current paper -, a different mutation is present in either of the alleles: a transition at the first nucleotide of intron 6 (IVS6 + $1 G \rightarrow A)$, disrupting the splice site consensus sequence of intron 6 , and a single-nucleotide insertion in exon 11 (c.1219insT), predicting a frame shift at codon $411 .^{11}$ Both mutations are not considered to be compatible with normal translation.

Recent findings have indicated that the phenotype of Scott platelets is more complex than earlier anticipated. In the patient's platelets, agonist-induced PS exposure is greatly diminished but not completely absent, while apoptosisinduced PS exposure is also reduced. ${ }^{13}$ Furthermore, after $\mathrm{Ca}^{2+}$ elevation Scott platelets display: a reduced microparticle formation; a lack of membrane blebbing and formation of ballooning structures responses that are strongly associated with PS exposure; ${ }^{14}$ diminished plateletdependent fibrin formation; ${ }^{15}$ and alterations in phospholipid profiles implicated in membrane scrambling. ${ }^{16}$ We hypothesized that this complex phenotypical change is a consequence of substantial alterations in platelet signal transduction, which can be directly or indirectly related to a deficiency in anoctamin- 6 expression.

To investigate the phenotype of Scott 


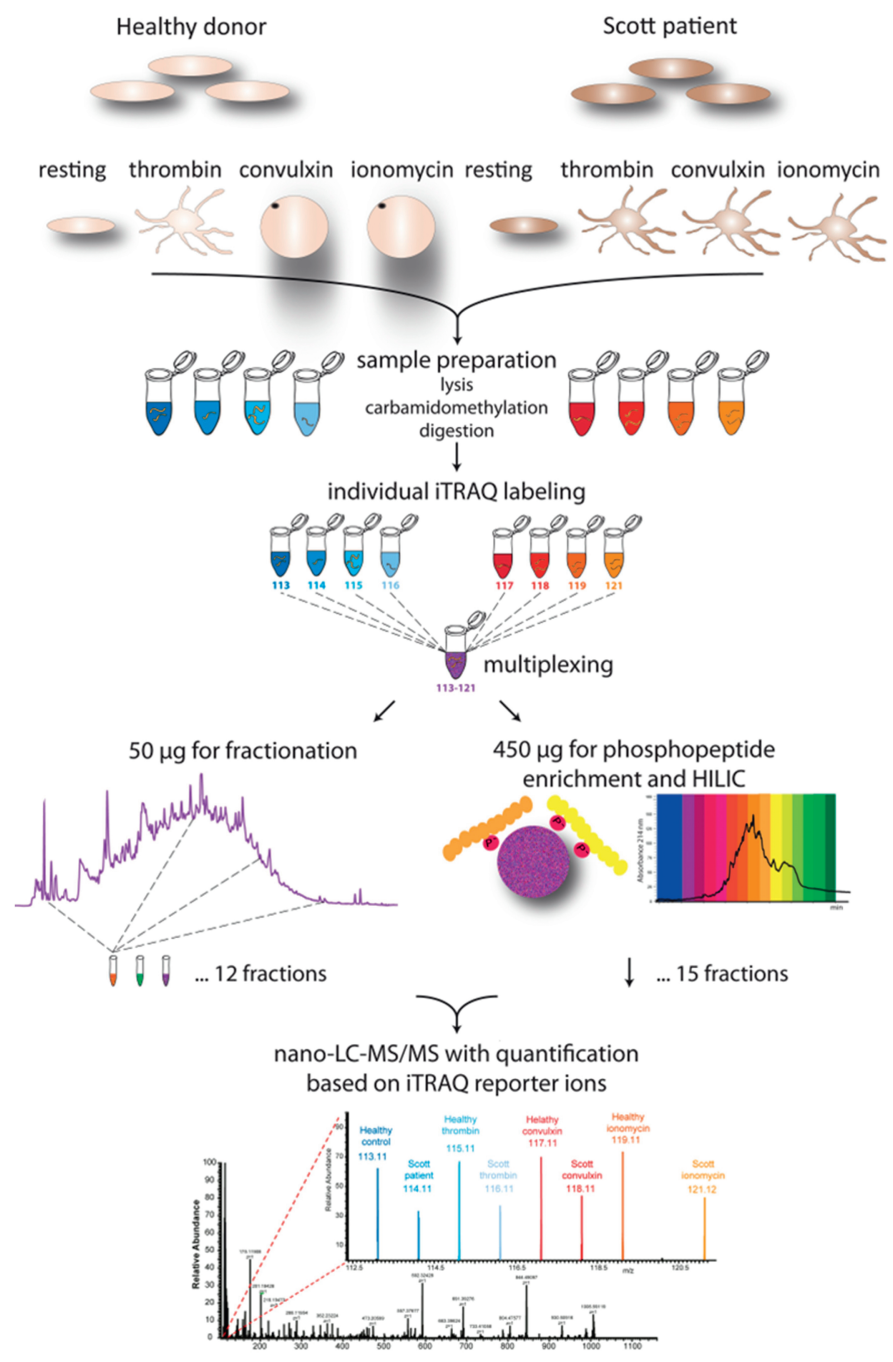

Figure 1. Strategy and workflow for combined determination of platelet quantitative (phospho)proteomics. Purified washed platelets from a healthy donor and the Scott patient remained resting or were stimulated by thrombin, convulxin/thrombin or ionomycin for 30 minutes, as described in the methods section. After lysis and digestion with trypsin, all the samples were subjected to individual labelling with 8-plex iTRAQ reagent (113, 114, $115,116,117,118,119$ and 121). For assessment of the quantitative proteome and the phosphoproteome, all samples were pooled in a 1:1 ratio; $10 \%$ of the pooled sample was used for global proteome analysis and the remaining $90 \%$ for phoshoproteome analysis $500 \mu \mathrm{g}$ of the eight samples were labelled with one of the stable isotopic iTRAQ labels, i.e. iTRAQ 113, 114, 115, 116, 117, 118, 119 or 121 . The labelled samples were multiplexed and fractionated in two different ways. Fractions were analysed by LC-MS on Orbitrap XL. To increase the coverage of the human platelet proteome, a two-step $\mathrm{TiO}_{2}$ enrichment for phosphopeptides first with low and then with high specificity was conducted. Samples analysed by nano-LC-MS/MS on a Q-Exactive mass spectrometer. 
platelets in more detail, we performed a quantitative analysis of the protein expression levels and of phosphorylation state in Scott platelets. We used highly sensitive

quantitative

mass

spectrometric techniques, which have previously led to the identification and quantification of the majority of platelet proteins. ${ }^{17-20} \quad$ Furthermore, we determined the calpain cleavage pattern of activated Scott platelets following a novel analysis of neo-N-terminal protein cleavage sites. By taking advantage of recent technologies, all these posttranslational modifications could be assessed from small platelet samples and related to changes in platelet function.

\section{Methods}

Blood collection and platelet isolation

Blood was obtained from four healthy volunteers and a Scott syndrome patient 11,13 after full informed consent (Helsinki declaration). Protocols were approved by the local Medical Ethics Committees. Blood samples were collected into $1 / 6$ volume of acid-citrate glucose solution (ACD, $80 \mathrm{mM}$ trisodium citrate, $52 \mathrm{mM}$ citric acid and $180 \mathrm{mM}$ glucose). Plateletrich plasma (PRP) was obtained by

\begin{tabular}{|c|c|c|c|c|c|c|}
\hline & \multirow[b]{2}{*}{ Assumed function class } & \multirow{2}{*}{$\begin{array}{c}\text { Control } \\
\text { \#/class \% }\end{array}$} & \multicolumn{2}{|c|}{ Quantitative Scott vs. control } & \multicolumn{2}{|c|}{ Phospho sites Scott vs. control } \\
\hline & & & decreased \% & increased \% & decreased $\%$ & increased \% \\
\hline 1 & Cytoskeleton actin-myosin & 3.1 & $3.2(4)$ & $3.4(3)$ & $16.2(6)$ & $9.7(60)$ \\
\hline 2 & Cytoskeleton intermediate & 0.3 & $0.8(1)$ & 0 & 0 & 0 \\
\hline 3 & Cytoskeleton microtubule & 2.5 & $0.8(1)$ & $4.5(4)$ & $5.4(2)$ & $4.8(30)$ \\
\hline 4 & Cytoskeleton receptor-linked & 1.6 & $0.8(1)$ & $3.4(3)$ & $13.5(5)$ & $9.0(56)$ \\
\hline 5 & Endosome proteins & 1.0 & $0.8(1)$ & 0 & 0 & $0.6(4)$ \\
\hline 6 & ER \& Golgi proteins & 5.4 & $4.0(5)$ & $5.7(5)$ & $2.7(1)$ & $1.1(7)$ \\
\hline 7 & Glucose metabolism & 1.1 & 0 & $2.3(2)$ & 0 & $0.5(3)$ \\
\hline 8 & Lysosome \& peroxisome proteins & 1.4 & $0.8(1)$ & $2.3(2)$ & 0 & $0.3(2)$ \\
\hline 9 & Membrane \& protein trafficking & 5.4 & $5.6(7)$ & $2.3(2)$ & $2.7(1)$ & $5.2(32)$ \\
\hline 10 & Membrane receptors \& channels & 8.1 & $11.2(14)$ & $6.8(6)$ & $2.7(1)$ & $14.2(88)$ \\
\hline 11 & Mitochondrial proteins & 8.9 & $12.0(15)$ & $3.4(3)$ & 0 & $0.2(1)$ \\
\hline 12 & Other metabolism & 10.9 & $15.3(19)$ & $20.5(18)$ & 8.1 (3) & $1.9(12)$ \\
\hline 13 & Other nuclear proteins & 3.1 & $1.6(2)$ & $4.5(4)$ & 0 & 3.1 (19) \\
\hline 14 & Proteasome & 5.7 & $4.8(6)$ & 0 & $5.4(2)$ & $2.3(14)$ \\
\hline 15 & Protein kinases \& phosphatases & 5.6 & $2.4(3)$ & 3.4 (3) & $10.8(4)$ & $8.4(52)$ \\
\hline 16 & Protein processing & 1.1 & $3.2(4)$ & 0 & $2.7(1)$ & $0.8(5)$ \\
\hline 17 & Secretory proteins & 3.5 & $8.8(11)$ & $6.8(6)$ & $2.7(1)$ & $0.3(2)$ \\
\hline 18 & Signalling \& adapter proteins & 12.0 & $12.0(15)$ & $13.6(12)$ & $21.6(8)$ & $15.9(99)$ \\
\hline 19 & Small GTPases \& regulators & 5.1 & $1.6(2)$ & $6.8(6)$ & $2.7(1)$ & $11.4(71)$ \\
\hline 20 & Transcription \& translation & 6.4 & $2.4(3)$ & $6.8(6)$ & 0 & $4.2(26)$ \\
\hline \multirow[t]{2}{*}{21} & Unknown & 7.9 & 0 & $3.4(3)$ & $2.7(1)$ & $6.1(38)$ \\
\hline & Total & $100(4190)$ & $100(125)$ & 100 (88) & $100(37)$ & $100(621)$ \\
\hline
\end{tabular}

Table I. Overview of differences in the quantitative and phosphoproteome of Scott platelets compared to healthy control platelets. Unique proteins of the quantitative proteome and phosphoproteome were assigned to 21 assumed platelet function classes. Second column points to numbers of proteins per class (expressed as \%) for healthy control platelets, according to the previously published proteome ${ }^{20}$. For the quantitative proteome of Scott platelets, numbers of proteins are shown with decreased or increased expression. For the phosphoproteome of Scott platelets (combination of convulxin/thrombin and ionomycin stimulation), numbers of phosphopeptides are shown with decreased or increased phosphorylation. 
centrifuging at $260 \mathrm{~g}$ for 15 minutes. $^{21}$

After addition of $1 / 15$ volume of $A C D$, platelets were pelleted by centrifugation at $870 \mathrm{~g}$ for 15 minutes. The platelets were resuspended in Hepes buffer $\mathrm{pH}$ 6.6 (10 mM Hepes, $136 \mathrm{mM} \mathrm{NaCl}, 2.7$ $\mathrm{mM} \mathrm{KCl}, 2 \mathrm{mM} \mathrm{MgCl} 2$ and $0.1 \%$ glucose) by carefully excluding the bottom layer of red blood cells. After addition of ACD (1/15 volume) and apyrase $(1 \mathrm{U} / \mathrm{ml})$, platelets were centrifuged again at 2000 $\mathrm{g}$ for 5 minutes in an Eppendorf centrifuge, and resuspended in Hepes buffer pH 7.45 (10 mM Hepes, 136 mM $\mathrm{NaCl}, 2.7 \mathrm{mM} \mathrm{KCl}, 2 \mathrm{mM} \mathrm{MgCl}, 0.1 \%$ glucose), again by excluding the bottom layer of erythrocytes. Purity of the final platelet suspensions was checked with a Thrombocounter and from microscopic preparations. Contamination with red blood cells was $<1: 15,000$, contamination with leukocytes was $<1: 20,000$.

\section{Stimulation of washed platelets}

Purified, washed platelets $\left(1.5 \times 10^{8} / \mathrm{ml}\right)$ in Hepes buffer pH 7.45 (10 mM Hepes, $136 \mathrm{mM} \mathrm{NaCl}, 2.7 \mathrm{mM} \mathrm{KCl}, 2 \mathrm{mM} \mathrm{MgCl}$, $0.1 \%$ glucose) containing $2 \mathrm{mM} \mathrm{CaCl}_{2}$ were left untreated or were activated with thrombin (4 nM), convulxin/thrombin (100 ng/ml, $4 \mathrm{nM}$ ) or ionomycin $(10 \mu \mathrm{M})$ for 30 minutes at $37^{\circ} \mathrm{C}$ under non-stirring conditions. Where indicated, Sub-samples were analysed by flow cytometry for PS exposure using FITC-labelled annexin A5, as described before. ${ }^{13}$ In control experiments, washed platelets $(1.5 \mathrm{x}$ $10^{8} / \mathrm{ml}$ ) were activated with ionomycin (10 $\mu \mathrm{M})$ in the presence or absence of calpain inhibitor calpeptin $(200 \mu \mathrm{M})$ for 30 minutes, or with the pro-apoptotic agent ABT-7373 (10 $\mu \mathrm{M})$ in the presence or absence of caspase inhibitor QVD-OPh (20 $\mu \mathrm{M}) 60$ minutes at at $37{ }^{\circ} \mathrm{C}$. Chemicals and (ant)agonists were obtained from sources described before. ${ }^{21}$

For proteomics analysis, reactions were stopped by addition of 1 volume of lysis buffer $(50 \mathrm{mM}$ Tris, 1\% SDS, $150 \mathrm{mM}$ $\mathrm{NaCl}, 1$ tablet PhosStop/10 ml, pH 7.8).22 Lysed samples were immediately frozen and stored at $-80^{\circ} \mathrm{C}$ until usage.

\section{Western blot analysis}

Washed platelets $\left(5 \times 10^{8} / \mathrm{ml}\right)$ were left untreated or activated by convulxin (200 $\mathrm{ng} / \mathrm{ml})$ plus thrombin (8 $\mathrm{nM})$ or ionomycin $(20 \mu \mathrm{M})$ in the presence of 2 $\mathrm{mM} \mathrm{CaCl} 2$ for 30 minutes at $37{ }^{\circ} \mathrm{C}$ under non-stirring conditions. Samples of resting and activated platelets were lysed with ice-cold $4 x$ lysis buffer $(600$ mM NaCl, 10 mM Tris, 4 mM EGTA, 4 mM EDTA, 4\% NP40). Samples (10 $\mu \mathrm{g}$ proteins) were separated on $8 \%$ SDSPAGE gels, and transferred to PVDF blotting membranes by semi-dry transfer. ${ }^{21} \quad$ Membranes were immunoblotted with the following antibodies: Ab762 against the full length 
$\beta_{3}$-chain (1:10000), Ab754 against the incubation at $56{ }^{\circ} \mathrm{C}$ with $10 \mathrm{mM}$ intracellular amino acid 754 neo-N- dithiothreitol. Free sulfhydryl groups terminus of the cleaved $\beta_{3}$-chain (1:1000), were alkylated with $30 \mathrm{mM}$ or $\alpha$-tubulin (1:1000). Incubation with iodoacetamide for 30 minutes at room secondary horse radish peroxidasetemperature. For filter-aided sample coupled antibody (1:1000) was overnight at $4{ }^{\circ} \mathrm{C}$, and visualisation with an $\mathrm{ECL}$ system. Quantification was performed by densitometric analysis of stained blots. ${ }^{21}$

Sample digestion and preparation for quantitative (phospho)proteomics

Platelet proteomics analyses were $200 \mathrm{mM}$ guanidinium hydrochloride and performed, basically following procedures reported earlier. ${ }^{17,20,22}$ For each platelet sample ( $5 \times 10^{8}$ platelets), protein concentrations were determined using a bicinchoninic acid protein assay kit according to the manufacturer's protocol (Pierce, Thermo-Fisher). preparation, $150 \mathrm{\mu g}$ of protein per sample were loaded onto a $30 \mathrm{kDa}$ molecular weight cut-off spin filter, as described elsewhere. ${ }^{23,24}$

Proteins were digested in triethylammonium bicarbonate (TEAB) buffer $\mathrm{pH}$ 8.0, consisting of $50 \mathrm{mM}$ TEAB, $2 \mathrm{mM} \mathrm{CaCl}$, in the presence of trypsin (1:20 w/w, Sigma, $\mathrm{T}-1426)$ at $37{ }^{\circ} \mathrm{C}$, as described before ${ }^{22}$. After incubation for 7 hours, digested peptides were collected by centrifugation at $13,800 \mathrm{~g}$ for 25 minutes. Filters were additionally washed with $50 \mu \mathrm{l}$ of $50 \mathrm{mM}$ TEAB and Cysteines were reduced by 30 minutes $50 \mu$ of LC-MS grade water to increase

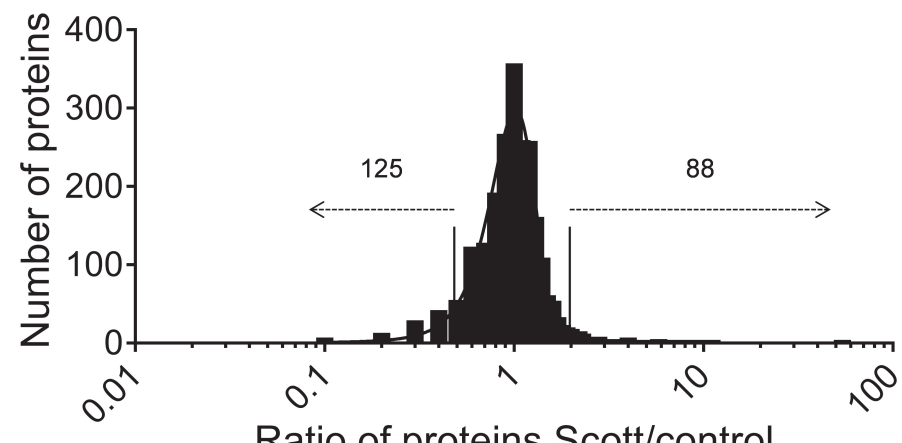

Ratio of proteins Scott/control

Figure 2. Differences in quantitative proteome of Scott and control platelets. In total 2,225 unique proteins were relatively quantified in platelet samples from the Scott patient and a healthy control subject, and were plotted as a function of the protein number per ratio class. Curve parameters: mean $=1.02, S D=0.27$. Ratios $<0.48$ (mean -2 SD) and ratios $>1.56$ (mean +2 SD) were considered as relevant differences. Of the 2,225 proteins, 213 proteins (9.5\%) fell into these categories: 125 proteins with low expression and 88 proteins with high expression in Scott platelets. For pairs of healthy controls subjects $(n=4)$, similar analysis yielded $\sim 40$ proteins in either category $<$ (mean $-2 \mathrm{SD})$ and $>$ (mean $+2 \mathrm{SD})$. 


\begin{tabular}{|c|c|c|c|c|c|}
\hline $\begin{array}{l}\text { Uniprot } \\
\text { number }\end{array}$ & $\begin{array}{l}\text { Gene } \\
\text { name }\end{array}$ & Protein name & $\begin{array}{c}\text { Copies/control } \\
\text { platelet }\end{array}$ & $\begin{array}{c}\text { Ratio } \\
\text { Scott/control }\end{array}$ & Assumed function class \\
\hline \multicolumn{6}{|c|}{ Top 15 decreased expression } \\
\hline Q4KMQ2 & ANO6 & Anoctamin-6 & 3976 & 0.03 & Membrane receptors \& channels $(10)$ \\
\hline P18859 & ATP5J & ATP synthase-coupling factor 6 , mitochondrial & 9996 & 0.09 & Mitochondrial proteins (11) \\
\hline P53602 & $M V D$ & Diphosphomevalonate decarboxylase & 1256 & 0.12 & Other metabolism (12) \\
\hline P06702 & S100A9 & Protein S100-A9 & 1166 & 0.13 & Signalling \& adapter proteins (18) \\
\hline Q5JRX3 & PITRM1 & Presequence protease, mitochondrial & 1018 & 0.16 & Mitochondrial proteins (11) \\
\hline P28676 & $G C A$ & Grancalcin & 1199 & 0.18 & Secretory proteins (17) \\
\hline P81605 & $D C D$ & Dermcidin & 968 & 0.19 & Secretory proteins (17) \\
\hline P17655 & CAPN2 & Calpain-2 catalytic subunit & 1425 & 0.19 & Signalling \& adapter proteins (18) \\
\hline Q3SXM5 & $H S D L 1$ & Inactive hydroxysteroid dehydrogenase-like protein 1 & 2370 & 0.19 & Mitochondrial proteins (11) \\
\hline P54886 & $A L D H 18 A 1$ & Delta-1-pyrroline-5-carboxylate synthase & 1475 & 0.21 & Other metabolism (12) \\
\hline P08311 & CTSG & Cathepsin G & n.d. & 0.24 & Secretory proteins (17) \\
\hline P22307 & $S C P 2$ & Non-specific lipid-transfer protein & 1727 & 0.24 & Other metabolism (12) \\
\hline Q8IZ07 & ANKRD13A & Ankyrin repeat domain-containing protein $13 \mathrm{~A}$ & 1103 & 0.25 & Unknown (21) \\
\hline Q6NUK1 & SLC25A24 & Calcium-binding mitochondrial carrier protein SCaMC-1 & 2210 & 0.26 & Mitochondrial proteins (11) \\
\hline Q12792 & TWF1 & Twinfilin-1 & 1012 & 0.26 & Cytoskeleton actin-myosin (1) \\
\hline $\begin{array}{l}\text { Uniprot } \\
\text { number }\end{array}$ & $\begin{array}{l}\text { Gene } \\
\text { name }\end{array}$ & Protein name & $\begin{array}{c}\text { Copies/control } \\
\text { platelet }\end{array}$ & $\begin{array}{c}\text { Ratio } \\
\text { Scott/control }\end{array}$ & Assumed function class \\
\hline \multicolumn{6}{|c|}{ Top 15 increased expression } \\
\hline P29972 & $A Q P 1$ & Aquaporin-1 & n.d. & 54.10 & Membrane receptors \& channels (10) \\
\hline P18065 & IGFBP2 & Insulin-like growth factor-binding protein 2 & 975 & 8.78 & Signalling \& adapter proteins (18) \\
\hline 014639 & ABLIM1 & Actin-binding LIM protein 1 & 1120 & 7.64 & Cytoskeleton receptor-linked (4) \\
\hline Q96KC8 & DNAJC1 & DnaJ homolog subfamily $\mathrm{C}$ member 1 & $\mathrm{TiO}_{2}$ & 7.38 & ER \& Golgi proteins (6) \\
\hline P57088 & TMEM33 & Transmembrane protein 33 & 2497 & 6.23 & Membrane receptors \& channels (10) \\
\hline 095671 & ASMTL & $\mathrm{N}$-acetylserotonin O-methyltransferase-like protein & 1035 & 5.84 & Other metabolism (12) \\
\hline 060890 & OPHN1 & Oligophrenin-1 & 1527 & 5.21 & Small GTPases \& regulators (19) \\
\hline Q92616 & GCN1L1 & Translational activator GCN1 & 808 & 5.02 & Transcription \& translation (20) \\
\hline Q01415 & GALK2 & $\mathrm{N}$-acetylgalactosamine kinase & 1323 & 4.61 & Other metabolism (12) \\
\hline P68104 & EEF1A1 & Elongation factor 1 -alpha 1 & 4521 & 4.05 & Transcription \& translation (20) \\
\hline Q9P035 & PTPLAD1 & Very-long-chain 3-hydroxyacyl-ACP dehydratase 3 & 929 & 4.04 & Other metabolism (12) \\
\hline Q9UPM8 & AP4E1 & AP-4 complex subunit epsilon-1 & 632 & 3.98 & ER \& Golgi proteins (6) \\
\hline Q12805 & EFEMP1 & EGF-containing fibulin-like extracellular matrix protein 1 & 1414 & 3.95 & Secretory proteins (17) \\
\hline Q96PD5 & PGLYRP2 & $\mathrm{N}$-acetylmuramoyl-L-alanine amidase & n.d. & 3.95 & Secretory proteins (17) \\
\hline P05388 & RPLPO & $60 \mathrm{~S}$ acidic ribosomal protein $\mathrm{P} 0$ & 986 & 3.85 & Transcription \& translation (20) \\
\hline
\end{tabular}

Table II. Top 15 of decreased (top) and increased (bottom) expression levels of proteins in Scott platelets. Relative abundance is determined for 2,225 identified proteins in unstimulated platelets from the Scott patient and a healthy control subject (see Figure 2). Shown are the top 15 of proteins with highest decrease or increase in expression levels in the patient's platelets. Indicated are Uniprot numbers and common names of genes and proteins. Estimated copy numbers per platelet (healthy subject) are taken from the previously published proteome ${ }^{20}$. All proteins were assigned to 21 assumed platelet function classes, based on GeneOntology classifications. Abbreviations: n.d., not determined; $\mathrm{TiO}_{2}, \mathrm{TiO}_{2}$ enrichment protocol.

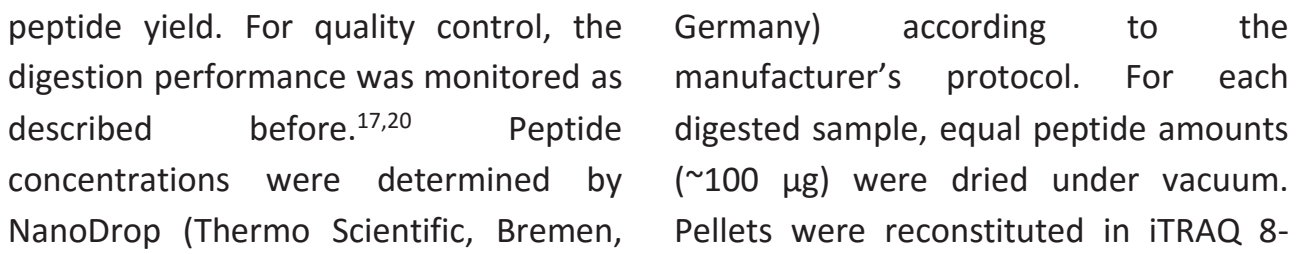


plex solution buffer (AB Sciex, Dreieich, Germany) and labelled according to the manufacturer's protocol. The eight differently labelled activation states from the control subject and Scott patient were pooled in a 1:1 ratio and the volume was reduced under vacuum. Subsequently, $10 \%$ of the pooled sample was desalted by $\mathrm{C}_{18}$ solid phase extraction (SPEC $\mathrm{C}_{18} \mathrm{AR}, 4 \mathrm{mg}$ bed, Agilent Technologies), according to manufacturer's protocol ${ }^{25}$. The pooled sample was dried under vacuum and reconstituted in $10 \mathrm{mM}$ ammonium acetate $\mathrm{pH} 6.0$ (solvent $\mathrm{A}$ ).

Platelet global proteome analysis using iTRAQ labels

iTRAQ global proteome analysis was performed as a quality control to check for possible changes in relative protein abundance after platelet stimulation. This ensured that differences in phosphorylation pattern (up/downregulated) are not due to changes in protein abundance. Therefore, $40 \mu \mathrm{g}$ of the pooled peptide samples were separated by HPLC on a $\mathrm{C}_{18}$ column (Agilent Zorbax; $1 \mathrm{~mm}$ inner diameter (ID) x $15 \mathrm{~cm} ; 5 \mu \mathrm{m}$ particle size; $300 \AA$ pore size, Agilent Technologies). The U3000 HPLC system (Thermo Scientific) was used with a flow rate of $60 \mu \mathrm{l} /$ minute and a binary gradient ranging from $3-60 \%$ solvent B (10 mM ammonium acetate, $84 \%$ acetonitrile, $\mathrm{pH}$ 6.0) in 75 minutes.
Twenty concatenated fractions were collected every minute. All fractions were individually analysed by nano LCMS/MS, using an UltiMate 3000 nanoRSLC system online-coupled to a QExactive mass spectrometer. Each fraction was loaded onto a trap column (Acclaim PepMap100 $\mathrm{C}_{18}$ trap column; $100 \mu \mathrm{m} \times 2 \mathrm{~cm}$ ) with $0.1 \%$ trifluoroacetic acid at flow rate of $20 \mu \mathrm{l} /$ minute. This was followed by separation of peptides on the main column (PepMap100 $\mathrm{C}_{18}$ main column; $75 \mu \mathrm{m} \times 50 \mathrm{~cm}$ ), using a binary gradient ranging from $3-42 \%$ solvent B during 140 minutes at $60{ }^{\circ} \mathrm{C}$ and a flow rate of $250 \mathrm{nl} /$ minute. In the Q-Exactive mass spectrometer, survey scans were acquired at resolution of 70,000 using an automatic gain control (AGC) target value of $3 \times 10^{6}$. Subsequently, MS/MS spectra of the 15 most intense ions were acquired with (i) a resolution of 17,500 , (ii) an isolation width of $2.0 \mathrm{~m} / \mathrm{z}$; (iii) a normalised collision energy of 35; (iv) an AGC target value of $1 \times 10^{6}$ ions; ( $v$ ) a maximum injection time of 250 milliseconds; (vi) and dynamic exclusion of 12 seconds with underfill ratio of $10 \%$. The first fixed mass was set to $105 \mathrm{~m} / \mathrm{z}$.

Global proteome data were interpreted as follows. Raw data were processed with the program Proteome Discoverer 1.4 (Thermo-Fisher Scientific); data were searched against the Uniprot human database (August 2012; 20,232 target 


\section{A}
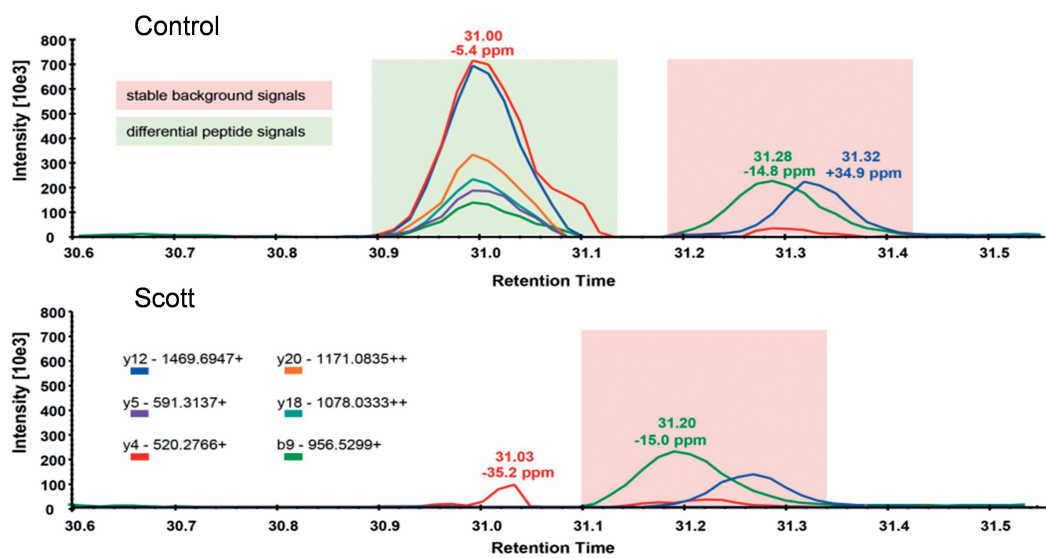

B
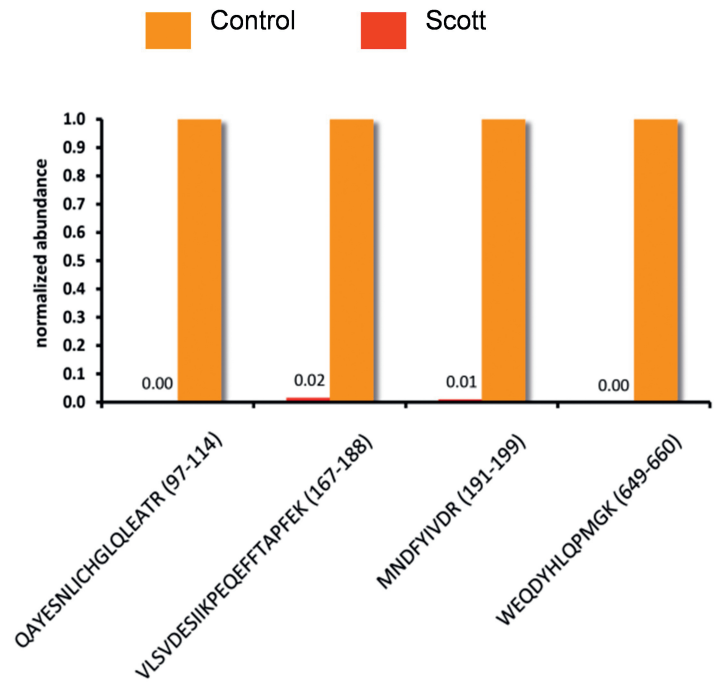

Figure 3. Quantitation of anoctamin-6 peptides in Scott platelets using parallel reaction monitoring (PRM). High-resolution quantification of tryptic anoctamin-6 fragments by PRM. (A) Representative data of the anoctamin-6 peptide VLSVDESIIKPEQEFFTAPFEK (amino acids 167-188). Whereas the correct peptide at retention time of 31.2 minutes can only be detected in the sample from the control subject, the background peaks at this retention time have the same intensity for both samples. Owing to the high mass deviation of $-35.2 \mathrm{ppm}$ and the incorrect peak pattern, the residual signal at 31.03 minutes in the Scott sample (8x lower than in the control) cannot be assigned to this peptide. (B) Summary of the normalised abundance of four quantified anoctamin- 6 peptides in Scott and control platelets, representing different parts of the 910 amino acids. Intensities of the control sample were set to 1.0 and compared to those of the patient sample. The minor residual signals in the Scott patient can be attributed to noise, because of deviation in mass and peak pattern. 


\begin{tabular}{|c|c|c|c|c|c|c|c|}
\hline \multirow[t]{2}{*}{$\begin{array}{l}\text { Uniprot } \\
\text { number }\end{array}$} & \multirow[t]{2}{*}{$\begin{array}{l}\text { Gene } \\
\text { name }\end{array}$} & \multirow[t]{2}{*}{ Protein name } & \multirow[t]{2}{*}{$\begin{array}{l}\text { Phospho- } \\
\text { site }\end{array}$} & \multicolumn{3}{|c|}{ Ratio Scott/control (phospho) } & \multirow[t]{2}{*}{ Assumed function class } \\
\hline & & & & Thr & Cvx/Thr & Iono & \\
\hline \multicolumn{8}{|c|}{ Top 15 decreased phospho-sites } \\
\hline 095810 & $S D P R$ & Cavin-2 (PS-p68, phosphatidylserine-binding protein) & Ser114 & 0.62 & 0.27 & 0.12 & Signalling \& adapter proteins (18) \\
\hline P05867 & PLEK & Pleckstrin & Thr341 & 0.32 & 0.21 & 0.49 & Cytoskeleton actin-myosin (1) \\
\hline O75324 & SNN & Stannin & Thr507 & 1.21 & 0.44 & 0.26 & Signalling \& adapter proteins (18) \\
\hline P29350 & PTPN6 & Tyrosine-protein phosphatase non-receptor type 6 & Ser82 & 1.01 & 0.47 & 0.26 & Protein kinases \& phosphatases (15) \\
\hline Q05655 & PRKCD & Protein kinase $\mathrm{C}$ delta type & Thr73 & 1.09 & 0.42 & 0.31 & Protein kinases \& phosphatases (15) \\
\hline P54578 & USP14 & Ubiquitin carboxyl-terminal hydrolase 14 & Ser109 & 0.77 & 0.41 & 0.33 & Proteasome (14) \\
\hline Q8NHG8 & ZNRF2 & E3 ubiquitin-protein ligase ZNRF2 & Ser332 & 0.87 & 0.51 & 0.37 & Proteasome (14) \\
\hline Q99719 & SEPT5 & Septin-5 (Cell division control-related protein 1) & Ser698 & 0.29 & 0.69 & 0.23 & Cytoskeleton receptor-linked (4) \\
\hline Q9Y2Q0 & ATP8A1 & Phospholipid-transporting ATPase IA (P4-ATPase flippase) & Ser49 & 0.46 & 0.54 & 0.40 & Membrane receptors \& channels (10) \\
\hline Q86UX7 & FERMT3 & Fermitin family homolog 3 (Kindlin-3) & Thr311 & 0.92 & 0.53 & 0.45 & Cytoskeleton receptor-linked (4) \\
\hline Q9H4B7 & TUBB1 & Tubulin beta- 1 chain & Tyr536 & 0.85 & 0.70 & 0.28 & Cytoskeleton microtubule (3) \\
\hline Q8N699 & MYCT1 & Myc target protein 1 & Ser31 & 0.76 & 0.66 & 0.35 & Signalling \& adapter proteins (18) \\
\hline Q13976 & PRKG1 & cGMP-dependent protein kinase 1 & Ser1178 & 0.47 & 0.36 & 0.69 & Protein kinases \& phosphatases (15) \\
\hline Q12982 & $B N I P 2$ & BLC2 & Ser114 & 0.31 & 0.19 & 0.47 & Signalling \& adapter proteins (18) \\
\hline P61026 & RAB10 & Ras-related protein Rab-10 & Ser1076 & 0.99 & 0.68 & 0.45 & Small GTPases \& regulators (19) \\
\hline \multirow[t]{2}{*}{$\begin{array}{l}\text { Uniprot } \\
\text { number }\end{array}$} & $\begin{array}{l}\text { Gene } \\
\text { name }\end{array}$ & Protein name & $\begin{array}{l}\text { Phospho- } \\
\text { site }\end{array}$ & \multicolumn{3}{|c|}{ Ratio Scott/control (phospho) } & Assumed function class \\
\hline & & & & Thr & Cvx/Thr & lono & \\
\hline \multicolumn{8}{|c|}{ Top 15 increased phospho-sites } \\
\hline P78559 & MAP1A & Microtubule-associated protein $1 \mathrm{~A}$ & Ser391 & 6.23 & 6.54 & 8.02 & Cytoskeleton microtubule (3) \\
\hline Q9UDY2 & $T J P 2$ & Tight junction protein ZO-2 & Ser899 & 1.58 & 4.84 & 9.67 & Membrane receptors \& channels (10) \\
\hline Q6VY07 & PACS1 & Phosphofurin acidic cluster sorting protein 1 & Ser168 & 1.53 & 4.68 & 8.01 & ER \& Golgi proteins (6) \\
\hline Q0ZGT2 & NEXN & Nexilin & Thr144 & 1.71 & 3.39 & 9.16 & Cytoskeleton actin-myosin (1) \\
\hline O95819 & MAP4K4 & Mitogen-activated protein kinase kinase kinase kinase 4 & Thr144 & 1.48 & 4.03 & 7.88 & Protein kinases \& phosphatases (15) \\
\hline Q8TF64 & GIPC3 & PDZ domain-containing protein GIPC3 & Thr144 & 1.39 & 4.18 & 7.36 & Unknown \\
\hline Q9Y490 & TLN1 & Talin-1 & Thr142 & 5.96 & 6.16 & 5.09 & Cytoskeleton receptor-linked (4) \\
\hline O60229 & KALRN & Kalirin (Huntingtin-associated protein-interacting protein) & Thr517 & 1.34 & 3.98 & 6.32 & Small GTPases \& regulators (18) \\
\hline Q96G03 & PGM2 & Phosphoglucomutase-2 & Thr59 & 4.62 & 3.93 & 4.74 & Glucose metabolism (7) \\
\hline 014639 & ABLIM1 & Actin-binding LIM protein 1 & Ser301 & 1.04 & 2.97 & 5.00 & Cytoskeleton receptor-linked (4) \\
\hline Q9P035 & PTPLAD1 & Very-long-chain (3R)-3-hydroxyacyl-CoA dehydratase 3 & Ser111 & 1.46 & 3.23 & 3.86 & Other metabolism (12) \\
\hline P42331 & \multicolumn{2}{|c|}{ ARHGAP25 Rho GTPase-activating protein 25} & Ser703 & 1.32 & 2.40 & 4.46 & Small GTPases \& regulators (18) \\
\hline P78559 & MAP1A & Microtubule-associated protein $1 \mathrm{~A}$ & Ser86 & 1.42 & 2.31 & 4.11 & Cytoskeleton microtubule (3) \\
\hline Q8ND76 & CCNY & Cyclin-Y (Cyclin box protein 1) & Ser138 & 0.91 & 2.07 & 4.22 & Signalling \& adapter proteins (18) \\
\hline P27987 & ITPKB & Inositol-trisphosphate 3-kinase B & Thr638 & 1.12 & 3.47 & 2.87 & Signalling \& adapter proteins (18) \\
\hline
\end{tabular}

Table III. Top 15 of decreased (top) and increased (bottom) phosphorylation patterns in proteins of Scott platelets. Ratios are determined for phosphorylation changes of 1,566 phosphopeptides from Scott and control platelets, stimulated with thrombin, convulxin/thrombin or ionomycin. Shown are the top 15 of highest decreases or increases in phosphorylation in Scott platelets (ranked for combination of convulxin/thrombin and ionomycin stimulation) compared to control platelets per agonist condition. Also indicated are Uniprot accessions and common names of genes and proteins. Proteins were assigned to 21 assumed platelet function classes, based on GeneOntology classifications. Colour code: red = decreased, green = increased in the patient's platelets.

sequences). Mascot and Sequest were used as search algorithms with the following settings: (i) trypsin as enzyme allowing two missed cleavages, (ii) iTRAQ 8-plex at $\mathrm{N}$-termini and lysines and carbamidomethylation of Cys residues as fixed modifications, (iii) oxidation of methionine as variable modification, (iv) mass tolerances for MS and MS/MS were set to $10 \mathrm{ppm}$ and $0.02 \mathrm{Da}$, respectively. False discovery rate (FDR) estimation for the level of peptide spectrum matches 
was performed using the peptide validator node with filtering for $1 \%$ FDR (high confidence filter) and the reporter ion quantifier node.

ratios for the 8 samples, an artificial $113 / 113$ ratio was created and set to 1.0 per protein. For each protein, a median of all iTRAQ ratios $(113 / 113, \ldots, 121 / 113)$ was calculated and the individual ITRAQ ratios were divided by this median to obtain relative abundance values. For normalisation of potential systematic errors, correction factors for each channel were calculated based on the median relative abundance over all proteins. Subsequently, ratios between the stimulated and basal conditions for the patient and control platelets were calculated. Proteins which had ratios larger than $2 \times$ SD above or below the mean value were considered as regulated.

\section{Label free global proteome analysis}

To exclude isolation interference in ionbased quantifications, we verified the global proteome by an additional labelfree quantification workflow. Therefore, $35 \mu \mathrm{g}$ protein samples from unstimulated platelets were separately processed and digested, as mentioned above. After digestion control, samples were individually fractionated on a $\mathrm{C}_{18}$ column (BioBasic-18; $0.5 \mathrm{~mm}$ ID x $15 \mathrm{~cm}$; $5 \mu \mathrm{m}$ particle size; $300 \AA$ pore size). An UltiMate 3000 liquid chromatography
Unique proteins quantified if at least 2 unique peptides were considered. As Proteome Discoverer only provided 7 system (Thermo-Fisher Scientific) was used with a flow rate of $12.5 \mu \mathrm{l} /$ minute and a binary gradient ranging from 3-60\% solvent J (10 mM ammonium acetate, 84\% acetonitrile, $\mathrm{pH}$ 6.0) in 75 minutes. Four concatenated fractions were collected. Each fraction was individually analysed by nano LC-MS/MS, using an UltiMate 3000 nano-RSLC system online-coupled with an Orbitrap Fusion mass spectrometer. Fractions were loaded onto a trap column (Acclaim PepMap100 $\mathrm{C}_{18}$ trap column; $100 \mu \mathrm{m} \times 2 \mathrm{~cm}$ ) with $0.1 \%$ trifluoroacetic acid at flow rate of 20 $\mu \mathrm{l} /$ minute, followed by separation on the main column (PepMap100 $\mathrm{C}_{18}$ main column; $75 \mu \mathrm{m} \times 50 \mathrm{~cm}$ ) using a binary gradient ranging from $3-42 \%$ solvent $B$ during 100 minutes at $60{ }^{\circ} \mathrm{C}$ and a flow rate of $250 \mathrm{nl} /$ minute. Survey scans were acquired at a resolution of 60,000 with target values of $4 \times 10^{5}$ and maximum injection time of 50 milliseconds. Then, MS/MS spectra of the 20 most intense ions were acquired in the ion trap, using HCD with a collision energy of 35 , a target value of $1 \times 10^{4}$ ions, a maximum injection time of 50 milliseconds, and a dynamic exclusion of 12 seconds.

Data analysis and label free quantification were performed using the Progenesis LC-MS software version 4.1 
from Nonlinear Dynamics (Newcastle upon Tyne, UK) in combination with the programme PeptideShaker $0.29 .{ }^{25}$ Fractions were aligned pairwise and four peak lists were exported and searched with $\mathrm{X}$ !Tandem Jackhammer using searchGUI 1.18.4 ${ }^{26}$ as well as Mascot 2.4 (Matrix Science), and a concatenated target/decoy version of the human Uniprot database (August 2012; 20,232 target sequences). The following search parameters were used: (i) trypsin as protease with a maximum of two missed cleavages, (ii) carbamidomethylation of Cys as fixed, and (iii) oxidation of Met as

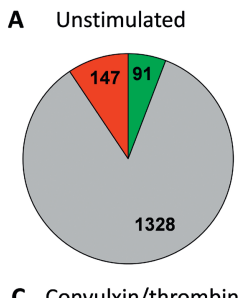

C Convulxin/thrombin

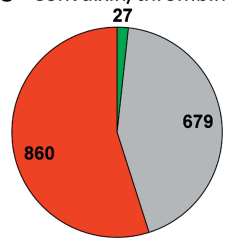

Phosphopeptides: variable modification. MS and MS/MS tolerances were set to $10 \mathrm{ppm}$ and 0.5 Da. Search results were combined using PeptideShaker (http://code.google.com/p/peptideshaker/) and filtered at an FDR of $1 \%$ on the peptide spectrum match, peptide and protein levels. Results from paired fractions were reimported into Progenesis. Peptide sequences containing oxidized Met and pyro-Glu were omitted from further data analysis and only proteins with at least two unique peptides were considered for quantification. For all proteins,

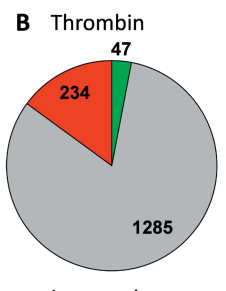

D Ionomycin

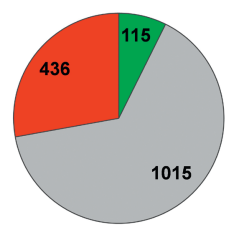

decreased, $\square$ increased

Figure 4. Changes of phosphoproteome in Scott platelets subjected to strong activation. iTRAQ-labelled digests from control and Scott platelets were simultaneously analysed for phosphopeptide presence: unstimulated, or stimulated for 30 minutes with thrombin, convulxin/thrombin or ionomycin. Per quantified phosphopeptide, median ratios were calculated to determine relative changes in phosphorylation upon platelet activation with indicated agonist (activation ratios per subject). Activation ratios per subject were classified as changed when outside the range of mean \pm 2 SD (mean $=0.97, \mathrm{SD}=0.18$ ); hence, decreased (ratio $\leq 0.61$ ), unchanged (ratio 0.61-1.33) or increased (ratio $\geq 1.33$ ). Panels indicate changes in phosphopeptides for (un)stimulated Scott platelets; clockwise: green = decreased, grey = unchanged, red = increased. (A) Distribution of changes in phosphopeptide ratio of unstimulated platelets (ratio: Scott unstimulated/control unstimulated). (B-D) Distribution of changes in phosphopeptide ratios after platelet stimulation (ratio: effect agonist on Scott platelets/effect agonist on control platelets); stimulation with thrombin (B), convulxin/thrombin (C), or ionomycin (D). 


\begin{tabular}{|c|c|c|c|c|c|c|c|c|c|c|c|}
\hline \multirow{2}{*}{$\begin{array}{l}\text { Uniprot } \\
\text { number }\end{array}$} & \multirow[t]{2}{*}{$\begin{array}{l}\text { Gene } \\
\text { name }\end{array}$} & \multirow[t]{2}{*}{ Protein name } & \multirow{2}{*}{$\begin{array}{c}\text { Cleave } \\
\text { site }\end{array}$} & \multirow[t]{2}{*}{$\begin{array}{l}\text { AA } \\
\text { P2 }\end{array}$} & \multirow{2}{*}{$\begin{array}{l}\text { AA } \\
\text { P1 }\end{array}$} & \multirow[t]{2}{*}{$\begin{array}{l}\text { AA } \\
\text { P1' }\end{array}$} & \multicolumn{3}{|c|}{ Ratio Scott/control (cleavage) } & \multirow[t]{2}{*}{ Inhib. } & \multirow[t]{2}{*}{ Assumed function class } \\
\hline & & & & & & & Thr & Cvx/Thr & Iono & & \\
\hline \multicolumn{12}{|c|}{ Top 15 decreased $N$-terminal cleavage } \\
\hline Q14432 & PDE $3 A$ & cGMP-inhibited 3',5'-cyclic phosphodiesterase A & Asn596 & Q & G & $\mathrm{N}$ & 0.94 & 0.08 & 0.77 & $0 \%$ & Signalling \& adapter proteins (18) \\
\hline Q9UJU6 & $D B N L$ & Drebrin-like protein & Ala183 & A & K & A & 0.47 & 0.19 & 3.73 & $0 \%$ & Cytoskeleton actin-myosin (1) \\
\hline Q9Y490 & TLN1 & Talin-1 & $\mathrm{Ala} 2504$ & 1 & A & A & 0.93 & 0.22 & 1.73 & $0 \%$ & Cytoskeleton receptor-linked (4) \\
\hline Q0ZGT2 & NEXN & Nexilin (F-actin-binding protein) & Leu312 & L & $\mathrm{k}$ & $\mathrm{L}$ & 0.84 & 0.23 & 2.32 & $0 \%$ & Cytoskeleton actin-myosin (1) \\
\hline Q15942 & $z y x$ & Zyxin & Asp369 & M & Q & $\mathrm{D}$ & 0.92 & 0.23 & 1.26 & $0 \%$ & Cytoskeleton actin-myosin (1) \\
\hline P53621 & COPA & Coatomer subunit alpha & Ser413 & $\mathrm{K}$ & $\mathrm{R}$ & s & 0.73 & 0.23 & 0.06 & $1 \%$ & Membrane \& protein trafficking (9) \\
\hline 000429 & DNM1L & Dynamin-1-like protein & Asp627 & L & L & $\mathrm{D}$ & 1.09 & 0.24 & 1.68 & $0 \%$ & Cytoskeleton microtubule (3) \\
\hline Q7L591 & DOK3 & Docking protein 3 & Gly412 & L & $\mathrm{H}$ & G & 1.11 & 0.25 & 1.09 & $0 \%$ & Signalling \& adapter proteins (18) \\
\hline O43294 & TGFB111 & TGF beta-1-induced transcript 1 protein & Leu210 & L & G & $\mathrm{L}$ & 0.90 & 0.26 & 1.14 & $0 \%$ & Signalling \& adapter proteins (18) \\
\hline P50552 & VASP & Vasodilator-stimulated phosphoprotein & Ser329 & $T$ & $\mathrm{~T}$ & S & 0.74 & 0.27 & 2.37 & $0 \%$ & Signalling \& adapter proteins (18) \\
\hline B2RUZ4 & SMIM1 & Small integral membrane protein 1 & $\mathrm{Ala} 25$ & L & G & A & 0.86 & 0.27 & 1.74 & $0 \%$ & Cytoskeleton receptor-linked (4) \\
\hline P49841 & GSK3B & Glycogen synthase kinase- 3 beta & Ala394 & $\mathrm{T}$ & $\mathrm{N}$ & A & 0.67 & 0.27 & 1.50 & $0 \%$ & Protein kinases \& phosphatases (15) \\
\hline 095810 & $S D P R$ & Cavin-2 (PS-p68, phosphatidylserine-binding protein) & Tyr395 & $\mathrm{v}$ & R & $\mathrm{Y}$ & 0.48 & 0.30 & 1.52 & $2 \%$ & Signalling \& adapter proteins (18) \\
\hline Q15691 & MAPRE1 & Microtubule-associated protein RP/EB family member 1 & Ala171 & $\mathrm{T}$ & A & A & 0.77 & 0.31 & 2.74 & $0 \%$ & Cytoskeleton microtubule (3) \\
\hline 015117 & FYB & FYN-binding protein & Gly93 & $\mathrm{R}$ & $\mathrm{F}$ & G & 0.77 & 0.32 & 2.74 & $1 \%$ & Signalling \& adapter proteins (18) \\
\hline \multirow[t]{2}{*}{$\begin{array}{l}\text { Uniprot } \\
\text { number }\end{array}$} & $\begin{array}{l}\text { Gene } \\
\text { name }\end{array}$ & Protein name & $\begin{array}{c}\text { Cleave } \\
\text { site }\end{array}$ & $\begin{array}{l}\text { AA } \\
\text { P2 }\end{array}$ & $\begin{array}{l}\text { AA } \\
\text { P1 }\end{array}$ & $\begin{array}{l}\text { AA } \\
\text { P1 }\end{array}$ & \multicolumn{3}{|c|}{ Ratio Scott/control (cleavage) } & hib. & Assumed function class \\
\hline & & & & & & & Thr & Cvx/Thr & lono & & \\
\hline \multicolumn{12}{|c|}{ Top 15 increased $\mathrm{N}$-terminal cleavage } \\
\hline P21333 & FLNA & Filamin-A & Ser468 & $P$ & $R$ & S & 1.65 & 8.57 & 1.44 & $100 \%$ & Cytoskeleton receptor-linked (4) \\
\hline A5A3E0 & POTEF & POTE ankyrin domain family member $F$ & Asp922 & A & L & $\mathrm{D}$ & 1.01 & 8.40 & 0.82 & $82 \%$ & Cytoskeleton actin-myosin (1) \\
\hline P21333 & FLNA & Filamin-A & Ser310 & $\mathrm{T}$ & R & S & 2.22 & 6.03 & 1.28 & $100 \%$ & Cytoskeleton receptor-linked (4) \\
\hline P08514 & $\Pi G A 2 B$ & Integrin alpha-llb & Gly367 & $P$ & $\mathrm{R}$ & G & 2.38 & 3.72 & 2.00 & $100 \%$ & Membrane receptors \& channels (10) \\
\hline Q9UBC2 & EPS15L1 & Epidermal growth factor receptor substrate 15 -like 1 & Ser560 & $\mathrm{H}$ & R & s & 1.65 & 3.61 & 0.41 & $7 \%$ & Membrane \& protein trafficking (9) \\
\hline Q562R1 & ACTBL2 & Beta-actin-like protein 2 & Val220 & c & Y & $\mathrm{v}$ & 1.03 & 3.45 & 0.82 & $46 \%$ & Cytoskeleton actin-myosin (1) \\
\hline Q16643 & DBN1 & Drebrin & Ala635 & w & D & A & 3.41 & 2.83 & 2.32 & $65 \%$ & Cytoskeleton receptor-linked (4) \\
\hline Q96w6 & GMPPA & Mannose-1-phosphate guanyltransferase alpha & Ser413 & $\mathrm{s}$ & $R$ & s & 2.76 & 2.81 & 1.26 & $100 \%$ & Other metabolism (12) \\
\hline 014964 & HGS & Hepatocyte growth factor-regulated tyr kinase substrate & Ser432 & G & $\mathrm{R}$ & s & 1.16 & 2.59 & 0.16 & $98 \%$ & Signalling \& adapter proteins (18) \\
\hline P07996 & THBS1 & Thrombospondin-1 & Gly25 & $\mathrm{E}$ & s & G & 1.64 & 2.45 & 0.76 & $97 \%$ & Secretory proteins (17) \\
\hline Q7LDG7 & RASGRP2 & RAS guanyl-releasing protein 2 (CaIDAG-GEFI) & Ser487 & L & R & s & 2.23 & 2.38 & 1.11 & $91 \%$ & Small GTPases \& regulators (19) \\
\hline P35579 & МҮH9 & Myosin-9 & Ala625 & Q & v & A & 2.38 & 2.35 & 1.84 & $82 \%$ & Cytoskeleton actin-myosin (1) \\
\hline $\mathrm{P} 62942$ & FKBP1A & Peptidyl-prolyl cis-trans isomerase FKBP1A & Gly2 & & M & G & 2.08 & 2.30 & 0.82 & $81 \%$ & Protein kinases \& phosphatases (15) \\
\hline 095810 & SDPR & Cavin-2 (PS-p68, phosphatidylserine-binding protein) & Tyr399 & G & $\mathrm{s}$ & $\mathrm{Y}$ & 3.96 & 2.29 & 2.56 & $1 \%$ & Signalling \& adapter proteins (18) \\
\hline P62937 & PPIA & Peptidyl-prolyl cis-trans isomerase A & Val2 & & M & $\mathrm{v}$ & 1.97 & 2.29 & 0.90 & $85 \%$ & Protein processing (16) \\
\hline
\end{tabular}

Table IV. Top 15 of decreased (top) and increased (bottom) neo- $\mathrm{N}$-terminal cleavage sites in proteins of Scott platelets. Ratios are determined for the appearance of neo-N-termini of 1,613 peptides in Scott and control platelets, activated with thrombin, convulxin/thrombin or ionomycin. Shown are the top 15 of highest decreases or increases in neo-N-termini formed in Scott platelets (ranked for convulxin/thrombin), compared to control platelets per agonist condition. Ratios are calculated as: (effect of agonist in Scott platelets) / (effect of agonist in control platelets). Indicated are two amino acids (AA) P2 and P1 prior to the cleavage site, and the neo-Nterminal amino acid $\mathrm{P}^{\prime}$ at the cleavage site. Blue colour refers to amino acids with a predicted positive contribution to calpain-mediated cleavage. Colour code: red = decreased, green = increased in the patient's platelets. Column Inhib. refers to the confirmative experiment, showing residual cleavage in the presence of calpain inhibitor calpeptin in ionomycin-stimulated platelets from a control subject $(0 \%=$ blue $=$ no residual cleavage in the presence of calpeptin).

normalised abundances per sample were obtained, and ratios between Scott and control platelets were calculated.

\section{Platelet phosphoproteome analysis}

For phosphopeptide analysis of the pooled ITRAQ samples, a $\mathrm{TiO}_{2}$-based phosphopeptide enrichment protocol was conducted, as described. ${ }^{27}$ Enriched phosphopeptides were fractionated with a U3000 HPLC-rapid separation liquid chromatography

(Thermo-Fisher

Scientific) system running in hydrophilic interaction liquid chromatography (HILIC) mode. Peptides were loaded on a selfpacked HILIC column (Polar phase TSKgel Amide-80; $150 \mu \mathrm{m}$ ID $\times 15 \mathrm{~cm}$ length; 5 $\mu \mathrm{m}$ particle size; $80 \AA$ pore size, Tosoh 
Bioscience, Germany) and separated using a binary gradient ranging from $5-40 \%$ solvent D (mobile phase solvent C: $98 \%$ acetonitrile, $0.1 \%$ trifluoroacetic acid; solvent $\quad D: 0.1 \%$ trifluoroacetic acid) within 40 minutes at a flow rate of 4 $\mu \mathrm{l} /$ minute. Eluting peptides were collected in 9 fractions. The separation procedure was repeated as required. ${ }^{22}$

\section{LC-MS analysis of phosphopeptides}

All HILIC fractions were analysed by nano-LC-MS/MS using an RSLC-nano system, online coupled to a LTQ-Orbitrap Velos mass spectrometer (both ThermoFisher Scientific). Peptides were preconcentrated on a self-packed precolumn (Kinetex; $100 \mu \mathrm{m}$ ID x $2 \mathrm{~cm}$ length; $2.6 \mu \mathrm{m}$ particle size; $100 \AA$ pore size) at a flow rate of $20 \mu \mathrm{l} /$ minute and further separated on a self-packed main column (Kinetex, $75 \mu \mathrm{m}$ ID x $30 \mathrm{~cm}$ length; $2.6 \mu \mathrm{m}$ particle size; $100 \AA$ pore size) using a binary gradient (solvent $\mathrm{E}$ : $0.1 \%$ formic acid; solvent F: $84 \%$ acetonitrile, $0.1 \%$ formic acid) ranging from $3-45 \%$ solvent $F$ during for 75 minutes at a flow rate of $250 \mathrm{nl} /$ minute at $60{ }^{\circ} \mathrm{C}$. In the LTQ-Orbitrap Velos MS higher collision-induced dissociation (HCD) fragmentation was used; survey scans were acquired with a resolution of 30,000 using the polysiloxane $\mathrm{m} / \mathrm{z}$ 371.1012 as lock mass. ${ }^{28}$ Subsequently, MS/MS spectra of the 5 most intense ions were acquired with (i) a resolution of 7,500 (ii) an isolation width of $2.0 \mathrm{~m} / \mathrm{z}$; (iii) a normalised collision energy of 50 ; (iv) an AGC target value of $1 e^{5}$ ions; ( $v$ ) a maximum injection time of 200 milliseconds; (vi) and a dynamic exclusion of 12 seconds. Reaction tubes containing $10 \%$ ammonium water were placed in front of the ion source to compensate for the iTRAQ-induced increase of peptide charge states. ${ }^{29}$

Data analysis and confidence of determination of phosphopeptides

Raw data were processed with the program Proteome Discoverer 1.3 (Thermo-Fisher Scientific) using Sequest and Mascot as search algorithms. MS/MS spectra were searched against a human Uniprot database (July 2012; 20,232 target sequences) using the following search settings: (i) trypsin with a maximum of two missed cleavages; (ii) carbamidomethylation of Cys (+57.0214 Da) as well as iTRAQ 8-plex (+304.2053 $\mathrm{Da}$ ) at peptide $\mathrm{N}$-termini and Lys residues as fixed modifications; (iii) oxidation of Met (+15.9949 Da) as well as phosphorylation of Ser/Thr/Tyr (+79.9663 Da) as variable modifications; (iv) MS and MS/MS tolerances of $10 \mathrm{ppm}$ and $0.02 \mathrm{Da}$, respectively. FDR estimation on the level of peptide spectrum matches (PSMs) was performed using the peptide validator node, and phosphorylation site localisation was determined using 
phospho-RS. ${ }^{30}$ The PSMs were filtered for 1\% FDR (high confidence filter), and only phosphopeptides with phospho-RS probabilities $\geq 90 \%$ were considered as confident. Raw data and Proteome Discoverer search results will deposited in the ProteomeXchange repository. ${ }^{31}$

Obtained ITRAQ ratios were normalised based on the ITRAQ global proteome analysis in order to compensate for systematic errors. For determination of confident phosphorylation sites at the peptide and protein level a ready-to-use Excel macro provided by Mechtler lab (http://ms.imp.ac.at/?goto=phosphors) was used. Peptides were grouped based on their sequences, protein accessions and phosphorylation sites. Next, normalised abundance per channel was calculated, as mentioned above for the global proteome. Ratios between the Scott patient and control donor was calculated per condition. Cut-offs for potential regulation level were defined as for the ITRAQ global proteome.

Sample digestion and preparation for determination of neo N-terminal cleavage sites

Proteins were precipitated using ice-cold ethanol. Pellets from 8 selected samples were resuspended in $10 \mu \mathrm{l} 10 \%$ SDS under ultrasonication (3x for 10 seconds). These samples were then diluted to $1 \%$ SDS with 0.5 M TEAB containing $20 \%$ isopropanol (v/v). iTRAQ 8-plex reagents in isopropanol $(40 \mu \mathrm{l})$ were added and allowed to react for 2 hours at $25{ }^{\circ} \mathrm{C}$. Subsequently, all 8 samples were pooled and the reaction was quenched with 60 $\mathrm{mM}$ glycine (10 minutes at room temperature), followed by incubation with $130 \mathrm{mM}$ hydroxylamine to reverse side reactions at hydroxyl groups (10 minutes at room temperature).

For proteolytic digestion, the multiplex sample was divided into two aliquots (160 $\mu \mathrm{g}$ proteins each), which were subjected to ethanol precipitation. Samples were resuspended in $0.2 \mathrm{M}$ guanidine $\mathrm{HCl}$ and $50 \mathrm{mM}$ TEAB buffer and $2 \mathrm{mM} \mathrm{CaCl}_{2}$ (final concentrations). Trypsin (Sigma, T1426) was added at enzyme/protein ratio of $1: 20$. After 14 hours trypsinisation at $37{ }^{\circ} \mathrm{C}$, reactions were stopped with $1 \%$ trifluoroacetic acid, and the proteolytic digest was controlled using monolithic reversed phase chromatography, as described. ${ }^{22}$ Generated peptides were desalted using $\mathrm{C}_{18}$ solid phase tips (SPEC $\mathrm{C}_{18} \mathrm{AR}, 4 \mathrm{mg}$ bed, Agilent Technologies) as follows: activation with $100 \mu \mathrm{l}$ of $100 \%$ acetonitrile, followed by equilibration with $100 \mu \mathrm{l}$ of $0.1 \%$ trifluoroacetic acid. Bound peptides were washed two times with $0.1 \%$ of formic acid ( $/ / v)$, and then eluted with $100 \mu \mathrm{l}$ of $70 \%$ acetonitrile with $0.1 \%$ formic acid (v/v). Sample were dried under vacuum and aliquots of $1 \mu \mathrm{g}$ were analysed with LC-MS to assess the labelling efficiency by calculating the 
ratio between the modified and $\mathrm{mM} \mathrm{KH}_{2} \mathrm{PO}_{4}, 250 \mathrm{mM} \mathrm{KCl}$ in $20 \%$ unmodified lysines at PSM level. acetonitrile, $\mathrm{pH} 2.7)$, and solvent I (10 $\mathrm{mM} \mathrm{K \textrm {K } _ { 2 }} \mathrm{PO}_{4}, 600 \mathrm{mM} \mathrm{NaCl}$ in $20 \%$ Charge-based fractional diagonal acetonitrile, $\mathrm{pH}$ 2.7). The following chromatography for determination of neo-N-terminal cleavage sites

The dried peptide pellets were gradient steps were performed: $100 \%$ solvent $\mathrm{G}$ for 10 minutes; followed by a resuspended in $52 \mu \mathrm{l}$ of SCX solvent $\mathrm{G}$ linear ramp from $0-15 \%$ solvent $H$ in 9 minutes; after 9 minutes at $15 \%$, solvent (10 $\mathrm{mM} \mathrm{KH} \mathrm{PO}_{4}$ in $20 \%$ acetonitrile, $\mathrm{pH}$ $\mathrm{H}$ was increased to $30 \%$ over 8 minutes; 2.7). In the first dimension peptide after 11 minutes at $30 \%$, solvent $\mathrm{H}$ was samples (160 $\mu \mathrm{g}$ ) were separated at a increased to $100 \%$ in 5 minutes; after 5 flow rate of $80 \mu \mathrm{l} /$ minute using a U3000 minutes, solvent I was increased to $100 \%$ HPLC system (Thermo-Fisher Scientific), a in 1 minute; after 5 minutes at 100\% of $150 \times 1 \mathrm{~mm}$ polysulfoethyl A column solvent I, solvent $\mathrm{G}$ was increased to $100 \%$ (PolyLC; 5 um particle size; $200 \AA$ pore in 1 minute; and the column was size, Columbia), and a tertiary buffer equilibrated for 20 minutes.

system of strong cation exchange buffers, The five collected fractions i.e. solvent $\mathrm{G}$ (see above), solvent $\mathrm{H}$ (10 (corresponding to charge states $+1,+2$,

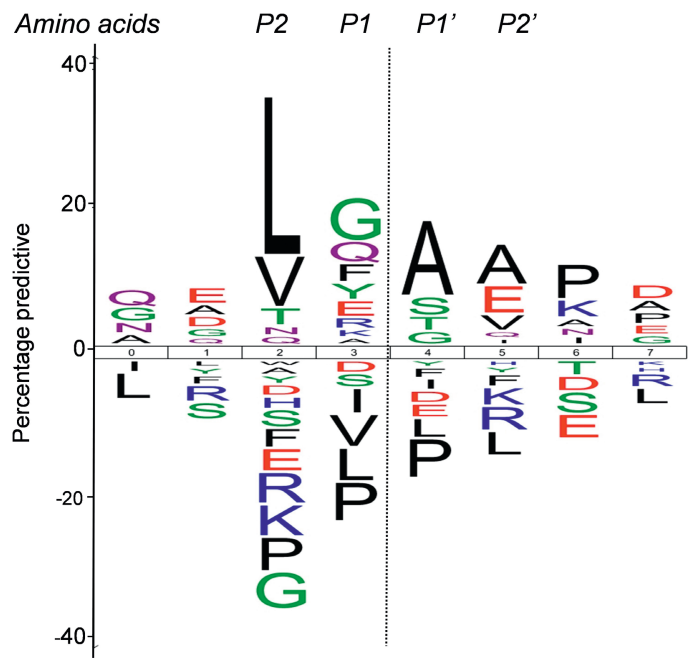

Figure 5. Prediction model of calpain cleavage sites of platelet proteins. Analysis of in vitro digestion of a platelet lysate with calpain by LC-MS, identifying 2,224 unique peptides, corresponding to 375 proteins. Icelogo representation of P4-P4' positions (4 amino acids upstream to 4 amino acids downstream of cleavage site) to visualise consensus patterns. Large size characters indicate amino acids with a large positive or negative predictive contribution to calpain cleavage. In this model, calpain cleavage sites contained at least 2 positive amino acifs at positions P2, P1 and P1'. 
$+3,+4$ and >+4) were dried under vacuum and resuspended in $50 \mathrm{mM}$ $\mathrm{Na}_{2} \mathrm{HPO}_{4} \quad(\mathrm{pH}$ 7.8). Free $\mathrm{N}$-termini of internal peptides were blocked by trideutero to $100 \%$ in 5 minutes; after 5 minutes, solvent I was increased to $100 \%$ in 1 minute; after 5 minutes at $100 \%$ of solvent I, solvent $\mathrm{G}$ was increased to $100 \%$ in 1 minute; and the column was equilibrated for 20 minutes.

The five collected fractions (corresponding to charge states $+1,+2$, $+3,+4$ and $>+4)$ were dried under vacuum and resuspended in $50 \mathrm{mM}$ $\mathrm{Na}_{2} \mathrm{HPO}_{4}$ (pH 7.8). Free $\mathrm{N}$-termini of internal peptides were blocked by trideutero (d3)-acetylation to induce a charge state shift. Therefore, trideutero $\mathrm{N}$-hydroxysuccinimide acetate (d3-NHS acetate) was added to a final concentration of $20 \mathrm{mM}$ and the sample was incubated for 1 hour at $37{ }^{\circ} \mathrm{C}$, followed by a second addition step of 10 $\mathrm{mM}$ d3-NHS acetate. After 2 hours, reactions were quenched by 10 minutes treatment with $60 \mathrm{mM}$ glycine, followed by 10 minutes treatment with $130 \mathrm{mM}$ hydroxylamine (room temperature). Fractions were dried under vacuum and desalted using Poros Oligo R3 reversedphase material (Applied Biosystems). Desalted fractions were solubilised in 52 $\mu \mathrm{l}$ buffer and were separately subjected to re-chromatography under the same conditions as above. Final fractions enriched in $\mathrm{N}$-terminal peptides were used for LC-MS analysis.

LC-MS analysis for determination of neo$\mathrm{N}$-terminal cleavage sites

Dried eluates were resuspended into 15 $\mu \mathrm{l}$ of $0.1 \%(\mathrm{v} / \mathrm{v})$ trifluoroacetic acid, and each fraction was analysed by nano-LCMS/MS using a Q-Exactive Plus mass spectrometer online-coupled to the nano-RSLC HPLC system (both ThermoFisher Scientific). LC separation was performed as follows: each fraction was loaded onto a $\mathrm{C}_{18}$ reversed phase column (100 $\mu \mathrm{m} \times 2 \mathrm{~cm}$ nano-trap) with $0.1 \%$ trifluoroacetic acid at a flow rate of 20 $\mu \mathrm{l} /$ minute for 10 minutes, followed by separation of the peptides on a $\mathrm{C}_{18}$ reversed phase main column ( $75 \mu \mathrm{m} \times 50$ $\mathrm{cm}$ ) using a binary gradient from $3-42 \%$ solvent $\mathrm{H}$ at a flow rate of $0.25 \mu \mathrm{l} /$ minute for 140 minutes at $60^{\circ} \mathrm{C}$.

Samples were measured in datadependent acquisition mode acquiring full MS scans at a resolution of 70,000, and the 15 most abundant ions (top 15) were selected for MS/MS at a resolution of 17,500. Target values were set to $1 \mathrm{x}$ $10^{6}$ for MS and $2 \times 10^{5}$ for MS/MS scans. Maximum injection times were 120 and 200 milliseconds, respectively. A normalised collision energy of 30 was used, and the first fixed mass was set to $100 \mathrm{~m} / \mathrm{z}$. For strong cation exchange charge state fractions $+3,+4$ and $+5,10 \%$ ammonia solution was placed in front of 
the ion source to compensate for database (December 2014; 13,414 target increased charge states, as described ${ }^{28}$. sequences). For peptide identification For analysis of the +1 fraction, Proteome Discoverer software version fragmentation of singly charged peptides 1.4 (Thermo-Fisher Scientific) was used was allowed, excluding $\mathrm{m} / \mathrm{z}$ values of with Mascot 2.4 (Matrix Science) as singly charged ions occurring in previous search engine, reporter ion quantifier blank runs. Generated raw data were and percolator nodes. Enzyme searched against the human Uniprot specificities were set to semi-Arg-C.

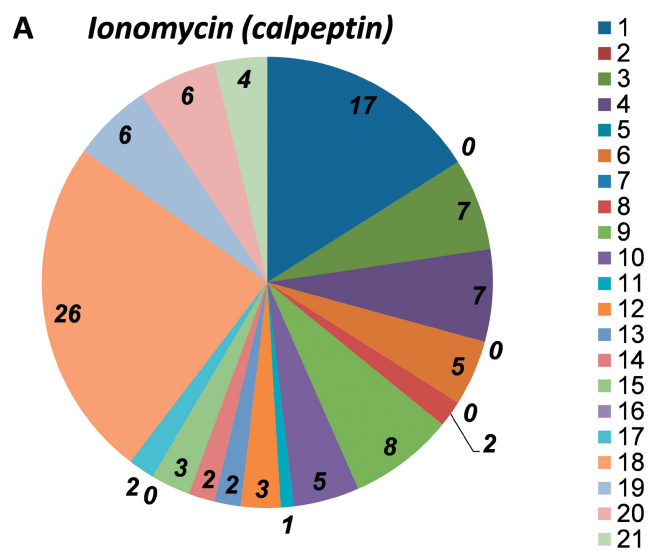

B $\quad A B T-737(Q V D-O P h)$

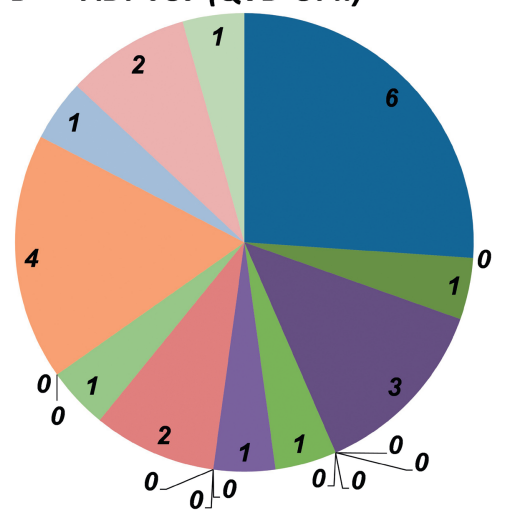

Figure 6. Class distribution of calpain-cleaved (A) and caspase-cleaved (B) proteins in platelets. Control platelets were stimulated with ionomycin (30 minutes) or ABT-737 (60 minutes) in the presence or absence of calpain inhibitor calpeptin or caspase inhibitor QVD-OPh (see Suppl. Table I). (A) Distribution of 106 identified calpain-cleaved proteins over platelet function classes ( $>3$-fold increased cleavage with ionomycin and $>50 \%$ reduction with calpeptin). (B) Distribution of 23 identified caspase-cleaved proteins over platelet function classes (>3-fold increased cleavage with ABT-737 and >50\% reduction QVD-OPh). 
To enable the quantification of two classes of $\mathrm{N}$-terminal peptides, i.e. those with $\mathrm{N}$-terminal iTRAQ label and those with endogenous $\mathrm{N}$-acetylation, a twostep search strategy was performed. First, data were searched with iTRAQ-8plex $(+304.2053 \mathrm{Da})$ as fixed modification at Lys and peptide $\mathrm{N}$-termini; second, ITRAQ 8plex of Lys and $\mathrm{N}$-terminal acetylation (+ $42.0105 \mathrm{Da}$ ) of $\mathrm{N}$-termini were set as fixed modifications. In both cases, carbamidomethylation of Cys $(+57.0214 \mathrm{Da})$ was selected as fixed and oxidation (+15.9949 Da) of methionine as variable modification. Mass tolerances were set to $10 \mathrm{ppm}$ for MS and $0.02 \mathrm{Da}$ for MS/MS. Identified peptides were filtered for high confidence corresponding to an FDR $<1 \%$ at the PSM level, and a search engine rank of 1 . The reporter ion quantifier node was adjusted according to the search settings.

Data analysis for determination of neo$\mathrm{N}$-terminal cleavage sites

Quantified modified peptides were grouped if they represented the same gene, sequence and modification state, to sum reporter intensities from each condition individually. Normalisation was done as described for the phosphoproteome data. Again, to scale the data per generated entry, each of the eight reporter intensities were divided by their median. The obtained scaled values were used to assess the normalised abundance for each sample (condition). Ratios between samples were calculated, followed by a $\log 2$ transformation.

Assessment of consensus calpain cleavage motif. Lysates of unstimulated normal platelets were in vitro digested with calpain. Digestion was conducted for 30 minutes at $37{ }^{\circ} \mathrm{C}$ in $100 \mathrm{mM} \mathrm{NaCl}$ and $3 \mathrm{mM} \mathrm{CaCl}_{2}$ (pH 7.5 with Tris) using filter-aided sample preparation; calpain (Calbiochem) was added in a protein/enzyme ratio of $2: 1 \quad(\mathrm{w} / \mathrm{w})$. Control samples did not contain calpain. Monolithic HPLC confirmed the extensive generation of digested peptides, which was absent in the control sample. The calpain-digested sample was analysed with LC-MS, and data were processed as above, but with enzyme specificity set to 'none'. This resulted in the identification of 2,224 unique peptides at $1 \%$ FDR, corresponding to 375 identified proteins. Subsite nomenclature according to Schechter and Berger was used to assess the specificity of calpain cleavage. ${ }^{32}$ After defining the P4-P4' positions (i.e., from 4 amino acids downstream to 4 amino acids upstream of the cleavage site), Icelogo software (http://iomics.ugent.be/icelogoserver/m ain.html) ${ }^{33}$ was used to visualise potential consensus cleavage patterns. All unique peptides identified from the Scott patient $\mathrm{N}$-terminal analysis were 
then sorted according to their agreement with the established consensus motif.

\section{Results and Discussion}

Combined assessment of quantitative and phospho-proteome of Scott platelets To assess the consequences of anoctamin 6 deficiency for platelet protein composition and phosphorylation, well-purified washed platelets (contamination with erythrocytes $<1: 15,000$, with leukocytes $<1: 20,000)$ were obtained from healthy control donors and a Scott patient. The platelets were kept resting or were stimulated in $\mathrm{CaCl}_{2}$-containing medium using with saturating, high concentrations of thrombin (8 $\mathrm{nM})$, convulxin/thrombin ( $200 \mathrm{ng} / \mathrm{ml}, 8 \mathrm{nM}$ ) or ionomycin $(20 \mu \mathrm{M})$ for a prolonged time of 30 minutes. For representative healthy control subjects, fractions with PS exposure of resting platelets or platelets stimulated for 30 minutes with thrombin, convulxin/thrombin or ionomycin were $0.5 \pm 0.2 \%, 9 \pm 2 \%, 51 \pm$ $3 \%$ and $88 \pm 4 \%$, respectively (means \pm $\mathrm{SEM}, n=3$ ). For platelets from the Scott patient, corresponding fractions with PS exposure were $0.6 \pm 0.2 \%, 1.5 \pm 0.5 \%$, $1.7 \pm 0.5 \%$ and $2.0 \pm 0.6 \%$, respectively (means \pm SEM, $n=3$ ). This confirmed that the patient's platelets were greatly impaired in agonist-induced PS exposure, such in agreement with earlier results with platelets from the same patient. ${ }^{13}$
Furthermore, the stimulated Scott platelets were unable to membrane blebbing and formation of balloon structures (data not shown). Samples of the resting and activated platelets $(2 \mathrm{x}$ $10^{8}$ platelets) from patient and a control subject were then used for trypsin digestion and with 8-plex iTRAQ reagents (Figure 1). After combination of subsamples, 8-plex preparations were employed for quantifying relative protein expression levels, and after a $\mathrm{TiO}_{2}$ enrichment procedure, for quantifying differences in phosphopeptide levels. Other samples were used for determination of neo-N-terminal residues originating from in situ protease activities during platelet activation.

Changes in quantitative proteome of Scott platelets

For platelets from the patient and the control subject, 2,225 unique proteins were quantified with at least 2 unique peptides in the label free analysis. This corresponds to approximately $55 \%$ of the estimated platelet proteome. ${ }^{20}$ Estimated copy numbers per platelet ranged from 87,000 (filamin A) to $<500$ copies (detection threshold) for low abundant proteins. The relative abundances of proteins in control platelets were highly similar as described before. ${ }^{20}$ For each individual protein, the ratio was calculated between values for Scott and control platelets. Plotting these 
ratios as frequency distribution data resulted in a Gaussian distribution curve (Figure 2), with as mean $1.02 \pm 0.27$ (SD). Taking $>95 \%$ confidence, we considered ratios with a deviance from mean larger or smaller than $2 \times$ SD as indicative for differential regulation. Based on these thresholds, a total of $9.6 \%$ proteins were potentially changed in expression in the Scott platelets, i.e. 125 proteins decreased and 88 proteins increased (Figure 2). When comparing pairs of healthy controls subjects $(n=4)$, a similar ratioed protein profile analysis gave $\sim 40$ proteins in either category (data not shown).

As described earlier and based on GeneOntology groupings, ${ }^{18}$ all proteins identified in the quantitative proteome were categorised into 21 assumed platelet function classes. As indicated in Table I, changes in expression were most frequently observed in proteins of the following classes: Membrane receptors \& channels (class 10), Mitochondrial proteins (class 11), Other metabolism (class 12), and Signalling \& adapter molecules (class 18). This is in accordance with the relatively high numbers of proteins in these classes.

The protein with the strongest downregulation in Scott platelets was anoctamin 6 (gene ANO6, ratio <0.03). A targeted MS analysis using parallel reaction monitoring of four major peptide fragments of anoctamin 6 (i.e. amino acids 97-114, 167-188, 191-199 and 649-661) indicated that the residual signal in the Scott samples could be attributed to noise, because of clear deviations in mass and peak pattern (Figure 3A-B). It was thus concluded that the level of anoctamin 6 in Scott platelets was below the detection limit, i.e. 50-100 times reduced in comparison to healthy controls.

The top 15 of most decreased protein levels in Scott platelets (Table II-top) further include mitochondrial proteins (genes ATP5J, HSDL1, PITRM1, SLC25A24) with different functions, as well as a number of proteases, i.e. the $\mathrm{Ca}^{2+}$ dependent calpain-2 (CAPN2) and the secretory cathepsin G (CTSG). This top 15 of most increased protein levels in Scott platelets (Table II-bottom) surprisingly contains the membrane channel protein aquaporin-1 (AQP1), which was previously not identified in platelets; ${ }^{20}$ proteins involved in transcription/translation (EEF1A1, GCN1L1, RPLPO); and further the RhoGTPase-activating protein oligophrenin (OPHN1), a protein deficient in patients with rare oligophrenia which has previously been shown to be involved in glycoprotein-VI induced platelet activation. ${ }^{34}$ Targeted re-analysis of the MS spectra confirmed the increased presence of $A Q P 1$ peptides in the Scott sample (not shown). 
A All neo-N-termini
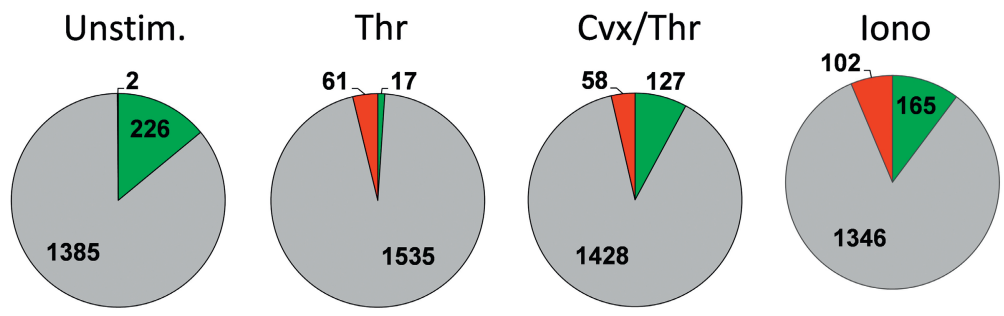

B Calpain-cleaved neo-N-termini
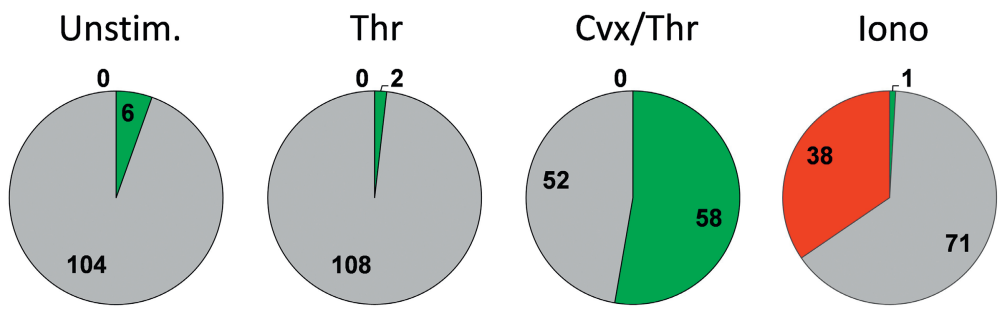

Neo-N-termini: $\square$ decreased, $\square$ increased

\section{Calpain-cleaved neo-N-termini}

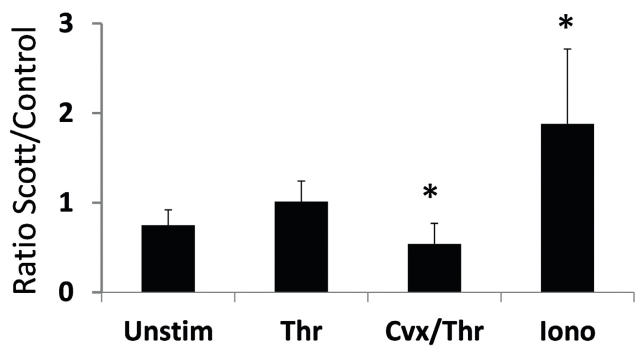

Figure 7. Changes of protein cleavage pattern in Scott platelets subjected to strong activation. Samples of Scott and control platelets were left unstimulated (Unstim), or were stimulated for 30 minutes with thrombin (Thr), convulxin/thrombin ( $\mathrm{Cvx} / \mathrm{Thr}$ ) or ionomycin (Iono). Median ratios were calculated per neo-N-terminal peptide to determine changes in protein cleavage upon platelet activation with indicated agonist, as for Figure 4 (ratios Scott/control). Ratio changes were classified as decreased (ratio $\leq 0.49$ ), unchanged (ratio 0.50-1.99) or increased (ratio $\geq 2.00$ ) in the Scott platelets. (A) Panels indicate changes in all 1,613 neo-N-terminal peptides per agonist condition for (un)stimulated Scott platelets; clockwise: green = decreased, grey = unchanged, red $=$ increased. $(B)$ Panels indicate changes in 110 neo-N-terminal peptides identified as calpain-cleaved (see Suppl. Table IA) per agonist condition. (C) Mean ratios Scott/control of 110 neo-N-terminal peptides identified as calpain-cleaved per agonist condition. ${ }^{*} \mathrm{P}<0.03$ vs. thrombin. 
Changes in phosphorylation profile of activated Scott platelets

From the $\mathrm{TiO}_{2}$-enriched samples, 1,566 phosphopeptides corresponding to 716 unique proteins could be relatively quantified in the eight samples from Scott and control platelets. In the absence of agonist, ratios for Scott/control platelets were decreased or increased in 5-9\% of the phosphopeptides (Figure 4A). Long-term (30 minutes) stimulation with thrombin markedly enhanced the fraction of phosphopeptides with increased phosphorylation in the patient's platelets to $15 \%$ (Figure $4 \mathrm{~B}$ ), which fraction was further enhanced to $55 \%$ after stimulation with convulxin/thrombin and to $28 \%$ after stimulation with ionomycin (Figure 4C-D). When combining all phosphopeptide Scott/control ratios after stimulation with convulxin/thrombin and ionomycin - i.e. conditions where the patient's platelets are defective in PS exposure - much more proteins were increased in phosphorylation at one or more sites (i.e. 621) than decreased (i.e. 37), as indicated in Table I. Assignment tabling indicated that in majority Scott proteins of the following function classes were increased in phosphorylation: Cytoskeleton(-linked), Membrane receptors \& channels, Protein kinases \& phosphatases, Signalling \& adaptor proteins, and Small GTPases and regulators (Table 1). Zooming in to individual proteins revealed decreased phosphorylation (Table III-top) of key cytoskeletal proteins (genes FERMT3, PLEK, SEPT5, TUBB1), and proteins implicated in PS exposure, i.e. BLC2 (BNIP2), a phospholipid flippase (ATP8A1) and protein kinase $C \delta(P R K C D)^{3,7,35}$. The top 15 of highest increases in phosphorylation (Table III-bottom) include four cytoskeletal-(associated) proteins (genes ABLIM1, MAP1A, NEXN, $T N L 1$ ), and the tight-junction protein ZO2 (TJP2). These lists contain considerable overlap with the phosphoproteome changes reported for human platelets activated with thrombin or oxidised phospholipids. ${ }^{36}$ Together, these data suggested that the altered phosphorylation pattern of Scott platelets upon strong stimulation in particular involves cytoskeletal (-linked) proteins and regulators of PS exposure.

Identification of platelet proteins cleaved by calpains or caspases

Platelet PS exposure is known to be accompanied by increased activity of cytosolic proteases. Thus, platelet stimulation with the strong $\mathrm{Ca}^{2+}$ elevating agents convulxin/thrombin or ionomycin leads to high activation of calpain isoforms, ${ }^{13,21}$ whereas platelet stimulation with the pro-apoptotic agent ABT-737 leads to caspase activation. ${ }^{7}$ As detailed in the methods section, we 
developed a procedure for small scale assessment of neo- $\mathrm{N}$-terminal peptides that are formed due to protein cleavage by active intra- or extra-cytosolic proteases. Given that the literature does not provide clear indications of the consensus sites in proteins for calpain- or caspase-induced cleavage, we followed two approaches to identify such substrates. In the first approach, lysates of control platelets were digested in vitro with purified calpain, after which the digested sample was analysed with LCMS. This resulted in identification of 2,224 unique peptides corresponding to 375 proteins. Using the scheme created by Schechter and Berger, ${ }^{31}$ amino acids around the neo-N-termini were defined that were positively or negatively predictive for cleavage by calpain (Figure 5). In the second approach, control platelets were stimulated with ionomycin or ABT-737 in the presence or absence of calpain inhibitor calpeptin or caspase inhibitor QVD-Oph. ${ }^{13,21}$ Analysis of the neo-N-termini by LC-MS revealed 227 neo-N-termini peptides with $>3$-fold increased levels in ionomycin-stimulated platelets, 180 of which were inhibited by calpeptin but not by QVD-Oph (Suppl. Table IA). These 180 calpain-cleaved neo$\mathrm{N}$-terminal peptides corresponded to 106 proteins, which almost completely overlapped with the proteins identified in the first approach (data not shown). Included in the list were proteins previously found to be cleaved in PSexposing platelets, namely Src kinase

\section{Control}

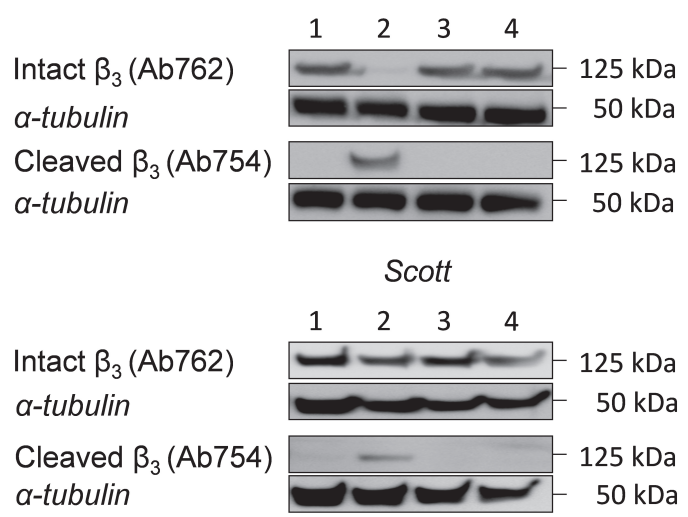

Figure 8. Reduced calpain-dependent cleavage of integrin $\beta_{3}$ chain in Scott platelets. Purified platelets from control subjects or Scott patient $\left(5 \times 10^{8} / \mathrm{ml}\right)$ were preincubated for 10 minutes with vehicle or one of the calpain inhibitors, calpeptin $(200 \mu \mathrm{M})$ or MDL-28170 (200 $\mu \mathrm{M})$. The platelets were unstimulated or were stimulated with convulxin/thrombin for 30 minutes. Western blots of samples were stained for full-length, intact integrin $\beta_{3}$ with Ab762 or cytosolic cleaved integrin $\beta_{3}$ with Ab754. Blots were reprobed with anti- $\alpha$-tubulin Ab as protein loading control. Data are representative for 3 experiments. Lane 1, resting platelets; lanes 2-4, convulxin/thrombin stimulated platelets; lane 2, vehicle treatment; lane 3 calpeptin treatment; lane 4, MDL-28170 treatment. 
(SRC) and talin-1 (TLN1). ${ }^{21}$ Function class analysis indicated that the majority of these proteins clustered into Cytoskeleton (-linked) classes, Membrane \& protein trafficking, and Signalling \& adapter proteins (Figure 6A). On the other hand, in apoptotic ABT-737stimulated platelets, 45 neo-N-termini showed a $>3$-fold increase, 23 of which were inhibited by QVD-Oph but not calpeptin (Suppl. Table IB). The corresponding 23 proteins were mostly categorised as Cytoskeletal(-linked) and Signalling \& adaptor proteins (Figure 6B). Together, these results point to patterns of non-overlapping cleavage sites by calpain and caspases of particularly cytoskeletal-associated and signalling proteins.

Changes in $\mathrm{N}$-terminal proteome of activated Scott platelets

Unstimulated and stimulated platelets from the Scott patient and control subject were subsequently analysed for the presence of differential cleavage patterns. Abundance ratios of 1,613 quantified neo- $\mathrm{N}$-terminal peptides (3 technical replicates) were assessed for the eight samples from Scott and control platelets (unstimulated; stimulated with thrombin, convulxin/thrombin or ionomycin). As indicated in Figure 7A, a limited number of cleaved peptides is increased or decreased $(5-17 \%)$ in the Scott platelets when compared to the control platelets, at all activation conditions. Interestingly, the top-15 of decreased neo- $\mathrm{N}$-terminal peptides in the Scott patients (arranged according to ratios with the PS-exposing agonists, convulxin/thrombin and ionomycin) showed in the majority a cleavage pattern with two or more of our consensus amino acids for calpain cleavage and with a complete inhibitory effect of calpeptin, as established for control platelets (Table IV-top). These included cytoskeleton-linked proteins (genes DBLN, DNM1L, MAPRE1, NEXN, SMIM1, TLN1 and ZYX) and key regulatory signalling proteins $(D O K 3, F Y B$, GSK3B, PDE3A, VASP). In contrast, the top-15 of increased expression of neo-Nterminal peptides in the Scott patients mostly concerned a variety of proteins with cleavage sites containing an arginine at position $\mathrm{P}_{1}$ and a lack of inhibitory effect of calpeptin (Table IVbottom). Hence, these cleavage sites are unlikely to be calpain-mediated. Collectively, this suggested that the activated Scott platelets are characterised by a decreased calpaindependent formation of neo-N-termini. Interestingly, the majority of identified calpain cleavage sites differ from previous neo-N-termini lists from human platelets, ${ }^{37}$ likely because these were established for stored, unstimulated platelets rather than from activated platelets, as in the present paper. 
Further data analysis was then performed to confirm this hypothesis, by comparing only the neo-N-terminal peptides that were identified as calpain substrates (Suppl. Table IA). This resulted in a list of 110 peptides, which in case of unstimulated or thrombin-stimulated platelets were similar in expression for the Scott patient and control subject (Figure 7B). However, after convulxin/thrombin stimulation 58 neo$\mathrm{N}$-termini peptides were less present in the Scott platelets, and after ionomycin stimulation 38 peptides were more abundant in the Scott platelets. In agreement with this, the mean ratios between Scott and control platelets for all 110 peptides was lowered after convulxin/thrombin stimulation and raised after ionomycin stimulation (Figure 7C). Hence, these data pointed to a reduced calpain activity in the Scott platelets when stimulated with convulxin/thrombin, and an increased calpain activity after ionomycin stimulation. The latter difference is surprising, but can be explained by the protection of Scott platelets to PS exposure and phospholipid membrane dysregulation at the high intracellular $\mathrm{Ca}^{2+}$ concentration reached with ionomycin, which may prolong the calpain activity before the cells collapse. Further evidence for decreased calpain activity in convulxin/thrombinstimulated Scott platelets came from
Western blotting of platelet samples. ${ }^{21}$ Using an antibody recognising the intact cytosolic $\mathrm{N}$-terminal site of the integrin $\beta_{3}$-chain (Ab762) and an antibody recognising a calpain-cleaved neo- $\mathrm{N}$ terminal site in the $\beta_{3}$-chain (Ab754), it appeared that Scott platelets showed a lower reduction in the Ab762 band and lower appearance of the Ab754 band (Figure 8). The staining with Ab754 was completely antagonised with two calpain antagonists, calpeptin and MDL-28170, thus demonstrating a calpain-mediated protein cleavage.

\section{Conclusion}

In this paper, we provide for the first time a full analysis of the protein composition, protein phosphorylation state and protein cleavage pattern after platelet stimulation with established strong $\mathrm{Ca}^{2+}$-mobilising agonists (convulxin/thrombin and ionomycin). These agonists induce PS exposure and membrane blebbing in platelets from normal subjects, but not from the rare Scott patients. This advanced proteomic profiling provides novel insight into the altered protein composition and posttranslational protein machinery explaining the major $\mathrm{Ca}^{2+}$ and cytoskeleton-dependent membrane alterations in Scott syndrome platelets. Quantitative proteomics analysis reveals, in addition to a major reduction in anoctamin 6, up-regulation of the 
channel protein aquaporin-1.

Phosphopeptide analysis indicated major differences in Scott and control platelets, after stimulation with convulxin/thrombin or ionomycin, in proteins linked to the cytoskeleton,

\section{References}

1. Toti F, Satta N, Fressinaud E, Meyer D, Freyssinet JM. Scott syndrome, characterized by impaired transmembrane migration of procoagulant phosphatidylserine and haemorrhagic complications, is an inherited disorder. Blood. 1996;87:1409-15.

2. Zwaal RF, Schroit AJ. Pathophysiological implications of membrane phospholipid asymmetry in blood cells. Blood. 1997;89:1121-32.

3. Bevers EM, Comfurius P, Dekkers DW, Harmsma M, Zwaal RF. Regulatory mechanisms of transmembrane phospholipid distributions and pathophysiological implications of transbilayer lipid scrambling. Lupus. 1998;7 Suppl. 2:S126-31.

4. Thomas CP, Morgan LT, Maskrey BH, Murphy RC, Kuhn H, Hazen SL, Goodall AH, Hamali HA, Collins PW, O'Donnell VB. Phospholipid-esterified eicosanoids are generated in agonist-activated human platelets and enhance tissue factordependent thrombin generation. I Biol Chem. 2010;285:6891-903.

5. Kmit A, van Kruchten R, Ousingsawat J, Mattheij NJ, Senden-Gijsbers B, Heemskerk JW, Scheiber R, Bevers EM, Kunzelmann K. Calcium-activated and apoptotic phospholipid scrambling induced by Ano6 can occur independently of Ano6 ion currents. Cell Death Disease. 2013;4:e611.

6. Smeets EF, Heemskerk JW, Comfurius P, Bevers EM, Zwaal RF. Thapsigargin amplifies the platelet procoagulant response caused by thrombin. Thromb Haemost. 1993;70:1024-9.

7. Schoenwaelder SM, Yuan Y, Josefsson EC, White MJ, Tao Y, Mason KD, O'Reilly LA, Henley KJ, Ono A, Hsiao S, Willcox A, Roberts AW, Huang DCS, Salem HH, Kile BT, Jackson SP. Two distinct pathways regulate platelet phosphatidylserine regulating phosphatidylserine exposure, or implicated in signalling. Analysis of the neo-N-termini in Scott platelets revealed major changes in calpain-cleaved cytoskeleton-linked and key signalling proteins.

exposure and procoagulant function. Blood. 2009;114:663-6.

8. Cosemans JM, Schols SE, Stefanini L, de Witt S, Feijge MA, Hamulyak K, Deckmyn H, Bergmeier W, Heemskerk JW. Key role of glycoprotein Ib/V/IX and von Willebrand factor in platelet activationdependent fibrin formation at low shear flow. Blood. 2011;117:651-60.

9. Heemskerk JW, Mattheij N, Cosemans JM. Platelet-based coagulation: different populations, different functions. J Thromb Haemost. 2013;11:2-11.

10. Suzuki J, Umeda M, Sims PJ, Nagata S. Calciumdependent phospholipid scrambling by TMEM16F. Nature. 2010;468:834-8.

11. Castoldi E, Collins PW, Williamson PL, Bevers EM. Compound heterozygosity for 2 novel TMEM16F mutations in a patient with Scott syndrome. Blood. 2011;117:4399-400.

12. Kunzelmann K, Nilius B, Owsianik G, Schreiber R, Ousingsawat J, Sirianant L, Wanitchakool P, Bevers EM, Heemskerk JW. Molecular functions of anoctamin 6 (TMEM16F): a chloride channel, cation channel, or phospholipid scramblase? Pflügers Arch. 2014;466:407-14.

13. Mattheij NJ, Gilio K, van Kruchten R, Jobe SM, Wieschhaus AJ, Chishti AH, Collins P, Heemskerk JW, Cosemans JM. Dual mechanism of integrin $\alpha_{11 b} \beta_{3}$ closure in procoagulant platelets. J Biol Chem. 2013;288:13325-36.

14. Heemskerk JW, Kuijpers MJ, Munnix IC, Siljander PR. Platelet collagen receptors and coagulation. A characteristic platelet response as possible target for antithrombotic treatment. Trends Cardiovasc Med. 2005;15:86-92.

15. Wielders SJ, Broers J, ten Cate H, Collins PW, Bevers EM, Lindhout T. Absence of platelet- 
dependent fibrin formation in a patient with Scott syndrome. Thromb Haemost. 2009;101:76-82.

16. Clark SR, Thomas CP, Hammond VJ, Aldrovandi M, Wilkinson GW, Hart KW, Murphy RC, Collins PW, O'Donnell VB. Characterization of platelet aminophospholipid externalization reveals fatty acids as molecular determinants that regulate coagulation. Proc Natl Acad Sci USA 2013;110:5875-80.

17. Burkhart JM, Schumbrutzki C, Wortelkamp S, Sickmann A, Zahedi RP. Systematic and quantitative comparison of digest efficiency and specificity reveals the impact of trypsin quality on MS-based proteomics. J Proteomics. 2012;75:1454-62.

18. Burkhart JM, Gambaryan S, Watson SP, Jurk K, Walter U, Sickmann A, Heemskerk JW, Zahedi RP. What can proteomics tell us about platelets? Circ Res. 2014;114:1204-19.

19. Scholten A, Preisinger C, Corradini E, Bourgonje VJ, Hennrich ML, van Veen TA, Swaminathan PD, Joiner ML, Vos MA, Anderson ME, Heck AJ. Phosphoproteomics study based on in vivo inhibition reveals sites of calmodulin-dependent protein kinase II regulation in the heart. J Am Heart Assoc. 2013;2:e000318.

20. Burkhart JM, Vaudel M, Gambaryan S, Radau S, Walter U, Martens L, Geiger J, Sickmann A, Zahedi RP. The first comprehensive and quantitative analysis of human platelet protein composition allows the comparative analysis of structural and functional pathways. Blood. 2012;120:e73-82

21. Mattheij NJ, Gilio K, van Kruchten R, Jobe SM, Wieschhaus AJ, Chishti AH, Collins P, Heemskerk JW, Cosemans JM. Dual mechanism of integrin $\alpha_{11 \mathrm{~b}} \beta_{\text {巴 }}$ closure in procoagulant platelets. J Biol Chem. 2013;288:13325-36.

22. Beck F, Geiger J, Gambaryan S, Veit J, Vaudel M, Nollau P, Kohlbacher O, Martens L, Walter U, Sickmann A, Zahedi RP. Time-resolved characterization of CAMP/PKA-dependent signaling reveals that platelet inhibition is a concerted process involving multiple signaling pathways. Blood. 2014;123:e1-e10.

23. Manza LL, Stamer SL, Ham AJ, Codreanu SG, Liebler DC. Sample preparation and digestion for proteomic analyses using spin filters. Proteomics. 2005;5:1742-5.

24. Wisniewski JR, Zougman A, Mann M. Combination of FASP and StageTip-based fractionation allows in-depth analysis of the hippocampal membrane proteome. J Proteome Res. 2009;8:5674-8.

25. Vaudel M, Burkhart JM, Zahedi RP, Oveland E, Berven FS, Sickmann A, Martens L, Barsnes H. PeptideShaker enables reanalysis of MS-derived proteomics data sets. Nat Biotechnol. 2015;33: 22-4.

26. Vaudel M, Barsnes $H$, Berven FS, Sickmann A, Martens L. SearchGUI: An open-source graphical user interface for simultaneous OMSSA and X!Tandem searches. Proteomics. 2015;11:996-9.

27. Engholm-Keller $K$, Birck P, Storling J, Pociot $F$, Mandrup-Poulsen T, Larsen MR. TiSH: a robust and sensitive global phosphoproteomics strategy employing a combination of $\mathrm{TiO}_{2}$, SIMAC, and HILIC. J Proteomics. 2012;75:5749-61.

28. Olsen JV, de Godoy LM, Li G, Macek B, Mortensen P, Pesch R, Makarov A, Lange O, Horning S, Mann M. Parts per million mass accuracy on an Orbitrap mass spectrometer via lock mass injection into a C-trap. Mol Cell Proteomics. 2005;4:2010-21.

29. Thingholm TE, Palmisano G, Kjeldsen F, Larsen MR. Undesirable charge-enhancement of isobaric tagged phosphopeptides leads to reduced identification efficiency. J Proteome Res. 2010;9:4045-52.

30. Taus T, Kocher T, Pichler P, Paschke C, Schmidt A, Henrich C, Mechtler K. Universal and confident phosphorylation site localization using phosphoRS. J Proteome Res. 2011;10:5354-62.

31. Vizcaino JA, Cote RG, Csordas A, Dianes JA, Fabregat A, Foster JM, Griss J, Alpi E, Birim M, Contell J, O'Kelly G, Schoenegger A, Ovelleiro D, Perez-Riverol $Y$, Reisinger $F$, Rios $D$, Wang $R$, Hermjakob $H$. The PRoteomics IDEntifications (PRIDE) database and associated tools: status in 2013. Nucleic Acids Res. 2013;41:D1063-9.

32. Schechter I, Berger A. On the size of the active site in proteases. I. Papain. Biochem Biophys Res Commun. 1967;27:157-62.

33. Maddelein D, Colaert N, Buchanan I, Hulstaert N, Gevaert K, Martens L. The iceLogo web server and 
SOAP service for determining protein consensus sequences. Nucleic Acids Res. 2015 (in press).

34. Bleijerveld OB, van Holten TC, Preisinger C, van der Smagt JJ, Farndale RW, Kleefstra T, Willemsen MH, Urbanus RT, de Groot PG, Heck AJ, Roest M, Scholten A. Targeted phosphotyrosine profiling of glycoprotein VI signaling implicates oligophrenin1 in platelet filopodia formation. Arterioscler Thromb Vasc Biol 2013;33:1538-43.

35. Gilio K, Harper MT, Cosemans JM, Konopatskaya O, Munnix IC, Prinzen L, Leitges M, Liu Q, Molkentin JD, Heemskerk JW, Poole AW. Functional divergence of platelet protein kinase $C$
(PKC) isoforms in thrombus formation on collagen. J Biol Chem. 2010;285:23410-9.

36. Zimman A, Titz B, Komisopoulou E, Biswas S, Graeber TG, Podrez EA. Phosphoproteomic analysis of platelets activated by pro-thrombotic oxidized phospholipids and thrombin. Plos One. 2014;9:e84488.

37. Prudova A, Serrano K, Eckhard U, Fortelny N, Devine DV, Overall CM. TAILS N-terminomics of human platelets reveals pervasive metalloproteinase-dependent proteolytic processing in storage. Blood. 2014;124:e49-e60. 
Supplemental Table IA

\begin{tabular}{|c|c|c|c|c|c|c|c|}
\hline \multirow[t]{2}{*}{$\begin{array}{l}\text { Uniprot } \\
\text { number }\end{array}$} & \multirow[t]{2}{*}{ Gene name } & \multirow[t]{2}{*}{ Protein name } & \multirow[t]{2}{*}{ Cleavage sites } & \multicolumn{3}{|c|}{ Effect ionomycin (mean) } & \multirow[t]{2}{*}{ Function class } \\
\hline & & & & vehicle & calpeptin & QVD-Oph & \\
\hline \multicolumn{8}{|c|}{ lonomycin-induced neo-N-termini (ratio >3.0) } \\
\hline P53396 & $A C L Y$ & ATP-citrate synthase & A441 & 32.1 & $1 \%$ & $120 \%$ & 12 \\
\hline Q562R1 & ACTBL2 & Beta-actin-like protein 2 & V220 & 3.1 & $46 \%$ & $65 \%$ & 1 \\
\hline P12814 & ACTN1 & Alpha-actinin-1 & $\mathrm{Y} 12, \mathrm{M} 13$ & 20.8 & $1 \%$ & $62 \%$ & 1 \\
\hline P61160 & ACTR2 & Actin-related protein 2 & S304 & 314.4 & $15 \%$ & $90 \%$ & 1 \\
\hline 043306 & $A D C Y 6$ & Adenylate cyclase type 6 & V106 & 3.8 & $10 \%$ & $70 \%$ & 18 \\
\hline P54819 & AK2 & Adenylate kinase 2 , mitochondrial & M2 & 4.3 & $81 \%$ & $85 \%$ & 11 \\
\hline Q4KMQ2 & ANO6 & Anoctamin-6 & S38 & 13.4 & $0 \%$ & $74 \%$ & 10 \\
\hline Q8NEU8 & APPL2 & DCC-interacting protein 13-beta & D645 & 25.1 & $0 \%$ & $64 \%$ & 18 \\
\hline Q8N392 & ARHGAP18 & Rho GTPase-activating protein 18 & E180 & 9.7 & $0 \%$ & $76 \%$ & 19 \\
\hline O43150 & ASAP2 & Arf-GAP with $\mathrm{SH} 3, \mathrm{ANK}$ and $\mathrm{PH}$ domains protein 2 & K806 & 5.6 & $3 \%$ & $91 \%$ & 19 \\
\hline Q9NT62 & ATG3 & Ubiquitin-like-conjugating enzyme ATG3 & A184 & 14.4 & $0 \%$ & $85 \%$ & 9 \\
\hline P06576 & ATP5B & ATP synthase subunit beta, mitochondrial & T50 & 3.4 & $73 \%$ & $82 \%$ & 11 \\
\hline P21281 & ATP6V1B2 & V-type proton ATPase subunit B, brain isoform & A13 & 6.6 & $0 \%$ & $91 \%$ & 8 \\
\hline Q9UI12 & ATPIF1 & ATPase inhibitor, mitochondrial & G26 & 5.3 & $85 \%$ & $91 \%$ & 11 \\
\hline Q9UBW5 & BIN2 & Bridging integrator 2 & $\mathrm{~K} 34, \mathrm{~A} 412$ & 64.8 & $0 \%$ & $99 \%$ & 4 \\
\hline Q05682 & CALD1 & Caldesmon & N30, T86, Q87, V88, Y160, I & 24.8 & $1 \%$ & $89 \%$ & 1 \\
\hline P27797 & CALR & Calreticulin & E18 & 3.7 & $98 \%$ & $97 \%$ & 6 \\
\hline Q01518 & CAP1 & Adenylyl cyclase-associated protein 1 & V21 & 9.3 & $0 \%$ & $89 \%$ & 1 \\
\hline P04632 & CAPNS1 & Calpain small subunit 1 & A68, E71, A74, Y87, A92 & 13.7 & $10 \%$ & $91 \%$ & 18 \\
\hline P78371 & сCT2 & T-complex protein 1 subunit beta & L6 & 33.5 & $0 \%$ & $59 \%$ & 6 \\
\hline O95674 & CDS2 & Phosphatidate cytidylyltransferase 2 & A48 & 25.5 & $2 \%$ & $71 \%$ & 12 \\
\hline P30622 & CLIP1 & CAP-Gly domain-containing linker protein 1 & S44 & 5.6 & $11 \%$ & $102 \%$ & 3 \\
\hline P09496 & CLTA & Clathrin light chain A & A95 & 98.9 & $0 \%$ & $98 \%$ & 9 \\
\hline P10909 & $C L U$ & Clusterin & S131 & 3.6 & $84 \%$ & $84 \%$ & 17 \\
\hline Q8IY22 & CMIP & C-Maf-inducing protein (c-Mip) & \$439 & 6.3 & $8 \%$ & $113 \%$ & 18 \\
\hline Q99439 & CNN2 & Calponin-2 & L14 & 21.5 & $3 \%$ & $67 \%$ & 1 \\
\hline Q6PJW8 & CNST & Consortin & G18 & 37.2 & $0 \%$ & $80 \%$ & 10 \\
\hline P31146 & CORO1A & Coronin-1A & A417, G423 & 17.8 & $2 \%$ & $99 \%$ & 1 \\
\hline Q9BR76 & CORO1B & Coronin-1B & A428 & 13.3 & $0 \%$ & $97 \%$ & 18 \\
\hline P20674 & $\operatorname{COX} 5 A$ & Cytochrome $c$ oxidase subunit $5 \mathrm{~A}$, mitochondrial & S42 & 5.8 & $90 \%$ & $90 \%$ & 11 \\
\hline P10606 & COX5B & Cytochrome $\mathrm{c}$ oxidase subunit 5B, mitochondrial & $\mathrm{A} 32$ & 3.8 & $99 \%$ & $104 \%$ & 11 \\
\hline P43155 & CRAT & Carnitine O-acetyltransferase & K29 & 3.2 & $83 \%$ & $93 \%$ & 12 \\
\hline P46109 & CRKL & Crk-like protein & A115 & 7.1 & $1 \%$ & $72 \%$ & 18 \\
\hline P10619 & CTSA & Lysosomal protective protein & A29 & 3.4 & $87 \%$ & $91 \%$ & 8 \\
\hline Q14247 & CTTN & Src substrate cortactin & S113, T337 & 6.0 & $16 \%$ & $119 \%$ & 1 \\
\hline Q16643 & DBN1 & Drebrin & L242 & 14.3 & $0 \%$ & $78 \%$ & 1 \\
\hline Q9UJU6 & $D B N L$ & Drebrin-like protein & A183 & 98.7 & $0 \%$ & $88 \%$ & 4 \\
\hline Q08495 & DMTN & Dematin & A199 & 5.5 & $6 \%$ & $97 \%$ & 1 \\
\hline 000429 & DNM1L & Dynamin-1-like protein & D627 & 37.6 & $0 \%$ & $132 \%$ & 3 \\
\hline 060496 & DOK2 & Docking protein 2 & D358 & 30.3 & $1 \%$ & $97 \%$ & 18 \\
\hline Q7L591 & DOK3 & Docking protein 3 & S209, G412, G413 & 9.1 & $3 \%$ & $74 \%$ & 18 \\
\hline P13639 & EEF2 & Elongation factor 2 & V2 & 3.1 & $113 \%$ & $107 \%$ & 20 \\
\hline P55884 & EIF3B & Eukaryotic translation initiation factor 3 subunit B & A97 & 4.5 & $1 \%$ & $90 \%$ & 20 \\
\hline P50402 & $E M D$ & Emerin & G106 & 7.1 & $106 \%$ & $96 \%$ & 1 \\
\hline Q9UBC2 & EPS15L1 & Epidermal growth factor receptor substrate 15 -like 1 & S560 & 5.6 & $7 \%$ & $77 \%$ & 6 \\
\hline Q9Y624 & F11R & Junctional adhesion molecule A & $\mathrm{S} 28$ & 3.9 & $80 \%$ & $86 \%$ & 10 \\
\hline P00488 & $F 13 A 1$ & Coagulation factor XIII A chain & S305 & 3.6 & $97 \%$ & $95 \%$ & 17 \\
\hline Q8N5J2 & FAM63A & Protein FAM63A & A29 & 18.4 & $2 \%$ & $53 \%$ & 21 \\
\hline Q86UX7 & FERMT3 & Fermitin family homolog 3 (Kindlin-3) & T79, S199 & 4.5 & $81 \%$ & $105 \%$ & 4 \\
\hline Q86UX7 & FERMT3 & Fermitin family homolog 3 (Kindlin-3) & L334, G336, S337 & 122.3 & $0 \%$ & $99 \%$ & 4 \\
\hline P02671 & FGA & Fibrinogen alpha chain & A20, D21, G538 & 7.3 & $76 \%$ & $93 \%$ & 17 \\
\hline Q9Y613 & FHOD1 & $\mathrm{FH} 1 / \mathrm{FH} 2$ domain-containing protein 1 & A2 & 3.9 & $75 \%$ & $79 \%$ & 4 \\
\hline P21333 & FLNA & Filamin-A & $\mathrm{A} 12, \mathrm{~A} 13, \mathrm{G} 14, \mathrm{~A} 15$ & 61.5 & $0 \%$ & $59 \%$ & 4 \\
\hline P21333 & FLNA & Filamin-A & A1026, G1526 & 15.3 & $0 \%$ & $68 \%$ & 4 \\
\hline P21333 & FLNA & Filamin-A & S1520, Y1832 & 4.2 & $104 \%$ & $99 \%$ & 4 \\
\hline 015117 & FYB & FYN-binding protein & G25, G93, G224, S256 & 18.5 & $1 \%$ & $116 \%$ & 18 \\
\hline Q14C86 & GAPVD1 & GTPase-activating protein and VPS9 domain protein 1 & S746 & 25.4 & $0 \%$ & $105 \%$ & 19 \\
\hline
\end{tabular}




\begin{tabular}{|c|c|c|c|c|c|c|c|}
\hline P17174 & GOT1 & Aspartate aminotransferase, cytoplasmic & $\mathrm{A} 2$ & 4.5 & $67 \%$ & $67 \%$ & 12 \\
\hline P07359 & GP1BA & Platelet glycoprotein lb alpha chain & G574 & 23.2 & $0 \%$ & $45 \%$ & 10 \\
\hline P14770 & GP9 & Platelet glycoprotein IX & T17 & 4.3 & $128 \%$ & $138 \%$ & 10 \\
\hline P43304 & GPD2 & Glycerol-3-phosphate dehydrogenase, mitochondrial & A43 & 3.6 & $80 \%$ & $89 \%$ & 11 \\
\hline P62993 & GRB2 & Growth factor receptor-bound protein 2 & D166 & 14.2 & $0 \%$ & $69 \%$ & 18 \\
\hline P49841 & GSK3B & Glycogen synthase kinase- 3 beta & A394 & 30.9 & $0 \%$ & $90 \%$ & 15 \\
\hline P06396 & GSN & Gelsolin & G33, V53 & 3.9 & $108 \%$ & $98 \%$ & 1 \\
\hline P06396 & GSN & Gelsolin & S412 & 4.2 & $12 \%$ & $48 \%$ & 1 \\
\hline P00390 & GSR & Glutathione reductase, mitochondrial & Q48 & 26.9 & $0 \%$ & $50 \%$ & 11 \\
\hline P14317 & HCLS1 & Hematopoietic lineage cell-specific protein & V63, V308 & 13.3 & $6 \%$ & $111 \%$ & 18 \\
\hline P61978 & HNRNPK & Heterogeneous nuclear ribonucleoprotein $\mathrm{K}$ & S366 & 14.4 & $0 \%$ & $96 \%$ & 20 \\
\hline P11021 & HSPA5 & 78 kDa glucose-regulated protein (GRP-78) & A298 & 3.0 & $93 \%$ & $98 \%$ & 6 \\
\hline Q13418 & ILK & Integrin-linked protein kinase & S324 & 3.6 & $118 \%$ & $103 \%$ & 15 \\
\hline Q13576 & IQGAP2 & Ras GTPase-activating-like protein IQGAP2 & G15 & 12.3 & $0 \%$ & $67 \%$ & 19 \\
\hline P08514 & ITGA2B & Integrin alpha-Ilb & S432 & 3.5 & $103 \%$ & $145 \%$ & 10 \\
\hline P27987 & ITPKB & Inositol-trisphosphate 3-kinase B & S352 & 16.7 & $6 \%$ & $86 \%$ & 12 \\
\hline Q8IVT5 & KSR1 & Kinase suppressor of Ras 1 & A531 & 3.7 & $13 \%$ & $81 \%$ & 19 \\
\hline Q14847 & LASP1 & LIM and SH3 domain protein 1 & K187, A191, S198 & 15.1 & $0 \%$ & $78 \%$ & 1 \\
\hline O43561 & LAT & Linker for activation of T-cells family member 1 & $\mathrm{~T} 174, \mathrm{~A} 175$ & 9.6 & $6 \%$ & $122 \%$ & 18 \\
\hline Q3ZCW2 & LGALSL & Galectin-related protein & $\mathrm{S} 24, \mathrm{~S} 25, \mathrm{~A} 29$ & 13.2 & $1 \%$ & $170 \%$ & 21 \\
\hline P49257 & LMAN1 & Protein ERGIC-53 & G316 & 6.9 & $1 \%$ & $45 \%$ & 6 \\
\hline Q93052 & $L P P$ & Lipoma-preferred partner & $\mathrm{A} 302, \mathrm{~N} 406$ & 27.6 & $0 \%$ & $88 \%$ & 13 \\
\hline P50851 & LRBA & Lipopolysaccharide-resp and beige-like anchor protein & V1591 & 25.4 & $0 \%$ & $118 \%$ & 18 \\
\hline Q32MZ4 & LRRFIP1 & Leucine-rich repeat flightless-interacting protein 1 & A710 & 64.7 & $0 \%$ & $87 \%$ & 20 \\
\hline Q9Y608 & LRRFIP2 & Leucine-rich repeat flightless-interacting protein 2 & A301, D352, A554, S560 & 35.1 & $1 \%$ & $91 \%$ & 18 \\
\hline Q9UNF1 & MAGED2 & Melanoma-associated antigen D2 & S265 & 6.9 & $1 \%$ & $76 \%$ & 21 \\
\hline Q15691 & MAPRE1 & Microtubule protein RP/EB family member 1 & A171 & 55.0 & $0 \%$ & $110 \%$ & 3 \\
\hline Q15555 & MAPRE2 & Microtubule protein RP/EB family member 2 & S50, A171 & 35.3 & $1 \%$ & $70 \%$ & 3 \\
\hline Q9H3U5 & MFSD1 & Major facilitator superfamily domain protein 1 & $\mathrm{~A} 13$ & 6.5 & $0 \%$ & $62 \%$ & 10 \\
\hline Q13201 & MMRN1 & Multimerin-1 (EMILIN-4) & A296 & 3.4 & $18 \%$ & $64 \%$ & 17 \\
\hline Q9Y6C9 & MTCH2 & Mitochondrial carrier homolog 2 & S56 & 3.2 & $81 \%$ & $77 \%$ & 18 \\
\hline Q96S97 & MYADM & Myeloid-associated differentiation marker & T15 & 3.4 & $11 \%$ & $114 \%$ & 18 \\
\hline Q8N699 & MYCT1 & Myc target protein 1 & S114 & 5.0 & $4 \%$ & $79 \%$ & 20 \\
\hline P35579 & МҮH9 & Myosin-9 & Q890, A891, L895, A897, 19 & 38.5 & $0 \%$ & $88 \%$ & 1 \\
\hline P55209 & NAP1L1 & Nucleosome assembly protein 1-like 1 & M43, G58, E61, T62 & 9.4 & $90 \%$ & $100 \%$ & 13 \\
\hline O43639 & NCK2 & Cytoplasmic protein NCK2 & Y271 & 21.0 & $0 \%$ & $86 \%$ & 18 \\
\hline Q0ZGT2 & NEXN & Nexilin & L249, L312, G568, S569 & 38.1 & $8 \%$ & $74 \%$ & 1 \\
\hline P07237 & P4HB & Protein disulfide-isomerase & D18 & 3.9 & $97 \%$ & $97 \%$ & 6 \\
\hline Q6VY07 & PACS1 & Phosphofurin acidic cluster sorting protein 1 & S781 & 8.9 & $0 \%$ & $141 \%$ & 6 \\
\hline Q14432 & PDE3A & cGMP-inhibited 3',5'-cyclic phosphodiesterase A & N596 & 23.6 & $0 \%$ & $95 \%$ & 18 \\
\hline 076074 & PDE5A & cGMP-specific 3',5'-cyclic phosphodiesterase & Q15 & 62.8 & $0 \%$ & $6 \%$ & 18 \\
\hline P30101 & PDIA3 & Protein disulfide-isomerase $\mathrm{A} 3$ & $\mathrm{~S} 25$ & 4.0 & $100 \%$ & $100 \%$ & 6 \\
\hline P13667 & PDIA4 & Protein disulfide-isomerase A4 & A24 & 4.1 & $87 \%$ & $91 \%$ & 6 \\
\hline Q96HC4 & PDLIM5 & PDZ and LIM domain protein 5 & A392, Q395 & 5.2 & $10 \%$ & $82 \%$ & 18 \\
\hline P00491 & $P N P$ & Purine nucleoside phosphorylase & S59 & 4.4 & $80 \%$ & $74 \%$ & 11 \\
\hline Q9H2U2 & PPA2 & Inorganic pyrophosphatase 2 , mitochondrial & A33 & 3.7 & $74 \%$ & $80 \%$ & 11 \\
\hline P02775 & PPBP & Platelet basic protein & $\mathrm{N} 44, \mathrm{G} 48$ & 4.1 & $115 \%$ & $108 \%$ & 17 \\
\hline Q86WR7 & PROSER2 & Proline and serine-rich protein 2 & A206, R369 & 6.2 & $6 \%$ & $115 \%$ & 21 \\
\hline Q14289 & PTK2B & Protein-tyrosine kinase 2-beta (FAK) & A403 & 13.4 & $0 \%$ & $88 \%$ & 15 \\
\hline Q99952 & PTPN18 & Tyrosine-protein phosphatase non-receptor type 18 & R398 & 4.6 & $15 \%$ & $80 \%$ & 15 \\
\hline P54727 & $R A D 23 B$ & UV excision repair protein RAD23 homolog B & A264 & 5.3 & $8 \%$ & $92 \%$ & 14 \\
\hline Q8TC12 & RDH11 & Retinol dehydrogenase 11 & S229 & 4.0 & $70 \%$ & $110 \%$ & 12 \\
\hline Q96AA3 & RFT1 & Protein RFT1 homolog & G2 & 4.5 & $67 \%$ & $70 \%$ & 6 \\
\hline Q9H4X1 & $R G C C$ & Regulator of cell cycle RGCC & D70 & 3.1 & $25 \%$ & $71 \%$ & 18 \\
\hline Q9NS28 & RGS18 & Regulator of G-protein signaling 18 & S66 & 4.2 & $132 \%$ & $107 \%$ & 19 \\
\hline O14828 & SCAMP3 & Secretory carrier-associated membrane protein 3 & A123 & 11.5 & $0 \%$ & $69 \%$ & 9 \\
\hline O95810 & $S D P R$ & Cavin-2 (PS-p68, Phosphatidylserine-binding protein) & T260, S398, Y399, A400 & 21.9 & $3 \%$ & $94 \%$ & 18 \\
\hline Q15019 & SEPT2 & Septin-2 & A21 & 14.2 & $0 \%$ & $60 \%$ & 1 \\
\hline O75563 & SKAP2 & Src kinase-associated phosphoprotein 2 (Pyk2) & S271 & 3.1 & $20 \%$ & $67 \%$ & 18 \\
\hline 014745 & $S L C 9 A 3 R 1$ & $\mathrm{Na}+/ \mathrm{H}+$ exchange regulatory cofactor $\mathrm{NHE}-\mathrm{RF} 1$ & $\mathrm{E} 121, \mathrm{~A} 274, \mathrm{~S} 280$ & 30.0 & $0 \%$ & $102 \%$ & 18 \\
\hline Q14BN4 & SLMAP & Sarcolemmal membrane-associated protein & G488 & 26.6 & $0 \%$ & $74 \%$ & 3 \\
\hline B2RUZ4 & SMIM1 & Small integral membrane protein 1 & A25 & 13.9 & $0 \%$ & $103 \%$ & 4 \\
\hline
\end{tabular}




\begin{tabular}{|c|c|c|c|c|c|c|c|}
\hline O60749 & SNX2 & Sorting nexin-2 & S119 & 14.2 & $1 \%$ & $131 \%$ & 9 \\
\hline P12931 & $S R C$ & Proto-oncogene tyrosine-protein kinase Src & G65, A79 & 30.3 & $0 \%$ & $100 \%$ & 18 \\
\hline Q9UEW8 & SтKз9 & STE20/SPS1-related proline-alanine-rich protein kinase & G436 & 41.8 & $1 \%$ & $116 \%$ & 18 \\
\hline Q9UMZ2 & SYNRG & Synergin gamma & G1119 & 23.2 & $0 \%$ & $85 \%$ & 9 \\
\hline Q96C24 & SYTL4 & Synaptotagmin-like protein 4 & S346 & 8.3 & $1 \%$ & $60 \%$ & 9 \\
\hline P37802 & TAGLN2 & Transgelin-2 & G5 & 3.4 & $37 \%$ & $79 \%$ & 17 \\
\hline Q4KMP7 & TBC1D10B & TBC1 domain family member 10B (Rab27A-GAP-beta) & G312 & 3.5 & $10 \%$ & $94 \%$ & 19 \\
\hline Q8N9U0 & $T C 2 N$ & Tandem C2 domains nuclear protein & S194 & 105.5 & $0 \%$ & $90 \%$ & 13 \\
\hline Q92734 & TFG & Protein TFG & L187 & 3.7 & $19 \%$ & $88 \%$ & 9 \\
\hline O43294 & TGFB111 & TGF beta-1-induced transcript 1 protein & A163, L210 & 16.4 & $0 \%$ & $113 \%$ & 18 \\
\hline P07996 & THBS1 & Thrombospondin-1 & N19, S405, G471 & 5.7 & $102 \%$ & $102 \%$ & 17 \\
\hline Q9UDY2 & TJP2 & Tight junction protein ZO-2 & A129 & 5.7 & $0 \%$ & $227 \%$ & 18 \\
\hline Q9Y490 & TLN1 & Talin-1 & Q163, S467, M468, Q473 & 16.5 & $12 \%$ & $108 \%$ & 4 \\
\hline Q9Y490 & TLN1 & Talin-1 & A839, A1576, S1582 & 7.0 & $11 \%$ & $69 \%$ & 4 \\
\hline Q9Y490 & TLN1 & Talin-1 & A2504 & 15.1 & $2 \%$ & $150 \%$ & 4 \\
\hline Q969X1 & TMBIM1 & Protein lifeguard 3 & G68 & 26.6 & $0 \%$ & $35 \%$ & 8 \\
\hline Q8WWA1 & TMEM40 & Transmembrane protein 40 & S8, S41, D119 & 29.4 & $5 \%$ & $82 \%$ & 10 \\
\hline Q9NYL9 & $T M O D 3$ & Tropomodulin-3 & T34, D178 & 31.4 & $0 \%$ & $89 \%$ & 1 \\
\hline P67936 & TPM4 & Tropomyosin alpha- 4 chain & Q19 & 11.1 & $2 \%$ & $50 \%$ & 1 \\
\hline Q9Y3Q8 & TSC22D4 & TSC22 domain family protein 4 & A188 & 31.7 & $0 \%$ & $116 \%$ & 20 \\
\hline Q99816 & TSG101 & Tumor susceptibility gene 101 protein & S202 & 3.5 & $19 \%$ & $88 \%$ & 9 \\
\hline P68366 & TUBA4A & Tubulin alpha-4A chain & E433 & 19.1 & $0 \%$ & $72 \%$ & 3 \\
\hline Q9H4B7 & TUBB1 & Tubulin beta- 1 chain & E26 & 20.3 & $2 \%$ & $60 \%$ & 3 \\
\hline Q9BZV1 & UBXN6 & UBX domain-containing protein 6 & A89 & 3.5 & $16 \%$ & $123 \%$ & 14 \\
\hline P50552 & VASP & Vasodilator-stimulated phosphoprotein & $\mathrm{S} 128, \mathrm{~A} 250, \mathrm{E} 265, \mathrm{E} 282$ & 33.4 & $2 \%$ & $82 \%$ & 18 \\
\hline P50552 & $V A S P$ & Vasodilator-stimulated phosphoprotein & S329, E330, T331 & 38.8 & $0 \%$ & $89 \%$ & 18 \\
\hline Q9BRP8 & WIBG & Partner of $\mathrm{Y} 14$ and mago & Q123 & 4.7 & $0 \%$ & $162 \%$ & 20 \\
\hline O43516 & WIPF1 & WAS/WASL-interacting protein family member 1 & $\mathrm{~S} 344, \mathrm{~A} 394$ & 24.4 & $4 \%$ & $96 \%$ & 1 \\
\hline Q15942 & $z y x$ & Zyxin & V36, E111, Q243 & 5.0 & $32 \%$ & $188 \%$ & 4 \\
\hline Q15942 & $z Y X$ & Zyxin & Q368, D369, V378 & 25.1 & $0 \%$ & $77 \%$ & 4 \\
\hline
\end{tabular}




\begin{tabular}{|c|c|c|c|c|c|c|c|}
\hline \multirow[t]{2}{*}{$\begin{array}{l}\text { Uniprot } \\
\text { number }\end{array}$} & \multirow[t]{2}{*}{ Gene name } & \multirow[t]{2}{*}{ Protein name } & \multirow[t]{2}{*}{ Cleavage sites } & \multicolumn{3}{|c|}{ Effect ABT-737 (mean) } & Assumed function c \\
\hline & & & & vehicle & QVD-Oph & calpeptin & \\
\hline \multicolumn{8}{|c|}{$A B T-737-i n d u c e d$ neo-N-termini (ratio >3.5) } \\
\hline P12814 & ACTN1 & Alpha-actinin-1 & S6 & 35.2 & $6 \%$ & $115 \%$ & 1 \\
\hline P54819 & $A K 2$ & Adenylate kinase 2 , mitochondrial & S4 & 4.8 & $81 \%$ & $105 \%$ & 11 \\
\hline Q8NEU8 & APPL2 & DCC-interacting protein 13-beta & D645 & 49.0 & $80 \%$ & $102 \%$ & 6 \\
\hline O43182 & ARHGAP6 & Rho GTPase-activating protein 6 & S366 & 38.0 & $3 \%$ & $113 \%$ & 19 \\
\hline P06576 & ATP5B & ATP synthase subunit beta, mitochondrial & A47 & 10.1 & $81 \%$ & $96 \%$ & 11 \\
\hline Q7Z460 & CLASP1 & CLIP-associating protein 1 & G1219 & 8.7 & $12 \%$ & $123 \%$ & 3 \\
\hline P20674 & $\operatorname{COX5A}$ & Cytochrome $\mathrm{c}$ oxidase subunit $5 \mathrm{~A}$, mitochondrial & $\mathrm{S} 42$ & 4.5 & $124 \%$ & $114 \%$ & 11 \\
\hline Q9UBC2 & EPS15L1 & Epidermal growth factor receptor substrate 15 -like 1 & S560 & 12.7 & $5 \%$ & $92 \%$ & 9 \\
\hline P00488 & F13A1 & Coagulation factor XIII A chain & Y305 & 3.5 & $90 \%$ & $95 \%$ & 17 \\
\hline Q86UX7 & FERMT3 & Fermitin family homolog 3 (Kindlin-3) & S345 & 82.8 & $3 \%$ & $117 \%$ & 4 \\
\hline Q86UX7 & FERMT3 & Fermitin family homolog 3 (Kindlin-3) & T79, S199, G336, S337 & 4.5 & $82 \%$ & $97 \%$ & 4 \\
\hline P02671 & $F G A$ & Fibrinogen alpha chain & A20, D21 & 7.2 & $94 \%$ & $96 \%$ & 17 \\
\hline Q9Y613 & FHOD1 & $\mathrm{FH} 1 / \mathrm{FH} 2$ domain-containing protein 1 & G10 & 55.8 & $3 \%$ & $105 \%$ & 1 \\
\hline P21333 & FLNA & Filamin-A & G1337, G1505 & 53.1 & $8 \%$ & $115 \%$ & 4 \\
\hline P07359 & GP1BA & Platelet glycoprotein lb alpha chain & V481 & 12.8 & $15 \%$ & $125 \%$ & 10 \\
\hline P06396 & GSN & Gelsolin & G33, V53 & 4.0 & $78 \%$ & $95 \%$ & 1 \\
\hline P06396 & GSN & Gelsolin & G404 & 78.4 & $6 \%$ & $101 \%$ & 1 \\
\hline Q27J81 & INF2 & Inverted formin-2 & $\mathrm{A} 1052$ & 33.8 & $37 \%$ & $146 \%$ & 1 \\
\hline P05106 & ITGB3 & Integrin beta-3 & G27 & 7.2 & $111 \%$ & $114 \%$ & 10 \\
\hline O43561 & LAT & Linker for activation of T-cells family member 1 & S84 & 4.3 & $51 \%$ & $145 \%$ & 18 \\
\hline O75427 & LRCH4 & Leucine-rich repeat and calponin homology protein 4 & S359 & 9.7 & $10 \%$ & $112 \%$ & 21 \\
\hline Q32MZ4 & LRRFIP1 & Leucine-rich repeat flightless-interacting protein 1 & A741 & 28.0 & $1 \%$ & $148 \%$ & 20 \\
\hline P35579 & MYH9 & Myosin-9 & $\mathrm{S} 1154$ & 23.6 & $4 \%$ & $117 \%$ & 1 \\
\hline P55209 & NAP1L1 & Nucleosome assembly protein 1 -like 1 & G58 & 65.9 & $6 \%$ & $106 \%$ & 20 \\
\hline Q0ZGT2 & NEXN & Nexilin & G568 & 90.4 & $4 \%$ & $89 \%$ & 1 \\
\hline P30101 & PDIA3 & Protein disulfide-isomerase $\mathrm{A} 3$ & $\mathrm{~S} 25$ & 3.8 & $108 \%$ & $96 \%$ & 6 \\
\hline P13667 & PDIA4 & Protein disulfide-isomerase A4 & A24 & 4.4 & $107 \%$ & $90 \%$ & 6 \\
\hline O00151 & PDLIM1 & PDZ and LIM domain protein 1 & S84 & 4.6 & $56 \%$ & $98 \%$ & 4 \\
\hline P47712 & PLA2G4A & Cytosolic phospholipase A2 & A523 & 35.2 & $5 \%$ & $116 \%$ & 18 \\
\hline Q9NS28 & RGS18 & Regulator of G-protein signaling 18 (RGS18) & S66 & 5.2 & $76 \%$ & $98 \%$ & 19 \\
\hline O75563 & SKAP2 & Src kinase-associated phosphoprotein 2 (Pyk2) & S271 & 54.3 & $1 \%$ & $157 \%$ & 18 \\
\hline Q9NRL3 & STRN4 & Striatin-4 & G341 & 8.2 & $25 \%$ & $172 \%$ & 18 \\
\hline Q15833 & STXBP2 & Syntaxin-binding protein 2 & A2 & 4.2 & $88 \%$ & $93 \%$ & 9 \\
\hline P07996 & THBS1 & Thrombospondin-1 & N19, S405 & 6.4 & $115 \%$ & $100 \%$ & 17 \\
\hline Q9Y490 & TLN1 & Talin-1 & E2007 & 4.3 & $93 \%$ & $95 \%$ & 4 \\
\hline Q9UKE5 & TNIK & TRAF2 and NCK-interacting protein kinase & G853 & 5.6 & $15 \%$ & $115 \%$ & 15 \\
\hline Q5T4S7 & UBR4 & E3 ubiquitin-protein ligase UBR4 & $\mathrm{S} 2904$ & 17.1 & $7 \%$ & $108 \%$ & 14 \\
\hline P45974 & USP5 & Ubiquitin carboxyl-terminal hydrolase 5 & D768 & 38.0 & $2 \%$ & $113 \%$ & 14 \\
\hline
\end{tabular}


Chapter 9

General discussion 
In-depth analysis of the formation of procoagulant, phosphatidylserine-

\section{exposing platelets}

As explained in Chapter 1, platelets become procoagulant due to calcium-or apoptosis-induced

phospholipid

scrambling and surface exposure of phosphatidylserine..$^{1-3}$ The exposure of phosphatidylserine, readily detected with the probe annexin A5, greatly stimulates the binding and activation of coagulation factors to produce factor $\mathrm{Xa}$ and thrombin..$^{4-6}$ However, the overview Chapter $\mathbf{2}$ indicates that the role of coagulation in thrombus formation and stabilisation is broader than earlier thought and also includes clot retraction. The combined ligands collagen and thrombin appears to be key triggers of the platelet procoagulant response, and evoke a potent $\mathrm{Ca}^{2+}$ signal via glycoprotein $\mathrm{VI}$ and the proteaseactivated receptors $1 / 4$, respectively (Chapter 3). Another finding is the assistant role in phosphatidylserine exposure of the formation of a mitochondrial permeability transition pore (MPTP) and of the store-operated $\mathrm{Ca}^{2+}$ entry (SOCE) pathway, which pathways likely enforce the cytosolic $\mathrm{Ca}^{2+}$ mobilisation with $\mathrm{Ca}^{2+}$ from mitochondrial and extracellular origin, respectively.

In Chapter 6, it is described that platelet treatment with the pro-apoptotic agent ABT-737 results in the formation of two distinct

subpopulations

of phosphatidylserine-exposing platelets, one with moderate and one with high annexin A5 binding. A relevant question arising is whether the moderate annexin A5-binding platelets are also limitedly active in supporting thrombin generation. However, this does not seem to be case, as the Jackson and Goodall groups have shown that thrombin generation curves obtained with ABT737-stimulated platelets are similar to those obtained with collagen receptor peptide-stimulated platelets., 7,8 Our in vitro experiments with Scott platelets deficient in anoctamin-6 - showed a partly reduced ABT-737-induced formation in the patient's platelets of particularly the high annexin A5-binding binding fraction. On the other hand, the Scott platelets were unaffected in the ABT-737-induced and caspase-mediated phosphatidylserine exposure, thus excluding a major role of anoctamin- 6 in the apoptosis pathway. Together, these data suggest the presence of a secondary $\mathrm{Ca}^{2+}$-dependent mechanism of phosphatidylserine exposure, mediated by anoctamin-6 - and hence absent in Scott platelets - and responsible for the high annexin A5 binding fraction.

A previous finding from our laboratory is that the integrin $\alpha_{\| 1} \beta_{3}$ becomes secondarily inactivated in platelets undergoing $\quad \mathrm{Ca}^{2+}$-dependent phosphatidylserine exposure. ${ }^{9,10}$ Based 
on early reports this was explained by proteolytic degradation of the membrane cytoskeleton. ${ }^{11}$ The studies described in Chapter 4 have re-examined this in more detail, and provide molecular evidence that calpain cleaves several cytosolic proteins, not only the integrin $\beta_{3}$-chain, but also signalling proteins operating downstream of integrin $\alpha_{\| b} \beta_{3}$ such as Src kinase and talin-1, in phosphatidylserine-exposing platelets stimulated via both the collagen and thrombin receptors. Control experiments indicated that platelet stimulation with thrombin alone did not induce integrin closure, protein cleavage nor phosphatidylserine exposure. These findings were confirmed in the neo- $\mathrm{N}$ terminal proteomics analysis of Chapter 8, as further discussed below. Together, this suggests that in phosphatidylserineexposing platelets both the integrin $\alpha_{\| 1 b} \beta_{3}$ and integrin-dependent signalling pathways are abrogated due to intracellular cleavage of the concerning proteins.

A number of additional experiments in Chapter 4 revealed the calpain isoform involved in this multiple protein cleavage. Intracellular cleavage of the integrin $\beta_{3}$-chain, Src kinase and talin- 1 in phosphatidylserine-exposing platelets could completely be prevented by calpeptin and MDL-28170, which are known to be specific inhibitors of calpain protease activity. ${ }^{12,13}$ On the other hand, activated platelets from mice deficient in the calpain-1 isoform (Capn1 ${ }^{--}$) showed normal cleavage activity of these proteins. It is known that platelets contain both the calpain-1 and calpain-2 isoforms at appreciable levels, and that calpain-2 becomes active at higher cytosolic calcium concentrations in comparison to calpain-1.14,15 Hence, we concluded that especially the calpain-2 isoform is responsible for the proteolytic degradation of integrin-linked proteins. Unfortunately, this could not be confirmed in mice, since Capn2-deficient mice are embryonically lethal. ${ }^{16}$ For the future, it is an option to generate conditional and platelet-specific Capn2deficient mice in order to confirm the proteolytic role of calpain-2 in phosphatidylserine-exposing platelets.

Another finding of Chapter 4 was that the general calpain inhibitors calpeptin and MDL-28170 abrogated the integrin $\beta_{3}$-chain cleavage, but incompletely blocked the integrin closure. This points to the existence of a second mechanism of integrin closure in phosphatidylserineexposing platelets that is not mediated by calpain. Markedly, in Scott platelets, integrin closure was completely inhibited by calpeptin or MDL-28170, suggesting that the second mechanism involves the channel activity of anoctamin-6. Considering that Scott syndrome platelets are essentially devoid of $\mathrm{Ca}^{2+}$ dependent phospholipid scrambling and 
membrane blebbing, ${ }^{17}$ it is not unlikely that the major membrane disturbances seen in phosphatidylserine-exposing platelets partially prevent the secondary closure of activated integrins.

Procoagulant platelets are known to undergo a dramatic morphological change by forming blebbing and ballooning structures, which processes are accompanied by degradation of the actin membrane skeleton. ${ }^{1}$ The precise mechanisms underlying membrane blebbing and ballooning are still unclear, but the increased volume of phosphatidylserine-exposing platelets implicates fluid entry. Hypothetically, this can be either osmotically drives, i.e. following massive ion entry, ${ }^{1}$ or due to the presence of water channels or aquaporins. ${ }^{18}$. In Chapter 8, we provide for a compensatory role of aquaporin-1 which seems to be upregulated in Scott platelets showing limited blebbing. In Chapter 7, we observed that ionomycininduced platelet ballooning was impaired in a hypertonic media, which is suggestive for at least a partial involvement of osmotic water entry. However, further research is needed to distinguish between the possibilities of ballooning driven by either ion or water channels. More evidence should come from currently performed inhibitor studies and experimentation with channel-deficient mice.
Phosphatidylserine-exposing platelets versus coated platelets

As indicated in Chapter 1, coated platelets have been identified in the literature in at least three distinct ways: (i) irreversible retention of factor $\mathrm{V}$, fibrinogen and other proteins via transglutaminase-mediated cross-linking; (ii) high $\alpha_{11 \mathrm{~b}} \beta_{3}$-independent, transglutaminase-dependent binding of fibrinogen; (iii) surface exposure of phosphatidylserine. ${ }^{19,20}$ The original hypothesis of the Dale group was that transglutaminases establish the formation of a protein coat around platelets by a serotonin-dependent cross-linking process. ${ }^{20}$ In Chapter 5, we have taken this up and used a novel probe (Rhod-A14) to measure the activity of transglutaminases on the surface of activated platelets. Dual stimulation of human platelets via their collagen and thrombin receptors led to considerable incorporation of this probe in a way dependent on transglutaminase activity, as confirmed by various control experiments. The findings point to an incomplete overlap of the populations of phosphatidylserine-exposing and coated platelets (defined as platelets incorporating Rhod-A14). Furthermore, time courses indicated that the exposure of phosphatidylserine was faster than the incorporation of Rhod-A14. On the other hand, the Rhod-A14 binding (i.e., formation of a protein coat) did not 
prevent binding of labelled annexin A5 or factor $X a$ to the platelet surface. This suggests that, in at least part of the coated platelets, the procoagulant activity is maintained and, hence the protein coat must consist of a loose protein network. This in fact agrees with the literature, where coated platelets have been described as platelets capable to bind annexin $A 5$ and factor $V(a) .{ }^{21,22}$ Another relevant observation was that platelet stimulation with thrombin alone led to high fibrin(ogen) binding, but not to Rhod-A14 incorporation or phosphatidylserine exposure.

The precise role and origin of individual transglutaminases - tissue-type transglutaminase and coagulation factor XIII - was difficult to study in a human system, since factor XIII is present in both plasma and platelets, and platelets also contain tissue-type transglutaminase. ${ }^{21,23}$ For this reason, we used mice deficient in factor XIII-A, which is the factor XIII subunit containing the catalytic site. These animals survive normally and have normal platelet count. ${ }^{24}$ Interestingly, incorporation of the Rhod-A14 probe was completely absent with the collagen/thrombinactivated knockout platelets, which suggested that mouse platelets have no or low expression of tissue-type transglutaminase. In contrast, fibrinogen binding and phosphatidylserine exposure were unaffected in the factor XIII-A- deficient mice. We concluded that, in mouse, the formation of coated, transglutaminase-active platelets fully relies on the presence of factor XIII and that coated platelet formation is not required for platelet procoagulant activity. Subsequent flow perfusion studies, also using integrin inhibitors, indicated that murine factor XIII-A and integrin $\alpha_{\| 1} \beta_{3}$ have a non-redundant role in the formation of fibrin fibres at the platelet surface under flow conditions. By implication, these results indicate that coated platelets provide a scaffold for the formation of fibrin in thrombus formation.

Together, the results of Chapter 5 point a mechanism for coated platelet formation, as depicted in Figure 1: initial collagen/thrombin receptor-induced $\alpha_{\| 1 b} \beta_{3}$ activation allows fibrin(ogen) binding, preceding the phosphatidylserine exposure. Subsequent activity of transglutaminases at the platelet surface leads to consolidation of the fibrin(ogen) at the platelet surface. This initial fibrin(ogen)containing protein coat then acts as a scaffold for platelet-driven extension of fibrin fibres into the blood plasma (Figure 1). This scheme may illustrate the importance of coated platelet formation in thrombosis and haemostasis.

The Scott syndrome and anoctamin-6 Recently, a critical role was proposed for 
anoctamin-6 (ANO6 gene) in the dependent integrin cleavage and integrin regulation of phospholipid scrambling closure. The data of Chapter 6 indicated and phosphatidylserine exposure. ${ }^{25}$ Indeed, dysfunctional mutations in the ANO6 gene have been reported in two unrelated Scott patients in the USA and the United Kingdom ${ }^{26}$. Furthermore, in a Scott patient from France, ${ }^{27}$ also a that the defect in phosphatidylserine exposure in the UK Scott patient was essentially confined to agonist/calciumdependent phospholipid scrambling and did not extend to apoptosis- dependent phospholipid scrambling. The data of mutation in the ANO6 gene has also Chapter 7 showed that in both human been traced (E. Freyssinet, personal communication). In Chapters 6 and 7 we raised the question whether the anoctamin-6 channel can also be platelets (Scott) and mouse platelets with deficiency in anoctamin-6, the calcium/agonist-induced

phosphatidylserine exposure was greatly involved in other characteristic changes diminished, but not completely of procoagulant platelets, such as abrogated. While some residual membrane blebbing/ballooning, phosphatidylserine exposure was microparticle formation, calpain- observed in platelets from the Scott

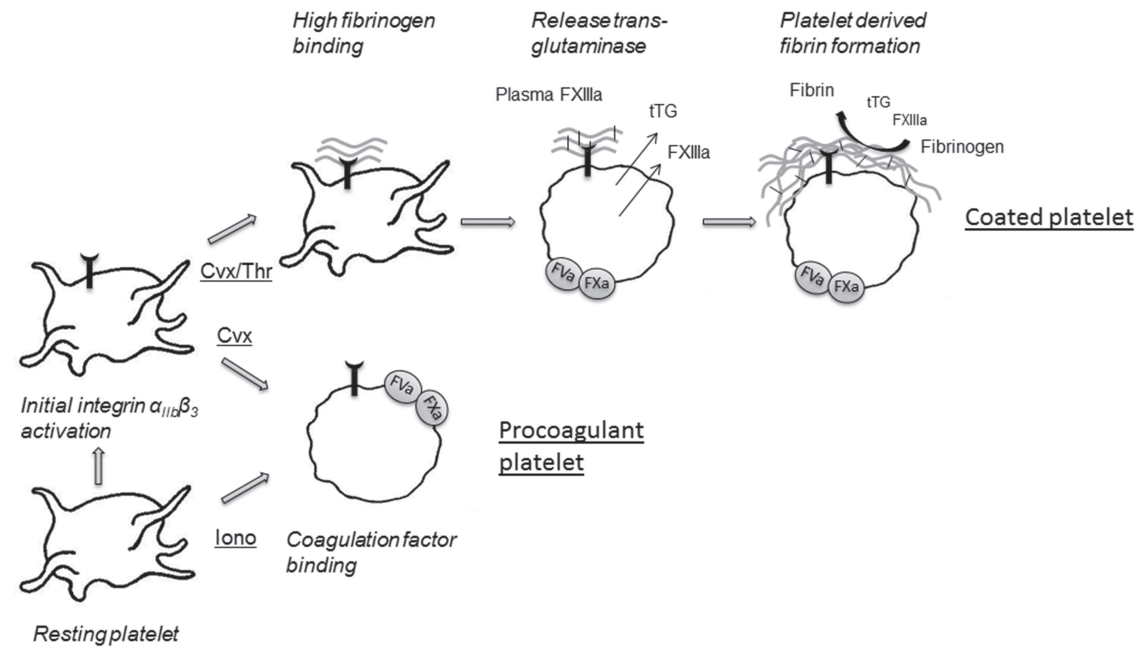

Figure 1. Scheme of formation of procoagulant and coated platelets. Resting platelets can develop into procoagulant, PS-exposing platelets without initial integrin activation when stimulated with the $\mathrm{Ca}^{2+}$-ionophore ionomycin (lono). When stimulated via collagen and thrombin receptors (Cvx/Thr = convulxin/thrombin), procoagulant platelets show initial integrin activation, which is followed by integrin closure. Coated platelets are characterized by initial high fibrinogen binding, which crosslinks via transglutaminase activity (FXIIla) to a coat of fibrin(ogen) at the platelets surface. Although coated platelets are covered with a fibrin coat, their ability to bind coagulation factors (FVa, FXa) is not affected. 
patients and the Ano6-deficient mice, in either case the membrane blebbing and balloon formation was completely abolished (Table 1). Most likely, these 'swelling' responses are a consequence of ion influx via the membrane channel formed by anoctamin-6. Indeed, several groups have presented evidence that anoctamin-6 acts as a channel transmitting $\mathrm{Ca}^{2+}$-dependent chloride and cation currents. ${ }^{28-30}$ The absence of cation/chloride influx could well explain the absence of membrane blebbing and ballooning in the patient's platelets. On the other hand, experiments in Chapter 7 performed with sodium or chloridefree buffers did not show changes in the amount of ballooning, indicating that this osmotic response is not driven by $\mathrm{Na}^{+}$or $\mathrm{Cl}^{-}$influx alone. Whether anoctamin-6 is directly involved in membrane blebbing and ballooning, or whether it regulates the osmotic activity via other cation and anion channels is still to be established.

The Scott syndrome has been described as a moderate bleeding disorder, with haemorrhagic episodes only after trauma or childbirth. ${ }^{31}$ Our data presented in Chapter 7 point to limited hemostatic insufficiency in mice deficient in anoctamin-6, as mouse tail bleed times were moderately increased and platelet aggregation properties were unchanged. Furthermore, we measured non-zero, residual phosphatidylserine exposure of Scott and Ano6 ${ }^{-1}$ platelets

\begin{tabular}{|c|c|c|c|c|c|}
\hline & Procoagulant & Apoptotic & Coated & Role for Ano6 & Chapter/ref \\
\hline Integrin activation & + & - & + & - & 5 \\
\hline Integrin closure & + & - & + & $+/-$ & 4,5 \\
\hline PS exposure & + & + & + & + & $5,6,7$ \\
\hline Ballooning & + & + & + & + & 7,8 \\
\hline Intracellular cleavage & + (calpain) & + (caspase) & + & - & $4,7,8$ \\
\hline $\begin{array}{l}\text { Coagulation factor } \\
\text { binding }\end{array}$ & + & + & + & + & 5 \\
\hline $\begin{array}{l}\text { High fibrinogen } \\
\text { binding }\end{array}$ & - & - & + & - & 5 \\
\hline $\begin{array}{l}\text { Transglutaminase } \\
\text { activity }\end{array}$ & - & ? & + & ? & 5 \\
\hline
\end{tabular}

Table 1. General characteristics of procoagulant, apoptotic and coated platelets. While there is a large overlap in properties between procoagulant and apoptotic platelets, a major difference between these two platelet populations is the inability of apoptotic platelets to display integrin activation and as a consequence lack of secondary integrin closure. Properties such as PS exposure, ballooning, intracellular protein cleavage and coagulation factor binding are displayed in both procoagulant and apoptotic platelets. Coated platelets have some additional characteristics in comparison to procoagulant platelets, such as initial high fibrinogen binding and surface-bound transglutaminase activity. The table furthermore highlights the role for the 'scramblase' protein anoctamin-6 in each of these platelet features. The chapters of this thesis describing the indicated characteristics of these platelet populations are shown in the last column. 
during thrombus formation, which may offer an explanation for the limited severity of the bleeding phenotype. Western blots indicated greatly reduced expression of anoctamin- 6 in platelets from the patient and the mice. Advanced proteomic profiling pointed to complete the absence of anoctamin- 6 expression in the Scott cells, as shown in Chapter 8. Interestingly, in human and mouse blood samples we found evidence for the presence of alternative splice variants of the ANO6 (Ano6) gene. These splice variants might be of functional importance during embryonic development and later life. However, our current data do not point to a significant role of these splice variants in the residual phosphatidylserine exposure or morphological changes in human Scott syndrome or mouse Ano6-deficient platelets.

As an overview of the present findings, Table 1 shows the role of anoctamin- 6 in the formation of procoagulant, apoptotic and coated platelets. Overall, it appears that the procoagulant platelet response in highly dependent on anoctamin-6, while anoctamin- 6 only plays a partial and minimal role in apoptotic and coated platelets.

Proteomics as a tool to understand the phenotypic properties of Scott platelets In chapter 8 we use a novel tool to perform both quantitative proteomics, phosphoproteomics and neo-N-terminal peptide identification in one single sample. The advantage of this tool is the ability to investigate the presence of the protein, the phosphorylation state of the protein and the presence of calpain specific cleavage sites at once. In this way the amount of activation is exactly equal between the phosphoproteome and calpain specific cleavage patterns. By using these methods we were able to identify thousands of proteins in healthy platelets as well as platelets from the Scott patient, and could determinate the amount of phosphorylation after specific activation and the amount of calpainspecific cleavage.

As described above, platelets from the Scott patient and anoctamin- 6 deficient mice are greatly impaired in calciumdependent phosphatidylserine exposure and membrane blebbing. Chapter 8 describes that, in addition to anoctamin6 , the expression of several other proteins is changed in Scott platelets. In particular, Scott platelets displayed a marked up-regulation of the channel protein aquaporin-1, which was confirmed by peptide identification mapping. Aquaporin-1 expression in platelets has also been reported in recent proteomic analyses (Solari F et al. 2015 unpublished). Further research is needed to elucidate if in Scott platelets the water channel aquaporin-1 may have a compensatory role in 
phosphatidylserine exposure and membrane blebbing.

Proteins which are further significantly decreased in protein levels in the Scott patients compared to control platelets, could be assigned to the functional classes mitochondrial proteins (genes ATP5J, HSDL1, PITRM1, SLC25A24) with different functions, as well as a number of proteases, i.e. the $\mathrm{Ca}^{2+}$-dependent calpain-2 (CAPN2) and the secretory cathepsin G (CTSG). The decreased amount of the proteases present in the Scott patient could explain the decreased $\mathrm{N}$-terminal cleavage we observed further on in Chapter 8. The top 15 of most increased protein levels in Scott platelets further includes proteins involved in transcription/translation

(EEF1A1, GCN1L1, RPLPO); and the Rho-GTPaseactivating protein oligophrenin (OPHN1). Previous literature pointed to an abnormal protein tyrosine phosphorylation pattern in Scott syndrome platelets. ${ }^{32}$ The phosphoproteome analysis of Chapter 8 showed comparable phosphorylation profiles of Scott platelets and control platelets after thrombin stimulation. However, strong platelet activation with convulxin/thrombin or ionomycin greatly decreased the overlap in phosphorylation profile; much more proteins were increased in phosphorylation at one or more sites than decreased in Scott platelets in comparison to the control platelets. Strikingly, only after these two specific conditions the patient's platelets are defective in phosphatidylserine exposure. The altered phosphorylation pattern of Scott platelets upon strong stimulation in particular involves cytoskeletal(-linked) proteins and regulators of phosphatidylserine exposure. This could explain in some part the deficiency of Scott platelets to induced the ballooningstructure and the lack of phosphatidylserine exposure.

It has been described that proteases of the calpain family - in platelets with high cytosolic $\mathrm{Ca}^{2+}$ concentration - and of the caspase family - in apoptotic platelets -, generated in activated platelets specific neo-N-termini. ${ }^{33}$ We could identify 180 calpain-cleaved neo- $\mathrm{N}$-terminal peptides after platelet activation by the $\mathrm{Ca}^{2+}$ elevating agent ionomycin, which corresponded to 106 proteins. Specificity for calpain as the responsible protease was straightened by the fact that these terminal peptides could not be observed in the presence of the general calpain inhibitor calpeptin. Function class analysis indicated that the majority of these proteins clustered into the classes: Cytoskeleton (-linked), Membrane \& protein trafficking, and Signalling \& adapter proteins. In agreement with previously published data we observed cleavage of Src kinase $(S R C)$ and talin-1 (TLN1) in phosphatidylserine-exposing 
platelets (Chapter 8). Only a limited number of cleaved peptides is differential (increased + decreased 5$17 \%)$ between Scott platelets and control platelets. The top-15 decreased neo- $\mathrm{N}$ terminal peptides in the Scott patient could be assigned to the functional classes: cytoskeleton-linked proteins (genes DBLN, DNM1L, MAPRE1, NEXN, SMIM1, TLN1 and ZYX) and key regulatory signalling proteins $(D O K 3, F Y B$, GSK3B, PDE3A, VASP).

The observed decrease in calpain activity could be explained by the fact that Scott syndrome platelets appear to have decreased expression numbers of several proteases. But on the other hand,

\section{References}

1. Heemskerk JW, Vuist WM, Feijge MA, Reutelingsperger CP, Lindhout T. Collagen but not fibrinogen surfaces induce bleb formation, exposure of phosphatidylserine, and procoagulant activity of adherent platelets: evidence for regulation by protein tyrosine kinase-dependent $\mathrm{Ca} 2+$ responses. Blood 1997;90:2615-2625.

2. Schoenwaelder SM, Yuan $Y$, Josefsson EC, White MJ, Yao Y, Mason KD, O'Reilly LA, Henley KJ, Ono A, Hsiao S, Willcox A, Roberts AW, Huang DC, Salem HH, Kile BT, Jackson SP. Two distinct pathways regulate platelet phosphatidylserine exposure and procoagulant function. Blood 2009;114,:663-666.

3. Goodwin CA, Wheeler-Jones CP, Kakkar VV, Deadman JJ, Authi KS, Scully MF. Thrombin receptor activating peptide does not stimulate platelet procoagulant activity. Biochem Biophys Res Commun 1994;202:321-327.

4. Hemker HC, van Rijn JL, Rosing J, van Dieijen G, Bevers EM, Zwaal RF. Platelet membrane involvement in blood coagulation. Blood Cells 1983;9:303-317. decreased cleavage of proteins by calpain would make it possible that protein phosphorylation sites which are normally cleaved of in control platelets are still present in Scott platelets. In this way the increased phosphorylation pattern of multiple proteins in the Scott syndrome patients, could be explained by the decreased amount of protein cleavage. Hence, thanks to this novel combined proteomics analysis, we have additional clues on proteins which are differently regulated in Scott platelets and could conclude that a solely role for anoctamin-6 in the observed defects in Scott syndrome platelets can be excluded.
5. Thiagarajan P, Tait JF. Collagen-induced exposure of anionic phospholipid in platelets and plateletderived microparticles. J Biol Chem 1991;266:24302-24307.

6. Bevers EM, Comfurius P, van Rijn JL, Hemker HC, Zwaal RF. Generation of prothrombin-converting activity and the exposure of phosphatidylserine at the outer surface of platelets. Eur J Biochem 1982;122:429-436.

7. Jackson SP, Schoenwaelder SM. Procoagulant platelets: are they necrotic? Blood 2010;116:2011-2018.

8. Vogler M, Hamali HA, Sun XM, Bampton ET, Dinsdale D, Snowden RT, Dyer MJ, Goodall AH, Cohen GM. BCL2/BCL-X(L) inhibition induces apoptosis, disrupts cellular calcium homeostasis, and prevents platelet activation. Blood 2011;117:7145-7154.

9. Munnix IC, Kuijpers MJ, Auger J, Thomassen CM, Panizzi P, van Zandvoort MA, Rosing J, Bock PE, Watson SP, Heemskerk JW. Segregation of platelet aggregatory and procoagulant microdomains in thrombus formation: regulation by transient integrin activation. Arterioscler Thromb Vasc Biol2007; 27:2484-2490. 
10. Cosemans JM, Iserbyt BF, Deckmyn H, Heemskerk JW. Multiple ways to switch platelet integrins on and off. J Thromb Haemost 2008;6:1253-1261.

11. Fox JE. Regulation of platelet function by the cytoskeleton. Adv Exp Med Biol 1993;344:175185.

12. Tsujinaka $T$, Kajiwara $Y$, Kambayashi J, Sakon M, Higuchi N, Tanaka T, Mori T. Synthesis of a new cell penetrating calpain inhibitor (calpeptin). Biochem Biophys Res Commun 1988;153:12011208.

13. Mehdi S, Angelastro MR, Wiseman JS, Bey P. Inhibition of the proteolysis of rat erythrocyte membrane proteins by a synthetic inhibitor of calpain. Biochem Biophys Res Commun 1988;157:1117-1123.

14. Kraemer BF, Weyrich AS, Lindemann S. Protein degradation systems in platelets. Thromb Haemost 2013;110:920-924.

15. Randriamboavonjy V, Fleming I. All cut up! The consequences of calpain activation on platelet function. Vascul Pharmacol 2012;56:210-215.

16. Dutt $P$, Croall DE, Arthur JS, Veyra TD, Williams $K$, Elce JS, Greer PA. m-Calpain is required for preimplantation embryonic development in mice. BMC Dev Biol 2006;6:3.

17. Toti F, Satta N, Fressinaud E, Meyer D, Freyssinet JM. Scott syndrome, characterized by impaired transmembrane migration of procoagulant phosphatidylserine and hemorrhagic complications, is an inherited disorder. Blood 1996;87:1409-1415.

18. Suzuki M, Tanaka S. Structure and diverse functions of vertebrate aquaporins. Seikagaku 2014;86:41-53.

19. Dale GL. Coated-platelets: an emerging component of the procoagulant response. J Thromb Haemost 2005;3:2185-2192.

20. Dale GL, Friese P, Batar P, Hamilton SF, Reed GL, Jackson KW, Clemetson KJ, Alberio L. Stimulated platelets use serotonin to enhance their retention of procoagulant proteins on the cell surface. Nature 2002;415:175-179.

21. Alberio LJ, Clemetson KJ. All platelets are not equal: COAT platelets. Curr Hematol Rep 2004;3:338-343.

22. Colucci G, Stutz $M$, Rochat $S$, Conte $T$, Pavicic $M$, Reusser M, Giabbani E, Huynh A, Thurlemann C, Keller $\mathrm{P}$, Alberio $\mathrm{L}$. The effect of desmopressin on platelet function: a selective enhancement of procoagulant COAT platelets in patients with primary platelet function defects. Blood 2014;123:1905-1916.

23. Puszkin EG, Raghuraman V. Catalytic properties of a calmodulin-regulated transglutaminase from human platelet and chicken gizzard. J Biol Chem 1985;260:16012-16020.

24. Inbal A, Lubetsky A, Krapp T, Castel D, Shaish A, Dickneitte G, Modis L, Muszbek L. Impaired wound healing in factor XIII deficient mice. Thromb Haemost 2005;94:432-437.

25. Suzuki J, Umeda M, Sims PJ, Nagata S. Calciumdependent phospholipid scrambling by TMEM16F. Nature 2010;468:834-838.

26. Castoldi E, Collins PW, Williamson PL, Bevers EM. Compound heterozygosity for 2 novel TMEM16F mutations in a patient with Scott syndrome. Blood 2011;117:4399-4400.

27. Flores-Nascimento MC, Orsi FL, Yokoyama AP, Pereira FG, Lorand-Metze I, De Paula EV, Castro V, Annichino-Bizzacchi JM. Diagnosis of Scott syndrome in patient with bleeding disorder of unknown cause. Blood Coagul Fibrinolysis 2012;23:75-77.

28. Kunzelmann K, Nilius B, Owsianik G, Schreiber R, Ousingsawat J, Sirianant L, Wanitchakool P, Bevers EM, Heemskerk JW. Molecular functions of anoctamin 6 (TMEM16F): a chloride channel, cation channel, or phospholipid scramblase? Pflugers Arch 2014;466:407-414.

29. Martins JR, Faria D, Kongsuphol P, Reisch B, Schreiber R, Kunzelmann K. Anoctamin 6 is an essential component of the outwardly rectifying chloride channel. Proc Natl Acad Sci U S A 2011;108:18168-18172.

30. Tian Y, Schreiber R, Kunzelmann K. Anoctamins are a family of Ca2+-activated $\mathrm{Cl}$ - channels. J Cell Sci 2012;125:4991-4998.

31. Satta N, Toti F, Fressinaud E, Meyer D, Freyssinet JM. Scott syndrome: an inherited defect of the procoagulant activity of platelets. Platelets 1997;8:117-124.

32. Dachary-Prigent J, Pasquet JM, Fressinaud E, Toti F, Freyssinet JM, Nurden AT. Aminophospholipid exposure, microvesiculation and abnormal protein tyrosine phosphorylation in the platelets of a patient with Scott syndrome: a study using physiologic agonists and local anaesthetics. $\mathrm{Br} J$ Haematol 1997;99:959-967.

33. Maddelein D, Colaert N, Buchanan I, Hulstaert N, Gevaert K, Martens L. The iceLogo web server and SOAP service for determining protein consensus sequences. Nucleic Acids Res 2015;43:W543-6. 

Summary 
Platelets play important roles in thrombus formation. They adhere to the damaged vascular wall, form a platelet plug, and stimulate the coagulation process. It is considered that two types of platelets are formed in a growing thrombus: aggregating and procoagulant platelets. Chapter 1 describes that these two platelet populations are discriminated by the rise in intracellular $\mathrm{Ca}^{2+}$ concentration. While a transient rise in intracellular calcium is sufficient for platelet integrin $\alpha_{11 b} \beta_{3}$ activation and secretion - two processes that are implicated in platelet aggregation -, a high, sustained rise in $\mathrm{Ca}^{2+}$ is required for the exposure of phosphatidyl serine (PS), which enables platelet to become procoagulant. Prolonged high intracellular $\mathrm{Ca}^{2+}$ concentrations activate the scrambling of membrane phospholipids, and as a consequence surface exposure of PS. This provides a surface for coagulation factor binding and ensuing thrombin generation. The underlying mechanisms and consequences of procoagulant platelet formation are investigated in this thesis.

In chapter 2, background information is given on the multifaceted process of arterial thrombus formation and vascular occlusion. In this overview, we describe how the classical concept of arterial thrombus formation and vascular occlusion, driven by platelet activation and fibrin formation, can be extended and fine-tuned. Key processes controlling the stability of a thrombus are: (i) initial platelet integrin activation controlling platelet aggregation, which can be reversible and result in shedding of platelet emboli; (ii) contact-dependent signaling, stabilizing the platelet aggregates; and (iii) thrombin and fibrin generation in plasma via the intrinsic and extrinsic coagulation pathways. The latter provide the thrombus with a fibrin network, but still allow shedding of platelet-fibrin emboli (microclots). A list of over 40 published studies with genetically modified mice points to key roles of platelet as well as plasma proteins in the control of thrombus stability after vascular injury.

Elaborating on the capability of procoagulant platelets in a thrombus to interact with (anti)coagulation factors and support blood coagulation, chapter 3 provides an overview of the different ways how platelets act in a model of cellbased control of coagulation. Platelets with elevated $\mathrm{Ca}^{2+}$ and exposed PS stimulate thrombin and fibrin generation, whilst platelets with activated $\alpha_{\| 1 b} \beta_{3}$ rather regulate clot retraction. Only few physiological agonists, particularly those stimulating the collagen receptor, glycoprotein VI (GPVI), are capable of inducing PS exposure by themselves. On the other hand, a larger number of agonists, including von Willebrand factor, fibrinogen, thrombin, ADP, antibodies 
and thrombospondin, appears to enhance the process of (GPVI-mediated) PS exposure, by stimulating their respective receptors. In most cases the co-agonists act by increasing the $\mathrm{Ca}^{2+}$ signal towards a prolonged high $\mathrm{Ca}^{2+}$ rise. Mechanisms for $\mathrm{Ca}^{2+}$ elevation that contribute to PS exposure include: $\mathrm{Ca}^{2+}$ mobilization from the endoplasmic reticulum via inositol trisphosphate receptors; store-operated $\mathrm{Ca}^{2+}$ entry via STIM1 and Orai1 channels; and release of mitochondrial $\mathrm{Ca}^{2+}$ via mitochondrial permeability transition pore formation.

Chapter 4 aims to reveal how PSexposing platelets disconnect from a thrombus by inactivation of their integrins. It was demonstrated that integrin $\alpha_{11 b} \beta_{3}$ inactivation in procoagulant platelets relies on a sustained high intracellular $\mathrm{Ca}^{2+}$, stimulating intracellular cleavage of the integrin $\beta_{3}$ chain as well as talin, and Src kinase. Inhibition of calpain activity completely abolished protein cleavage, but only partly suppressed $\alpha_{11 \mathrm{~b}} \beta_{3}$ inactivation. Since the inactivation of $\alpha_{11 b} \beta_{3}$ was unchanged in platelets from mice deficient in calpain-1, we proposed a role of the calpain-2 isoform, with is known to become active at relatively high $\mathrm{Ca}^{2+}$ levels. Scott syndrome platelets displayed reduced $\alpha_{\| b} \beta_{3}$ inactivation with the remaining integrin activity fully dependent on calpain. In platelets from Ppif-deficient mice, lacking mitochondrial permeability transition pore formation, we found that agonist-induced PS exposure and $\alpha_{\| b} \beta_{3}$ inactivation were reduced. Treatment of human platelets with cyclosporin A (targeting the same process) gave a similar phenotype. Together, these data point to a dual mechanism of $\alpha_{11 b} \beta_{3}$ inactivation via calpain(-2) cleavage of integrinassociated proteins and via anoctamin-6dependent phospholipid scrambling with an assistant role of mitochondrial pore formation.

Coated platelets, formed by collagen and thrombin activation, have been characterized in different ways, such as by the formation of a protein coat of $\alpha$ granular proteins, by exposure of procoagulant PS or by fibrinogen binding. Moreover, their functional role has remained unclear. In chapter 5, we used a novel transglutaminase probe, RhodA14, to identify subpopulations of platelets with a cross-linked protein coat, and compared these with other platelet activation characteristics, using a panel of platelet function assays. Platelet stimulation with convulxin/thrombin resulted in initial integrin $\alpha_{11 b} \beta_{3}$ activation, the appearance of a platelet population with high fibrinogen binding independently of active integrins, but dependent on the presence of thrombin -, followed by PS exposure and binding of factors $\mathrm{Va}$ and Xa. Specifically, the transglutaminase-active

platelets, 
detected with Rhod-A14, formed as a subpopulation of the PS-exposing platelets. This staining pattern was confirmed in tissue-factor triggered platelet-rich plasma. Markedly, the high fibrin(ogen) and Rhod-A14 binding were antagonized by combined inhibition of transglutaminase activity and integrin $\alpha_{11 b} \beta_{3}$. In thrombi formed on collagen, Rhod-A14 again bound to a subpopulation of PS-exposing platelets via transglutaminase activity and later, under coagulant conditions, to fibrin fibers. Markedly, in thrombi from mice deficient in factor XIII, but not in wildtype thrombi, platelet-driven fibrin formation and Rhod-A14 binding were abolished by $\alpha_{11 b} \beta_{3}$ blockage. Together, this made us conclude that transglutaminase-active coated platelets, with initial $\alpha_{\| 1} \beta_{3}$ activation and high fibrinogen binding, function in plateletdependent fibrin fiber formation via factor XIII and $\alpha_{11 \mathrm{~b}} \beta_{3}$.

Scott syndrome, a bleeding disorder caused by defective phospholipid scrambling and PS exposure, has been associated with mutations in the gene for anoctamin-6 (ANO6, previously indicated as TMEM16F). In chapter 6 , the processes of apoptosis- and agonistinduced PS exposure are studied in platelets from a Scott patient, lacking anoctamin-6. Apoptosis-dependent PS exposure was studied with the $\mathrm{BH} 3-$ mimetic ABT-737. In control platelets,
ABT-737 gave two distinct fractions with moderate and high PS exposure. Markedly, the high PS-exposing fraction was substantially reduced in Scott platelets. From these and other observations, we concluded that, although anoctamin- 6 is not critically involved in PS exposure upon apoptosis, it does increase PS exposure in a subset of the apoptotic platelets. High, but not moderate, PS exposure in platelets was suppressed by chelation of intracellular $\mathrm{Ca}^{2+}$, whereas caspase inhibition completely abolished ABT-737-induced PS exposure in both Scott and control platelets. On the other hand, high PS exposure as induced by the high $\mathrm{Ca}^{2+}$ mobilizing agonists convulxin/thrombin, fully relied on mitochondrial depolarization and was virtually absent in Scott platelets. Finally, PS exposure induced by collagen/thrombin was partly affected in Scott platelets, indicating that next to an anoctamin-6-dependent pathway, also another pathway to PS exposure exists. The residual PS exposure was insensitive to inhibition of caspases or mitochondrial depolarization. In sum, these results demonstrate that TMEM16F-dependent and -independent phospholipid scrambling can be induced in platelets upon apoptosis, aging, and activation.

In chapter 7, the role of anoctamin-6 in platelet responses was further studied using genetically modified mice deficient 
in this protein. In addition, mice were used lacking other candidate proteins of phospholipid scramblase, i.e. anoctamin1 and the $\mathrm{Ca}^{2+}$-dependent $\mathrm{K}^{+}$channel Kca3.1 (Gardos channel). Anoctamin-6 deficient mice showed normal collageninduced thrombus formation, but low residual PS exposure. Platelets from these mice did not display $\mathrm{Ca}^{2+}$ dependent formation of ballooned structures, had reduced integrin $\beta_{3}$-chain cleavage and a moderately affected apoptosis-dependent PS exposure. All these altered responses are observed in human Scott platelets as well. Markedly, deficiency in anoctamin- 6 resulted in a reduced viability; and the surviving anoctamin-6-deficient mice had increased tail bleeding times. No platelet phenotype was observed in mice lacking the related ion-channel anoctamin-1, or mice lacking the Kca3.1 Gardos channels. In conclusion, mouse deficiency of Ano6 but not of other channels, affects viability and phenocopies the complex activation changes in hemostatically impaired human Scott platelets.

Considering that platelets from Scott patients have a complex phenotype including lack of PS exposure, balloon formation and microparticle shedding -, we hypothesized in chapter 8 that changes in several protein levels and post-translational protein modifications contribute to this phenotype. To investigate this, we compared platelets from healthy control donors and a Scott patient by highly sensitive and advanced (phospho)proteomics analysis. Quantitative proteomics $(2,225$ unique proteins) indicated changed expression levels of about 200 proteins in the Scott platelets compared to control platelets. Alterations in expression were most frequently observed in proteins of the following function classes: membrane receptors \& channels, mitochondrial proteins, metabolic and signaling \& adapter proteins, such in accordance with the relatively high numbers of expressed proteins in these classes. In Scott platelets, anoctamin- 6 could not be detected, whereas the channel protein aquaporin-1 was highly upregulated. Analysis of 1,566 unique phosphopeptides (corresponding to 716 proteins) indicated major phosphorylation differences between Scott and control platelets after stimulation with convulxin/thrombin or ionomycin. In Scott platelets, a limited number of proteins were decreased in phosphorylation (e.g., proteins linked to the cytoskeleton or regulating PS exposure); a much higher number was increased in phosphorylation (e.g., cytoskeleton-linked, membrane and signaling proteins). Furthermore, we identified a total of 1,613 neo-N-termini - in majority formed by intracellular cleavage of proteins -, with substantial differences between Scott and control 
platelets. In total, we identified 180 neo- proteomic profiling provides novel $\mathrm{N}$-terminal peptides (corresponding to insight into the altered protein 106 proteins) that are generated due to composition and post-translational calpain activity. In comparison, we protein machinery explaining the major identified a distinct set of 23 neo- $N-\mathrm{Ca}^{2+}$ and cytoskeleton-dependent termini (corresponding to 23 proteins) as membrane alterations in Scott syndrome caspase-regulated. In Scott platelets, platelets.

most calpain-cleaved neo-N-termini In chapter $\mathbf{9}$, the most important findings were lower in level after of this thesis are discussed in view of the convulxin/thrombin stimulation (in current literature. It is argued that the particular peptides from cytoskeleton- mouse studies and the proteomic linked and key signaling proteins), and analyses employed have let to more higher in level after ionomycin insight into the complex mechanism stimulation (a variety of proteins). In underlying the procoagulant platelet summary, we postulate that advanced response. 
Samenvatting 
Bloedplaatjes spelen een belangrijke rol in het proces van trombusvorming. Ze hechten aan een beschadigd bloedvat, vormen een bloedplaatjesprop, en stimuleren vervolgens het stollingsproces. In een aangroeiende trombus kunnen bloedplaatjes in twee vormen aanwezig zijn, namelijk als aggregerende cellen en als stollingsactieve (procoagulante) bloedplaatjes. In hoofdstuk 1 van dit proefschrift is beschreven dat deze twee polpulaties van bloedplaatjes van elkaar onderscheiden kunnen worden door de stijging van hun intracellulaire vrije calciumconcentratie. Terwijl een kortstondige verhoging in vrij calcium voldoende is voor het activeren van integrine $\alpha_{\| 1} \beta_{3}$ en de uitscheiding van actieve substanties - twee processen die betrokken zijn bij de plaatjesaggregatie -, is een continu verhoogd vrij calcium nodig voor het verschijnen van fosfatidylserine (PS) op het membraanoppervlakte, waardoor de stolling in gang gezet kan worden. Een blijvend verhoogd calcium zorgt voor de translocatie van PS van de binnenzijde naar de buitenzijde van het celmembraan. Hierna dient het geëxposeerde PS als bindingsplaats voor diverse stollingsfactoren, als gevolg waarvan via de stollingscascade trombine wordt gevormd. De signaleringspaden die in het bloedplaatje plaatsvinden voor deze procoagulante activiteit, worden in dit proefschrift besproken.

In hoofdstuk 2 wordt achtergrondinformatie gegeven over de processen die betrokken zijn bij vasculaire occlusie en een arteriële trombose, dat wil zeggen het afsluiten van een slagader door een bloedstolsel. In dit hoofdstuk wordt beschreven hoe het klassieke idee van occlusieve arteriële trombusvorming, aangestuurd door het activeren van bloedplaatjes en het vormen van een fibrinenetwerk, moet worden uitgebreid en verfijnd. Enkele belangrijke processen die de stabiliteit van een trombus beïnvloeden zijn: 1) de initiële activatie van integrines op bloedplaatjes, een proces dat omkeerbaar is waardoor bloedplaatjes van de trombus kunnen loslaten; 2) de intracellulaire signalering die nodig is voor stabiel contact tussen de bloedplaatjes, waardoor de aggregaten stabiliseren; en 3) de vorming van trombine en fibrine in het omliggende bloedplasma via de zogenoemde intrinsieke en extrintieke stollingscascaden. Het resultaat is een trombus met een omringend fibrinenetwerk, waarvan echter nog steeds emboli kunnen loslaten die zowel bloedplaatjes als fibrine bevatten, de zogenaamde microclots. Een analyse van meer dan 40 gepubliceerde studies met genetisch gemodificeerde muizen laat zien dat eiwitten van zowel bloedplaatjes 
als bloedplasma een belangrijke rol spelen bij het controleren van de stabiliteit van een trombus die gevormd wordt in de slagaders.

De stollingsactieve (procoagulante) bloedplaatjes in een trombus gaan een interactie aan met (anti)stollingsfactoren en daarmee de bloedstolling beïnvloeden. In hoofdstuk $\mathbf{3}$ is een overzicht gegeven op welke verschillende manieren bloedplaatjes dit proces kunnen controleren. Terwijl bloedplaatjes met een verhoogd intracellulair calcium en geëxposeerd PS een sterk stimulerend effect hebben op de vorming van trombine en fibrine, zijn plaatjes met geactiveerd integrine $\alpha_{11 b} \beta_{3}$ actief in samentrekken van de trombus. Slechts enkele fysiologische agonisten, in het bijzonder activatoren van de collageenreceptor glycoproteïne VI (GPVI), zijn in staat om PS-expositie op te wekken. Aan de andere kant zijn er diverse plaatjesagonisten, zoals von Willebrand factor, fibrinogeen, trombine, $A D P$, antilichamen en trombospondine, die het proces van GPVI-gemedieerde PS-expositie kunnen versterken. In de meeste gevallen zorgt de co-stimulatie van GPVI met een van de andere receptoren voor een langdurige verhoging van het intracellulaire calcium. Mechanismen die betrokken zijn bij dit calciumsignaal en die dus bijdragen aan het exposeren van PS zijn: calciummobilisatie vanuit het endoplasmatisch reticulum via inositoltrifosfaatreceptoren, extracellulaire calciuminstroom met behulp van de STIM1 en Orai1 eiwitten, en het vrijlaten van mitochondrieel calcium via de vorming van een permeabiliteits transitie-porie.

Het inactiveren van integrines op het membraan van PS-exposerende bloedplaatjes kan leiden tot het loslaten van plaatjes van een trombus. Het doel van hoofdstuk $\mathbf{4}$ was om het mechanisme van integrine-inactivering te onthullen. Aangetoond wordt dat deze inactivering het gevolg is van een aanhoudend verhoogde intracellulaire calciumconcentratie en het intracellulair knippen van diverse sigenaleringseiwitten, zoals de integrine $\beta_{3}$ keten, taline en Src-kinase. Remmen van calpaïnes (intracellaire calciumproteases) resulteeerde in een volledige onderdrukking van het knippen van bovenstaande eiwitten. Echter de inactivering van het integrine werd maar gedeeltelijk onderdrukt door dergelijke remmers. Verder bleek de inactivering van $\alpha_{\| 1 \mathrm{~b}} \beta_{3}$ ongewijzigd in bloedplaatjes van muizen die deficient zijn in calpaïne1 , op basis waarvan wij concludeerden dat vooral de calpaïne-2 isovorm (werkzaam bij hogere calciumconcentraties) betrokken is bij het knippen en inactiveren van het integrine. Een interessante bevinding was dat bloedplaatjes van een Scott 
patiënt een verminderde inactivering van $\alpha_{11 b} \beta_{3}$ lieten zien, waarbij de overgebleven inactivering volledig afhankelijk was van calpaïne-activiteit. Verder bleken ook de bloedplaatjes van Ppif-deficiënte muizen met een mitochondrieel defect verminderd in agonist-geïnduceerde PS-expositie alsmede in $\alpha_{\| 1 b} \beta_{3}$ inactivering. Behandeling van mensen bloedplaatjes met cyclosporine A (gericht op eenzelfde miotochondrieel proces) gaf vergelijkbare effecten. Samen wijzen deze resultaten op een tweedelig mechanisme van inactivering van integrine $\alpha_{\| 1 b} \beta_{3}$, namelijk een calpaïne(2)-geïnduceerde knip van integrines en daarmee geassocieerde eiwitten, en de scrambling van membraanfosfolipiden met daarbij een rol van mitochondriële porievorming.

De zogenoemde gecoate bloedplaatjes worden gevormd na activering met zowel collageen als trombine. Deze populatie van bloedplaatjes wordt in de literatuur op verschillende manieren gekarakteriseerd, zoals door een mantel van $\alpha$-granulaire eiwitten, de aanwezigheid van procoagulante activiteit met geëxposeerd PS, of door hoge binding van fibrinogeen aan de bloedplaatjes. Onduidelijk is ook de functionele rol van gecoate bloedplaatjes. In hoofdstuk 5 hebben wij gebruik gemaakt van een nieuwe transglutaminase probe, Rhod-A14, om de populatie van gecoate bloedplaatjes eenduidig te identificeren. Tevens beschrijft dit hoofdstuk experimenten om de functies van gecoate bloedplaatjes beter in kaart te brengen. Stimulering van bloedplaatjes met convulxine/trombine resulteert in een initiële activering van integrine $\alpha_{11 \mathrm{~b}} \beta_{3}$, en het verschijnen van een populatie met een hoge fibrinogeenbinding - welke niet afhankelijk is van integrines, maar wel van trombine. Vervolgens exposeren deze bloedplaatjes PS en binden ze de stollingsfactoren Va en Xa. Opmerkelijk is dat de transglutaminase-actieve bloedplaatjes slechts een subpopulatie vormen van de PS-exposerende bloedplaatjes. Soortgelijke resultaten zijn verkregen in bloedplaatjes-rijk plasma dat gestimuleerd is met weefselfactor. Een andere opmerkelijke bevinding is dat de hoge fibrinogeenbinding en de RhodA14 binding tegen kan worden gegaan, wanneer zowel de transglutaminaseactiviteit als integrine $\alpha_{\| b} \beta_{3}$ geblokkeerd worden. Tijdens de trombusvorming aan collageen bindt de Rhod-A14 probe eerst aan PS-exposerende bloedplaatjes via transglutaminase-activiteit en in een later stadium aan de fibrinedraden die rond de trombus worden gevormd. In afwezigheid van stollingsfactor XIII (een transglutaminase) en gelijktijdig blokkeren van integrine $\alpha_{11 b} \beta_{3}$ blijken er geen fibrinedraden meer te ontstaan vanuit de bloedplaatjes in de trombus. 
Concluderend kunnen we stellen dat de transglutaminase-actieve gecoate bloedplaatjes, met initiële integrine $\alpha_{\| 1} \beta_{3}$ activering en hoge fibrinogeen-binding, een rol spelen in de fibrinevorming via factor XIII en $\alpha_{\| 1} \beta_{3}$.

Het Scott syndroom is een zeldzame bloedingsafwijking, welke geassocieerd is met een defect in de scrambling van de fosfolipiden en de expositie van PS. Patiënten met dit syndroom hebben mutaties in het gen anoctamine-6 (ANO6, voorheen aangeduid als TMEM16F). In hoofdstuk 6 is de apoptose- en agonistgeïnduceerde PS-expositie bestudeerd in de bloedplaatjes van een Scott patiënt. Apoptose-geïnduceerde PS-expositie werd opgewekt met behulp van het medicijn ABT-737. In controle bloedplaatjes geeft ABT-737 twee verschillende fracties van PSexposerende bloedplaatjes, namelijk met matige en hoge PS-expositie. In de Scott plaatjes zien we dat de fractie met hoge PS-expositie sterk verminderd is. Deze en andere observaties geven aan dat hoewel anoctamine- 6 geen kritische rol speelt bij apoptose-geïnduceerde PSexpositie, het wel zorgt voor een toegenomen PS expositie in een subset van de bloedplaatjes. De fractie met hoge PS-expositie, maar niet die met matige PS-expositie, kan onderdrukt worden door wegvangen van het intracellulaire calcium. Remming van de caspase-activiteit leidt echter tot volledige onderdrukking van de PSexpositie geïnduceerd door ABT-737 in de bloedplaatjes van patiënt en controles. De plaatjesagonisten convulxine en trombine veroorzaken hoge PS-expositie middels een proces, dat volledig afhankelijk is van mitochondriële depolarisatie. Deze PS-expositie is vrijwel afwezig in Scott bloedplaatjes. Anderzijds is de PS-expositie met collageen en trombine slechts gedeeltelijk afwezig in de Scott bloedplaatjes. Dit laatste geeft aan dat er naast de anoctamine-6 afhankelijke route, ook nog een andere route kan zorgen voor agonistgeïnduceerde PS-expositie. De residuele PS-expositie in bloedplaatjes van de Scott patiënt is niet gevoelig voor de remming van caspasen of mitochondriële depolarisatie. Samengevat geven deze resultaten aan dat zowel anoctamine-6afhankelijke als -onafhankelijke scrambling van fosfolipiden plaats vindt in bloedplaatjes die in apoptose gaan of middels hun collageen- en trombinereceptoren geactiveerd worden.

In hoofdstuk $\mathbf{7}$ is de rol van anoctamine6 bij de activering van bloedplaatjes verder onderzocht met behulp van genetisch gemodificeerde muizen, die dit eiwit niet tot expressie brengen Daarnaast zijn muizen bestudeerd waarin andere kandidaateiwitten voor het fosfolipiden-scramblase ontbreken, namelijk anoctamine-1 of het calciumafhankelijke kaliumkanaal Kca3.1 
(Gardos-kanaal).

Anoctamine- 6

deficiënte muizen hadden een normale collageen-geïnduceerde trombusvorming (plaatjesaggregatie), maar een substantieel doch niet compleet defect in PS-expositie van de collageengehechte bloedplaatjes. Verder toonden bloedplaatjes van deze muizen geen calcium-afhankelijke ballonvorming, en waren ze aanmerkelijk verlaagd in het knippen van integrine $\beta_{3}$. Ook lieten deze plaatjes een gedeeltelijk verminderde apoptose-afhankelijke PS-expositie zien. Al deze afwijkingen blijken ook te bestaan in de bloedplaatjes van een Scott patiënt. Uitschakelen van het anoctamine- 6 gen in muizen leidde tot een duidelijk verminderde levensvatbaarheid; de enkele overlevende anoctamine-6 deficiënte muizen hadden een verhoogde staartbloedingstijd. Anderzijds konden wij geen afwijkend fenotype noteren in de bloedplaatjes van muizen, die anoctamine-1 of het Gardos-kanaal missen. Concluderend kan gesteld worden dat een defect in antoctamine- 6 maar niet in de andere ionkanalen van invloed is op de levensvatbaarheid, en dat de bloedplaatjes van anoctamine- 6 deficiënte muizen dezelfde kenmerken en defecten vertonen als aanwezig in bloedplaatjes van de Scott patiënt.

Gezien het complexe fenotype van de Scott bloedplaatjes - defecten in PSexpositie,

ballonvorming micropartikel-vorming -, postuleren wij in hoofdstuk $\mathbf{8}$ dat er meerdere veranderingen moeten zijn in het eiwitpatroon van de bloedplaatjes van Scott patiënten. Om dit te onderzoeken hebben we de bloedplaatjes van gezonde controle-donoren vergeleken met die van een patiënt middels een zeer gevoelige en geavanceerde (fosfo)proteomics analyse. Kwantitatieve analyse van het proteoom van 2225 unieke eiwitten gaf aan dat minder dan $10 \%$ van de eiwitten veranderingen vertoonden in relatieve expressie. De veranderingen die er waren werden waargenomen in eiwitten van de volgende functieklassen: membraanreceptoren en kanalen, mitochondriële eiwitten, metabole eiwitten en signalering/adapter-eiwitten. Detailonderzoek toonde aan dat het eiwit anoctamine- 6 niet te detecteren was in de Scott bloedplaatjes, terwijl het kanaaleiwit aquaporine-1 sterk verhoogd was ten opzichte van controlebloedplaatjes. Analyse van het fosfoproteoom resulteerde in 1566 unieke fosfopeptiden (overeenkomend met 716 eiwitten). Er bleken duidelijke verschillen tussen bloedplaatjes van de patiënt en controle in de fosforyleringsstatus van diverse eiwitten, in het bijzonder na stimulatie met convulxine/trombine of ionomycine. In geactiveerde Scott bloedplaatjes vertoonde een beperkt aantal eiwitten 


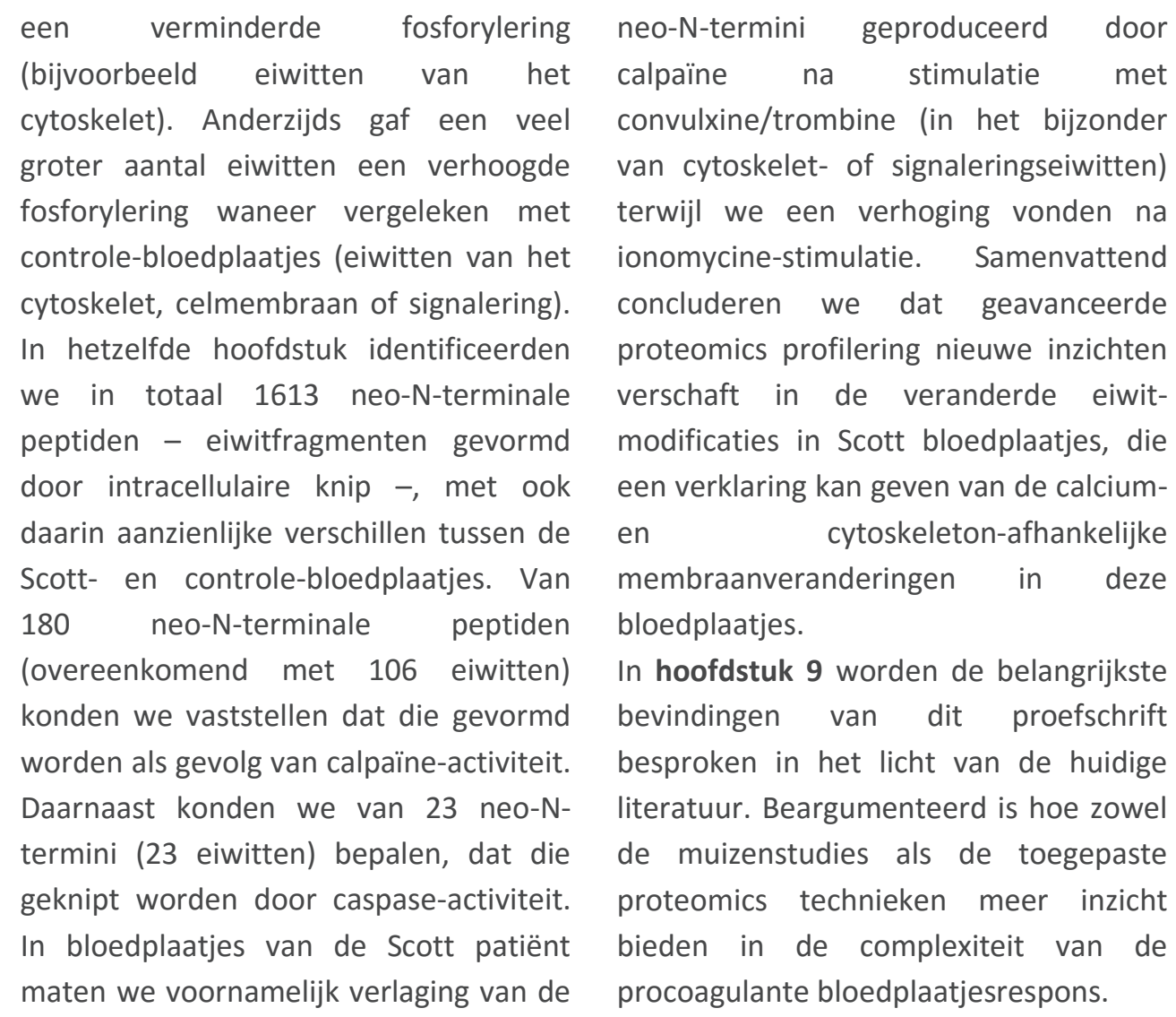



Dankwoord 
Het is zo ver, mijn promotie is ten einde gekomen. Een promotie afronden is iets speciaals. Dit kan niet tot stand komen zonder de hulp en steun van collega's, vrienden en familie, waarvoor ik mijn dank uitspreek.

Allereerst wil ik mijn promotieteam bedanken. Judith, mijn co-promoter, jij hebt me eigenlijk vanaf dag één onder je hoede genomen. Je deur stond altijd open voor vragen, leuke gesprekken en een kritische kijk op mijn bevindingen en meningen. Beste Johan, bedankt dat $u$ mij de mogelijkheid heeft gegeven om mijn promotieonderzoek te doen binnen de plaatjesgroep. Ik heb het altijd fijn gevonden om mijn signalerings interesse te kunnen delen. Uw deur stond, en staat nog steeds, open voor vragen of hulp. Bedankt!

Mijn directe collega's, de plaatjesgroep, wat ben ik blij dat ik mijn promotieonderzoek heb mogen doen in zo'n leuke en gemotiveerde groep. Met jullie waren die lange dagen die wij soms moesten maken door de proeven met patiëntenbloed helemaal niet erg. Ik heb genoten van onze vele uitjes en etentjes samen!

Lieve Susanne, wat had ik zonder jou gemoeten al die jaren;). Ik kon altijd terecht bij jou voor een luisterend oor, maar wat hebben we vooral veel gelachen samen. Hoewel ik je nu niet meer dagelijks zie, vind ik het erg fijn dat we nog zo veel contact hebben. Ik ben er dan ook mega blij mee dat je vandaag weer achter me staat als paranimf! Constance, Magdi, Roosje, Erik, Karen en Jilke bedankt voor de gezelligheid op onze kamer, ik wens jullie het allerbeste toe voor de toekomst. Nog een extra bedankje voor Constance, voor de vele hulp met de FACS proeven en de tripjes naar Duitsland. Ohw en natuurlijk niet te vergeten onze nachtelijke trip naar een gesloten vliegveld in Luik;). Heel veel succes nog met je PhD! Hi Magdi, although you recently started when I left the department, it was very nice to meet you $(;)$.

Lieve Frauke en Tom, met jullie gezelligheid in de buurt waren die flow-proeven nog niet zo heel erg! Bedankt voor jullie hulp en positiviteit. Heel veel succes beiden met de afronding van jullie PhD. Frauke, ik mis toch wel onze gesprekken over darts, nagellakjes en Primark bezoeken;). Marijke en Marion, wat was het fijn om bij jullie even binnen te lopen voor de kleine vraagjes en hulp. Paola, als half lid van de plaatjesgroep, hoorde jij er toch helemaal bij. Hopelijk kunnen we in de toekomst onze ski reis nog eens hervatten, al is het alleen voor de amaretto-appel drankjes en gezelligheid. Simone, jij maakte mijn lunch altijd wat interessanter en leuker. Wat heb 
ik genoten van je verhalen! Siamack, heel veel succes met je AlO plek in Sittard, ik denk dat we elkaar daar in de toekomst wel vaker gaan treffen. Remco en Ankie, ik wens jullie het allerbeste toe en bedankt voor jullie hulp.

Roger, toch een speciaal bedankje voor jou. Bedankt voor de kans die je me hebt gegeven om een tijdje weer je directe collega te zijn. Hoewel onze wegen nu weer even zullen scheiden, kan het niet anders zijn dan dat ik je in de toekomst weer zal treffen. Bedankt voor je hulp, vertrouwen en vriendschap. Lieve Moniek, mijn ander ex-collega'tje, fijn om te zien dat je je weg gevonden hebt! Ik wens je heel veel geluk toe in Eindhoven en je verdere carrière als wiskunde lerares.

Ook een woord van dank voor de overige werknemers van de afdeling Biochemie, voor hun behulpzaamheid, de leuke sfeer en waardevolle adviezen die ik heb mogen ontvangen. De jaarlijkse uitjes, borrels en academische jaaropeningen zal ik niet vergeten!

Dear Prof. Bernard Nieswandt, Dr. Atilla Braun, Prof. Kunzelmann, Prof. Vortkamp, Prof. Sickmann, Dr. Zahedi, Prof. Chisthi, Prof. Torti and Dr. Shawn Jobe, I would like to thank you and the colleagues of your group for your willingness and enthusiasm to collaborate. I felt always very welcome at your lab. Without your help and the help of all the co-authors of my articles not mentioned before, my thesis would not have got that far. Thank you to you all.

Zonder de vele bloeddonaties van vrijwilligers had ik mijn onderzoek niet kunnen uitvoeren. Hartelijk dank hiervoor.

Lieve Lieke, Nicki en Monique, bedankt voor jullie vriendschap! Ondanks dat onze levens flink zijn veranderd in de laatste jaren, vinden we nog steeds tijd om elkaar te zien en spreken. Bedankt voor jullie luisterend oor en de afleiding waar jullie voor zorgde buiten mijn werk om. Ik hoop dat onze vriendschap nog heel wat jaren mee gaat! Lieve Laura, wat ben ik blij dat ook jij mijn paranimf wil zijn. Beiden op dezelfde middelbare school, beiden op de uni in Maastricht, beiden promoveren en nu kunnen we allebei beginnen aan onze opleidingsplek! Eigenlijk hebben we al heel veel samen mee gemaakt en hoop dat hier nog heel wat jaren bij zullen komen. Bedankt aan jou en Daan voor alle gezellige uitjes en etentjes. 
Mijn (schoon)familie (:) jullie wisten dat ik onderzoek deed naar bloedplaatjes, maar wat dat nu precies in hield was altijd een raadsel voor jullie. Juist om die reden kon ik altijd helemaal afschakelen in jullie aanwezigheid en bezig zijn met andere dingen in het leven. Bedankt dat jullie er altijd voor me waren en jullie me de nodige afleiding hebben gegeven op momenten dat ik dat zo goed kon gebruiken. Lief zusje, wat is het fijn om te zien dat jij je draai gevonden hebt met werk en in jullie huisje. Fijn dat we binnenkort weer wat sneller kunnen afspreken, al moet die wandeling met Milo aan het strand er toch nog van komen;).

Lieve Paul, ondanks dat ik je het laatste jaar niet gemakkelijk heb gemaakt met onze verhuizing naar het noorden en nu weer terug, heb je altijd volledig achter me gestaan bij elke beslissing. Bedankt voor je steun en raad op de juiste momenten. Ik kijk uit naar onze toekomst samen!

Last but not least, lieve pap en mam, zonder jullie enorm vertrouwen en steun was ik niet zo ver gekomen. Ik denk niet dat ik de woorden kan vinden om uit te drukken hoe dankbaar ik jullie ben voor alles wat jullie voor me hebben gedaan!! 
Curriculum vitae 
Nadine Mattheij werd geboren op 19 augustus 1987 te Sittard. In 1999 begon zij haar middelbare schoolopleiding aan het Trevianum College te Sittard, waar zij in 2005 haar VWO-diploma behaalde met als afstudeerprofiel Natuur \& Gezondheid met Beeldende Vorming in het vrije deel. In 2005 begon zij de bacheloropleiding Moleculaire Levenswetenschappen aan de Universiteit Maastricht. Na het behalen van haar bachelor-graad in 2008, volgde zij aan dezelfde universiteit de masteropleiding Clinical Molecular Sciences. Haar afstudeerstage, naar de rol van endotheline-1 bij de vasoconstrictie, deed zij bij de vakgroep Farmacologie van de Universiteit Maastricht, waarna zij in 2010 haar master-diploma ontving. Op 1 augustus 2010 begon zij haar promotie-onderzoek binnen het Cardiovascular Research Institute Maastricht (CARIM) bij de vakgroep Biochemie van de Universiteit Maastricht. Onder leiding van Prof. Dr. J.W.M. Heemskerk en Dr. J.M.E.M. Cosemans voerde zij onderzoek uit in het domein trombose en hemostase, zoals beschreven in dit proefschrift. Als promovendus presenteerde zij haar onderzoek op internationale congressen in Maastricht, Bath (Groot-Brittannië), Amsterdam, Birmingham (GrootBrittannië) en Le Bischenberg (Frankrijk). Een deel van dit onderzoek verrichtte zij in de laboratoria van Dr. S. Jobe in Atlanta (GA, USA), Prof. Dr. A. Chishti in Boston (MA, USA), Prof. Dr. B. Nieswandt in Würzburg (Duitsland), Prof. Dr. M. Torti in Pavia (Italië), en van Prof. Dr. K. Kunzelmann in Regensburg (Duitsland). Na werkzaam te zijn voor 7 maanden als Medical Advisory and Communication Specialist bij het farmaceutisch bedrijf Janssen Biologic te Leiden, startte ze in december 2015 als klinisch chemicus in opleiding aan het Zuyderland ziekenhuis te Sittard en Heerlen. 
Nadine Mattheij was born on August 191987 in Sittard. In 1999 she started secondary school at the Trevianum in Sittard were she received her Atheneum degree in 2005 with the specialization Nature \& Health with Visual Education in the free part. In 2005 she started her Bachelor in Molecular Life Sciences at Maastricht University. After earning her bachelor's degree in 2008, she studied at the same university the master Clinical Molecular LifeSciences. Her internship, investigating the role of endothelin-1 in vasoconstriction, was performed at the Department of Pharmacology at Maastricht University, after which she received her master's degree in 2010. On the $1^{\text {st }}$ of August 2010 she started her PhD research at the Department of Biochemistry of the Cardiovascular Research Institute Maastricht (CARIM) at the University of Maastricht. Under direct supervision of Prof. Dr. J.W.M. Heemskerk and Dr. J.M.E.M. Cosemans she performed research in the field of thrombosis and hemostasis as described in this thesis. As a PhD student, she presented her research at international conferences in Maastricht, Bath (UK), Amsterdam, Birmingham (UK) and Le Bischenberg (France). Part of this research she conducted in the laboratories of Dr. S. Jobe in Atlanta (GA, USA), Prof. Dr. A. Chishti in Boston (MA, USA), Prof. Dr. B. Nieswandt in Würzburg (Germany), Prof. Dr. M. Torti in Pavia (Italy) and Prof. Dr. K. Kunzelmann in Regensburg (Germany). After working for seven months as a Medical Advisory and Communication Specialist at the pharmaceutical company Janssen Biologics in Leiden, she started in December 2015 as a clinical chemist in training at the Zuyderland hospital in Sittard and Heerlen. 



\section{Publications}




\section{Full papers}

1. Meens MJ, Mattheij NJ, Nelissen J, Lemkens P, Compeer MG, Janssen BJ, De Mey JG. Calcitonin gene-related peptide terminates long-lasting vasopressor responses to endothelin 1 in vivo. Hypertension. 2011;58:99-106.

2. Meens MJ, Mattheij NJ, van Loenen PB, Spijkers L, Lemkens P, Nelissen J, Compeer MG, Alewijnse AE, De Mey. G-protein $\beta \gamma$ subunits in vasorelaxing and anti-endothelinergic effects of calcitonin gene-related peptide. JG. Br J Pharmacol. 2012;166:297-308.

3. Heemskerk JW, Mattheij NJ, Cosemans JM. Platelet-based coagulation: different populations, different functions. J Thromb Haemost. 2013;11:2-16.

4. Van Kruchten R, Mattheij NJ, Saunders C, Feijge MA, Swieringa F, Wolfs JL, Collins PW, Heemskerk JW, Bevers EM. Both TMEM16F-dependent and TMEM16Findependent pathways contribute to phosphatidylserine exposure in platelet apoptosis and platelet activation. Blood. 2013;121:1850-7.

5. Mattheij NJ, Gilio K, van Kruchten R, Jobe SM, Wieschhaus AJ, Chishti AH, Collins P, Heemskerk JW, Cosemans JM. Dual mechanism of integrin $\alpha_{11 b} \beta_{3}$ closure in procoagulant platelets. J Biol Chem. 2013;288:13325-36.

6. Kmit A, van Kruchten R, Ousingsawat J, Mattheij NJ, Senden-Gijsbers B, Heemskerk JW, Schreiber R, Bevers EM, Kunzelmann K. Calcium-activated and apoptotic phospholipid scrambling induced by Ano6 can occur independently of Ano6 ion currents. Cell Death Dis. 2013;4:e611.

7. Cosemans JM, Angelillo-Scherrer A, Mattheij NJ, Heemskerk JW. The effects of arterial flow on platelet activation, thrombus growth, and stabilization. Cardiovasc Res. 2013;99:342-52.

8. Kuijpers MJ, van der Meijden PE, Feijge MA, Mattheij NJ, May F, Govers-Riemslag J, Meijers, Renné T, Heemskerk JW, Cosemans JM. Factor XII regulates the pathological process of thrombus formation on ruptured plaques. Arterioscler Thromb Vasc Biol. 2014;34(8):1674-80.

9. Karshovska E, Zhao Z, Blanchet X, Schmitt MM, Bidzhekov K, Soehnlein O, von Hundelshausen P, Mattheij NJ, Cosemans JM, Megens RT, Koeppel T, Schober A, Hackeng TM, Weber C, Koenen RR. Hyperreactivity of junctional adhesion molecule A-deficient platelets accelerates atherosclerosis in hyperlipidemic mice. Circ Res. 2015;116(4):587-99.

10. Kuijpers MJ*, Mattheij NJ*, Cipolla L, van Geffen JP, Lawrence T, Donners MM, Boon L, Lievens D, Torti M, Noels H, Gerdes N, Cosemans JM, Lutgens E, 
Heemskerk JW. Platelet CD40L modulates thrombus growth via phosphatidylinositol 3-Kinase $\beta$, and not via CD40 and ІкB Kinase $\alpha$. Arterioscler Thromb Vasc Biol. 2015; 2015;35(6):1374-81.

11. Agbani EO, van den Bosch MT, Brown E, Williams CM, Mattheij NJ, Cosemans JM, Collins PW, Heemskerk JW, Hers I, Poole AW. Coordinated membrane ballooning and procoagulant spreading in human platelets. Circulation. 2015 Oct 13;132(15):1414-24.

12. Mattheij NJ, Braun A, van Kruchten R, Pircher J, Castoldi E, Baaten C, Kuijpers M, Ehlen HW, Poole A, Vortkamp A, Schreiber R, Kunzelmann K, Nieswandt B, Cosemans JM, Heemskerk JW. The Scott syndrome protein anoctamin 6 regulates multiple responses in procoagulant platelets including membrane phospholipid scrambling. FASEB J. 2015 (Epub ahead of print)

13. Mattheij NJ, Swieringa F, Lang-Berny M, May F, Suylen D, Nolte M, Hackeng T, McCarty O, van der Meijden PE, Heemskerk JW, Cosemans JM. Coated platelets: non-redundant roles of transglutaminases and integrin $\alpha_{11 \mathrm{~b}} \beta_{3}$ in platelet-fibrin formation distinct from phosphatidylserine exposure. Resubmitted to Haematologica

14. Mattheij NJ, Solari F, Burkhart J, Swieringa F, Collins PW, Cosemans JM, Sickmann A, Heemskerk JW, Zahedi R. Altered phosphorylation profile of Scott syndrome platelets revealed by quantitative phosphoproteomics. Submitted

15. Swieringa $F^{*}$, Solari FA*, Feijge MA, Mattheij NJ, Beck F, Stumpel CT, Sickmann A, van der Meijden PE, Körver-Keularts IM, Zahedi RP*, Heemskerk JW*. Multiple changes in novel protein kinase A phosphorylation targets identified in platelets from patients with impaired Gsa signaling. Submitted

16. Beck F, Geiger J, Gambaryan S, Loroch S, Mattheij NJ, Mindukshev I, Pötz O, Burkhart JM, Fufezan C, Heemskerk JW, Walter U, Zahedi RP, Sickmann A. Timeresolved phosphoproteomics points to novel central nodes in platelet activation and inhibition. Submitted

\section{Abstracts}

1. Mattheij NJ, Meens MJ, De Mey JG. G-protein $\beta$ Y subunits in vasorelaxing and antiendothelinergic effects of calcitonin gene-related peptide. Proc. TI Pharma spring meeting 2010, Utrecht, The Netherlands.

2. Meens MJ, Mattheij NJ, van Essen H, Compeer MG, Janssen BJ, De Mey JG. Calcitonin gene-related peptide terminates endothelin-1-induced vasoconstriction 
and vasopressor responses. $12^{\text {th }}$ Symposium on Vascular Neuroeffector Mechanisms, Odense, Denmark. Acta Physiologica, Suppl. July 2010.

3. Mattheij NJ, Meens MJ, De Mey JG. Role of G-protein subunits in arterial effects of CGRP. $12^{\text {th }}$ Symposium on Vascular Neuroeffector Mechanisms, Odense, Denmark. Acta Physiologica, Suppl. July 2010.

4. Van Kruchten R, Wolfs JL, Feijge MA, Mattheij NJ, Collins P, Heemskerk JW, Bevers EM. Role of TMEM16F in agonist-induced but not apoptosis-induced phosphatidylserine exposure in Scott platelets, XXIII ${ }^{\text {th }}$ Congress of the International Society on Thrombosis and Haemostasis (ISTH), Kyoto, Japan, 2011. J Thromb Haemost, Suppl. July 2011.

5. Mattheij NJ, Gilio K, van Kruchten R, Feijge MA, Bevers EM, Jobe SM, Cosemans JM, Heemskerk JW. Regulation of integrin closure in procoagulant platelets. XXIII Congress of the International Society on Thrombosis and Haemostasis (ISTH), Kyoto, Japan, 2011. J Thromb Haemost, Suppl. July 2011.

6. Mattheij NJ, Gilio K, Van Kruchten R, Shawn JM, Du X, Wieschhaus AJ, Chishti AH, Collins PW, Heemskerk JW, Cosemans JM Regulation of integrin closure in procoagulant platelets. Proc. British Society for Haemostasis \& Thrombosis and the UK Platelet Annual Joint Scientific Meeting 2012, Bath, United Kingdom.

7. Van Kruchten R, Mattheij NJ, Saunders C, Feijge MA, Collins PW, Heemskerk JW, Bevers EM. Scott syndrome platelets demonstrate presence of TMEM16Fdependent and -independent phospholipid scrambling in both platelet apoptosis and platelet activation. Proc. $1^{\text {st }}$ EUPLAN Platelet Conference, Maastricht, The Netherlands.

8. Mattheij NJ, Gilio K, Van Kruchten R, Shawn JM, Wieschhaus AJ, Chishti AH, Collins PW, Heemskerk JW, Cosemans JM. Dual mechanism of integrin closure in procoagulant platelets. Proc. $1^{\text {st }}$ EUPLAN Platelet Conference, Maastricht, The Netherlands.

9. Kuijpers M , Mattheij NJ, Cipolla L, Cosemans JM, Lievens D, Donners M, Swieringa F, Mastenbroek T, Torti M, Lutgens E, Heemskerk JW. A role for CD40L signalling in platelet activation and thrombus formation that is independent of CD40. XXIVth Congress of ISTH, Amsterdam, The Netherlands. J Thromb Haemost, Suppl. June 2013.

10. Mattheij NJ, Braun A, van Kruchten R, Cosemans JM, van der Meijden P, Baaten C, Ehlen H, Schreiber R, Vortkamp A, Collins P, Bevers EM, Ousingsawat J, Kunzelmann K, Nieswandt B, Heemskerk JW. The Scott syndrome protein anoctamin 6 (TMEM16F) regulates multiple cell death responses including 
membrane phospholipid scrambling in platelets. XXIVth Congress of ISTH, Amsterdam, The Netherlands. J Thromb Haemost, Suppl. June 2013

11. Mattheij NJ, Berny-Lang M, van de Vijver P, Hackeng T, McCarty O, Cosemans JM, Heemskerk JW. Functional characteristics of coated platelets. XXIV th congress of ISTH, Amsterdam, The Netherlands. J Thromb Haemost, Suppl. June 2013

12. Mattheij NJ, Braun A, van Kruchten R, Cosemans JM, van der Meijden P, Baaten C, Ehlen H, Schreiber R, Vortkamp A, Collins P, Bevers EM, Ousingsawat J, Kunzelmann K, Nieswandt B, Heemskerk JW. The Scott syndrome protein anoctamin 6 (TMEM16F) regulates multiple cell death responses including membrane phospholipid scrambling in platelets. Proc. $15^{\text {th }}$ UK Platelet Group Meeting, Birmingham, United Kingdom

13. Mattheij NJ, de Witt S, Mastenbroek T, Zieger B, Cosemans JM, Heemskerk JW. Human platelet STIM1 and ORAI1 are essential in store-operated calcium entry and thrombus formation under venous conditions. Proc. $2^{\text {nd }}$ EUPLAN Conference, Le Bischenberg, France.

14. Mattheij NJ, Solari F, Burkhart J, Swieringa F, Collins PW, Cosemans JM, Sickmann A, Zahedi R, Heemskerk JW. Altered phosphorylation profile of Scott syndrome platelets as revealed by quantitative phosphoproteomics. Proc. $2^{\text {nd }}$ EUPLAN Conference, Le Bischenberg, France.

15. Solari F, Mattheij NJ, Burkhart J, Swieringa F, Collins PW, Cosemans JM, Sickmann A, HeemskerkJW, Zahedi R. Calpain-dependent cleavage in highly activated platelets revealed by quantitative N-terminal ChaFRADIC: alterations in Scott syndrome. Proc. HUPO $13^{\text {th }}$ Annual World Congress, Madrid, Spain.

16. Mattheij NJ, Solari F, Burkhart J, Swieringa F, Collins PW, Cosemans JM, Sickmann A, Zahedi R, Heemskerk JW. Altered phosphorylation profile of Scott syndrome platelets as revealed by quantitative phosphoproteomics. Proc. HUPO $13^{\text {th }}$ Annual World Congress, Madrid, Spain.

\section{International oral presentations}

1. Mattheij NJ, G-protein $\beta \gamma$ subunits in vasorelaxing and anti-endothelinergic effects of calcitonin gene-related peptide, $12^{\text {th }}$ Symposium on Vascular Neuroeffector Mechanisms, Odense, Denmark (July 2010).

2. Mattheij NJ, Regulation of integrin closure in procoagulant platelets, $1^{\text {st }}$ European Platelet Conference (EUPLAN), Maastricht, The Netherlands (September 2012). 
3. Mattheij NJ, Regulation of integrin closure in procoagulant platelets, British Society on Haemostasis \& Thrombosis and the UK platelet annual joint scientific Meeting 2012, Bath, United Kingdom (October 2012).

4. Mattheij NJ, The Scott syndrome protein anoctamin 6 (TMEM16F) regulates multiple cell death responses including membrane phospholipid scrambling in platelets, XXIVth Congress of the International Society on Thrombosis and Haemostasis, Amsterdam, The Netherlands (July 2013).

5. Mattheij NJ, Functional characteristics of coated platelets, XXIVth Congress of the International Society on Thrombosis and Haemostasis, Amsterdam, The Netherlands (July 2013).

6. Mattheij NJ, The Scott syndrome protein anoctamin 6 (TMEM16F) regulates multiple cell death responses including membrane phospholipid scrambling in platelets, $15^{\text {th }}$ UK Platelet Group Meeting, Birmingham, United Kingdom (September 2013).

7. Mattheij NJ, Altered phosphorylation profile of Scott syndrome platelets as revealed by quantitative phosphoproteomics, $2^{\text {nd }}$ EUPLAN Conference, Le Bischenberg, France (September 2014). 


\section{Appendix}

\section{Platelet CD40L Modulates Thrombus Growth Via Phosphatidylinositol 3-Kinase $\beta$, and Not Via CD40 and IkB Kinase $\alpha$}

Kuijpers $\mathrm{MJ}^{1^{*}}$, Mattheij $\mathrm{NJ}^{1^{*}}$, Cipolla $\mathrm{L}^{2}$, van Geffen $\mathrm{JP}^{1}$, Lawrence $\mathrm{T}^{3}$, Donners $\mathrm{MM}^{4}$, Boon $\mathrm{L}^{5}$, Lievens $\mathrm{D}^{6}$, Torti $\mathrm{M}^{2}$, Noels $\mathrm{H}^{7}$, Gerdes $\mathrm{N}^{6}$, Cosemans $\mathrm{JM}^{1}$, Lutgens $\mathrm{E}^{5,8}$, Heemskerk JW ${ }^{1}$

${ }^{1}$ Department of Biochemistry CARIM, Maastricht University, Maastricht, The Netherlands; ' ${ }^{2}$ Department of Biology and Biotechnology, University of Pavia, Pavia, Italy; ${ }^{3}$ Division of Biochemistry, Centre d'Immunologie de Marseille-Luminy, AixMarseille Université, Marseille; ${ }^{4}$ Department of Molecular Genetics, CARIM, Maastricht University, Maastricht, The Netherlands; ${ }^{5}$ Bioceros, Utrecht, The Netherlands; 'Institute for Cardiovascular Prevention, Ludwig-MaximiliansUniversity, Munich, Germany; ${ }^{7}$ Institute for Molecular Cardiovascular Research (IMCAR), RWTH Aachen University, Aachen, Germany; ${ }^{8}$ Academic Medical Center, University of Amsterdam, Amsterdam, The Netherlands

Arterioscler Thromb Vasc Biol. 2015;35:1374-81

Reprinted with permission 


\begin{abstract}
Objective - To investigate the roles and signaling pathways of CD40L and CD40 in platelet-platelet interactions and thrombus formation under conditions relevant for atherothrombosis. Approach and Results - Platelets from mice prone to atherosclerosis lacking CD40L $\left(\mathrm{Cd} 40 \mathrm{gg}^{-/-} \mathrm{Apoe}^{-/-}\right)$showed diminished $\alpha_{11 \mathrm{~b}} \beta_{3}$ activation and $\alpha$-granule secretion in response to glycoprotein $\mathrm{VI}$ stimulation, whereas these responses of $\mathrm{CD} 40$ - deficient platelets $\left(\mathrm{Cd}_{400^{-/-}} \mathrm{Apoe}^{-/-}\right)$were not decreased. Using blood from $\mathrm{Cd} 4 \mathrm{Olg}^{-/-} \mathrm{Apoe^{-/- }}$ and $\mathrm{Cd}_{4 \mathrm{O}^{-/-} \mathrm{Apoe}}^{-/-}$mice, the glycoprotein VI-dependent formation of dense thrombi was impaired on atherosclerotic plaque material or on collagen, in comparison with $A p o e^{-/-}$blood. In all genotypes, addition of CD4OL to the blood enhanced the growth of dense thrombi on plaques and collagen. Similarly, CD40L enhanced glycoprotein VI-induced platelet aggregation, even with platelets deficient in CD40. This potentiation was antagonized in $P i k 3 c b^{R / R}$ platelets or by inhibiting phosphatidylinositol 3-kinase $\beta$ (PI3K $\beta$ ). Addition of CD4OL also enhanced collagen-induced Akt phosphorylation, which was again antagonized by absence or

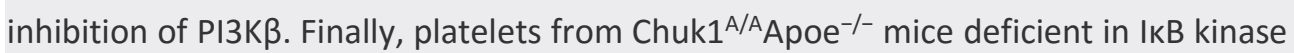
$\alpha$ (IKK $\alpha$ ), implicated in CD40 signaling to nuclear factor (NF) $\mathrm{KB}$, showed unchanged responses to $\mathrm{CD} 40 \mathrm{~L}$ in aggregation or thrombus formation. Conclusions - Under atherogenic conditions, CD40L enhances collagen-induced platelet-platelet interactions by supporting integrin $\alpha_{11 b} \beta_{3}$ activation, secretion and thrombus growth via PI3K $\beta$, but not via CD40 and IKK $\alpha / N F K B$. This role of CD4OL exceeds the no more than modest role of CD40 in thrombus formation.
\end{abstract}

\section{Introduction}

Atherothrombosis is a life-threatening clinical condition that can result in myocardial infarction or stroke because of thrombus formation on rupture or erosion of an atherosclerotic plaque. ${ }^{1}$ Both in vivo and in vitro studies have indicated that collagen is one of the main platelet-adhesive components of atherosclerotic plaques, causing platelet activation through the signaling collagen receptor, glycoprotein VI (GPVI). ${ }^{2-4}$ Collagen-dependent thrombus formation is a complex and highly orchestrated process. Key steps are the adhesion of platelets to collagen, the activation of flowing platelets into aggregates via secreted autocrine mediators, such as ADP and thromboxane $A 2$; the activation of integrin $\alpha_{11 b} \beta_{3}$ via a phosphoinositide 3-kinase (PI3K) pathway to allow stable platelet-platelet interactions; and the formation of phosphatidylserineexposing platelets, which support thrombin generation and fibrin formation. ${ }^{5}$ Platelets express substantial 
levels of the membrane glycoprotein CD40 (TNFR-SF5), which is an ubiquitous member of the tumor necrosis factor receptor (TNFR) superfamily. ${ }^{6,7}$ The alleged counter-receptor is CD40L (TNFSF5 and CD154), which belongs to the TNF superfamily and is present on human platelets at $\approx 1600$ copies/platelet. ${ }^{8}$ In activated platelets, CD40L can be cleaved from the membrane by extracellular proteases, yielding a functional, extracellular peptide that is usually indicated as soluble CD40L. ${ }^{9,10}$ Several reports point to a key role of platelet CD4OL in atherosclerosis and atherothrombosis. Patients with (re)current cardiovascular disease often show increased levels of circulating soluble $\mathrm{CD} 40 \mathrm{~L}$, predominantly originating from platelets. ${ }^{11,12}$ In mouse models, deficiency in Apoe or Ldlr leads to elevation of plasma lipids and predisposes for atherosclerosis. In these atherogenic mice, we and others have reported that additional deficiency in CD40L $\left(\mathrm{Cd}_{\left.40 \mathrm{Og}^{-/-}\right)}\right.$or CD40 $\left(\mathrm{Cd}_{40} \mathrm{O}^{-/-}\right)$ markedly impairs plaque development. ${ }^{13,14}$ Furthermore, we have shown that the injection of activated $\mathrm{Cd}_{40 \mathrm{Og}^{-/-}}$platelets to $\mathrm{Apoe}^{-/-}$mice suppresses platelet-leukocyte aggregate formation, subsequent inflammation, and the platelet-dependent progression of atherosclerosis. ${ }^{15-17}$ The CD4OL-CD40 axis may also play a role in the crosstalk of platelets themselves, and thus contribute to the stability of platelet thrombi. For instance, in mice deficiency in either CD40L or CD40 was found to protect against microvascular thrombosis when the animals were challenged by lipopolysaccharide. ${ }^{7}$ Other studies have suggested a mechanism, in which CD4OL interacts with CD40-TRAF2 and stimulates the classical nuclear factor (NF) KB pathway in platelets. ${ }^{18,19}$ In agreement with this postulation, pharmacological inhibition of NFKB was shown to suppress platelet activation. ${ }^{20}$ However, some reports indicate that the cleaved CD40L can interact with a different counter-receptor in both mouse and human platelets, namely the integrin $\beta_{3}$ chain. ${ }^{21,22}$ The binding of CD40L can support $\alpha_{\| b} \beta_{3}$-dependent activation processes that have been implicated in thrombus stability. In this article, we aimed to unravel the roles and the underlying signaling pathways of CD40L and CD40 in platelet activation and thrombus formation under conditions relevant for atherothrombosis. For this purpose, we used blood from $\mathrm{Apoe}^{-/-}$mice also deficient in CD40 or CD40L, prone to atherosclerosis, to investigate the activation pathways of platelets stimulated by collagen or plaque tissue via the GPVI receptor. 


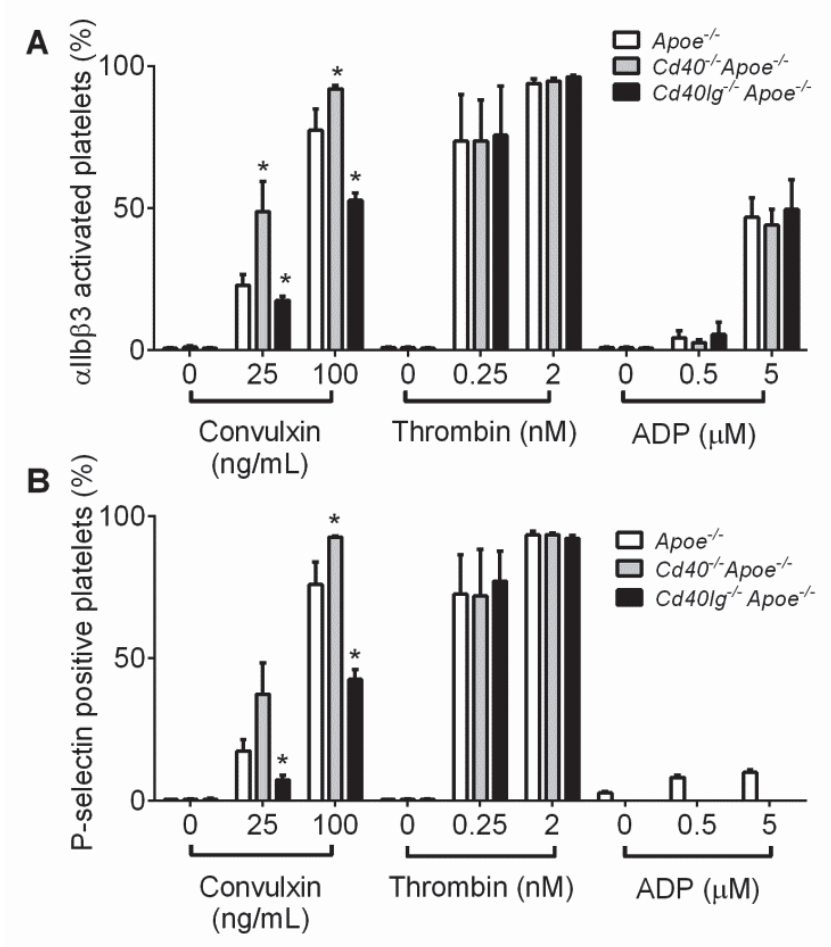

Figure 1. Agonist-induced integrin activation and secretion by Apoe ${ }^{-/-}$platelets lacking CD40 or CD40L. Washed platelets from $\mathrm{Apoe}^{-/-}, \mathrm{Cd} 4 \mathrm{O}^{-/-} \mathrm{Apoe} \mathrm{e}^{-/-}$, or $\mathrm{Cd} 4 \mathrm{O} \mathrm{g} \mathrm{g}^{-/-} \mathrm{Apoe^{-/- }}$ mice were activated with the glycoprotein $\mathrm{VI}$ agonist convulxin (25-100 $\mathrm{ng} / \mathrm{mL})$, thrombin $(0.25-2 \mathrm{nmol} / \mathrm{L})$ or ADP $(0.5-5 \mu \mathrm{mol} / \mathrm{L})$. Using flow cytometry, activation of integrin $\alpha_{\| b} \beta_{3}$ was determined with PE-labeled JON/A monoclonal antibody (mAb; A), and P-selectin expression with FITC (fluorescein isothiocyanate)-labeled anti-CD62P mAb (B). Mean \pm SEM ( $n=3-5),{ }^{*} P<0.05$.

\section{Materials and Methods}

Materials and Methods are available in the online-only Data Supplement.

\section{Results}

To compare the roles of platelet CD40 and CD4OL under conditions relevant for atherosclerosis and atherothrombosis, we used $A_{p o e^{-/}}$mice with high plasma lipid levels and prone to atherosclerosis. ${ }^{23}$ Platelets were isolated from $\mathrm{Apoe}^{-/-}, \mathrm{Cd} 4 \mathrm{O}^{-/-} \mathrm{Apoe}^{-/-}$, and

Cd4Olg ${ }^{-/-} \mathrm{Apoe}^{-/-}$mice, and stimulated with key receptor agonists, that is, convulxin activating the collagen receptor GPVI, ${ }^{24} A D P$ as an agonist stimulating the $P 2 Y_{1} / P 2 Y_{12}$ receptors, and thrombin stimulating the PAR3/4 receptors. ${ }^{5}$ Platelet activation properties were compared by flow cytometry. Deficiency in CD40 led to increased integrin $\alpha_{\| 1} \beta_{3}$ activation (measured with PE-JON/A monoclonal antibody) and 

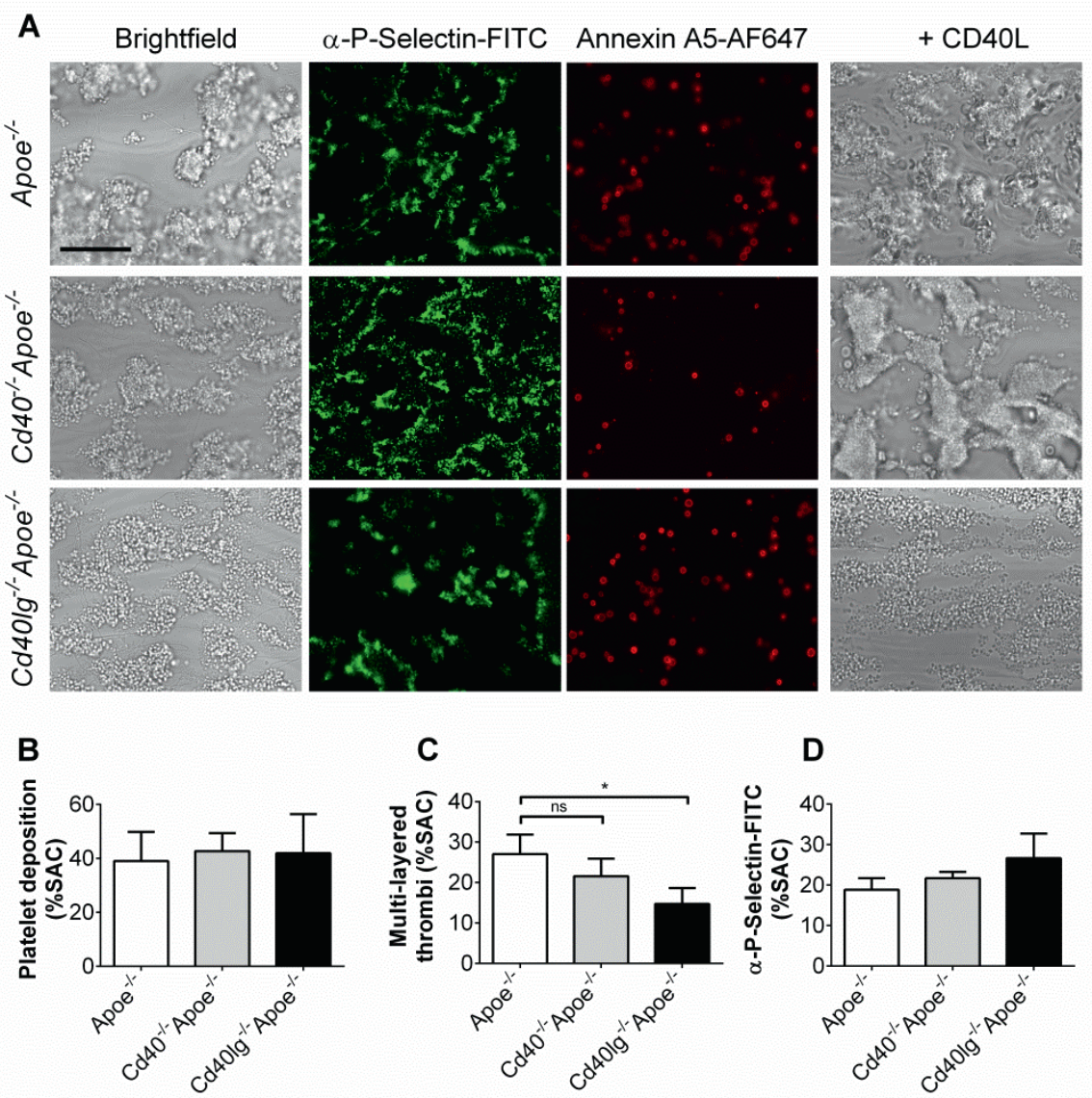

C

D

E
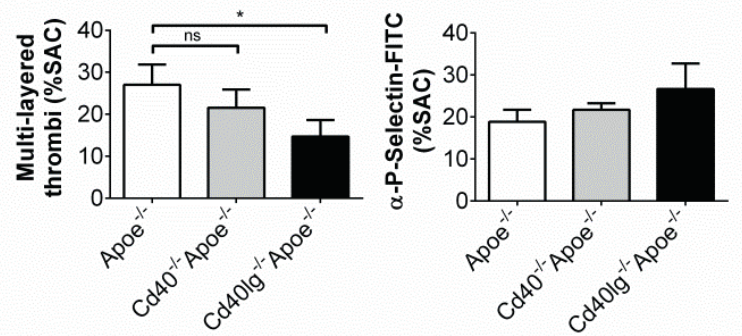

$\mathbf{F}$
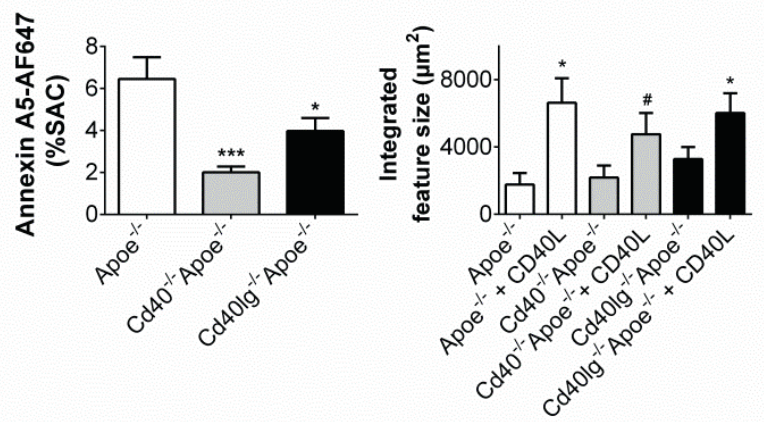

Figure 1. Agonist-induced integrin activation and secretion by Apoe ${ }^{-/-}$platelets lacking CD40 or CD40L. Washed platelets from $\mathrm{Apoe}^{-/-}, \mathrm{Cd}_{4} \mathrm{O}^{-/-} \mathrm{Apoe} \mathrm{e}^{-/}$, or $\mathrm{Cd} 4 \mathrm{O} \mathrm{g} \mathrm{g}^{-/-} \mathrm{Apoe} \mathrm{e}^{-/-}$mice were activated with the glycoprotein $\mathrm{VI}$ agonist convulxin (25-100 ng/mL), thrombin $(0.25-2 \mathrm{nmol} / \mathrm{L})$ or ADP $(0.5-5 \mu \mathrm{mol} / \mathrm{L})$. Using flow cytometry, activation of integrin $\alpha_{11 b} \beta_{3}$ was determined with PE-labeled JON/A monoclonal antibody (mAb; A), and P-selectin expression with FITC (fluorescein isothiocyanate)-labeled anti-CD62P mAb (B). Mean \pm SEM $(n=3-5), \quad * P<0.05$. 
increased $\alpha$-granule secretion (measured with FITC (fluorescein isothiocyanate)labeled anti-P-selectin monoclonal antibody), when the platelets were stimulated with a low or high dose of convulxin (Figure 1A and 1B). In marked contrast, deficiency in CD40L led to reduced $\alpha_{\| b} \beta_{3}$ activation and $\alpha$-granule secretion after stimulation with convulxin. Responses triggered by thrombin or ADP were not changed in the CD40- or CD40L-deficient platelets. Thrombin, as a strong agonist, showed a rather steep dose-response curve with substantial integrin activation and $\mathrm{P}$ selectin expression already at 0.25 $\mathrm{nmol} / \mathrm{L}$. At lower thrombin doses, these responses became highly variable (not shown). Stimulation with ADP resulted in high $\alpha_{11 b} \beta_{3}$ activation, but not in $\alpha$ granule secretion, as previously demonstrated. ${ }^{25}$ Taken together, these results suggest that, in $\mathrm{Apoe}^{-/-}$mice, platelet $\mathrm{CD} 40 \mathrm{~L}$ and $\mathrm{CD} 40$ play nonidentical roles in GPVI-induced integrin activation and $\alpha$-granule secretion.

Earlier experiments have demonstrated a primary role of GPVI in platelet adhesion and thrombus formation on plaque tissue or collagen at arterial flow conditions. ${ }^{2,3}$ We used this method of in vitro thrombus formation to investigate the roles of CD40 and CD40L in Apoe $e^{-/-}$ mice prone to develop atherosclerosis. Therefore, blood from $\mathrm{Apoe}^{-/,}$,

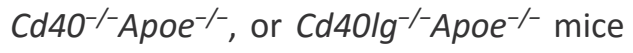
was perfused over murine plaque material at high wall shear rate, and the thrombi formed were analyzed by brightfield and fluorescence microscopy (Figure 2A). Image analysis gave for each genotype a similar deposition of platelets on plaque material (Figure 2B), albeit the overall size of platelet aggregates was smaller in the absence of CD40 or CD4OL (Figure 2C). Whereas P-selectin expression was similar for all genotypes, phosphatidylserine exposure (indicating procoagulant activity) was significantly reduced for $\mathrm{Cd}_{4 \mathrm{O}^{-/-}} \mathrm{Apoe}^{-/-}$and

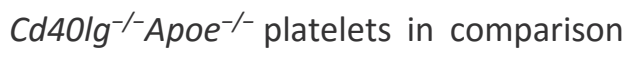
with $\mathrm{Apoe}^{-/-}$platelets (Figure 2D and 2E). Blood perfusion over collagen gave comparable results: whereas platelet deposition was similar for each genotype, the build-up of large thrombi was consistently diminished in the absence of CD40L. This difference seemed most clearly from the area covered by multilayered aggregates, which was significantly lowered in the absence of CD40L, but not in the absence of CD40 (Figure IA-IC in the online-only Data Supplement). Again, phosphatidylserine exposure was reduced in the absence of CD40 or CD40L, whereas P-selectin expression was unaltered (Figure ID and IE in the online-only Data Supplement).

To determine the ability of cleaved CD40L to support thrombus formation, blood samples from $\mathrm{Apoe}^{-/-}$, 

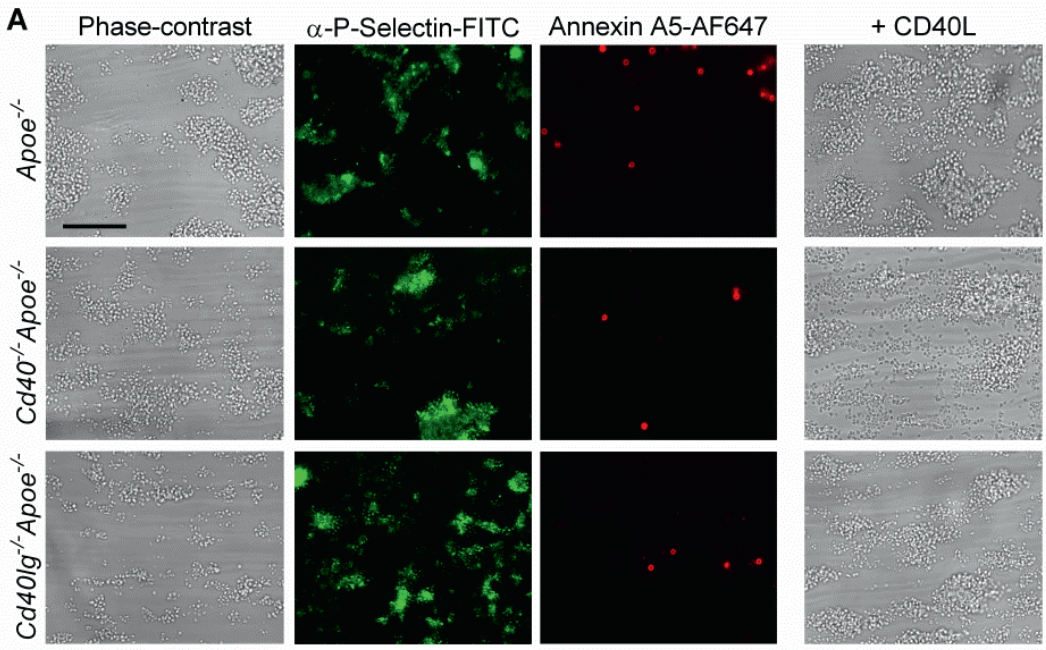

B

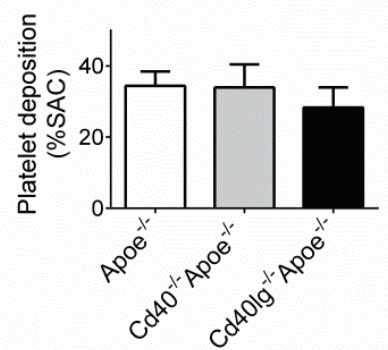

D

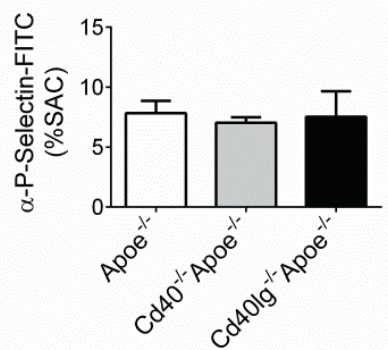

C

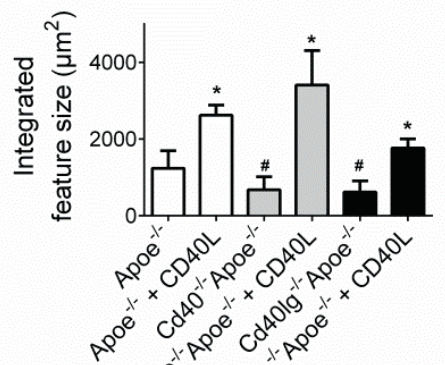

E

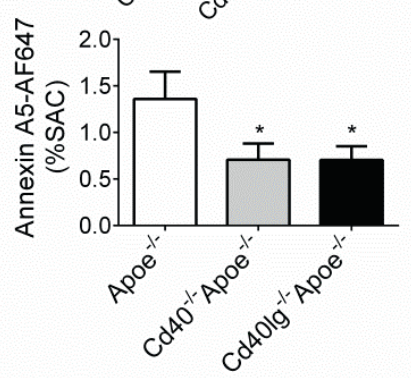

Figure 2. Increased thrombus formation on atherosclerotic plaque material by added CD40L in all genotypes. Blood from Apoe-/-, Cd4O-/-Apoe-/-, or Cd4Olg-/-Apoe-/- mice was anticoagulated with PPACK (H-dphenylalanyl-prolyl-arginyl chloromethyl ketone)/heparin, and perfused over murine plaque material at $1000 \mathrm{~s}-1$ for 4 minutes. Blood samples were preincubated with CD40L $(1 \mu \mathrm{g} / \mathrm{mL})$, where indicated. Thrombi were stained by postperfusion with FITC (fluorescein isothiocyanate)-labeled anti-P-selectin monoclonal antibody and AF647annexin A5. A, Representative brightfield and fluorescence images (bar, $50 \mu \mathrm{m}$ ). B, Quantification of surface area coverage (\%SAC) of platelet deposition. C, Quantification of integrated feature size from brightfield images. ${ }^{*} P<0.05$ compared with no CD40L, $\# P<0.05$ compared with Apoe-/-. D and E, Quantification of P-selectin expression and phosphatidylserine exposure from fluorescence images. Mean \pm SEM $(n=3-5), * P<0.05$. 


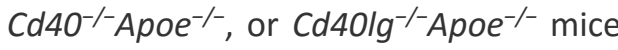
were preincubated with $\mathrm{CD} 40 \mathrm{~L}$ peptide before the perfusion. For all genotypes, this resulted in a substantial increase in thrombus formation on plaque material (Figure 2A) and on collagen (Figure IA in the online-only Data Supplement). Quantification learned that in the presence of CD40L peptide larger platelet aggregates were formed on plaque material (Figure $2 \mathrm{C}$ ), which were best detected as multilayered aggregates on collagen (Figure $1 \mathrm{~F}$ in the online-only Data Supplement), regardless of the genotype, that is, also with platelets deficient in CD40 or CD40L. Expression of P-selectin and phosphatidylserine exposure were not affected by the CD40L preincubation (not shown). Further experiments using blood from $\mathrm{Apoe}^{-/-}$ mice indicated that preincubation of the blood with a blocking antibody against CD40L caused a reduction in the formation of multilayered aggregates showing less $\alpha_{11 b} \beta_{3}$ activation, thus indicating a role of autologous CD4OL in the thrombus growth (Figure II in the online-only Data Supplement).

Other authors have reported a stimulating effect of the cleaved CD4OL on platelet aggregation in response to low doses of agonists. ${ }^{18,19}$ To investigate this in more detail, we examined this in Apoe $^{-/-}$mouse platelets also deficient in CD40L or CD40. Using platelets from $\mathrm{Apoe}^{-/-}, \quad \mathrm{Cd}_{40} \mathrm{O}^{-/-} \mathrm{Apoe}^{-/-}, \quad$ or

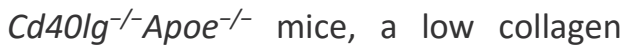
dose $(0.5 \mu \mathrm{g} / \mathrm{mL})$ did not result in appreciable aggregation nor shape change, whereas a high dose $(5 \mu \mathrm{g} / \mathrm{mL})$ induced maximal aggregation for all

B

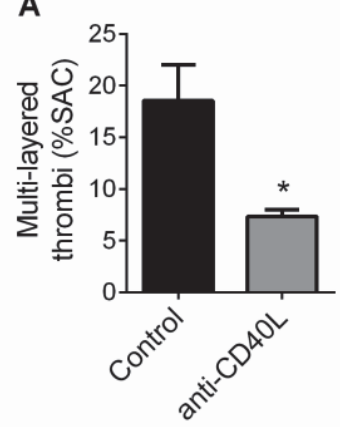

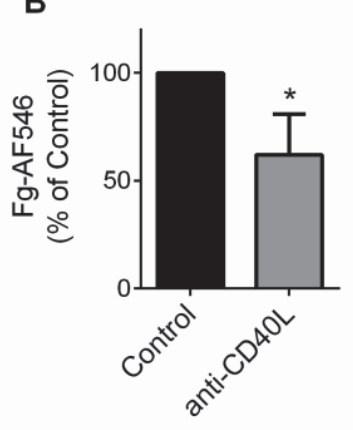

Supplementary Figure II. Inhibition of CD40L modulates thrombus growth on collagen. Blood from Apoe-/- mice was anticoagulated with PPACK/heparin, supplemented with fibrinogen-AF546 $(10 \mu \mathrm{g} / \mathrm{mL})$ and perfused over collagen at $1000 \mathrm{~s}-1$ for 4 minutes. Blood samples were pre-incubated with a blocking antibody against murine CD40L $(20 \mu \mathrm{g} / \mathrm{mL})$ or control. A, Quantification of surface area covered by multi-layered thrombi (\%SAC as percentage of control). B, Quantification of fluorescence images of AF546-fibrinogen. Means \pm SEM ( $n=3$ ), $* P<0.05$. 
A
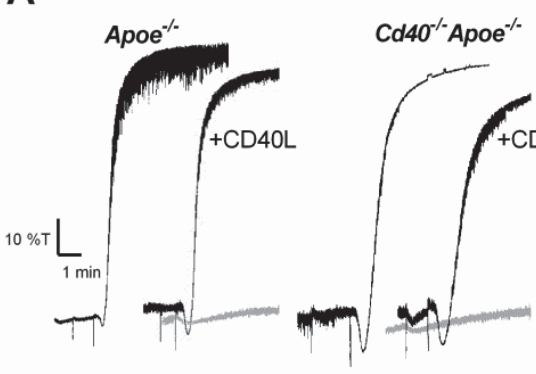

B
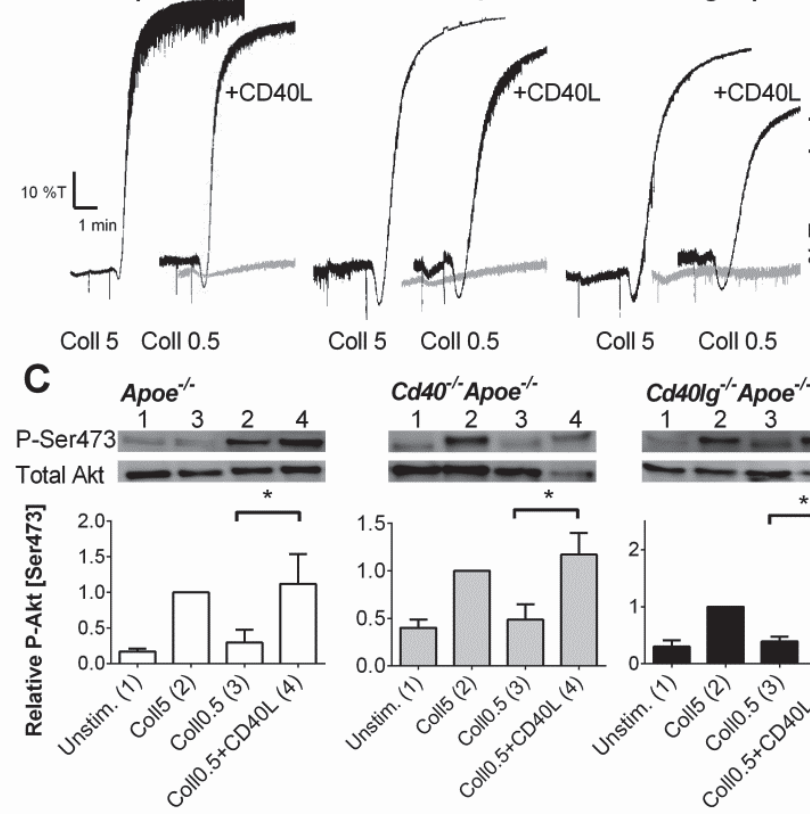

Cd40lg ${ }^{-/-}$Apoe $^{-/ 2}$
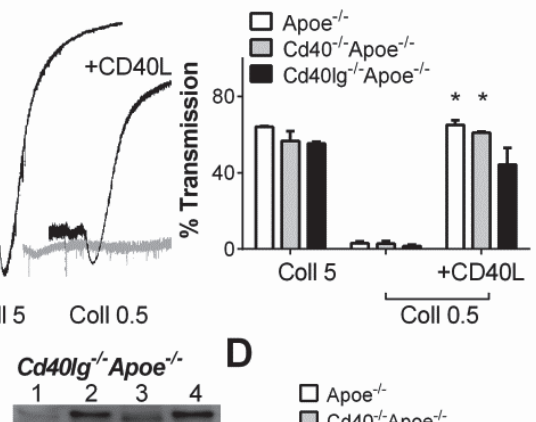

D
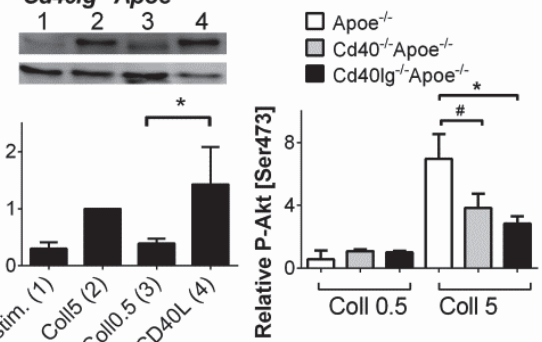

Figure 3. Enhancing role of CD40L in collagen-induced platelet aggregation and Akt phosphorylation. Washed platelets $(2.5 \times 108 / \mathrm{mL})$ from $\mathrm{Apoe}^{-/-}, \mathrm{Cd} 4 \mathrm{O}^{-/-} \mathrm{Apoe^{-/- }}$, or $\mathrm{Cd} 4 \mathrm{Olg}^{-/-} \mathrm{Apoe}^{-/-}$mice were incubated with $\mathrm{CD} 40 \mathrm{~L}$ (1 $\mu \mathrm{g} / \mathrm{mL}$ ) for 30 minutes, and subsequently stimulated with the glycoprotein $\mathrm{VI}$ agonist, collagen (coll, 0.5-5 $\mu \mathrm{g} / \mathrm{mL}$ ). A, Representative aggregation traces. B, Maximal platelet aggregation (maximal change in light transmission). C and D, Platelet samples were taken from aggregation cuvettes after 10 minutes. Shown are representative western blots, and quantification of Akt phosphorylation at Ser473 and of total Akt. Lane 1: unstimulated platelets (unstim.), lane 2: collagen $5 \mu \mathrm{g} / \mathrm{mL}$, lane 3: collagen $0.5 \mu \mathrm{g} / \mathrm{mL}$, lane 4 : collagen 0.5 $\mu \mathrm{g} / \mathrm{mL}+\mathrm{CD} 40 \mathrm{~L}$. Bars indicate relative phosphorylation of Akt (relative to total Akt), compared with high collagen (C), or compared with unstimulated platelets (D). Mean \pm SEM ( $n=3-4),{ }^{*} P<0.05, \# P=0.06$.

genotypes (Figure $3 \mathrm{~A}$ and $3 \mathrm{~B}$ ). Although exogenous $\mathrm{CD} 40 \mathrm{~L}$ alone was without effect, together with low collagen it caused near-maximal aggregation in all genotypes, including in platelets from the CD40-deficient mice. Taken together, these data point to a role of (cleaved) CD40L acting at least in part independently of CD40. In pilot experiments, we considered the possible involvement of another TNFR-TNF axis, that is, of the LIGHT receptor (TNFR-SF14) and LIGHT (TNF-SF14), which were reported to be present in platelets. ${ }^{26}$ However, a blocking antibody against this receptor was unable to inhibit the enhancement by CD40L of platelet responses (not shown).

Considering the major role of the PI3K/Akt signaling pathway in integrin activation, ${ }^{27}$ we compared the ability of collagen to induce phosphorylation at 
Ser473 of Akt in platelets from the CD40and CD40L-deficient mice. The low dose of collagen $(0.5 \mu \mathrm{g} / \mathrm{mL})$ not causing platelet aggregation was also unable to stimulate Akt phosphorylation, whereas the high collagen dose $(5 \mu \mathrm{g} / \mathrm{mL})$ led to an increased phosphorylation by 4 to 6 times (Figure 3C). Markedly, this collagen-induced phosphorylation of Akt

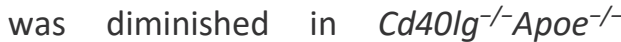
platelets and tended to be lower in

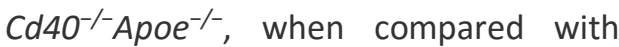
Apoe $^{-/}$platelets (Figure 3D). Addition of CD40L alone did not evoke Akt phosphorylation (not shown), but in combination with low collagen, it caused a similar increase in phosphorylation in platelets from all genotypes (Figure 3C). Given that this phosphorylation is a prerequisite for integrin activation, ${ }^{28,29}$ these results suggest a key signaling role of PI3K- $\beta$ in the stimulating effect of $\mathrm{CD} 40 \mathrm{~L}$ on collagen-induced platelet aggregation.

To further study the involvement of PI3K in CD40L-dependent platelet responses, we performed aggregation experiments with platelets from $P i k 3 c b^{R / R}$ mice, expressing a catalytically inactive K805R mutant of PI3K- $\beta$, that is, an isoform that has previously been shown to control collagen-dependent signaling events. ${ }^{30}$

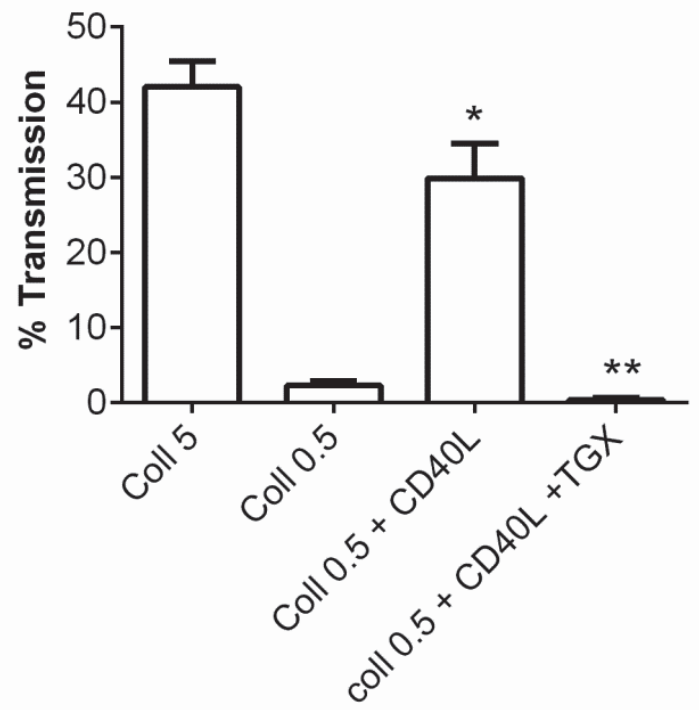

Supplementary Figure III. Inhibition of PI3K-b abrogates CD40L enhancement of collagen-induced platelet aggregation. Washed platelets from wildtype mice $(2.5 \times 108 / \mathrm{mL})$ were pre-incubated with CD40L $(1 \mu \mathrm{g} / \mathrm{mL}) \mathrm{and}$ TGX-221 (1 $\mu \mathrm{M})$ ), as indicated. Aggregation was induced with collagen (coll 0.5-5 $\mathrm{g} / \mathrm{mL}$ ), and maximal amplitude of light transmission was measured. Means \pm SEM $(n=4-10), * P<0.05$ compared to low collagen, $* * P<0.05$ compared to low collagen + CD4OL. 

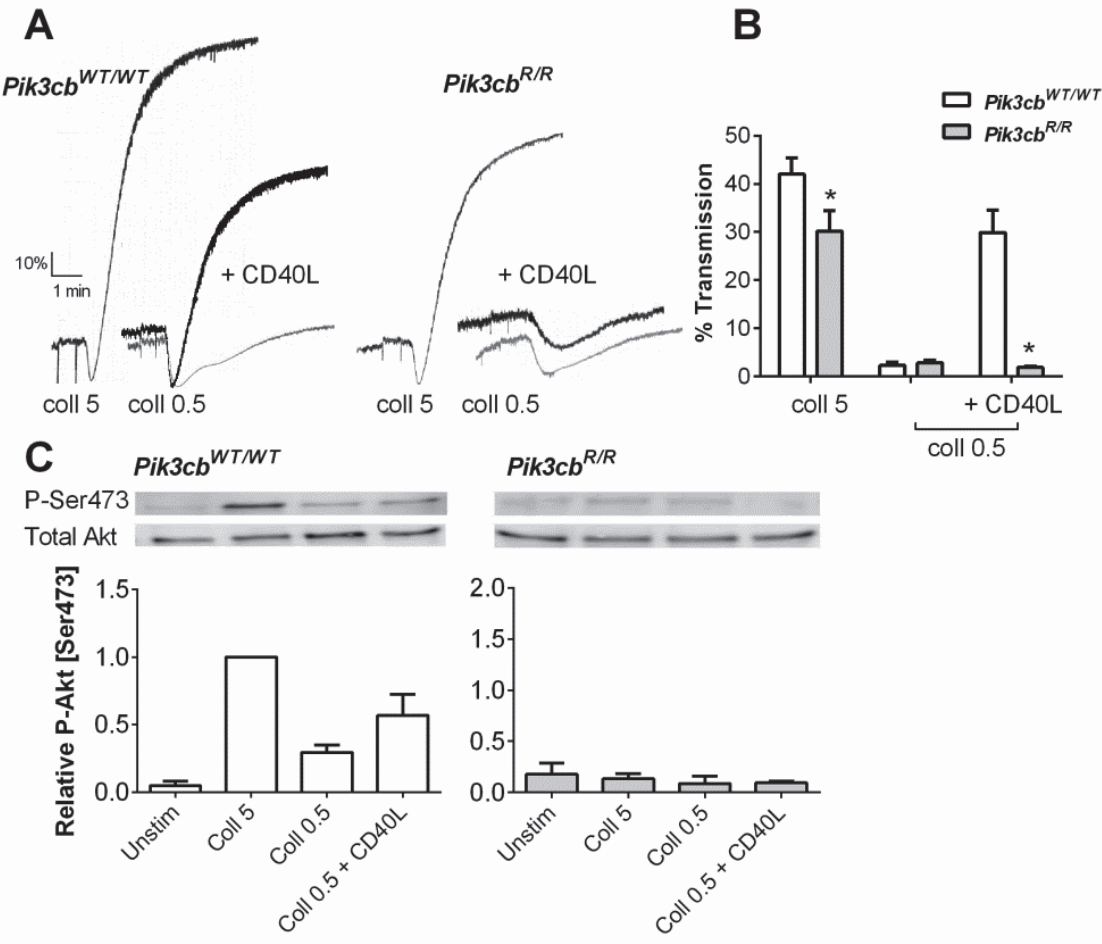

Figure 4. Enhancing role of $\mathrm{CD} 40 \mathrm{~L}$ in collagen-induced platelet aggregation and Akt phosphorylation via PI3K- $\beta$. Washed platelets from $P i k 3 c b^{R / R}$ or corresponding wildtype mice $\left(P i k 3 c b^{\mathrm{WT} / \mathrm{WT}}\right.$ ) were activated with collagen (coll, $0.5-5 \mu \mathrm{g} / \mathrm{mL}$ ), as described in Figure 3. A, Representative aggregation traces. B, Quantification of platelet aggregation (maximal change in light transmission). Mean \pm SEM ( $n=5-6)$. C, Representative western blots and quantification of Akt phosphorylation at $\mathrm{Ser}^{473}$ and of total Akt. Bars show relative phosphorylation of Akt (relative to total Akt), compared with high collagen (wild-type). Mean $\pm \operatorname{SEM}(n=3), * P<0.05$ compared with wildtype.

When stimulated with high collagen, the aggregation of $P i k 3 c b^{R / R}$ platelets was considerably reduced but not annulled (Figure 4A), which is in agreement with published results. ${ }^{31}$ With low collagen, exogenous CD4OL failed to enhance the aggregation of $P i k 3 c b^{R / R}$ platelets, in contrast to the large effect of CD40L seen with wildtype (Pik3cb $\left.b^{W T / W T}\right)$ platelets (Figure 4A and 4B). Markedly, $\mathrm{CD} 40 \mathrm{~L}$ was also unable to stimulate Akt phosphorylation in $P i k 3 c b^{R / R}$ platelets (Figure 4C). Additional confirmation for a role of PI3K- $\beta$ came from the observation that the PI3K- $\beta$-specific inhibitor, TGX221 , abolished the stimulating effect of CD40L on collagen-induced aggregation (Figure III in the online-only Data Supplement).

Perfusion experiments were subsequently performed with blood from $P i k 3 c b^{R / R}$ and $P i k 3 c b^{W T / W T}$ mice over a 
collagen surface. In case of $P i k 3 c b^{R / R}$ blood, the thrombi consisted of much smaller platelet aggregates, when compared with the wild-type (Figure IV in the online-only Data Supplement). For $P i k 3 c b^{R / R}$ thrombi, P-selectin expression was unchanged, whereas phosphatidylserine exposure was reduced. Notably, addition of $\mathrm{CD} 40 \mathrm{~L}$ to blood samples increased the size of platelet aggregates for wild-type, but not
$P i k 3 c b^{R / R}$ mice. Confirming experiments were performed in the presence of TGX221. When TGX-221-treated Apoe ${ }^{-/-}$ blood, was flowed over collagen or plaque material, this resulted in thrombi with smaller platelet aggregates and reduced phosphatidylserine exposure (Figure $\mathrm{V}$ in the online-only Data Supplement).

Largely based on pharmacological evidence, a role has been proposed for

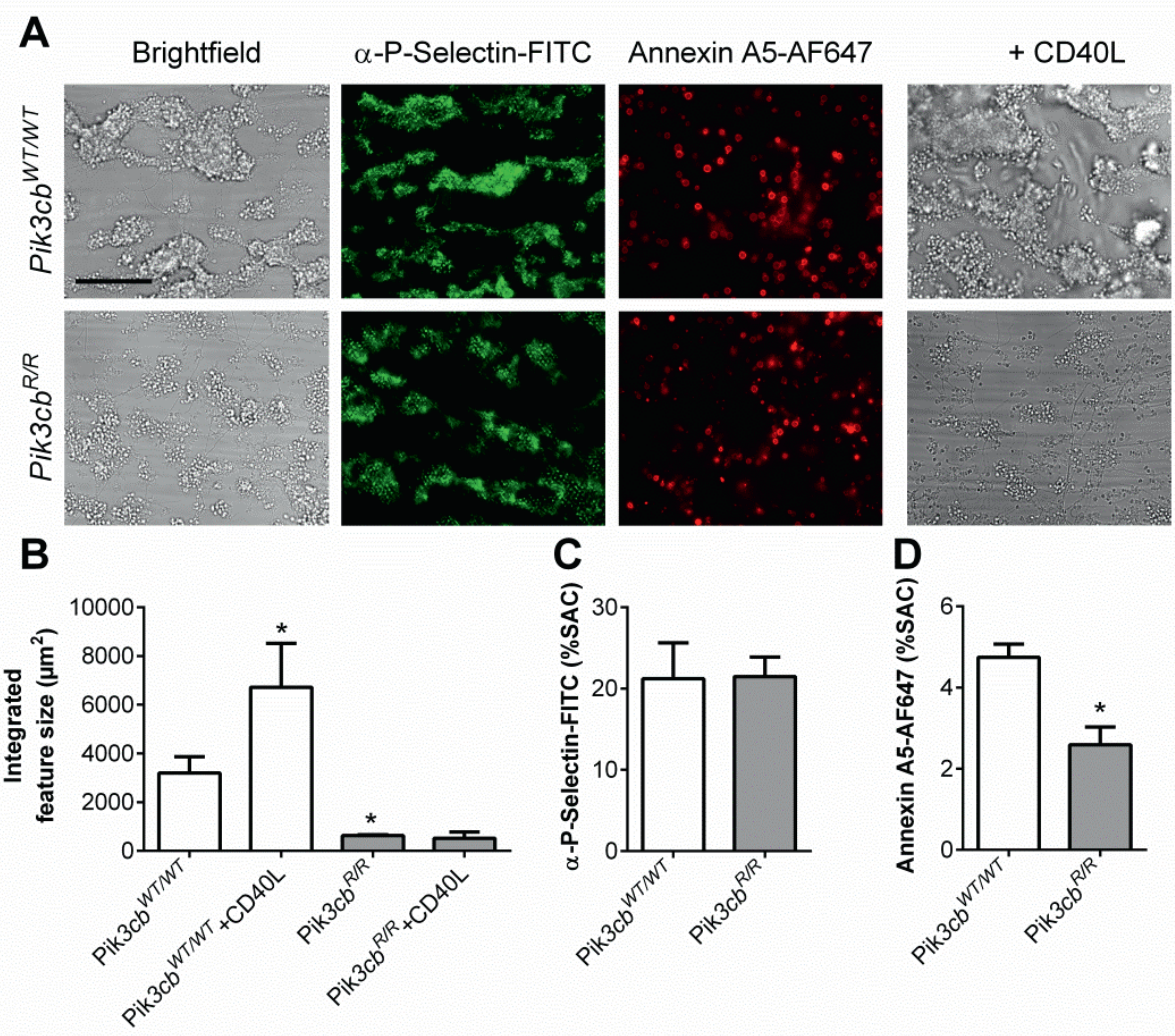

Supplementary Figure IV. Enforcing role of CD40L in thrombus formation on collagen via PI3K-b. Blood from $P i k 3 c b R / R$ or corresponding wildtype mice $\left(P i k 3 c b^{W T / W T}\right)$ was perfused over collagen at $1000 \mathrm{~s}^{-1}$ for 4 minutes. Pre-incubation with CD40L $(1 \mu \mathrm{g} / \mathrm{mL})$ was as indicated. A, Representative brightfield and fluorescence images (bar, $50 \mu \mathrm{m}$ ). B, Quantification of integrated feature size. C-D, Quantification of P-selectin expression and phosphatidylserine exposure. Means \pm SEM $(n=3-4),{ }^{*} P<0.05$ vs. $P i 3 k 3 c b^{W T / W T}$. 
NFKB pathways in CD40L- and CD40dependent platelet responses. ${ }^{19}$ To take this further, we first studied effects of the NFKB inhibitor Ro-106-9920 (2.5-25 $\mu \mathrm{mol} / \mathrm{L}$, targeting $\mathrm{I}-\mathrm{KB} \alpha$ ) and IKB kinase (IKK) inhibitor VII $(0.1-10 \mu \mathrm{mol} / \mathrm{L}$, targeting IKK $\beta$ ) on mouse platelet aggregation. Markedly, either compound caused a similar degree of inhibition on the aggregation responses induced by collagen alone or by collagen plus CD4OL (data not shown). Because these compounds also suppressed thrombinand collagen-induced calcium responses, we suspected off-target effects. For the I-KB $\alpha$ inhibitor BAY 11-7082, an alternative mode of action in platelets has already been shown. ${ }^{32}$

In nucleated cells, CD40 ligation is known to trigger several pathways leading to activation of NFKB.33 The noncanonical pathway proceeds via phosphorylation of the regulatory protein IKK $\alpha$, which relieves the default inhibition of $K B$ kinase (p100) to induce signaling downstream of NFKB.34 To evaluate a contribution of this pathway in CD40Lmediated platelet activation, we used Chuk $1^{A / A} \mathrm{Apoe}^{-/-}$mice, which are homozygous for an activation-resistant mutation of $1 \mathrm{KK} \alpha{ }^{35}$ Markedly, in platelets from IKK $\alpha$-deficient mice, the ability of CD40L to enhance aggregation was not affected (Figure 5A). Flow studies further indicated that the size of platelet aggregates on collagen was not different for control $A p o e^{-/-}$and Chuk1 ${ }^{A / A} A_{p o e}{ }^{-/-}$blood (Figure 5B-5D). Surprisingly, phosphatidylserine exposure was increased in thrombi from Chuk $1^{A / A} \mathrm{Apoe}^{-/-}$mice (Figure 5E). Together, these results indicate that the stimulatory effect of CD40L on thrombus growth is not mediated via the IKK $\alpha$ pathway to NFKB.

\section{Discussion}

The glycoproteins CD4OL and CD40 play major roles in autoimmune and inflammatory reactions mediated by $\mathrm{T}$ cells, endothelial cells, and leukocytes, by stimulating signaling toward $\mathrm{NFKB}$ activation. ${ }^{36,37}$ For the CD4OL-CD40 dyad, involvement has been reported of the noncanonical and canonical NFkB pathways. ${ }^{33}$ Cross-talk of CD40L and CD40 has also been shown for plateletleukocyte and platelet-endothelial cell interactions and, as such implicated in the progression of mouse atherosclerosis ${ }^{13,15,38}$ and neointima formation. ${ }^{16}$ Here, we investigated the importance of the CD4OL-CD40 axis for establishment of platelet-platelet interactions using mice with an atherogenic $\mathrm{Apoe}^{-/-}$background, that is, conditions where these platelet glycoproteins are considered to contribute to plaque progression. Our data indicate that CD4OL and CD40 have, in part, different roles in platelet aggregation and thrombus growth. 

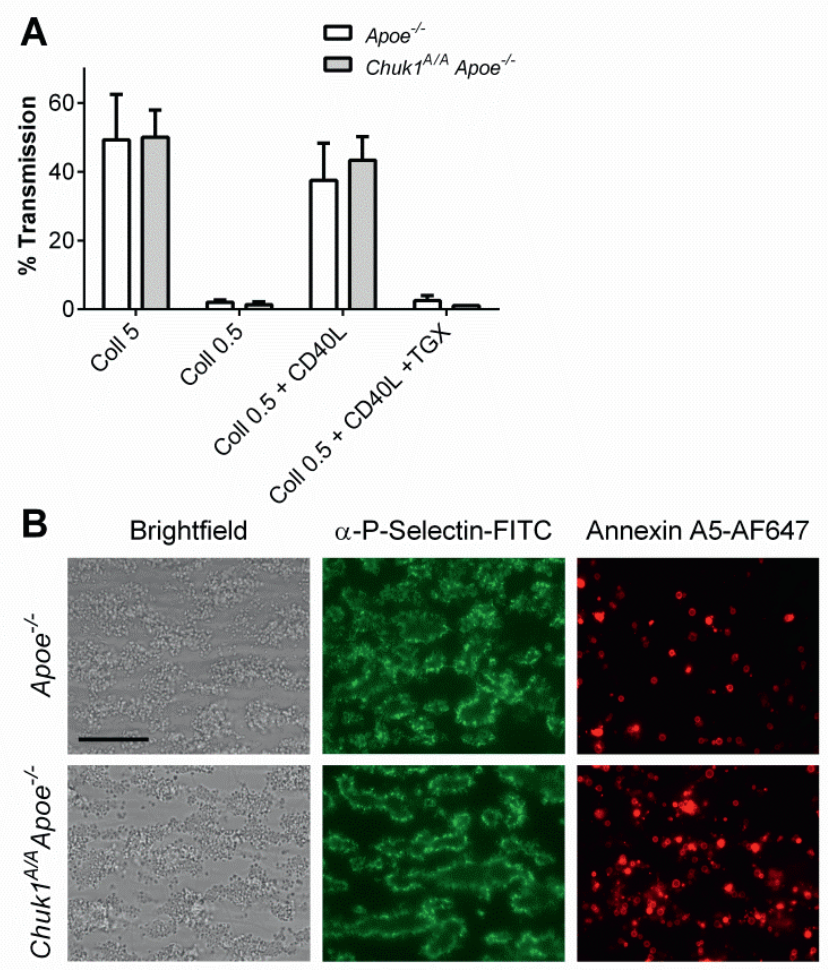

C

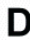

E

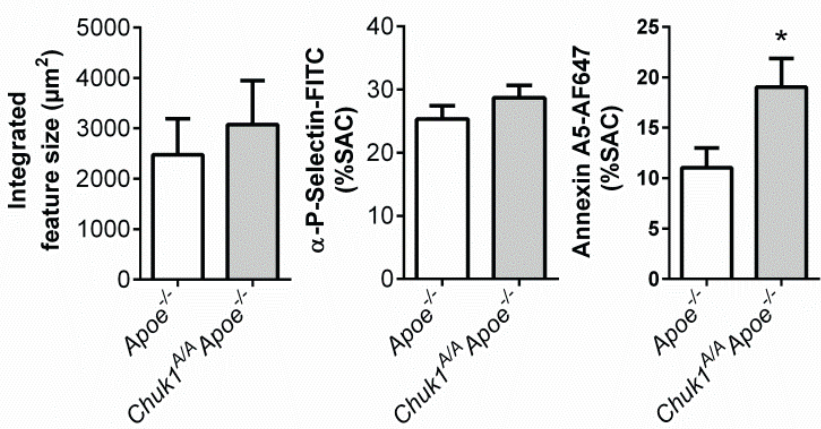

Figure 5. Enhanced platelet aggregation and thrombus formation by CD40L are independent of IкB kinase $\alpha$. A, Washed platelets from Apoe-/- or Chuk1A/AApoe-/- mice were activated with collagen (coll, $0.5-5 \mu \mathrm{g} / \mathrm{mL}$ ), as described in Figure 3. Samples were preincubated with TGX-221 (1 $\mu \mathrm{mol} / \mathrm{L})$, where indicated. Data are quantification of platelet aggregation (maximal change in light transmission). Mean $\pm S E M(n=3-6)$. B, Mouse blood anticoagulated with PPACK ( $\mathrm{H}$-d-phenylalanyl-prolyl-arginyl chloromethyl ketone)/heparin was perfused over collagen at $1000 \mathrm{~s}-1$ for 4 minutes. Thrombi were stained, as for Figure 2 . Shown are representative brightfield and fluorescence images (bar, $50 \mu \mathrm{m}$ ). C, Quantification of percentage surface area coverage (\%SAC) of platelets. D and $\mathbf{E}$, Quantification of P-selectin expression and phosphatidylserine exposure from fluorescence images. Mean \pm SEM $(n=6-7)$. 
In studies of whole blood thrombus formation on plaque material or collagen, in which platelet adhesion and activation are known to be triggered by $\mathrm{GPVI}, 2,39$ we found that deficiency in CD40L or CD40 (not significant with collagen) impaired the formation of large, multilayered platelet aggregates. This reduced thrombus growth did not coincide with altered $\alpha$-granule secretion (P-selectin expression), but was accompanied by reduced phosphatidylserine exposure, an event that also is mediated by the collagen receptor GPVI. ${ }^{24}$ In accordance with these findings, others have reported that deficiency of $\mathrm{CD} 40 \mathrm{~L}$ alone (no $A p o e^{-/-}$) leads to reduced arterial thrombus formation in vivo. ${ }^{21}$ In earlier work, we have found that deficiency of CD40 alone causes a small, insignificant reduction in platelet deposition on collagen. ${ }^{16}$ Together, these results point to a moderate contribution of CD4OL and CD40 in collagen-dependent thrombus growth.

Flow cytometric studies gave, in part, similar results. When triggered with the GPVI agonist convulxin, platelets from Apoe $^{-/}$mice lacking CD40L showed a reduced integrin activation and secretion. However, platelets lacking CD40 responded by a higher integrin activation and higher P-selectin expression. The apparent different response of

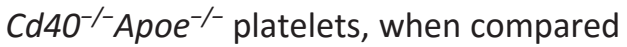

with the measurement of thrombus formation, can be explained by the fact that in flow cytometry all platelets become activated by the added GPVI agonist, whereas during thrombus formation only those platelets in direct contact with the collagen are activated via GPVI and the other platelets respond to paracrine agents. ${ }^{5,40}$ Hence, it seems that in thrombus-forming experiments the apparent gain-of-function of $\mathrm{Cd}_{40} \mathrm{O}^{-/} \mathrm{Apoe}^{-/-}$platelets is overruled by non-GPVI-mediated secondary processes.

The dissociation seen in flow cytometry between the phenotypes of $\mathrm{CD} 40 \mathrm{~L}$ or CD40 deficiency is one indication for, in part, dissimilar roles of platelets CD40L and CD40. Further confirmation for a role of CD40L independently of CD40 in platelet-platelet interactions comes from (1) the observed thrombusreducing effect by blocking CD40L, and (2) the enhanced platelet aggregation and thrombus formation noticed by supplementation of $\mathrm{CD} 40 \mathrm{~L}$ even for $\mathrm{Cd} 4 \mathrm{O}^{-/} \mathrm{Apoe}^{-/-}$platelets lacking CD40. Hence, we could not reproduce the finding from others that knockout of CD40 abolishes CD40Ldependent platelet aggregation. ${ }^{18}$ The reason for this difference remains unclear. Taken together, our data imply that, in the stimulating platelet aggregation and thrombus growth, CD40L acts as least, in part, independently of CD40. 
A Collagen
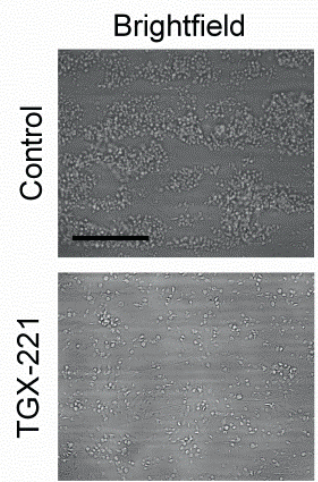

B

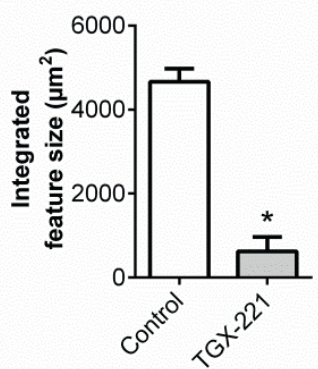

FITC-Annexin A5
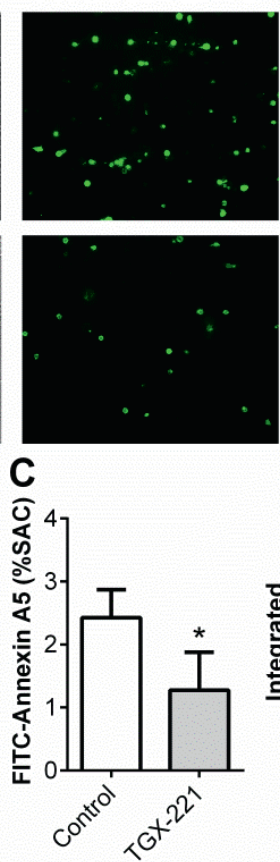

D Plaque

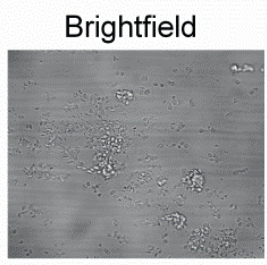

FITC-Annexin A5
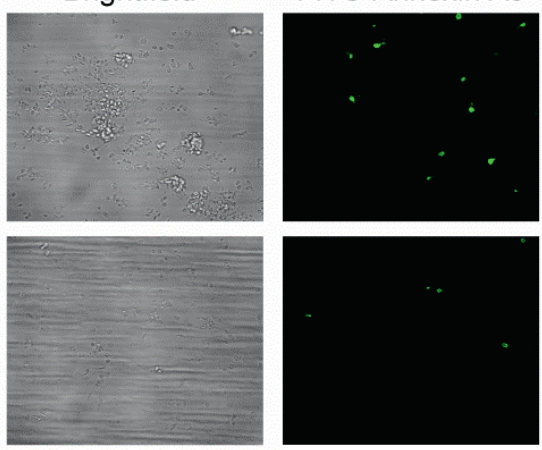

E

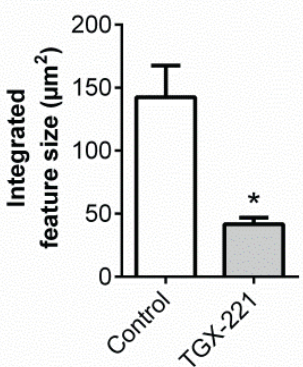

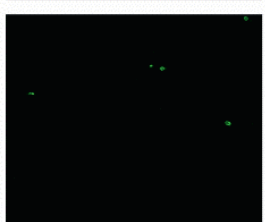

$F$

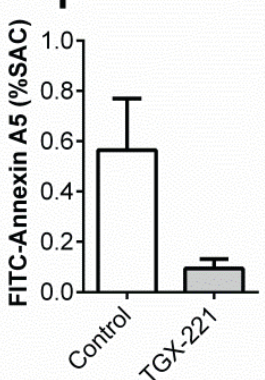

Supplementary Figure V. Role of PI3K- $\beta$ in thrombus formation on collagen or plaque material. Blood from $A_{p o e^{-/}}$mice was perfused over collagen or plaque material at $1000 \mathrm{~s}^{-1}$ for 4 minutes. Blood samples were preincubated with TGX-221 (1 $\mu \mathrm{M})$ or vehicle (DMSO). Thrombi were stained and images were analyzed as for Figure 2. A, D, Representative brightfield and fluorescence images (bar, $50 \mu \mathrm{m}$ ). B, E, Quantification of integrated feature size from brightfield images. C, F, Quantification of phosphatidylserine exposure (\%SAC). Means \pm SEM $(\mathrm{n}=3-5), * P<0.05$ vs. control.

Another novel finding is the role of PI3K$\beta$ (using deficient mice and inhibitor TGX221) and its downstream target Akt (based on Ser473 phosphorylation) in the enhancing effect of CD40L on collageninduced platelet aggregation and thrombus formation. This role of PI3K- $\beta$ is in good agreement with the literature, demonstrating that this kinase is a major regulator of Akt phosphorylation and downstream integrin activation in response to various platelet agonists. ${ }^{31,41-43}$ Other authors have suggested that CD40L in platelets signals via p38 mitogen-activated protein kinase, ${ }^{19}$ or via tyrosine phosphorylation of the integrin $\beta_{3}$ chain. ${ }^{22}$ These pathways may coexist and help to support the establishment of plateletplatelet interactions. Of interest, a comparable signaling pathway, involving PI3K and Akt, has been proposed for 
endothelial cells, but in this case elicited by CD40 and leading to NFKB activation. ${ }^{37}$

The unchanged collagen-induced aggregation and thrombus formation with $\mathrm{Apoe}^{-/-}$platelets deficient in IKK $\alpha$ activity $\left(\right.$ Chuk $\left.1^{A / A}\right)$, as well as the unchanged ability of CD40L to stimulate aggregation of these platelets, points to a no more than minor role of the noncanonical IKK $\alpha / \mathrm{NFKB}$ pathway whether or not triggered via CD40 - in platelet-platelet interactions. In this respect, we like to note that evidence for a role of the NFKB pathway in CD40dependent platelet function is largely based on the use of pharmacological inhibitors. ${ }^{19}$ We suspect that at least some of these inhibitors have effects on platelet responses (eg, $\mathrm{Ca}^{2+}$ signaling), that are not mediated via NFKB. However, several reports using IKK $\beta$ knockout mice point to a regulatory role of the canonical NFKB pathway in platelet secretion and glycoprotein shedding. ${ }^{44,45}$ Hence, we cannot rule out a role for this IKK $\beta /$ NFKB pathway in platelet activation responses evoked by CD40L independently of CD40.

Interestingly, in studying thrombus formation, we observed an increase in

\section{References}

1. Ruggeri ZM. Platelets in atherothrombosis. Nat Med. 2002;8:1227-1234.

2. Cosemans JM, Kuijpers MJ, Lecut C, Loubele ST, Heeneman S, Jandrot-Perrus M, Heemskerk JW. phosphatidylserine exposure of Chuk $1^{A / A} A_{p o e^{-/-}}$platelets, which we consider as further evidence that the IKK $\alpha$ / NFKB pathway does not contribute to the role of CD40L. A mechanistic explanation for this unexpected finding is beyond the scope of this article but, not unlikely, the platelet proteome is altered by deficiency in one of the key enzymes of the NFKB transcription factor pathway. Yet, the stimulating role of CD40L on platelet aggregation and thrombus formation seems to be retained in Chuk $1^{A / A} A p o e^{-/-}$platelets.

Reports to date indicate that the cleavage of CD40L from activated platelets proceeds relatively slow and involves the matrix metalloproteinases 2 and 9, as well as integrin $\alpha_{\| 11} \beta_{3 .}{ }^{9,10,46}$ Given these kinetics, our data suggest a role of both platelet-associated CD4OL and cleaved $\mathrm{CD} 40 \mathrm{~L}$ in controlling thrombus growth. Taken together, we find that CD40L at least in part acting independently of CD40 is another of the (integrin-dependent) platelet-derived factors that contribute to the stable formation of large thrombi, especially under atherogenic conditions.

Contribution of platelet glycoprotein VI to the thrombogenic effect of collagens in fibrous atherosclerotic lesions. Atherosclerosis. 2005;181:19-27. 
3. Penz S, Reininger AJ, Brandl R, Goyal P, Rabie T, Bernlochner I, Rother E, Goetz C, Engelmann B, Smethurst PA, Ouwehand $\mathrm{WH}$, Farndale $\mathrm{R}$, Nieswandt B, Siess W. Human atheromatous plaques stimulate thrombus formation by activating platelet glycoprotein VI. FASEB J. 2005;19:898-909.

4. Kuijpers MJ, Gilio K, Reitsma S, Nergiz-Unal R, Prinzen L, Heeneman S, Lutgens E, van Zandvoort MA, Nieswandt B, Egbrink MG, Heemskerk JW. Complementary roles of platelets and coagulation in thrombus formation on plaques acutely ruptured by targeted ultrasound treatment: a novel intravital model. J Thromb Haemost. 2009;7:152-161.

5. Versteeg $\mathrm{HH}$, Heemskerk JW, Levi M, Reitsma PH. New fundamentals in hemostasis. Physiol Rev. 2013;93:327-358.

6. Inwald DP, McDowall A, Peters MJ, Callard RE, Klein NJ. CD40 is constitutively expressed on platelets and provides a novel mechanism for platelet activation. Circ Res. 2003;92:1041-1048.

7. Gavins FN, Li G, Russell J, Perretti M, Granger DN. Microvascular thrombosis and CD40/CD40L signaling. J Thromb Haemost. 2011;9:574-581.

8. Burkhart JM, Vaudel M, Gambaryan S, Radau S, Walter U, Martens L, Geiger J, Sickmann A, Zahedi RP. The first comprehensive and quantitative analysis of human platelet protein composition allows the comparative analysis of structural and functional pathways. Blood. 2012;120:e73-e82.

9. Choi WS, Jeon OH, Kim DS. CD40 ligand shedding is regulated by interaction between matrix metalloproteinase- 2 and platelet integrin alpha(Ilb)beta(3). J Thromb Haemost. 2010;8:1364-1371.

10. Rahman $M$, Zhang S, Chew M, Syk I, Jeppsson B, Thorlacius $H$. Platelet shedding of CD40L is regulated by matrix metalloproteinase- 9 in abdominal sepsis. J Thromb Haemost. 2013;11:1385-1398.

11. Varo $N$, de Lemos JA, Libby $P$, Morrow DA, Murphy SA, Nuzzo R, Gibson CM, Cannon CP, Braunwald E, Schönbeck U. Soluble CD40L: risk prediction after acute coronary syndromes. Circulation. 2003;108:1049-1052.
12. Tousoulis D, Androulakis E, Papageorgiou N, Briasoulis A, Siasos G, Antoniades C, Stefanadis C. From atherosclerosis to acute coronary syndromes: the role of soluble CD40 ligand. Trends Cardiovasc Med. 2010;20:153-164.

13. Mach F, Schönbeck U, Sukhova GK, Atkinson E, Libby $\mathrm{P}$. Reduction of atherosclerosis in mice by inhibition of CD40 signalling. Nature. 1998;394:200-203.

14. Lutgens E, Lievens D, Beckers L, et al. Deficient CD40-TRAF6 signaling in leukocytes prevents atherosclerosis by skewing the immune response toward an antiinflammatory profile. J Exp Med. 2010;207:391-404.

15. Lutgens E, Gorelik L, Daemen MJ, de Muinck ED, Grewal IS, Koteliansky VE, Flavell RA. Requirement for CD154 in the progression of atherosclerosis. Nat Med. 1999;5:1313-1316.

16. Donners MM, Beckers L, Lievens $D$, et al. The CD40-TRAF6 axis is the key regulator of the CD40/CD40L system in neointima formation and arterial remodeling. Blood. 2008;111:4596-4604.

17. Lievens D, Zernecke A, Seijkens T, et al. Platelet CD40L mediates thrombotic and inflammatory processes in atherosclerosis. Blood. 2010;116:4317-4327.

18. Yacoub D, Hachem A, Théorêt JF, Gillis MA, Mourad W, Merhi Y. Enhanced levels of soluble CD40 ligand exacerbate platelet aggregation and thrombus formation through a CD40-dependent tumor necrosis factor receptor-associated factor2/Rac1/p38 mitogen-activated protein kinase signaling pathway. Arterioscler Thromb Vasc Biol. 2010;30:2424-2433.

19. Hachem A, Yacoub D, Zaid Y, Mourad W, Merhi Y. Involvement of nuclear factor $\mathrm{KB}$ in platelet CD40 signaling. Biochem Biophys Res Commun. 2012;425:58-63.

20. Malaver E, Romaniuk MA, D'Atri LP, Pozner RG, Negrotto S, Benzadón R, Schattner M. NF-kappaB inhibitors impair platelet activation responses. $J$ Thromb Haemost. 2009;7:1333-1343.

21. André P, Prasad KS, Denis CV, He M, Papalia JM, Hynes RO, Phillips DR, Wagner DD. CD40L stabilizes arterial thrombi by a beta3 integrindependent mechanism. Nat Med. 2002;8:247252 
22. Prasad KS, Andre P, He M, Bao M, Manganello J, Phillips DR. Soluble CD40 ligand induces beta3 integrin tyrosine phosphorylation and triggers platelet activation by outside-in signaling. Proc Natl Acad Sci U S A. 2003;100:12367-12371.

23. Nergiz-Unal R, Cosemans JM, Feijge MA, van der Meijden PE, Storey RF, van Giezen JJ, oude Egbrink MG, Heemskerk JW, Kuijpers MJ. Stabilizing role of platelet $\mathrm{P} 2 \mathrm{Y}(12)$ receptors in shear-dependent thrombus formation on ruptured plaques. PLoS One. 2010;5:e10130.

24. Siljander $P$, Farndale RW, Feijge MA, Comfurius $P$, Kos S, Bevers EM, Heemskerk JW. Platelet adhesion enhances the glycoprotein VIdependent procoagulant response: Involvement of p38 MAP kinase and calpain. Arterioscler Thromb Vasc Biol. 2001;21:618-627.

25. Kuijpers MJ, de Witt $S$, Nergiz-Unal $R$, van Kruchten R, Korporaal SJ, Verhamme P, Febbraio M, Tjwa M, Voshol PJ, Hoylaerts MF, Cosemans JM, Heemskerk JW. Supporting roles of platelet thrombospondin-1 and CD36 in thrombus formation on collagen. Arterioscler Thromb Vasc Biol. 2014;34:1187-1192.

26. Rowley JW, Oler AJ, Tolley ND, Hunter BN, Low EN, Nix DA, Yost CC, Zimmerman GA, Weyrich AS. Genome-wide RNA-seq analysis of human and mouse platelet transcriptomes. Blood. 2011;118:e101-e111.

27. Jackson SP, Schoenwaelder SM, Goncalves I, et al. PI 3-kinase p110beta: a new target for antithrombotic therapy. Nat Med. 2005;11:507514.

28. Gibbins JM. Platelet adhesion signalling and the regulation of thrombus formation. I Cell Sci. 2004;117:3415-3425.

29. Gratacap MP, Guillermet-Guibert J, Martin V, Chicanne G, Tronchère $H$, Gaits-lacovoni $F$, Payrastre B. Regulation and roles of PI3K $\beta$, a major actor in platelet signaling and functions. Adv Enzyme Regul. 2011;51:106-116.

30. Canobbio I, Stefanini L, Cipolla L, Ciraolo E, Gruppi C, Balduini C, Hirsch E, Torti M. Genetic evidence for a predominant role of PI3Kbeta catalytic activity in ITAM- and integrin-mediated signaling in platelets. Blood. 2009;114:2193-2196.
31. Martin V, Guillermet-Guibert J, Chicanne G, Cabou C, Jandrot-Perrus $M$, Plantavid $M$, Vanhaesebroeck B, Payrastre B, Gratacap MP. Deletion of the p110beta isoform of phosphoinositide 3-kinase in platelets reveals its central role in Akt activation and thrombus formation in vitro and in vivo. Blood. 2010;115:2008-2013.

32. Lee HS, Kim SD, Lee WM, Endale $M$, Kamruzzaman SM, Oh WJ, Cho JY, Kim SK, Cho HJ, Park HJ, Rhee MH. A noble function of BAY 117082: Inhibition of platelet aggregation mediated by an elevated CAMP-induced VASP, and decreased ERK2/JNK1 phosphorylations. Eur J Pharmacol. 2010;627:85-91.

33. Oeckinghaus A, Hayden MS, Ghosh S. Crosstalk in NF-KB signaling pathways. Nat Immunol. 2011;12:695-708.

34. Sun SC. Non-canonical NF-KB signaling pathway. Cell Res. 2011;21:71-85.

35. Cao Y, Bonizzi G, Seagroves TN, Greten FR, Johnson R, Schmidt EV, Karin M. IKKalpha provides an essential link between RANK signaling and cyclin D1 expression during mammary gland development. Cell. 2001;107:763-775.

36. Law CL, Gewal IS. Therapeutic interventions targeting CD40L (CD154) and CD40: the opportunities and challenges. In:Grewal IS, ed. Therapeutics of the TNF Superfamily. 2009;647:836.

37. Chakrabarti S, Blair P, Freedman JE. CD40-40L signaling in vascular inflammation. J Biol Chem. 2007;282:18307-18317.

38. Lievens D, Eijgelaar WJ, Biessen EA, Daemen MJ, Lutgens $E$. The multifunctionality of $C D 40 L$ and its receptor CD40 in atherosclerosis. Thromb Haemost. 2009;102:206-214.

39. Nieswandt B, Brakebusch C, Bergmeier W, Schulte V, Bouvard D, Mokhtari-Nejad R, Lindhout $T$, Heemskerk JW, Zirngibl $H$, Fässler $R$. Glycoprotein VI but not alpha2beta1 integrin is essential for platelet interaction with collagen. EMBO J. 2001;20:2120-2130.

40. Kuijpers MJ, Schulte V, Bergmeier W, Lindhout $T$, Brakebusch C, Offermanns $S$, Fässler R, Heemskerk JW, Nieswandt B. Complementary roles of glycoprotein $\mathrm{VI}$ and alpha2beta1 integrin 
in collagen-induced thrombus formation in flowing whole blood ex vivo. FASEB J. 2003;17:685-687.

41. Gilio K, Munnix IC, Mangin P, Cosemans JM, Feijge MA, van der Meijden PE, Olieslagers $S$, Chrzanowska-Wodnicka MB, Lillian R, Schoenwaelder S, Koyasu S, Sage SO, Jackson SP, Heemskerk JW. Nonredundant roles of phosphoinositide 3-kinase isoforms alpha and beta in glycoprotein VI-induced platelet signaling and thrombus formation. I Biol Chem. 2009;284:33750-33762.

42. Schoenwaelder SM, Ono A, Nesbitt WS, Lim J, Jarman K, Jackson SP. Phosphoinositide 3-kinase p110 beta regulates integrin alpha Ilb beta 3 avidity and the cellular transmission of contractile forces. J Biol Chem. 2010;285:2886-2896.

43. Consonni A, Cipolla L, Guidetti G, Canobbio I, Ciraolo E, Hirsch E, Falasca M, Okigaki M, Balduini
C, Torti M. Role and regulation of phosphatidylinositol 3-kinase $\beta$ in platelet integrin $\alpha 2 \beta 1$ signaling. Blood. 2012;119:847-856.

44. Karim ZA, Zhang J, Banerjee M, Chicka MC, Al Hawas R, Hamilton TR, Roche PA, Whiteheart SW. IKB kinase phosphorylation of SNAP- 23 controls platelet secretion. Blood. 2013;121:4567-4574.

45. Wei $S$, Wang $H$, Zhang G, Lu Y, An X, Ren S, Wang Y, Chen Y, White JG, Zhang C, Simon DI, Wu C, Li Z, Huo Y. Platelet IKB kinase- $\beta$ deficiency increases mouse arterial neointima formation via delayed glycoprotein Iba shedding. Arterioscler Thromb Vasc Biol. 2013;33:241-248.

46. Otterdal K, Pedersen TM, Solum NO. Release of soluble CD40 ligand after platelet activation: studies on the solubilization phase. Thromb Res. 2004;114:167-177. 

